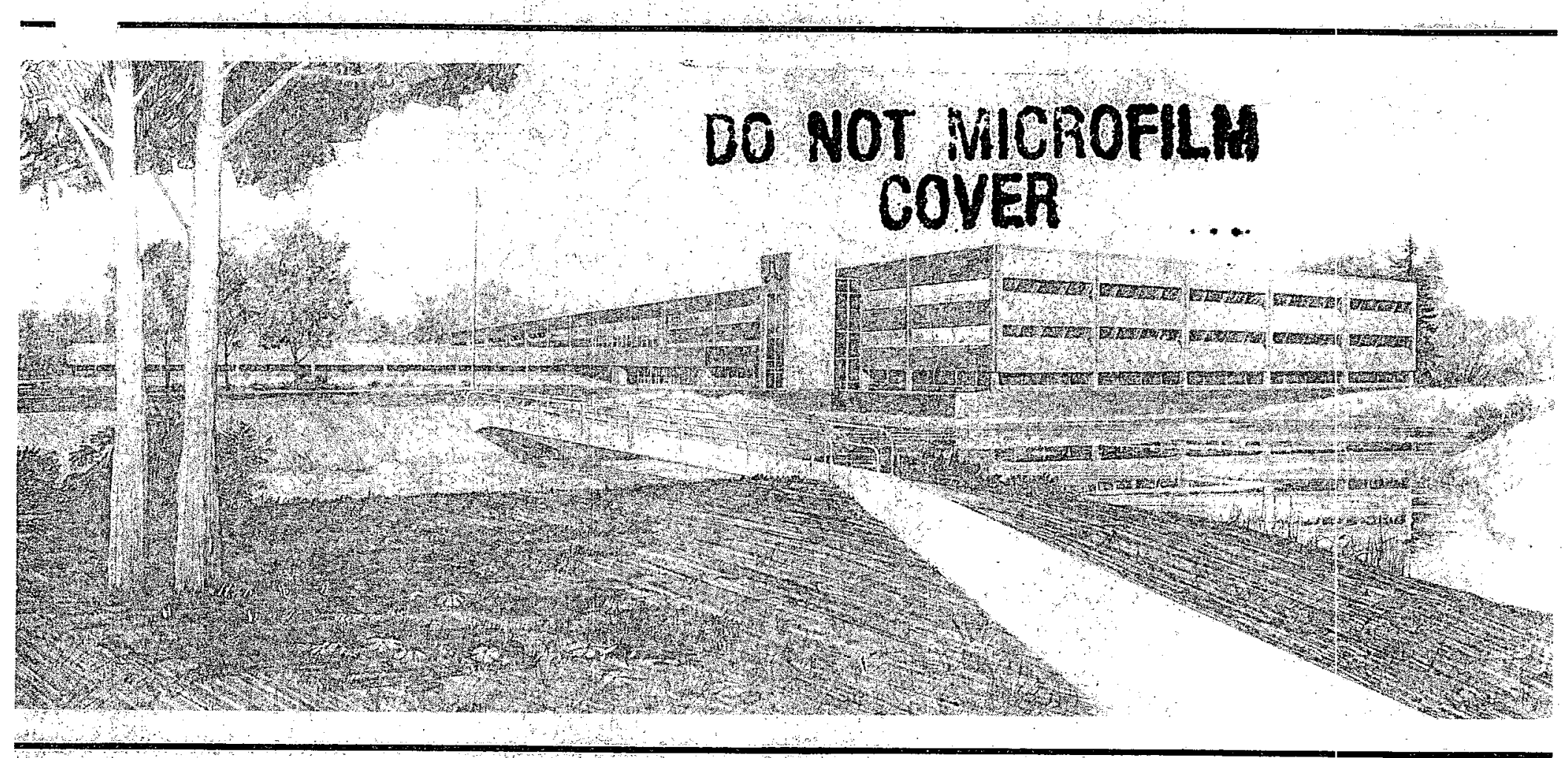

Idaho National Engineering Laboratory

Operated by the U.S. Department of Energy

\title{
Theory, Design, and Operation of Liquid Metal Fast Breeder Reactors, Including Operational Health Physics
}

Steven R. Adams

October 1985

Prepared for the

\section{U.S. Nuclear Regulatory Commission}




\section{DISCLAIMER}

This report was prepared as an account of work sponsored by an agency of the United States Government. Neither the United States Government nor any agency Thereof, nor any of their employees, makes any warranty, express or implied, or assumes any legal liability or responsibility for the accuracy, completeness, or usefulness of any information, apparatus, product, or process disclosed, or represents that its use would not infringe privately owned rights. Reference herein to any specific commercial product, process, or service by trade name, trademark, manufacturer, or otherwise does not necessarily constitute or imply its endorsement, recommendation, or favoring by the United States Government or any agency thereof. The views and opinions of authors expressed herein do not necessarily state or reflect those of the United States Government or any agency thereof. 


\section{DISCLAIMER}

Portions of this document may be illegible in electronic image products. Images are produced from the best available original document. 

employees, makes any warranty, express or implied, or assumes any legal liability or responsibility for the accuracy, completeness, or usefulness of any information, apparatus, product, or process disclosed, or represents that its use would not infringe privately owned rights. Reference herein to any specific commercial product, process, or service by trade name, trademark, manufacturer, or otherwise does not necessarily constitute or imply its endorsement, recommendation, or favoring by the United States Government or any agency thereof. The views and opinions of authors expressed herein do not necessarily state or reflect those of the United States Government or any agency thereof.

Distribution Category: R1, R7

NUREG/CR--4375;

TI86 004392

\title{
THEORY, DESIGN, AND OPERATION OF LIQUID METAL FAST BREEDER REACTORS, INCLUDING OPERATIONAL HEALTH PHYSICS
}

\author{
Steven R. Adams
}

Published October 1985

\author{
Idaho National Engineering Laboratory \\ EG\&G Idaho, Inc. \\ Idaho Falls, Idaho 83415
}

\author{
Alan K. Roecklein \\ NRC Project Manager
}

Prepared for the

Division of Facility Operations

Office of Nuclear Regulatory Research

U.S. Nuclear Regulatory Commission

Washington, D.C. 20555

Under Contract No. DE-AC07-76ID01570

FIN No. A6314 


\begin{abstract}
A comprehensive evaluation was conducted of the radiation protection practices and programs at prototype LMFBRs with long operational experience. Installations evaluated were the Fast Flux Test Facility (FFTF), Richland, Washington; Experimental Breeder Reactor II (EBR-II) Idaho Falls, Idaho; Prototype Fast Reactor (PFR) Dounreay, Scotland; Phenix, Marcoule, France; and Kompakte Natriumgekuhlte Kernreak Toranlange (KNK II), Karlsruhe, Federal Republic of Germany. The evaluation included external and internal exposure control, respiratory protection procedures, radiation surveillance practices, radioactive waste management, and engineering controls for confining radiation contamination. The theory, design, and operating experience at LMFBRs is described. Aspects of LMFBR health physics different from the LWR experience in the United States are identified. Suggestions are made for modifications to the NRC Standard Review Plan based on the differences.
\end{abstract}

FIN No. A6314-Occupational HP at LMFBRs 


\section{EXECUTIVE SUMMARY}

A study funded by the Nuclear Regulatory Commission (NRC) was conducted to identify and describe the differences between Light Water Reactor (LWR) and Liquid Metal Fast Breeder (LMFBR) health physics programs. The NRC will use the information to update the Standard Review Plan. The Nuclear Regulatory Commission's Standard Review Plan (SRP) is prepared for the guidance of the Office of Nuclear Reactor Regulation's staff responsible for review of applications to construct and operate nuclear power plants. The SRP provides the NRC review staff sufficient information to evaluate the applications to ensure that the nuclear power plant can be constructed and operated without undue risk to the health and safety of the public.

In a coordinated work effort with Argonne National Laboratory-West (ANL-W) in 1983, health physics programs at operating LMFBR facilities in the United States, Scotland, France, and the Federal Republic of Germany were evaluated. An extensive literature review was also made concerning the theory, design, and operating experience at past and present LMFBRs.

The health physics evaluation included defining the radiological source terms at LMFBRs and characterizing them qualitatively and quantitatively throughout the reactor systems. Investigated were radiation surveillance or monitoring methods, radiation protection practices and programs dealing with external and internal exposure control, waste management, respiratory protection procedures, and engineering controls for confining radiation and contamination. Elements of the health physics programs unique to LMFBRs have been identified.

The primary differences in the operational health physics programs at LMFBRs are principally owing to the use of sodium as a coolant. Use of sodium introduces unique radiological source terms, $\mathrm{Na}-24$ and Na-22. Sodium also presents distinct challenges in the handling of radioactive waste and in doing maintenance on sodium-wetted equipment. Personnel at LMFBRs require training in sodium technology to meet the special challenges. Since the power density is higher in an LMFBR than in an LWR, and the neutrons in an LMFBR are not slowed down to thermal energies by the sodium, the potential for high energy neutron leakage from the core is greater in an LMFBR than in an LWR. Operational health physics experience at LMFBRs with radiation and contamination control has been highly satisfactory. Personnel exposure are very low in comparison to LWRs.

Gaseous radionuclides present in LMFBR effluents are $\mathrm{Ne}-23$, Ar-39, Ar-41, noble gases, and tritium. The only gaseous radionuclide produced in LMFBRs that exceeds that of an LWR at comparable thermal power is tritium. Comparison of liquid radioactive waste produced at LMFBRs with that produced at LWRs shows that the volume and activity released at LMFBRs to be orders of magnitude smaller. However, solid waste disposal at LMFBRs will require more research and development for converting contaminated sodium to inert compounds suitable for disposal.

Methods used for monitoring liquid and gaseous effluents at LMFBRs were not found to be different than at LWRs. Process monitoring of sodium purity, measuring and recording of radioactive concentrations in plant sodium, and the use of cold traps for maintaining control of sodium impurities in the liquid coolant system were found to be very different from the analogous LWR water chemistry technology. The potential role of cold trapping for removing radioactive products from the coclant of LMFBRs has not been fully explored. A systematic study of cold trapping performance in operating reactors is highly desirable.

Sections of the NRC Standard Review Plan (NUREG-0800) pertaining to occupational health physics will require substantial modification before they can be applied to LMFBRs. The modifications are owing mainly to the use of sodium coolant. Regulatory Guides $1.8,1.33,8.8,1.112,8.2$, and 8.10 will require changes in order to be applicable to LMFBRs. Other acceptance criteria used in the Standard Review Plan that will have to be modified for use in licensing LMFBRs are NURECi-0718, $-0737,-0103,-0123$, and -0212 .

Future research and development needs for LMFBRs are related to health physics instrumentation, secondary containment studies, radiological source term kinetics in containment and the environment, and the use of probabilistic risk assessment for dose optimization. 
Appendix A discusses in depth the theory, design, and operating experience of LMFBRs. It discusses the physics of breeding, major design objectives, and mechanical and thermal systems design. The review of operational experience includes the reactor features and operating history of early experimental LMFBRs, early power and test reactors, and the prototype reactors. 


\section{CONTENTS}

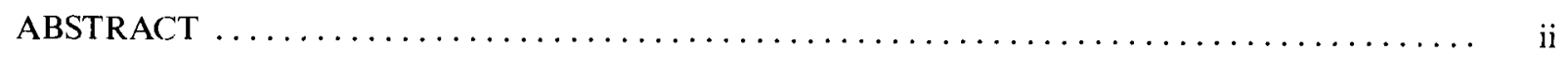

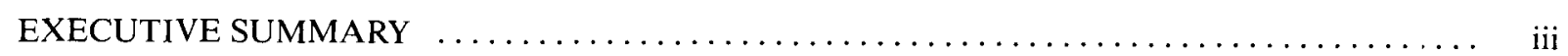

THE BREEDER REACTOR AND NUCLEAR POWER $\ldots \ldots \ldots \ldots \ldots \ldots \ldots \ldots \ldots \ldots \ldots$

RADIATION PROTECTION AT LIQUID METAL FAST BREEDER REACTOR PLANTS $\ldots \ldots \quad 2$

Operational Health Physics Program Responsibilities $\ldots \ldots \ldots \ldots \ldots \ldots \ldots \ldots \ldots \ldots \ldots$

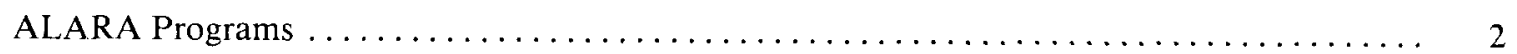

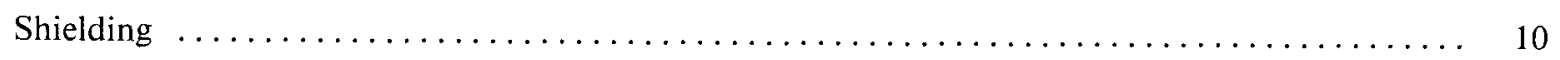

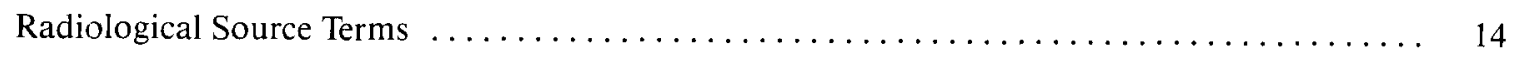

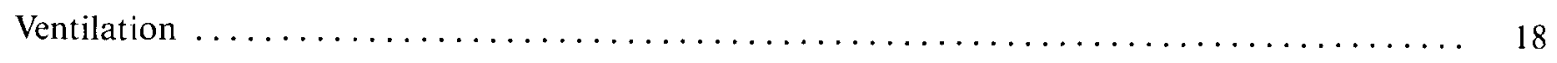

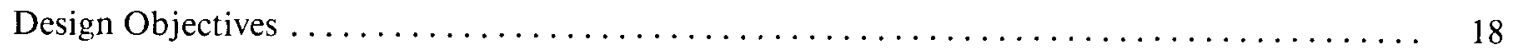

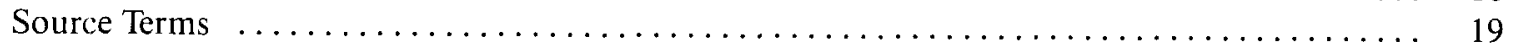

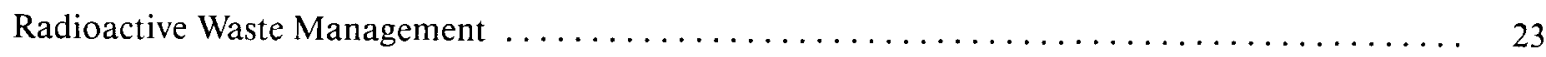

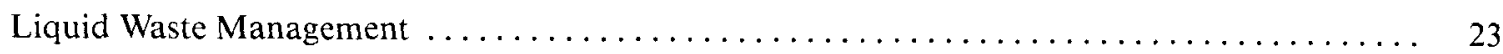

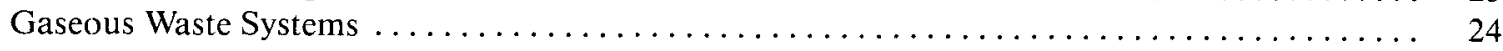

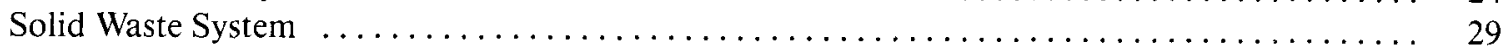

Process and Effluent Radiological Monitoring Systems $\ldots \ldots \ldots \ldots \ldots \ldots \ldots \ldots \ldots \ldots \ldots \ldots$

Sodium Impurity Monitoring and Analysis Systems $\ldots \ldots \ldots \ldots \ldots \ldots \ldots \ldots \ldots \ldots \ldots \ldots \ldots$

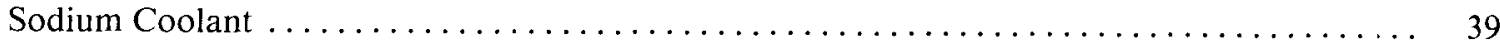

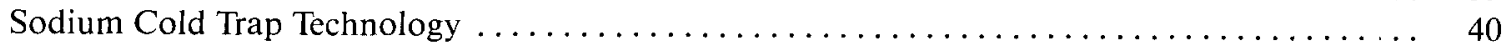

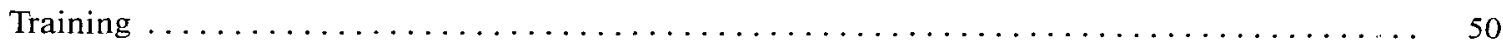

COMPARISON OF LMFBR HEALTH PHYSICS PROGRAM WITH THE REQUIREMENTS

OF THE USNRC STANDARD REVIEW PLAN $\ldots \ldots \ldots \ldots \ldots \ldots \ldots \ldots \ldots \ldots \ldots \ldots \ldots \ldots \ldots$

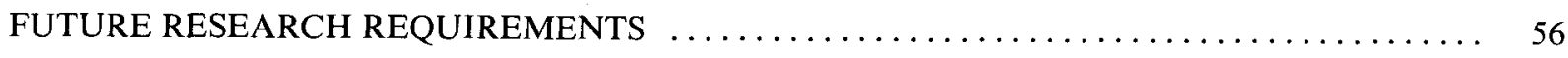

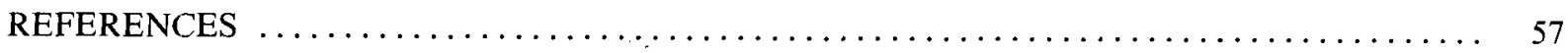

APPENDIX A-LIQUID METAL FAST BREEDER REACTOR: THEORY, DESIGN, AND OPERATIONAL EXPERIENCE $\ldots \ldots \ldots \ldots \ldots \ldots \ldots \ldots \ldots \ldots \ldots \ldots \ldots \ldots \ldots \ldots \ldots \ldots \ldots \ldots \ldots$

\section{FIGURES}

1. Tritium and hydrogen concentration in EBR-II sodium coolant systems $\ldots \ldots \ldots \ldots \ldots \ldots \ldots 28$

2. GLASS activities data failure of a metal-fueled driver element at EBR-II $\ldots \ldots \ldots \ldots \ldots \ldots .34$ 
3. Three-dimensional plot of xenon gas tag nodes for the experimental subassemblies in EBR-II during Run 111

4. Schematic of a sodium cold trap for MASCOT calculations

\section{TABLES}

1. Man-rem expenditures per year $[\mathrm{MW} / \mathrm{y}(\mathrm{t})]$ for LMFBRs and $\mathrm{LWRs} \ldots \ldots \ldots \ldots$

2. Man-rem expenditures at the Dounreay Nuclear Power Development Establishment ........ 5

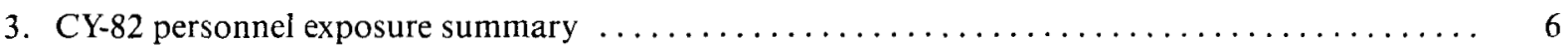

4. Summary of routine radiation survey data during FFTF Cycle $1 \ldots \ldots \ldots$

5. Exposure histories for EBR-II work groups $\ldots \ldots \ldots \ldots \ldots \ldots \ldots \ldots \ldots \ldots \ldots \ldots$

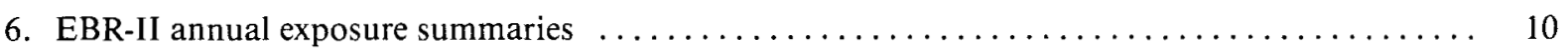

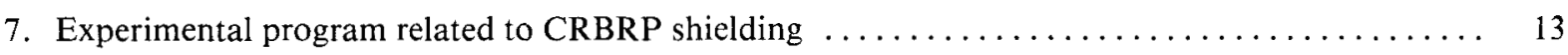

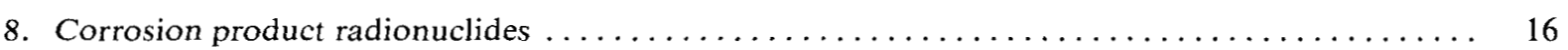

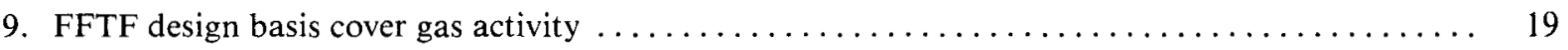

10. ANL-WEST and EBR-II radioactive gaseous releases, $1968-1978 \ldots \ldots \ldots \ldots \ldots$

11. Comparison of LMFBR liquid radioactive waste production with U.S. PWRs . . . . . . . 24

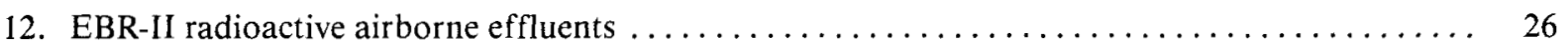

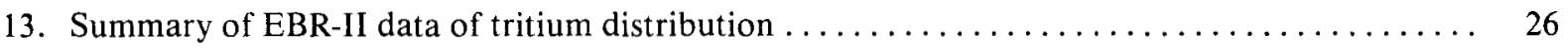

14. Methods used to identify sources of fission-product release in EBR-II $\ldots \ldots \ldots \ldots$

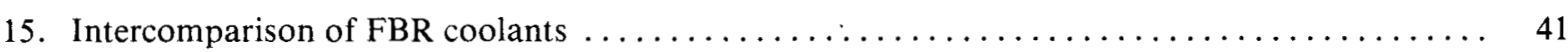

16. General guidelines for IHTS cold trap design $\ldots \ldots \ldots \ldots \ldots \ldots \ldots \ldots \ldots \ldots \ldots$

17. Radionuclides detected in primary circuit cold traps of FMFBRs $\ldots \ldots \ldots \ldots \ldots$

18. Purification coefficients for the BOR-60 cold trap $\ldots \ldots \ldots \ldots \ldots \ldots \ldots \ldots \ldots \ldots \ldots \ldots \ldots \ldots \ldots$

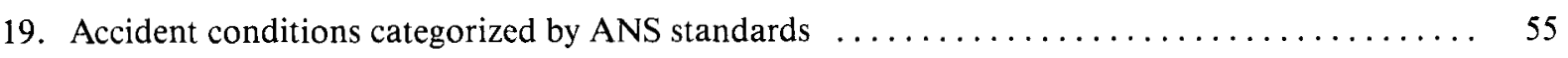




\section{THEORY, DESIGN, AND OPERATION OF LIQUID METAL FAST BREEDER REACTORS, INCLUDING OPERATIONAL HEALTH PHYSICS}

\section{THE BREEDER REACTOR AND NUCLEAR POWER}

Early nuclear physicists often speculated on reactors of the future in terms of their being a source of commercial power. One of their concerns was the long-range availability of $\mathrm{U}-235$ and $\mathrm{Pu}-239$. Fermi and Zinn, especially, became intrigued with the idea of breeding plutonium from U-238, and as early as the spring of 1944 they discussed the possibility of building a fast-neutron breeder reactor to demonstrate the feasibility of the breeding concept. Eventually this interest resulted in the development of the world's first fast neutron reactor, Clementine, at Los Alamos, New Mexico in 1946. By December 20, 1951, the first usable amounts of electricity to be generated from a nuclear power reactor were produced from a liquid metal fast breeder reactor (LMFBR), EBR-1, at Arco, Idaho.

In the 34 years after EBR-1, four LMFBRs in the 250- to 600-MWe power range began producing electricity and desalinizing water in three European countries, and construction on a 1200-MWe LMFBR neared completion. By the end of this decade it is expected that LMFBRs in the 1200- to 1600-MWe range will be under construction in four countries-the United Kingdom, France, West Germany, and the U.S.S.R. Eight nations on three continents will be operating LMFBR power reactors or fast test reactors within the next ten years. For many countries with few indigenous energy resources, the dream that began in the middle of the 20th century of a safe, economical, inexhaustive, and practically independent energy source appears likely to become a reality early in the 21 st century.
In the development of LMFBRs, it was recognized that the potential for accidental release of radiation and radioactive materials is present as it is in any nuclear reactor system. A considerable portion of the overall technical effort expended within the nuclear industry in LMFBR development has been allocated to minimize the potential releases. This safety awareness, which consciously permeates the process from conceptual design of a reactor through the licensing process and long-term operation, ensures that LMFBRs will be operated so as to minimize any undue risk to the health and safety of facility personnel and the public, and prevent harm to the environment.

One element of the safety program at LMFBRs is health physics. Operational Health Physics is concerned with radiological engineering and protection, personnel and environmental monitoring, and plant chemistry.

This NUREG reviews the operational health physics programs at LMFBRs and compares and contrasts them with the programs at light water reactors (LWRs). The body reviews LMFBR operational health physics program objectives, radiation shielding, air contamination control, waste programs, sodium chemistry, and training. The extensive appendix reviews the theory, design, and operational experience at LMFBRs during the last 34 years. 


\section{RADIATION PROTECTION AT LIQUID METAL FAST BREEDER REACTOR PLANTS}

\section{Operational Health Physics Program Responsibilities}

Radiation protection management at nuclear generating stations is responsible for operational health physics activities at the plant. Radiation management ensures enforcement of radiation standards and procedures, reviews proposed methods of plant operation, participates in development of plant documents, and assists in the plant training program by providing specialized training in radiation protection. During preoperational tests and after plant start-up, it provides health physics coverage for all operations, including maintenance, fuel handling, waste disposal, and decontamination. It is responsible for personnel and in-plant radiation monitoring, environmental surveys and monitoring, and health physics instrument calibration, and maintains records of personal exposures, and in-plant radiation and contamination levels. It is responsible for ensuring that plant personnel exposures are maintained as low as is reasonably achievable (ALARA) through implementation of an established ALARA program.

Operational Health physics management is responsible for providing an adequate program of health surveillance for all plant operations involving potential radiation hazards. They inform the plant manager of all radiation hazards and conditions relating to potential exposures, contamination of plant and equipment, or contamination of site and environs. Their responsibilities include training and supervising health physics technicians, planning and scheduling monitoring and surveillance services, scheduling technicians to aroundthe-clock shift coverage as required, and maintaining current data files on radiation and contamination levels, personal exposures, and work restrictions. They ensure that operations are carried out within the provisions of the appropriate radiological hygiene standards and procedures; they establish an ALARA program to maintain the occupational radiation doses as low as reasonably achievable; and they provide assistance and advice to the plant manager during radiological emergencies. These responsibilities are implemented by an operational health physics program.
The primary responsibilities and objectives of the operational health physics programs at an LMFBR facility are no different than those at a light water reactor (LWR) plant. However, the organization, personnel, and training required to meet these responsibilities are somewhat different at the LMFBR facility.

The differences in operational health physics programs at LMFBRs principally result from the use of sodium as the reactor coolant. A few substantive modifications in the organization and administration of a health physics program designed for a LWR are required for its use at an LMFBR. An LMFBR health physics program necessitates the factoring of industrial hygiene and safety in the use of sodium into radiation protection, modifying training requirements to include sodium technology, reviewing the analytical models used in preoperational siting studies to determine the quantitative effects sodium has on releases to the environment, and modifying, if necessary, the environmental monitoring program.

Personnel education, experience, and training requirements for an LMFBR operational health physics program differ only slightly from those at an LWR. LMFBRs require personnel trained in handling and decontaminating sodium wetted surfaces, sodium chemistry, and monitoring sodium purity.

Radiation protection procedures associated with bioassay, instrument design, health physics surveys, waste disposal of contaminated sodium, and fire protection engineering are also different at an LMFBR.

Differences in the operational health physics programs at LMFBR facilities are discussed below with respect to ALARA, shielding, radiological source terms, waste management, process and effluent monitoring, sodium impurity monitoring, and training.

ALARA Programs. The primary responsibility of operational health physics management is to reduce the radiation dose to workers to as low as is 
practicable, commensurate with sound economics and operating practices. Paragraph 20.1 (c) of 10 CFR 20, "Standards for Protection Against Radiation," states, in part, that NRC licensees should make every reasonable effort to maintain radiation exposure as far below the limits specified in that part as practicable. NRC Regulatory Guide 8.8 (RG 8.8), "Information Relevant to Maintaining Occupational Radiation Exposure as Low as is Reasonably Achievable (Nuclear Power Reactors)," is addressed to applicants for a license and tells them what information is relevant and should be included in their application with respect to keeping occupational radiation exposure to employees to as low as is reasonably achievable (ALARA). RG 8.8 applies only to nuclear power reactors. RG 8.10 describes to all specific licensees the general operating philosophy, which is the necessary basis for a program of maintaining occupational exposures ALARA.

Operational health physics management has established formal programs at nuclear generating stations to ensure that occupational radiation exposures to employees are kept ALARA. An ALARA program has full management commitment to the overall objectives of ALARA. It publishes for the design and operating group's specific administrative documents and procedures that emphasize the importance of ALARA throughout the design, testing, start-up, operation, and maintenance phases of the reactor. The program continually appraises management of radiological conditions in the operating reactor by its on-site health physics staff. The effectiveness of the ALARA program is reviewed and appraised at a corporate ALARA committee consisting of representatives from the design, operations, and radiation protection groups. The committee consists of key management and technical staff who have extensive backgrounds in reactor radiation control, including such areas as reactor layout, shielding, personnel access control, ventilation, waste management, area and personnel monitoring, reactor operations, and reactor maintenance. The committee periodically evaluates the overall ALARA program by assessing trends in occupational exposures or other radiation control problems, by reviewing reactor operating reports and radiation exposure profiles, and by conducting on-site audits of the ALARA effort.

Specific authority and responsibilities of the ALARA committee include the following:
- Authority from upper management for implementing an ALARA program with the organizational freedom to ensure development and implementation of ALARA policies

- Responsibility to ensure that the ALARA program incorporates ALARA management philosophy and regulatory requirements, with specific goals and objectives for their implementation

- Responsibility to ensure that the ALARA program has an effective measurement system, periodically reviewing the measurement system's results and determining the degree of the system's success.

- Authority for producing proceclures and practices by which specific ALARA goals and objectives will be achieved.

- Authority to obtain resources needed to achieve goals and objectives necessary to maintain ALARA occupational radiation exposures

- Responsibility to ensure that the ALARA program is implemented from initial planning through decommissioning of the plant

- Responsibility to review plant design features, operating procedures, and maintenance practices, and to audit the on-site radiation control program, to ensure that the objectives of the ALARA program are attained

- Responsibility to ensure that experience gained during the operation of nuclear power plants relative to in-plant radiation control is factored into revisions of operating procedures, where necessary to ensure that procedures indeed do meet the objectives of the ALARA program

- Responsibility to evaluate trends in the exposure of station personnel, and if found adverse to take action to correct them.

Findings of the ALARA committee are promptly reported to top management, with appropriate recommendations for improvement or correction. 
Responsibilities of radiation protection management with respect to the ALARA program include the following:

- Personnel are made aware of management's commitment, their group's ALARA goals, and their personal responsibilities

- A well supervised radiation protection program exists, with well defined responsibilities

- Workers receive sufficient training

- Modification to equipment and maintenance procedure is made when it will substantially reduce exposure at reasonable cost

- Adequate staff exists to determine the location, operation, and job categories associated with radiation exposure in the facility

- Radiation protection staff examine ways to reduce exposure

- Adequate equipment and supplies for radiation protection is provided.

ALARA activities associated with the design, fabrication, construction, and preoperational testing activities involve the interaction of multiple engineering disciplines, such as radiation analysis, shielding, system, and component designers. Although radiation fields at LMFBR facilities may differ qualitatively and quantitatively from an LWR, the same analytical techniques can be applied. Health physics management establish review and control procedures designed to incorporate and evaluate specific ALARA features. Review and controls include the following:

- Established acceptable radiation exposure levels

- Components and systems designed to achieve exposure and shielding objectives

- Appropriate documentation available to the ALARA committee so they can evaluate and manage the achieving of radiation exposure objectives
- Reviews by experienced health physicists to ensure the use of applicable current LMFBR information.

Plant management is responsible for developing plant radiation exposure objectives for specific functions and systems. Allocations are developed for estimated radiation exposure, which are based on the consideration of the total staff required to operate and maintain the facility, and the radiation exposure objectives for individuals as well as the group. Objectives are also developed for radiation exposures of contract and utility personnel.

After radiation exposure objectives, shielding criteria, radiation source terms, and time-access requirements are identified, system designers proceed with the objective to reduce total annual radiation exposure associated with the system to a level as low as reasonably achievable.

Management is assisted in its control of individual system design features that influence radiation exposure at an LMFBR by the performance of collective occupational radiation assessment. This assessment is described in RG 8.19 for LWRs. The dose assessment process consists of the following evaluations:

- Dose for specific categories of cells (primary heat transfer cells, reactor containment building, reactor service building, etc.)

- Dose by skill classification (operators, mechanical maintenance, electrical maintenance, etc.)

- Dose by system (auxiliary sodium, etc.)

- Dose by individual piece of major equipment.

This information is compiled from input data provided by the following: the component, manhours of operation and maintenance required for each significant system component, frequency of activity, and the cell or building number. This, together with the predicted cell dose rate forms the basis of radiation exposure studies.

Radiation exposure information is periodically reviewed and updated as the system and component 
design and analysis are developed. Using this system, the significant contributors to radiation exposure can be identified, and appropriate ALARA action can be taken. The cognizant radiation protection engineers and the shielding designers from each reactor manufacturer and the architect engineer participate in the reviews by approving the shielding design of each component. All changes to plant design are reviewed and the impact on ALARA determined. An ALARA program for normal operations, refueling, in-service inspection, and maintenance activities at LMFBRs can be developed that fully meet the intent of NRC Regulatory Guides 8.8 and 8.10, and 10 CFR 20 .

The review of operational health physics programs discerned no differences between LMFBR and LWR facilities in their organization and administration of ALARA programs that can be credited solely to the type of reactor involved. Evaluation of the ALARA programs at the five LMFBRs visited in this investigation showed that differences of LMFBR organization and administration are more a function of licensing agency priorities and country of origin than of reactor type.

The review found more noteworthy the differences between LMFBR and LWR facilities in their implementation of ALARA programs. During both normal and off-normal operations during the lifetime of the plant, the LMFBR presents radiological hazards that stand apart from the LWR. Examples are potentially very large beta-gamma dose rate ratios during maintenance, tritium instead of noble gases as the primary source term to the environment, handling of contaminated sodium, and training of plant personnel in sodium technology. Specific differences are discussed throughout the rest of this Section.

Experience at Operating LMFBRs. Experience with radiation and contamination control at LMFBRs has been highly satisfactory, having extremely low levels of personnel exposure and only limited need for restrictions on access. As shown in Table 1, the man-rem expenditures per $\mathrm{MW} / \mathrm{y}_{(\mathrm{t})}$ compares very favorably with LWRs.

Dounreay-Radiation doses received by the staff at the Dounreay Nuclear Power Development Establishment are extremely low, as indicated in Table 2. Doses are assessed by measurement of film badges, which are changed each month. Doses are compared with the film threshold and are seldom distinguishable from it. In no year has the total dose above film threshold (film threshold is 0.01 rad per film), excluding deemed doses as described below, amounted to more than 3.3 man-rem. Plant operations contributing most to this dose are repairs to hot cell windows and component decontamination. For example, work on hot cell windows in 1980 contributed a total of 1.1 man-rem, or nearly $50 \%$ of the dose actually measured above threshold. To achieve this low level, steel shield locks were placed above the fuel storage tank and a

Table 1. Man-rem expenditures per year [MWy(t)] for LMFBRs and LWRs

$\begin{array}{lc}\text { Reactor Type } & \text { Man-Rem/MWy(t) } \\ \text { BWR } & 0.92 \\ \text { PWR } & 0.5 \\ \text { LMFBRs } & \\ & \\ \text { Phenix } & \\ \text { FFTF } & 0.32 \\ \text { DFR } & 0.99 \\ & 0.45\end{array}$

Table 2. Man-rem expenditures at the Dounreay Nuclear Power Development Establishment

\begin{tabular}{lllll} 
& \multicolumn{3}{c}{ Year } \\
\cline { 2 - 4 } & $\underline{1980}$ & $\underline{1981}$ & $\underline{1982}$ \\
Average rem/year for radiation workers at the reactor facility & 0.23 & 0.15 & 0.22 \\
Total man-rem at the establishment & 83.0 & 59.0 & 77.3
\end{tabular}


portable lead shield was suspended behind the window being maintained. As another example, the total dose was 0.3 man-rem when maintenance work was done on the fuel charge machine. This does not include preparatory decontamination, which was estimated to have contributed a further dose no greater than 0.3 man-rem.

The total registered dose annually, although low in comparison with that for other types of nuclear reactors, is dominated by components that are attributed rather than actually measured. "Deemed" doses are attributed at the maximum rate allowable ( $0.42 \mathrm{rem} / \mathrm{month})$ per every film lost or damaged, and is assumed that every member of the workforce receives the film threshold dose $(0.01 \mathrm{rem})$. The threshold dose is the minimum detectable dose that can be measured with the film badge. Clearly, these aspects become even more important as doses are reduced. Attention is being given to ways of reducing the attributed components, so that the actual dose can be more precisely quantified.

Shielding of the reactor top has proven very satisfactory with general levels of radiation in microrad per hour range at full power. Some additions have been made to the shielding in localized areas, and consequently there are now only a very few places where radiation fields are even a few tens of a millirad per hour. The secondary sodium pipework, which links the intermediate heat exchangers in the reactor tank with the steam generators in an adjacent building, is unshielded. In localized areas of low occupancy, the radiation level from this pipework is up to 3 millirad per hour. Radiation levels from fuel and active handling hardware are similarly low.
A single-barrier contamination control zone is established on the reactor top when access is gained during shutdown to the primary circuit. No significant contamination problems have arisen. Experience in other areas of the plant has been similar. Only on few occasions has it been necessary to set up an active area with a double-barrier enclosure.

Monitoring the air in the building that contains the reactor and irradiated fuel storage cell has shown negligible airborne activity. At the end of each year, the filters from the air monitors are analyzed using gamma spectrometry. Although evidence of Co-60, Mn-54, and Cs-137 has been found, total activity is equivalent to the exposure of a single filter to one maximum permissible concentration (MPC) for 1 hour. Tritium levels are routinely monitored throughout the plant and are well below allowable concentrations. Samples of boiler water average one hundredth of the level allowed in drinking water. Airborne tritium levels (from steam leaks) are less than one thousandth of the derived air concentration allowed by regulations.

Discharges from the plant stack have been limited to noble gases and are indistinguishable from background. Estimates of gas blanket leakage, together with measured concentrations of xenon-133 and xenon-135, suggest the release of not more than three curies in a year. No other species, such as I-131, or long-lived particulates has been detected by the stack monitor. Tritium is released in gaseous form from the gas blankets above sodium surfaces and from decontamination facilities. The total release is estimated to amount to about 150 curies annually.

FFTF-Plant personnel radiation exposures at FFTF are low, as shown in Table 3. The values

Table 3. CY-82 personnel exposure summary

\begin{tabular}{|c|c|c|c|c|c|c|}
\hline \multirow[b]{2}{*}{ Group } & \multicolumn{2}{|c|}{ 1st Quarter } & \multicolumn{2}{|c|}{ 2nd Quarter } & \multicolumn{2}{|c|}{ 3rd Quarter } \\
\hline & $\begin{array}{c}\text { Number in } \\
\text { Group }\end{array}$ & $\begin{array}{l}\text { mrem/ } \\
\text { Person }\end{array}$ & $\begin{array}{c}\text { Number in } \\
\text { Group }\end{array}$ & $\begin{array}{l}\text { mrem/ } \\
\text { Person } \\
\end{array}$ & $\begin{array}{c}\text { Number in } \\
\text { Group }\end{array}$ & $\begin{array}{l}\text { mrem/ } \\
\text { Person } \\
\end{array}$ \\
\hline Operations & 105 & 27 & 99 & 9 & 105 & 4 \\
\hline Maintenance & 143 & 16 & 138 & 16 & 134 & 2 \\
\hline IEM Cell & 22 & 4 & 23 & 4 & 33 & 1 \\
\hline Others & 65 & 16 & 16 & 7 & 97 & 6 \\
\hline
\end{tabular}


shown are within the statistical variation in the dosimetry system for very low doses, and are at preoperational levels. Maximum individual dose for a quarter was $220 \mathrm{mrem}$ and was associated with maintenance personnel working at another reactor facility during the second quarter. The highest exposure for personnel not associated with work at another reactor facility was less than $50 \mathrm{mrem}$ for a quarter.

General area radiation levels have been very low. Dose rates measured in routinely occupied areas were less than the $0.2 \mathrm{mrem} / \mathrm{h}$ designed value. The few exceptions to design levels involved low-level, small area streaming through shield penetrations. For example, the maximum shield contact reading was $8 \mathrm{mrem} / \mathrm{h}$ on a shield located about $10 \mathrm{ft}$ above floor level. Other streaming locations are equally inaccessible or in areas with extremely low occupancy.

Table 4 summarizes routine radiation survey data. The values were extracted from weekly routine survey reports and do not reflect special situations, such as entry into cells containing primary sodium and maintenance on radioactive systems. Special radiation surveys were performed for these operations and the data are discussed below.

Routine radioactive contamination surveys are also conducted. No contamination was detected in the routinely occupied areas during the first operational period (cycles 1A and 1B) at FFTF. Local contamination control areas exist for specific tasks performed under radiation work procedures.

Radiation surveys conducted in support of radiation work in the reactor show direct levels ranging from background to about $1 \mathrm{rem} / \mathrm{h}$. Contamination levels ranged from background to about $60,000 \mathrm{dpm} / 100 \mathrm{~cm}^{2}$. The $1 \mathrm{rem} / \mathrm{h}$ direct radiation was associated with primary sodium cover gas sampling evolutions during cycle $1 \mathrm{~A}$. The radiation level was at contact with the gas tag sample trap (GTST) prior to installation of the shipping cover. With the shipping cover in place, the contact radiation level was $80 \mathrm{mrem} / \mathrm{h}$, and personal exposure during the sampling evolution was limited to about $5 \mathrm{mrem}$. The $60,000 \mathrm{dpm} / 100 \mathrm{~cm}^{2}$ contamination level was associated with fuel handling, and was a direct reading on a sodium contaminated floor valve.

An initial entry into cell 489 on July 8,1982 (following cycle $1 \mathrm{~A}$ ), showed general area radiation levels less than $0.5 \mathrm{mrem} / \mathrm{h}$. A maximum reading of $1 \mathrm{mrem} / \mathrm{h}$ was obtained in contact vrith a pipe containing primary sodium.

An entry into cell 490 on June 26, 1982, showed general area levels less than $1 \mathrm{mrem} / \mathrm{h}$. The maximum loose contamination level in cell 490 was about $5,000 \mathrm{dpm} / 100 \mathrm{~cm}^{2}$. Radiation and contamination levels associated with the IEM cell, the sodium removal system, and the radioactive liquid waste system were low, less than a few $\mathrm{mrem} / \mathrm{h}$, and less than about $10,000 \mathrm{dpm} / 100 \mathrm{~cm}^{2}$ removable contamination.

EBR-II-Table 5 summarizes the radiation exposure for EBR-II during 1970 through 1977. Data are provided for personnel in four major categories: reactor operations, instrumentation and control maintenance, reactor systems mechanical maintenance, and health physics.

The reactor operations group is composed of four crews that man the continuous operation of the EBR-II. Each crew consists of 14 pecple, three of which are management. The remainder of reactor operations indicated in Table 5 is made up of dayshift management and professionals in direct technical support of EBR-II.

The operating crews have 11 technicians who perform water and sodium sampling, control room operation, and data recording for the power plant, reactor plant, and sodium boiler building. Each of the data recording areas have general radiation background levels of less than $5 \mathrm{mR} / \mathrm{h}$, except for the sodium boiler building, which has an area radiation field of about $20 \mathrm{mR} / \mathrm{h}$ and requires about 10 minutes occupancy per shift by one data recorder. The conditions stated above are for normal full-power operation; radiation levels are lower during shutdown periods.

The instrumentation and control system maintenance group provides two technicians to work on each of the four operating crews for routine instrument maintenance and calibration. The remainder of the group of about 25 are management, professionals, and dayshift personnel who support the experiments program and plant modification. Their work area radiation levels vary, depending on plant condition, work routine, plant modification, or experiment support.

The reactor crew was staffed by six or less personnel during the report period, 1970-1977, and is 
Table 4. Summary of routine radiation survey data during FFTF Cycle 1

\begin{tabular}{|c|c|c|c|c|c|c|}
\hline \multirow{2}{*}{\multicolumn{2}{|c|}{ Location }} & \multicolumn{4}{|c|}{$\begin{array}{l}\text { Dose Rate } \\
(\mathrm{mrem} / \mathrm{h})\end{array}$} & \multirow[b]{2}{*}{ Comments } \\
\hline & & $\begin{array}{c}\text { General Area } \\
\text { Average } \\
\text { During Cycle } \\
\end{array}$ & $\begin{array}{c}\text { Maximum } \\
\text { Local During } \\
\text { Cycle } \\
\end{array}$ & $\begin{array}{l}\text { Maximum } \\
\text { Local On } \\
10 / 30 / 82 \\
\end{array}$ & $\begin{array}{c}\text { Dose Rate } \\
\text { Dependent } \\
\text { On Reactor } \\
\text { Power } \\
\end{array}$ & \\
\hline 1. & RSB, 500, Radioactive & 0.5 & 4 & 0.5 & No & $\begin{array}{l}4 \mathrm{mrem} / \mathrm{h} \text { due to temporary storage of IEM } \\
\text { Cell components. }\end{array}$ \\
\hline 2. & RSB, 550, General Area & 0.2 & 1 & 1 & No & $1 \mathrm{mrem} / \mathrm{h}$ due to floor valve adapter. \\
\hline 3. & RSB, 520, Rm. 204 & 0.2 & 0.2 & 0.2 & No & $\begin{array}{l}\text { Looking for potential leaking to secondary } \\
\text { chilled water from IEM Cell Removal } \\
\text { System. }\end{array}$ \\
\hline 4. & RSB, 520, General Area & 0.2 & 0.2 & 0.2 & No & $\begin{array}{l}\text { Local dose could be dependent on cladding } \\
\text { breach \& release of fission gasses. }\end{array}$ \\
\hline 5. & RSB, 543, General Area & 0.2 & 0.2 & 0.2 & No & Same comment as for 4 . \\
\hline 6. & RSB, 533, General Area & 0.2 & 4 & 0.2 & No & $\begin{array}{l}4 \mathrm{mrem} / \mathrm{h} \text { due to small leak of }{ }^{41} \mathrm{Ar} \text { from } \\
\text { RAPS instrument line. }\end{array}$ \\
\hline 7. & HTS-S, 550, General Area & 0.2 & 0.2 & 0.2 & No & - \\
\hline 8. & $\begin{array}{l}\text { HTS-S, Room } 481,493 \text {, } \\
\text { and } 482\end{array}$ & 0.2 & 2 & 2 & Yes & $\begin{array}{l}2 \mathrm{mrem} / \mathrm{h} \text { due to valve stem penetration and } \\
482(\mathrm{P}-633) \text { into Cell } 489 \text {, reactor at } 100 \% \\
\text { Source }{ }^{24} \mathrm{Na} \text {. }\end{array}$ \\
\hline 9. & HTS-S, 550, Room 485 & 0.2 & 3 & 2 & Yes & $\begin{array}{l}2 \& 3 \mathrm{mrem} / \mathrm{h} \text { due to }{ }^{24} \mathrm{Na} \text { radiation stream- } \\
\text { ing around shield plug to Cell } 492-\mathrm{E} \text {, reactor } \\
\text { at } 100 \% \text {. }\end{array}$ \\
\hline 10 . & RCB, 580 Mezzanine & 0.2 & 3 & 1 & Yes & $\begin{array}{l}1 \& 3 \mathrm{mrem} / \mathrm{h} \text { due to contact measurement } \\
\text { on low level flux monitor cooling system. } \\
\text { Source is transported activation products } \\
\text { and } 16 \mathrm{~N} .\end{array}$ \\
\hline 11. & RCB, 550, General Area & 0.2 & 0.5 & 0.2 & No & $\begin{array}{l}\text { General area dose rates in RCB at full power } \\
\text { are not significantly different from back- } \\
\text { ground. } 0.5 \mathrm{mrem} / \mathrm{h} \text { in Primary Sodium } \\
\text { Pump } 1 \mathrm{Pit} \text {. }\end{array}$ \\
\hline 12. & RCB, Head Compartment & 0.2 & 6 & 6 & No & $\begin{array}{l}6 \mathrm{mrem} / \mathrm{h} \text { due to depleted uranium shielding } \\
\text { in two small local areas. General area } 0.2 \\
\mathrm{mrem} / \mathrm{h} \text {. }\end{array}$ \\
\hline 13. & $\mathrm{RCB}, 520$, Room 540 & 0.2 & 0.2 & 0.2 & No & - \\
\hline 14. & RCB, Stairway 517 West & 0.2 & 0.6 & 0.6 & Yes & - \\
\hline 15. & RCB, 520 Room 564 & 0.2 & 0.5 & 0.5 & Yes & $\begin{array}{l}0.5 \text { mrem.h at locked barrier to restricted } \\
\text { access radiation zone. }\end{array}$ \\
\hline 16. & RCB, 520, Room 5548 & 0.2 & 0.2 & 0.2 & No & - \\
\hline 17. & $\mathrm{RCB}, 500$, Room 562 & 0.2 & 0.2 & 0.2 & No & 一 \\
\hline 18. & RCB, 500, Room 570 & 0.2 & 9 & 9 & Yes & $\begin{array}{l}9 \mathrm{mre} / \mathrm{h} \text { due to }{ }^{24} \mathrm{Na} \text { radiation streaming } \\
\text { around shield plug to Cell } 567 \text { (EM pump } \\
\text { cell), reactor at } 100 \% \text { power. }\end{array}$ \\
\hline 19. & RCB, 520, Room 5538 & 0.2 & 0.2 & 0.2 & No & - \\
\hline 20. & $\mathrm{RCB}, 500$, Room 565 & 0.2 & 0.2 & 0.2 & No & 一 \\
\hline 21. & RCB, 520 , Room 5368 & 0.2 & 8 & 6 & Yes & $\begin{array}{l}8 \mathrm{mrem} / \mathrm{h} \text { due to }{ }^{24} \mathrm{Na} \text { radiation streaming } \\
\text { through penetrationin a small, localized area } \\
\text { about } 10 \text { feet above floor. }\end{array}$ \\
\hline 22. & RCB, 500, Room 561 & 0.2 & 0.5 & 0.5 & Yes & $\begin{array}{l}0.5 \mathrm{mrem} / \mathrm{h} \text { due to }{ }^{24} \mathrm{Na} \text { radiation streaming } \\
\text { around shield door to } 532 \mathrm{C} \text {. }\end{array}$ \\
\hline 23. & RCB, 520, Room 522B & 0.2 & 0.5 & 0.5 & Yes & $\begin{array}{l}9.5 \mathrm{mem} / \mathrm{h} \text { at locked gate to } 552 \mathrm{~A} \text {, source is } \\
24 \mathrm{Na} \text { radiation streaming into } 552 \mathrm{~A} \text { from } \\
\text { HTS (521) }\end{array}$ \\
\hline
\end{tabular}


Table 5. Exposure histories for EBR-II work groups

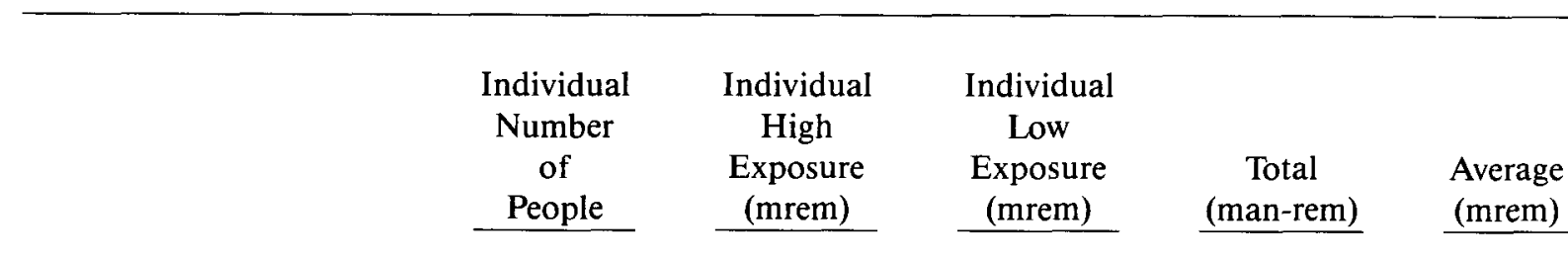

Rx Operations

$\begin{array}{rrrrrr}1970 & 51 & 200 & 0 & 1.100 & 21 \\ 1971 & 48 & 440 & 0 & 3.210 & 66 \\ 1972 & 52 & 600 & 0 & 2.600 & 50 \\ 1973 & 60 & 320 & 0 & 3.275 & 55 \\ 1974 & 58 & 495 & 0 & 5.435 & 92 \\ 1975 & 65 & 475 & 0 & 6.675 & 103 \\ 1976 & 67 & 455 & 0 & 6.953 & 104 \\ 1977 & 69 & 510 & 0 & 10.047 & 183\end{array}$

I\&C Instrumentation
1970
1971
1972
1973
1974
1975
1976
1977

Rx Crew E Maintenance
13

18

18

14

26

31

34

33
500

740

765

350

1330

430

625

543

1.810

139

4.120

6.150

2.290

6.840

4.470

5.980

3.982

66

50

55

92

83
1970
1971
1972
1973
1974
1975
1976
1977

1095

1420

965

715

715

1595

1210

1224

Health Physics
1970
1971
1972
1973
1974
1975
1976
1977

140
300
485
380
210
160
260
251

2.280

3.735

3.749 
the highest exposure group. The group inserts and removes all highly radioactive experiments, and performs the maintenance of fuel handling equipment. The group also handles deposition of irradiation test hardware.

The health physics group provides the necessary radiological controls for routine operation and for the protection of personnel while they are performing their tasks. This is accomplished by four technicians on day shift and one technician on each off-shift.

Health Physics technicians normally perform routine surveillance, conduct radiation level measurement, and perform surveys to assess contamination. The day shift technicians also support the mechanical and electrical maintenance activities, and experimental activities as required.

Table 6 summarizes the exposure required to operate EBR-II during the report period, 1970 through 1977. This includes the number of exposure personnel, the individual high exposure, and the average exposure of the group. There has been a steady increase in man-rem from 1974 through 1977. From Tables 5 and 6 , the following can be noted:
- The average exposure and the total manrem were significantly higher in 1977 than previous years for reactor operations personnel

- The INC instrumentation group exposures have been reasonably steady, with a significant decrease in 1977

- The reactor crew showed an increase in individual low exposure, with other items being reasonably steady for the last 3 years

- The Health Physics group shows few fluctuations in radiation exposure

- The highest individual exposure in 1977 was 1224 mrem, compared to the U.S. DOE limit of $5000 \mathrm{mrem}$.

\section{Shielding}

The ALARA criteria of NRC RG 8.8 are important to containing personnel radiation exposure to very low levels. The guide explains that merely controlling the maximum dose to individuals is not sufficient; the collective dose to all reactor plant

Table 6. EBR-II annual exposure summaries

\begin{tabular}{lcccc}
\hline Year & Number of People & $\begin{array}{c}\text { Individual High } \\
\text { Exposure } \\
\text { (mrem) }\end{array}$ & $\begin{array}{c}\text { Total } \\
\text { (man-rem) }\end{array}$ & $\begin{array}{c}\text { Average } \\
\text { (mrem) }\end{array}$ \\
1970 & 73 & 1095 & 8.145 & 112 \\
1971 & 76 & 1420 & 14.795 & 195 \\
1972 & 79 & 1065 & 15.100 & 191 \\
1973 & 82 & 670 & 8.81 & 107 \\
1974 & 96 & 1330 & 16.355 & 170 \\
1975 & 109 & 1595 & 20.800 & 191 \\
1976 & 114 & 1210 & 21.828 & 191 \\
1977 & 116 & 1224 & 23.176 & 200 \\
\hline
\end{tabular}


personnel must also be kept ALARA. This is an important point; the total man-rem collective dose could increase because of inefficiencies involved in having to use a large number of individuals to accomplish such tasks as maintenance and repairs. RG 8.8 mentions numerous exposure reduction techniques that can be used to lower dose rates and occupational exposures. Many of the techniques are concerned with minimizing the radiological source terms. Where this is not possible, shielding is an effective way to reduce the effect the radiological source term has on occupational exposure.

Shielding is designed to provide radiation protection to operating personnel, the general public, and plant equipment. Shield design must perform a variety of functions to provide this radiological protection under normal operating conditions. These functions are as follows:

- To permit operating personnel access to required portions of the plant in order that they may operate the reactor and its associated systems at rated power and normal capacity (including routine inspections and maintenance of accessible equipment)

- To permit personnel to refuel the reactor (including those functions required to prepare new fuel for reactor service and ship spent fuel for reprocessing or storage)

- To permit access within a reasonable time after reactor shutdown to the high radiation portions of the restricted area (which are maintained as exclusion areas during normal operation)

- To limit the neutron activation of secondary and intermediate sodium, such that the induced radiation dose rates from this radioactive source will not require establishing restricted areas

- To maintain as continuous access areas during normal operations all areas of the site outside of the reactor containment building, reactor service buildings, cells in the plant service buildings, and any secondary sodium piping penetration cells at the intermediate/ reactor containment building interface

- To protect structural components, equipment, and nuclear instruments in order that required functions are safely provided throughout the lifetime of the plant

- To limit the radiation exposure of operating personnel and the general public to that less than required by applicable sections of 10 CFR 20, 50, and 100 .

The thickness of shield walls are set by both shielding and structural requirements. Walls are usually constructed of ordinary concrete. LMFBR concrete shield walls can be errected according to the standards used for LWRs (see Regulatory Guide 1.69 and ANSI N101.6). In some local areas, other shielding materials, such as steel, are used. Shield walls constructed of block have usually been avoided, for seismic considerations. Shield walls or portions of shield walls subject to removial to permit access for equipment repair or replacement are designed to be knocked out and replaced, or provided with removable access plugs. In order to minimize the number of areas in the plant with high radiation levels, cells that contain significant radioactive sources are grouped.

Shielding calculations for determining wall thickness can be performed by a computer code with a detailed geometric model that represents the significant three-dimensional aspects of the sources and shields. Codes used in the shielding arlalysis of LWRs are adequate for LMFBRs. Outside the reactor cavity, the sources present are activated sodium, fission, and corrosion products.

Computer programs employed in the design of shield walls use the discrete ordnance trarisport or point kernel integration techniques to analyze the bulk shielding provided by the walls. In areas of the shield containing discontinuities, such as ducts and penetrations, the design methods employ transport and point kernel scattering methods to provide shielding equivalent to the surrounding bulk shielding in the vicinity of the duct or penetration.

Shield walls with locked access doors are used to isolate high radiation areas of the plant. In addition, these areas are equipped with audible or visible alarms that signal to a control point that a high radiation area is being entered. All locked radiation areas are equipped such that no individual can be prevented from leaving them.

Access to cells containing radioactive-bearing components are provided through the walls or ceiling. The effectiveness of the shielding in meeting 
the design dose rates external to the cells is maintained by use of shield doors or shield plugs, which, if made of concrete have the same thickness as the shield wall penetrated. If other shielding materials are used, the design thickness provides shielding equivalent to that of the wall. Steps and off-sets are provided in all shielding doors and plugs to minimize radiation streaming. For areas requiring multiple penetrations, shielded cavities and chaseways are provided.

Shield performance and design, and basic nuclear data, are being verified to support LMFBR systems. A series of experimental configurations simulating portions of LMFBR shield systems have been designed and experiments have been conducted. The principal experimental program has been conducted at Oak Ridge National Laboratory. A number of other experiments related to shielding have been conducted in the Argonne National Laboratory and support the Clinch River Breeder Reactor Project (CRBRP) nuclear design. The latter program, which provides data useful in evaluating neutron flux and gamma flux distributions in LMFBRs, is described below.

In general, three types of experiments have been conducted to support shielding design: (a) experiments to measure the basic neutron and gamma attenuation characteristics of candidate materials for use in LMFBR shields, (b) experiments to parametrically define shield configuration and dimensional effects on shielding performance, and (c) prototypic or simulation experiments of portions of LMFBR shield systems. In addition to these three types of experiments, measurements of neutron cross section data in the candidate LMFBR shield materials have been conducted. The LMFBR shielding experiment program has progressed from experiments designed to support the FFTF system, to experiments to support the CRBRP system. The scope of experimental programs conducted on FFTF shielding have provided a sound base of experimental data for method and nuclear data verification. FFTF experiments were conducted from 1969 through 1973; LMFBR shielding experiments were initiated in 1973 with emphasis on CRBRP shielding beginning in 1974. ${ }^{1-12}$

The ORNL shielding experiment program was conducted at the ORNL power shielding facility. Experimental configurations employed a collimated beam of neutrons from the TSR reactor configuration as an approximate planar source of neutrons incident on slab simulations of LMFBR shield systems. Simula- tions of experiments used either the bare beam or simulations of calculated neutron energy spectrum incident on the specific portion of the LMFBR shield system, for example, at the reactor core-blanket interface. The design of spectrum modifiers to simulate incident spectrum have been used extensively in TSF programs.

Experiments related to CRBR shield design and conducted in the FFTF program on the TSF were (a) mock-up experiments of the lower shield region of the fuel assemblies, which included representation of the streaming paths between assemblies and through-shield orifice holes, (b) mock-up experiments of the reactor vessel closure assembly penetration gaps, which included parametric investigation of offsets and gap widths for annual gaps and slits in iron, (c) deep-penetration neutron attenuation experiments in sodium, carbon steel, and stainless steel, (d) mock-up experiments to define neutron streaming in the primary inlet and outlet piping penetrations of the reactor cavity wall, the isolation valve cell, and the shield walls adjacent to the heat transport system (HTS) cells, and (e) mock-up experiments of the reactor closure head and head compartment shield system to define neutron and gamma shield effectiveness. These experiments employed spectrum modifiers to obtain prototypic neutron spectra incident on shield systems. The CRBR shielding program has expanded from this original FFTF program to include a number of experiments simulating the material and laminar configurations of tentative LMFBR radial, upper axial, and lower axial shields, and provide tests of calculation methods in prototypic shield configurations. Table 7 describes the scope (completed and planned) of program experiments to support LMFBR shielding design.

In addition to the experiments conducted at the ORNL power shielding facility, an extensive program of experimental analysis has been conducted by ONRL with the reactor manufacturers. These programs were employed to test methodology and basic nuclear data in terms of design solutions of LMFBR shields. The purpose of experimental analysis program was manifold in that it has provided (a) guidance in experiment planning, to ensure adequate data for testing methods and basic nuclear data, (b) guidance in planning the development of design methods required to design shielding for LMFBRs, (c) reactor manufacturers with the vehicle to test and use the methodology prior 
Table 7. Experimental program related to CRBRP shielding

\begin{tabular}{|c|c|c|}
\hline Experiment & Sponsor ${ }^{\mathrm{a}}$ & Objective \\
\hline $\begin{array}{l}\text { Radial blanket and } \\
\text { shield simulation }\end{array}$ & LMFBR & $\begin{array}{l}\text { Provide experimental verification of } \\
\text { neutron flux attenuation through radial } \\
\text { blanket and radial shield simulation }\end{array}$ \\
\hline Near core gamma & CRBR & $\begin{array}{l}\text { Provide experimental verification of } \\
\text { gamma heating rate distributions in } \\
\text { (1) stainless steel and Inconel radial } \\
\text { shield configurations and (2) at core- } \\
\text { blanket and blanket-shield interfaces }\end{array}$ \\
\hline Upper axial shield & CRBR & $\begin{array}{l}\text { Provide experimental verification of } \\
\text { neutron attenuation methods based on } \\
\text { the CRBR reactor closure head simula- } \\
\text { tion with sodium pool simulation }\end{array}$ \\
\hline $\begin{array}{l}\text { Reactor vessel support } \\
\text { area }\end{array}$ & CRBR & $\begin{array}{l}\text { Provide experimental verification of } \\
\text { methods used to analyze reactor vessel } \\
\text { support area neutron streaming }\end{array}$ \\
\hline Concrete rebar & CRBR & $\begin{array}{l}\text { Provide experimental verification of } \\
\text { neutron flux attenuation and secondary } \\
\text { gamma production of reinforced } \\
\text { concrete }\end{array}$ \\
\hline LLFM & & $\begin{array}{l}\text { Provide experimental verification of ex- } \\
\text { vessel LLFM neutron flux and count rate }\end{array}$ \\
\hline Sodium pipe chaseway & $\begin{array}{l}\text { FFTF, } \\
\text { CRBR }\end{array}$ & $\begin{array}{l}\text { Provide experimental verification of } \\
\text { neutron streaming in sodium pipe } \\
\text { chaseway }\end{array}$ \\
\hline $\begin{array}{l}\text { Effect of shield } \\
\text { heterogeneities- } \\
\text { upper axial and } \\
\text { radial shields }\end{array}$ & LMFBR & $\begin{array}{l}\text { Provide experimental determination of } \\
\text { streaming effects due to composition } \\
\text { heterogeneities (Upper Axial and Radial } \\
\text { Shields) }\end{array}$ \\
\hline $\begin{array}{l}\text { Duct streaming- } \\
\text { lower axial shield }\end{array}$ & LMFBR & $\begin{array}{l}\text { Provide experimental determination of } \\
\text { streaming effects due to composition } \\
\text { heterogeneities (Lower Axial Shield) }\end{array}$ \\
\hline $\begin{array}{l}\text { Annular gap and } \\
\text { slit streaming }\end{array}$ & FFTF & $\begin{array}{l}\text { Measure neutron streaming through iron } \\
\text { shields with annular gaps or slits simu- } \\
\text { lating closure head shielding. }\end{array}$ \\
\hline $\begin{array}{l}\text { Core assembly } \\
\text { shield streaming }\end{array}$ & FFTF & $\begin{array}{l}\text { Provide experimental verification of } \\
\text { streaming through coolant holes of core } \\
\text { shields. }\end{array}$ \\
\hline
\end{tabular}


Table 7. (continued)

\begin{tabular}{lll}
\hline \multicolumn{1}{c}{ Experiment } & Sponsor & \multicolumn{1}{c}{ Objective } \\
\hline Sodium penetration & FFTF & $\begin{array}{l}\text { Measure shielding effectiveness of } \\
\text { sodium pool attenuation through up to } \\
15 \text { feet of sodium. }\end{array}$ \\
Inconel penetration & FFTF & $\begin{array}{l}\text { Measure neutron shielding effectiveness } \\
\text { of Inconel shielding material. }\end{array}$ \\
Gamma ray experiment & FFTF & $\begin{array}{l}\text { Provide experimental verification of } \\
\text { neutron transmission through } 34 \text { inches } \\
\text { of carbon and provide verification of } \\
\text { transmitted gamma spectra and dose. }\end{array}$
\end{tabular}

a. Sponsor of experimental involved in providing guidance to AEC-RRD for the specific project. LMFBR experiments are through efforts of reactor manufacturers.

to, or in parallel with, design analyses, and (d) correlation of the design analysis of portions of the CRBR shield system in order to experiment and provide realistic estimates of the uncertainties and experimental-to-calculated bias associated with shield performance. The last item provides a sound basis for shield design in that the detailed design support calculations performed by reactor manufacturers and the independent support calculations performed by ORNL used the techniques and methods demonstrated in the experiment analysis effort.

Results from the LMFBR experiment and experiment analyses programs have demonstrated the validity of the analytical techniques and shield design methods. Detailed results and comparisons of these structures are documented in References 3 through 13.

Radiological Source Terms. In an LMFBR, cladding and in-vessel structural materials become radioactive from the neutron flux. Radioactive species build up in the primary circuit external to the core, caused by neutron activated material corroding out of the piping walls and subsequently being transported in the primary liquid sodium to the primary components (for example, pumps, heat exchangers, valves, and sodium purification systems). The deposition of these radioactive species gives rise to gamma radiation fields intense enough to cause difficulties in maintenance and repair operations. Moreover, such repairs have required large amounts of manpower and have resulted in long plant shutdowns, neither of which is economically favorable. The corrosion product transport (or "crud transport" problem as it is called in water reactor technology) is well known, and considerable maintenance experience has been gained on both water and sodium-cooled reactors.

Calculations made for reactor plants operating with long fuel cycles and at high core outlet temperatures $\left(600^{\circ} \mathrm{C}\right)$ predict radiation levels above $1 \mathrm{R} / \mathrm{h}$ adjacent to the primary system after decay of the sodium $24{ }^{14-16}$

Present reactors, with lower outlet temperatures and shorter fuel cycles, substantially reduce corrosion product transport, to produce radiation levels of about $100 \mathrm{mR} / \mathrm{h}$ is being observed. Extrapolation of calculations to the existing reactor situation results in reasonable agreement 17 .

Reactor experience and test loop data show that both the release of irradiated material and its distribution within the circuit are nonuniform. The most abundant corrosion product in LMFBR nuclides is $\mathrm{Mn}-54$. Co-60 and Co-58 are also produced but are not released at as high a rate as $\mathrm{Mn}-54$, nor are they transported throughout the circuit to the same degree. A major fraction of the deposited corrosion product activity adheres to the deposition site and is not removed by sodium draining or sodium removal processes.

No one control method has been shown sufficient to solve all of the activated corrosion product 
transport problem; a combination of methods is required. Methods under investigation have to do with the effect of oxygen concentration in the sodium, and sodium temperature on nuclide release, development of traps, improved fuel cladding alloys, and removing deposited activity (decontamination). Trapping and decontamination show promising early results. Reduction of the oxygen level of the sodium to correspond with the $115^{\circ} \mathrm{C}$ cold trap temperature is only partially effective at reducing Mn-54 and Co-60 release.

Table 8 presents information concerning the significant radionuclides and activated corrosion product transport. The most prevalent nuclides seen in LMFBRs are Mn-54 and Co-60; others are observed in smaller quantities. It can be seen from the Table that little can be done to eliminate Mn-54, whereas some control over Co-60 formation is possible by restricting the cobalt content of fuel cladding and ducts to $0.05 \%$, and by restricting the use of cobalt-based bearing and hard-facing materials.

LMFBR Experience. At the Dounreay fast reactor, repair of a leak that took place in a radiation field equal to that predicted for high-temperature LMFBR operation required several hundred people and several months downtime for repair. ${ }^{18}$ At the BR-5 LMFBR in the USSR, fission products, Mn-54, and Co-60 were observed on piping. Treatment of the piping with acid etches was necessary to removal all of the deposited radioactivity. ${ }^{19-20}$ At the BOR-60 reactor in the USSR, radiation levels of up to $100 \mathrm{mR} / \mathrm{h}$ adjacent to primary system piping was observed after 3 years of operation. The core outlet temperature varied between 510 and $550^{\circ} \mathrm{C}$. The $\mathrm{Co}-60$ and $\mathrm{Mn}-54$ radioactivity was spread throughout the circuit with greater nuclide deposition in the cold leg. ${ }^{21}$ At the KNK-II reactor in Germany, radiation levels of $100 \mathrm{mR} / \mathrm{h}$ were measured near the heat exchangers after 146 days of full power operation. The core outlet temperature was $550^{\circ} \mathrm{C}$. The radiation level was reduced only about $15 \%$ by draining the sodium. The principal nuclides were Mn54, Co-60, Zn-65, and Ag-110m. Mn-54 tended to preferentially deposit on a nickel rich surface in the hot leg but not the cold leg. 22 It is noteworthy that considerable Ta-182 was produced in the KNK-II core, but only small amounts were detected in the piping. At the Rapsodie reactor in France, radioactive in $\mathrm{Mn}-54$ was observed throughout the piping system, particularly in the cold leg. Very little Co-60 was observed. Radiation levels up to $200 \mathrm{mR} / \mathrm{h}$ were observed on the pump and piping. Washing with water and alcohol, and treatment with a relatively mild nitric-phosphoric acid solution were all ineffective at removing deposited radioactivity; the acid etch was somewhat more effective than the other treatments. ${ }^{23-24}$ At the EBR-II reactor, deposited Mn-54 and Co-60 have been observed on the pump and heat exchanger and in the cold trap. Examination of 316 SS fuel cladding from a high temperature fuel test showed substantial preferential corrosion of Mn-54 and preferential retention of Co-58 and Co-60 at $650^{\circ} \mathrm{C}$, but very little at $510^{\circ} \mathrm{C} .25-26$

The radiation levels observed in the plants above are in reasonable agreement by a factor of three with those predicted using the techniques of References 14 and 27. A significant result is that the contribution of "nuclear corrosion" (recoil ejection plus fast neutron sputtering) has been shown unimportant, in apparent disagreement with earlier hypothesis. ${ }^{28}$ Using the techniques of References 14 and 27, it has been calculated that a uniform removal rate of $25 \mu / \mathrm{yr}$ by fast neutron sputtering will lead to primary system radiation levels well in excess of $10 \mathrm{R} / \mathrm{h}$, which is contrary to actual observations in operating reactors.

Before operational data on LMFBRs became available, investigators in the United States, Germany, Japan, and the United Kingdom began nuclide release and deposition studies in small test loop systems. The need for mass transport data, in addition to that generated from the more conventional corrosion studies of steel and sodium, has arisen for two reasons: (a) it can be shown that an average material corrosion rate of 5-10 $\mu / \mathrm{yr}$ for fuel cladding (completely satisfactory with a wall-thinning standpoint) will give rise to intolerable radiation levels near the primary system components, and (b) the problem nuclides (Mn and $\mathrm{Co}$ ) are present as only minor constituents of the cladding alloys. Existing corrosion theories do not treat minor alloying element behavior in sufficient detail.

Most corrosion and deposition studies (such as found in References 25, 29-34) investigated the release and deposition of Co-60, Mn-54, Fe-59, Cr-51, and Co-50, at temperatures between $550^{\circ} \mathrm{C}$ and $600^{\circ} \mathrm{C}$. The oxygen level in sodium was controlled by cold trapping and measured by a variety of methods: cold trap temperatures were in the range of $115-160^{\circ} \mathrm{C}$. These studies agreed with reactor observations and with each other; the most significant similarities and clifferences are as follows:

- Mn-54 was the most abundant nuclide reduced from irradiated stainless steel; $\mathrm{Cr}-51$, 
Table 8. Corrosion product radionuclides

\begin{tabular}{|c|c|c|c|c|}
\hline Nuclide & $\begin{array}{c}\text { Formation } \\
\text { Reactions(s) }\end{array}$ & $\begin{array}{c}\text { Half-Life } \\
\text { (days) } \\
\end{array}$ & $\begin{array}{l}\text { Gamma-Ray } \\
\text { Energy, MeV }\end{array}$ & Comments \\
\hline $\mathrm{Mn}-54$ & $\begin{array}{l}\mathrm{Fe}-54(n, p)^{\mathrm{a}} \\
\operatorname{Mn}-55(\mathrm{n}, 2 \mathrm{n})\end{array}$ & 313 & 0.84 & $\begin{array}{l}\text { The most prevalent nuclide. } \\
\text { Eliminating all the others still } \\
\text { leaves a significant problem. }\end{array}$ \\
\hline Co-60 & $\begin{array}{l}\operatorname{Co}-59(n, \gamma) \\
\operatorname{Ni}-60(n, p)\end{array}$ & 1913 & $1.17,1.33$ & $\begin{array}{l}\text { Source is Co impurity in } \\
\text { nickel and Co-base wear pads, } \\
\text { bearings, and hardfacing } \\
\text { materials. }\end{array}$ \\
\hline $\mathrm{Co}-58$ & $\mathrm{Ni}-58(\mathrm{n}, \gamma)^{\mathrm{a}}$ & 71 & 0.81 & $\begin{array}{l}\text { Use of a ferritic steel for fuel } \\
\text { cladding eliminates most } \\
\text { Co- } 58 \text {. }\end{array}$ \\
\hline $\mathrm{Fe}-59$ & $\begin{array}{l}\mathrm{Fe}-58(\mathrm{n}, \gamma)^{\mathrm{a}} \\
\operatorname{Co}-59(\mathrm{n}, \mathrm{p})\end{array}$ & 45 & $1.10,1.29$ & - \\
\hline Ta-182 & $\mathrm{Ta}-181(\mathrm{n}, \gamma)$ & 115 & $1.12,1.11$ & $\begin{array}{l}\text { Source concentration increases } \\
\text { in Nb-bearing steel is used in } \\
\text { the neutron flux. }\end{array}$ \\
\hline $\mathrm{Zn}-65$ & $\mathrm{Zn}-64(\mathrm{n}, \gamma)$ & 243 & 1.11 & $\begin{array}{l}\text { Sorce is } \mathrm{Zn} \text { in sodium or from } \\
\text { contamination by } \mathrm{ZnCrO}_{3} \\
\text { rust-proofing paint. }\end{array}$ \\
\hline Ag-110m & $\operatorname{Ag}-109(n, \gamma)$ & 253 & $\begin{array}{l}0.65,0.76 \\
1.47\end{array}$ & $\begin{array}{l}\text { Suspected source is } \mathrm{Ag} \\
\text { impurity in nickel. This nuclide } \\
\text { has not been observed in the } \\
\text { significant quantities in the } \\
\text { U.S. }\end{array}$ \\
\hline Cr-51 & $\begin{array}{l}\operatorname{Cr}-50(n, \gamma)^{a} \\
\operatorname{Cr}-52(n, 2 n) \\
\operatorname{Fe}-54(n, \gamma)\end{array}$ & 28 & 0.32 & $\begin{array}{l}\text { Although substantial, low } \\
\text { gamma energy makes } \mathrm{Cr}-51 \\
\text { transport inconsequential. }\end{array}$ \\
\hline
\end{tabular}

a. Dominant reaction.

$\mathrm{Fe}-59$, Co-60, and $\mathrm{Co}-58$ were released in proportionally lesser amounts. However, the high concentrations, long half-life, and high energy gamma radiation of Co-60 make it a more important problem than $\mathrm{Cr}-51$, Co-58, or $\mathrm{Fe}-59$, which have been observed only in small amounts in actual reactor operation.

- For the most part, Mn-54 was transported throughout the test circuits and deposited more heavily in the lower temperature portion of the loops. Co-60 and $\mathrm{Cr}-51$ showed preferential deposition in the loop hot legs. Mn-54 deposited in loop hot legs in the first few hundred hours of loop operation, and gradually migrated to the lower temperature regions.

- The loop cold traps were more or less ineffective in removing radioactivity at rates 
more than proportional to the cold trap fractional flow. They did, however, act as irreversible sinks for whatever cobalt and manganese deposited in them. The concentration of Mn-54 in cold traps apparently depends on how much Mn-54 has deposited upstream of the cold trap branch line. This suggests that to be most effective as a radionuclide sink, the cold trap branch line should come from a reactor hot leg or above the core.

- Reducing the oxygen level by reducing cold trap temperature resulted in an apparent reduction in the Co-60 source rate but only a small decrease in the Mn-54 source term. Quantitative determination of source rates have shown Mn-54 to be preferentially released and Co-60 to be preferentially retained from irradiated $316 \mathrm{SS}$ specimens. ${ }^{25,35}$

- At all locations in the test loop, deposition was enhanced at regions of increased fluid turbulence, where the hydrodynamic boundary layer thickness is reduced. The significance of this data is that increased nuclide deposition can be expected on pumps, valves, and other locations where additional turbulence is introduced. Unfortunately, maintenance problems are expected to occur at these regions. On the other hand, the data can aid in the design of nuclide traps to enhance deposition of the nuclides and prevent their spread into the reactor primary system.

- Radioactive material was firmly deposited on the test system piping at temperatures above $400^{\circ} \mathrm{C}$; sodium removal processes such as draining, water, steam, or alcohol rinse removed very little activity. Use of acid solutions was necessary to remove deposited activity (described in References 20, 23, 24, and 34). Significant penetration of activity large than $10 \mu$ into the pipe wall has been observed even at $400^{\circ} \mathrm{C}$. Under certain conditions, deposits build up to a limiting thickness and then are sheared off. ${ }^{34}$ The phenomenon could have practical implications for removing deposits from an intermediate heat exchanger in a pool reactor.

- Good agreement does not exist between test loop data and reactor operating experience in the case of Co-60 deposition patterns. Proportionately more Co-60 is reported in reactor cold legs and cold traps than in the test loops. Also, examination of fuel pins at the top of an EBR-II fuel assembly $(0.5 \mathrm{~m}$ above the fuel zone) showed no preferential deposition of Co-58 or Co-60 on the fuel pin surface.

Usually, radionuclide behavior is the same in loop and pool reactors. However, distinctive behaviors are sometimes observed, for example, the behavior of particulates in sodium. This is important because sodium is the primary coolant for all of the reactors except DFR, where it is NaK. DFR has another speciality: a vented fuel element. This causes the fission product inventory of the DFR coolant to be very high. The behavior of radionuclides in the DFR's primary system, therefore, cannot always be compared with the results of other reactors.

Experience with radionuclides in operating reactors has had varying degrees of importance to health physics in particular systems and at different times. A.s mentioned, activated corrosion products are most important for system contamination, in particular Mn54, Co-60, and $\mathrm{Co}-58$. Fission products become more important after operation with defective fuel elements; of these, next to Cs-137, Cs-134, and I-131, the nuclides $\mathrm{Zr} / \mathrm{Nb}-95, \mathrm{Ba} / \mathrm{La}-140, \mathrm{Ce}-141$ and $\mathrm{Ce}-\mathrm{I} 44$ are of most concern. It has been reported that the radioactivities of the corrosion products Co-60 and Mn-54, and of the fission products $\mathrm{Ba} / \mathrm{La}-140$ and $\mathrm{Nb}-95$, are comparable to each other in reactor operations where 0.1 to $0.2 \%$ of the fuel elements are defective, arid that the deposited corrosion product activity has been constant over three years. 36 Published tables present the radionuclides detected in reactor systems. ${ }^{37}$ Research programs have investigated the behavior of radionuclides in primary systems for BOR-60,38,39 DFR, 40 EBR-II, ${ }^{41}$ RAPSODIE and PHENIX, 42 and KNKII. ${ }^{43}$ Additional information is available on radionuclide transport for PHENIX ${ }^{44}$ and the effect of the special run beyond cladding breach (RBCB) program on radionuclides in the primary system at EBR.II. ${ }^{45-}$ 48

Summarizing all corrosion and deposition experience gained with operating LMFBRs, it can be concluded that, so far, activation product radionuclides in primary systems have not been a serious problem for operation. Extended downtime because of large radiation doses has been reported only from DFR. 49 However, knowledge of the behavior of radionuclides 
in primary systems is very important in order to be prepared for difficulties arising from system contamination.

There are two major sources of fissile materials in an LMFBR reactor system. The first is surface contamination of new fuel elements during their fabrication. Generally, $10^{-8} \mathrm{~g}$ of fissile material per $\mathrm{cm}^{2}$ of surface is found, the fissile material usually reported in U-235 equivalents. The second source of fissile material is fuel released from defective fuel elements. Even if the amount of fuel released cannot be predicted, and assuming very small releases of fuel, after operation of a reactor with defective fuel pins, the released fuel will dominate other contamination.

$\mathrm{UO}_{2}, \mathrm{PuO}_{2}$, and $(\mathrm{U}, \mathrm{Pu}) \mathrm{O}_{2}$ react with sodium if the oxygen potential of the fuel or sodium is large enough. ${ }^{50}$ Because the oxides themselves are stable in clean sodium, transport of fissile materials by sodium will be either in the form of oxide particles, because of the extremely low solubility of the oxides, or of reaction products with sodium, such as $\mathrm{Na}_{3} \mathrm{MO}_{4}$ (with $\mathrm{M}=\mathrm{U}$ or $\mathrm{Pu}$ ). In any case, as with other oxideforming nuclides, the fissile material concentration in sodium will be very low, and rapid deposition or plateout will occur. 51

Observations of operating reactors confirm the plateout of fissile material. The concentration of plutonium and uranium in the sodium at EBR-II has always been below detection levels: less than $0.5 \mathrm{pCi} / \mathrm{g}$ sodium of $\mathrm{Pu}-239 / 240$, and less than $1 \mathrm{ppb}$ U. 41,47 Similar low values were reported for RAPSODIE. However, higher concentrations were found for this reactor after cladding failures. Values of up to $200 \mathrm{pCi} / \mathrm{g}$ sodium for $\mathrm{Pu}-239 / 240$ and up to $2 \mathrm{ppm}$ for uranium were found. ${ }^{52}$ There is a wide scattering of the measured data (a factor of 10), probably because the transport is primarily of particulates. Widely scattered data were again observed during investigations of the cold trap baskets of DFR. It is estimated of DFR that the primary system contains less than $10 \mathrm{~g}$ uranium and less than $10 \mathrm{mg}$ plutonium. 40 The special condition of vented fuel elements at DFR have to be kept in mind, however, when attempting to transfer these data to other reactor systems.

In an experiment that purposely used defective fuel pins with artificial cladding defects of $30 \mathrm{~mm}^{2}$, about $4 \mathrm{mg}$ of fuel were released to the sodium from a fresh pin and $1.4 \mathrm{~g}$ from a preir- radiated pin that had $10.6 \%$ burnup. Over $97 \%$ of the released fuel was firmly bound to the SS surface of the system and could only be removed with strong acids: ${ }^{53-54}$

The expression "tramp fuel" is often used in the nuclear industry and is defined as the amount of fuel in a reactor system in the core region responsible for the background level of fission products in the primary system. Reported values are in the range of a few mg U-235 equivalent. Such a value can be explained by the surface contamination of fresh fuel elements mentioned above. Data from EBR-II indicate, however, that the tramp fuel is in particulate form. ${ }^{55}$ The literature does not report an increasing amount of tramp fuel in reactors. This is probably a result of improved fuel management procedures.

It is concluded from thermodynamic considerations and from observations of sodium systems that the concentration of fissile materials in the circulating sodium is very small. Strong deposition on the walls of the system and particulate transport to the cold traps will occur. All available information from operating reactors are, however, very meager, indicating that fuel in the primary system has not been a problem for operating reactors.

\section{Ventilation}

Design Objectives. As they relate to radiation protection, the design objectives of the heating, ventilating, and air conditioning system (HVAC) are the same for LMFBRs as LWRs during normal operations, including anticipated operational occurrences. The design objectives are as follows:

- To limit in-plant buildup of airborne radioactivity during normal plant operations so that exposure to a person from radioactive materials in the air will not exceed the design radiation dose rate for a specific habitable zone; plant ventilation complies with the requirements of $10 \mathrm{CFR} 20$, Appendix B, Table 1

- To limit the migration of airborne radioactivity from areas of high radiation potential to areas of low radiation potential

- To ensure habitability of the main control room during any postulated abnormal condition, to enable control or shutdown of the plant 
- To provide the capability to isolate the reactor containment building atmosphere after an accidental release of radioactivity.

Design objectives, equipment, instrumentation, and methodologies for airborne radioactivity monitoring at LMFBRs do not differ significantly from those at LWRs. Present fixed and mobile continuous air monitors are employed in conjunction with portable air sampling equipment to satisfy the requirements of 10 CFR 20 , and to verify that radioactive atmospheric contamination is as low as reasonably achievable. Monitoring is continuous in frequently occupied operating areas adjacent to potential radioactive sources, in frequently occupied areas including radiation zones or cells that house numerous process system control panels, and in ventilation that serves the reactor containment building or reactor service building.

Source Terms. Gaseous radionuclides produced in LMFBRs include the activation products, Ne-23, $\mathrm{Ar}-39$, and Ar-41; the noble gases, xenon and krypton; and tritium.

Fission product gases are produced during the fission process, both directly from fission and from the decay of radionuclides to stable gases, as in the decay of iodine to xenon. Most of the fission gas is xenon. The second most abundant gas is krypton. The yield of stable fission product gas, i.e., the fraction of fission products that become stable gas atoms for a mixed $\mathrm{UO}_{2}-\mathrm{PuO}_{2}$ fast reactor is about 0.27 .56

Much of the fission gas produced in the unrestructured fuel, where temperatures are lowest, is retained in the fuel grains during normal operation. In the equiaxed and columnar grain regions, most of the fission gas escapes to the central void region or through cracks to the fuel cladding interface.

The processes by which fission gas bubbles nucleate, grow, defuse, and eventually collect and condense at grain boundaries are extremely complex. Below a temperature of about $1300 \mathrm{~K}$, fission gas mobility is very low and essentially no gas escapes. Between 1300 and $1900 \mathrm{~K}$, atomic motion allows some diffusion to take place, such that over a long period of time an appreciable amount of gas can reach escape surfaces. Above $1900 \mathrm{~K}$, thermal gradients can, in days or months, drive gas bubbles and pores over distances comparable to grain sizes. Gas release then occurs when bubbles reach a crack or other surface connected directly with a free volume.
Another source of radioactive gases in an LMFBR is reactor cover gas. Activation of impurities in the sodium, and direct activation of Ar-40 to Ar-41, contribute to the activity in the cover gas. Even $\mathrm{Ne}-23$ appears from an $(n, p)$ reaction with $\mathrm{Na}-23$, but its half life is short $(38 \mathrm{~s})$. The main design requirements, however, for shielding and ventilation control, is based on permitting reactor operation with leakage occurring in a specified fraction of the fuel pins. For FFTF, this fraction of defective pins was set at $1 \%$. Calculated activity caused by fission gas in the reactor cover gas for this design basis condition is presented in Table 9. Since failed fuel will likely never approach $1 \%$, actual activities will likely be far below these levels. Table 10 lists the radioactive gaseous releases at ANL-W and EBR-II. The data in these Tables demonstrate that the concentration of the fission gas and the activation noble gases are comparable.

\section{Table 9. FFTF design basis cover gas activity}

\begin{tabular}{lll}
\multicolumn{1}{c}{ Isotope } & & $\begin{array}{l}\text { Activity } \\
\left(\mathrm{Ci} / \mathrm{m}^{3}\right)\end{array}$ \\
$\mathrm{Xe}-131 \mathrm{~m}^{\mathrm{a}}$ & & $5.43 \times 10^{-1}$ \\
$\mathrm{Xe}-133 \mathrm{~m}$ & & $1.47 \times 10^{1}$ \\
$\mathrm{Xe}-133$ & & $2.67 \times 10^{2}$ \\
$\mathrm{Xe}-135$ & & $1.26 \times 10^{3}$ \\
$\mathrm{Kr}-83 \mathrm{~m}$ & & $6.82 \times 10^{1}$ \\
$\mathrm{Kr}-85 \mathrm{~m}$ & & $1.34 \times 10^{2}$ \\
$\mathrm{Kr}-85$ & & $9.30 \times 10^{-9}$ \\
$\mathrm{Kr}-87$ & & $1.80 \times 10^{2}$ \\
$\mathrm{Kr}-88$ & & $2.64 \times 10^{2}$
\end{tabular}

a. The $m$ designates the metastable state.

Because noble gases do not form chemical compounds under LMFBR conditions, it should be possible to describe their behavior by models, involving solubilities and diffusion coefficients in sodium. ${ }^{57}$ In reality, however, simple equilibria are not obtained and more empirical models are required. Mcreover, it is important to distinguish between fission gases dissolved in the sodium and those transported as bubbles.

Cover gas bubbles are always contained in the sodium of reactors. ${ }^{58-60}$ Fission gas bubibles are released from failed fuel elements. It is generally 
Table 10. ANL-WEST and EBR-II radioactive gaseous releases, 1968-1978

\begin{tabular}{|c|c|c|}
\hline Year & Total ANL-W Curies & EBR-II Curies $^{\text {a }}$ \\
\hline 1968 & 837 & $0.01(0.001 \%)$ \\
\hline 1969 & 130 & 0.0 \\
\hline 1970 & 84 & $0.1 \quad(0.1 \%)$ \\
\hline 1971 & 74 & $8.6(12 \%)$ \\
\hline 1972 & 127 & 20 \\
\hline 1973 & 803 & $(84 \%)$ \\
\hline 1974 & 666 & $(77 \%)$ \\
\hline 1975 & 669 & $(72 \%)$ \\
\hline 1976 & 556 & $(68 \%)$ \\
\hline 1977 & 635 & $(73 \%)$ \\
\hline 1978 & 297 & $(48 \%)$ \\
\hline
\end{tabular}

a. EBR-II percentage of total ANL-W shown in parentheses.

accepted that fission gas bubbles are transferred to the cover gas within minutes, even after breakdown of bubbles into small sizes, as is assumed for EBR-II. ${ }^{61}$

Tramp fuel and bare fuel surfaces in contact with sodium, as in the case of cladding failures, and in some case even "leakers," will produce such low concentrations of fission gases that the fission gases will not be detected by the failed fuel detection systems. The delay in the release of dissolved gases to the cover gas may be caused by several effects:

- Diffusion controlled processes at the sodium/cover gas interface $62-63$

- For Xe-133 and Xe-135, the operation of the cold trap in the sodium circuit.

- Characteristics of the system in question, such as mixing and flow conditions.

The first case is important for some special experiments and is not generally associated with LMFBR operations. The second case is connected with observations of some reactors where the concentration of $\mathrm{Xe}-133$ and Xe-135 in the cover gas could be reduced by operating a cold trap in the sodium. It has been shown in this case that the iodine precursors are adsorbed on the stainless steel surfaces in the cold trap. ${ }^{64}$ No explanation is available why the xenon formed by the decay of adsorbed iodine remains within the sodium system.
In LMFBRs, the last case is the most significant in the delay of dissolved gases to the cover gas. The delay is usually expressed in the form of a delay or degassing probability, $\lambda d .{ }^{65}$ For radioactive nuclides with a decay constant for the radioactive decay, $\lambda_{i}$, a simple model for equilibrium conditions may be written:

$R F_{i}=R_{i} / P_{i}=\frac{\lambda_{d}}{\lambda_{\delta}+\lambda_{i}}$,

Where RF is the release fraction or the ratio between the release rate, $R$, and the production rate, $P$, for a nuclide, i. ${ }^{65}$ From the shape of a curve of measured $\dot{R} F_{i}=\left(f \lambda_{j}\right)$, Brunson derived $\lambda_{d}$ values for EBR-II. ${ }^{65}$ Expressed in the form of a degassing delay half life rather than a probability, he found $\lambda_{\mathrm{d}}$ equal to 7.7 hours.

In other measurements, Brunson found a degassing half-life for EBR-II of 2.7 hours, as well as the longer one. Even with relatively small and simple experimental facilities, such as the fission product loop described in Reference 64, two half-lives for degassing were found, one between 17 and $32 \mathrm{~min}$ utes, the other between 80 and 200 minutes. The shorter one can be explained by a defusion controlled process at the sodium/cover gas interface. Calculations of $\lambda_{\mathrm{d}}$ from the Xe-135/Xe-135 m ratios resulted in even shorter degassing delay half-lives of $4.4 \mathrm{~min}$ utes at $240^{\circ} \mathrm{C}$ to 9.6 minutes at $390^{\circ} \mathrm{C} .66$ 
The measured delay is actually delay of the total system, including releases from the fuel to the sodium, transport within the sodium system, and often even the delay within the cover gas system itself. ${ }^{67}$ The values given for delay times are therefore always only valid for the system investigated. The cover gas bubble concentration in the sodium will influence the release behavior very strongly, because the exchange of dissolved gases within the bubble is very intense and the transport of the bubble to the cover gas is rapid. For example, the BR-5 reactor contained large amounts of argon cover gas in the circulating sodium and no delay for the degassing of fission gases was reported. The BOR-60 and BN-350 reactors, on the other hand, did not have such a bubble problem, and delay half-lives of about 5.5 and 15 hours, respectively, have been published. 38,69 In all other operating reactors investigated, the delay half-lives are in the range of hours, with the exception of DFR, because of its vented fuel elements.

Tritium. Tritium generated in the reactor core is of concern because it is extremely mobile and will diffuse in the fuel and control rod cladding and migrate through the liquid sodium coolant systems. Production of tritium in an LMFBR is greater than that in an LWR at comparable thermal power. The primary means by which tritium is produced in nuclear power plants are by neutron absorption in boron and through ternary fission.

Three boron reactions that produce tritium in nuclear reactors are as follows:

$$
\begin{aligned}
& \mathrm{B}^{10}(\mathrm{n}, 2 \alpha) \mathrm{T} \\
& \mathrm{B}^{11}(\mathrm{n}, \mathrm{T}) \mathrm{Be}^{9} \\
& \mathrm{~B}^{10}(\mathrm{n}, \alpha) \mathrm{Li}^{7}(\mathrm{n}, \mathrm{n} \alpha) \mathrm{T} .
\end{aligned}
$$

The first reaction is the most common in both thermal and fast reactors. The other two are not as favorable; $\mathrm{B}^{11}(\mathrm{n}, \mathrm{T}) \mathrm{Be}^{9}$ has a high neutron threshold energy of approximately $9.6 \mathrm{MeV}, \mathrm{B}^{10}(\mathrm{n}, \alpha) \mathrm{Li}^{7}$ has a small cross section for both fast and thermal neutrons. All three reactions have higher cross sections for high energy neutrons than for thermal neutrons, and tritium production by boron reactions will be greater in fast than in thermal reactors. Tritium produced by irradiation of boron may be the predominant source of tritium activity in an LMFBR containing boron control rods. ${ }^{70}$

Ternary fission is the fissioning of an atom into one minor and two major fission products. The minor fis- sion product is generally tritium. The average thermal fission yield for tritium in atoms per fission is about $0.01 \%\left(0.8 \times 10^{-4} \mathrm{~T} /\right.$ fission $) .{ }^{71-72}$ The major species released from a thermal reactor is $\mathrm{HTO}$. $71-72$

An $82-\mathrm{MWt}$ pressurized water reactor produces $11000 \mathrm{Ci}$ of tritium by ternary fission and $1380 \mathrm{Ci}$ by boron reactions per year. ${ }^{70}$ The fast fission yield for tritium from U-235 and Pu-239 was measured to be $2 \times 10^{-4} \mathrm{~T}$ per fission, which is 2 to 3 times the ternary fission yield for thermal neutrons. ${ }^{71}$ Other calculations and measurements have shown that tritium yield by fast fission for $\mathrm{Pu}-239$ is $2.25 \mathrm{x}$ that of $\mathrm{U}-235.70$

Two of the potentially more troublesome paths for tritium escape from an LMFBR are the heat transfer surfaces of the steam generator system and the walls of the containment piping for primary sodium. Oxide coatings on these surfaces may significantly reduce the permeability of hydrogen isotopes by as much as 2 or 3 orders of magnitude. ${ }^{73-76}$ Directly measured tritium permeation data for unoxidized and oxide coated metal and alloys are scarce. In early tritium transport calculations, the permeation inhibiting nature of oxide coatings was not taken into account when computing permeation losses. ${ }^{77-78}$ Since, an extensive series of measurements has been made on the permeation rate of tritium through unoxidized "clean" and steam oxidized Croloy (Fe-225 Cr-1 Mo). ${ }^{79-80}$ The material is a leading candidate for construction of LMFBR steam generators. Recent tritium permeation data for oxidized Types 304 and $316 \mathrm{SS}$, from which the sodium containment vessels and piping will be fabricated, have also been incorporated into newer transport models for tritium. ${ }^{81}$ Oxide coating to inhibit tritium permeation through structural materials is a major feature. Under normal conditions, all exterior sodium containment surfaces will be oxidized to some degree. Therefore, accurate tritium permeation clata are needed for both oxidized and unoxidized metals and alloys in an LMFBR environment. Protective oxide barriers are expected to be the seconid most effective means of controlling tritium release, cold trapping being the most important.

The efficiency of tritium removal by cold trapping strongly depends on hydrogen sources in the sodium coolant. ${ }^{82}$ Because of the predominant coprecipitation mechanism in cold traps, large hydrogen influxes from the steam generator are beneficial; however, these same large influxes also shorten cold trap lifetime. Thus, accurate experimental data for hydrogen influx rates are vital. The 
data would allow cold trap designs to be optimized, and the complex interrelationship between hydrogen and tritium in the sodium coolant in tritium and hydrogen transport models to be characterized completely. At CRBR, production of tritium in the $\mathrm{B}_{4} \mathrm{C}$ control rods as a function of rod position was calculated using the computer code CRSSA (Control Rod Steady State Analysis). The production rate of tritium was calculated to vary from 37 to $92 \mathrm{Ci} / \mathrm{d}$, depending on reactivity control requirements. The average during a fuel cycle from the source was calculated to be about $62 \mathrm{Ci} / \mathrm{d}$.

At CRBR, the tritium yield rates from ternary fission were calculated to be $1.7 \times 10^{-4}$ and $2.2 \times 10^{-4}$ tritium atoms for fission of plutonium and uranium, respectively. The estimated production rate from this source is $22 \mathrm{Ci} / \mathrm{d}$.

The third significant source of tritium at CRBR is from neutron interaction with the lithium contaminant in the primary coolant. Two reactions are present, $\mathrm{Li}^{6}(\mathrm{n}, \alpha) \mathrm{H}^{3}$ and $\mathrm{Li}^{7}(\mathrm{n}, \mathrm{n} \alpha) \mathrm{H}^{3}$. The first of the reactions dominates. The estimated production rate from this source is $5 \mathrm{Ci} / \mathrm{d}$.

The average production of tritium for CRBR from all sources over one fuel cycle is approximately $89 \mathrm{Ci} / \mathrm{d} .83$

Steady state in the cover gas system at EBR-II exists when there is no excess cover gas leakage and the activity of tritium at that time in the cover gas is within $1 \sigma$ of the norm $\left(2.97 \pm 0.86 \times 10^{-5} \mu \mathrm{Ci} /\right.$ $\mathrm{mL} .84$ The norm was determined by averaging the measured activity of tritium in the cover gas over a 9-month period. The cover gas leak rate was determined by measuring the activity of the gaseous fission product Xe-133 in the cover gas relative to the reactor building air. During normal operating conditions, the cover gas leak is $\sim 10 \mathrm{~mL} / \mathrm{s}$, the Xe- 133 activity in the reactor building is below $1.1 \mathrm{x}$ $10^{-8} \mu \mathrm{Ci} / \mathrm{mL}$, and the Xe-133 activity in the cover gas remains fairly constant.

Xe-133, but not tritium, is one of the fission gases released from a ruptured element. The Xe- 133 activity in the cover gas, and therefore the reactor building air, increases rapidly during the release, whereas tritium activity in the reactor building air and cover gas remain steady. In some instances, the activities of $\mathrm{Xe}-133$ and tritium in the reactor building air have increased simultaneously because of excess cover gas leakage caused by extensive fuel handling. ${ }^{84}$

The average activity of tritium in the reactor building air at the $1 \mathrm{~m}$ level measured under steady state condition was $7.34 \pm 0.59 \times 10^{-10} \mu \mathrm{Ci} / \mathrm{mL}$; the maximum and minimum activities measured under steady state were $1.08 \pm 0.32 \times 10^{-9} \mu \mathrm{Ci} / \mathrm{mL}$ and $4.77 \pm 0.18 \times 10^{-10} \mu \mathrm{Ci} / \mathrm{mL}$ respectively. ${ }^{84}$

The tritium that leaks into the EBR-II reactor building air from the cover gas is mostly unoxidized ( $\mathrm{T}_{2}$ and $\mathrm{HT}$ ), because of the low oxygen concentration in the cover gas and the primary sodium. Greater than $99 \%$ of the tritium in air is naturally converted by isotope exchange and oxidation to HTO. The percentage of HTO in the reactor building air from cover gas leakage varies with the residence time of the tritium in the air before sampling. 84 The occupational and general public exposure limits for tritium is based on the chemical form HTO, which is 25000 times more hazardous than $\mathrm{T}_{2}$ or $\mathrm{HT} .{ }^{85}$ The average concentration of tritium activity measured in the EBR-II reactor building air was approximately four orders of magnitude below the occupational limits for the HTO species. The highest tritium activity measured in EBR-II reactor building air was approximately three orders of magnitude below the occupational limits. ${ }^{84}$

Tritium activity in EBR-II reactor building air is not currently monitored but can be calculated from the cover gas leakage rate and cover gas tritium activity, which are both measured routinely. The tritium activity can also be inferred by monitoring other fission products in the reactor building air. The activities of Xe-135 and Xe-133 are regularly monitored and will exceed occupational limits well before occupational limits of tritium are exceeded. For example, the occupational limits for Xe-135 and tritium would be exceeded in 0.41 days and 5.2 days, respectively, during reactor building isolation if the activities of Xe-135 and tritium and cover gas are at background levels and the cover gas leak rate is 400 times steady state. ${ }^{84}$ If the Xe-133 and $\mathrm{Xe}-135$ activities in the cover gas are decreased an order of magnitude below the equilibrium background levels by decay after shutdown and by selective removal during purification of the cover gas, tritium activity in the reactor building air cannot be inferred from the Xe-133 or Xe-135 activity in the reactor building air. 


\section{Radioactive Waste Management}

\section{Liquid Waste System}

Design Objectives. An LMFBR liquid radiological waste system is designed to process contaminated liquids prior to reuse or release into the environment. As with an LWR, design objectives of an LMFBR are to purify and reuse waste liquids where possible and to minimize the total activity in liquid effluents in the total volume of concentrates that will require drum or other storage. The basic approach is to process liquid rad waste so that virtually all radioactive materials are contained in solid material, to load all the solid radioactive material into containers that meet Department of Transportation regulations, and to transfer the containers to a licensed contractor for processing or disposal. Under normal operating conditions, any radioactive waste released will be as low as is reasonably achievable and less than the limits sets by 10 CFR 20.

The source of low level waste at LMFBRs are drains for floors, equipment, laboratories, personal decontamination showers, and maintenance shop. Sources of intermediate level waste are fission products, fuel, and corrosion products having plated out or deposited on components cleaned in decontamination facilities.

Releases from LMFBRs. The liquid radioactive waste from PHENIX consists of wash water from the washing of fuel elements prior to shipment to the reprocessing plant, and the washing of components withdrawn from the reactor core prior to repair or storage. These liquid wastes are transported by special tank trucks to the waste treatment station at Marcoule. As of April 1980, shipments to the Marcoule plant represented some $2700 \mathrm{~m}^{3}$, corresponding to an activity of $580 \mathrm{Ci}$. Liquid waste from the PHENIX plant represents $\sim 1500 \mathrm{~L} / \mathrm{MWy}_{\mathrm{t}}$ or $0.18 \mathrm{mCi} / \mathrm{MWy}_{\mathrm{t}}$ of liquid waste production.

No radioactive liquid waste is produced by operation of the EBR-II reactor or within the containment building except for controlled liter batch quantities of water/alcohol used for component decontamination. ${ }^{86}$ Therefore, no liquid waste system has been installed within the containment building. Components and equipment to be repaired or discarded are cleaned to remove or react the attending sodium. Radioactive liquid is pro- duced by the reaction of water/alcohol with the radioactive sodium that adheres to items. The cleaning is done in the sodium component maintenance shop.

Tritium is produced in EBR-II and eventually released in the liquid stream. ${ }^{86-87}$ Ternary fission is the major source of the tritium, which is released to the primary sodium coolant. Although more tritium is generated in the boron carbicle control rods and is present in materials studied in experimental subassemblies, it is quantitatively retained in the boron carbide at the temperatures reached in EBR-II and is not released to the coolant. Approximately $90-95 \%$ of the tritium produced in ternary fission is released from the fuel through the SS cladding to the primary sodium coolant. $\$ 6$

The level of tritium in the steam-turbine condensate averages about $10 \mathrm{pCi} / \mathrm{cm}^{3}$. The makeup rate for the steam system is $38 \mathrm{~m}^{3}$ of water/day; therefore, the tritium release through the steam system is about $380 \mu \mathrm{Ci} / \mathrm{d}$. At a plant factor of $70 \%$, this totals about $0.1 \mathrm{Ci} / \mathrm{y}$.

The Prototype Fast Reactor (PFR), the Fast Reactor Fuel Processing Building, and associated laboratories and support facilities at the Lounreay Nuclear Power Development Establishment produce low to high level liquid radioactive waste. The high level liquid radioactive waste contairs fission products from the fast reactor fuel reprocessing building. They are transferred to shielded tanks in the reprocessing plant for sampling and analysis and then dispatched to underground storage tanks that are continuously cooled to remove the heat generated by the decaying fission products. The activity of these liquid radioactive wastes is reduced by a factor of about 500 during the first five years of storage. All remaining aqueous wastes are collected in storage tanks in the solvent extraction plant where they are monitored, sampled, and analyzed. They are then piped to vessels for treatment by a flocculation process. A slurry containing the radioactive material is produced and separated from the water, and is transferred to settling tanks where it is stored for eventual recycling. The liquid residue is piped and held in tanks, where its activity is monitored to ensure that it is within the limits set by the Secretary of State for Scotland before being discharged to sea through an undergrourd pipeline. The liquid releases are limited to less than $6000 \mathrm{Ci}$ of alpha and beta emitters in any three consecutive months, and in which no more than $600 \mathrm{Ci}$ 
can be strontium- 90 or $60 \mathrm{Ci}$ transuranics. Studies show that release of these liquid aqueous wastes become associated with fine suspended nonorganic particulate material, which adheres to the nets of fishermen. The fishermen dry their nets on the beach for a period of $36 \mathrm{~h}$, which allows beta emitters, $\mathrm{Ce} / \mathrm{Pr}-144$ and Run/Rh-106 to become fixed to the nets. The maximum calculated dose to the fisherman's hands from these fixed beta emitters is 5 rem. 88

Current operating procedures at LMFBRs for liquid rad waste systems are analogous to those being used at LWRs. The basic operations in the systems are evaporation and ion exchange. These, and ancillary collection, storage, and fluid transport operations, separate the activity from the liquid waste. The detailed procedures that are part of the LWR technology and found in Reference Safety Analysis Reports for standardized LWR plants, and in-plant procedures for operating LWRs, are adequate also for LMFBRs. Types of components in LMFBR liquid waste systems, including capacity, flow rate, size, weight, design code, and seismic classification are similar to those normally used in LWR plants. Process and radiation instrumentation used to measure the flow, pressure, temperature, liquid level, radiation level, and $\mathrm{pH}$ of the liquid rad waste stream at LMFBRs were found to be the same as those used at LWRs. ${ }^{89}$ Table 11 compares radioactive liquid releases from LMFBRs with those from the average US commercial LWR. Caution should always be taken against making simplistic comparisons of radioactive releases with the energy generated, because of the many factors that affect the amount of radioactive materials released, such as the condition of the fuel, primary system integrity, effluent and radioactive waste treatment systems, and the extent to which these systems are used. EBR-II, for example, generates liquid waste not on the basis of power produced, but on the number of subassemblies removed and washed. The data for the Phenix reactor includes the period during which repair work and changes were made to the damaged intermediate heat exchanger, which produced large quantities of liquid waste during a reactor shutdown. Nevertheless, the overall environmental release from liquid waste per unit of energy generated is considered to be a reasonable index for comparing an LMFBR with a commercial LWR. The data in Table 11 demonstrate that present LMFBRs produce orders of magnitude less liquid waste quantities per megawatt year thermal power production, and one to several orders of magnitude less activity in their liquid waste, as a function of power produced.

\section{Gaseous Waste Systems}

Design Objectives. LMFBR design objectives for a gaseous waste system at, like those of LWRs, are to keep the level of radioactive material in the plant effluence to the environment as low as reasonably achievable. Extensive effort has been made in developing system designs that have resulted in minimizing or eliminating gaseous release of radioactive material to the environment during normal plant operations. LMFBR plant design objectives in the United States include conformance with the requirements of $10 \mathrm{CFR} 20$. The radioactive gaseous releases at LMFBRs compare favorably with those at commercial nuclear power plants. Radioactive airborne effluence from LMFBRs consist of noble gas fission products (which include isotopes of xenon and krypton and their daughter products), activation products entrained in the argon

Table 11. Comparison of LMFBR liquid radioactive waste production with U.S. PWRs

Radioactive Waste Produced

Reactor

Phenix

FFTF

EBR-II

U.S. PWR (average)

\begin{tabular}{cc}
\multicolumn{2}{c}{ Radioactive Waste Produced } \\
\hline $\begin{array}{c}\text { Volume of Liquid } \\
{[\mathrm{L} / \mathrm{MWy}(\mathrm{t})]}\end{array}$ & $\begin{array}{c}\text { Activity of Liquid } \\
{[\mathrm{Ci} / \mathrm{MWy}(\mathrm{t})]}\end{array}$ \\
\cline { 2 - 2 } $1,372.0$ & 0.29 \\
71.5 & $1.58 \mathrm{E}-5$ \\
$3,811.0$ & $3.07 \mathrm{E}-3$ \\
$54,000.0$ & 2.795
\end{tabular}

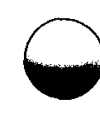

.

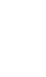

.

.

.

.


cover gas, and tritium. Tritium is the most significant radioactive gaseous effluent at an LMFBR. Tritium is generated during operation primarily by ternary fission and by activation of $\mathrm{B}_{4} \mathrm{C}$ control rods. A small amount of tritium is generated by neutron activation of lithium and boron, which are impurities in both the sodium coolant and the core and blanket fuel. Tritium behaves much like hydrogen and, at the elevated temperatures found in LMFBRs, diffuses in stainless steel and other reactor containment material. It is, therefore, of particular importance to closely monitor the tritium in the coolant system and to discern the relationship between the tritium concentration and the various reactor operating parameters. Tritium transport through an LMFBR, and the performance of tritium control methods, must be carefully monitored to minimize tritium release to the environment.

Releases of Gaseous Radioactive Waste. The major portion of EBR-II gaseous waste releases prior to 1970 originated from the argon cover gas system. The reactor core is immersed in a primary containment vessel that contains approximately $325 \mathrm{~m}^{3}$ of molten sodium. Immediately above the surface of the sodium is an $18-\mathrm{m}^{3}$ plenum region filled with argon. Because of a positive pressure differential, any leakage gas is combined with the atmosphere in the containment building. Approximately $2.5 \mathrm{~m}^{3} / \mathrm{s}$ of the building atmosphere is withdrawn through the shield cooling system and through HEPA filters, and combined with another $0.75 \mathrm{~m}^{3} / \mathrm{s}$ that is withdrawn through the thimble-cooling system and also passed through HEPA filters. The combined flow of $3.2 \mathrm{~m}^{3} / \mathrm{s}$ is then passed through a radiation monitor and through a blower to the $60-\mathrm{m}$ high stack. Approximately $2.1 \mathrm{~L} / \mathrm{min}$ of argon cover gas from the cover glass plenum is discharged through monitoring devices into the radioactive gaseous waste disposal system downstream of the HEPA filters. Table 12 presents annual releases of radioactive gases from the reactor containment building for the years 1979 through 1981 .

From 1970 to 1976 , there was an expansion of the testing of fuel elements in the run-to-claddingbreach (RTCB) program. Such operation produced breached fuel elements, and the fission product and noble gas concentrations increased. In order to establish the identity of the subassembly containing the failed elements, continued reactor operation was sometimes necessary, thereby increasing fission product concentrations in the argon cover gas and the containment building. It then became necessary to purge the cover gas system to reduce the fission product concentration in the reactor building. The purge-discharge rate (a maximum of $0.08 \mathrm{~m}^{3} / \mathrm{min}$ ) was determined by identifying the nature and concentration in the containment, so that discharges did not exceed acceptable limits. The purge exhaust during this time bypassed the HEPA filters and went directly into the stack.

The concentration of radionuclides in the containment building increased in proportion to the activity of the argon cover gas. Under off-normal conditions of cover gas activity, samples from the containment building were taken and analyzed. If the activity level was within predetermined acceptable limits, the containment building atrnosphere was purged directly to the outside atrnosphere through a $3 \mathrm{~m}^{3} / \mathrm{s}$ centrifugal blower. (This was in addition to that processed through the HEPA filters.)

In 1977, anticipation that breached elements in the run beyond-cladding-breach ( $R B C B$ ) program would release substantial quantities of fission products to the primary system, especially fission gases, the cover gas cleanup system (CGCS) was installed. The system processes primary cover gas to remove fission gases in a cryogenic column. Effectiveness of the system, and substantial reductions in the gas leakage rate through the primary tank cover to the building containment, sharply reduced the release of fission gases to the environment via the waste gas stack, as shown in Table 12. This reduction applies to both the RBCB and RTCB programs, which are being conducted simultaneously.

The CGCS became operational in June 1977. Releases from EBR-II in 1977 prior to CGCS operation totaled 411 curies. Although the RBCB program results in greater fission gas releases to the cover gas, releases after the startup of the CGCS totaled only 50 curies. Prior to June 1977, Xe-135 and Xe-133 comprised the large majority of the radionuclides releases to the environment via the EBR stack. Since that time, approximately three fourths of the radioactive gaseous effluent has consisted of Xe-135 and Xe-133, and one folırth has consisted of $\mathrm{Kr}-85$, as shown in Table 12.

Tritium is produced in EBR-II by ternary fissions in the core, and by neutron bombardment of the $\mathrm{B}_{4} \mathrm{C}$ portion of the control rods. Tritium production from $\mathrm{B}_{4} \mathrm{C}$ can be ignored when evaluating tritium transport in EBR-II, since essentially $100 \%$ of the tritium produced from $\mathrm{B}_{4} \mathrm{C}$ is retained in the control rods at EBR-II temperatures. ${ }^{70}$ The ternary fast fission yield 


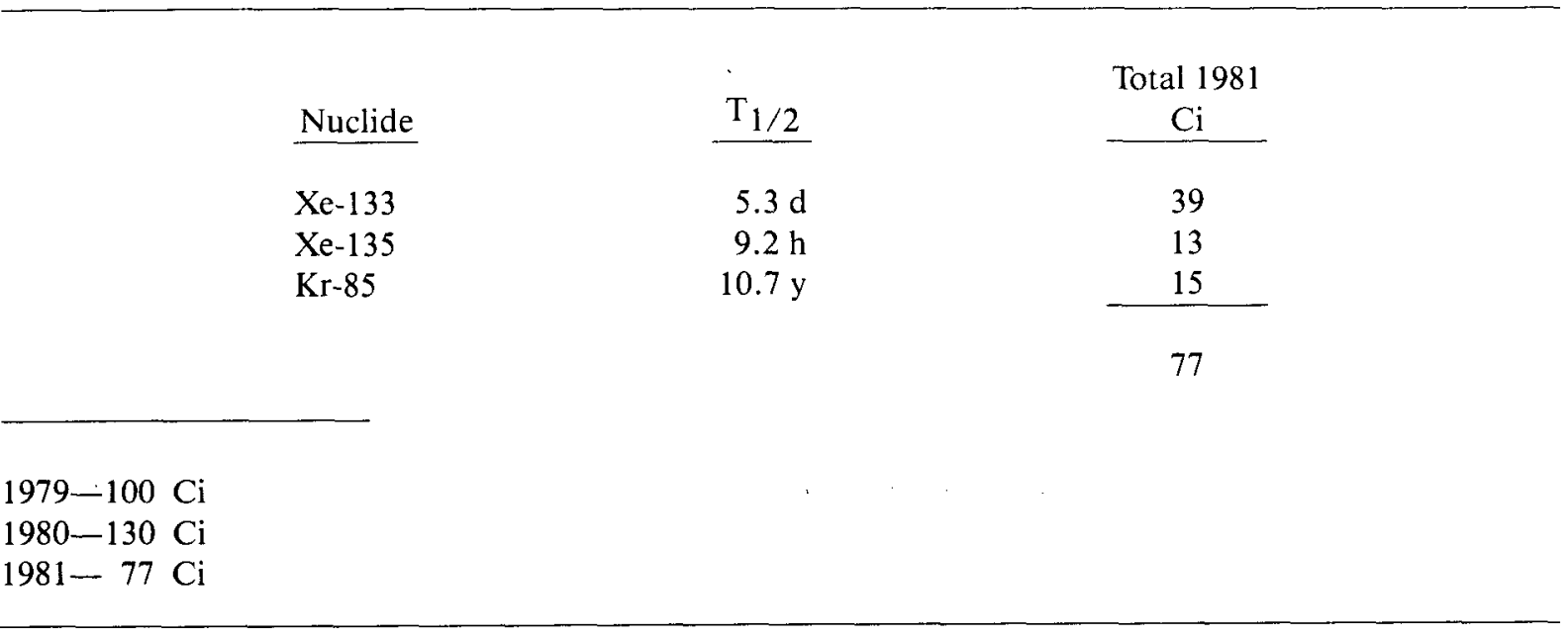

in EBR-II for U-235 is reported to be $2 \times 10^{-4} \mathrm{~T} /$ fission, or 1 atom of tritium per 5000 fissions. The thermal fission rate is $2.7 \times 10^{21}$ fissions/MWd, so the production rate of tritium at EBR-II at full power $(62.5 \mathrm{MWt})$ is $3.4 \times 10^{19}$ atoms of tritium/day, or $1.65 \mathrm{Ci} / \mathrm{d} .{ }^{77,84}$

As shown in Table 13, 90-95\% of the tritium produced by ternary fission in EBR-II is transferred to the primary sodium and is dispersed throughout the primary circuit by bulk transport of the coolant. From the primary circuit, tritium may (a) permeate through the SS sodium containment into the inert cells surrounding the piping, (b) permeate through the intermediate heat exchanger (IHX) tubes into the secondary circuit, (c) escape by leakage from the primary system cover gas, (d) coprecipitate with hydrogen in the primary cold traps, and (e) decay to He-3. Tritium that reaches the secondary circuit through the IHX may (a) permeate through the secondary sodium containment walls into the surrounding air cells, (b) permeate through the walls of a steam generator tubes into the water/steam system, (c) escape by leakage from the secondary system cover gas, (d) coprecipitate with hydrogen in the secondary cold traps, and

\section{Table 13. Summary of EBR-II data ${ }^{a}$ of tritium distribution}

\section{Location}

Fuel

Primary sodium

Primary coldtrap

Areas outside primary sodium system:

Primary argon

Secondary sodium

Secondary argon

Steam system
Tritium

$(\%)$

$5-10$

4

83-88
Typical Sample Activity (Ci)

(Ci)

15.5

a. Data taken between 1972 and 1974 . 
(e) decay to He-3. Approximately $83-88 \%$ of the produced tritium is removed by the primary cold trap. 84

The rate of permeation through the sodium containment walls is a function of wall thickness, the surface area exposed to tritium, the tritium concentration in the sodium coolant, the Sievert's law constant for tritium in sodium, and the permeability of tritium through the reactor construction materials. ${ }^{82}$ The rate of tritium permeation through the walls of the IHX is also a function of these same variables; however, the driving force for the process is caused by the difference in tritium concentration in the primary and secondary sodium circuits. Two of the potentially more troublesome paths for tritium escape from an LMFBR are the heat transfer surfaces of the steam generator system and the walls of the containment piping for the primary sodium. It is well known that the outside coating on these surfaces may significantly reduce the permeability of hydrogen isotopes by as much as two or three orders of magnitude.73-76,82 However, directly measured tritium permeation data for unoxidized and oxidized coated metals and alloys are scarce.

An experiment was carried out at EBR-II to provide data for which the tritium permeation rate across the IHX was determined. The intermediate heat transport system cold trap of EBR-II was bypassed from May 20 to June 8, 1977, and tritium concentration increases in the primary heat transport systems (PHTS) and the intermediate heat transport system (IHTS) sodium were recorded with in-sodium tritium meters (ISTM) that had been recently installed in the reactor. $90-91$ The tritium flux across the tube wall was calculated from the physical properties of the construction material, such as area, thickness, and tritium permeability in Type 304 SS.

The tritium and hydrogen distributions were predicted for the 9 days during which data were recorded. The calculation represented a transient case, since the secondary cold trap was off-line during the entire period. Figure 1 compares the results of this simulation with the experimental data for tritium and hydrogen levels in the PHTS and IHTS sodium of EBR-II. The solid lines represent the profiles predicted with the transport model; the symbols represent the actual operating data. Hydrogen concentration data of the PHTS were not available. Agreement between the calculated and experimental values is good for the time interval studied.
Previous to the experiment, because data was lacking, the Sievert's constant for tritium and sodium was assumed to be equal to that for hydrogen and sodium. ${ }^{77}$ The Sievert's constant for tritium in sodium has been estimated on the basis of decomposition pressure in the analogous $\mathrm{LiH}$, LiD, and LiT systems, and the associated isotope effects. 92

A transport model has been used to predict tritium and hydrogen distribution in CRBR. Rates of tritium loss from reactor containment materials have also been calculated. 82 The predicted tritium and hydrogen profiles and release rates are strongly affected by two factors: (a) the permeationretarding nature of oxide coatings, particularly on stream generator tubes and sodium coolant piping, and (b) the rate of hydrogen ingress to the secondary coolant circuit caused by steam generator corrosion. In regard to the first factor, a reference case was established in which all structural and heat transfer surfaces were assumed to be oxide free. Maximum tritium and hydrogen permeation rates through the construction materials were obtained, as well as upper limit values for tritium release rates from reactor subsystems. In regard to the second factor, the effectiveness of cold traps directly depends on the hydrogen ingress rate from the steam generator. Since tritium is most elfectively removed from the coolant by coprecipitate with hydrogen in the cold traps, large hydrogen influxes from the steam generator should produce high cold trapping efficiency. However, the useful lifetime of sodium cold traps is greatly reduced by large hydrogen influxes. Cold trap designs must be optimized, and anticipated tritium and hydrogen burden in both primary and secondary cold traps must be determined.

At the Phenix reactor, the gaseous waste discharge from 1974 to 1981 totaled only $970 \mathrm{Ci}$, for an average value of about $0.5 \mathrm{Ci} /$ day. Nearly all of this activity was owing to Xe-135. In 1953, Phenix began testing a cryogenic cleanup system for xenon radioisotopes. Currently, the Phenix off-gas system includes only a delay line. The volume of the cover gas in the Phenix reactor is only about $40 \mathrm{~m}^{3}$, with a radionuclide concentration of approximately $5 \mathrm{Ci} / \mathrm{m}^{3}$, most of which is from xenon and krypton radioisotopes. The only activation products detected were $\mathrm{Ne}-23,1.5 \times 10^{-1} \mathrm{mCi} / \mathrm{mL}$ and Ar- 41 , at $5 \times 10^{-2} \mathrm{mCi} / \mathrm{mL}$. At this time the Phenix reactor does not have a cover gas cleanup system. 93 


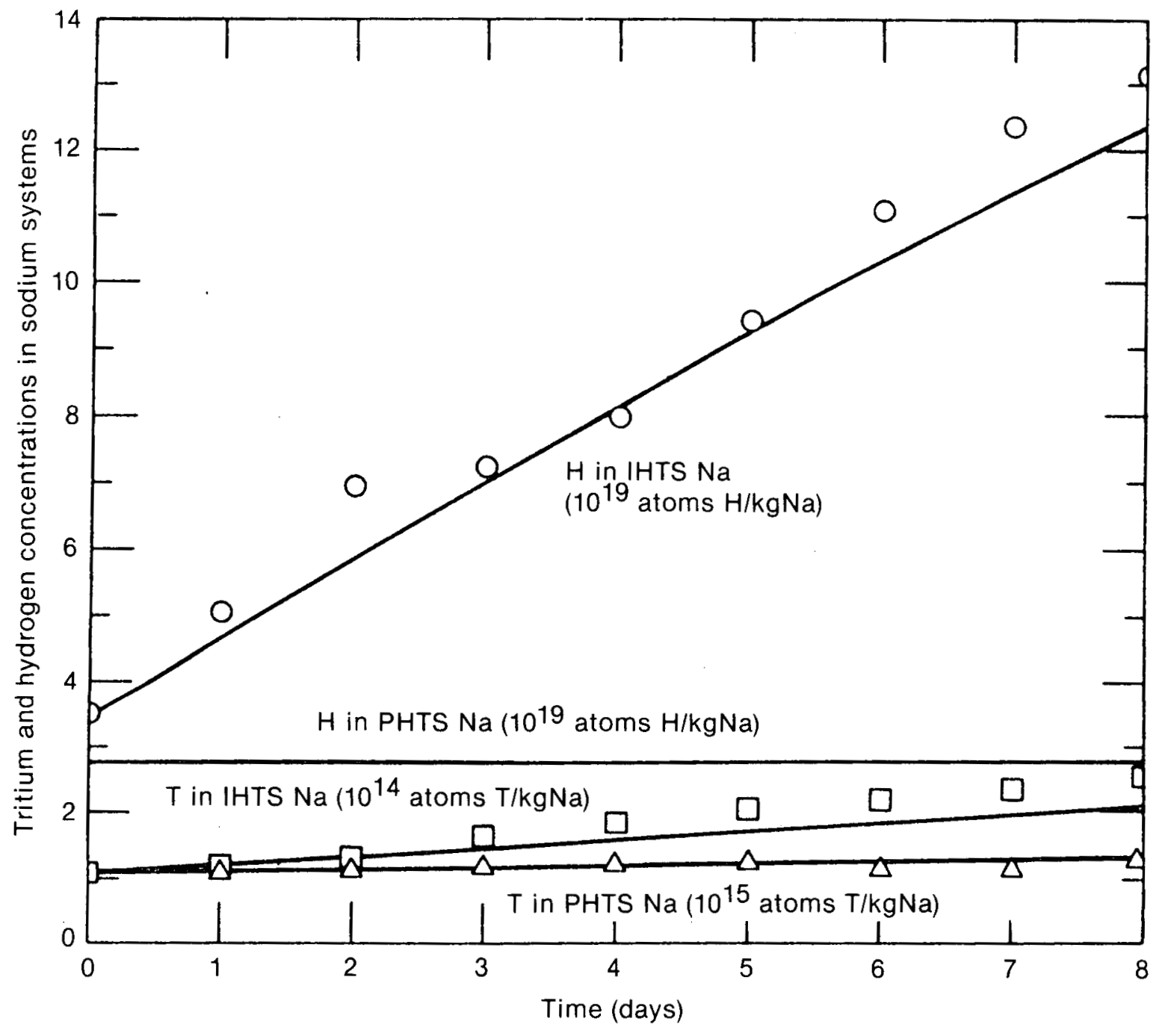

Figure 1. Tritium and hydrogen concentration in EBR-II sodium coolant systems.

At the Prototype Fast Reactor (PFR), the most significant radioactive gaseous effluent is $\mathrm{Ne}-23$. Total radioactive gaseous effluents emitted from PFR are equivalent to 4-5 derived air concentration (DAC) hours per year. 94

KNK-II releases are, on average, approximately $10 \mathrm{Ci} / \mathrm{yr}$. Nearly $400 \mathrm{Ci}$, mostly Xe-133, were released in April 1979 during the first fuel leakage incident. At full power and operating with no defective fuel pins, KNK-II releases were $180 \mathrm{mCi}$ $\mathrm{Ar}-41 / \mathrm{m}^{3}, 2-3 \mathrm{mCi} \mathrm{Zn}-135 / \mathrm{m}^{3}, 1 \mathrm{mCi} \mathrm{Zn}-133 / \mathrm{m}^{3}$, and $0.5 \mathrm{mCi} \mathrm{Kr}-87, \mathrm{Kr}-88, \mathrm{Kr}-85 \mathrm{~m} / \mathrm{m}^{3}$, all believed from the presence of tramp uranium, for the emission rates are not linear but an exponential function of reactor power. 95
During the cycle-1 operation at FFTF, four noble gas releases occurred that were above background. These include the following:

- Approximately $116 \mathrm{mCi}$ of noble gases were released via the lower reactor service building (RSB) exhaust over a 21-hour period on May 22, 1982. The source of this release was a leaking instrument tubing connection.

- Approximately $1.1 \mathrm{Ci}$ of noble gases were released via the combined containment exhaust over the period of May 15-28, 1982. The source of this release was the end containment cell atmosphere processing system (CAPS) flood exhaust. 
- About $60 \mathrm{mCi}$ of noble gases were released from a cover gas leak in a gas tank sample trap connection. The release occurred intermittently over a 15 -hour period on September 28, 1982. The total release time was 5 hours.

- Approximately $12 \mathrm{mCi}$ of noble gases were released when an O-ring was inadvertently omitted from a reactor cover gas grab sample cylinder connection. This release occurred over a 3-hour period on October 29, 1982.

The tritium concentration in the primary cover gas and interim decay storage cover gas at FFTF is in the range of $10^{-11}$ to $10^{-12} \mathrm{Ci} / \mathrm{mL}$. Samples of the secondary cover gas impurities at FFTF have tritium concentrations in the range of $10^{-12}$ to $10^{-14} \mathrm{Ci} / \mathrm{mL} .96$ Radioactive gaseous effluents at FFTF since Cycle 1 have averaged $\sim 0.117 \mathrm{Ci}$ / MWy thermal.

During the years 1963 to 1979 , EBR-II has emitted an average of $19.6 \mathrm{Ci}$ of noble gases per/MWy, and $39.18 \mathrm{Ci}$ tritium/MWy. Since the start of the run-tocladding-breach (RTCB) program in 1973, total radioactive gaseous releases have increased to about $120 \mathrm{Ci} / \mathrm{MWy}$. In anticipation that the breached elements in the run-beyond-cladding-breach (RBCB) program would release significantly higher quantities of radioactive gaseous effluents to the primary system, the cover gas system, and the environment, a cover gas cleanup system was installed in 1979. Subsequent to installation of the cleanup system, radioactive gaseous effluents from EBR-II have dropped considerably, to about $18.6 \mathrm{Ci} / \mathrm{MWy}$.

Radioactive gaseous effluents at commercial nuclear plants from the years 1960 through 1976, have averaged $35.8 \mathrm{Ci} / \mathrm{MWy}$. This is significantly higher than the radioactive gaseous effluents emitted from LMFBRs.

\section{Solid Waste System}

Design Objectives. Solid rad waste systems should be designed to process and package solid wastes that are to be shipped off site for disposal. Packaging must be such that the surface dose rate will be in compliance with the Department of Transportation regulations.
The system should be designed to handle, package, and store three sources of waste: concentrated liquids, compactible solids, and noncompactible solids. It should be designed to perform its function with radiation hazards to plant personnel as low as reasonably achievable through the use of proper layout and arrangement, coupled with adequate shielding. Equipment should be selected, arranged, and shielded to permit operation, inspection, and maintenance, with minimal exposure to personnel. All operations should be monitored to ensure that radiation concentrations in accessible areas are below the exposure limits set by 10 CFR 20.

The design of solid rad waste systems are based on widespread experience in the nuclear industry, spanning more than two decades. Reference 97 contains a review of solid rad waste practices at nuclear power plants. In particular, the incorporation of concentrated liquid rad waste in cement is widely and routinely used in power reactor plants. The packaging of solid material for disposal by burial is also standard practice.

The operating procedures for handling the five types of input streams in a solid rad waste system at an LMFBR are as follows:

- Concentrated liquids, which include evaporator bottoms, spent resins, sodium contaminated ethyl alcohol, and tritiated water, are solidified. A fixed arnount of liquid rad waste can be metered into 55 -gallon drums that have been preloaded with cement. The drum can be capped, thoroughly mixed by tumbling, decontaminated by rinsing, monitored, stcred temporarily if need be, and transfelred to a licensed contractor for disposal.

- Compactible solids such as rag:, paper, and rubber seals, can be collected at various points throughout the plant and transferred to a solid rad waste system, as is done at LWR plants.

- Noncompactible solids include used support tools, contaminated filters, metal from cutting operations such as an intermediate heat exchanger tube bundle, valves, and vapor traps. The low activity 
noncompactible solids can be placed in 55 gallon drums, capped, decontaminated, monitored, and placed in temporary storage. Spent filter cartridges from the liquid rad waste system can be remotely placed in concrete line 55-gallon drums and placed in storage prior to shipment in the same manner as other noncompactible solids.

- Radioactive sodium will be present as a result of fuel handling. This metallic sodium can be transferred to the rad waste system in 55-gallon drums. Since no waste disposal site will accept sodium, it is placed in temporary storage on site or processed into a nonmetalic form, such as a carbonate or carbide, and stored on site.

- The primary and intermediate cold traps are the sources of sodium bearing waste. Primary cold traps should be designed for the life of a plant and not expected to be removed. If replacement of a cold trap becomes necessary, it can be drained of bulk sodium and stored in a designated location. Intermediate cold traps are not designed for the life of the plant, will require removal, and storage must be provided.

Solid Waste System Experience at LMFBRs. At EBR-II, a small quantity of solid waste is produced. A major portion (by volume but not by radioactivity) of this solid radioactive waste is the accumulation of wipe rags, plastic containers, shoe covers, and other industrial solids associated with working with radioactive materials during maintenance. Reactor components such as thermocouples, nuts and bolts, and other hardware are disposed of as solid radioactive waste. Radiation from these components is generally low level $(<10 \mathrm{mR} / \mathrm{h})$.

Another source of solid waste is elemental sodium in bulk form, which is produced in small quantities during maintenance. This sodium is collected in 3.8-L cans, which are placed in metal drums and covered with sand. Because of low radiation levels, these drums are stored in a covered trailer until the sodium can be treated. Approximately $500 \mathrm{~L}$ of elemental sodium are presently in cold traps used in the reactor coolant system to control oxygen. The traps are removed from the system when their efficiency has dropped below preset levels, and they are stored in a radioactive storage building if the levels are low, less than $100 \mathrm{mR} / \mathrm{h}$. When the radioactivity is high, they are stored with shielding in a metal container underground in an interim storage facility at Argonne National Laboratory-West (ANL-W), designated as the radioactive scrap and waste facility. Storage of the cold traps is awaiting development of a treatment process.

Most of the solid radioactive waste is generated at the hot fuels examination facility (HFEF). This waste results from the disassembly, assembly, and inspection activities of EBR-II subassemblies, discarding of used experimental hardware, preparation of reactor blanket subassemblies for storage, and inspection activities of LMFBR related tests that are performed by other organizations. Solid waste is also produced when the evaporator bottoms are solidified. The solid wastes are of the following categories: low-level nontransuranic, intermediate nontransuranic (up to $10,000 \mathrm{R} / \mathrm{h}$ ), low-level transuranic, intermediate level transuranic (up to $1000 \mathrm{R} / \mathrm{h}$ ), low and intermediate level transuranic, and nontransuranic waste with sodium, and bulk sodium at the intermediate level.

The chemistry laboratories that support EBR-II produce solid waste from maintenance and operations. These wastes comprise low and intermediate levels but the volume is low and there is no elemental sodium.

Radioactive solid waste is handled by several different methods, depending on the radiation levels and the content of the waste. Low-level nontransuranic compactible waste is collected in plastic bags and hand carried to and placed in specific strategically located dumpsters. The dumpsters are then trucked to the INEL Radioactive Waste Management Complex (RWMC) operated by EG\&G, Idaho, where the waste is compacted prior to storage. EG\&G Idaho has reported compaction greater than 10:1.

Prior to December 1977, low-level nontransuranic, noncompatible waste was placed in cardboard boxes; the boxes were placed in dumpsters and sent to the RWMC. Bulky or heavy items were boxed in wooden boxes. These boxes were then sent to the RWMC for storage. Since December 1977, this low-level waste has been collected in 208-L steel drums. The drums are held in a cupboard van until the van is full and then sent to the RWMC. Items too large for the drum are placed in standard-sized plastic lined wooden boxes painted with fire retarded paint. The boxes are available in sizes up to $1.2 \times 1.2 \times 2.4 \mathrm{~m}$. 
Low-level transuranic waste is placed in Department of Transportation (DOT) specification 17C drums equipped with a $2.3-\mathrm{mm}$ rigid poly liner, or in fiberglass DOT specification 19A boxes. The filled containers are sent to the RWMC for storage. However, no transuranic waste has yet been generated as a result of EBR-II operations.

Intermediate level waste with radiation levels up to $10,000 \mathrm{R} / \mathrm{h}$ is generated within HFEF as a result of the disassembly of EBR-II driver subassemblies prior to inspection or shipment of fuel to the reprocessing plant. Intermediate waste from HFEF is remotely packaged in 1.8-m long, 295-mm ID carbon steel cans. These cans are then inserted into a stainless steel outer can and either seal-welded or gasket-closed. The cans that do not contain elemental sodium are sent to the RWMC for interim storage. Cans containing elemental sodium are sent to ANL-W, RSWF, for storage. No intermediate level transuranic waste is generated by EBR-II.

A total of $9.7 \mathrm{~m}^{3}$ of solid radioactive waste, with a total activity of $19.8 \mathrm{mCi}$, was transformed from FFTF to the 300 area at Hanford for processing. The waste originated from the following activities:

- Interim examination and maintenance (IM) cell decontamination and maintenance

- Maintenance and storage facility decontamination and maintenance

- Sodium removal system maintenance

- Heat transport system south sampling and maintenance

- Miscellaneous maintenance in the plant

- Radioactive liquid waste sampling and load out station.

At the Phenix reactor, low level waste is handled essentially like as it is at EBR-II. Intermediate waste is transported to the Marcoule center and stockpiled in pits. The total quantity of these transported intermediate wastes to date amounts to about 60 tons, and corresponds to an activity of about 8 million $\mathrm{Ci}$. The irradiated fuel is transported to the chemical reprocessing plant at La Haque or at Marcoule. Approximately 100 metric tons of solid sodium is storaged on site.
Attempts have been made to reprocess the sodium from the Rhapsodie reactor to remove the fission products, but with very little success. 93

Whether sodium waste is disposed of in a landfill or in a permanent depository, it will be necessary to convert it to a nonmetallic, stable compound to minimize its subsequent reaction and transport in the environment. Various types of glasses containing silica and sodium monoxide may be suitable as such stable compound. For example, the composition of ordinary window glass is $17 \% \mathrm{Na}_{2} \mathrm{O}, 6 \%$ $\mathrm{CaO}, 1 \% \mathrm{Al}_{2} \mathrm{O}_{3}$, the remainder being $\mathrm{SiO}_{2}$. The volume of this glass made from a given mass of elemental sodium is approximately 3 times the original volume of the sodium.

Ordinary window glass is not ideal for disposal of radioactive sodium from the standpoint of leaching of fission products by water. However, other glass compositions have been developed as candidate materials for encapsulation of high-level waste from fuel reprocessing. 98

These glasses typically contain both silica and sodium monoxide in various $\mathrm{Si}$ : Na ratios. l.t may be efficient to use the sodium monoxide from sodium waste disposal as one of the feed materials for production of special purpose glasses in the disposal of radioactive sodium.

The processes that would be suitable for converting radioactive sodium to an acceptable compound for waste disposal must meet certain performance criteria related to the presence of radioactive contaminants and transuranics. These criteria include (a) low cost, (b) simplicity, to allow remote operation, (c) safety, to prevent uncontrolled reaction, (d) suitability for incorporation into a disposable form, and (e) minimum release of radioactivity.

Disposal of sodium and other alkali metals have been accomplished by a variety of methods, depending on the requirements of each situation.

The most frequently used methods have been (a) reaction with alcohol, (b) reaction with steam or water vapor, (c) reaction with concentrated caustic solutions, and (d) burning. The alcohol reaction processes have been used extensively for removing sodium from reactor components, but the quantities processed have been small to moderate, in the $0.1-$ to 50-kg masses. ${ }^{99-100}$ Data were obtained on reaction rates and solubility of sodium in alcohol. The initial 
reaction rate increases exponentially with temperature; at $335 \mathrm{~K}$ the rate is $0.064-\mathrm{kg}$ sodium $/ \mathrm{m}^{2}$-s on a horizontal sodium surface. ${ }^{99-100}$ However, the rate decreases precipitously to essentially zero when the sodium concentration in alcohol reaches $5 \mathrm{wt} \%$.

Some factors that could limit the use of the alcohol reaction process are as follows. The sodium content of the alcohol must be kept low, thereby requiring continuous regeneration of alcohol by distillation during the reaction. The insoluble precipitates from the distillation must be further processed, and difficulties arise in reducing the product to a solid because of the presence of a variety of organic compounds. Disposal of liquid waste containing radioactive isotopes by landfill burial is not acceptable; therefore, disposal of the waste from the alcohol process presents formidable problems. Other factors include the flammability of the alcohol and the necessity for processing the sodium in batches.

In the early days of sodium technology, some quantities of sodium were reacted directly with water by dumping the sodium into a large outdoor water pool. This method, although effective and rapid, is obviously unsatisfactory for radioactive sodium. An improvement in the dumping method of the sodium in water was developed for disposal of large quantities of sodium under water. ${ }^{101} \mathrm{Liq}$ uid sodium was sprayed into water at a sufficiently high Reynolds number (greater than 45,000 ) to ensure disposal of the sodium. The depth of injection was approximately $3 \mathrm{~m}$, to ensure complete reaction before the metallic sodium could reach the surface. Adaptation of this process for use in a shielded, alpha containment facility, may be difficult because of the need to control gas and water flows and to handle the hydrogen and water evolution.

The sodium water reaction can be controlled by diluting the water and thus controlling the rate of access of water to the sodium. Two methods of water dilution have been used successfully, namely, the use of steam and the use of water vapor and nitrogen. 102 These processes have been widely used throughout the world, primarily for removal of residual sodium from components to be reused in the reactors. Methods of this type include (a) the use of moist argon or nitrogen at EBR-II, (b) the use of an atomized water spray in France, (c) steam cleaning in the U.S., Germany, the UK, and the USSR, and (d) the use of water vapor in nitrogen as practices in the U.S., UK, and Germany. A wide range of experience has been gained in actual sodium-cleaning operation at reactor facilities using this diluted water method. The disadvantages of the method include the liquid waste $(\mathrm{NaOH}$ solution in water) that must be dried for disposal, and the evolution of hydrogen and carry-over of moisture in the gas stream. This hydrogen and moisture must be treated appropriately to remove fission products before venting to the environment.

Third is reaction with a concentrated caustic solution and is related to the process developed for direct reaction of sodium with water. ${ }^{101}$ Liquid sodium (or $\mathrm{NaK}$ ) is dispersed in a pool of concentrated $(14 \mathrm{M}) \mathrm{NaOH}$ while water is periodically injected to control the caustic concentrations. This caustic solution process was used to dispose of the $\mathrm{NaK}$ from the decommissioned EBR-I reactor. ${ }^{103-}$ 104 The NaK was injected into the caustic with a spray nozzle designed to atomize the $\mathrm{NaK}$ in a stream of nitrogen. The disposal operation was accomplished smoothly. However, converting the process for operation in a shielded, alpha containment facility would present difficulties relating to moisture, hydrogen handling, and liquid waste disposal.

The sodium burning process has been used extensively, both in open areas where the smoke was released to the environment and in closed facilities where the smoke was removed by water scrubbing. $101,105,106$ Although the burning process is effective in consuming metallic sodium, the sodium monoxide smoke necessitates cleaning operations after the burning is complete. Large volumes of gas must be treated to remove fission products and liquid waste from the scrubber. Products from the wash down operations must be treated to form solid waste. The burning chamber also requires periodic cleaning to avoid accumulation of prohibitively high activity levels; this cleaning introduces an additional difficulty into the method.

Dissolution of sodium in a heavy metal such as lead or mercury, used in the USSR for cleaning reactor components. A process using this concept was patented in the United States as a method for disposing of large quantities of contaminated sodium. ${ }^{107}$ The process is designed to divide the large heat of reaction into three approximately equal energy steps: (a) dissolution of sodium in lead, (b) contacting the leadsodium alloy with molten $\mathrm{NaOH}$ and sparging with oxygen to drive the sodium $\left(\mathrm{as}_{2} \mathrm{~N}\right)$ into solution in the $\mathrm{NaOH}$, and (c) injecting steam into the molten $\mathrm{NaOH}$ to convert the dissolved $\mathrm{Na}_{2} \mathrm{O}$ into $\mathrm{NaOH}$. 
The molten $\mathrm{NaOH}$ is then drawn off periodically for disposal as solid waste. An attractive feature of this process is that there are theoretically no effluent gases and no aqueous waste to be processed. However, the process requires high temperatures $(>700 \mathrm{~K})$ and complicated liquid flow manipulations.

At Argonne National Laboratory West, two methods have been developed and tested on a small scale for converting sodium waste to inert compounds suitable for disposal. The first method is direct oxidation of the sodium after dispersal in a silica matrix. The sodium is mixed with silica and oxidized in a rotary drum reactor. The product is suitable for making glass when other stabilizing compounds are added. The second method is the reaction of elemental sodium with molten $\mathrm{NaOH}$ at $450^{\circ} \mathrm{C}$ and subsequent injection of steam into the melt to convert the reaction products $\left(\mathrm{Na}_{2} \mathrm{O}\right.$ and $\mathrm{NaH}$ ) to additional $\mathrm{NaOH}$. The reaction is smooth and easily controlled, with a low probability of runaway reaction. The end product is molten $\mathrm{NaOH}$, which can be cast into drums for further treatment or disposal. The advantages of these two methods over more conventional aqueous processes are the elimination of aqueous wastes and the elimination or minimization of gaseous effluents. ${ }^{108}$ Another methodology being investigated at EBR-II for the disposal of radioactive sodium waste is based on converting it to a carbonate or carbide form. 109

\section{Process and Effluent Radiological Monitoring Systems}

Design Objectives. Process radiation monitors are placed at LMFBRs to evaluate plant equipment performance and to measure, indicate, and record the radioactive concentration in plant process and effluent streams during normal operation and anticipated operational occurrences. Radiation monitoring of process systems provides early warning of equipment malfunctions indicative of potential radiological hazards. Monitoring of liquid and gaseous effluents under normal operating conditions are done in accordance with NRC Regulatory Guide 1.21. The number, sensitivities, ranges, and locations of the radiation detectors can be determined by requirements of the specific monitored process during normal and postulated abnormal conditions. All radiation monitors should be designed so that saturation of detectors during severe accident conditions will not cause erroneously low readings. Continuous radiation monitors presently found at LMFBRs are equipped with power supplies, microprocessor and accessories, and indication and local alarm indicator lights. Each monitor is capable of transmitting radioactivity level and alarm status information for display and logging in the control room with redundant display and logging equipment, and are designed in compliance with IEEE 279-1971. Pericdic sampling of primary sodium, secondary sodium, exvessel sodium, and cover gases is conducted to alert the operator of any abnormal conditions that may be developing. Both local and remote licjuid samples are taken. Isotopic analysis of process samples at LMFBRs in the United States is performed by automated spectrum analysis systems that satisfy the reporting requirements of Regulatory Guide 1.21.

LMFBR Experience. The fission products released from a fuel element with breached cladding in EBR-II have been monitored in several ways. Before 1972, the fuel element failures were caused by defective closure wells and the like. Although xenon tags were included in experimental elements after 1969 , none of the early failed elements had them. The early period was characterized by lengthy searches for sources of fission gas release.

From 1973, intentional endurances, or run-tocladding-breach (RTCB) tests produced an increasing number of failures. Generally, however, these failures were well separated in time and did release xenon tags. Experience was gained in correcting the tag compositions or changes caused by in-reactor exposure, and identification was quite rapid.

From about 1977, when reference FFTF fuels tests approached radiation exposure goals, RTCB tests of advanced fuel element design were begun and run-beyond-cladding breach (RBCB) testing was started, and incidents of failure sharply increased. During this period, an average of 10-15 failures occurred per year. The period was characterized by an increasing number of occasions when several failures occurred in the reactor at the same time.

The ways in which breached elements have been identified and removed from EBR-II from 1967 to April 1979 are described in References 110 to 121.

The main cover gas activity monitor now in use at EBR-II is the germanium lithium argon s.canning system, or GLASS, which was developed from previous systems. ${ }^{122-123}$ Argon is extracted from a 
cover gas, aged for about four minutes to allow the $\mathrm{Ne}-23$ activity to decay away, and monitored in a $25-\mathrm{mL}$ chamber above a coaxial $\mathrm{Ge}(\mathrm{Li})$ gamma detector. Signals are fed into a dedicated computer used as a 1024-channel analyzer. The activities of $\mathrm{Kr}-85 \mathrm{~m}, \mathrm{Kr}-88, \mathrm{Xe}-133, \mathrm{Xe}-135, \mathrm{Xe}-135 \mathrm{~m}$, and Xe138 are routinely monitored by the GLASS.

During normal full power operation, there is a little cover gas activity, because of the fissioning of 2-5 mg of "tramp" uranium. This background has remained constant and is thought to be caused by some fixed contamination in the core that resulted from use of reprocessed driver fuel elements between 1964 and 1968. The background activity is entirely swamped by the fission gas released from breached elements. Figure 2 shows a typical change in cover gas activities from failure of an experimental driver fuel element. Such failures are characterized by an initial increase in Xe-135m activity, which arises from decay iodine in the sodium bond that escapcs before the stored fission gas.

Any delayed neutrons (DNs) released from a breached element are detected in a bypass stream of sodium by the fuel element rupture detector (FERD), which was upgraded in March 1978. 124-126 The new FERD system is improved slightly in counting efficiency and, more importantly, exhibits a more stable and reproducible behavior. Detection is accomplished by $\mathrm{BF}_{3}$ counters embedded in a moderator stack that surrounds a sample duct containing primary coolant aged about 20 seconds. A FERD loop flow reduction technique has been developed to analyze the age of DNs, which supplies additional diagnostic information relating to the size and conditions of the breach. $127-128$

Samples of primary sodium are periodically taken by a sodium overflow sampler to analyze for

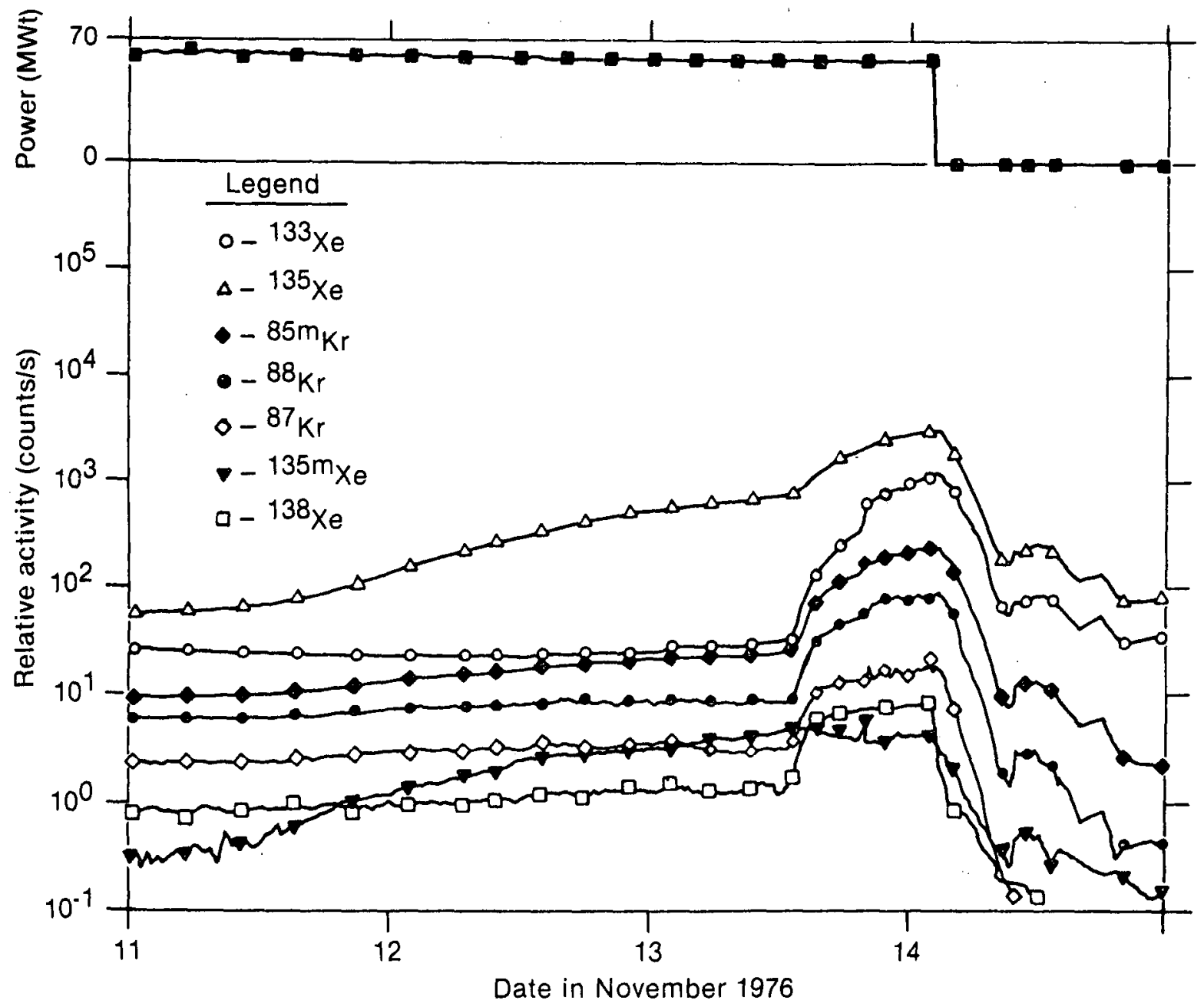

Figure 2. GLASS activities data failure of a metal-fueled driver element at EBR-II. 
the presence of 1-131, Cs-137, U-235, and Pu-237. In this device, up to four $10-\mathrm{mL}$ Pyrex beakers are filled to overflowing with sodium in an inert atmosphere; after five days of cooling, the beakers are removed and their contents analyzed. Throughout the course of EBR-II history, plutonium has never been detected by the overflow sampler at the limit of detectability of $5 \mathrm{pg} / \mathrm{g}$ of sodium. Similarly, only twice has uranium been detected above the detectability limit of $1 \mathrm{ng} / \mathrm{g}$. This experience confirms that exposure of metal or ceramic fuels to the primary sodium has been minimal.

With the advert of limit RBCB testing, a more sensitive device, the only distillation unit, or OLDU was installed and made operational in 1978. In the OLDU, a sample of about $150 \mathrm{~g}$ of primary sodium is heated and volatilized. Nonvolatile impurities are left in the sample cup and may be analyzed immediately, since decay of $\mathrm{Na}-24$ activity is not required. With OLDU operational, plutonium in the primary sodium has been occasionally measured above its detection limit. 129

Eleven methods developed at EBR-II are being used for the identification of fuel element failures; Table 14 lists and briefly describes them. The first five methods in the Table were used in EBR-II operations from 1965 to 1973 , when there was no accompanying release of a xenon tag. With one exception, these methods involved the measurement of fission gas activity in the cover gas and were nonspecific. The fourth method predicted failures on the basis of experience; it was of use for homogeneous groups of fuel elements such as the EBR-II metal driver fuel in which there was a welldefined mode of failure. ${ }^{130}$ Identification frequently involved many reactor shutdowns and startups and 5 to 10 days of lost operating time. Confirmation of an identification was always the absence of short-lived fission gas activity upon resumption of full power.

The remaining methods of identification in the table were, in general, developed and used in EBR-II operations since 1973. The predominant method in the table is No. 8, the identification of a xenon tag from a failed fuel pin assembly. However, all 11 methods have been used when appropriate. For example, the Xe-131/Xe-134 ratio has proven useful in distinguishing between failure of a uranium fissioning metal driver-fuel element and failure of a plutoniumbearing experimental element. 129
The xenon tags used at EBR-II consist of about $1 \mathrm{~mL}$ of a unique mixture of the stable xenon isotopes, Xe-124, Xe-126, Xe-128, and Xe-129, which is added to all elements in a given fuel assembly. The tags are blended from three components: natural xenon, natural xenon $5 \%$ enriched in Xe-124, and pure $\mathrm{Xe}-128$. One hundred forty tag compositions have been produced, with Xe-129/Xe-124 ratio increments of 1.25 and Xe-128/Xe 124 ratio increments of 4 . Figure 3 shows a typical threedimensional plot of the tag nodes that correspond to the experimental subassemblies in the reactor during reactor Run 111.

Whenever a failure occurred before 1977 , the xenon content in about $0.5 \mathrm{~m}^{3}$ (1-20th) of the argon-cover-gas volume was adsorbed on a cooled charcoal trap, later released by heating, and collected for analysis on a laboratory mass spectrometer. In this "manual mode," sampling was limited to once every $10 \mathrm{~h}$ and was complicated by the need to prevent personal exposure. Nevertheless, considerable accuracy was obtained, and released tag volumes of $0.04 \mathrm{~mL}$ could be readily used for identification.

In 1978, when the cover gas cleanup system (CGCS) became fully operational, a 7.5 -cm radius, $60^{\circ}$ sector, mass spectrometer was installed on line with the tag trap analysis system. ${ }^{131}$ Although the instrument functioned well and reliably, it had an inadequate resolution for $\mathrm{Xe}-133$, which is an important isotope in determining subassembly failures, and the instrument was also difficult to maintain at optimum performance. In May 19\&0, it was replaced with a new $15-\mathrm{cm}$ radium spectrometer that had been specially designed to have an abundant sensitivity of greater than one in 30,000 at 133 atomic mass units, to be sensitive to analysis of very small samples, and to be more easily maintained. The performance of this new instrument has been extremely gratifying. It has allowed, for example, the routine analysis of background samples that contain less than $0.002-\mathrm{mL}$ xencin tag in the cover gas volume of about $10^{7} \mathrm{~mL}$, and in which Xe-124 can be measured with a precision of $1 \%$ at a low fraction of 0.0015 of the xenon isotopes. 128 This value exceeds the best sensitivity that could be obtained by the use of a manual method by an order of magnitude, whereas the $7.5-\mathrm{cm}$ instrument was worse by a factor of four or five. 
Table 14. Methods used to identify sources of fission-product release in EBR-II

\begin{tabular}{|c|c|c|c|}
\hline Method & Purpose & Advantages & Disadvantages \\
\hline $\begin{array}{l}\text { Fission-gas } \\
\text { volume }\end{array}$ & $\begin{array}{l}\text { Identifies suspects by } \\
\text { gas release }\end{array}$ & $\begin{array}{l}\text { Eliminates low- } \\
\text { burnup suspects }\end{array}$ & $\begin{array}{l}\text { Usually limited } \\
\text { applicability }\end{array}$ \\
\hline $\begin{array}{l}\text { Ratio } \\
{ }^{133} \mathrm{Xe}\end{array}$ & $\begin{array}{l}\text { Discriminates } \\
\text { between metal and } \\
\text { oxide }\end{array}$ & $\begin{array}{l}\text { Identifies type and } \\
\text { burnup of suspect }\end{array}$ & $\begin{array}{l}\text { Ratio changes } \\
\text { for same element } \\
\text { affected by fuel and } \\
\text { breach geometry }\end{array}$ \\
\hline $135 \mathrm{~m}_{\mathrm{Xe}}$ & $\begin{array}{l}\text { Indicates release } \\
\text { of bond sodium }\end{array}$ & Rapid & $\begin{array}{l}\text { None; occasion- } \\
\text { ally overlooked }\end{array}$ \\
\hline $\begin{array}{l}\text { Weibull failure } \\
\text { analysis }\end{array}$ & $\begin{array}{l}\text { Ranks suspects by } \\
\text { failure probability }\end{array}$ & $\begin{array}{l}\text { Predicts breach in } \\
\text { advance; helps } \\
\text { rank otherwise } \\
\text { equal suspects }\end{array}$ & $\begin{array}{l}\text { Assumes common } \\
\text { mode of failure; } \\
\text { limited by previous } \\
\text { experience }\end{array}$ \\
\hline Flux-tilting & $\begin{array}{l}\text { Narrows down sus- } \\
\text { pects to a section } \\
\text { of the core }\end{array}$ & Easy to perform & $\begin{array}{l}\text { Suspect must be } \\
\text { adjacent to control } \\
\text { rod; only positive } \\
\text { response is meaning- } \\
\text { ful }\end{array}$ \\
\hline $\begin{array}{l}\text { Ratio } \\
128 \mathrm{Xe}^{134} \mathrm{Xe} /\end{array}$ & $\begin{array}{l}\text { Determines burnup } \\
\text { level of untagged } \\
\text { element }\end{array}$ & $\begin{array}{l}\text { Eliminates sus- } \\
\text { pect with too } \\
\text { high or low } \\
\text { burnup }\end{array}$ & $\begin{array}{l}\text { For small release, } \\
\text { natural background } \\
\text { contamination } \\
\text { can be significant }\end{array}$ \\
\hline $\begin{array}{l}\text { Ratio }{ }^{131} \mathrm{Xe} / \\
{ }^{134} \mathrm{Xe}\end{array}$ & $\begin{array}{l}\text { Descriminates } \\
\text { between metal and } \\
\text { oxide }\end{array}$ & $\begin{array}{l}\text { Uses stable high- } \\
\text { yield isotopes } \\
\text { of xenon }\end{array}$ & $\begin{array}{l}\text { Can be affected } \\
\text { by tag in low- } \\
\text { burnup elements }\end{array}$ \\
\hline Xenon tag & $\begin{array}{l}\text { Identifies suspects } \\
\text { by tag }\end{array}$ & $\begin{array}{l}\text { Limits choice to } \\
\text { one to three } \\
\text { suspects }\end{array}$ & $\begin{array}{l}\text { Exposure changes } \\
\text { in tag; sometimes } \\
\text { small tag releases; } \\
\text { contamination }\end{array}$ \\
\hline $\begin{array}{l}\text { Fission-gas and } \\
\text { tag volumes }\end{array}$ & $\begin{array}{l}\text { Discriminates sus- } \\
\text { pects with similar } \\
\text { tag compositions }\end{array}$ & $\begin{array}{l}\text { Ranks xenon-tag } \\
\text { suspects }\end{array}$ & $\begin{array}{l}\text { As above; also, } \\
\text { early tag volumes } \\
\text { were variable }\end{array}$ \\
\hline $\begin{array}{l}\text { Lift-and-hold } \\
\text { test }\end{array}$ & $\begin{array}{l}\text { Identifies suspects } \\
\text { by gas release }\end{array}$ & $\begin{array}{l}\text { Confirms suspect } \\
\text { subassembly in } \\
\text { fuel handling }\end{array}$ & $\begin{array}{l}\text { Shutdown required; } \\
\text { only positive } \\
\text { response meaningful } \\
\text { time consuming }\end{array}$ \\
\hline $\begin{array}{l}\text { FUM isolation } \\
\text { test }\end{array}$ & $\begin{array}{l}\text { Identifies suspects } \\
\text { by gas release }\end{array}$ & $\begin{array}{l}\text { Confirms suspect } \\
\text { subassembly at } \\
\text { operator's } \\
\text { convenience; mini- } \\
\text { mizes inter- } \\
\text { ference from } \\
\text { cover-gas activity }\end{array}$ & $\begin{array}{l}\text { As above; can tolerate } \\
\text { only low decay-heat } \\
\text { level in discharged } \\
\text { subassembly }\end{array}$ \\
\hline
\end{tabular}




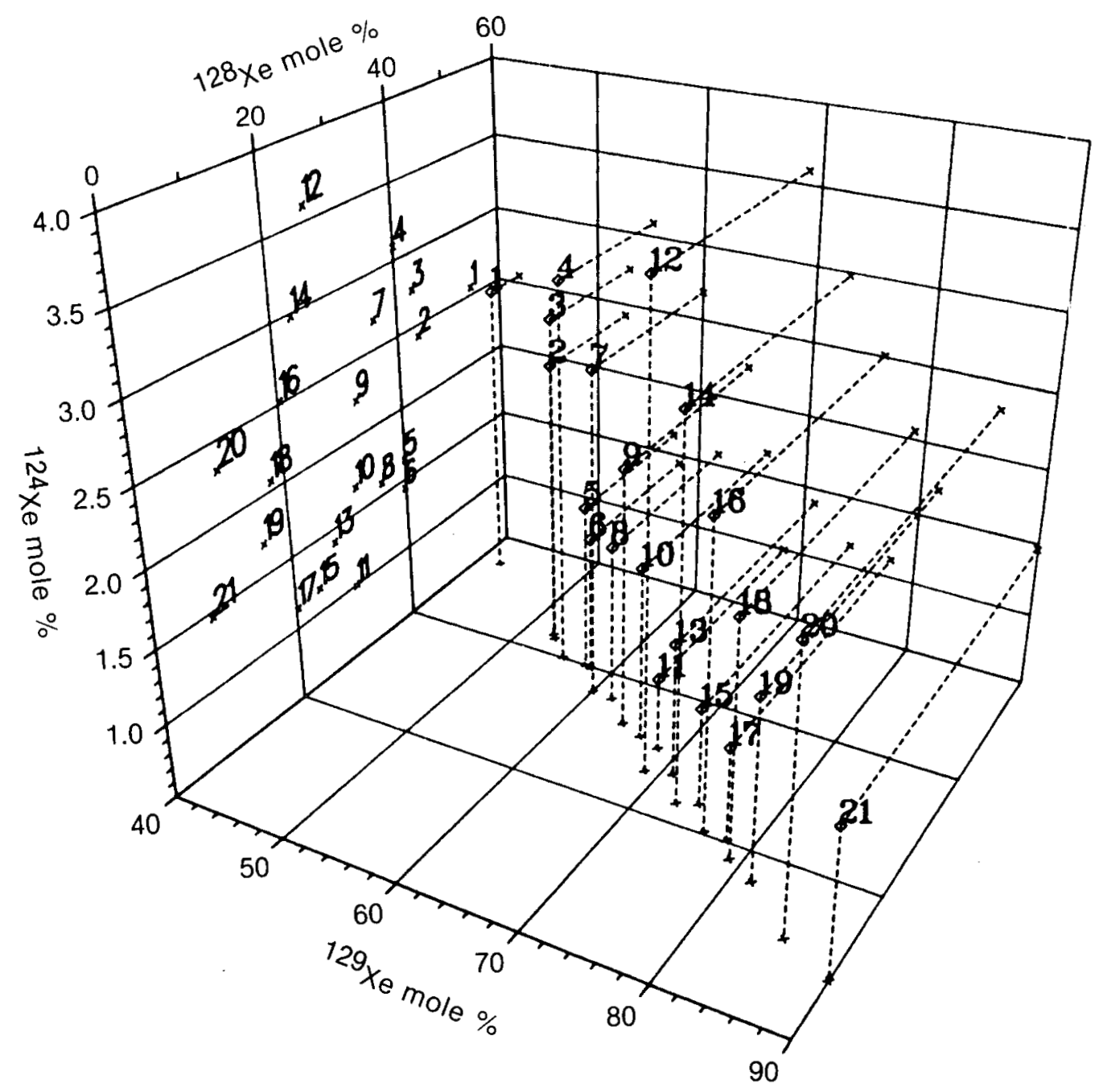

Figure 3. Three-dimensional plot of xenon gas tag nodes for the experimental subassemblies in EBR-II during Run 111.

The mass spectrometer is operated automatically by the computer of the tag trap system and is therefore required to be on-line whenever the reactor is at power. The instrument has operated with a minimum of down time. Routine replacement of the source filament is required every five months, and the turbo molecular pumps have had slight bearing problems. The most serious, but easily remedied problem, has been the removal of hydrocarbons after system shutdowns.

Although shifts in tag composition caused by incore exposure were anticipated early, the magnitude of the shifts was not. Major changes were caused by burnout of Xe-124 by neutron capture and by production of Xe-128 by an $(n, \alpha)$ reaction of fission product I-127. During several early tag releases, these effects caused considerable confusion in iden- tification and extra operating time was lost. However, empirical correction and, later, the result of tag exposure tests and calculations have removed the uncertainty caused by composition change. Computer programs are now used to update compositions of all xenon tags in the reactor for every run. $131-133$

Both the impurity monitoring and analysis system (IMAS) and the fuel failure monitoring system (FFMS) monitor FFTF argon cover gas. The IMAS monitors argon cover gas for process control and detection of adsorber pin leakage. The FFMS monitors the cover gas to detect any fuel pin, test pin, or adsorber pin leakage. Upon detection of a leaking pin, samples of cover gas are taken to the laboratory and analyzed to identify the exact fuel assembly, test assembly, or adsorber assembly that contains the leaking pin. 
The IMAS is used to perform the following argon monitoring and sampling functions:

- Continuous monitoring of concentrations of oxygen, hydrogen, nitrogen, methane, and carbon monoxide in all primary argon cover gas systems, with on-line gas chromatographs for process control

- Monitoring concentrations of helium in the heat transport system (HTS) because the presence of significant quantities of helium at nominal zero reactor power indicate an adsorber pin leak

- Providing argon to the FFMS for on-line fuel failure monitoring

- Obtaining periodic bulk samples of argon cover gas from the primary and secondary HTS and closed loop systems (CLS) for laboratory analysis.

The argon cover gas for the primary coolant systems is directly sampled from the gas equalization line connecting the reactor vessel and the sodium overflow vessel, and from each primary CLS surge tank. A continuous closed-loop circulating flow is provided to a gas chromatograph, located in the HTS service building-south. The chromatograph sampling head selects each gas sequentially for analysis. Argon compressors circulate the sample gas.

Pneumatically operated isolation valves are automatically closed by the plant protection system (PPS) when required, to ensure containment isolation of lines from the primary systems.

Argon cover gas in the secondary system is sampled manually from the HTS secondary expansion tanks and the CLS secondary surge tanks, using grab sample cylinders.

The FFMS provides the following:

- On-line monitoring to detect escape of fission gas from a leaking fuel assembly into the cover gas, or the escape of activated tag gas from a leaking absorber assembly

- Sampling equipment and analytical procedures to locate the leaking assembly.
Cover gas used for the reactor heat transport primary system is scanned continuously with an intrinsic germanium diode gamma detector. Fission gas isotopes are monitored to detect fuel failures, and Xe-125 is monitored to detected an absorber pin failure when the reactor is at power. An alarm is activated in the reactor control room if an abnormal activity level is detected for any of these isotopes.

The level of activity detected by the monitor varies from a background of 1 to 10 counts per second to as high as $10^{5}$ counts/s during a rapid gas escape.

Cover gas is monitored in the cover gas monitor module by passing a continuous controlled flow through a small, liquid-nitrogen cooled, activated charcoal, sample column adjacent to the gamma sensitive germanium diode. Use of the sample column and thin detector permits accurate monitoring under conditions of high background radiation.

The technique for locating a failed fuel or absorber assembly is based on the use of a unique mixture of xenon and krypton in fuel and adsorber pins. These tag gas mixtures are loaded into the pins at the time of fabrication.

All individual pins of a given fuel assembly contain the same unique isotopic mixture consisting of one standard $\mathrm{cm}^{3}$ of xenon and one standard $\mathrm{cm}^{3}$ of krypton. All individuals pins of a given absorber assembly contain the same unique isotopic mixture consisting of two standard $\mathrm{cm}^{3}$ of xenon and two standard $\mathrm{cm}^{3}$ of krypton. Over 106 unique mixtures are used for the driver, open test, the absorber assemblies of the core. Each time a fuel or absorber pin failure is detected, cover gas samples are obtained with a tag gas sampling trap.

Failure assemblies are identified by matching the results of a mass spectrometer analysis with previ= ously determined analysis of all tag gas mixtures in the reactor, suitably corrected for burnup and background.

Unlike EBR-II, the FFTF, FFMS is not automated and, it takes approximately $6 \mathrm{~h}$ for the segregation of the xenon, krypton, and argon isotopes. Few tag samples exceed $25 \mu \mathrm{Ci} / \mathrm{cm}^{3}$. An ion chamber-type survey instrument (JUNO) is used to determine if the tag gas sample bomb exceeds the operational safety limit of $500 \mathrm{mrem} / \mathrm{h} .{ }^{134}$ 


\section{Sodium Impurity Monitoring and Analysis Systems}

Sodium Coolant. The choice of coolant for a fast breeder reactor probably has a greater effect on the overall physical plant layout and on operational health physics than any other design selection. Whereas the coolant strongly influences the neutronic behavior of the core and provides a direct framework for the consideration of cladding materials, the most recognizable effect of the coolant selection is its effect on major components such as pumps, steam generators, heat exchangers, shielding, and instrumentation.

Liquid metal sodium has been selected as the coolant for all major fast breeder power reactor projects underway around the world. As a consequence, the properties of sodium and its implication for design must be given particular attention. As options having received attention to date the gas coolants, helium and steam, have been given limited attention, as have other metal coolants.

The very high power density in an LMFBR core of $\sim 400$ watts/liter compared to $\sim 100$ watts/liter for an LWR places very stringent requirements on the heat transfer properties of a coolant candidate. A large heat transfer coefficient is desirable for optimum heat removal. Sodium is superior from the standpoint of heat transfer characteristics, though helium and steam can be driven hard enough, given sufficient driving pressure, to accomplish the required tasks.

Whereas any coolant has some moderating effect on the neutron spectrum, the degree of moderation taking place is proportional to the atomic mass and the density. Sodium, with a mass of 23 , is clearly heavier than either helium or steam, but when the density effect is taken into account, the heliumcooled reactor yields the hardest spectrum; steam yields the softest spectrum because of its hydrogen content; and sodium provides an intermediate spectrum. Because of the spectrum differences, helium has a slight intrinsic advantage in terms of achievable breeding ratios. Another neutronic consideration is the effect of coolant activation. Helium, having a neutron capture cross section of essentially zero, is not activated. Steam becomes somewhat radioactive by the neutron activation of oxygen, but the impact on design is minor. Sodium activation, however, attains a high degree of short half-life activation. $\mathrm{Na}-23$ is activated to $\mathrm{Na}-24$, which decays through a beta emission with an attendant release of 1.37 and $2.75 \mathrm{MeV}$ gammas to $\mathrm{Mn}-24$. This activation has led to the inclusion of an intermediate coolant loop for sodium cooled systems to ensure that all radiation is confined to the primary loop. Other reasons for including an intermediate loop in LMFBR systems are to protect the core from possible pressure surges or positive reactivity effects caused by hydrogen moderation should a steam generator leak occur and result in a sodium water reaction, and to protect the steam generator from radioactive corrosion and fission products.

A final neutronics consideration concerns the reactivity effect of coolant loss during an accident. The large density change associated with sodium loss can cause an appreciable change in the neutron spectrum and associated positive reactivity feedback. None of the gas cooling media exhibits such a characteristic, though a thorough safety analysis of such systems does cover the very remote posisibility of water entering the core as a result of a major break or depressurization. Under such conditions, similar variations in reactivity could occur.

In order for a reactor coolant to perform its heat removal function, a fraction of the total power output must be used to pump the coolant through the core. Hence, it is of interest to compare pumping requirements for the various coolant candidates. For a typical size plant, sodium coolant requires the least, and helium requires the most, pumping power. Other liquid metals are written off, largely because of their much larger pumping requirements. ${ }^{135}$

Sodium is quite compatible with the preferred cladding candidates. However, because sodium has been chosen as the coolant, much research has been directed to every facet of its in-core environment, in order to determine any long-term deleterious effects. Summarized below are the main categories where effort has been focused to isolate possible problem areas.

- The principal metallic elements in the cladding, such as iron, chromium and nickel, are very slowly dissolved in sodium from the hot core region and deposited in the cooler areas. This long-term uniform attack is called cladding thinning or wastage. Although this amounts to only tens of micrometers $/ y$ at $700^{\circ} \mathrm{C}$, it must be considered in the overall load-bearing capacity of the cladding, which is stressed by internal fission gas pressure. 
- Each of the principal metallic elements mentioned above has a different dissolution rate in sodium. Hence, selective leaching occurs, and the composition of the steel at the outer surface is eventually altered. The effect, though small, is normally deleterious, since chromium and nickel are removed faster than iron. Some of the more significant problems arising from the dissolution of minor constituents or activation products from the steel in the core are discussed below.

- The dissolved metal deposited in the colder regions of the intermediate heat exchanger can lead to high heat transfer resistance or reduced heat exchanger efficiency. The deposits can become thick enough that coolant driving pressure must be increased in order to maintain desired flow. Some long-term silicon deposits have been observed at EBR-II. ${ }^{136}$ The silicon, originating as a minor constituent in the steel, forms a compound with sodium which, if precipitated in core assembly coolant channels, can influence pumping power or local flow conditions.

- Though small in quantity, sodium transport and deposition of manganese and cobalt in the intermediate heat exchanger and other primary system components, can cause high enough radiation fields to affect routine maintenance.

- In LMFBR secondary sodium systems that incorporate dissimilar materials in different regions of the circuit, nonmetallic elements such as carbon and nitrogen are known to migrate as a result of chemical activity differences. Ferritic steel is susceptible to decarbonization when exposed to high-temperature sodium because of its inherently high carbon activity and large carbon defusion coefficient. The carbon loss from this material in a sodium environment leads to a significant reduction in tensile strength and stress rupture life. Furthermore, the carbon transferred to the sodium can carbonize the austenitic stainless steel used in the intermediate heat exchangers and piping in the same circuit, with a resultant loss in ductility of the stainless steel. Because sodium is the trans- port media for the general corrosion of cladding, the selective leaching of metallic elements, the transport and deposition of dissolved metals and radioactive species, and the transport of carbon, samples of sodium are usually extracted regularly and analyzed during normal operations at LMFBRs. On-line instruments have been developed to monitor sodium purity for both the primary and secondary systems. In addition to determining oxygen and carbon content, it is useful to monitor hydrogen levels, since this provides an indication of the tritium level in the cover gas of the primary system or steam generator leaks in the secondary system.

A principal advantage of sodium, beyond its excellent heat transfer properties, is that it does not require pressurization to prevent coolant boiling. This feature contrasts sharply with the thick-walled high-pressure systems required for helium or steam-cooled systems. Table 15 shows the pros and cons of sodium coolant and other items that bear on coolant selection.

Sodium Cold Trap Technology. In the operation of LMFBRs, it is necessary to maintain control of the amount of impurities in the liquid metal coolant system. The health physics department usually has the responsibility for sodium quality. Control of the level of such impurities as hydrogen and oxygen is required because of in-core metalic elements. Oxygen is sodium enhances the corrosion rate of austenitic stainless steel and the rate of embrittlement of refractory metals. Hydrogen may cause embrittlement of refractory metals. Both of these impurities form compounds with sodium whose solubility in sodium decreases with decreasing temperature, leading to precipitation and deposition of the compounds. All of these effects can increase maintenance requirements at the plant and thereby increase the radiation exposure to plant personnel. Many methods of treatment of the sodium to remove the impurities has been proposed and investigated. Among them are filtration, settling, centrifugation, distillation, chemical reaction, soluble gettering, and cold trapping. ${ }^{137}$

The most widely used method for control of the hydrogen and oxygen impurities in operating LMFBRs has been the use of cold traps because of their simplicity, economy of operation, and relative effectiveness. Optimization of cold trap design and operation can increase capacity and lifetime, thereby improving the overall economics of the system. 
Table 15. Intercomparison of FBR coolants

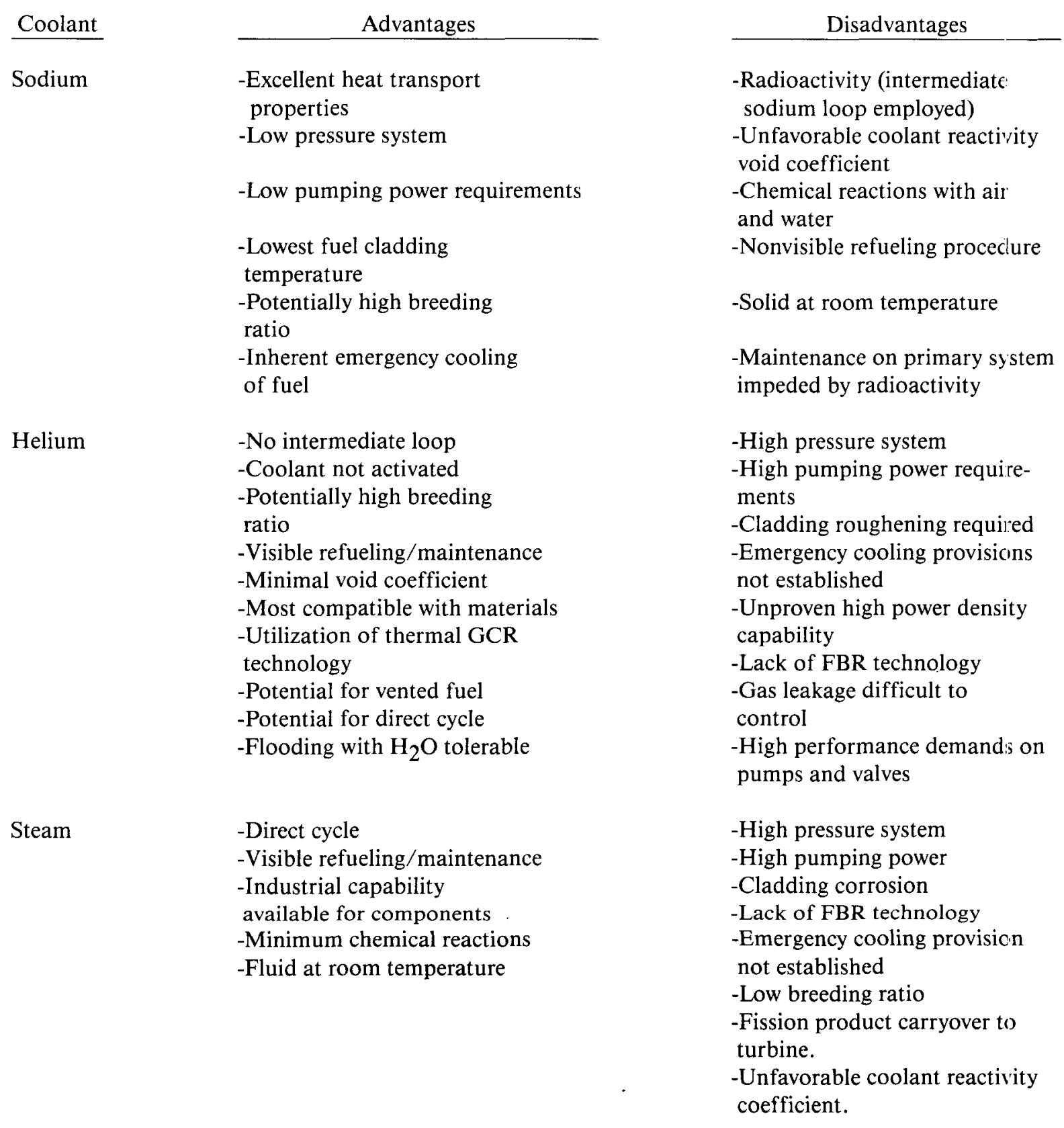

Sodium in the LMFBR intermediate heat transport system is subject to significant contamination by hydrogen derived from normal corrosion of the steam generator tubes. The Fe-2-1/4, Cr-1 Mo steel used in the steam generators oxidizes slowly in the steam environment, releasing nascent hydrogen, which defuses through the steel into the sodium. ${ }^{138}$ Most of this hydrogen defuses through the tubes into the sodium coolant and must be continuously removed.
Measurements of this corrosion rate on full-scale reactor systems have shown that the hydrogen source is very large $\left(1.8 \times 10^{-11} \mathrm{~g} \mathrm{H} / \mathrm{cm}^{2}\right.$-s $) .139$ The quantity of hydrogen thus entering the sodium in a typical 500-MWe LMFBR calculates to be about $25 \mathrm{~kg} / \mathrm{y}$. It is important that steady state hydrogen levels be maintained below $200 \mathrm{ppb}$ in the intermediate heat transport system sodium to permit early detection of possibly small steam genterator leaks that would introduce water into the 
sodium. The capability of a cold trap may be exceeded in a short time because of the increase in the pressure drop across the cold trap. Estimates indicate that a normal cold trap, when used to remove hydrogen from the sodium, has an expected lifetime of 12 to 18 months at full power operation. ${ }^{140}$ Replacement of intermediate heat transport system cold traps on an annual to 18 -month schedule would be prohibitively expensive and would result in large quantities of tritium-bearing waste sodium in the spent cold trap.

Figure 4 schematically depicts a typical forcedcirculation flow-through type cold trap. The sodium flow enters at the top, passes down through an annual region, laterally through an unpacked bottom region, up through the center region, and out of the cold trap to a heat exchanger, and then returns to the reactor system. In the coolant channel, NaK flows counter-current to the sodium flow in the annulus. Cold-trap operation is based on the dependence of impurities solubility with temperature; the lower the temperature, the less impurities such as oxides or hydrides remain soluble in the sodium. Under proper conditions, these impurities precipitate on the surfaces of the mesh packing for walls of the cold trap.

Early designs of cold traps have featured a narrow, unpacked or mesh-pack annulus with a large mesh pack central region. Examples are the Mine Safety Applications (MSA), Fermi, and EBR-II cold traps. ${ }^{141-143}$ Analysis of two of these traps indicates some deposition in the annulus but high utilization at the inlet to the center region. ${ }^{144}$ The reason for this behavior is thought to be that as the sodium passing through the unpacked annulus becomes cool to below the saturation limit for the impurity level present, the impurities precipitate out on the mesh. This is because the energy required to nucleate on a surface is less than the energy required to form a particle in the solution. There is also the possibility of micron size particles of $\mathrm{NaH}$ being in the sodium, but the coarseness of the mesh does not allow it to serve as an effective filter to trap any particles that are in the sodium.

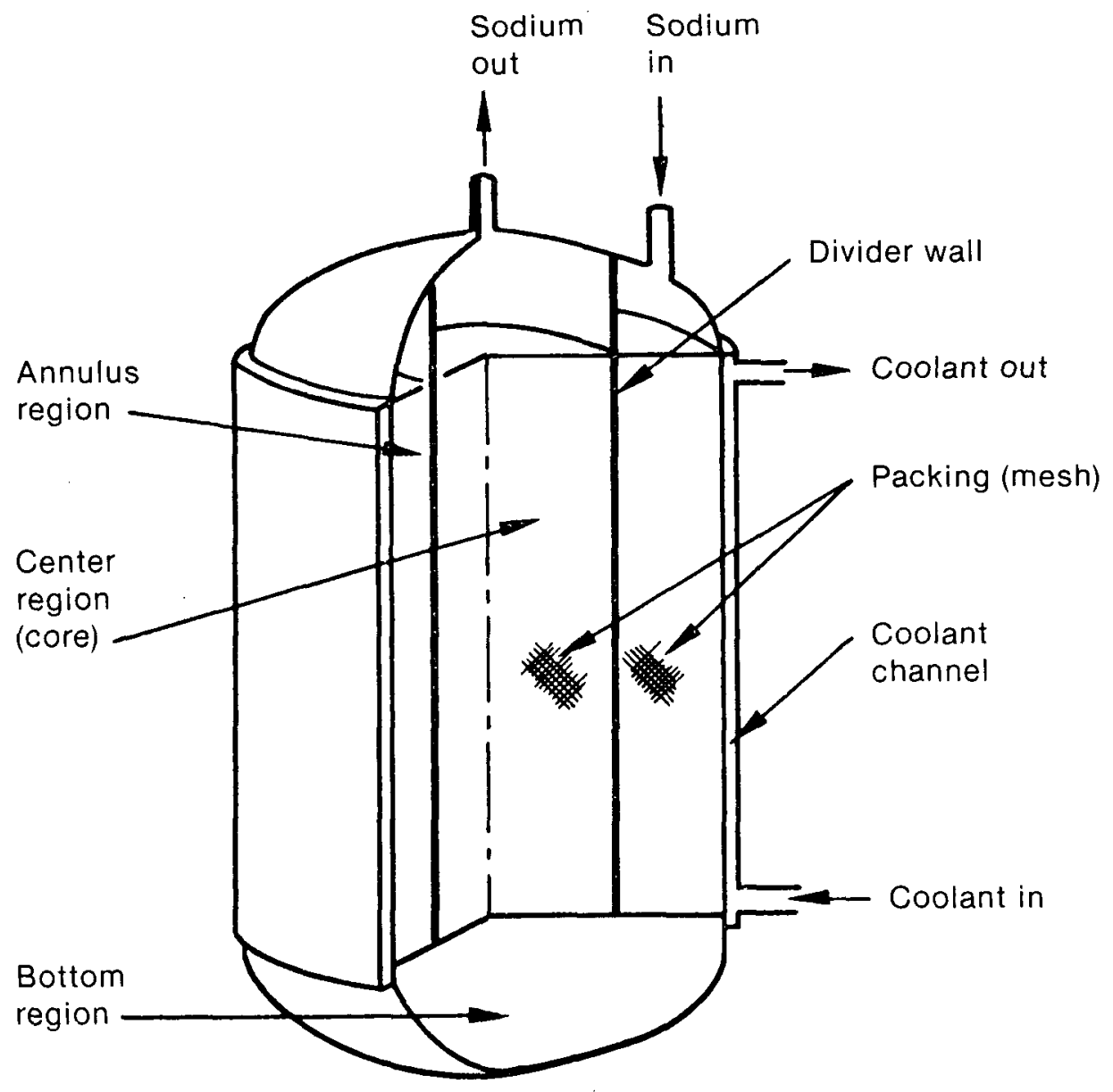

Figure 4. Schematic of a sodium cold trap for MASCOT calculations. 
The achieved capacity of cold traps has historically been low. Typically, only $10 \%$ of the total capacity of the cold trap is used before the pressure drop across the trap is too great, necessitating replacement of the trap. The increase in pressure drop is caused by local depositions of impurities, which occupy up to $90 \%$ of the available flow volume. A goal of 40 to $50 \%$ average use of cold packing capacity is theoretically attainable. 145

Parameters judged to be important factors in influencing the lifetime of a sodium cold trap are as follows:

- Sodium inlet flow rate

- Sodium inlet temperature

- Minimum sodium temperature in the cold trap

- Impurity present in the inlet sodium and its concentration level

- Mesh packing density

- Mesh packing wire diameter

- Location of the mesh packing

- Length-to-diameter ratio of mesh packing section

- Frontal flow area ratio (annulus/center section).

The length-to-diameter ratio is the ratio of the length of the annulus region to the outer diameter of the annulus region. The flow area ratio is the ratio of the total frontal area of the annulus region to the total frontal area of the center region.

There are many possible approaches to the choice of a system design for large-scale LMFBRs. The number and size of secondary systems on the reactor will guide the selection of the number and, to a degree, the size of the intermediate heat transport system cold traps. General guidelines given in Table 16 will aid the designer in the area of intermediate heat transport system cold trap design. These guidelines apply to forced circulation flow through type IHTS cold traps, calculated using the MASCOT code. ${ }^{145}$

It should be emphasized that verification of the performance of a proposed cold trap design will be required by operational testing prior to installation in a system. Because the performance of the cold trap is closely tied to inlet sodium temperature and impurity concentrations, the manner of control of this temperature and measurement of the impurity concentration must be addressed in the design of the cold trap system.

Though the principal role of the cold trap in the primary circuit is to control the concentration of dissolved oxygen impurity and, in the intermediate heat transport system, to control the concentration of hydrogen impurities, a number of radioactive impurities have been observed to be cold trapped also. Cold traps are not designed with this intention, and in the case of many such species it is not clear that the mechanism of cold trapping is precipitation from solution. The parameters that affect the phenomena of crystal nucleation, growth, and mass transfer, which are fundamental to cold trap performance, have been defined. ${ }^{146}$ The performance of a cold trap in relationship to a given radioactive species cannot be described simply, in terms of precipitation, and will be markedly sensitive to design and operating parameters. In addition to providing a site for crystal nucleation and growth, a cold trap is characterized by high residence time of the sodium, heat exchange, and flow conditions, which may be conducive to particulate deposition-depending on the design, on the high surface areas of steel in the trap internals and disodium monoxide at low temperatures compared to the remainder of the primary circuit on which deposition may occur preferentially, and on the structures conducive to the filtration of particulate material. The last aspect, in particular, may be sensitive to operating mode; it has been suggested that the PFR cold trap will only become an effective filtration unit for particles below 100 microns when the trap has a considerable inventory of disodium monoxide-type impurity through the mesh packing. ${ }^{147}$

The potential role of cold trapping as a means of removing radioactive products from the coolant of LMFBRs has not been explored fully. There have been few systematic studies of cold trapping performance in operating reactors, possibly as a result of the difficulty of carrying out such analysis; the information available is fragmentary and does not lead itself to generalization. Furthermore, the performance of the cold trap in removing radioactive products will be intrinsically related to the deposition behavior of these species in the remainder of the primary circuit, and this deposition behavior 
Table 16. General guidelines for IHTS cold trap design

Item

\section{General}

(H) Impurity source rate

Utilization, vol\%

Efficiency, $\%$

Lifetime, mo

\section{Design}

$\mathrm{L} / \mathrm{D}$ ratio

FAR

Mesh

Wire diameter, cm

Density, $\mathrm{g} / \mathrm{cm}^{3}$

Location

Size Range, L

Recommended pressure drop, $\mathrm{Pa}$

Operating

Maximum (H) impurity level, ppm

Temperature, ${ }^{\circ} \mathrm{C}$

Inlet sodium

Minimum sodium

Inlet $\mathrm{NaK}$ coolant (range)

Flow rate, $\mathrm{L} / \mathrm{s}$

Inlet sodium

Inlet $\mathrm{NaK}$ coolant ${ }^{\mathrm{a}}$
Guideline

Calculate based on heat-exchanger size, design, and materials

$>38$

$>75$

$>40$

1 to 1.5

4 to 8

$\sim 0.028$

$0.32-0.4$

Annulus only

$3000-7000$

$\sim 4.8 \times 10^{4}$

0.2

At or slightly $\left(1-2^{\circ} \mathrm{C}\right)$ above the saturation temperature for the impurity level in the inlet sodium

$114-125^{\circ} \mathrm{C}$

$65-85^{\circ} \mathrm{C}$

To yield a residence time of $10-15 \mathrm{~min}$

Equal to the sodium coolant rate established above

a. If gas coolant is used, then the flow rate is that required to remove the heat load and obtain the minimum trap temperature. 
will vary from system to system, as described previously. Table 17 lists radionuclides, excluding tritium and those of sodium, detected in LMFBR cold traps.

At Phenix, the only release of fission products to date is thought to have occurred as a consequence of a gas leak, rather than a fuel failure. ${ }^{148}$ The cesium levels observed were close to the minimum detection limits and not viewed as significant. Data indicate that cold trapping of radionuclides is inadequate for meaningful analysis at present. 149

At the RAPSODIE LMFBR, the efficiency of cold trapping of I-131 has been investigated using data on the kinetics of I-131 release from failed fuel and concentration changes in the primary sodium, defined as

$P=\frac{C_{e}-C_{s}}{C e}$

where

$\mathrm{P} \quad=$ the efficiency of cold trapping

$C_{\mathrm{e}}=$ the concentration of $\mathrm{I}-131$ at the entrance to cold trap

$\mathrm{C}_{\mathrm{S}}=$ the concentration at the exit.
The efficiency, $\mathrm{P}$, was found to be unity, or $100 \%$. Hence, all iodine released to the circuit was cold trapped after the required number of passes. In contrast, the maximum proportion of the Cs-137 inventory of the primary circuit observed to be cold trapped was $50 \%$. 150-151

More than $90 \%$ of the inventory of both iodine and cesium isotopes in the BR-5 primary circuit was cold trapped. ${ }^{152}$ In terms of the proportions cold trapped, the cold trap was found to be much less effective for $\mathrm{Zr} / \mathrm{Nb}-95$ and $\mathrm{Ba} / \mathrm{La}-140,152$

The BOR-60 cold trap system was specifically aimed at assessing the efficiency of removing, radioactive impurities as a function of design and operating parameters. Following decay of short-lived I-131 and Te-129m isotopes, $\sim 150 \mathrm{Ci}$ of long-lived isotopes had accumulated in the cold trap by June 1974. The principal contributors to this activity were Cs-137 (130 Ci), Cs-134 (9 Ci), and Co-60 $(2.5 \mathrm{Ci})$.

Purification of the sodium coolant achieved by cold trapping was quantified in two ways, as presented in Table 18. A purification coefficient was evaluated, where

$K=A_{c t}\left(A_{c}+A_{c t}\right)$

Table 17. Radionuclides detected in primary circuit cold traps of FMFBRs

Reactor

Phenix

Rapsodie

BR-5

BOR-60

EBR-II

DFR ( $\mathrm{Na} / \mathrm{K}$ coolant)

\section{Reference}

42

150

152

61

154,155

40
Radionuclide

Mn-54, Co-58, Co-60, Zn-65, Sb-124, Cs-134, Cs-136, Cs-137

I-131, Cs-137

Zr-Nb-95, I-131, I-133, I-135, Cs-136, Cs-137, Ba-La-140

Mn-54, Co-60, Zn-65, Zr-Nb-95, Ag-110rn, Sb-124, Sb-125, I-131, Cs-134, Cs-137

Mn-54, Co-60, Zn-65, Sb-124, Sb-125, I-131, Cs-134, Cs-137

Cr-51, Mn-54, Zn-65, Zr-Nb-95, Sb-124, Sb-125, Te-129m, I-131, Cs-134, Cs-137, Ba-La-140, Cs-141, Ce-144 
Table 18. Purification coefficients for the BOR-60 cold-trapa

\begin{tabular}{|c|c|c|c|}
\hline $\begin{array}{l}\text { Purification } \\
\text { Coefficient }\end{array}$ & $\mathrm{K}$ & $\mathrm{K}_{\mathrm{O}}$ & $\mathrm{K}_{\mathrm{b}}$ \\
\hline $\mathrm{Na}-22$ & 0.054 & 1 & 1 \\
\hline Co-60 & 0.21 & 0 & 88 \\
\hline $\mathrm{Zn}-65$ & 0.86 & 6.6 & 19 \\
\hline $\mathrm{Ag}-110 \mathrm{~m}$ & 0.043 & 0.83 & 0.75 \\
\hline Sb-124 & 0.22 & 4.4 & 6.2 \\
\hline I-131 & 0.99 & $1.5 \times 10^{4}$ & $2.1 \times 10^{4}$ \\
\hline Cs-134 & 0.32 & 4.0 & 15 \\
\hline Cs-136 & 0.30 & 5.2 & 15 \\
\hline Cs- 137 & 0.38 & 4.7 & 26 \\
\hline
\end{tabular}

a. Taken from Reference 1-153.

where

$$
\begin{aligned}
& A_{c t}= \text { total activity of an isotope in the cold } \\
& \text { trap }
\end{aligned}
$$

This coefficient, $\mathrm{K}$, is a function of plant design parameters. For example, the value of $\mathrm{K}$ for $\mathrm{Na}-22$ is equal to the ratio of the volumes of the cold trap and the primary circuit; for BOR-60, this ratio is 0.054 . A specific purification coefficient was also evaluated, which is independent of parameters such as cold trap volume (defined as the ratio of the specific activity in the settling zone), or the zone of filtration in the cold trap to the average specific activity of the same isotope taken over the circuit ( $\mathrm{K}_{\mathrm{o}}$ and $\mathrm{K}_{\mathrm{b}}$, respectively). These coefficients were found to be fairly constant for measurements over the period 1972-1973 for BOR-60 and were found to be independent of parameters such as cold trap volume.

Nearly all the iodine in the primary circuit is retained in the cold trap. The kinetics of cold trapping of I-131 were also investigated. An extraction constant of $0.12 \mathrm{~h}^{-1}$ was evaluated, corresponding to almost complete removal of I-131 from the main circuit after 24 h of operation of the cold trap. ${ }^{153}$

The performance of the cold trap with respect to cesium showed a marked variation with time, and virtually no further cold trapping of cesium was observed after 1973. The proportion of the total cesium inventory in the cold trap fell correspondingly from the values shown in Table 18 to 0.2 .

The distribution of isotopes in the cold trap was also investigated and found to be far from uniform. The concentrations of all isotopes investigated came to a maximum at the entrance to the first filtration zone.

Mn-54 was not cold trapped as readily as Co-60; $\mathrm{Zr} / \mathrm{Nb}-95$ was not cold trapped to any significant extent; and $\mathrm{Ba} / \mathrm{La}-140$ did not appear to be cold trapped.

Cold trapping at EBR-II is considered to occur either by a precipitation mechanism or by a segregation-adsorption mechanism, the latter mechanism applying to all fission and activation products. The segregation adsorption mechanism appears to be less effective than the precipitation mechanism for the removal of hydrogen and oxygen in the EBR-II cold traps. ${ }^{154-156}$

Studies conducted at EBR-II have demonstrated the following:

- I-131 was not removed effectively after a clad failure in July 1975; radioactive decay of the I-131 inventory was the major removal mechanism. This observation contrasts with other experiments at EBR-II 
where lowering of the sodium temperature produces a quantitative segregation of I-131 to metal surfaces. This segregation process provides the basis for an analytical method for I-131 used at EBR-II.

- During the first year of operation of the cold trap (1968-1969), 30\% of the total Cs-137 inventory was located in the cold trap. Subsequently, the absolute quantity of Cs-137 in the cold trap has remained effectively constant, and further cold trapping of the isotope does not appear to have occurred.

- The cold trap is extremely effective for Mn-54 removal, removing $\sim 60 \%$ per pass. However, the benefits derived from efficiency in this respect are dubious for continuously produced corrosion products such as Mn-54. This removal in the cold trap will not influence deposition on components upstream; most of the Mn-54 will deposit in the primary circuit and not enter the cold trap circuit.

Generally, radioactivity was not uniformly distributed in the cold trap. The level of activity was at a maximum at a point close to the inlet for the external cooling (employing NaK alloy) where most precipitation is thought to occur.

The cold trap at DFR was found to be highly effective for the removal of I-131 and Tc-129m; $\mathrm{Ba} / \mathrm{La}-140$ also segregated markedly to the cold trap. However, the efficiency of the cold trap in removing Cs-137 was deemed to be disappointingly low. The behavior of antimony was variable, and association with fuel particles was postulated.

The ease with which I-131 in the cold trap was removed by steam cleaning suggested it to be present as precipitated sodium iodine, whereas the acid cleaning required to remove $\mathrm{Te}-129 \mathrm{~m}$ was taken to indicate some weak chemical binding to the surface of the steel mesh cold trap basket. The decontamination behavior of $\mathrm{Ba} / \mathrm{La}-140$ (and the species $\mathrm{Zr} / \mathrm{Nb}-95$, Ce-141, and Ce-144) appeared indicative of fine surface oxide deposition. However, cesium appeared strongly bound to the steel of the cold trap, and penetration of the steel was postulated to explain the resistance of the cesium to decontamination procedures.

Observations on the cold trapping behavior of radionuclides are often in conflict, and the discrepan- cies remain largely unresolved. Before assessing the contribution that might be made by cold trapping to the removal of radioactive products from LMFBR primary circuits, it is desirable to consider the mechanism of cold trapping of specific radionuclides.

Appreciable segregation of Cs- 137 in cold traps has been reported under certain conditions. However, the conditions that will optimize cold trapping of Cs-137 have not been identified. Variations in the nature of steel surfaces, flow conditions, and the coolant chemistry within the cold trap may all account for the observable differences in cold trap efficiency at LMFBRs. A number of workers have conducted experiments in order to improve the understanding of cesium deposition behavior in sodium/stainless steel systems. Classically, a distribution coefficient, $\mathrm{K}$, is obtained to describe the distribution of cesium between its deposited form on a steel surface and its dissolved stage in sıdium, where

$\mathrm{K}=\frac{\text { atoms } \mathrm{Cs} / \mathrm{cm}^{-2} \text { steel surface }}{\text { atoms } \mathrm{Cs} / \mathrm{cm}^{-3} \mathrm{Na}}$.

It has been demonstrated for a variety of steel surfaces, cesium concentrations, and oxygen levels in sodium, that the $\log$ of $\mathrm{K}$ is inversely proportional to the absolute temperature. ${ }^{157-165}$ Hence, cesium will deposit preferentially on the cold steel surfaces in the cold trap. However, even taking the strongest temperature dependence reported does not offer a practical route for significant sesium removal from the coolant of an operating LMFBR, since the much greater surface area of the reactor will result in deposition of too high a proportion of the cesium outside the cold trap. ${ }^{160}$ This conclusion is similar to that reached in the context of the BOR-60 cold trap. ${ }^{161}$

The distribution coefficient, $\mathrm{K}$, has been found to strongly depend on the nature of the steel surface. ${ }^{157-160}$ Pretreatments such as polishing or preexposure to sodium at high temperature (about $600^{\circ} \mathrm{C}$ ) resulted in smaller values for $\mathrm{K}$. This is ascribed to the removal of oxide films, at the steel surface, on which cesium deposition occurs more favorably than on steel. ${ }^{159}$ Nickel and alumina have been shown to be more efficient cold trap packing materials for cesium removal. 157,159 Investigation has shown that disodium monoxide adsorbed cesium more effectively than steel. Hence, enhanced cesium removal could be obtained in a primary circuit cold trap in which oxygen is cold trapped continually. Such a system is 
penalized by the intrinsic requirement of periodic regeneration or replacement of the cold trap and by interactions with the aspects of coolant chemistry. Investigations of this effect have proven inconclusive. 161

The dissolved oxygen in the sodium influences cesium deposition on steel by the interaction of oxygen with the steel surface. 158,166 Cesium may be incorporated in corrosion products at steel surfaces. ${ }^{136}$ Some evidence suggests that there is little correlation between the enhancement of cesium cold trapping and the oxygen level of the sodium. $162-164$

Cesium adsorption at low temperatures may be controlled by interactions with nonmetallic impurities, and the strongest interaction occurs with hydrogen. ${ }^{167}$ A phase distribution coefficient, D, has been evaluated, where

$\mathrm{D}=\frac{\text { atoms } \mathrm{Cs} / \mathrm{g} \text { hydrogen in deposit }}{\text { atoms } \mathrm{Cs} / \mathrm{g} \text { sodium }}$.

At $120^{\circ} \mathrm{C}, \mathrm{D}$ has a value of $8.5 \times 10^{-5}$. This seems to indicate that hydrogen additions to the primary circuit, with subsequent cold trapping, will enhance the cesium removal.

Although distribution coefficient measurements for a range of concentrations of Cs-137 in sodium have been made, ${ }^{159}$ there remains a lack of long-term data obtained under controlled, representative conditions on the cold trapping behavior of cesium. The effects of indigenous levels of nonactive cesium impurity in the original sodium charge have been largely ignored. The nature of active cesium trapping sites remains obscure. Experience from BOR-60 and EBRIl suggests that such sites might have to be produced continually for regeneration of the cold traps.

Evidence indicates that cesium adsorption on surfaces is reversible and highly sensitive to a number of variables that may not be controlled suitably during LMFBR operation. These findings suggest that a trap for cesium should bind the cesium more strongly than the forces involved in adsorption, and that the nature of the bond should be insensitive to other concomitant phenomena.

The stabilities of cesium-graphite intercalation compounds and the sorption of cesium by graphite in liquid sodium have been investigated, 183-184 and it is concluded from them that cesium was trapped in two stages, the first involving a surface adsorption compound that subsequently yielded a more stable intercalation compound. The efficiency of trapping was further proved by using a high surface area charcoal (gas adsorption charcoal) that was thought to enhance the formation of the intercalation compound. Short-term experiments showed no adverse effects of preexposure to a sodium environment on trapping performance. The use of carbonaceous material for trapping cesium in the sodium coolant of an LMFBR primary circuit might give rise to unacceptable levels of carbon on steel components, as a consequence of carbon transfer. However, many forms of pure carbon are inefficient carbon sources for steel carburization in sodium, and the performance of high surface area graphite for charcoal in a sodium/ stainless steel system appears worthy of further investigation. ${ }^{185}$ Carbon trapped materials have functioned efficiently in the cover gas space above the sodium, though in this mode the occurrence of steel carburization may not be precluded.

In the EBR-II primary circuit sodium, the performance of reticulated vitreous carbon (RVC), a highly porous foam-like glassy carbon manufactured by Chemotronics, International, has been investigated for use in removing cesium from sodium. ${ }^{185}$ Favorable results have been obtained in the laboratory, and reactor tests conducted on graphite indicate that RVC is preferred for use in the reactor in view of its greater surface-to-volume ratio. RVC specimens were exposed at various temperatures to flowing sodium taken from the primary tank, which was maintained at $371^{\circ} \mathrm{C}$ and contained $0.3 \mu \mathrm{Ci} \mathrm{Cs-137/g}$ sodium throughout. Over the temperature range of $177-371^{\circ} \mathrm{C}$, it was found that RVC traps Cs-137 according to a relationship given as

$\log C=3,000 / T-9.889$,

where

$$
\begin{aligned}
\mathrm{C} & =\mathrm{C}-137 \text { saturation }\left(\mathrm{Ci} / \mathrm{cm}^{2}\right) \\
\mathrm{T} & =\text { temperature }(\mathrm{K}) .
\end{aligned}
$$

The trapping mechanism remains obscure; if the active surface involved is estimated correctly, then 75 molecular layers of Cs-137 will be present at the RVC surface at $177^{\circ} \mathrm{C}$. Furthermore, the material is said to be effective for Cs-134 and presumably for nonactive cesium. Therefore, it seems likely that a mechanism other than adsorption applies. 
The RVC for EBR-II that will handle the present Cs-137 inventory and the further release caused by the run-beyond-cladding-breach program will operate at $193^{\circ} \mathrm{C}$ and contain $10^{-2} \mathrm{~m}^{3} \mathrm{RVC}$, giving an effective surface area of $320 \mathrm{~m}^{2} .146$ The cesium trapped is placed within the cold trap and consists of an economizer, RVC, and crystallizer, and is surrounded by a 4 -in. lead shield. The normal sodium flow through this cesium trap is $12-15 \mathrm{gal} / \mathrm{min}$, which at this flow takes approximately four to five days to clean the entire sodium system at EBR-II. When the cesium trap was first in place, the total cesium inventory in the sodium was in the range of 120-150 Ci. Presently, the maximum cesium inventory in the sodium is $10 \mathrm{Ci}$ and is normally in the range of $2-3 \mathrm{Ci} .136$

Halogens released into liquid sodium are converted to sodium halides, which have a well-defined solubility in sodium, and have been measured experimentally. 168 The solubility of sodium iodide shows a very strong temperature dependence, but precipitation from solution of sodium iodide at low temperature in the cold trap of a primary circuit cannot be proposed as a method for I-131 removal, since iodine levels above the solubility limit, even at cold trap temperatures, are unlikely to be attained.

Generally, iodine appears to be amenable to cold trapping, but by adsorption rather than precipitation. The temperature dependence of a distribution coefficient, $\mathrm{K}$, defined for the case of cesium, has been evaluated for iodine by several investigators. $162-164,168,169$ There is some evidence that $K$ is concentration-dependent. ${ }^{168-169}$ The increase in values of $\mathrm{K}$ for decreasing temperature is sufficiently great that adsorption on steel surfaces in the cold trap will be significant in removing I-131 from the primary circuit of a reactor. ${ }^{167,169}$ The cold trapping efficiency will be further increased when disodium monoxide or sodium hydride are being precipitated in the cold trap because of a strong interaction between iodine and the hydride deposits. ${ }^{169}$ The observation from EBR-II contrasts with this conclusion, and it must be postulated that the surfaces in the EBR-II cold trap were deactivated, with respect to iodine adsorption, by the concomitant processes. ${ }^{154-155}$

A number of important fission products will be released into the sodium in the form of stable oxides. These include $\mathrm{Zr} / \mathrm{Nb}-95$ and $\mathrm{Ba} / \mathrm{La}-40$. Examination of the cold trapping behavior of these isotopes is effectively a treatment of small particle behavior. Assuming small particle sizes of less than 1 micron, the deposition behavior of $\mathrm{Zr} / \mathrm{Nb}-95$ and $\mathrm{Ba} / \mathrm{La}-140$ from sodium on steel surfaces might be described adequately in terms of liquidphase mass transfer control. However, the strong temperature dependence of $\mathrm{Ba} / \mathrm{La}-140$ deposition in BOR-160, implies the use of various liquid-phase mass transfer coefficients at different temperatures. ${ }^{170}$ These observations suggest that adsorption of $\mathrm{Ba} / \mathrm{La}-140$ on steel surfaces is more favorable at low temperatures; a similar observation has been made for strontium. ${ }^{171}$ In a practical system, these higher adsorptions at low temperatures will allow only a small proportion of the $\mathrm{Ba}$ / La-140 inventory to be cold trapped. This is in good agreement with observations on BR-5 and BOR-60, and with experimental data. $152,171,174$

Analysis of sodium/stainless steel systems shows that Co-60 deposition

- Is approximately proportional to sodium velocity at all temperatures

- Decreases with downstream distance

- Shows little variation with temperature above that from downstream behavior. ${ }^{172,175}$

In contrast, analysis of sodium/stainless steel systems has shown that Mn-54 deposition

- Shows no velocity dependence at high temperatures

- Increases with reducing temperature, especially approaching the minimum ternperature in the system

- Shows a velocity dependence at low temperatures. $172,174-176$

Co-60 deposition behavior is found to be controlled by laminar boundary layer, and Mn- 54 deposition behavior is controlled by solid state diffusion at high temperatures and by bulk deposition at low temperatures. These findings indicate that cold trapping will be ineffective for cobalt isotopes, but that Mn-54 might be cold trapped quite effectively on cold steel surfaces. Such conclusions are borne out by observations on RAPSODIE, EBR-II, and the KNK reactor, but contradicted by data from BOR-60. 154, 165,171,187-188 
A further phenomenon, which might enhance cold trapping of these transition metal species, is formation of complex oxides as a result of interaction between the metal in solution and the oxide at saturation in the cold trap sodium.

Analysis of the controlling atomic diffusion processes confirms that enhanced diffusion of some elements into nickel should occur. ${ }^{179}$ Hence, use of a trap fabricated in nickel mesh, rather than stainless steel, and placed at the core outlet, should prove effective for $\mathrm{Mn}-54$. Possible difficulties are the higher rate of bulk corrosion of nickel, compared with stainless steel, and the modification of the nickel surface by concomitant mass transfer of other elements. The use of a nickel substrate does not greatly influence cobalt deposition. 143,177

In screening tests on a wide variety of materials, mostly pure metals and alloys, it has been shown that pure nickel is the most effective getter for $\mathrm{Mn}-54$ of the materials tested. ${ }^{180} \mathrm{~A}$ number of traps using nickel foil have been fabricated and tested. These are made by rolling the foil onto a cylindrical form, with the spacing between successive layers of the foil being determined by a design embossed in the foil.

In application of this type of trap to a reactor, traps are situated at the end of subassemblies, downstream of corroding core components. Tests on prototypical designs have been carried out accordingly.

Initially, traps with very narrow interlaying spacing to maximize surface area were tested and found $82-92 \%$ efficient for Mn-54 removal in terms of activity retained in the trap, compared with that released to the remainder of the downstream test circuit. In order to reduce a very high pressure drop associated with this design, traps with wider interlayer spacings in different embossed patterns have been tested. Traps with twice the initial spacing have been shown to have equally high efficiency for Mn-54 removal, suggesting that trap surface area is not of overriding importance, and that lower surface area may be compensated by the increased sodium half length and turbulence. The efficiency of Co-60 removal is reduced on going to lower surface area, as would be expected.

The pressure drop associated with this design is acceptable in an EBR-II subassembly channel, and subsequent to satisfactory performance in hydraulic tests. An EBR-II test was successfully finished after 1 year of operation. ${ }^{181}$ Still wider spacings will have to be incorporated into this type of trap before the pressure drop would be acceptable in a commercial LMFBR.

The nickel used in fabrication of the traps has a very low cobalt impurity level $(<5 \mathrm{ppm})$ to avoid adding significantly to the Co-60 inventory in the reactor. Moreover, the corrosion rate of the nickel in the traps was not found excessive. The finding is based on weight change data, however, and estimation of corrosion losses by this method for a material that shows a strong tendency to pick up other materials (particularly iron) may be misleading. ${ }^{182}$ Release of nickel in subsequent deposition, and cooler parts of the reactor circuit, may lead to secondary trapping of $\mathrm{Mn}-54$, in the long term, at the surface of the components that the traps were intended to protect.

\section{Training}

The development of LMFBRs has required a vast design and experimental program in the field of sodium technology. Training and qualification programs in sodium technology, sodium systems, and components particular to LMFBRs are needed. The programs should address the selection, training, and retention of all individuals involved in operational health physics. In Europe, LMFBR operating experience demonstrated the specific needs for sodium and LMFBR simulator-based training courses. This section is essentially based on information gathered from the training programs set up in France by the Commissariat a I'Energie Atomique for the European LMFBR community and the sodium technology course of Atomics International.

Personnel such as reactor operators, radioactive waste operators, supervisors, radiological engineers, ALARA engineers, health physics technicians and supervisors, radiation contamination control engineers, chemists and chemical technicians, and other technical support should have extensive sodium training courses. These courses should cover the following:

- The chemical, physical, and nuclear properties of sodium.

- The solubilities of metals, gases, and nonmetals in liquid sodium, and factors that affect these solubilities, and the reactions of sodium with inorganic, ceramic, and organic materials. 
- The mechanisms of corrosion and mass transfer phenomena in sodium, their limiting factors, their measurement techniques, the corrosion behavior of metals in sodium, carbon, nitrogen, hydrogen, and oxygen transport in sodium, corrosion product deposition, and fission product transport.

- The purification, sampling, analysis, and the analytical instrumentation used on sodium systems.

- A study of the various process systems that make up an operating LMFBR, such as the sodium pumps, intermediate heat exchangers, valves, steam generators, aircooled heat dump exchangers, cold traps, vapor traps, and plugging meters.

- The mechanical properties of sodium systems, including their high-temperature properties, how these properties are determined, how they are interpreted, and how they are used as a basis for design, and the radiation effects on materials, and the metallurgical phenomena such as stress corrosion cracking.

- Sodium instrumentation and electrical systems such as flowmeters, level instruments, pressure instruments, temperature instruments, and leak detectors.

- The operational considerations in the use of sodium systems such as maintenance, storage and handling,

- Fire safety, and sodium-water reactions. The significant chemical and physical properties of sodium that should be studied due to their importance in the safe design and operation of LMFBR systems includes:

- Heat capacity of liquid and solid sodium as a function of temperature.

- The vapor pressure of sodium and its variation with temperature.

- The heat of vaporization, the latent heat of vaporization, the vapor heat capacity, and the relative contributions of sodium monomers and dimers as a function of temperature.
- The critical temperature, pressure, and volume of sodium.

- The electrical resistivity of sodum as a function of temperature.

- The density of liquid and solid sodium as a function of temperature.

- The coefficient of thermal expansion as a function of temperature and pressure.

- The isothermal compressibility of liquid sodium as a function of pressure.

- The thermal conductivity and diffusivity of sodium as a function of temperature.

- The kinematic and dynamic viscosity, surface tension, and Prandtl number of sodium as a function of temperature.

The most important nuclear properties of sodium are the neutron capture cross section of sodium reactions as a function of neutron energy, the associated neutron reaction, the products formed, their half-lives, and emissions. The chemical interactions that should be studied include the solubility of metals, gases, and nonmetals in liquid sodium, and the factors affecting their solubilities.

The reactive nature of sodium and the radioactive content of the coolant demand special study of the potential hazards involved in operating sodium systems. The subjects of particular concern include the following:

- The characteristics of sodium pool and spray fires, fire extinguishing methods, and detector types for both sodiun leaks and fires

- Sodium water reactions, their detection, their effects, and results of studies and tests carried out in this field.

The effective, safe, and economical use of sodium systems requires special knowledge for operation and maintenance. Repair and modification of a sodium system require special considerations, such as checking whether the system is completely drained, as well as checking the temperature distribution, the amount of oxide or other 
impurities present, and the need for an inert gas cover. Major work on a sodium system involving the cutting and replacing of pipe will require training distinctive from that for LWRs.

LMFBR simulators need to be designed for studies of operating rules, checking of operating procedures, and the training of reactor operators. The LMFBR simulators are able to model the following components:

- The core, including all types of subassemblies, and a neutron kinetics systems, which takes into account the majority of thermal feedbacks

- The primary sodium circuit, including all types of pumps

- Intermediate heat exchangers

- Secondary sodium circuits

- Steam generators

- The regulations systems, including any main safety alarm action positions.

Training on the LMFBR simulator should include the following:

- Core incidents, such as the rising or lowering of the control rod
- Tripping of one or more pumps with or without inertia acceleration or deceleration, in both the primary and secondary circuits

- Tripping of the valves actuating heat exchangers in the secondary circuit

- Cold startup and the use of the procedures allowing the passage from one power set up to another

- Normal and emergency procedures for reactor shutdown.

The sodium technology and LMFBR simulator-based courses described above are of the type taught at Cadarache, France, by the Commissariat a l'Energie Atomique for training personnel from Super Phenix. The Nersa Company, incorporating utilities from France, the Federal Republic of Germany, and Italy, also has its personnel trained at Cadarache. The training needs were originally defined for model testing and setting up of reactor component prototypes, operation of test facilities, and the commissioning and operation of the Rapsodie and Phenix Reactors. Since 1975, the school has taught designers, manufacturers, safety staff, and reactor operators in specialized courses in sodium technology and LMFBR operator training.

Sodium technology courses, such as the program at Cadarache, can be an excellent way to teach the fundamentals in understanding and working with a sodium system; sodium system design and application; and the operation, maintenance, and safety of sodium systems. 


\section{COMPARISON OF THE LMFBR HEALTH PHYSICS PROGRAM WITH THE REQUIREMENTS OF THE USNRC STANDARD REVIEW PLAN}

The Standard Review Plan for LWRs, NUREG0800, provides guidance for the USNRC Office of Nuclear Reactor Regulation staff responsible for review of applications to construct and operate nuclear power plants. The SRP defines the areas of review, acceptance criteria, review procedures, evaluation findings, and implementation requirements for the applicant's safety analysis report.

Those parts of the plan pertaining to occupational health physics were reviewed in this study to evaluate the Plan's requirements in light of experience gained at operating LMFBRs. The following sections of the SRP were reviewed Section 12.1, which discusses how the SAR is reviewed as it relates to ensuring that occupational radiation exposures (ORE) will be as low as is reasonably achievable; Section 12.2, which relates to radiation sources in normal operations, anticipated operational occurrences, and accident conditions affecting in-plant radiation protection; Sections 12.3 and 12.4 , which relate to radiation protection design features described in the SAR, taking into account design dose rates, anticipated operational occurrences, and accident conditions; and Section 12.5 , which relates to the operational radiation protection program.

The acceptance criteria for Section 12.1 are included in various subsections of 10 CFR 19 and 20, and several regulatory guides and NUREGs that provide information, recommendations, and guidance, and in general describe a basis acceptable to the NRC staff for implementing the requirements of 10 CFR 19 and 20.

The requirements for notices, instructions, and reports by licensees to individuals participating in license activities are established in 10 CFR 19. Standards for protection against radiation are discussed in 10 CFR 20. The REG Guides and NUREGs used for implementing the requirements of 10 CFR 19 and 20 will require modification for the licensing of LMFBRs.

Regulatory Guide 1.8, Personnel Selection and Training, used as a basis to the NRC staff for complying with the commission's regulations with regard to qualifications of radiation protection personnel, will need some modification to entail requirements for the training of personnel in sodium technology.
Regulatory Guide 1.33, Quality Assurarice Program Requirements (Operational), will also need some modification for implementation in LMFBRs. With the Regulatory Guide modification, the supporting NUREGs and ANSI Standards that address the quality requirements for PWRs and BWRs will need to be modified because of the sodium circuits in LMFBRs.

Regulatory Guide 8.8, Information Relevant to Insuring that Occupational Radiation Exposures at Nuclear Power Plants will be As Low As Reasonably Achievable, will need very little modification for implementing reference to LMFBRs. For example, Section 2, "Facility and Equipment Design Features," will need additional information on fission product source term estimates for LMFBRs. Section 2E, "Crud Control," will need guidance applicable to LMFBRs. Section 2F, "Isolation and Decontamination," will require guidance on the decontamination of sodium wetted materials and equipment. Section $2 \mathrm{H}$, "Resin and Sludge Treatment Systems," has very little applicability to LMFBRs, as it mostly applies to water circuits. It would be desirable to have information in this section on guidance for handling contaminated sodium. Sections 3 and 4 of Regulatory Guide 8.8 will not require extensive modifications for its implementation in LMFBRs. However, Section 4D on "Protective Equipment" should provide guidance for the protective clothing, equipment, and respiratory protective equipment for working in sodium aerosols or around sodium fires.

Section 12.2 of the SRP describes the requirements in the SAR as they relate to radiation sources in normal operations, anticipated operational occurrences, and accident conditions. It requires in the SAR a description of contained sources, airborne radioactive material sources, and the acceptance criteria that must be met in controlling these sources. Additional recommendations and guidance will be needed for the licensing of LMFBRs in this area. Specific guidance will be required for evaluating the potential radiological consequences of loss of fluid in core disruptive accidents in LMFBRs. Sufficient operating experience has been gained in the test, experimental, and demonstration LMFBRs to provide the typical long-term concentrations of principal radionuclides in the various circuits of the LMFBR power plants and the release of radioactive materials from LMFBRs. 
The basis used in developing shielding and ventilation design fission product source terms in the SRP will have to be modified to include LMFBRs.

Specific REG Guides and NUREGs need to be developed for providing information, recommendations, and guidance concerning the assumptions to be used for evaluating radiological consequences of postulated accidents at LMFBRs. Examples of accidents at LMFBRs to be considered are steam generator leaks, $\mathrm{Na}$ /water reactions, fuel failure propagation, rupture of primary pumping, pump failure or reactivity transient with the Plant Protection System operating, and successive failures of normally provided and maintained multiple barriers. Specific acceptance criteria for LMFBRs are necessary as required for LWRs in Regulatory Guide 1.112 and ANSI N237-1976 with regard to radiological source terms. As was done for LWRs in NUREG-0718 and 0737, the basis for acceptable shielding and ventilation design fission product source terms needs to be developed.

In Sections 12.3-12.4, "Radiation Protection Design Features in the SRP," the radiation zone designations during accident conditions are defined based on Regulatory Guides 1.3, 1.4, and 1.7. Regulatory positions need to be developed to provide future licensees with assumptions to be used for evaluating the potential radical consequences of loss-of-coolant accidents or other highconsequence accidents applicable to LMFBRs. Table 19 describes accident conditions categorized by ANS Standards.

Ventilation requirements in Sections 12.3-12.4 of the SRP will need to be modified with regard to their component design criteria and qualification testing to ensure compatibility with sodium systems. Additional criteria for component design and qualification testing need to be developed for the engineered safety features of the atmospheric cleanup system air filtration of LMFBRs. Criteria need to be developed for instrumentation for LMFBRs to assess plant conditions during and following an accident. The criteria should include the following:

- Variables to be monitored

- Design basis accident events

- The duration various instruments are qualified to function

- The variable ranges for monitoring.
Standard technical specifications for LMFBRs as they relate to radiation protection considerations and the applicability, format, and implementation of the technical specification package need to be developed. The ANSI standards and NUREGs listed in the SRP as recommendations, guidances, or information for LMFBR licensing should be acceptable for implementing the requirements of Sections 12.3-12.4 with respect to sampling airborne radioactivity, location and design criteria for area radiation monitors, criticality accident alarm system, concrete radiation shields, and general reactor shielding at LMFBRs.

Standard technical specifications for LMFBR designs as they relate to radiation protection considerations in the applicability, format, and implementation of the LMFBR construction firms technical specification package will need to be written, as they were for LWRs in NUREG-0103, -0123, -0212 , and -0718 .

The administrative organization of the radiation protection program (described in SRP Section 12.5), including the experience and qualification of the personnel and the information described for the implementation of Regulatory Guides $1.8,8.2,8.8$, and 8.10 , will not be significantly different for LMFBRs. The description of the bases and methods for monitoring and control of surface contamination for personnel and equipment, including the reporting practices for normal and off-normal or accident conditions, may need to be modified. Special air sampling and the issuance and use of respiratory equipment will be different at LMFBRs because of the effects of sodium. The description of physical and administrative measures for controlling access and stay times in radiation areas, the procedures and methods of operation for ensuring that occupational radiation exposure will be as low as reasonably achievable; and the description of methods, frequency, and procedures for conducting radiation surveys will not be significantly different at LMFBRs. Personnel protection equipment may have to be modified to be applicable to LMFBRs, because of the potential sodium spill and fires. Facilities and equipment to clean, sanitize, repair, and decontaminate personal protective equipment, monitoring equipment respirators, and other equipment involved in radiation protection, may need to be different at LMFBRs. These differences again are based on the use of sodium instead of water in the cooling system. 


\section{Category}

\section{PWR and BWR ${ }^{\mathrm{a}}$}

\section{Normal Operation}

Expected frequently during normal course of operation and maintenance

\section{Incidents of Moderate Frequency}

Any one may occur during a calendar year for a particular plant

III. Infrequent Events

May occur during the lifetime of a particular plant

\section{Limiting Faults}

Not expected to occur, but postulated because of potential for significant radioactive release; most drastic faults that must be designed against

\section{LMFBR $^{b}$}

\section{Normal Operation}

Expected frequently during normal course of operation and maintenance

\section{Anticipated Operational Occurrences}

May individually occur one or more times during the lifetime of the plant

\section{Postulated Accidents}

Not expected to occur, but included in the design basis to provide additional margins to ensure no undue risk to the health and safety of the public
Examples

Startup, shutdown, standby, power ascension from partial load to full power, cladding defects within tech specs, refueling

Inadvertent control rod group withdrawal, partial loss of core cooling, moderate cool-down, loss of off-site power, single error of operator

Loss of reactor coolant (with normal coolant makeup system only), secondary pipe break, fuel assembly in violation of tech specs, control tod withdrawal in violation of tech specs, unexplained reactivity insertion, complete loss of core flow (excluding pump locked rotor)

Major pipe rupture (up to and including doubleended rupture of largest pipe), fuel or structure movement due to core damage, ejection of single control rod, major secondary system pipe rupture (double-ended), coolant pump locked rotor

Startup, normal shutdown, standby, load following, cladding defect with tech specs, refueling

Tripping of Na pumps, failure of all off-site power, tripping of Turbine-Generator set, inadvertent control rod withdrawal

Spectrum of events appropriate to a specific design considering both the probability and consequences of the events (e.g., pipe rupture, large Na fire, large $\mathrm{Na}$-water reactor, rupture of radwaste system tank)

a. For a PWR, see Reference 187.

For a BWR, see Reference 188.

b. For an LMFBR, see References 189 and 190. 


\section{FUTURE RESEARCH REQUIREMENTS}

Further research and development are still necessary in the field of occupational health physics. Developmental needs related to LMFBRs are health physics instrumentation, secondary containment studies, studies external to containment, and probabilistic risk analysis.

Health physics instrumentation and personnel dosimetry techniques will need to be perfected for use in the extremely high beta-gamma radiation fields that can be encountered during maintenance on LMFBR components. During repair and maintenance on sodium pumps at EBR-Il, the betagamma dose rates in air were found to be 10,000:1. The source for this high beta dose rates was $\mathrm{Sr} / \mathrm{Y}-90$ that was impinged upon the impeller of the pump. The $\mathrm{Sr} / \mathrm{Y}-90$ was not removed during the normal steam/alcohol/water cleaning process. The typical health physics instrumentation used in surveying the pump components was not able to measure the intensity of the beta fields. Improved technology and applied techniques, as well as clear guidance, will be necessary to provide the worker with sufficient protection. Current dosimeters, instruments, and field control techniques for detecting, evaluating, and measuring nonpenetrating dose in high beta fields are deficient.

Secondary containment studies with regard to sodium leaks and fires will require study. Development is needed of ventilation systems and filter systems for sodium aerosols produced during fires. Prefilters like aqueous scrubbers and the performance of HEPA filters need to be studied. Sensors with faster response than the presently used hydrogen detector for small sodium leaks, less than $50 \mathrm{gal} / \mathrm{s}$, are needed.
Studies external to containment are required for a better understanding of the radiological source term for accidents and off-normal operations at LMFBRs. The present knowledge on sodium aerosols has shown that their inherent attenuation capability could be very important within containment. Trapping of gaseous and volatile fission products by the aerosols and high aerosol deposition studies have been shown to be significant. The engineered attenuation systems are very efficient in reducing the overall radioactivity release through the containment. Codes used in modeling the transfer of aerosols to the atmosphere need to be adapted to LMFBRs. The consequences of plume depletion, ground deposition, resuspension, and sodium aerosol chemistry, and the kinetics of transformation to flora and fauna and personnel dose must be studied.

Probabilistic risk assessment for optimization of radiation exposures to workers and the public needs to be developed for LMFBRs. Analytical techniques are needed for quantifying the implementation of ALARA programs so that proper cost-effectiveness criteria can be defined. Such techniques are presently being developed for optimizing the balance of worker dose versus increment reductions of public exposure and costs. These techniques are needed for LMFBRs.

The effects of sodium chemistry on the physiological behavior of activation and fission products should be studied. Recommendations by the National Council on Radiation Protection and Measurement (NCRP) and the International Commission on Radiological Protection assume certain physiochemical states for many radionuclides as a basis for estimating the doses to tissues and organs. There may be significant differences in these states for particular radionuclides because of the sodium coolant at an LMFBR. 


\section{REFERENCES}

1. L. P. Abagyan et al., Group Constant for Nuclear Reactor Calculations, Consultants Bureau Enterprises, Inc., New York, New York, 1964.

2. E. Storm and H. I. Israel, Photon Cross Sections from 0.001 to $100 \mathrm{MeV}$ for Elements 1 through 100, Los Alamos National Laboratory, LA-3753, 1967.

3. The ORNL Benchmark Experiment for Neutron Transport in Thick Sodium, Oak Ridge National Laboratory, ORNL-TM-3969.

4. Final Report on a Benchmark Experiment for Neutron Transport through Iron and Stainless Steel, Oak Ridge National Laboratory, ORNL-4892, 1973.

5. R. Rittenberger, J. Gibson, and J. Ritts, Radial Blanket and Shield Simulation Experiments-A.nalysis of Experimental Reports, Topical Report, Westinghouse, WARD-SS-3045-3, 1973.

6. FAST Reactor Experimental Shielding Monthly Progress Report, Oak Ridge National Labcratory, ORNL-TM-4364, 1973.

7. FAST Reactor Experimental Shielding Monthly Progress Report, Oak Ridge National Laboratory, ORNL-TM-4420, 1973.

8. FAST Reactor Experimental Shielding Monthly Progress Report, Oak Ridge National Laboratory, ORNL-TM-4469, October 1973.

9. FAST Reactor Experimental Shielding Monthly Progress Report, Oak Ridge National Laboratory, ORNL-TM-4514, November/December 1973.

10. FAST Reactor Experimental Shielding Monthly Progress Report, Oak Ridge National Laboratory, ORNL-TM-4592, January 1974.

11. FAST Reactor Experimental Shielding Monthly Progress Report, Oak Ridge National Laboratory, ORNL-TM-4611, February 1974.

12. FAST Reactor Experimental Shielding Monthly Progress Report, Oak Ridge National Laboratory, ORNL-TM-4402, July/August 1973.

13. FAST Reactor Analytical Shielding Monthly Progress Report, Oak Ridge National Laboratory, ORNL-TM-4482, July/August 1973.

14. W. L. Kuhn, A Computational Technique for Estimating Corrosion Product Releases in an LMFBR, Hanford Engineering Development Laboratory, HEDL-SA-1077, 1976.

15. A. Merkel and G. Menken, "Estimation of the Radiation Levels Near the Components in the SN/R-300 Primary System Induced by Deposition of Corrosion Products," Proceedings of the BNES International Conference on Liquid Alkali Metals, Nottingham, UK, 1973.

16. T. Yanagisawa, "Design Considerations of Fission and Corrosion Products in Primary System of MONJU," Paper No. 11, IAEA Specialists Meeting on Fission and Corrosion Products in Primary Systems of LMFBRs, Dimitrovgrad, USSR, 1975.

17. W. F. Brehm, "Radioactive Corrosion Product Transport and Control," Proceedings of the International Conference on Liquid Metal Technology in Energy Production, Champion, Pennsylvania, 1976. 
18. R. Mathews, "Location and Repair of a Leak in the Dounreay FAST Reactor Primary Circuit," J. British Nuclear Energy Society, 1969.

19. . A. E. Leypunski, "Study of the Five-Year Operation of the BR-5 Reactor," Paper No. 312, Third Geneva Conference on Peaceful Uses of Atomic Energy, Geneva, Switzerland, 1964.

20. I. A. Efimov, "BR-5 Primary Circuit Decontamination," Paper No. 17, IAEA Specialists Meeting, Demitrovgrad, USSR, 1975.

21. V. D. Kizin, "Studies of Radioactivity Buildup and Distribution in the BOR-60 Circuit," Paper No. 15, IAEA Specialists Meeting, Dimitrovgrad, USSR, 1975.

22. H. H. Stamm and K. C. Stade, "Corrosion Product Behavior in the Primary Circuit of the KNK. Nuclear Reactor Facility," Paper No. 5, IAEA Specialists Meeting, Dimitrovgrad, USSR, 1975.

23. R. DeFremont, "Decontamination Experience on Rapsodie," IAEA Specialists Meeting on Fission and Corrosion Products in Primary Systems of LMFBRs, Bensburg, Germany, in USERDA Report CONF-710959, 1971.

24. L. Costa, "Corrosion and Activity in the Primary Circuit of a Sodium Reactor-Code CORONA," Paper No. 3, IAEA Specialists Meeting, Dimitrovgrad, USSR, 1975.

25. W. F. Brehm, "Effect of Oxygen in Sodium upon Radionuclide Release from Austenitic Stainless Steel," HEDL-SA-985, Paper No. 29, IAEA Specialists Meeting, Dimitrovgrad, USSR, 1975.

26. J. R. Humphreys, "Problem Considerations in the U.S. Radioactivity Control Technology Program," Paper No. 20, IAEA Specialists Meeting, Dimitrovgrad, USSR, 1975.

27. T. J. Kabele, Activated Corrosion Product Transport Radiation Level Near FFTF Reactor and Closed Loop Primary System Component, Hanford Engineering Development Laboratory, HEDL-TME-72$71,1972$.

28. J. N. Anno and J. A. Walowit, "Analysis of Corrosion of Stainless Steel in a Sodium and High Radiation Environment," Nuclear Technology, 10, 1971, pp. 67ff.

29. W. F. Brehm, "Radioactive Material Transport and Flowing Sodium System," in Corrosion by Liquid Metals, Plenum Press, New York, New York, 1970.

30. P. Roy, USERDA Report GEAP-10394, 1971.

31. R. P. Colburn, "Transport of Activated Corrosion Product in Sodium Loops," Transactions of the American Nuclear Society, 17, 1973, pp. $165 \mathrm{ff}$.

32. G. Menken and H. Reichel, "Corrosion and Deposition Behavior of Co-60 and Mn-54 in the SNR Mockup Loop," Paper No. 6, IAEA Specialists Meeting, Dimitrovgrad, USSR, 1979.

33. N. Sekiguchi, "Behavior of Corrosion Products from Irradiated Stainless Steel and Flowing Sodium," Paper No. 8, IAEA Specialists Meeting, Dimitrovgrad, USSR, 1975.

34. K. T. Claxton and J. G. Collier, "Effects of Corrosion Product Transport in FAST Reactors," BNES Conference, Nottingham, England, 1973.

35. W. F. Brehm, "Techniques for Studying Corrosion and Deposition of Radioactive Materials in Sodium Loops," HEDL-SA-986, Paper No. 18, IAEA Specialists Meeting, Dimitrovgrad, USSR, 1975. 
36. B. D. Kizin et al., "Radioactivity in the Primary Circuit of the BOR-60 Fast Reactor," AT. Ehnerg. 44, 1978, pp. 492ff.

37. C. A. Erdman and A. B. Reynolds, "Radionuclide Behavior During Normal Operation of Liquid Metal Cooled Fast Breeder Reactors, Part 1, Production," Nuclear Safety, 16, 1975, pp. $43 \mathrm{ff}$.

38. N. Z. Krasnoyarov, V. I. Polyakov, and Y. V. Chechetkin, "Radioactive Product Behavior During the Operation of Sodium Cooled Reactors of the USSR," Proceedings of the International Conference on Liquid Metal Technology in Energy Production, Champion, Pennsylvania, May 3-6, 1976.

39. B. D. Kizin et al., Deposition of Radionuclides by Cold Trapping in the BOR-60, Kernforschungszentrum, Karlsruhe, KFK-TR-575, NIIAR-P-2'(296), 1977.

40. C. G. Allan, and T. A. H. Taylor, "Activity Deposition in DFR Primary Cold Trap," Proceedings of the International Conference on Liquid Metal Technology in Energy Production, Champion, Pennsylvania, May 3-6, 1976.

41. C. R. F. Smith and J. T. Holmes, Purity of EBR-II Sodium, 1967-1974, ANL-75-26, Chicago, Illinois, 1975.

42. J. Krenser and A. Lacroix, "Some Aspects of Sodium Technology Issues from the Operating Experience of Rapsodie and PHENIX," Proceedings of the International Conference on Liquid Metal Technology and Energy Production, Champion, Pennsylvania, 1976.

43. H. H. Stamm, "Sorption of Radionuclides on Sodium Sampling Vessels," Proceedings of the International Conference on Liquid Metal Technology in Energy Production, Champion, Pennsylvania, 1976.

44. M. Boutrais, "Sodium Analysis and Purification: Aerosols Trapping in PHENIX Reactor," Proceedings of the BNES International Conference on the Fast Reactor Power Station, London, UK, 1974.

45. D. F. Washburn et al., "Mixed Oxide Run Beyond Cladding Breach Test at EBR-II," Proceedings of the International Conference on Fast Breeder Reactor Fuel Performance, Monterey, California, 1979.

46. J. I. Sackett et al., "Preparations at EBR-II for Breached Element Operation," Transactions of the American Nuclear Society, 27, 1977, pp. $823 \mathrm{ff}$.

47. J. D. B. Lambert, F. S. Kirn, and E. R. Ebersole, "Experience with Breached Elements at EBR-II," Transactions of the American Nuclear Society, 27, 1977, pp. 820ff.

48. $\quad$ L. R. Monson et al., "Fission Product Control at EBR-II," Transactions of the American Nuclear Society, 27, 1977, pp. $822 \mathrm{ff}$.

49. R. R. Matthews and K. J. Henry, "Location and Repair of a Leak in the Dounreay Fast Reactor Primary Circuit," J. Br. Nucl. Energy Soc. 8, 1969, pp. 168ff.

50. M. J. Adamson, Sodium-Fuel Reaction Studies: Fuel Pellet Swelling Behavior and Alkali Metal-Oxide Fuel Reaction Thermodynamics, General Electric Company, GEAP-14093, 1976.

51. P. E. Bohaboy et al., "Performance of Failed Fuel in Fast Reactors," Proceedings of the International Conference on Fast Reactor Power Stations, London, 1974, pp. 349ff.

52. A. Tibi, J. Misraki, and J. P. Broutin, "La Contamination Alpha A Rapsodie," Fission and Corrosion Product Behavior in Primary Circuits of LMFBR'S, Proc. Meeting Dimitrovgrad, USSR, 1975, IAEA Report IWGFR/7, Vienna 12, 1976. 
53. W. Glauner et al., "Das Defekstavprogramm in SILOE, 1978," ReaktorErgebnisse Des Ersten Versuches, KFK Nacher. 2, 21.

54. S. Jacobi and G. Schmitl, "Release of Fission Products From Artificially Defected MFBR Oxide Fuel Pins," Proceedings of the International Conference on FAST Breeder Reactor Fuel Performance, Monterey, 1979, pp. $607 \mathrm{ff}$.

55. R. M. Fryer, L. A. Reyes, and R. V. Strain, "Response of EBR-II Delayed Neutron Monitor to Tramp Uranium and a Fission Product Source," Trans. Am. Nucl. Soc., 28, 1978, pp. 710ff.

56. A. E. Waltar and A. B. Reynolds, Fast Breeder Reactors, Pergamon Press, Elmsford, New York, 1981.

57. A. Cafasso et al., "The Solubilities of the Noble Gases in Liquid Sodium," Proceedings of the International Conference on Liquid Metal Technology in Energy Production, Champion, Pennsylvania, 1976, pp. 619ff.

58. R. H. S. Winterton, "Cover-Gas Bubbles in Recirculating Sodium Primary Coolant," Nuclear Engineering Design, 22, 1972, pp. $262 \mathrm{ff}$.

59. J. Saroul and R. Michael, Transfer of Rare Gases Through Liquid Sodium, Experiments ATENA, Commissariat A l'Energie Atomique, CEA-R-4579, 1974.

60. N. Aubert and M. Merle, "Gas Entrainment Problems in Sodium Cooled Nuclear Reactors," Proceedings of the Symposium on Two-Phase Flow and Cavitation in Power Generating Systems, Grenoble, 1976, pp. 293ff.

61. N. V. Polley, Bubbling from LMFBR Fuel Failures and Its Relevance to Failed Fuel Location, Central Electric Generating Board, Harwell, England, CEGB-RD/B/N 2837, 1973.

62. R. W. Kessie, Inert Gas Sodium Contracters, Argonne National Laboratory, ANL-7817, 1971, pp. $44 \mathrm{ff}$.

63. N. R. Chellew et al., "A Method for Detecting Fuel Cladding Penetration in LMFBR's by Monitoring the Sodium Coolant for I-135," Nucl. Technol, 2I, pp. $125 \mathrm{ff}$.

64. N. Mitsutsuka et al., "Fission Product Measurement in the In-Pile Fission Product Loop," Proceedings of the International Conference on Liquid Metal Technology in Energy Production, Champion, Pennsylvania, 1976, pp. 284ff.

65. G. S. Brunson, "Monitoring Fission Gas in EBR-II by High Resolution Gamma Spectrometry," Nucl. Technol, 25, 1975, pp. 553ff.

66. N. Mitsutsuka, "Method for Determining Degassing Constant of Xenon in Liquid Sodium," J. Nucl. Sci. Technol., 15, 1978, pp. 678ff.

67. W. B. Brenner and A. B. G. Washington, "Measurement of Fission Gas Release Rates From a $\mathrm{UO}_{2}$ Fuel Pin During Irradiation in a Fast Reactor," J. Br. Nucl. Energy Soc., 12, 1973, pp. 449ff.

68. J. R. Findlay, "The Migration of Fission Products Through Reactor Fuel Materials," Proceedings of Panel on Behavior and Chemical State of Irradiated Ceramic Fuels, IAEA, Vienna, 1974, pp. $211 \mathrm{ff}$.

69. N. V. Krasnoyarov, "Release of Gaseous Fission Products From Defect Fuel Pins of the Reactor BOR-60," At. Ehnerg., 38, 1975, pp. 67ff. 
70. B. R. Sehgal and R. H. Rempert, Trans. Am. Nucl. Soc., 14, 1971, pp. $779 f f$.

71. R. J. Budnitz, "Tritium Instrumentation for Environmental and Occupational Monitoring-A Review," Health Physics Journal, 26, 1974, pp. $165 \mathrm{ff}$.

72. J. T. Holmes and M. M. Wrightson, Plan for Studying Tritium Transport, Unpublished Argonne National Laboratory Report, 1975.

73. J. T. Bell and J. D. Redman, "Tritium Permeation Through Metals Under Steam Conditions," Proceedings of the Ninth Symposium on Fusion Technology, Commission of the European Communications, Pergamon Press, Oxford and New York, 1976, pp. 345ff.

74. R. A. Strehlow and H. C. Savage, "The Permeation of Hydrogen Isotopes Through Structured Metals at Low Pressures and Through Metals With Oxide Film Barriers," Nucl. Technol., 22, 1974, pp. $127 \mathrm{ff}$.

75. R. A. Strehlow and H. C. Savage, "Formation and Use of Oxide Films to Impede Outgassing of Metals," J. Nucl. Master, 53, 1974, pp. 323ff.

76. J. T. Bell, J. D. Redman, and F. J. Smith, "Oxides as Barriers to Tritium Permeation in Stearn Generators and Tritium Content in Controlled Thermonuclear Reactor Coolants," Proceeding of tine 24th Conference on Remote Systems Technology, 1976, pp. 3ff.

77. R. Kumar, Tritium Transport in an LMFBR, Argonne National Laboratory, ANL-80/89, 1974.

78. T. J. Kabele, Parametric Study of the Tritium Distribution in the FFTF, Hanford Engineering Development Laboratory, HEDL-TME 1974, pp. 74-6.

79. T. A. Renner, D. J. Raue, and C. C. McPheeters, "Tritium Permeation Through Steam Gererator Materials," Trans. Amer. Nucl. Soc., 126, 1977, pp. $216 \mathrm{ff}$.

80. V. A. Maroni et al., "Defects of Surface Environment and Bulk Composition on the Permeation of Hydrogen Isotopes Through Iron and Nickel Based Alloys," Symposium on Tritium in Nuclear Systems, lo7th AIME Annual Meeting, Denver, Colorado, February 26-March 2, 1978.

81. J. C. McGuire, "Tritium Permeation Through Oxidized 304 and 316 Stainless Steel," Symposium on Tritium in Nuclear Systems, 107th AIME Annual Meeting, Denver, Colorado, February 26-March 2.

82. T. A. Renner and C. C. McPheeters, Tritium and Hydrogen Transport in LMFBR Systems: EBR-II, $C R B R$, and FFTF, Argonne National Laboratory, ANL-78-64, 1978.

83. Project Management Corporation, Clinch River Breeder Reactor Project Preliminary Safety Analysis Report, vol. 11, sec. 11.1.4, Amendment 67, March 1982.

84. H. I. McCreery, A Study of Tritium Activity in the EBR-II Reactor Building Air, University of Idaho Master's Thesis, 1977.

85. D. J. Gorman, An Assessment of the Relative Hazards of $T_{2}$, and $T_{2} O$, Ontario Hydro Report, HPD78-1, Toronto, Canada, 1978.

86. L. C. Witbeck and R. M. Fryer, Waste Production and Management at EBR-II, Argonne Nattional Laboratory Report 79-14, 1979.

87. E. R. Ebersole, Tritium Control Technology, WASH 1269, 1973, pp. $286 \mathrm{ff}$. 
88. Dr. Graham Tyler, Private Communication, Dounreay Nuclear Power Development Association, June 29, 1983.

89. C. S. Abrams, Private Communication, Argonne National Laboratory-West, May 11, 1983.

90. C. C. McPheeters, S. D. Skladzien, and M. M. Osterhout, "Development and Testing of a Tritium Meter for Sodium Systems," Trans. Amer. Nucl. Soc., 28, 1977, pp. $787 \mathrm{ff}$.

91. S. B. Sklabzien et al., Tritium Meters for Use in LMFBR Sodium Coolant, Argonne National Laboratory, ANL-78-30, 1978.

92. B. A. Maroni et al., "Solution Behavior of Hydrogen Isotopes and Other Non-Metallic Elements in Liquid Lithium," Proceedings of the International Conference on Liquid Metal Technology and Energy Production, Champion, Pennsylvania, May 3-6, 1976, pp. 437ff.

93. P. Coulon, Private Communication, PHENIX, July 5, 1983.

94. Graham Tyler, Private Communication, Central Station, PFR, June 29, 1983.

95. K. C. Stade, Private Communication, KNK2, July 8, 1983.

96. P. R. Prevo and G. D. Carpenter, private communication, Hanford Engineering Development Laboratory, May 17, 1983.

97. A. H. Kibbey and H. W. Godbee, Critical Review of Solid Radioactive Waste Practices at Nuclear Power Plants, Oak Ridge National Laboratory, ORNL-4924, 1974.

98. W. A. Ross, "Characteristics of High Level Radioactive Waste Gasses," Trans. Amer. Nucl. Soc., 28, 1978 , pp. $357 \mathrm{ff}$.

99. J. G. Asquith et al., "Sodium Removal Technology-The Alcohol Process," Proceedings of the International Conference on Liquid Metal Technology and Energy Production, Champion, Pennsylvania, May 3-6, 1976, 1976, pp. 548ff.

100. H. Richard et al., "Experience From Purification of Sodium Wetted Components at the KNK Facility," Proceedings of the International Conference on Liquid Metal Technology and Energy Production, Champion, Pennsylvania, May 3-6, 1976, 1976, pp. $561 \mathrm{ff}$.

101. C. B. Johnson (ed.), "Sodium (NaK) Supplement," Liquid Metals Handbook, TID-5277.

102. C. W. Funk, "Review of Sodium Removal Processes Using Water," Proceedings of the International Conference on Liquid Metal Technology and Energy Production, Champion, Pennsylvania, May 3-6, 1976, 1976, pp. 554ff.

103. J. C. Commander et al., Decontamination and Decommissioning of the EBR-I Complex, Topical Report No. 3 NaK Disposal Pilot Test, Aerojet Nuclear Company, ANCR-11700, 1975.

104. E. W. Kendall and C. K. Wang, Decontamination and Decommissioning of the EBR-I Complex, Final Report, Aerojet Nuclear Company, ANCR-1242, 1975.

105. M. Sittig, Sodium: Its Manufacture, Properties, and Uses, Reinhold Publishing Corporation, New York, 1956, pp. 149ff.

106. DuPont Sodium Handling and Properties, E. I. duPont DeNemours and Company, Inc., Wilmington, Delaware. 
107. T. R. Johnson, Method for the Safe Disposal of Alkali Metals, U.S. Patent No. 4,320,615, June 28, 1977.

108. C. C. McPheeters, and R. D. Wolson, Disposal of Radioactive Sodium Waste, Argonne National Laboratory, ANL-78-87, 1978.

109. L. Whitback, Private Communication, Argonne National Laboratory-West, May 10, 1983.

110. K. C. Gross, Fission Product Releases to the Primary System of EBR-II from May 1979 to March 1980, Argonne National Laboratory, ANL-81-64, 1981.

111. R. R. Smith et al., Locating and Identifying the Source of the May 24, 1967, Fission Product Release to EBR-II, Argonne National Laboratory, ANL-75-43, 1969.

112. R. R. Smith, Origin of Fission Product Releases in EBR-II, November 23, 1967 to May 6, 1968, Argonne National Laboratory, ANL-7604, 1970.

113. R. M. Fryer et al., Symptoms and Detection of a Fission Product Release from an EBR-II Fuel Element: Case 1, Defect Above Fuel Elevation, Argonne National Laboratory, ANL-7605, 1970.

114. R. M. Fryer et al., Symptoms and Detection of a Fission Product Release from an EBR-II Fuel Element: Case 2, Defect Below Fuel Elevation, Argonne National Laboratory, ANL-7676, 1970.

115. G. S. Brunson, R. M. Fryer, and R. V. Strain, Experimental Irradiations of Fuel Elements Having Known Cladding Defects in EBR-II, Argonne National Laboratory, ANL-7782, 1971.

116. R. R. Smith et al., Fission Product Releases to the Primary System of EBR-II During 1971, Argonne National Laboratory, ANL-7956, 1972.

117. D. Y. C. So et al., Fission Product Releases to the Primary System of EBR-II from January 1974 to March 1975, Argonne National Laboratory, ANL-76-65, 1976.

118. B. Y. C. So et al., Fission Product Releases to the Primary System of EBR-II from April 1975 to March 1977, Argonne National Laboratory, ANL-79-26, 1979.

119. J. D. B. Lambert et al., "Recent Improvements in Identifying Fission Product Sources in the Experimental Breeder Reactor-II," Nucl. Technol, 39, 1978, pp. 275ff.

120. B. Y. C. So et al., Fission Product Releases to the Primary System of EBR-II from April 1977 to May 1978, Argonne National Laboratory, ANL-79-27, 1979.

121. B. Y. C. So et al., Fission Product Releases to the Primary System of EBR-II from June 1978 to April 1979, Argonne National Laboratory, ANL-80-102.

122. G. S. Brunson, "Monitoring Fission Gas in EBR-II by High Resolution Gamma Spectrometry," Nucl. Technol. 26, 1975, pp. 553ff.

123. G. S. Brunson, Germanium-Lithium Argon Scanning System (GLASS): Design and Experience Through 1974, Argonne National Laboratory, ANL-76-74, 1976.

124. K. G. Porges, EBR-II Fuel Element Failure Detectors, Reactor Physics Division Annual RejortJuly 1, 1963 to June 30, 1964, Argonne National Laboratory, ANL-7010, 1965, pp. $231 \mathrm{ff}$.

125. R. M. Fryer et al., Efficiency of the EBR-II FERD System as an Automatic Trip Device, Argonne National Laboratory, ANL-76-94, 1977. 
126. K. C. Gross et al., Development of a Methodology for Analysis of Delayed Neutron Signals, Argonne National Laboratory, ANL-79-67, 1980.

127. K. C. Gross and R. V. Strain, "Delayed Neutron Siqnal Characterization in a Fast Reactor," Nucl. Sci. Eng. 76, 1980, pp. $163 \mathrm{ff}$.

128. K. C. Gross et al., Fission Product Releases to the Primary System of EBR-II from April 1980 to March 1981, Argonne National Laboratory, ANL-83-80, 1983.

129. R. Villarreal, Private Communications, Argonne National Laboratory-West, May 11, 1983.

130. D. R. Seidel and R. E. Einziger, "In-Reactor Cladding Breach of EBR-II Driver Fuel Elements," Proceedings of the International Conference on Radiation Effects in Breeder Reactor Structural Materials, Scottsdale, Arizona, June 23, 1977, Metallurgical Soc. of AIME, New York, 1977.

131. L. R. Monson et al., "The EBR-II Cover Gas Cleanup System," IAEA, Symposium on Design, Construction, and Operating Experience of Demonstration Fast Breeder Reactors, Bologna, April 1014, 1978, p. 465.

132. B. Y. C. So and G. W. Stauffer, "MIXTAG-A Code to Identify the Components of a Mixture of Xenon Tags," Trans. Am. Nucl. Soc., 26, 1977, pp. 522ff.

133. K. C. Gross, POLYFAIL: A Program for Identification of Multiple Fuel Failures with Gas Tagging, Argonne National Laboratory, ANL-80-87, 1980.

134. F. Holze, Private Communications, Westinghouse, Hanford, FFTF, May 19, 1983.

135. K. Wirtz, Lectures on Fast Reactors, Kernforschungszentrum, Karlsruhe, 1973.

136. H. Olson, Private Communication, EBR-II, May 10, 1983.

137. O. J. Foust (ed.), Sodium-NaK Engineering Handbook, Vols. 1 and 5, Gordon and Breach, Science Publishers, Inc., New York, 1972.

138. C. C. McPheeters et al., Chemical Engineering Division, Sodium Technology Program Annual Progress Report, October 1979 September 1979, Argonne National Laboratory, ANL-81-21, 1981.

139. P. Roy and D. N. Rogers, "Hydrogen Burden from the Steam Side Corrosion in Sodium Heated Steam Generators," Nucl. Technol. 39, 1978, pp. 213ff.

140. C. C. McPheeters et al., Impurity Control Coolant Technology Program Semiannual Progress Report for Period Ending October 31, 1981, Oak Ridge National Laboratory, ORNL/MSP/1.9-82/1, 1981.

141. S. J. Rogers, Topical Report No. 9-Analysis of High Oxygen and High Carbon Cold Traps, MSA Research Corporation, Evans City, Pennsylvania, MSAR 67-203, 1967.

142. J. Herb et al., Examination of the Enrico Fermi Sodium Cold Trap, Westinghouse Electric Corporation, Pittsburg, WCAP-43-21, 1965.

143. M. M. Osterhout, "Control of Oxygen, Hydrogen, and Tritium in Sodium Systems at Experimental Breeder Reactor-II," Trans. Am. Nucl. Soc. 30, 1978, pp. $159 \mathrm{ff}$.

144. C. C. McPheeters and D. J. Raue, Computer Model for Analyzing Sodium Cold Traps, Argonne National Laboratory, ANL-83-36, 1983. 
145. V. M. Kolda and R. D. Wolson, A Design Study of High Performance Cold Traps for Removal of Hydrogen from Liquid Sodium, Argonne National Laboratory, ANL-83-83, 1983.

146. D. J. Hebditch et al., Sodium Purity Control in CRF-Mechanisms and Rates of Crystal Nucleation and Growth, Central Electric Generating Board, Harwell, England, R/M/N 775, 1974.

147. D. J. Hebditch and B. J. Gliddon, "Impurity Crystallization in Liquid Sodium Systems," Proceedings of the International Conference on Liquid Metal Technology in Energy Production, Chainpion, Pennsylvania, 1976, pp. 43ff.

148. J. Kremser, "Discussion," Proceedings of the International Conference on Liquid Metal Technology in Energy Production, Champion, Pennsylvania, 1976, pp. 58ff.

149. P. Coulon, Private Communication, PHENIX Nuclear Plant, Avignon, July 5, 1983.

150. M. Berlin and M. Cauvin, "Comporement des Radioiodides Dans le Circuit Primaire D'un Reacteur Rapide," Fission and Corrosion Product Behavior in Primary Circuits of LMFBRs, IAEA Report IWGFR/7, 1976, pp. 6ff.

151. R. Passcard, verbal presentation, IAEA Specialists Meeting on Fission and Corrosion Product Behavior in Primary Circuits of LMFBRs, Dimitrovgrad, USSR, 1975.

152. V. V. Orlov et al., "Some Problems of Safe Operation of the BR-5 Plant," Proceedings of the International Conference on Safety of Fast Reactors, Aix-en Provence, 1967, Bull. Inf. Sci. Tech., 1968, pp. $75 \mathrm{ff}$.

153. B. I. Polyakov et al., "Efficiency of the Purification of the Sodium Coolant in the BOR-60 Reactor from Radioactive Impurities by Means of a Cold Oxide Trap," At. Ehnerg. 38, 1975, pp. 171ff.

154. J. T. Holmes et al., "Sodium Technology at EBR-II," Proceedings of the International Conference on Liquid Metal Technology in Energy Production, Champion, Pennsylvania, 1976, pp. 12ff.

155. J. T. Holmes et al., "Sodium Purification by Cold Trapping at the EBR-II," Nucl. Technol. 32, 1977, pp. $304 \mathrm{ff}$.

156. C. C. McPheeters and D. J. Raue, Computer Model for Analyzing Sodium Cold Traps, Argonne National Laboratory, ANL-83-36, 1983.

157. M. H. Cooper and G. R. Taylor, "Cesium Sorption from Liquid Sodium," Trans. Am. Nucl. Soc. 11, 1968 , pp. 526ff.

158. M. H. Cooper and G. R. Taylor, "Cesium Cold Trapping in a Forced-Convection Sodium System," Trans. Am. Nucl. Soc. 12, 1969, pp. $611 \mathrm{ff}$.

159. M. H. Cooper and G. R. Taylor, "Measurement of Cesium Sorption Isotherms in Liquid Sodium," Nucl. Technol. 12, 1971, pp. 83ff.

160. J. Guon, "Studies of Cesium Deposition in a Sodium/Stainless Steel System," Trans. Am. Nucl. Soc., 12, 1969, pp. $612 \mathrm{ff}$.

161. J. Guon, "Effect of Surface/Liquid Partition on the Analysis of Impurities in a Sodium System," Trans. Am. Nucl. Soc. 14, 1971, pp. $625 \mathrm{ff}$.

162. H. Shinojima et al., "Fission Products Deposition in a Stainless Steel Sodium System," Fission and Corrosion Product Behavior in Primary Circuits of LMFBRs, IAEA Report IWGFR/7, 1976, pp. $96 \mathrm{ff}$. 
163. N. Mitsutsuka et al., "Fission Product Deposition in a Stainless Steel Sodium System," Proceedings of the International Conference on Liquid Metal Technology in Energy Production, Champion, Pennsylvania, 1976, pp. $291 \mathrm{ff}$.

164. N. Mitsutsuka, et al., "Cold Trapping of Fission Products in a Stainless Steel Sodium Loop," J. Nucl. Sci. Technol. 14, 1977, pp. 135ff.

165. N. Sagawa et al., "Transport and Deposition of Metals in a Sodium Stainless Steel System: III. Deposition of Cesium in Stainless Steel Capsules under a Large Temperature Gradient," J. Nucl. Sci. Technol. 12, 1975, pp. 413ff.

166. G. D. Zwetziq et al., "The Distribution of Fission Products in LMFBR Sodium Systems," Proceedings of the International Conference on Sodium Technology in Large Fast Reactor Designs, Argonne National Laboratory, ANL-7520, Part 1, 1968, pp. 527ff.

167. R. P. Colburn, "Fission Product Removal from Sodium by Hydride Slagging," Trans. Am. Nucl. Soc. 15, 1972, pp. 235ff.

168. C. G. Allan, "Solubility and Deposition Behavior of Sodium Bromide and Sodium Iodide in Sodium/Stainless Steel Systems," Proceedings of the BNES International Conference on Liquid Alkali Metals, Nottingham, 1973, pp. 159ff.

169. N. H. Cooper et al., "Behavior of Iodine in Sodium Systems," Trans. Am. Nucl. Soc. 15, 1972, p. 232.

170. B. D. Kizin et al., "Studies on Radioactivity Buildup and Distribution in the BOR-60 Circuit," Fission and Corrosion Product Behavior in Primary Systems of LMFBRs, IAEA Report IWGFR/7, 1976, pp. $150 \mathrm{ff}$.

171. J. C. Clifford et al., "Behavior of Fission Products in Sodium," IAEA Symposium on Alkali Metal Coolants, Vienna, 1966, pp. $759 \mathrm{ff}$.

172. G. Menken and H. Reichel, "Corrosion and Deposition Behavior of Co-60 and Mn-54 in the SNR Mockup Loop for the Primary Sodium System," Fission and Corrosion Product Behavior in Primary Systems of LMFBRs, IAEA Report IWGFR/7, 1976, pp. 63ff.

173. N. Sekiguchi et al., "Behavior of Corrosion Product from Irradiated Stainless Steel in Flowing Sodium," Fission and Corrosion Product Behavior in Primary Systems in LMFBRs, IAEA Report IWGFR/7, 1976, pp. 82ff.

174. W. F. Brehm et al., 1970, "Radioactive Material Transport in Flowing Sodium Systems," Corrosion by Liquid Metals, Plenum Press, New York, pp. $97 \mathrm{ff}$.

175. W. F. Brehm et al., "Techniques for Studying Corrosion and Deposition of Radioactive Materials in Sodium Loops," Fission and Corrosion Product Behavior in Primary Circuits of LMFBRs, IAEA Report IWGFR/7, 1976, pp. 172ff.

176. K. T. Claxton and J. G. Collier, "Mass Transport of Stainless Steel Corrosion Products in Flowing Liquid Sodium," J. Br. Nucl. Energy Soc. 12, 1973, pp. 63ff.

177. H. H. Stamm and K. C. Stade, "Corrosion Product Behavior in the Primary Circuit of the KNK Nuclear Reactor Facility," Fission and Corrosion Product Behavior in Primary Circuits of LMFBRs, IAEA Report IWGFR/7, 1976, pp. 36ff. 
178. L. Costa et al., "Corrosion et activative dans le circuit primaire d'un reactor au sodium-code," Corona, Fission and Corrosion Product Behavior in Primary Circuits of LMFBRs, IAEA Rejort IWGFR/7, 1976, pp. 17ff.

179. S. B. Fisher, "Atomic Diffusion in Alloys Exposed to Liquid Sodium," J. Nucl. Mater. 62, 1976, pp. $247 \mathrm{ff}$.

180. J. C. McGuire and W. F. Brehm, Progress in Radionuclide Trap Development, Hanford Engineering Development Laboratory, HEDL-TME-77-85, 1977.

181. J. C. McGuire and W. F. Brehm, "A Radionuclide Trap for Liquid Metal Cooled Reactors," Trans. Am. Nucl. Soc. 30, 1978, pp. 189 ff.

182. A. J. Hooper, "Application of Physical Examination Techniques in the Study of Corrosion and Dleposition in Liquid Metals," Proceedings of the BNES International Conference on Liquid Aikali Metals, Nottingham, 1973, pp. $201 \mathrm{ff}$.

183. F. J. Salzano and S. Aronson, "Kinetic Study of the Decomposition of Cesium-Graphite Lame:llar Compounds," J. Chem. Phys., 42, 1966, pp. 1323ff.

184. W. S. Clough and S. W. Wade, 1971, "Cesium Behavior in Liquid Sodium-The Effect of Carbon," J. Nucl. Energy. 25, pp. $445 \mathrm{ff}$.

185. A. W Thorley and C. Tyzack, "The Carborization of Stainless Steels in Sodium Containing Carbon Impurities and Its Effect on Mechanical Properties," DNES International Conference on the Effects of Environment on Material Properties in Nuclear Systems, London, 1971.

186. L. R. Monson et al., "Fission Product Control at EBR-II," Trans. Am. Nucl. Soc. 27, 1977, pp. $822 \mathrm{ff}$.

187. Nuclear Safety Criteria for the Design of Stationary Pressurized Water Reactor Plants, American Nuclear Society, La Grange Park, Illinois, ANS-51.1, N18.2, 1973.

188. Nuclear Safety Criteria for the Design of Stationary Boiling Water Reactor Plants, American Nuclear Society, La Grange Park, Illinois, ANSI/ANS-52.1, 1978.

189. General Safety Design Criteria for an LMFBR Nuclear Power Plant, American Nuclear Society, La Grange Park, Illinois, ANS-54.1, Trial Use Draft, April 1975.

190. LMFBR Safety Classification and Related Requirements, American Nuclear Society, La Grange Pårk, Illinois, ANS-54.6, Trial Use Draft, October 1979. 


\section{APPENDIX}

THEORY AND DESIGN OF LIQUID METAL FAST BREEDER REACTORS 
$\bullet$ 


\section{CONTENTS}

THEORY AND DESIGN OF LIQUID METAL FAST BREEDER REACTORS $\ldots \ldots \ldots \ldots \ldots$ A-I

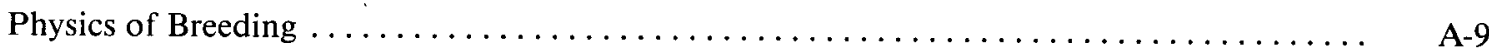

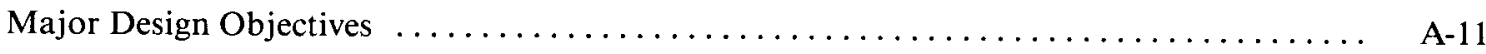

Mechanical and Thermal Systems Design $\ldots \ldots \ldots \ldots \ldots \ldots \ldots \ldots \ldots \ldots \ldots \ldots \ldots \ldots \ldots \ldots \ldots \ldots$

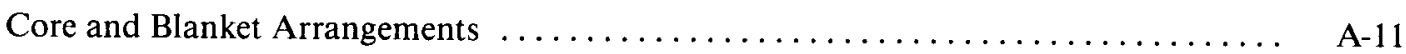

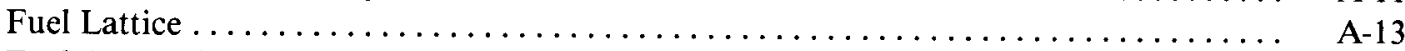

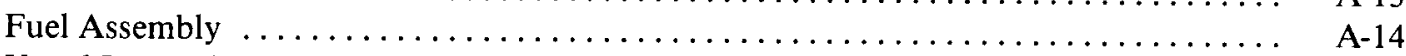

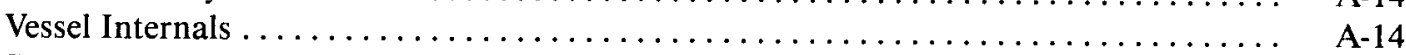

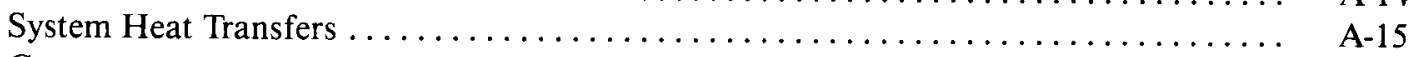

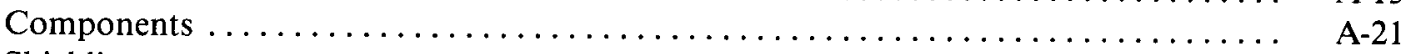

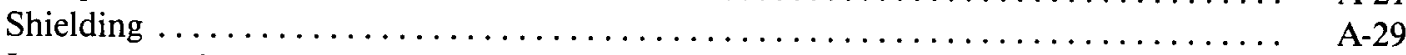

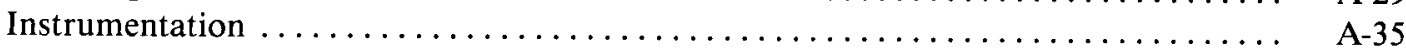

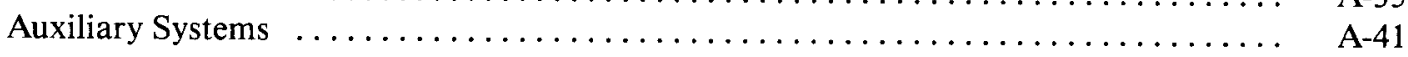

OPERATIONAL EXPERIENCE AT LMFBRS $\ldots \ldots \ldots \ldots \ldots \ldots \ldots \ldots \ldots \ldots \ldots \ldots \ldots \ldots \ldots \ldots$

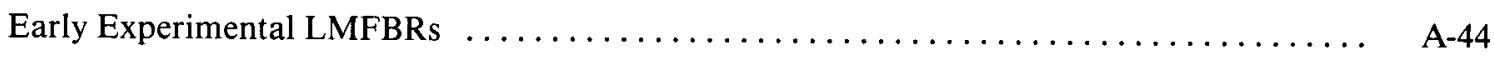

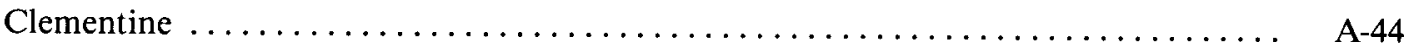

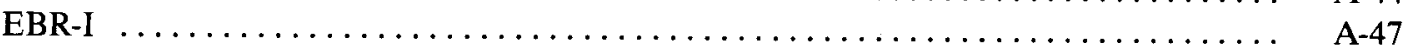

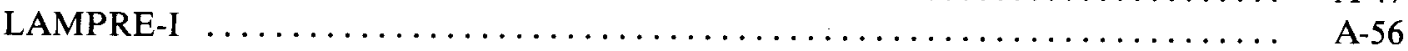

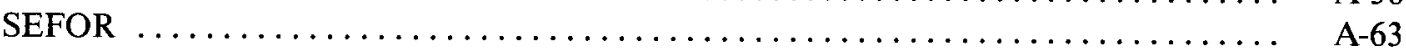

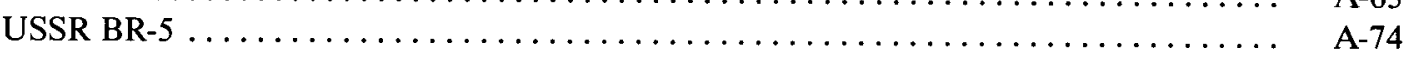

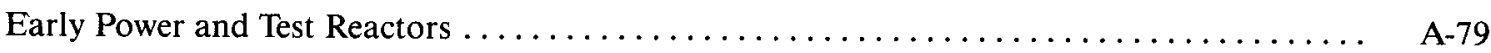

Federal Republic of Germany $\ldots \ldots \ldots \ldots \ldots \ldots \ldots \ldots \ldots \ldots \ldots \ldots \ldots \ldots \ldots \ldots \ldots \ldots$

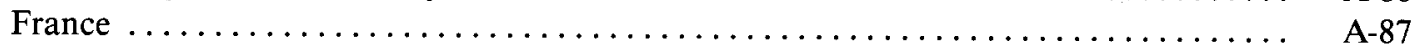

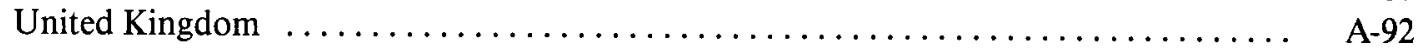

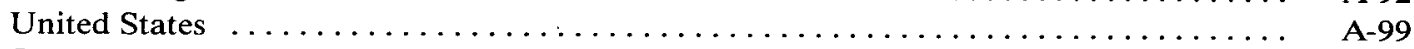

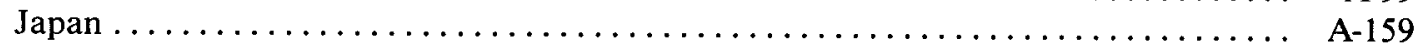

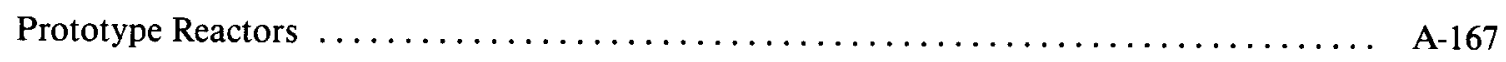

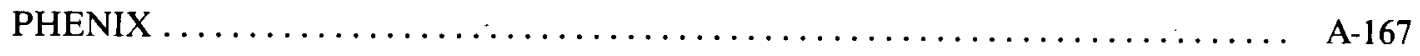

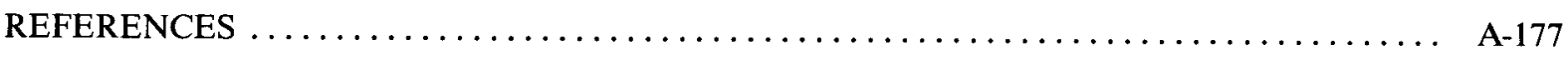

FIGURES

A-1. Uranium-238 Plutonium-239 conversion chain $\ldots \ldots \ldots \ldots \ldots \ldots \ldots \ldots \ldots \ldots \ldots$ A-10

A-2. Neutrons produced per absorption as a function of energy for fissile isotopes ........ A-10

A-3. External and internal breeding configuration $\ldots \ldots \ldots \ldots \ldots \ldots \ldots \ldots \ldots \ldots \ldots \ldots \ldots \ldots \ldots$

A-4. Typical homogeneous and heterogeneous LMFBR core/blanket arrangements incorporating internal breeding. 


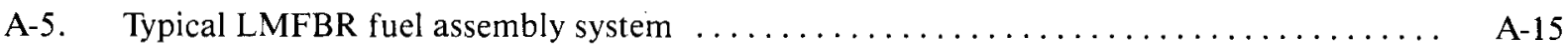

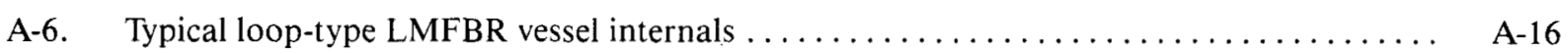

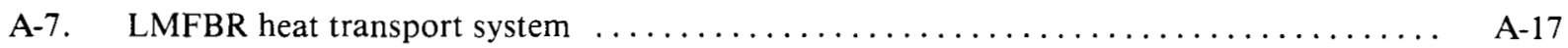

A-8. Plain view of Super Phenix pool, showing the four loops, four primary pumps, and

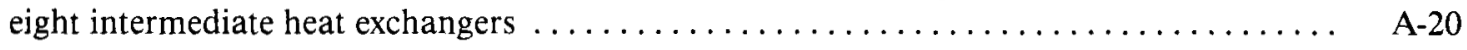

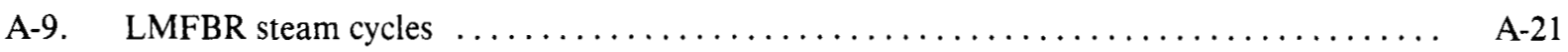

A-10. The Clinch River Breeder Reactor project design for plant control $\ldots \ldots \ldots \ldots \ldots \ldots$ A-22

A-11. Reactor vessel for the loop system of SNR-300 $\ldots \ldots \ldots \ldots \ldots \ldots \ldots \ldots \ldots \ldots \ldots \ldots$

A-12, Reactor tank for the pool system of Super Phenix $\ldots \ldots \ldots \ldots \ldots \ldots \ldots \ldots \ldots \ldots \ldots \ldots \ldots \ldots$

A-13. Details of the Super Phenix reactor tank and internals $\ldots \ldots \ldots \ldots \ldots \ldots \ldots \ldots \ldots \ldots$

A-14. Super Phenix's intermediate heat exchanger penetration into an insulated internal tank $\quad . \quad$ A-26

A-15. Construction of Super Phenix's roof/shield deck $\ldots \ldots \ldots \ldots \ldots \ldots \ldots \ldots \ldots \ldots$

A-16. Intermediate heat exchanger designs for the Super Phenix pool system and for the

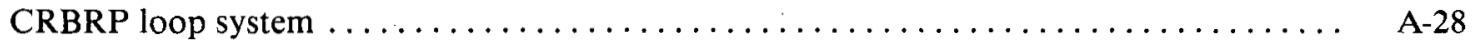

A-17. Temperature distributions in an integral superheater $\ldots \ldots \ldots \ldots \ldots \ldots \ldots \ldots \ldots \ldots \ldots \ldots$

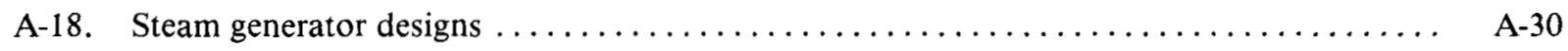

A-19. Instability in rise in wall temperature at the transition from nucleate to film boiling ..... A-32

A-20. Key shielding areas in CRBRP reactor and reactor enclosure system $\ldots \ldots \ldots \ldots \ldots \ldots$ A-34

A-21. Closure head assembly configuration of CRBRP $\ldots \ldots \ldots \ldots \ldots \ldots \ldots \ldots \ldots \ldots \ldots \ldots$

A-22. Flux monitoring set for CRBRP design $\ldots \ldots \ldots \ldots \ldots \ldots \ldots \ldots \ldots \ldots \ldots \ldots \ldots \ldots \ldots \ldots \ldots \ldots \ldots \ldots \ldots$

A-23. A typical thermowell assembly incorporating a resistance temperature detector
(RDT) for measuring sodium temperatures $\ldots \ldots \ldots \ldots \ldots \ldots \ldots \ldots \ldots \ldots \ldots \ldots \ldots$

A-24. Magnetic flowmeter and flow tube for large sodium coolant piping $\ldots \ldots \ldots \ldots \ldots \ldots$ A-38

A-25. Simplified diagram of eddy current flowmeter $\ldots \ldots \ldots \ldots \ldots \ldots \ldots \ldots \ldots \ldots \ldots \ldots \ldots \ldots$

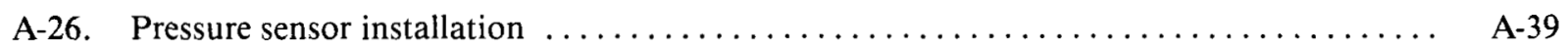

A-27. FFTF cover gas monitoring system $\ldots \ldots \ldots \ldots \ldots \ldots \ldots \ldots \ldots \ldots \ldots \ldots \ldots \ldots \ldots \ldots \ldots \ldots$

A-28. Induction sodium level probe schematic $\ldots \ldots \ldots \ldots \ldots \ldots \ldots \ldots \ldots \ldots \ldots \ldots \ldots \ldots \ldots \ldots$

A-29. Trace heating and insulation for 1 to 6 -in. pipe $\ldots \ldots \ldots \ldots \ldots \ldots \ldots \ldots \ldots \ldots \ldots \ldots \ldots \ldots$

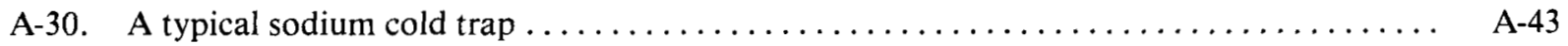


A-31. Cross section to the CLEMENTIN E reactor shield $\ldots \ldots \ldots \ldots \ldots \ldots \ldots \ldots \ldots \ldots \ldots \ldots$

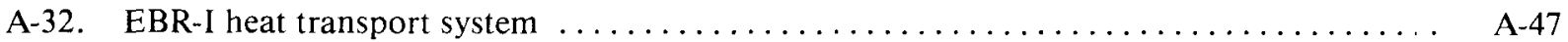

A-33. EBR-I Horizontal cross section at midpoint of MARK-II core $\ldots \ldots \ldots \ldots \ldots \ldots \ldots \ldots$ A-48

A-34. EBR-I Mark-II reactor-cutaway view $\ldots \ldots \ldots \ldots \ldots \ldots \ldots \ldots \ldots \ldots \ldots \ldots \ldots \ldots \ldots \ldots \ldots \ldots$

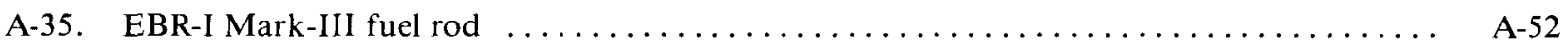

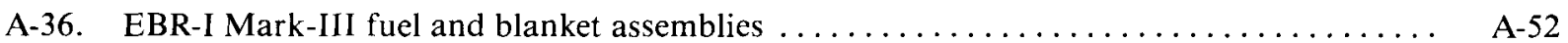

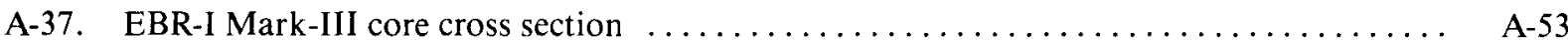

A-38. EBR-I Mark-III inner tank assembly $\ldots \ldots \ldots \ldots \ldots \ldots \ldots \ldots \ldots \ldots \ldots \ldots \ldots \ldots \ldots \ldots \ldots \ldots \ldots$

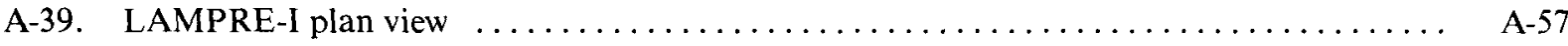

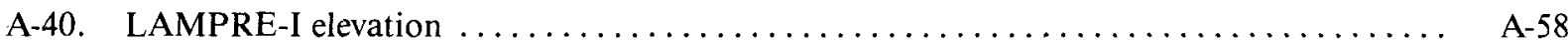

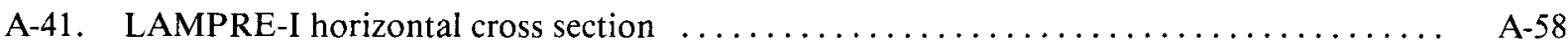

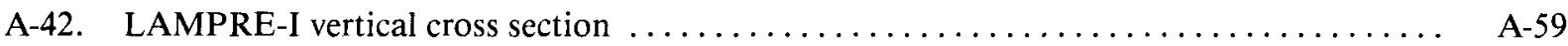

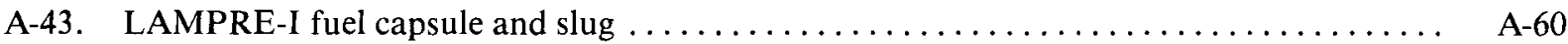

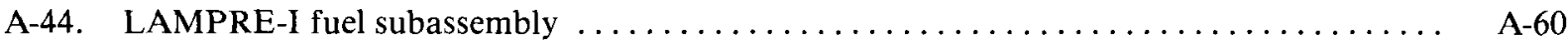

A-45. LAMPRE-I shield, vertical cross shielding $\ldots \ldots \ldots \ldots \ldots \ldots \ldots \ldots \ldots \ldots \ldots \ldots \ldots \ldots \ldots \ldots$

A-46. Reactivity loss during LAMPRE-I operation $\ldots \ldots \ldots \ldots \ldots \ldots \ldots \ldots \ldots \ldots \ldots \ldots \ldots \ldots \ldots \ldots$

A-47. LAMPRE-I core power and inlet and outlet temperature changes from

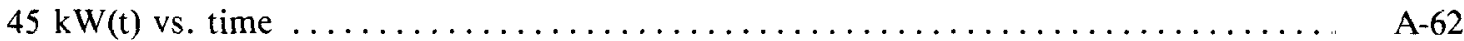

A-48. LAMPRE-I transfer functions for various power levels $\ldots \ldots \ldots \ldots \ldots \ldots \ldots \ldots \ldots$ A-62

A-49. LAMPRE-I plutonium-iron fuel density vs. temperature $\ldots \ldots \ldots \ldots \ldots \ldots \ldots \ldots \ldots$ A-63

A-50. SEFOR reactor building, elevation view $\ldots \ldots \ldots \ldots \ldots \ldots \ldots \ldots \ldots \ldots \ldots \ldots \ldots \ldots \ldots \ldots$

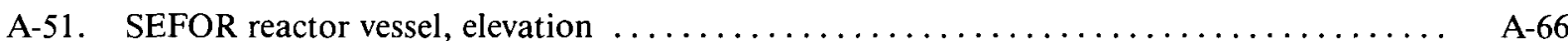

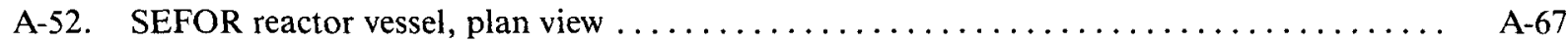

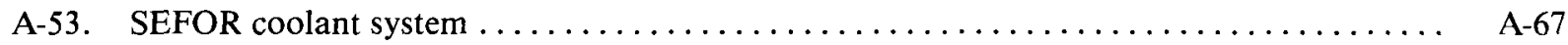

A-54. SEFOR reactor vessel nozzle elevation $\ldots \ldots \ldots \ldots \ldots \ldots \ldots \ldots \ldots \ldots \ldots \ldots \ldots \ldots \ldots \ldots \ldots \ldots \ldots$

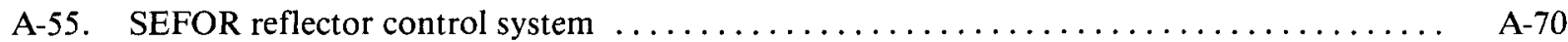

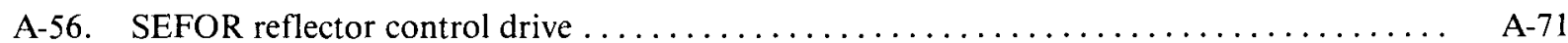

A-57. General arrangement of the USSR fast reactor BR-5 $\ldots \ldots \ldots \ldots \ldots \ldots \ldots \ldots \ldots \ldots \ldots \ldots$ 


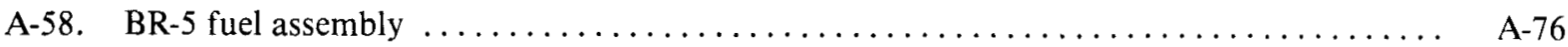

A-59. Vertical cross section of RAPSODIE reactor $\ldots \ldots \ldots \ldots \ldots \ldots \ldots \ldots \ldots \ldots \ldots \ldots \ldots \ldots \ldots$

A-60. Horizontal cross section of RAPSODIE reactor $\ldots \ldots \ldots \ldots \ldots \ldots \ldots \ldots \ldots \ldots \ldots \ldots \ldots$

A-61. Horizontal cross section of RAPSODIE reactor and shield $\ldots \ldots \ldots \ldots \ldots \ldots \ldots \ldots$ A-89

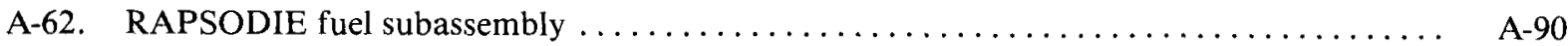

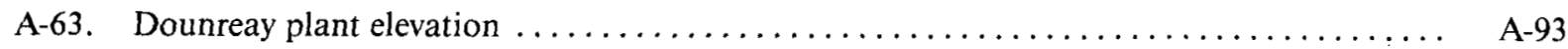

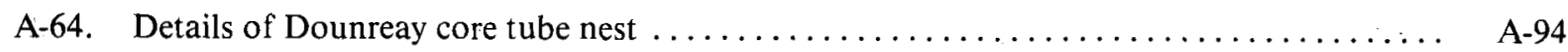

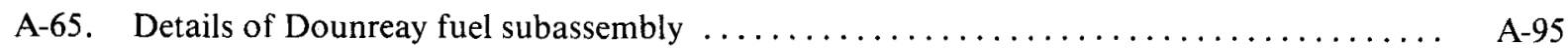

A-66. Arrangement of Dounreay primary circuit pipe work $\ldots \ldots \ldots \ldots \ldots \ldots \ldots \ldots \ldots \ldots$

A-67. Cutaway view of the Dounreay reactor vessel and rotating shields $\ldots \ldots \ldots \ldots \ldots \ldots$ A-97

A-68. EBR-II major reactor components and reactor primary tank $\ldots \ldots \ldots \ldots \ldots \ldots \ldots \ldots$ A-101

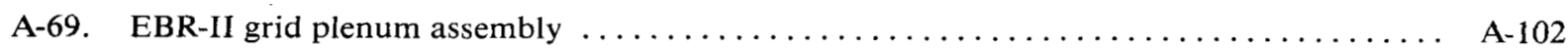

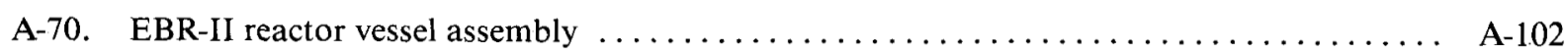

A-71. EBR-II primary neutron shield $\ldots \ldots \ldots \ldots \ldots \ldots \ldots \ldots \ldots \ldots \ldots \ldots \ldots \ldots \ldots \ldots \ldots \ldots \ldots$

A-72. EBR-II safety rod drive system $\ldots \ldots \ldots \ldots \ldots \ldots \ldots \ldots \ldots \ldots \ldots \ldots \ldots \ldots \ldots \ldots \ldots \ldots \ldots \ldots$

A-73. EBR-II control and safety rod drive systems $\ldots \ldots \ldots \ldots \ldots \ldots \ldots \ldots \ldots \ldots \ldots \ldots$

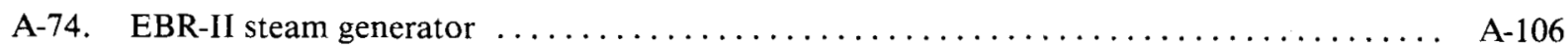

A-75. EBR-II principal fuel handling components $\ldots \ldots \ldots \ldots \ldots \ldots \ldots \ldots \ldots \ldots \ldots \ldots \ldots \ldots \ldots$

A-76. Vertical cross section of EBR-II reactor building $\ldots \ldots \ldots \ldots \ldots \ldots \ldots \ldots \ldots \ldots \ldots \ldots$

A-77. EBR-II blast shield and biological shield $\ldots \ldots \ldots \ldots \ldots \ldots \ldots \ldots \ldots \ldots \ldots \ldots$

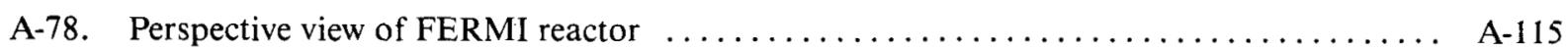

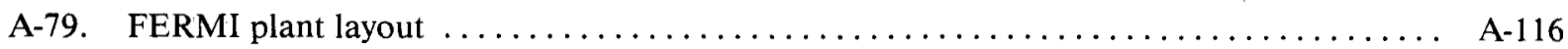

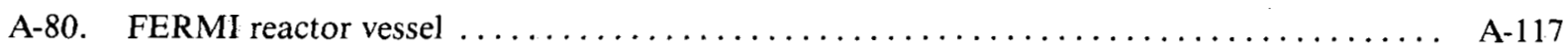

A-81. FERMI meltdown section $\ldots \ldots \ldots \ldots \ldots \ldots \ldots \ldots \ldots \ldots \ldots \ldots \ldots \ldots \ldots \ldots \ldots \ldots \ldots \ldots \ldots \ldots$

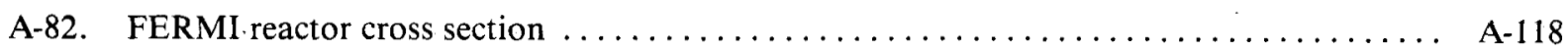

A-83. Isometric view of FERMI fuel assembly $\ldots \ldots \ldots \ldots \ldots \ldots \ldots \ldots \ldots \ldots \ldots \ldots \ldots$

A-84. FERMI fuel subassembly (external side view) $\ldots \ldots \ldots \ldots \ldots \ldots \ldots \ldots \ldots \ldots \ldots \ldots \ldots \ldots$

A-85. FERMI radial blanket subassemblies $\ldots \ldots \ldots \ldots \ldots \ldots \ldots \ldots \ldots \ldots \ldots \ldots \ldots \ldots \ldots \ldots \ldots \ldots \ldots \ldots$ 


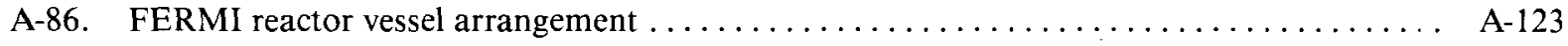

A-87. Vertical cross section of FERMI reactor building $\ldots \ldots \ldots \ldots \ldots \ldots \ldots \ldots \ldots \ldots \ldots \ldots \ldots \ldots \ldots$

A-88. Perspective view of the segment removal operation $\ldots \ldots \ldots \ldots \ldots \ldots \ldots \ldots \ldots \ldots$ A-130

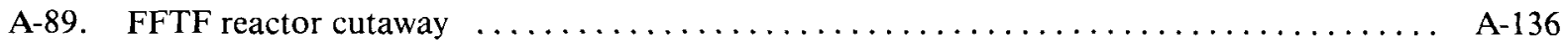

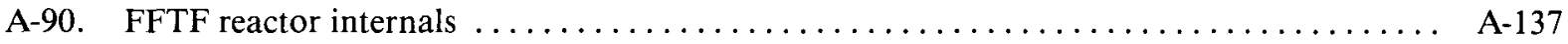

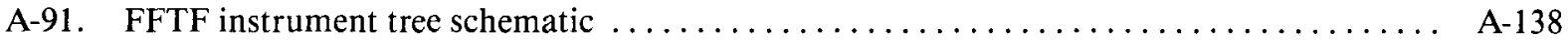

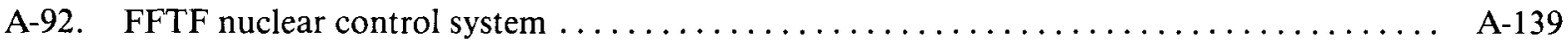

A-93. FFTF core support structure and core barrel $\ldots \ldots \ldots \ldots \ldots \ldots \ldots \ldots \ldots \ldots \ldots \ldots$

A-94. Arrangement of core strain mechanisms around core $\ldots \ldots \ldots \ldots \ldots \ldots \ldots \ldots \ldots$ A-141

A-95. Location of in-vessel storage modules $\ldots \ldots \ldots \ldots \ldots \ldots \ldots \ldots \ldots \ldots \ldots \ldots \ldots \ldots \ldots \ldots$

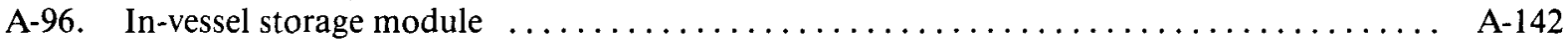

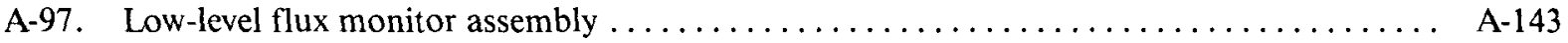

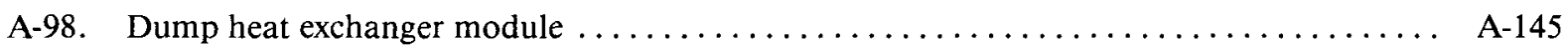

A-99. Sodium flow through FFTF reactor vessel $\ldots \ldots \ldots \ldots \ldots \ldots \ldots \ldots \ldots \ldots \ldots \ldots \ldots$ A-146

A-100. Heat transfer system primary loop piping $\ldots \ldots \ldots \ldots \ldots \ldots \ldots \ldots \ldots \ldots \ldots \ldots \ldots \ldots \ldots \ldots \ldots$

A-101. Heat transfer system primary pump with guard vessel $\ldots \ldots \ldots \ldots \ldots \ldots \ldots \ldots \ldots \ldots$ A-148

A-102. HTS intermediate heat exchanger and guard vessel $\ldots \ldots \ldots \ldots \ldots \ldots \ldots \ldots \ldots \ldots \ldots \ldots \ldots$

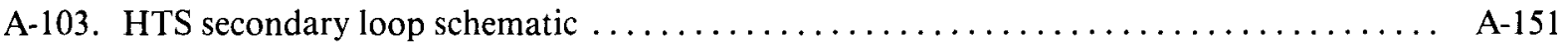

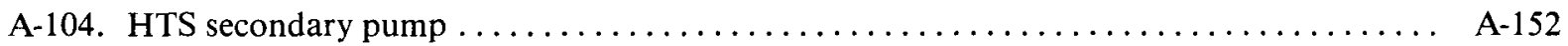

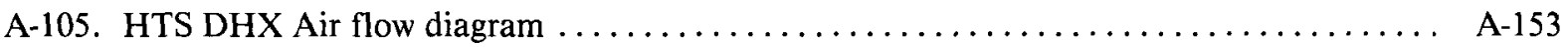

A-106. Typical plan of internal structures within the containment vessel $\ldots \ldots \ldots \ldots \ldots \ldots \ldots$ A-154

A-107. Typical cross section of internal structures within the containment vessel $\ldots \ldots \ldots \ldots \ldots$ A-154

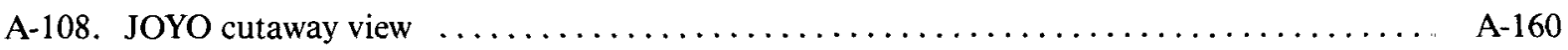

A-109. Vertical cross section of reactor and core configuration of JOYO $\ldots \ldots \ldots \ldots \ldots \ldots \ldots$ A-161

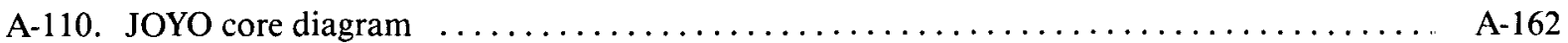

A-111. Fuel handling, charge/discharge mechanism $\ldots \ldots \ldots \ldots \ldots \ldots \ldots \ldots \ldots \ldots \ldots \ldots \ldots \ldots \ldots \ldots \ldots$

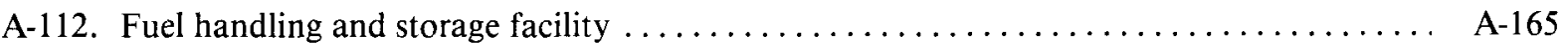

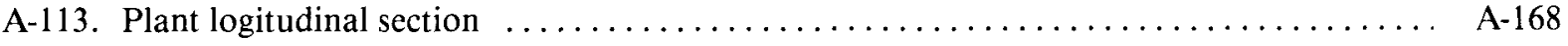




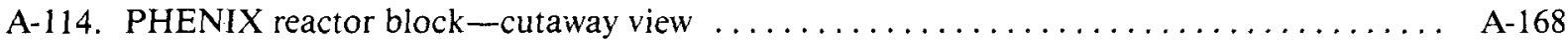

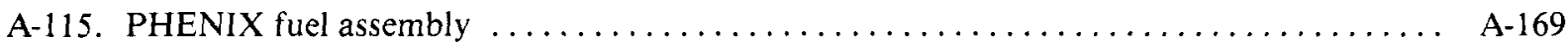

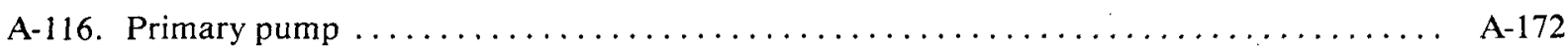

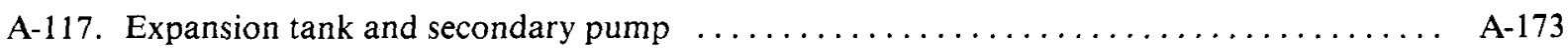

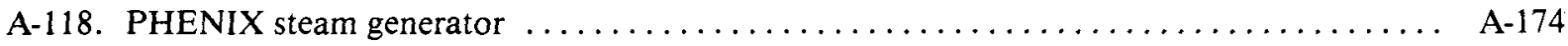

A-119. PHENIX intermediate heat exchanger $\ldots \ldots \ldots \ldots \ldots \ldots \ldots \ldots \ldots \ldots \ldots \ldots \ldots \ldots \ldots \ldots \ldots \ldots \ldots$

\section{TABLES}

A-1. Goals and design objectives for the breeder reactor $\ldots \ldots \ldots \ldots \ldots \ldots \ldots \ldots \ldots$ A-12

A-2. Comparison of homogeneous and heterogeneous cores $[1000 \mathrm{MW}(\mathrm{e})$ design $] \ldots \ldots \ldots$ A-14

A-3. Main design parameters for large fast breeder reactors $\ldots \ldots \ldots \ldots \ldots \ldots \ldots \ldots \ldots$ A-18

A-4. Calculated cover gas activity for the FFTF design basis, $1 \%$ pin failure $\ldots \ldots \ldots \ldots \ldots$ A-33

A-5. Contaminants monitored by a typical sodium purification system $\ldots \ldots \ldots \ldots \ldots \ldots$ A-43

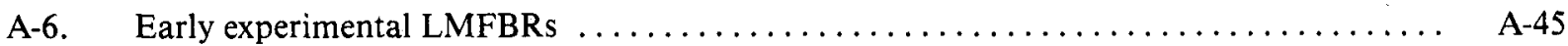

A-7. Reactivity control requirements $\ldots \ldots \ldots \ldots \ldots \ldots \ldots \ldots \ldots \ldots \ldots \ldots \ldots \ldots \ldots \ldots \ldots \ldots \ldots \ldots \ldots \ldots$

A-8. Early power and test reactors $\ldots \ldots \ldots \ldots \ldots \ldots \ldots \ldots \ldots \ldots \ldots \ldots \ldots \ldots \ldots \ldots \ldots \ldots \ldots \ldots \ldots \ldots$

A-9. Gamma spectrum six days after sampling $\ldots \ldots \ldots \ldots \ldots \ldots \ldots \ldots \ldots \ldots \ldots \ldots \ldots$

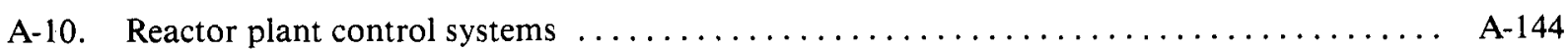

A-11. Summary of routine radiation survey data during FFTF Cycle $1 \ldots \ldots \ldots \ldots \ldots \ldots$ A-157

A-12. FFTF personnel exposure summary during Cycle 1 operations $\ldots \ldots \ldots \ldots \ldots \ldots \ldots \ldots$ A-159 


\section{APPENDIX}

\section{THEORY AND DESIGN OF LIQUID METAL FAST BREEDER REACTORS}

\section{Physics of Breeding}

To achieve breeding, a fertile isotope (thorium232, uranium-234, uranium-238, plutonium-240) must be converted via neutron capture into a fissile isotope (uranium-233, uranium-235, plutonium239 , plutonium-240). Figure A-1 shows the fertile conversion chain. The conversion ratio of fissile material produced to fissile material destroyed is greater than unity in breeder reactors. It is possible for the in-core conversion ratio to be less than one, while the breeding ratio (BR) for the entire reactor-the core plus the region of the reactor containing fertile fuel, known as the blanket - to be greater than unity. The breeding gain, $G$, is defined as $\mathrm{G}=\mathrm{BR}-1$. For a nuclear reactor to have $\mathrm{G}>0$, the fissile isotopes must be chosen very carefully for a given neutron energy spectrum. A high breeding gain can only be obtained with a fast neutron spectrum.

The number of neutrons produced per neutron absorbed during fission, can be calculated from the following relationship:

$\eta=\frac{\nu \sigma_{\mathrm{f}}}{\sigma_{\mathrm{f}}+\sigma_{\mathrm{c}}}=\frac{\nu}{1+\sigma_{\mathrm{c}} / \sigma_{\mathrm{f}}}=\frac{\nu}{1+\alpha}$

where

$$
\begin{aligned}
& \nu=\underset{\substack{\text { number } \\
\text { sion }}}{\nu \text { neutrons produced per fis- }} \\
& \alpha=\text { capture-to-fission ratio }\left(\sigma_{\mathrm{c}} / \sigma_{\mathrm{f}}\right) .
\end{aligned}
$$

The parameters $\nu$ and $\alpha$ are measured quantities, whereas $\eta$ is a derived quantity. For each of the primary fissile isotopes, $\nu$ is fairly constant for neutron energies up to about $1 \mathrm{MeV}$, about 2.5 for uranium-233 and uranium-235 and 2.9 for plutonium-239, and slowly rises at higher energy. However, $\alpha$ varies considerably with energy and between isotopes. A-1 For uranium-235 and plutonium-239, $\alpha$ rises sharply in the intermediate energy range between $1 \mathrm{eV}$ and $10 \mathrm{KeV}$ and then drops again at high energy; for uranium-233, $\alpha$ never rises appreciably. This behavior of $\nu$ and $\alpha$ produces the variations of $\eta$ with energy shown in Figure A-2. As a conceptual guide, the criterion for this can be expressed as:

$\eta=\mathrm{BR}+(1+\mathrm{L})$

where

$\mathrm{L}=$ unproductively lost neutrons, by absorption in any material other than fissile or fertile material or by leakage from the reactor

$\mathrm{BR}=$ Breeding ratio, fissile material produced by the fissile material destroyed.

A high value, greater than two, for $\eta$ is required for an acceptable breeding ratio. Figure A-2 shows that plutonium-239 is the best choice of fissile material in a fast breeder. Averaged over a typical $\mathrm{UO}_{2}-$ $\mathrm{PuO}_{2}$ fueled LMFBR spectrum, $\eta$ is equal to about 2.45. ${ }^{\mathrm{A}-1}$ Even higher breeder ratios can be obtained from fast reactors that use carbide fuels (UC-PuC) or metal fuels. This is because these fuels have greater fissile and fertile material densities and their average neutron energy is higher.

The time required for a particular breeder reactor to produce enough fissile material in excess of its own fissile inventory to fuel an identical reactor is the reactor doubling time, RDT. Doubling time is one of the figures of merit used to compare breeder reactor designs, different fast reactor fuels, and fuel cycle systems involving many breeder reactors. The reactor doubling time may be expressed in terms of the initial fissile inventory in a reactor, $M_{O}$ $(\mathrm{kg})$, and the fissile material gained during one year, $M_{g}(k g / y)$, where $M_{g}$ is a time-averaged difference between the fissile inventory at the beginning of a year and the fissile inventory at the end of the year.

$\mathrm{RDT}=\mathrm{M}_{\mathrm{o}} / \mathrm{M}_{\mathrm{g}}$

An accurate calculation of $\mathrm{M}_{\mathrm{g}}$ is difficult. $\mathrm{M}_{\mathrm{g}}$ can be approximated in terms of the breeding gain, 


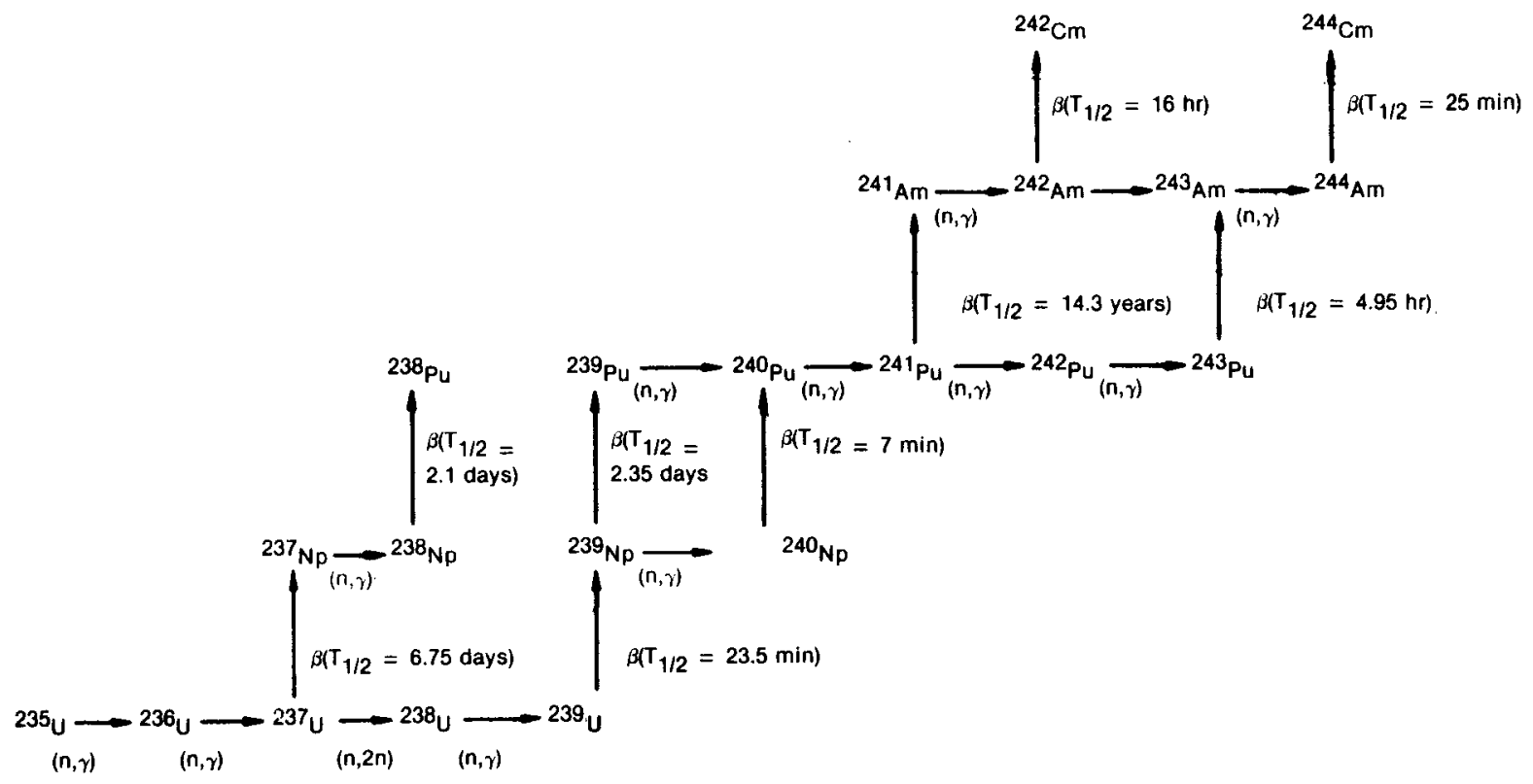

Figure A-1. Uranium-238 Plutonium-239 conversion chain.

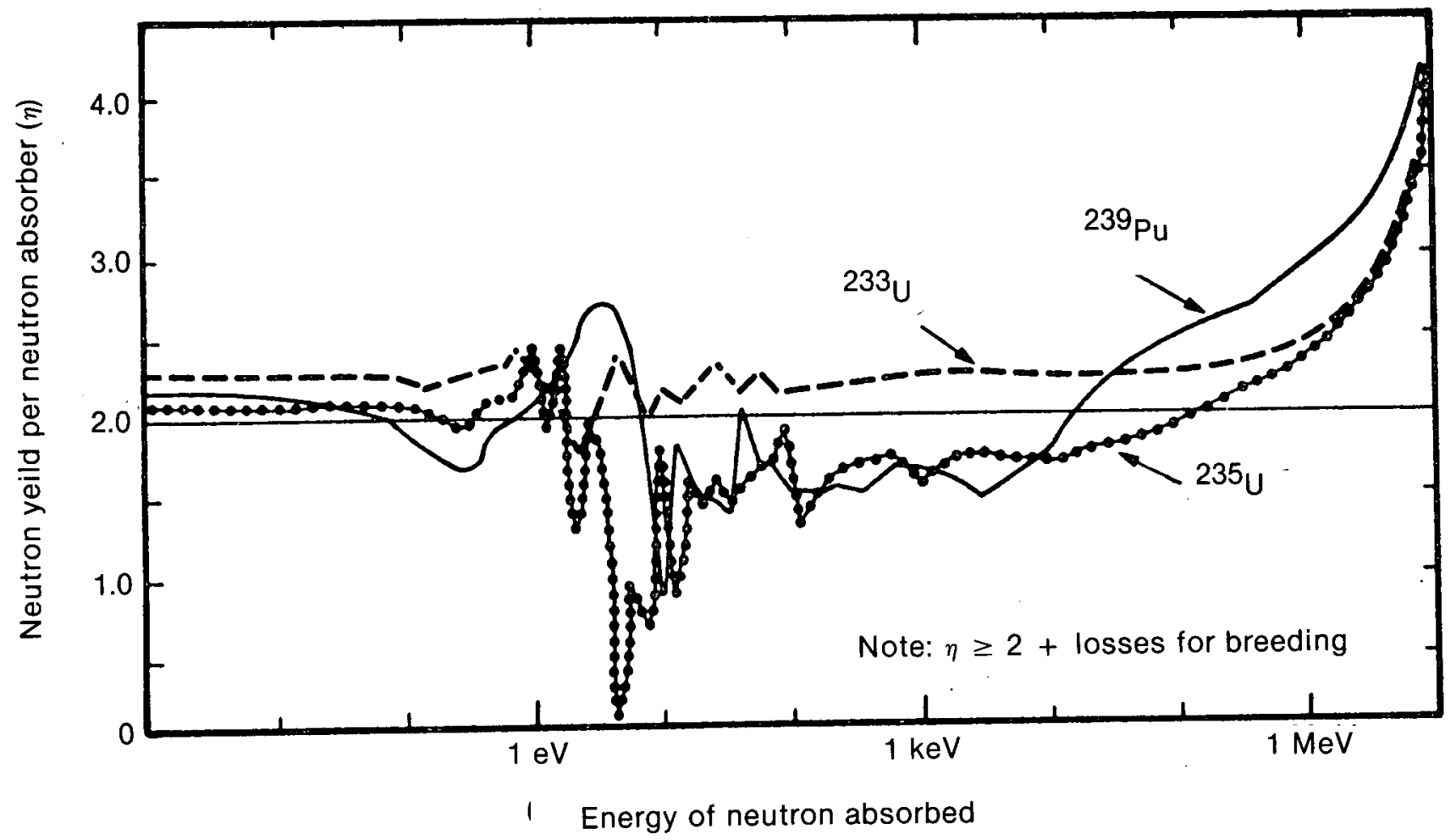

Figure A-2. Neutrons produced per absorption as a function of energy for fissile isotopes. 
$G$, reactor power in megawatts, $P$, fraction of time at rated power, $\mathrm{f}$, and $\alpha$ as

$\mathrm{M}_{\mathrm{g}} \cong \operatorname{GPf} \frac{(1+\alpha)}{2.7}$

hence,

$\mathrm{RDT}=\frac{2.7 \mathrm{M}_{\mathrm{o}}}{\operatorname{GPf}(1+\alpha)}$.

The doubling time is then measured in years and is proportional to the fissile specific inventory, $\mathrm{M}_{\mathrm{O}} / \mathrm{P}$, and inversely proportional to the breeding gain, $\mathrm{G}$. Although Equation (A-5) is a simple model and has no provisions for time spent by the fuel in the fuel cycle outside the reactor, fuel cycle losses, fissions in fertile material, and variations during the burnup cycle, it describes the sensitivity of the doubling time to the breeding gain and fissile specific inventory. More exact definitions of the doubling time, including system or fuel cycle inventory doubling time and compound system doubling time for equilibrium fuel cycles, are described in References A-2, A-3.

\section{Major Design Objectives}

The principal goals of breeder reactor design are safe operation, high breeding ratio, low doubling time, and low cost. Safe operations, in terms of design objectives, prescribe a conscious awareness of safety at every stage of design, and the attendant provision of reliable components and adequate safety margins for all normal and off-normal operations. A high breeding ratio is needed to reduce fuel doubling time. Fuel doubling times must be shorter than the doubling time of increasing electrical demand. Another important objective of any energy generating system is low cost. Overall fuel cycle considerations are of paramount importance. High burnup optimizes the use of high-fissile fuel and minimizes down time for refueling. An additional cost objective is the coordination of the breeder fuel cycle with that of the light water reactor (LWR) cycle. Minimizing capital cost, which is directly related to hardware requirements, puts a premium on systems that require the least expensive capital equipment commensurate with meeting the criteria for a safe and reliable operation. The specific reactor design objectives required to accomplish these goals are listed in Table A-1.

\section{Mechanical and Thermal Sy'stems Design}

This section provides brief descriptions of core and blanket arrangements, fuel configurations, vessel internals, heat transfer systems, shielding, instrumentation, and auxiliary systems. Discussions relate to several design operations presently being used or under consideration for use.

Core and Blanket Arrangements. Two choices exist regarding the arrangement of fertile and fissile fuels in the reactor to optimize breeding potential. In the external breeding concept, all fertile material is contained in the blanket surrounding the core; hence, all breeding takes place external to the core. In the internal, or in-core breeding concept, some fertile fuel pins are interspaced with fissile fuel within the core fuel economics. Figure A-3. illustrates the two choices.

The external breeding configuration results in a very hard spectrum, a low fissile inventory, and a good breeding ratio. Lack of in-core breeding results in a rapid reactivity loss with burnup, which requires frequent fuel changes, low burnup, a small doppler effect, few fast fissions in fertile material, a high fissile enrichment, and a thick blanket. A-4 Thus, design of prototype and demonstration LMFBRs allows for considerable internal or incore breeding.

Internal breeding core designs can be either homogeneous or heterogeneous. Figure $A-4$ shows top and side views of typical homogeneous; and heterogeneous core designs . Figure A-4a exemplifies a homogeneous core design because all of the fuel assemblies containing pure fertile fuel are located in the radial and axial blanket regions. Therefore, a relatively uniform or homogeneous mixture of fissile and fertile fuel is spread throughout the core. The central region indicates the core itself, which contains the initial load of fissile/fertile fuel. The outer region represents the radial blanket and shielding arrangement. The core typically contains two enrichment zones. The outer zone incorporates a higher fissile fuel content than the inner zone in order to effect a flatter radial power distribution. Control rods are normally boron-10, in the form of $\mathrm{B}_{4} \mathrm{C}$. 
Table A-1. Goals and design objectives for the breeder reactor

Goals

Safe operation

High breeding ratio

Low doubling time

Low cost
Accompanying Design Objectives

Reliable components, adequate containment margin

High neutron energy

High breeding gain, low fissile specific inventory

High burnup, compatibility with LWR cycle, minimal capital cost

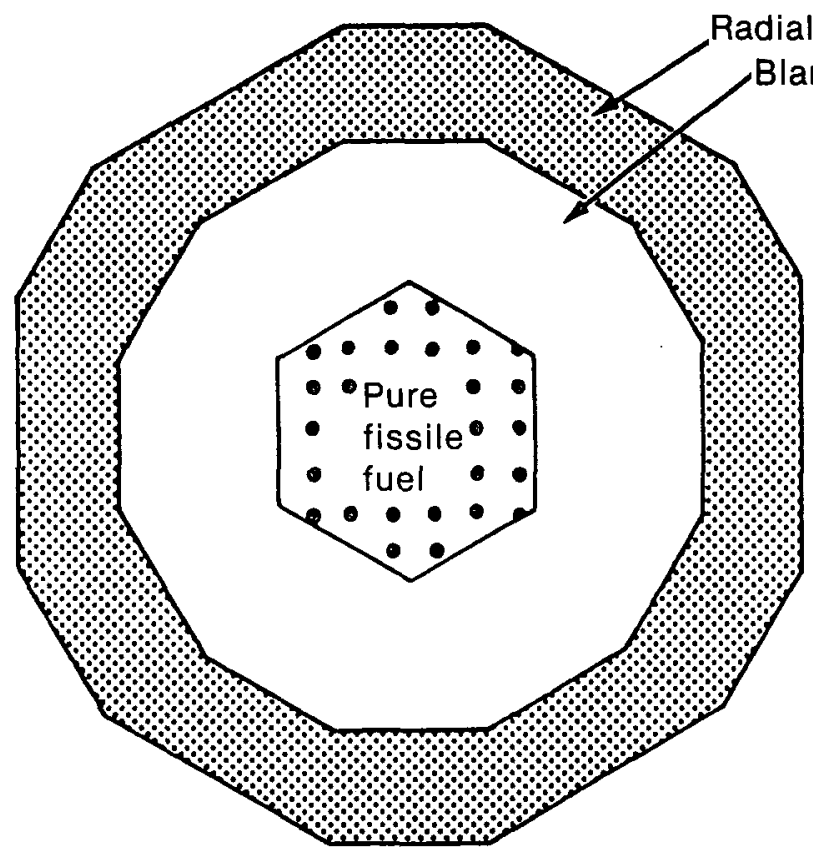

a) External breeding concept

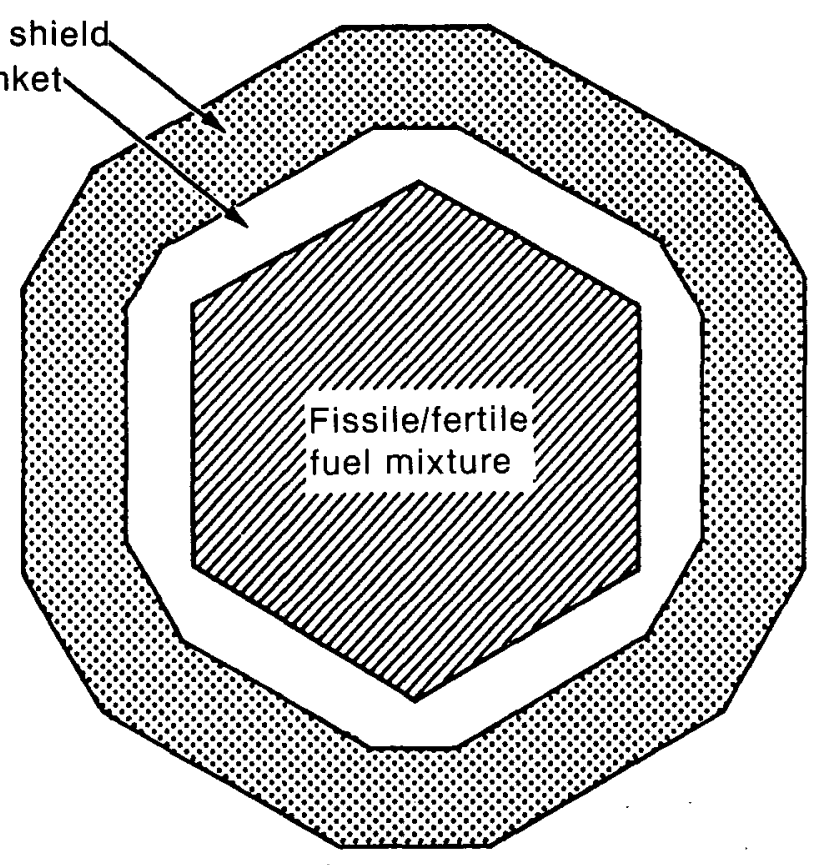

b) Internal or in-core breeding concept

Figure A-3. External and internal breeding configuration. 


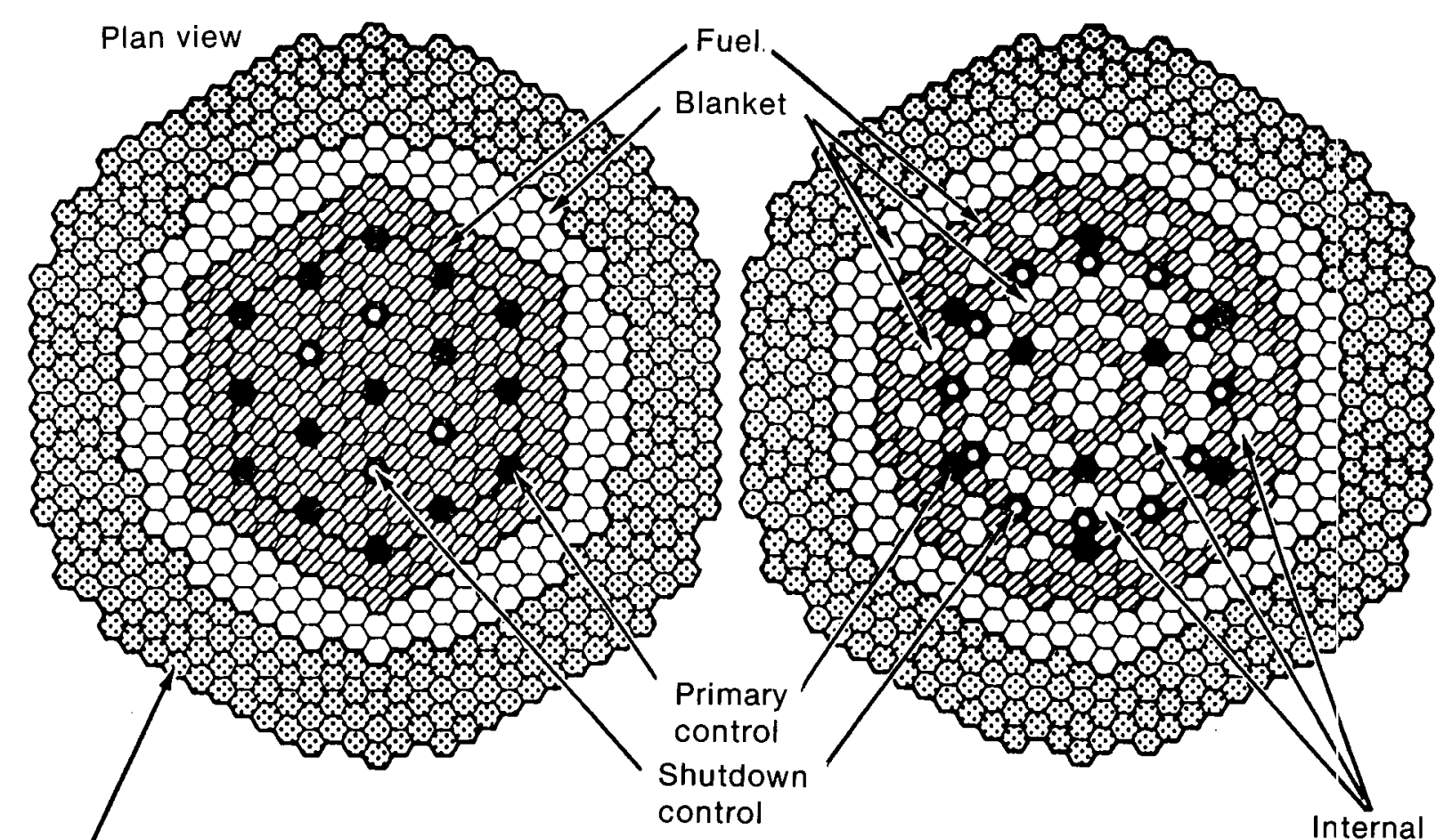

Radial shield!

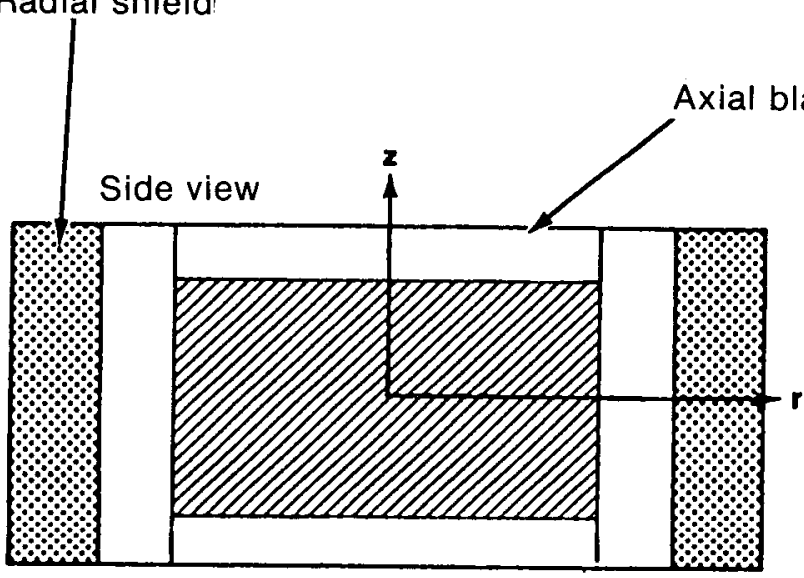

a) Homogeneous core

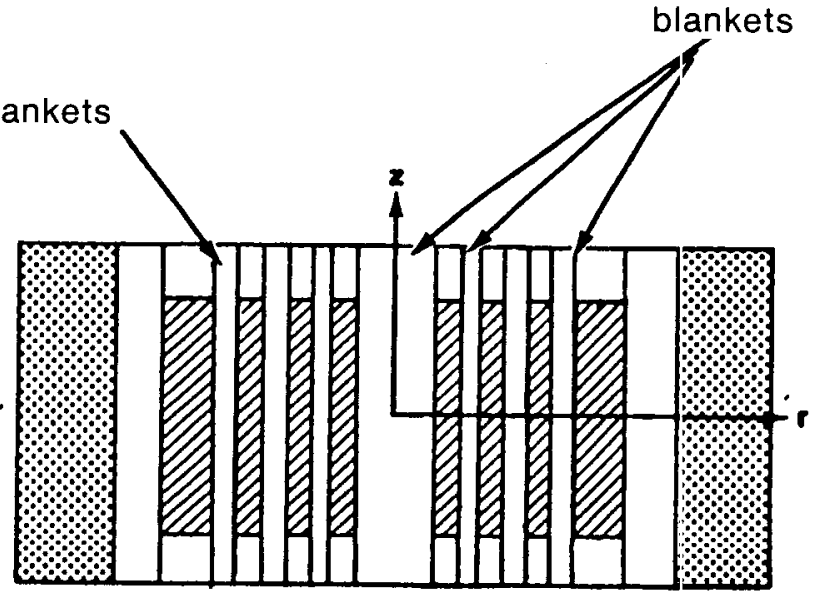

b) Heterogeneous core

Figure A-4. Typical homogeneous and heterogeneous LMFBR core/blanket arrangements incorporating internal breeding.

In the heterogeneous core design, the blanket assemblies, which contain pure fertile material, are distributed throughout the core region. The design yields a higher breeding ratio and reduced sodium void coefficients but requires higher fissile fuel inventories. A-5 The heterogeneous core configuration (illustrated in Figure A-4b) contains blanket assemblies at the center of the core and in concentric rings. Table A-2 compares $1000-\mathrm{MWe}$ homogeneous and heterogeneous designs. A-5
Fuel Lattice. There are great incentives to minimize the size of the LMFBR core. By reducing the coolant volume and structural material as miuch as possible, and thereby increasing the fuel yolume fraction, neutron leakage is decreased, the fissile fraction can be decreased, and reactivity can be increased for a given amount of fissile material.

A triangular lattice arrangement intrinsically allows a higher fuel volume fraction than does a 


\begin{tabular}{|c|c|c|}
\hline & Homogeneous & Heterogeneous \\
\hline Number of fuel assemblies ${ }^{b}$ & 276 & 252 \\
\hline Number of in-core blanket assemblies & - & 97 \\
\hline Number of ex-core blanket assemblies ${ }^{c}$ & 168 & 144 \\
\hline Number of control assemblies & 19 & 18 \\
\hline Number of enrichment zones & 3 & 1 \\
\hline Fissile mass $(\mathrm{kg})$ & 3682 & 4524 \\
\hline Pu fraction by zone (wt $\%$ ) & $13.5 / 14.9 / 20.3$ & 20.2 \\
\hline
\end{tabular}
a. From Reference A-4.
b. $271 \mathrm{pins} /$ fuel assembly, $1.22-\mathrm{m}$ core height, $7.9-\mathrm{mm}$ pin diameter, $0.36-\mathrm{m}$ axial blankets.
c. $127 \mathrm{pins} / \mathrm{blanket}$ assembly, $12-\mathrm{mm}$ pin diameter.

square lattice. The higher fuel volume fraction minimizes fissile loading mainly by reducing neutron leakage from the reactor. The triangular lattice or hexagonal structure has been selected for breeder reactor design. An LWR typically employs a square lattice because relatively larger spaces between fuel rods are needed to optimize the water-to-fuel ratio. The square lattice provides the space with relatively easy mechanical assembly.

Fuel Assembly. For the standard triangular pitch lattice, the pins are separated by a spiral wire wrap and assembled as a cluster of 217 pins within an assembly duct. A-5 Alternatively, grid spacers can be used to separate the fuel pins. Fuel pellets make up the active core region, and blanket pellets provide the axial boundaries. Fission gas plenums can be above or below the upper blanket region. Figure A-5 shows the geometric arrangement of the fuel, structure, and coolant. A table in the figure references the relationship between concentric (hexagonal) rows of pins and the number of pins in an assembly.

Vessel Internals. The core of an LMFBR is located on top of a core support structure, which is normally hung from the reactor vessel, or reactor tank, as shown in Figure A-6. An LMFBR does not require pressurization to keep the coolant in a liquid state; outlet pressures are near atmospheric. Consequently, the reactor vessel need only be thick enough to satisfy standard weight-bearing structural and safety requirements. A typical thickness may be on the order of $30 \mathrm{~mm}$, as compared to $300 \mathrm{~mm}$ for LWR systems.

Assemblies are slotted into positioning holes in the core support structure, and radial core restraints are normally provided at two axial locations. These locations are generally just above the active core near the top of the assemblies. Control rods enter from the top of the core, with the drive mechanisms located atop the vessel closure head. The vessel normally hangs from a support ledge, and the head is bolted to this structure. However, several variations in vessel support design have been used.

Sodium enters the lower inlet plenum, traverses up through the core and blanket regions, and collects in a large reservoir above the core before exiting to the intermediate heat exchanger (IHX). An 


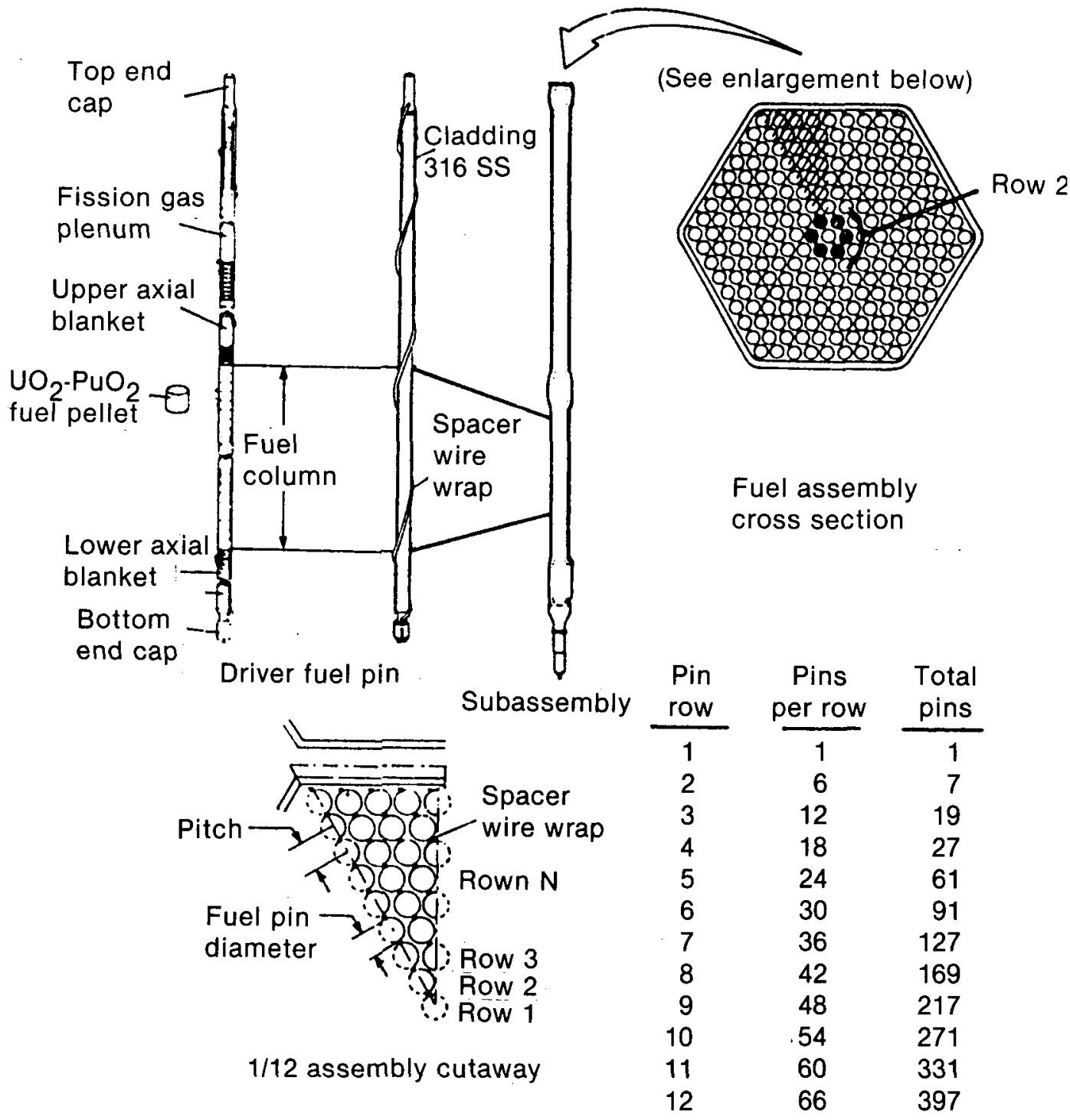

Figure A-5. Typical LMFBR fuel assembly system.

inert gas, usually argon, separates the sodium pool from the closure head.

\section{System Heat Transfers}

Pool and Loop System. Neutron activation of the sodium coolant in the primary heat transport system of an LMFBR requires that a secondary or intermediate heat transport system also be employed.

Two different arrangements have been devised to accomplish this; the IHX and the primary pump can be located inside the reactor tank, or they can be in adjacent hot cells with pipes connecting them to the reactor vessel. The first option is called the pool system, the second the loop system. In the loop system, there is a sequential series of components between the reactor and the turbine, each operating independently of the other loops in the system. Each loop consists of a single primary and secondary pump and one or more IHXs and secondary sodium system; there is no requirement that the number of primary pumps and loops be the same. Figure A-7 illustrates the heat transport systems for both the loop and pool designs. Table A-3 lists the systems selected for different plant designs. LMFBRs using the pool design include EBR-II, PHENIX, PFR, BN-600, Super PHENIX, CDFR, and $\mathrm{BN}-1600$. Those using the loop design include DFR, Fermi, Rapsodie, BOR-60, KNK-2, FBTR, JOYO, FFTF, PEC, BN-350, SNR-300, MONJU, CRBRP, and SNR-2. 


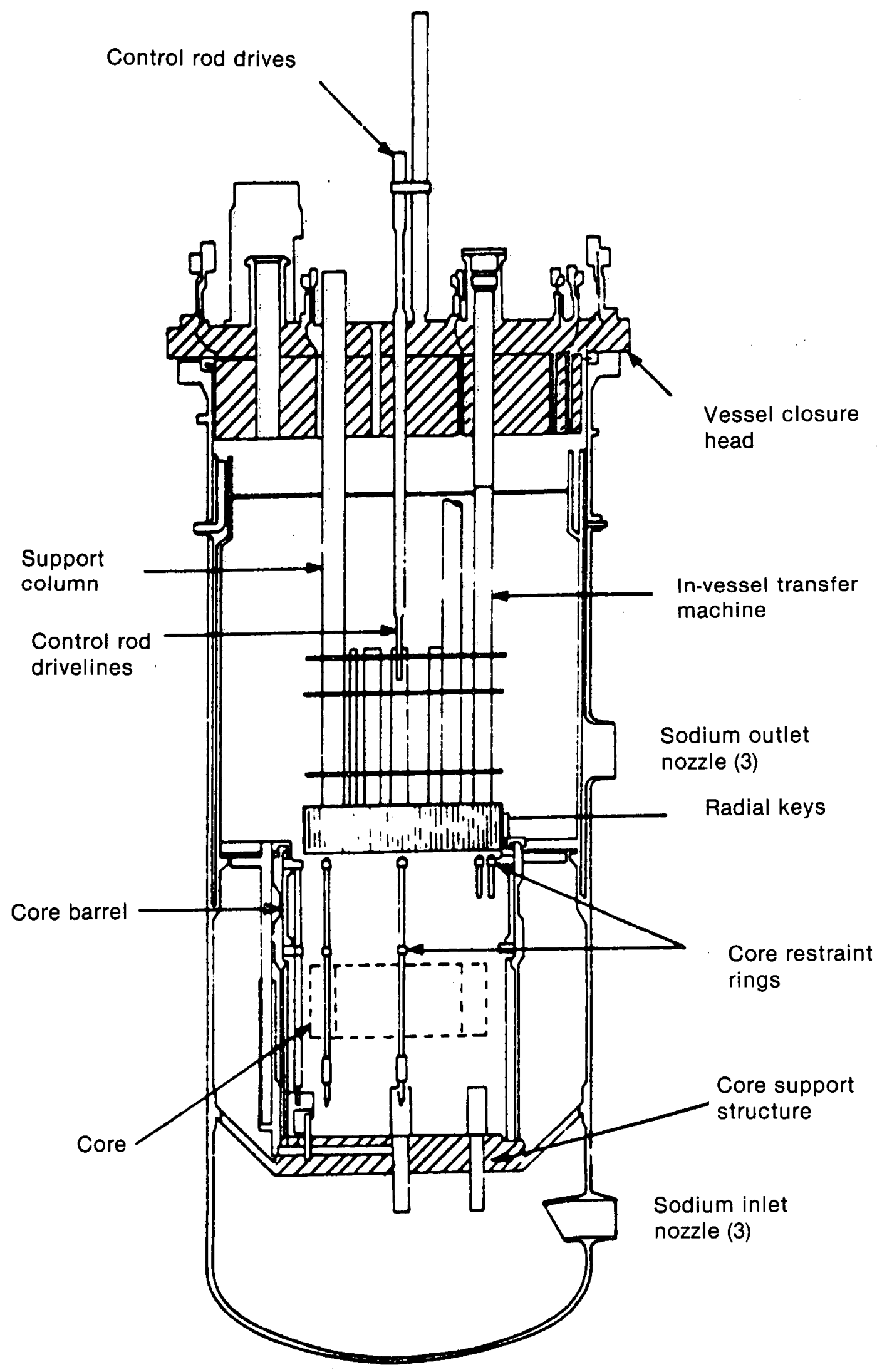

Figure A-6. Typical loop-type LMFBR vessel internals. 


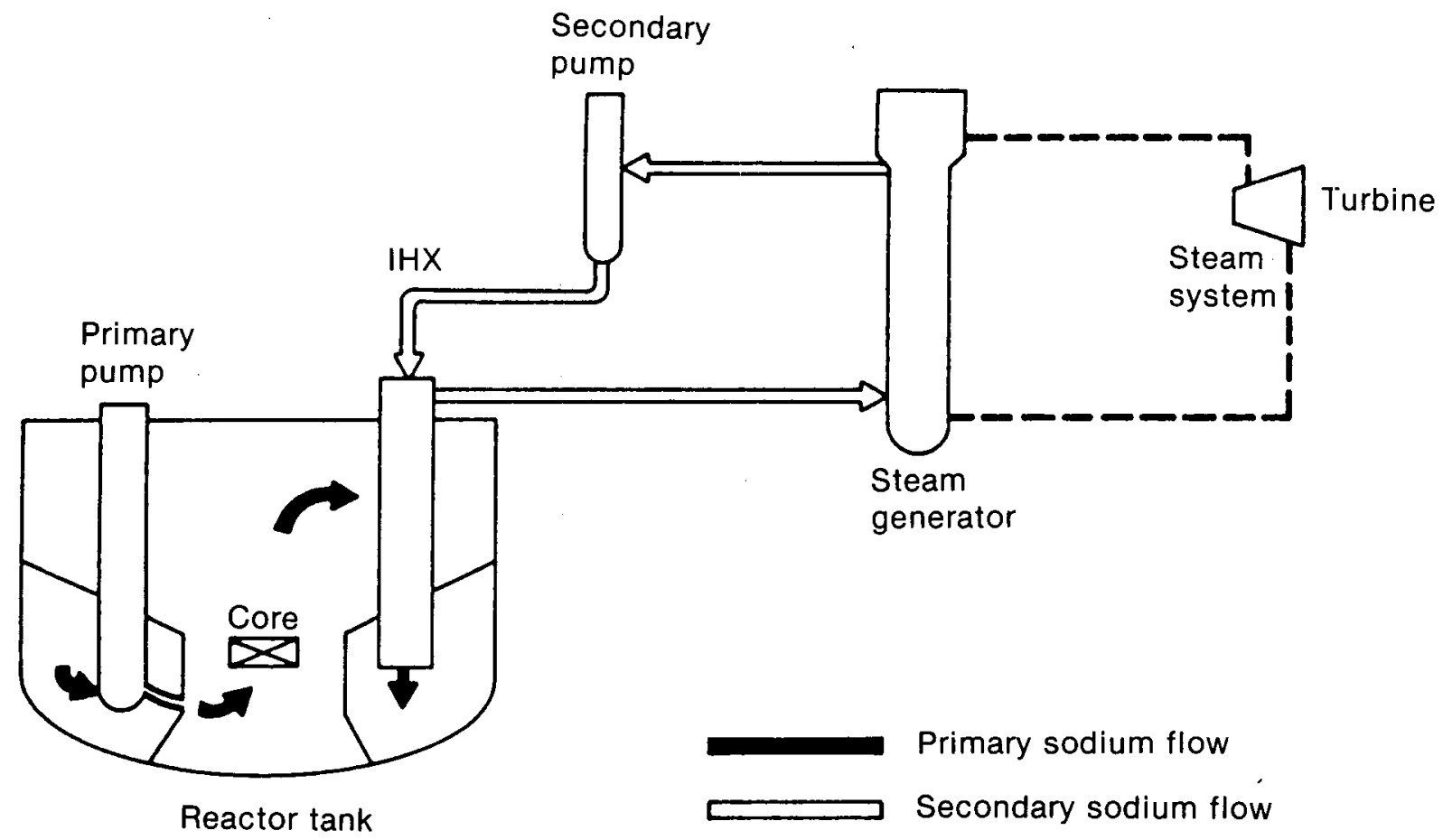

Figure A-7. LMFBR heat transport system.

There are advantages to both the loop and pool design. Loop designs include the following:

- Maintenance is simpler because components can be isolated in cells. The feature also allows greater flexibility in making system modifications and providing maintenance during reactor operation.

- Less neutron shielding is required to prevent neutron activation of the secondary shielding.

- The structural design of the vessel head is simpler than the deck roof of a pool reactor.

- The larger difference in vertical elevation of the IHX relative to the core in loop design enhances natural circulation over that of pool design. The difference allows more reliable prediction of the natural circulation in the primary coolant flow path.

Because of the smaller mass of sodium in the primary system in the loop design, there is a quicker response of the secondary sodium and steam systems to changes in the reactor and the primary sodium system. This influences the control and load following characteristics of the overall heat transport and steam system. Whether this is a net advantage relative to pool design is still unclear. ${ }^{\mathrm{A}-6}$

Advantages of the pool design are as follows:

- There is lower probability of a primary system being broken

- Leakage of primary system components and piping does not result in leakage from the primary system outside the reactor tank

- Sodium mass in the primary system is about three times that in a loop design, thus providing three times the heat capacity

- Temperature rise during off-norrnal transients is lower and time to reach boiling is longer if a heat sink is isolated

- The pool's large thermal inertia tends to dampen transient thermal effects in other parts of the system

- The cover gas system can be simpler, because the only free surface needed is that in the tank, an exception being the super PHENIX, where an actively controlled 
Table A-3. Main design parameters for large fast breeder reactors ${ }^{a}$

\begin{tabular}{|c|c|c|c|c|c|c|c|c|c|c|c|}
\hline & $\begin{array}{l}\text { BN. } 350 \\
\text { (USSR) } \\
\end{array}$ & $\begin{array}{c}\text { PHENIX } \\
\text { (France) }\end{array}$ & $\begin{array}{c}\text { PFR } \\
\text { (U.K.) }\end{array}$ & $\begin{array}{r}\text { SNR-300 } \\
\text { (Germany) } \\
\end{array}$ & $\begin{array}{l}\text { MONJU } \\
\text { (Japan) }\end{array}$ & $\begin{array}{c}\text { CRBRP } \\
\text { (U.S.) }\end{array}$ & $\begin{array}{l}\text { BN-600 } \\
\text { (USSR) }\end{array}$ & $\begin{array}{c}\text { Super } \\
\text { PHENIX } \\
\text { (France) } \\
\end{array}$ & $\begin{array}{l}\text { CDFR } \\
\text { (U.K.) }\end{array}$ & $\begin{array}{c}\text { SNR-2 } \\
\text { (Germany) } \\
\end{array}$ & $\begin{array}{l}\text { BN-1600 } \\
\text { (USSR) }\end{array}$ \\
\hline Electrical rating, $\mathrm{MW}$ & 350 (equiv) & 250 & 250 & 327 & 280 & 375 & 600 & 1200 & 1320 & 1300 & 1600 \\
\hline Thermal power, MW & 1000 & 568 & 600 & 770 & 714 & 975 & 1470 & 3000 & 3230 & 3420 & 4200 \\
\hline System & Loop & Pool & Pool & Loop & Loop & Loop & Poot & Pool & Pool & Loop & Pool \\
\hline Number of loops & 6 & 3 & 3 & 3 & 3 & 3 & 3 & 4 & 6 & 4 & 4 \\
\hline Primary pump location & Cold leg & Cold pool & Cold pool & Hot leg & Cold leg & Hot leg & Cold pool & Cold pool & Cold pool & Hot leg & Cold pool \\
\hline Number of IHXs per loop & 2 & 2 & 2 & 3 & 1 & 1 & 2 & 2 & 2 & 2 & 1 \\
\hline \multicolumn{12}{|l|}{ IHX temperatures } \\
\hline Reactor outlet, ${ }^{\circ} \mathrm{C}$ & 500 & 560 & 550 & 546 & 529 & 535 & 550 & 545 & 540 & 540 & 550 \\
\hline Reactor inlet, ${ }^{\circ} \mathrm{C}$ & 300 & 400 & 400 & 377 & 397 & 388 & 377 & 395 & 370 & 390 & 350 \\
\hline Secondary outlet, ${ }^{\circ} \mathrm{C}$ & 450 & 527 & 540 & 528 & 505 & 502 & 520 & 525 & 510 & 510 & 505 \\
\hline Secondary inlet, ${ }^{\circ} \mathrm{C}$ & - & - & - & 335 & 325 & 344 & - & 345 & 335 & 340 & 310 \\
\hline Steam generator & $\begin{array}{l}\text { Integral; } \\
\text { bayonet tube } \\
\text { evaporator, } \\
\text { U-tube } \\
\text { superheater }\end{array}$ & $\begin{array}{l}\text { Modular; } \\
\text { "S-shaped }\end{array}$ & $\begin{array}{l}\text { Separate; } \\
\text { U-tube }\end{array}$ & $\begin{array}{l}\text { Separate; } \\
\text { 2-straight } \\
\text { 1-helical }\end{array}$ & $\begin{array}{l}\text { Separate; } \\
\text { helical } \\
\text { coil }\end{array}$ & $\begin{array}{l}\text { Separate; } \\
\text { hockey } \\
\text { stick }\end{array}$ & $\begin{array}{l}\text { Separate; } \\
\text { straight } \\
\text { tube }\end{array}$ & $\begin{array}{l}\text { Integral; } \\
\text { helical } \\
\text { coil }\end{array}$ & $\begin{array}{l}\text { Integral; } \\
\text { helical } \\
\text { coil }\end{array}$ & $\begin{array}{l}\text { Integral; } \\
\text { helical } \\
\text { coil or } \\
\text { straight } \\
\text { tube }\end{array}$ & - \\
\hline Steam cycle & Recirculating & $\begin{array}{l}\text { Once-through } \\
\text { (Benson) }\end{array}$ & Recirculating & $\begin{array}{l}\text { Once-through } \\
\text { (Sulzer) }\end{array}$ & $\begin{array}{l}\text { Once-through } \\
\text { (Benson) }\end{array}$ & Recirculating & $\begin{array}{l}\text { Once-through } \\
\text { (Benson) }\end{array}$ & $\begin{array}{l}\text { Once-through } \\
\text { (Benson) }\end{array}$ & Once-through & Once-through & - \\
\hline \multicolumn{12}{|l|}{ Number of units per loop } \\
\hline Integral steam generators & - & - & - & - & - & - & - & 1 & - & 2 & - \\
\hline Separate evaporators & 2 & 12 & 1 & 3 & 1 & 2 & 1 & - & - & - & - \\
\hline Separate superheaters & 1 & 12 & 1 & 3 & 1 & 1 & 1 & - & - & - & - \\
\hline Steam drums & 0 & 1 & 1 & 0 & 0 & 1 & - & - & - & - & - \\
\hline Moisture separators & - & 1 & - & 1 & 1 & - & 1 & - & - & - & - \\
\hline Reheaters & 0 & 12 & 1 & 0 & 0 & 0 & 1 & 0 & - & - & - \\
\hline \multicolumn{12}{|l|}{ Turbine } \\
\hline Inlet pressure, $\mathrm{MPa}$ & 4.9 & 16.3 & 12.8 & 16.0 & 12.5 & 10.0 & 14.2 & 18.4 & 16.0 & 16.5 & I4.0 \\
\hline Inlet temperature, ${ }^{\circ} \mathrm{C}$ & 435 & 510 & 513 & 495 & 483 & 483 & 505 & 490 & 490 & 495 & 500 \\
\hline Number/rating, MW(e) & 1 & 1 & $1 / 250$ & 1 & 1 & $1 / 434$ & - & $2 / 600$ & $2 / 660$ & $1 / 1300$ & $2 / 800$ \\
\hline Type & $K-100-45$ & Condensing & Tandem compound & Condensing & Tandem compound & Tandem compound & K-200-130 & Condensing & Tandem compound & Single shaft & - \\
\hline
\end{tabular}


cover gas is used to reduce reactor vessel wall thermal stresses.

Steam Cycle. LMFBR core inlet and outlet temperatures are generally about 400 and $550^{\circ} \mathrm{C}$, respectively, and correspond, except for small heat losses, to the temperatures across the primary side of the IHX.A-7

Primary and secondary flows in the IHX are generally countercurrent, with log mean temperature differences between the primary and secondary sodium on the order of 30 to $40^{\circ} \mathrm{C}$. A-7 With the exception of the PFR, secondary flow is on the tube side in order to facilitate cleanup of sodium-water reaction products from the steam generator, should a leak occur there. ${ }^{A-8}$ Pressure on the secondary side is higher than on the primary side to avoid leakage of radioactive sodium to the secondary, in the event there are tube leaks.

An additional reason for placing the secondary on the tube side is that components of the heat transport system in both the primary and secondary system are arranged such that the thermal center of each component is above the thermal center of the previous component in the flow cycle.

Steam generators can be categorized as integral or separate. In an integral system, evaporation and superheating occur without separation of the water and the steam between the two processes. Many integral steam generators employ both evaporation and superheating within an integral unit (i.e., within the same shell). An example is the steam generators to be used in the Super PHENIX. Other integral steam generator systems employ separate components, as in the BN-350. Figure A-8 illustrates examples of integral steam generators.

In a separate steam generator, evaporation and superheating occur in different units, with steam separation between the two processes. Steam separation usually takes place in a steam drum or moisture separator, which are separate components between the evaporator and superheater. Steam separation can be incorporated as an integral part of the evaporator. Steam-water is always on the tube side, sodium on the shell side. The steamwater pressure is greater than the sodium pressure. In the event of a tube leak, steam or water will flow into the sodium. This will prevent contamination of the turbine with sodium oxide.
Figure A-9 illustrates four steam cycles, modifications of the basic Rankine cycle, being considered for LMFBRs.

The Benson cycle is a once-through superheated cycle, employing an integral steam generator. The Sulzer cycle is another once-through superheated cycle but it uses separate evaporators and superheaters with a moisture separator between them. The exit quality from the evaporator in the Sulzer cycle is high. For the SNR-300, it is purported to be $95 \%$. A-9,-10 CRBRP design states that exit quality from the evaporators in a recirculation superheater cycle is $50 \%$.

Plant Control. The factors involved in the control of an LMFBR heat transport system can be derived from the following brief outline of the plant control system developed for the CRBRP. Figure A-10 is a schematic of the two-level CRBRP plant control system. The systems provides automatic and manual control of the reactor, heat transfer system, turbine, and auxiliary systems for both normal and off-normal operation. The first level of control is the power load demand, which is established by either an automatic signal from the power grid load dispatching system or a plant-operator-determined setpoint. The supervisory controller receives the load demand signal and data on steam temperature, steam pressure, and generator output. The supervisory controller sends signals to each of the second-level controllers, which brings about any adjustments required in the reactor power level, system flows, and steam supply to match the power demand.

Each of the second-level controllers can be operated manually. Manual control is normally used when the plant is shut down, and during startup to bring the plant to a power level at which the automatic control system can be initiated. The automatic control system normally takes over at about $40 \%$ of maximum plant power.

The reactor controller receives a demand input regarding reactor power level from the supervisory controller and input of sodium temperature and neutron flux level in the reactor. The controller compares the flux level with the power demand signal to determine the change required to meet the demand. A trim signal from the steam temperature sensors is sent to the turbine throttle to maintain throttle conditions at a given temperature value. At the same time, information of core outlet temperature is used to modify the 


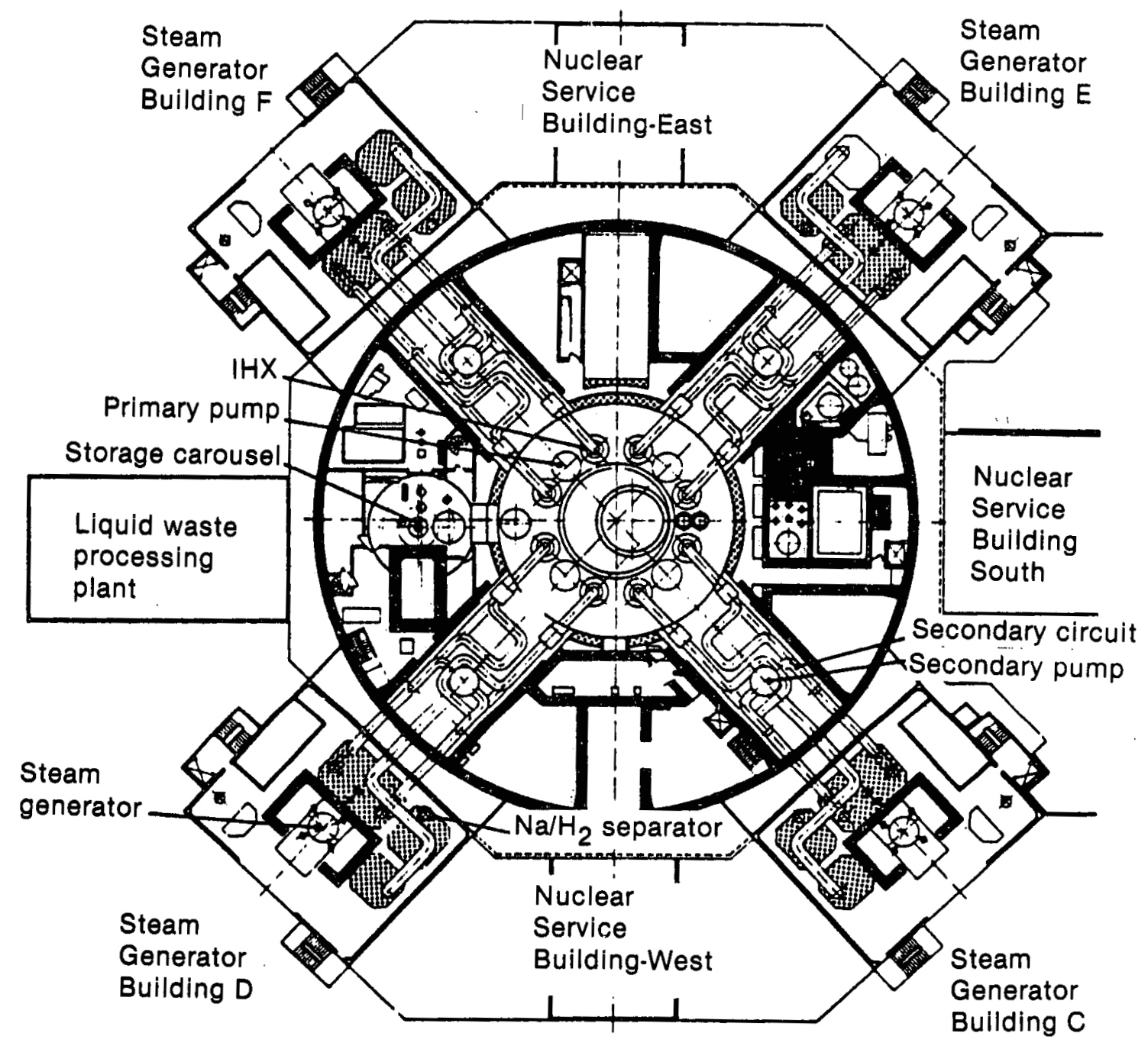

Figure A-8. Plain view of Super Phenix pool, showing the four loops, four primary pumps, and eight intermediate heat exchangers.

controller output so that core outlet temperature is maintained within predetermined limits. The resulting signal is a demand to the control rod drive mechanism controller to adjust the rod position to a point where the difference between power output and demand is minimized.

The primary and intermediate sodium flow controllers receive inputs of flow demand from the supervisory controller and sodium flow in the cold leg of each loop. The controller automatically compares the demand with the flow signal to determine if any changes are required. A trim signal is provided to the intermediate pump flow controller from the turbine throttle to maintain throttle pressure at the preset value. The resulting signal is a demand to the pump controllers, which also receive input from tachometers on each of the pumps. Comparison of the inputs result in a demand signal from the pump controllers to the pump drive controls for any changes in pump speed.

The steam drum and feedwater controller does not receive input from the supervisory controller because the steam drum level remains constant for all power levels. The controller receives inputs of flow in the main steam line, steam drum level, and flow in the feedwater line. Comparison of these inputs result in a demand signal to the feedwater control valves, which adjust flow to maintain steam drum level.

The turbine generator controller receives inputs of power load demand from the supervisory controller, steam flow temperature and pressure, turbine speed, and generator output. Flow, temperature, and pressure signals are combined to give mass steam flow information. The generator 


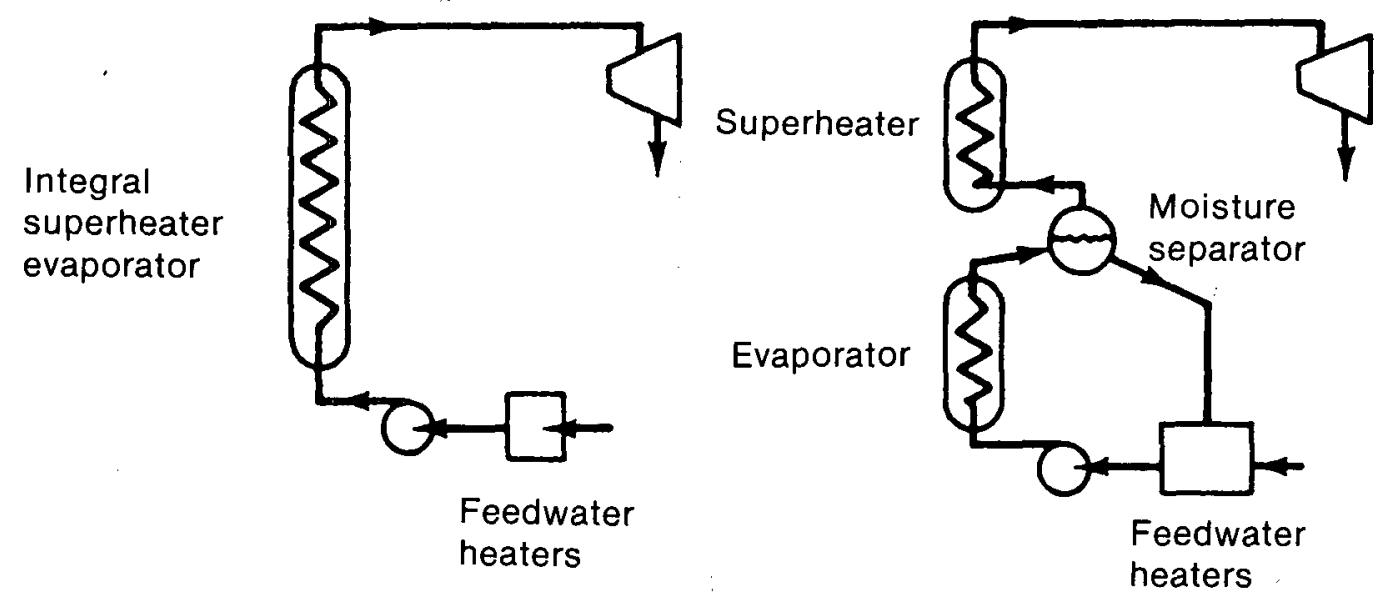

Once-through superheated (Benson cycle)

\section{Once-through superheated} (Sulzer cycle)

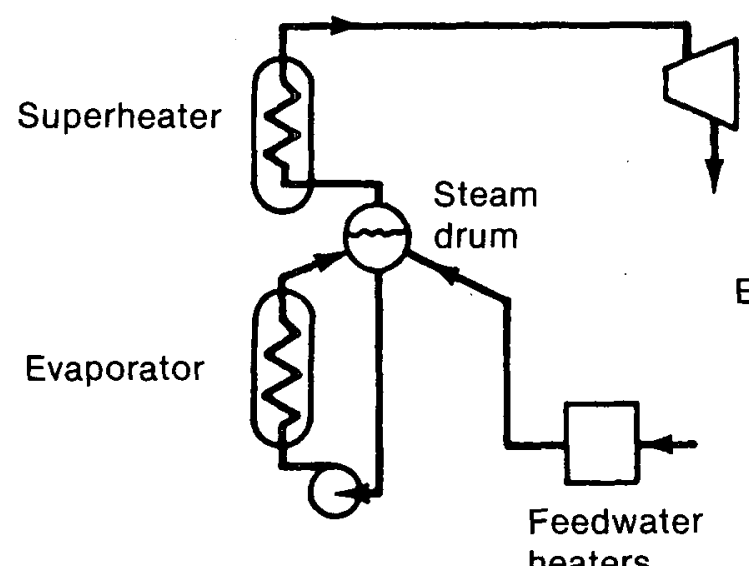

Recirculating superheated cycle

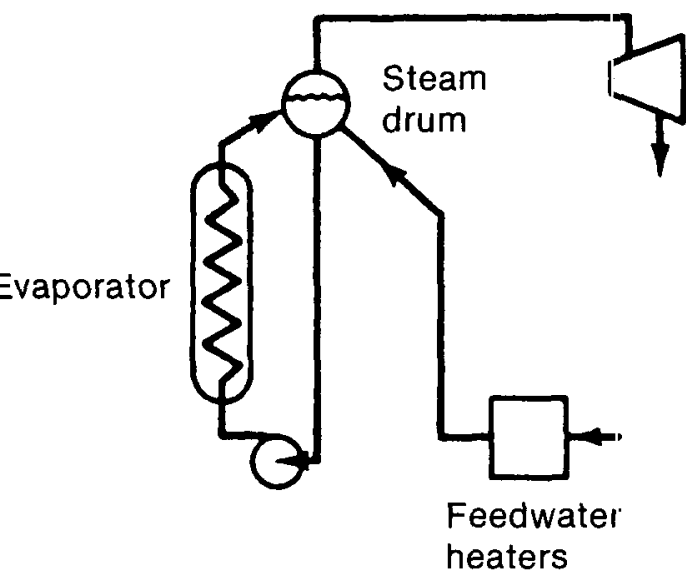

Saturated steam cycle

Figure A-9. LMFBR steam cycles.

output signal is compared to the power load demand to establish any requirements for power change. Comparison of these demands results in a signal from the turbine generator controller to the turbine throttle valve, which adjusts steam flow to meet the power load demand. The turbine speed signal is used to trim for small variations in turbine speed.

\section{Components}

Reactor Vessel and Reactor Tank. In a loop design, the reactor vessel is a vertical, cylindrical shell with a dome-shaped bottom. The vessel is hung at the top from a support ring. The fuel assemblies rest on a core support structure. Figure A-11 illustrates an example of a reactor vessel for a loop system, the SNR-300. In the SNR-300, the core support struc- ture is attached to an inner guard vessel (not present in CRBRP), which in turn is supported at the bottom by the reactor vessel. In the CRBRF design, the core support structure is attached to a core support ledge, which is attached to the side of the vessel. In both SNR-300 and CRBRP, a core barrel or jacket is joined to the core support structure and separates the sodium flowing through the core, blanket, and radial shielding from the surrounding sodium pool. An inlet flow structure guides the sodium from the inlet plenum to the fuel assemblies; an upper internal structure guides the flow from the assemblies into the outlet plenum. Containers for interim fuel storage during refueling are located outside the core barrel.

A guard vessel is located outside the reactor vessel to protect against any potential loss of sodium 


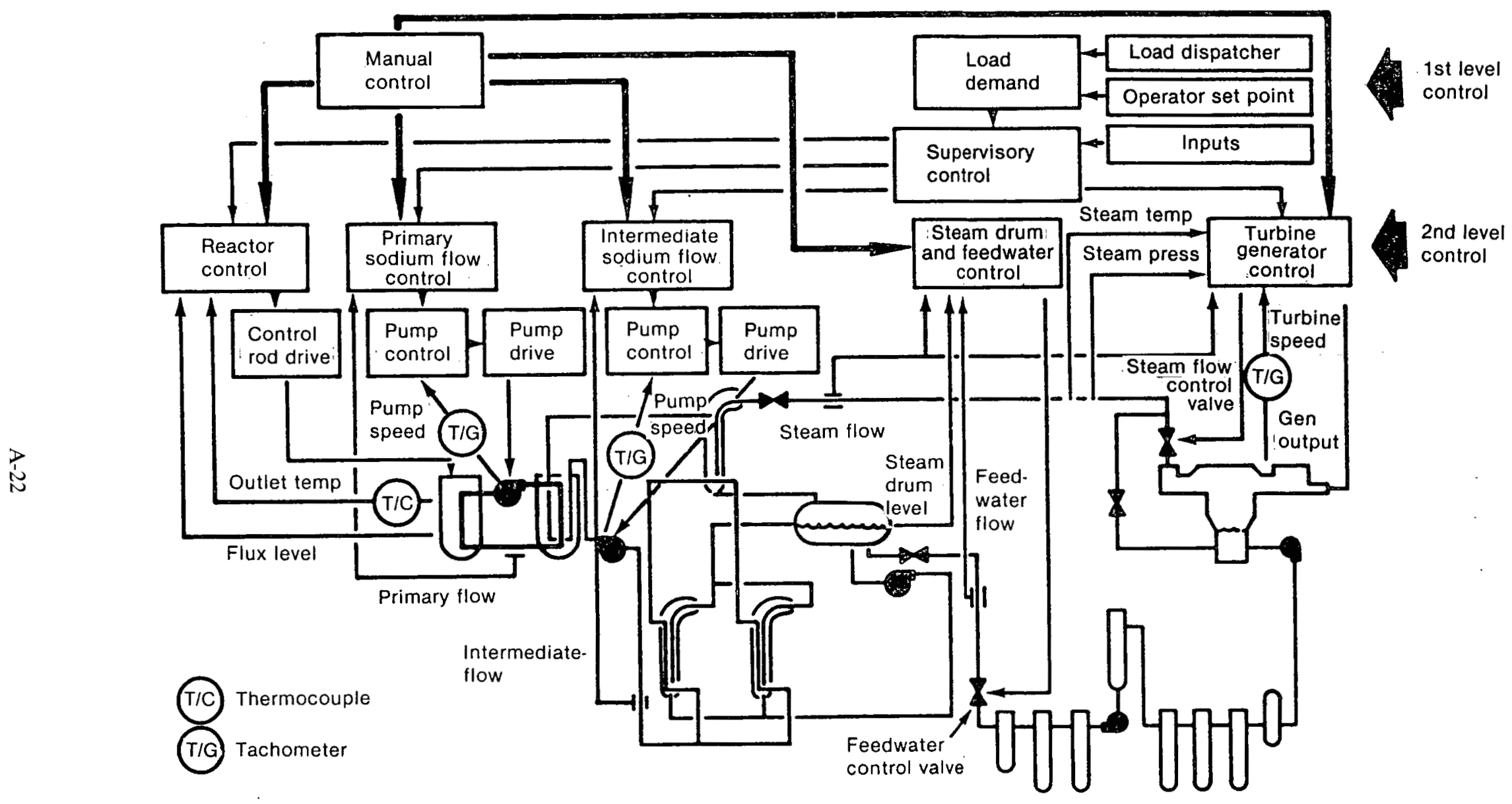

Figure A-10. The Clinch River Breeder Reactor project design for plant control. 


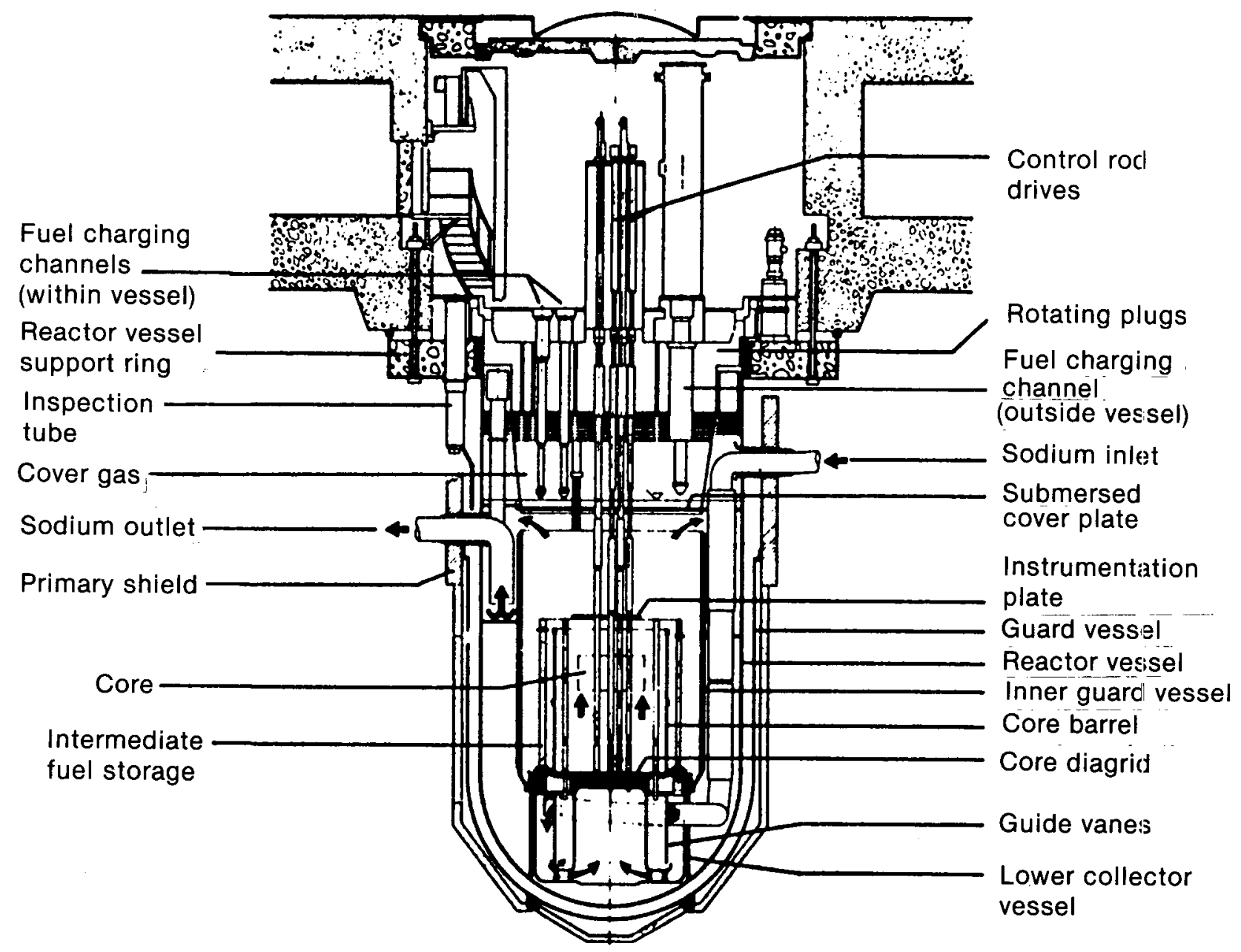

Figure A-11. Reactor vessel for the loop system of SNR-300.

from the vessel. The reactor and guard vessel are set in a reactor cavity. Both inlet and outlet sodium pipes enter above the guard vessel so that any pipe rupture within the reactor cavity will not result in sodium loss to the core. In the SNR-300, the inlet pipe penetrates the vessel above the outlet pipe, and runs down between the inner guard vessel and the reactor vessel to the inlet plenum below the core. In the FFTF and the CRBRP design, the inlet pipes run down between the reactor vessel and the guard vessel and enter the vessel near the bottom.

Several centimeters of argon gas cover the sodium, separating the sodium pool from the reactor head. The reactor head provides access for both control rod and refueling ports and is usually fabricated with several rotating plugs for refueling:

The reactor tank for a pool system is described by using the design adapted for Super PHENIX, the first commercial-sized pool reactor to be built.
The Super PHENIX reactor tank design is shown in Figure A-12. The tank is stainless steel, has a height and diameter of $19.5 \mathrm{~m}$ and $21 \mathrm{~m}$, respectively, and a wall thickness of approximately $50 \mathrm{~mm}$. It is hung from the deck that covers the tank.

Further details of the reactor tank and in ternals are shown in Figure A-13. A safety tank surrounds the reactor tank to contain sodium in the event of a leak. A baffle tank inside the reactor tank prevents the tank from exceeding the sodium reactor inlet temperature, accomplished by providing by-pass sodium flow from the inlet plenum to the annular space between the baffle and the reactor $\tan k s$.

Another internal tank is the insulated internal tank, which forms both a physical and thermal barrier between the hot and cold sodium. The penetrations for the primary pumps and IHXs are supported from the deck. Because of the large temperature variations, from the room temperature 


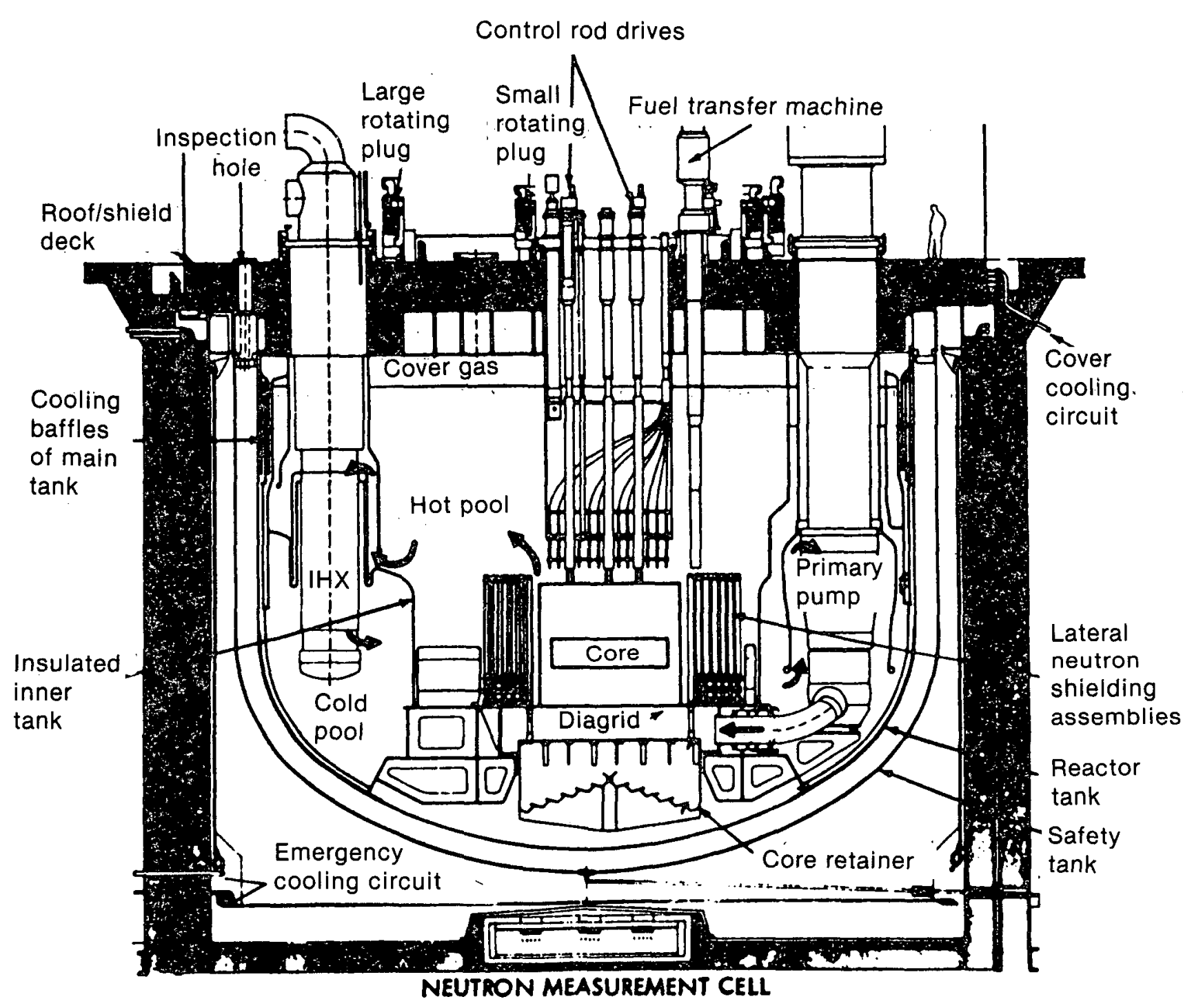

Figure A-12. Reactor tank for the pool system of Super Phenix.

above the deck to the sodium pool temperature below, the IHX penetrations of the insulated internal tank must accommodate 50 to $70 \mathrm{~mm}$ of axial expansion. A bell-jar type seal is used to accomplish this, as shown in Figure A-14. The pump fits loosely into a well that extends from the cold sodium to the deck so that no seal is required. Another problem for the pumps, however, involves the pipe connection to the inlet plenum. A flexible joint must be designed to accommodate the approximately $50-\mathrm{mm}$ radial and $100-\mathrm{mm}$ axial thermal expansion created by differences between the deck and pump operating temperatures.

Construction of the deck is illustrated in Figure A-15. It is composed of a steel web filled with concrete and is supported by the concrete vault that surrounds the reactor tank. The deck in turn supports the tank. The deck must also support primary pumps, IHXs, control rod drive, and fuel handling equipment, and must, in addition, be designed to remain leak-tight following potential deformation from a hypothetical core disruptive accident. As in the case of the loop system, the deck is separated from a sodium pool by a cover gas. In addition, the deck must be insulated from the hightemperature sodium. Even with insulation, some cooling of the deck is required. Insulation for the Super PHENIX is stainless steel gauze sandwiched between stainless steel foil. Similar insulation is also required to insulate the concrete walls surrounding the reactor tank.

Sodium Pumps. Sodium pumps in general use at LMFBRs are normally mechanical, vertical shaft, single-stage, double suction impeller, free surface, centrifugal pumps. 


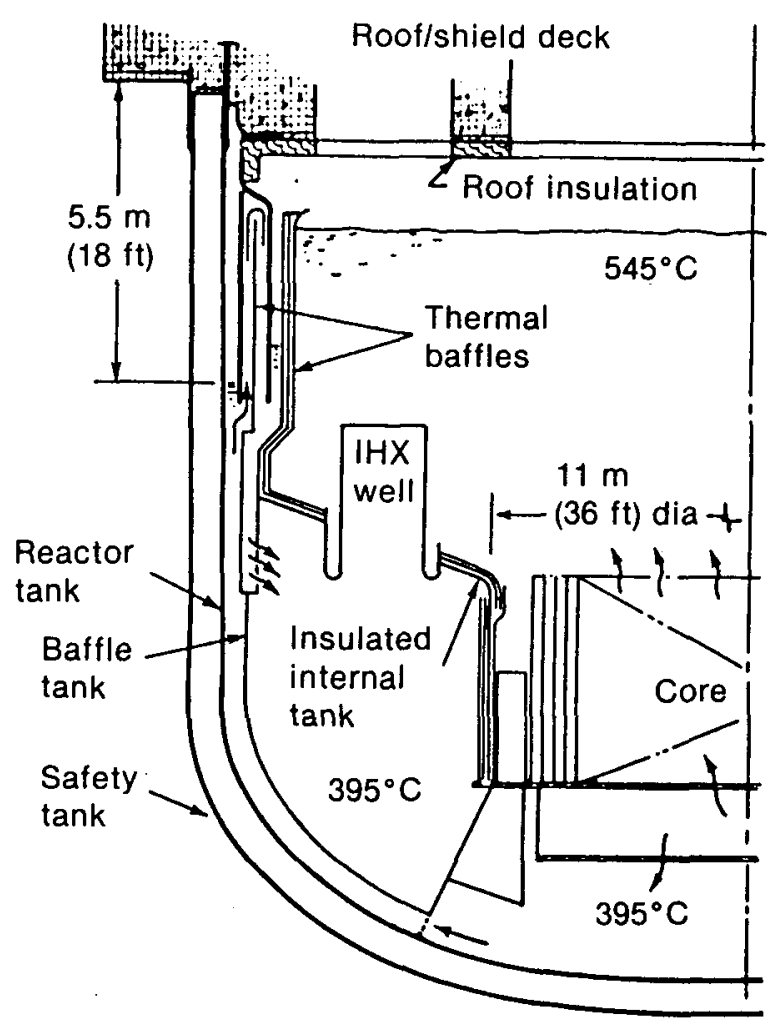

Figure A-13. Details of the Super Phenix reactor tank and internals.

Choices affecting pump design involve differences between primary pumps for the loop and pool systems, minor differences between primary and secondary pumps, and pump location. Important design choices include seal, bearings, impeller, and by-pass flow arrangements.

Electromagnetic pumps have also been used for LMFBRs, because sodium is an excellent electrical conductor. An electromagnetic pump is being used for the secondary sodium in EBR-II, and they have been used in SEFOR, in the primary circuit of the Dounreay fast reactor, and in the SLSF test train at ETR in Idaho. They are not used in the main loops in large LMFBR power plants, but they are being used in some back-up decay heat removal systems, for example in SNR-300 and Super PHENIX.

Only mechanical pumps are being used in large LMFBRs. Testing is underway in the United States on the use of a relatively small inducer-type mechanical pumping element in series with a large centrifugal pump to assist in meeting the strict suction requirements of an LMFBR centrifugal pump.
In a pool system, the primary pump is always located in the cold sodium. In a loop system, however, location of the primary pump can be either on the hot or the cold leg. The pump is located in the cold leg of all secondary systems because the advantages of a hot leg location existing for the primary loop are not present and also because it is important to pressurize the secondary sodium in the IHX in order to force flow from leaking tubes in the direction from the nonradioactive secondary to the radioactive primary.

In the loop design, there are some obvious advantages to seals and bearings, for exarnple, of placing the primary pump in the colder sodium environment of the cold leg. This was done in MONJU, BN-350, and most of the early experimental loop reactors. The hot leg has been selected for several loop designs, SNR-300, SNR-2, FFTF, and CRBRP. The main reason for choosing the hot leg involves suction requirements for primary system pumps. These requirements are stringent to accommodate the full range of anticipated transients. The basic argument can be explained briefly, however, by examining conditions during normal steady state operation.

The net positive suction head (NPSH) of a pump is the difference between the absolute pressure of the pump suction and the vapor pressure of the fluid pumped. Any pump has, inherent in its design, a minimum required NPSH at any given flow rate, to prevent cavitation. The available NPSH must, therefore, always be greater than this minimum value. The available NPSH can be obtained from the following relationship:

$$
\mathrm{NPSH}=\mathrm{H}_{\mathrm{p}}+\mathrm{H}_{\mathrm{z}}-\mathrm{H}_{1}-\mathrm{H}_{\mathrm{v}}
$$

where

$$
\begin{aligned}
\mathrm{H}_{\mathrm{p}}= & \begin{array}{l}
\text { pressure at the liquid surface of the } \\
\text { source from which the pump takes } \\
\text { suction, in this case the cover gas pres- } \\
\text { sure }
\end{array} \\
\mathrm{H}_{\mathrm{Z}}= & \begin{array}{l}
\text { hydrostatic head of the liquid source } \\
\text { above the impeller }
\end{array} \\
\mathrm{H}_{\mathrm{l}}= & \begin{array}{l}
\text { pressure drop losses in the piping and } \\
\text { equipment upstream of the pump }
\end{array} \\
\mathrm{H}_{\mathrm{V}}= & \begin{array}{l}
\text { vapor pressure of the fluid at the suc- } \\
\text { tion. }
\end{array}
\end{aligned}
$$




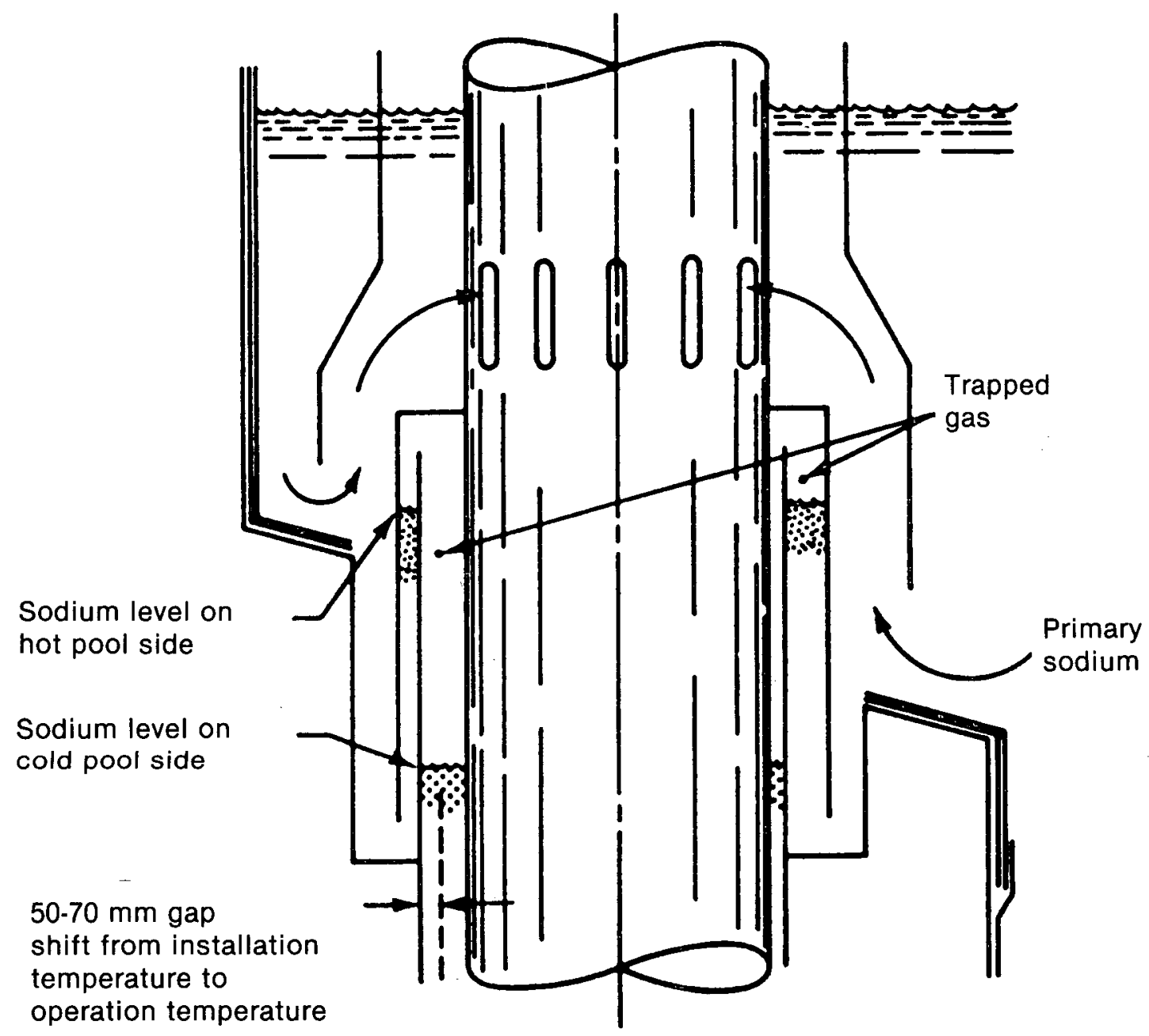

Figure A-14. Super Phenix's intermediate heat exchanger penetration into an insulated internal tank.

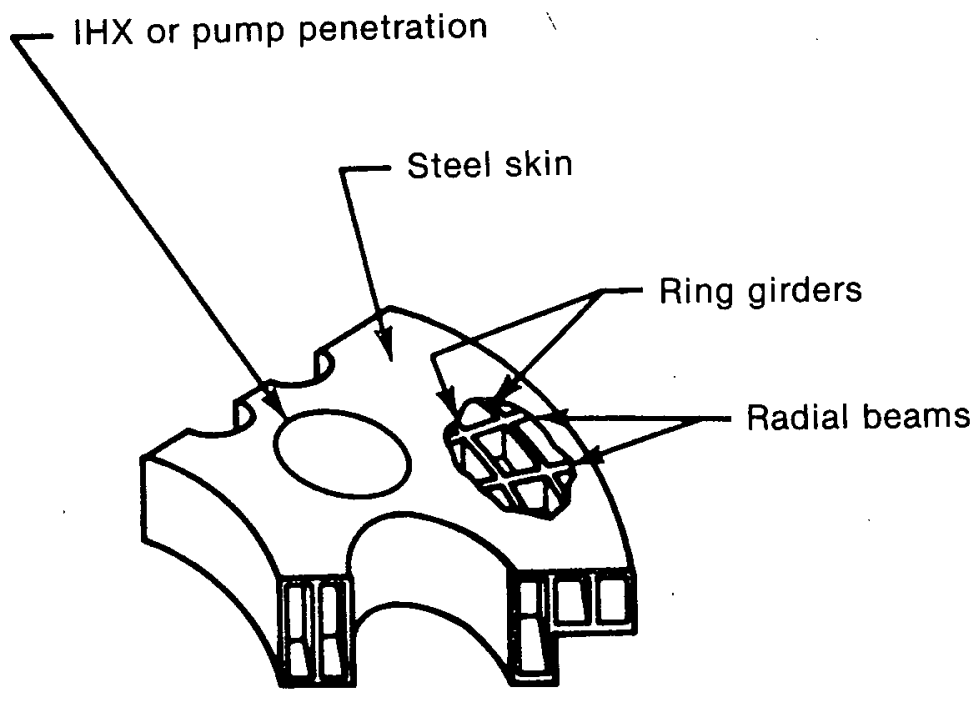

Figure A-15. Construction of Super Phenix's roof/shield deck. 
The pressure above the sodium surface in LMFBR primary pumps is equalized with the reactor cover gas pressure, $\mathrm{H}_{\mathrm{p}}$, and need be only slightly above atmospheric, just enough to prevent leakage of air or inert gas. The hydrostatic head, $\mathrm{H}_{\mathrm{Z}}$, controls the length of the primary shaft. The sodium vapor pressure, $\mathrm{H}_{\mathrm{v}}$, is small, on the order of only $1 \mathrm{kPa}$ for the hot leg sodium.

If the pump is on the hot leg, the pressure drop $\mathrm{H}_{1}$ includes only the losses through a short distance of the piping, plus vessel exit and pump entrance losses. With the pump on the cold leg, however, $\mathrm{H}_{1}$ must include the pressure drop through the IHX, plus additional piping. The IHX pressure drop is generally on the order of $50-100 \mathrm{kPa}$. To obtain a NPSH in the cold leg comparable to that in the hot leg would require an increase in the length of the pump shaft of $\mathrm{H}_{\mathrm{Z}}$, or to pressurize the argon cover gas in the reactor, $\mathrm{H}_{\mathrm{P}}$ or a combination. Pressurizing the cover gas would increase the potential for leakage of radioactive gas through the cover seals. Another option is to develop a more advanced pump that can operate with a lower NPSH. The difficulty of achieving these options is the reason for the hot leg location. The problem is further aggravated as LMFBR plant size increases, because the required NPSH for a particular pump increases within increasing rated capacity.

Intermediate Heat Exchangers. IHXs at all prototype and demonstration plants, with the exception of the BN-350, which uses U-tubes, are vertical counterflow, shell and tube heat exchangers with basically straight tubes. Figure A-16 illustrates an IHX for both a pool design (Super PHENIX) and a loop design (CRBRP). With the exception of PFR, the secondary sodium enters at the top and flows to the bottom through a central downcomer; flow is then reversed and returns up through the tubes. Primary sodium generally flows down on the shell side and exits at the bottom. Principal differences in IHXs between the loop and pool system appear at the entrance and exit flow nozzles.

The tube bundle must be mounted to allow for differential thermal expansion between the tubes and the shell. To accomplish this, the lower tube sheet is allowed to float, and, therefore, is supported by the tube bundles. The tubes are supported by the upper tube sheet. The CRBRP design shows a flexible bellows at the top of the downcomer to allow differential expansion between the downcomer and the tube bundle. An alternate method for accommodating the differential expan- sion, used in FFTF, is to design a bend in part of the tube bundle. A sine wave bend is used in PFR and CDFR.

Each of the eight IHXs at Super PHENIX includes 5380 tubes, 14-mm outside diameter, $12-\mathrm{mm}$ inside diameter, and $6.5-\mathrm{m}$ length. A remotely operated machine has been developed to seal off tubes that leak. Both 316 and 304 stainless steel are generally used in the IHX components.

Steam Generators. As discussed above in the "Steam Cycle" section, steam generators can be integral or separate. They can use tubes that are straight, helical, U-tube, or hockey-stick shaped. Either single- or double-wall tubes can be used. Table A-3 presents steam generator characteristics for the prototype and demonstration plants.

The choice of integral versus separate steam generators involves the selection of steam cycle (discussed in the "Steam Cycle" section above). Figure A-17 portrays the general shape of the temperature distributions in an integral unit. After boiling is complete, the steam can be superheated close to the inlet sodium temperature.

In separate steam generators, the subcooled heating and boiling take place in the evaporator, whereas the superheating occurs in the super:heater. Complete evaporation does not occur in the separate evaporator. CRBRP evaporators, exemplifying the recirculating cycle, were designed for $50 \%$ exit quality. Exit quality for the SNR-300 evaporators, which operate on the Sulzer once-through cycle, is $95 \%$. In both cases the steam is separated from the liquid before entering the superheater. As can be observed from Table A-3, both integral and separate systems have been widely used.

Several designs for steam generators have evolved, all having particular advantages and disadvantages. A fundamental consideration in each design is the method for accommodating thermal expansion. Figure A-18 presents examples of the basic configurations capable of providing such accommodations: helical coil, U-tube, and hockey stick. The figure also shows the straight tube configuration, which requires special provisions to accommodate thermal expansion, similar to those described for the IHX. Helical coils are used in Super PHENIX, CDFR, SNR-2, and MOJNU. U-tubes are used in PFR and in the BN-350 superheaters. Straight tubes are employed in BN-600, as well as in two loops in SNR-300. A third loop of SNR-300 incorporates a helical coil steam gerierator. 


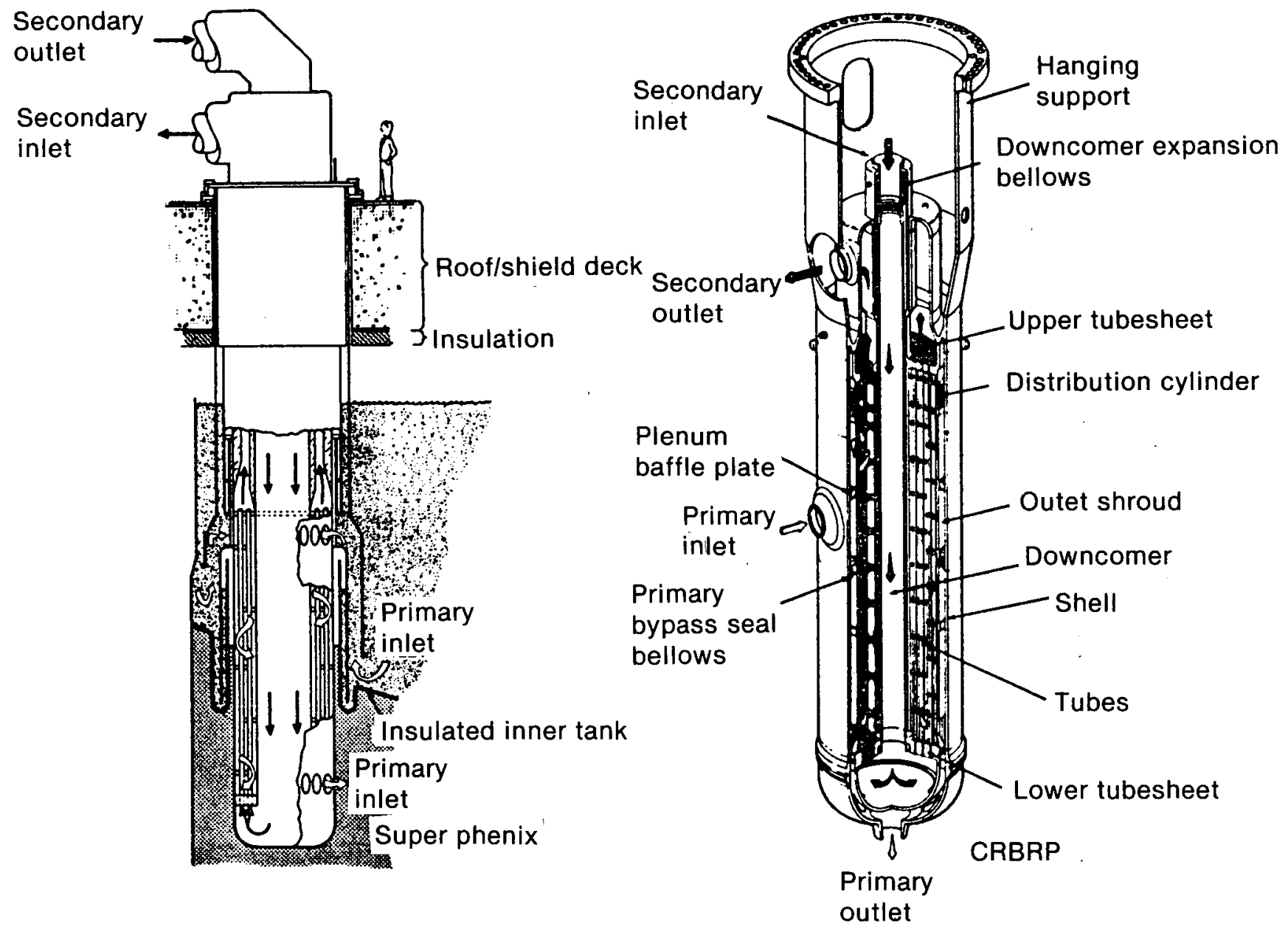

Figure A-16. Intermediate heat exchanger designs for the Super Phenix pool system and for the CRBRP loop system. 


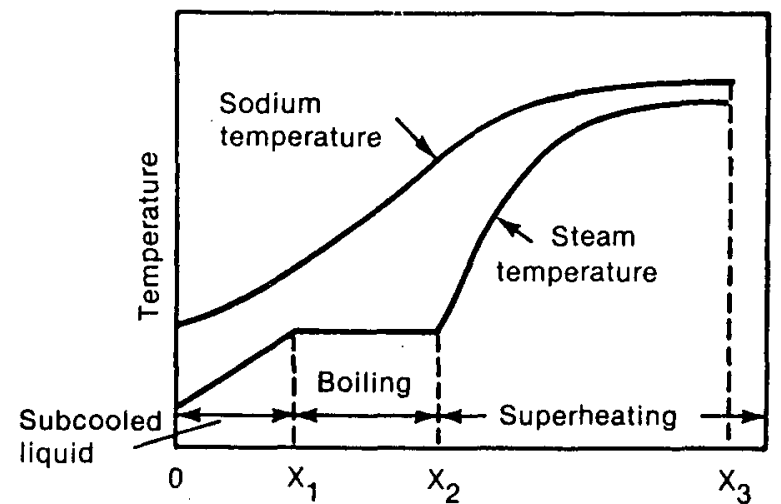

Figure A-17. Temperature distributions in an integral superheater.

Either helical coils or straight tubes will be used in SNR-2. In the United States, the hockey stick was selected and tested for the CRBRP. Design and development of both helical coil and straight tube designs are also underway. Another type of tube is used in the BN-350 evaporator called bayonet tubes. These tubes have a central tube surrounded by an annulus. Water flows down the central tube and a water-steam mixture flows back up the annulus.

Tube integrity is far more important for the LMFBR steam generator than for the LWR because of the potential chemical reaction between sodium and water. Early consideration was given to the use of double-walled tubes in which leaks could be detected from gas conditions between the two walls. Double-walled tubes are used, for example, in EBR-II and Dounreay fast reactor steam generators. However, when experiments demonstrated that sodium-water reactions could be adequately contained, the emphasis shifted to the simpler single-wall tube design, and all prototype and demonstration plants now use a single-wall tube. Some interest in double-wall tubes is being revived, but the argument that they might lead to greater steam generator reliability was more especially important for the early generator plant. Whereas experience with LMFBR steam generators has been reasonably encouraging, BN-350, PFR, and the Fermi reactor have all experienced difficulties with leaks.

Most steam generators, both tube and shell, are made of ferrite steel containing $2.25 \%$ chromium and $1 \%$ molybdenum, selected to minimize chloride stress corrosion. In some cases the material is stabilized with $1 \%$ niobium to reduce carbon loss to the sodium. Exceptions to this are the selection of Incalloy- $800^{\circledR}$ for Super PHENIX, and the use of austenitic stainless steel for the original PFR superheaters and reheaters.

An important condition in steam generator design is the transition between nucleate boiling and film boiling, or the departure from nucleate boiling. At this point, the temperature of the tube wall rises sharply and an instability in tube wall temperature occurs in the transition zone. This temperature behavior is illustrated schematically in Figure A-19. The transition occurs between $X_{1}$ and $X_{2}$. In this region, the tube wall is intermittently in contact with water or steam, and the wall temperature fluctuate rapidly. Such fluctuation, if too large a magnitude, can cause thermal fatigue of the tube, or structural changes that enhance water-side corrosion.

Shielding. Requirements for shield design are greater for fast reactors than for thermal reactors. The high energy neutron flux in an LMFBR is considerably higher than in an LWR, as is the highenergy neutron leakage from the core. Although the neutron production rate for an LMFBR and LWR have the same power level, or are comparable, the power density ( $\mathrm{kW}$ per liter) is higher for the LMFBR. Also, the neutrons in an LWR are slowed down to thermal energies close to the fission source, so that the high-energy leakage source for radiation of surrounding structures is relatively low.

LMFBR shielding can be discussed according to areas that require extensive shielding ancilysis and design. For both pool and loop designs, these areas include in-vessel radial shielding, the closure head assembly and its penetrations, and neutron flux monitors. For pool designs, special attention is required for the intermediate heat exchangers, where secondary sodium can be activated by neutrons. For loop designs, other key areas include the reactor vessel support area and the primary heat transport system pipeways. Other areas that require shielding include auxiliary piping penetrations, heating and venting system penetrations, shielding for cover gas and coolant purification systems, fuel handling equipment shielding, and biological shielding for areas that require personal access during normal pool operations.

Coolant and Cover Gas Radioactivity. The use of sodium as coolant in the LMFBR introduces shielding problems different from those in the LWR, as a result of neutron activation of the sodium. Sodium in nature is composed entirely of sodium-23. The $(\eta, \gamma)$ reaction in sodium produces 

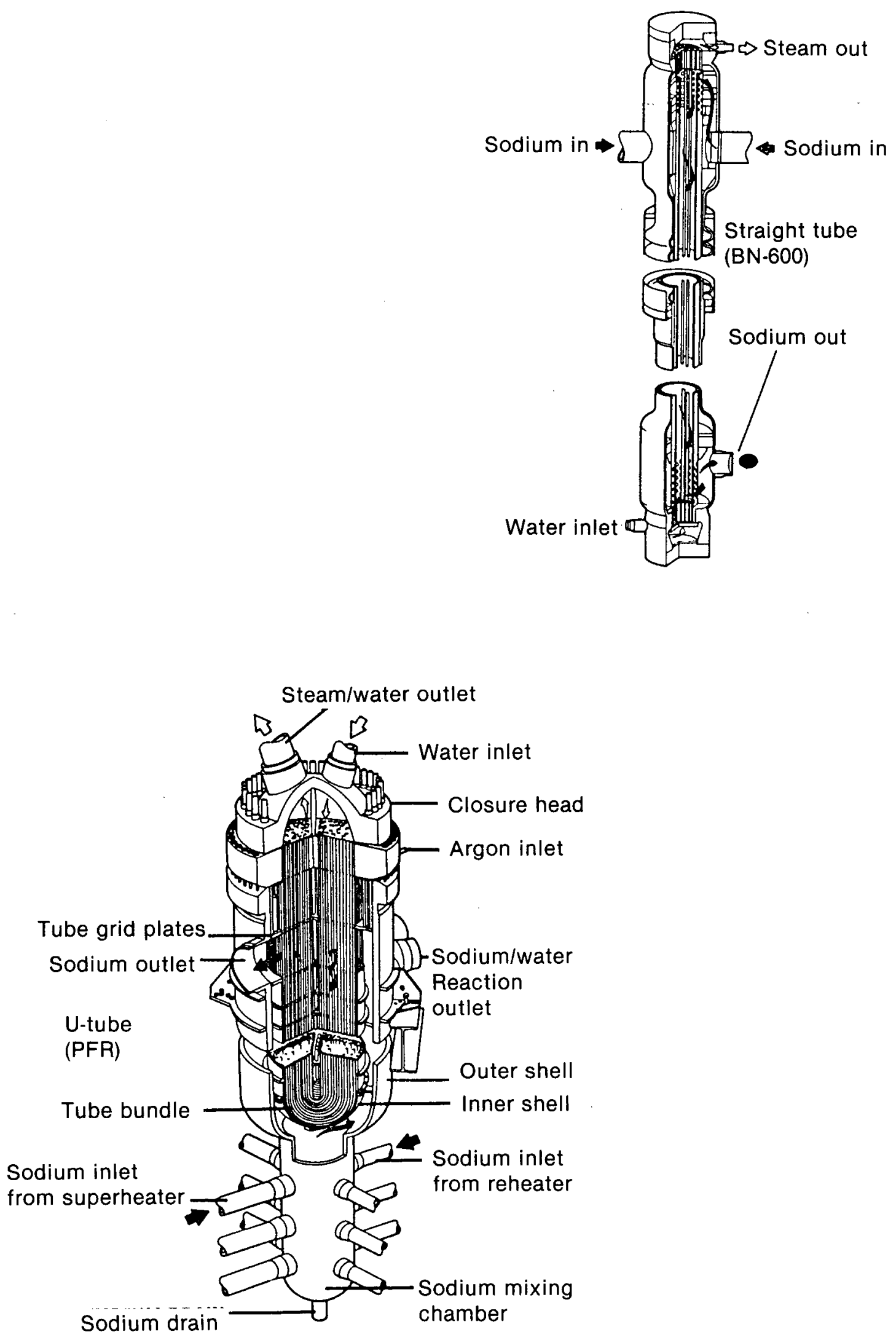

Figure A-18. Steam generator designs. 


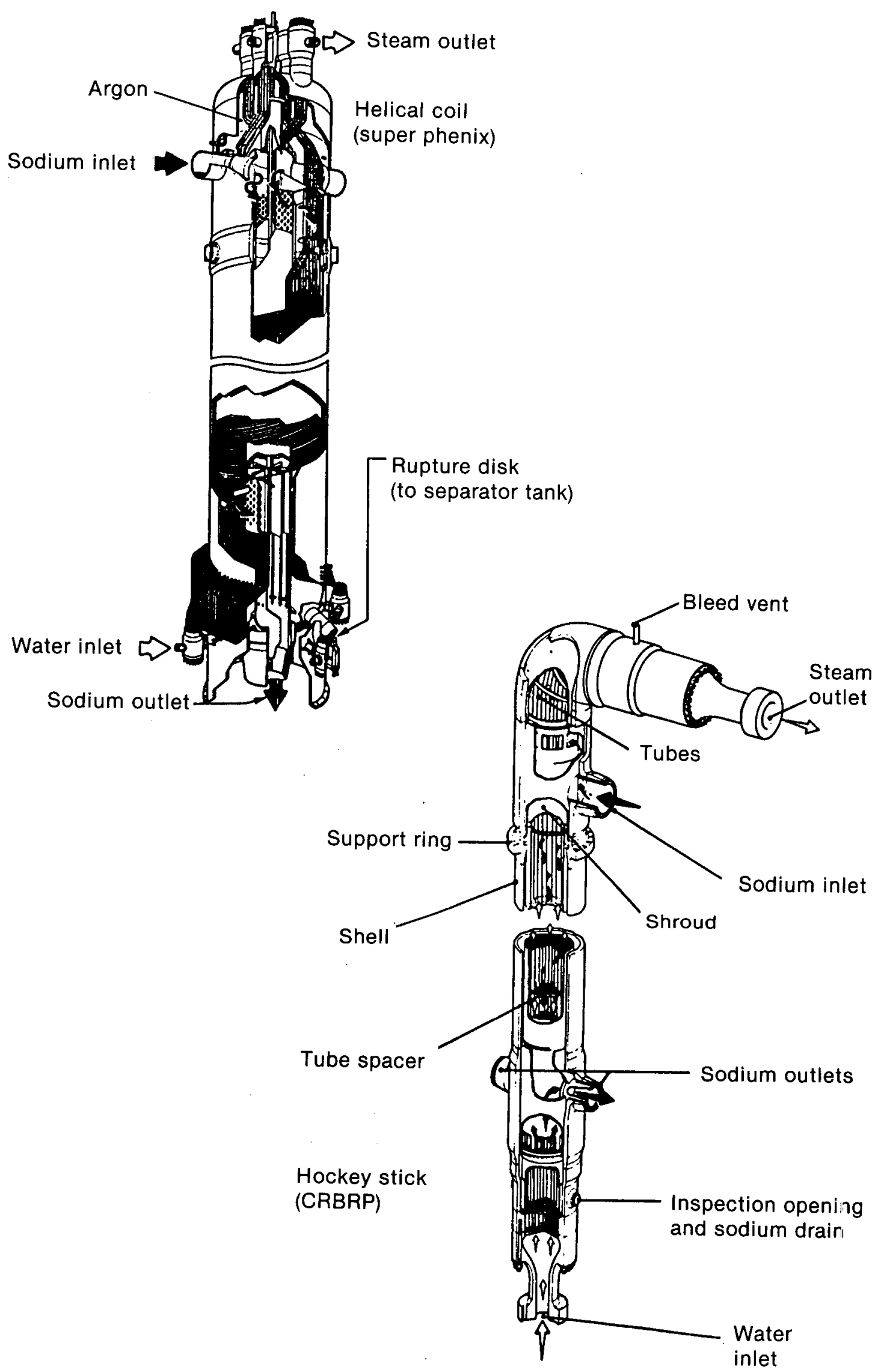

Figure A-18. (continued) 


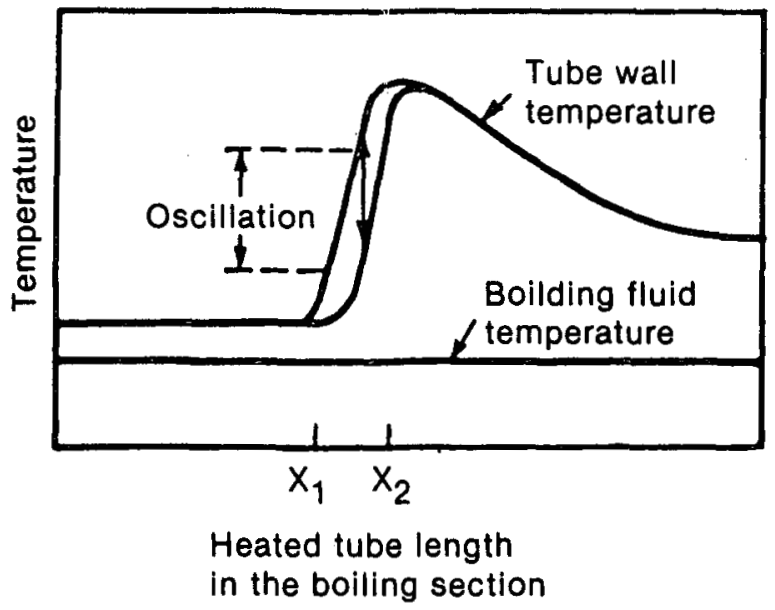

Figure A-19. Instability in rise in wall temperature at the transition from nucleate to film boiling.

radioactive sodium-24, which has a 15 -hour halflife, and emits both a 1.4- and 2.8-Mev gamma with decay. A $(\eta, 2 \eta)$ threshold reaction also occurs, producing sodium-22, which has a 2.6 -year halflife, and emits a $1.3-\mathrm{MeV}$ gamma. During operation, sodium-24 is the dominant activation product, and shielding against gammas from this source in the primary sodium is one of the important shielding problems in LMFBR design. Sodium-22 activity becomes the dominant activity in the sodium approximately 10 days after shutdown. For maintenance of primary pumps and IHXs, however, radioactivity from corrosion products becomes the most important radioactive source. The calculated sodium- 24 specific activity in the CRBRP primary sodium is $30 \mathrm{Ci} / \mathrm{kg}$ (based on a primary system sodium inventory of $6.4 \times 10^{5} \mathrm{~kg}$ ). For FFTF, the calculated sodium-24 activity is $11 \mathrm{Ci} / \mathrm{kg}$. For an early (1968) General Electric pool design, the calculated sodium-24 activity was $18 \mathrm{Ci} / \mathrm{kg}$, based on a primary system sodium inventory of $1.3 \times 10^{6} \mathrm{~kg}$. A-11 Calculated CRBRP sodium-22 specific activity, after 30 years of operation is $3.5 \mathrm{mCi} / \mathrm{kg}$. The corresponding FFTF value for sodium -22 is $1 \mathrm{mCi} / \mathrm{kg}$.

Another radiation source in an LMFBR is the reactor cover gas. Activation of impurities in the sodium, and direct activation of argon 40 to argon 41 , contribute to activity in the cover gas. Neon-23 appears from an $(\eta, \rho)$ reaction with sodium-23, but its half-life is short (38 seconds). The main design requirement, however, is to permit reactor operation with leakage occurring in a specified fraction of the fuel pins. For FFTF, this fraction of defective pins was set at $1 \%$. Table A-4 presents calculated activity caused by fission gas in the reactor cover gas for these design base conditions. Since failed fuel will likely never approach $1 \%$, actual activities will likely be far below these levels.

In-Vessel Shielding. In-vessel radial shielding is required to prevent excessive radiation damage to structural materials that must remain in a reactor for the lifetime of the plant, and to protect the vessel itself. Examples of in-vessel structures are the core barrel and the core restraint systems. Axial shielding below the core is needed to protect the core support structure. The shielding design must ensure that permanent components have an end-oflife ductility consistent with the threshold criterion for brittle fracture. In both FFTF and CRBRP design, the threshold of ductility is chosen to be $10 \%$ total elongation, the level that ensures a ductile mode of deformation up to failure, and permits conventional structural analysis methods and criteria to be used in design.

The radial blanket serves as the first shield between the core and the radial structure. FFTF has no blanket but uses removable radial reflectors to protect the fixed radial shield and the radial support structure and core barrel. Beyond the blanket are located removable radial shielding (RRS) assemblies. RRS assemblies contain rods of stainless steel or of nickel-based alloys compatible with sodium, such as Inconel. They have a high inelastic scattering cross section and are particularly effective in degrading the energy of fast neutrons. Iron is also effective, but less effective than nickel. Stainless steel is less expensive, however, than Inconel. The choice of material for CRBRP was narrowed to 316 stainless steel and Inconel-600. The shielding rods in the CRBRP design extends from the bottom of the lower axial blanket to the approximate top of the upper axial blanket. The shielding is in the form of rod bundles in order to allow cooling of the shield by sodium. The main heat sources in the shield are gammas from the core and blanket, and gammas generated in the shield itself both from inelastic scattering and neutron capture reactions. In FFTF, the radial reflectors are made up of hexagonal blocks of Inconel bolted together. Holes through the blocks provide cooling.

In CRBRP design, the RRS assemblies are surrounded by a fixed radial shield. The fixed radial shield is an annulus of 316 stainless steel, $0.146 \mathrm{~m}$ thick, which can experience relatively high fluence because it is not a loadbearing component. The 
Table A-4. Calculated cover gas activity for the FFTF design basis, $1 \%$ pin failure

\begin{tabular}{ll} 
Isotope & $\begin{array}{r}\text { Activity } \\
\left(\mathrm{Ci} / \mathrm{m}^{3}\right)\end{array}$ \\
\cline { 1 - 2 } $\mathrm{Kr}-83 \mathrm{~m}$ & $6.82 \times 10^{1}$ \\
$\mathrm{Kr}-85 \mathrm{~m}$ & $1.34 \times 10^{2}$ \\
$\mathrm{Kr}-85$ & $9.30 \times 10^{-9}$ \\
$\mathrm{Kr}-87$ & $1.80 \times 10^{2}$ \\
$\mathrm{Kr}-88$ & $2.64 \times 10^{2}$ \\
$\mathrm{Xe}-133 \mathrm{~m}$ & $5.43 \times 10^{-1}$ \\
$\mathrm{Xe}-133 \mathrm{~m}$ & $1.47 \times 10^{1}$ \\
$\mathrm{Xe}-133$ & $2.67 \times 10^{2}$ \\
$\mathrm{Xe}-135$ & $1.26 \times 10^{3}$
\end{tabular}

FFTF fixed radial shield is formed from flat plates to create a 12 -sided shield between the core and the core barrel.

In the pool design, graphite is usually incorporated into the radial shielding to moderate neutrons and allow them to be absorbed before reaching the IHX. $\mathrm{B}_{4} \mathrm{C}$ shielding is used near each IHX and primary pump in order to reduce activation of the structural material, thereby allowing maintenance as well as reducing secondary sodium activation by thermal neutrons in the IHXs.

An axial shield is located below the lower axial blanket to protect the core support structure and lower inlet modules. In CRBRP, this shield consists of a $0.51-\mathrm{m}$-long, 316 stainless steel shield block in each fuel, blanket, and control assembly. In FFTF, a lower shield and inlet orifice assembly is $0.54 \mathrm{~m}$ long. No special upper axial shielding is required for either FFTF or CRBRP because of the shielding provided by the upper sodium pool.

Pathways for neutron streaming from in-vessel components in CRBRP include the clearance gaps required in the design of the fixed radial shield, the cooling channels of the axial shielding set in each core assembly, the fission gas plenum of each core assembly, and interfaces between invessel components.
Reactor Enclosure System Shielding. Areas requiring shielding of the reactor enclosure system include component penetrations and interfaces in a closure head assembly, the reactor vessel support area, and the ex-vessel flux monitors in the reactor cavity. Figure A-20 illustrates these areas for CRBRP, which has a typical loop design. For a pool design, neutron flux levels at the tank support area and reactor cavity walls are lower than for the loop design, so shielding problems in these areas are less severe.

The CRBRP design solutions in these arees indicate the types of shielding problems encountered.

Figure A-21 shows the CRBRP closure head assembly (CHA). The main penetrations involve refueling components, control drive mechanisms, and the upper internals lifting mechanism. Radiation source terms that affect the CHA shielding design include neutron and gamma streaming of the step annuluses of the CHA penetrations or component interfaces, the radioactive cover gas below the CHA penetrations, and neutron and gamma penetrations through the CHA bulk shielding.

The sodium dip seals around the refueling plugs, shown in Figure A-21, presents the major shield design problem for the closure head assembly. 


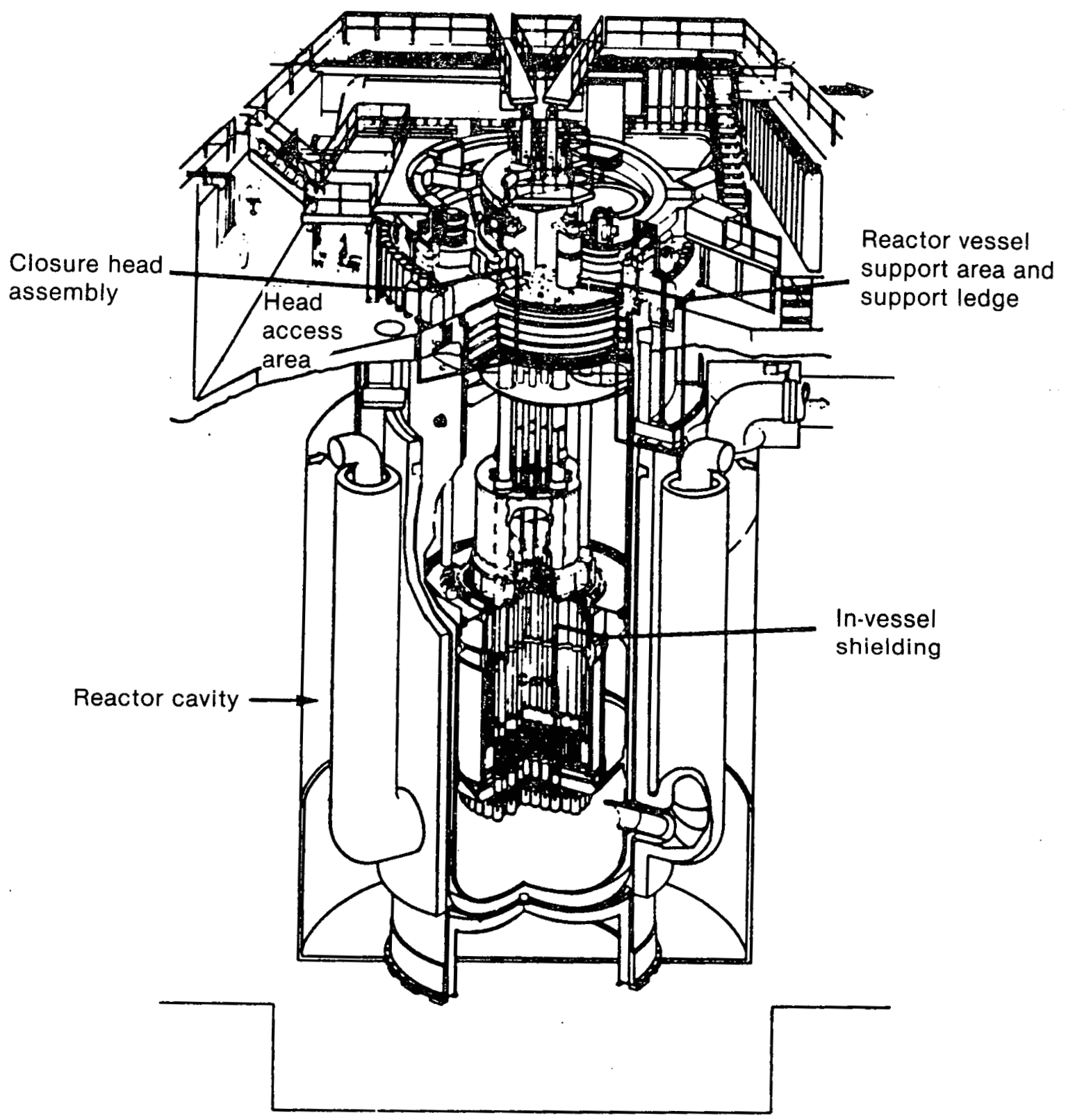

Figure A-20. Key shielding areas in CRBRP reactor and reactor enclosure system.

These seals form the barrier for the cover gas in the CHA rotating plug annuluses. CRBRP was designed to operate with $1 \%$ failed fuel. Radioactive fission product gases and the cover gas from this failed fuel requires about $0.3 \mathrm{~m}$ of steel shielding for personal access to the head access area. Dipseal tradeoff studies resulted in the location of the seals in the closure head, as shown in Figure A-21. Radiation through these dip seals is the largest contributor to the dose rate in the head access area.

In both FFTF and CRBRP designs, a canned $\mathrm{B}_{4} \mathrm{C}$ radiological shield is placed at the lower eleva- tion of the support ledge to stop thermal neutrons, and a carbon steel collar reduces the streaming gap at the vessel flange elevation. A concrete shield ring above the support ledge reduces radiation streaming into the head access area.

The source range flux monitor (SRFM), which monitors the core during shutdown and refueling, is located in the reactor cavity of the CRBRP. The neutron flux from the core that reaches the flux monitors must be great enough to allow monitoring of changes in core subcriticality, whereas neutron fluxes from extraneous sources and gamma dose 


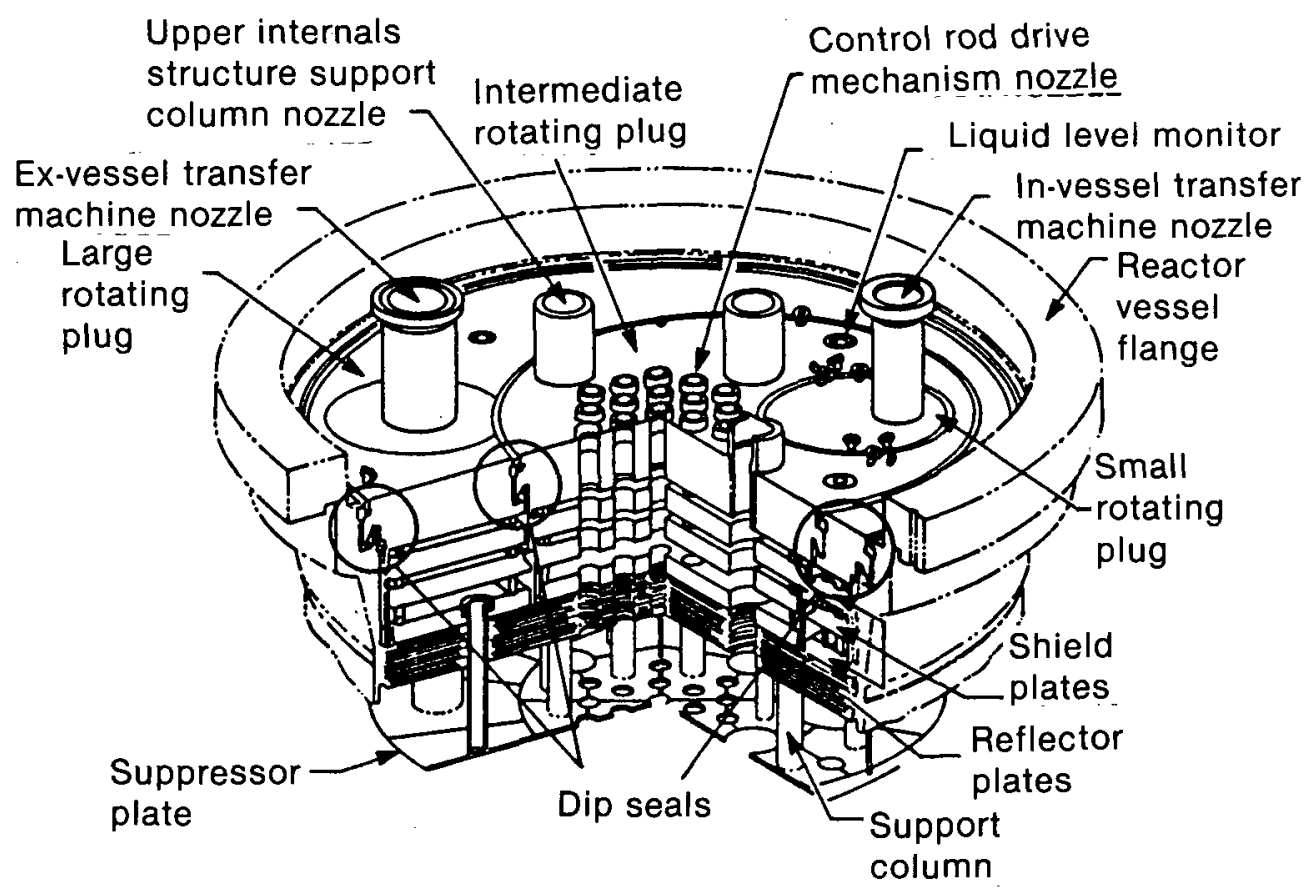

Figure A-21. Closure head assembly configuration of CRBRP.

rates must be sufficiently low. These objectives are accomplished by shielding at the SRFM. The shielding consists of a graphite moderator block, $0.51 \mathrm{~m}$ by $0.63 \mathrm{~m}$, surrounded by lead and $\mathrm{B}_{4} \mathrm{C}$ background shields. Neutron background, caused by fuel-in-transfer or fuel storage in the fuel transfer and storage assembly, is reduced by $\mathrm{B}_{4} \mathrm{C}$ shields in the reactor cavity. The gamma background at the SRFM is reduced to acceptable levels by surrounding the moderator block with lead to reduce gamma levels from the vessel, guard vessel, and sodium, and by using a high-purity aluminum alloy as the structural material for the SRFM to minimize its neutron activation gamma background.

Heat Transport System. The intermediate heat exchanger in the loop design system must be shielded from neutrons in order to prevent activation of the secondary sodium. In CRBRP, secondary sodium activation is held below $0.07 \mathrm{mCi} / \mathrm{kg}$. Ordinary concrete structural walls of the equipment cells provide the bulk shielding. Considerable design effort was required to reduce neutron streaming through the pipeways into the cells. Delayed neutron monitors for detecting fuel cladding failure were also placed in the CRBRP heat transport piping system; hence, the background neutron flux levels at these monitors must be minimized. A problem encountered in shielding design is the photoneutron production in the concrete cell walls. Photoneutrons are generated by the interac- tion of gamma rays from sodium-24 in the primary coolant pipes with deuterium in the concrete. In the CRPRP design, more than $80 \%$ of the neutron background at the delayed neutron monitors could be attributed to photoneutrons from the concrete. Nonhydrogeneous materials were specified for neutron background shielding around the monitors to minimize the neutron flux levels.

Instrumentation. All nuclear reactor sy'stems incorporate a high degree of instrumentation in order to provide continuous monitoring necessary for plant control. Much of the instrumentation, such as radiation monitoring, is common to all reactor types. The presence of a liquid metal, however, poses a few instrumentation challenges unique to LMFBR systems.

Core Parameter Monitoring. Variables such as flux, temperature, flow, and pressure must be determined in any nuclear reactor, but the sodium environment requires measurement techniques somewhat different from those of light water systems.

It was noted in the section on "Reactor Enclosure System Shielding" above that flux monitoring for a typical LMFBR system consists of a number of neutron detectors located in the reactor cavity external to the reactor vessel. In-core or in-vessel detectors may be used for initial start-up operation, but the neutron source from spontaneous fission of 
plutonium-240 is normally present and is strong enough to activate such remotely located detectors. An appreciable neutron source is also possible from americium-242, especially if recycled fuel is used.

Figure A-22 shows a flux monitoring set for the CRBRP design. The highly sensitive $\mathrm{BF}_{3}$ detectors are used for low-power operation, such as start-up and refueling. Uranium-235 fission chambers are employed for mid-range operations. And compensated ion chambers are used for power range measurements. Three sets, identical to that shown in Figure A-22, provide an overlapping range of flux monitoring to continuously record neutron flux from shutdown to more than full power. Electrical signals from these detectors, which are proportional to reactor power, are used for both reactor control and the plant protection system (PPS). Such signals also feed the data logging system and provide annunciator trips from the control room for out-of-limit conditions.

Sodium temperatures must be measured routinely throughout the primary and secondary circuits to calculate thermal power and determine loop operating conditions. Two types of detectors are in common use: resistant temperature detectors (RTDs) and thermocouples. The RTDs provide a highly accurate and reliable measurement to ensure that the plant is operating within design limits. The sensor for such a device typically consists of a double element of platinum contained within a sheet that is spring-loaded against the bottom of a thermowell, as illustrated in Figure A-23. Insertion of this sensor raises the possibility of a sodium leakage from the penetration in the event of thermowell failure. Whereas well failures in such devices appear to be rare, a backup cable penetration seal (as shown by the seal connection pad in Figure A-23) can prevent such leakage.

Coolant flow measurement must be made to complete the thermal power calculations and loop operating characteristics. Both the standard venturi flowmeter and a magnetic flowmeter are often used on liquid metal systems. The magnetic flowmeter is unique to liquid metal systems owing to the electric properties of the liquid metal coolant (see Figure A-24). The Venturi meter is highly accurate but suffers from a response time that is often too slow for control system and PPS use. The magnetic flowmeter, on the other hand, tends to be less accurate but exhibits rapid response. When the two are used in series, the Venturi meter can be used to achieve in-place calibration of the rapid-response magnetic flowmeter. It is possible to calibrate both types of meters by activating the sodium with a pulse neutron device and using a time-of-flight recording technique. The procedure was successfully employed in FFTF.

Another type of flowmeter made possible by the unique properties of the liquid metal is an eddy current flowmeter. Figure A-25 is a diagram of such a device used in measuring the rate of coolant discharge from an assembly into the upper sodium pool.

Liquid pressure measurements are normally made by routing a small column of the high-pressure liquid onto one side of a sensing diaphragm. This causes a complication when measuring sodium pressure because sodium solidifies well above room temperature. Trace heating could be provided to ensure liquid sodium conditions, but this has become unreliable for many applications. An alternative method often employed is to interface the sodium with $\mathrm{NaK}$ via a bellow system, as illustrated in Figure A-26. The $\mathrm{NaK}$ is a liquid at room temperature and can be used in a close tolerance pressure transducer assembly.

Fuel Failure Detection. The detection of a cladding breach in a fuel element can be normally accomplished by monitoring increased cover gas activity or by detecting the presence of delayed neutrons in the sodium leaving the reactor. Locating the fuel assembly containing the leaking fuel element is more difficult. Gas tagging offers one means for such identification.

A cover gas monitoring system normally exists to indicate the presence of fission products that escape the fuel pin. The most abundant fission products that escape are isotopes of the noble gases, xenon and krypton. Many of the fission products emit gamma rays with relatively low energy, around $100 \mathrm{KeV}$, and detection of such activity in a prevailing background of high energy neon-23 (440 KeV) and argon-41 (1300 KeV) gammas presents difficulties. The neon- 23 activity is considerably less in a pool type reactor, relative to a loop-type system, because of the larger holdup time, which allows the 38 s half-life neon- 23 to decay, and less turbulence in the pool level. However, numerous xenon isotopes emit relatively high energy gammas, and experience at EBR II and FFTF indicates detection of cladding failure for an LMFBR system is readily attainable. A-12,-13 


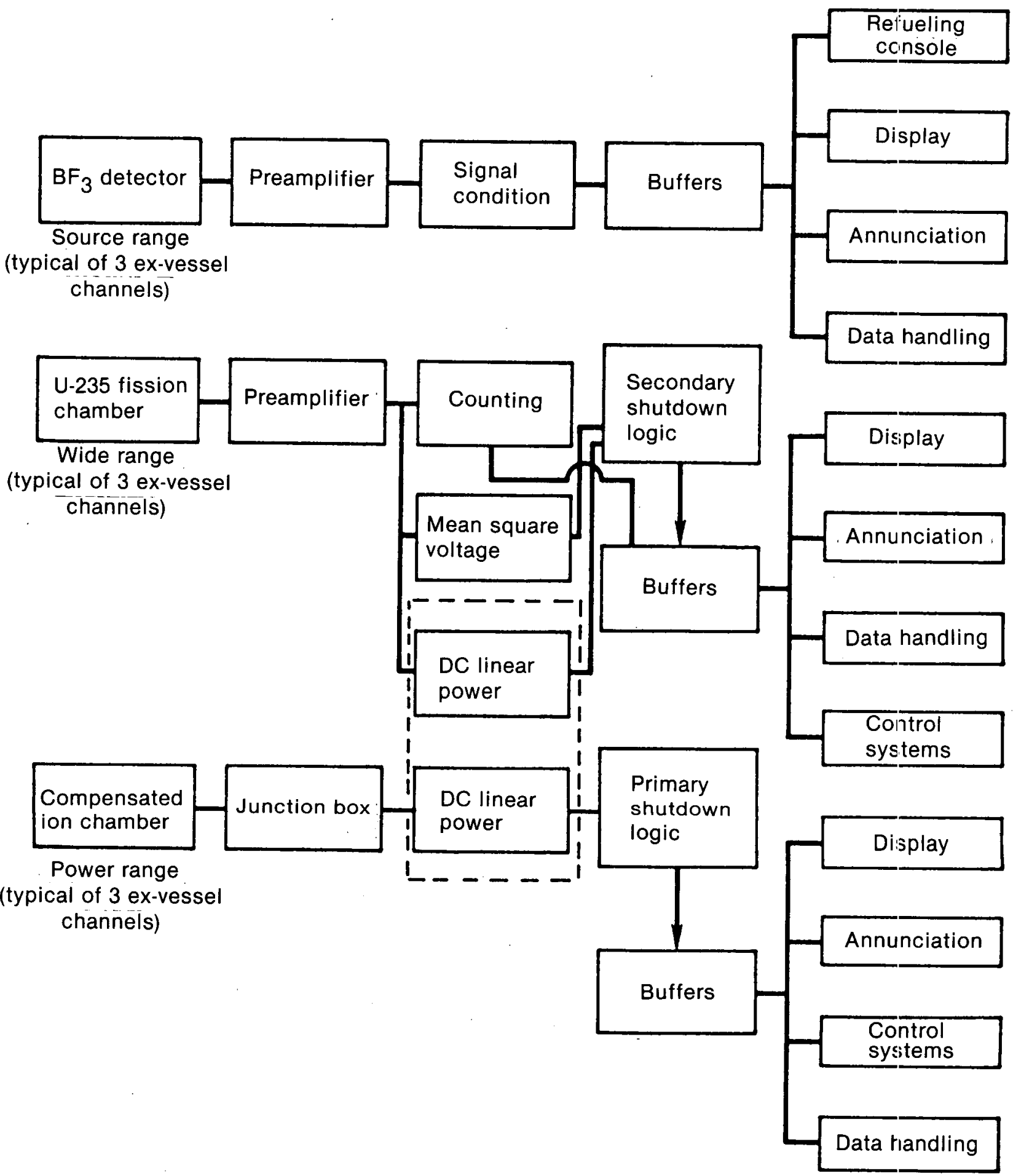

Figure A-22. Flux monitoring set for CRBRP design. 

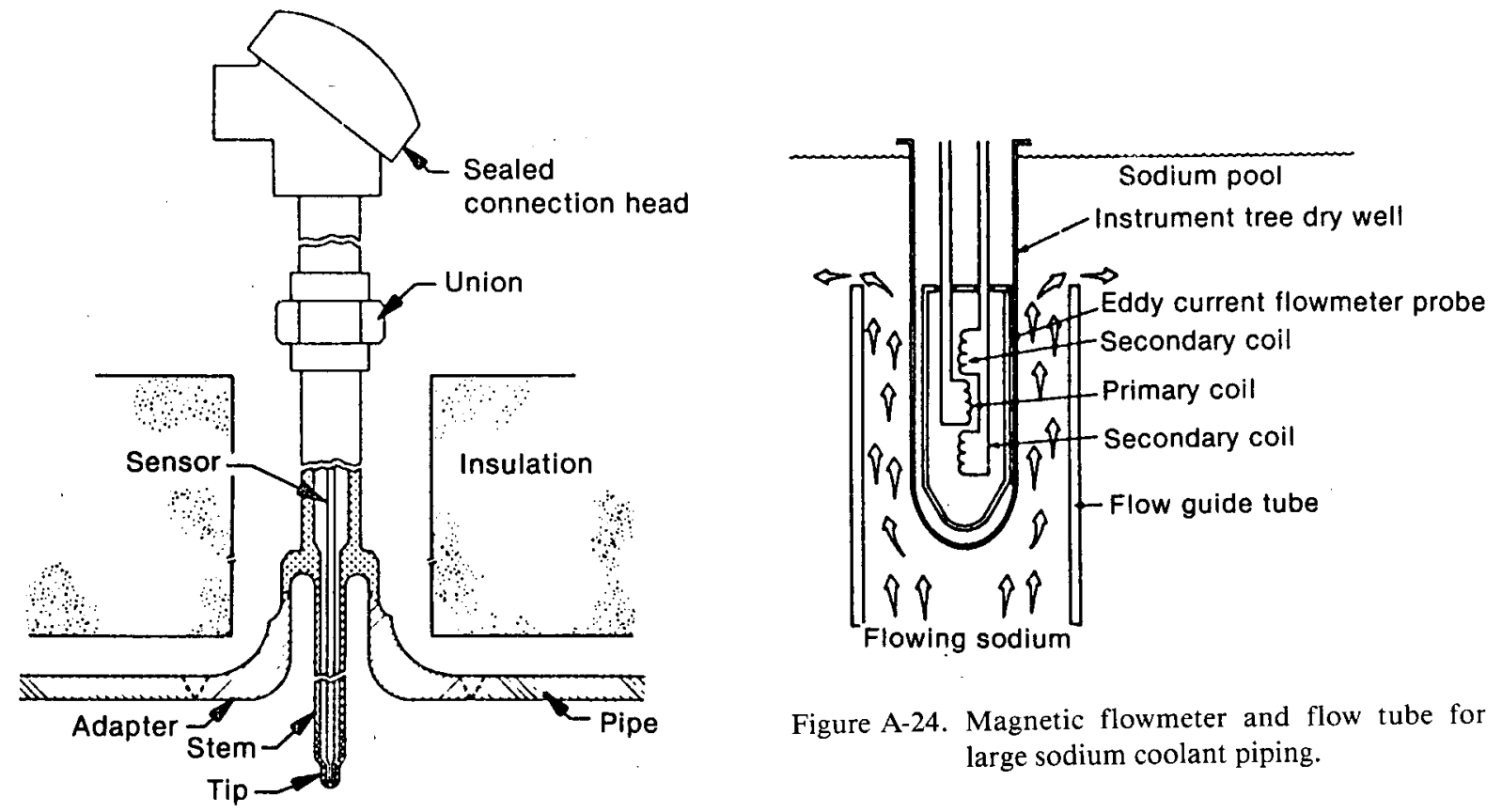

Figure A-24. Magnetic flowmeter and flow tube for large sodium coolant piping.

Figure A-23. A typical thermowell assembly incorporating a resistance temperature detector (RTD) for measuring sodium temperatures.

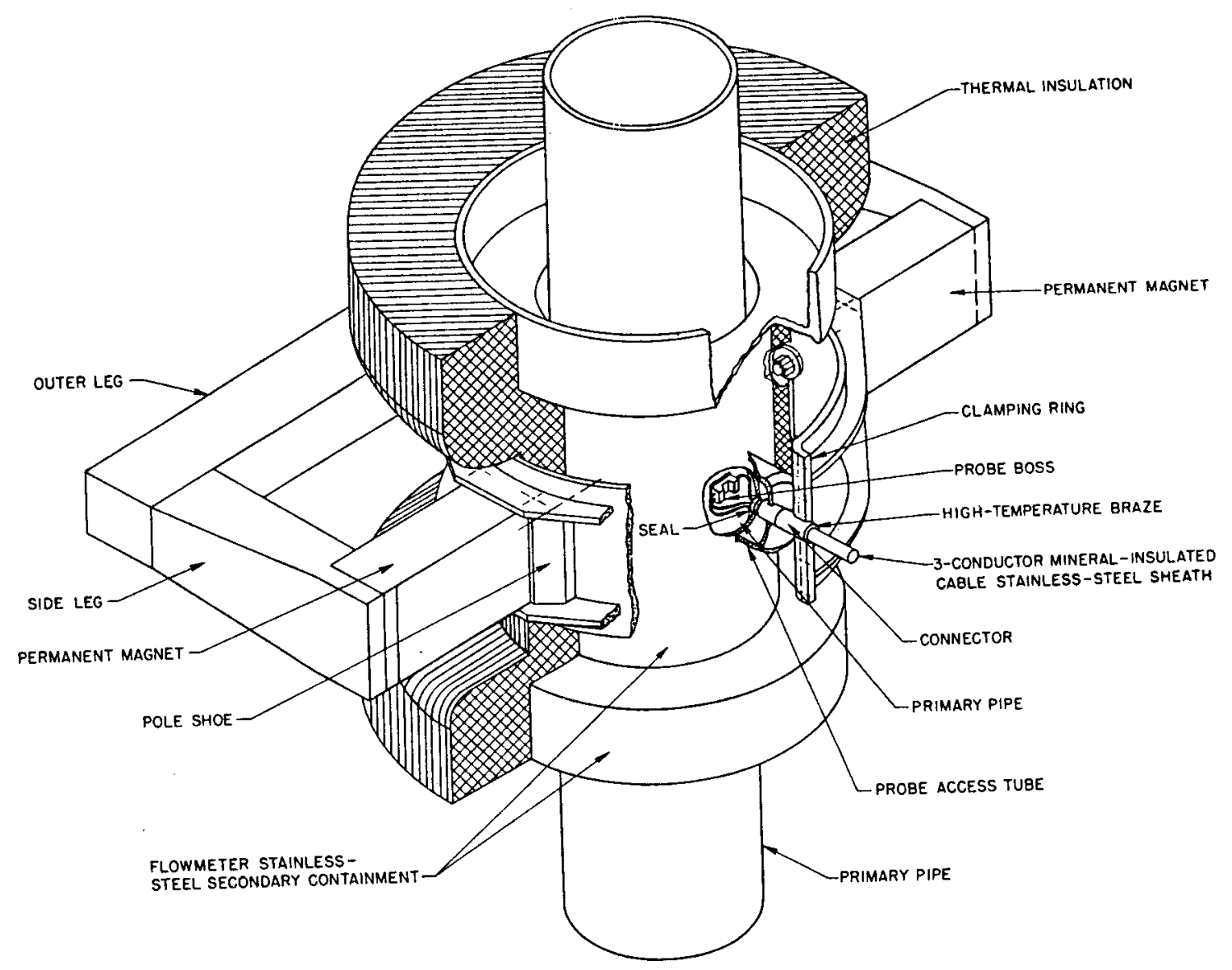

Figure A-25. Simplified diagram of eddy current flowmeter. 


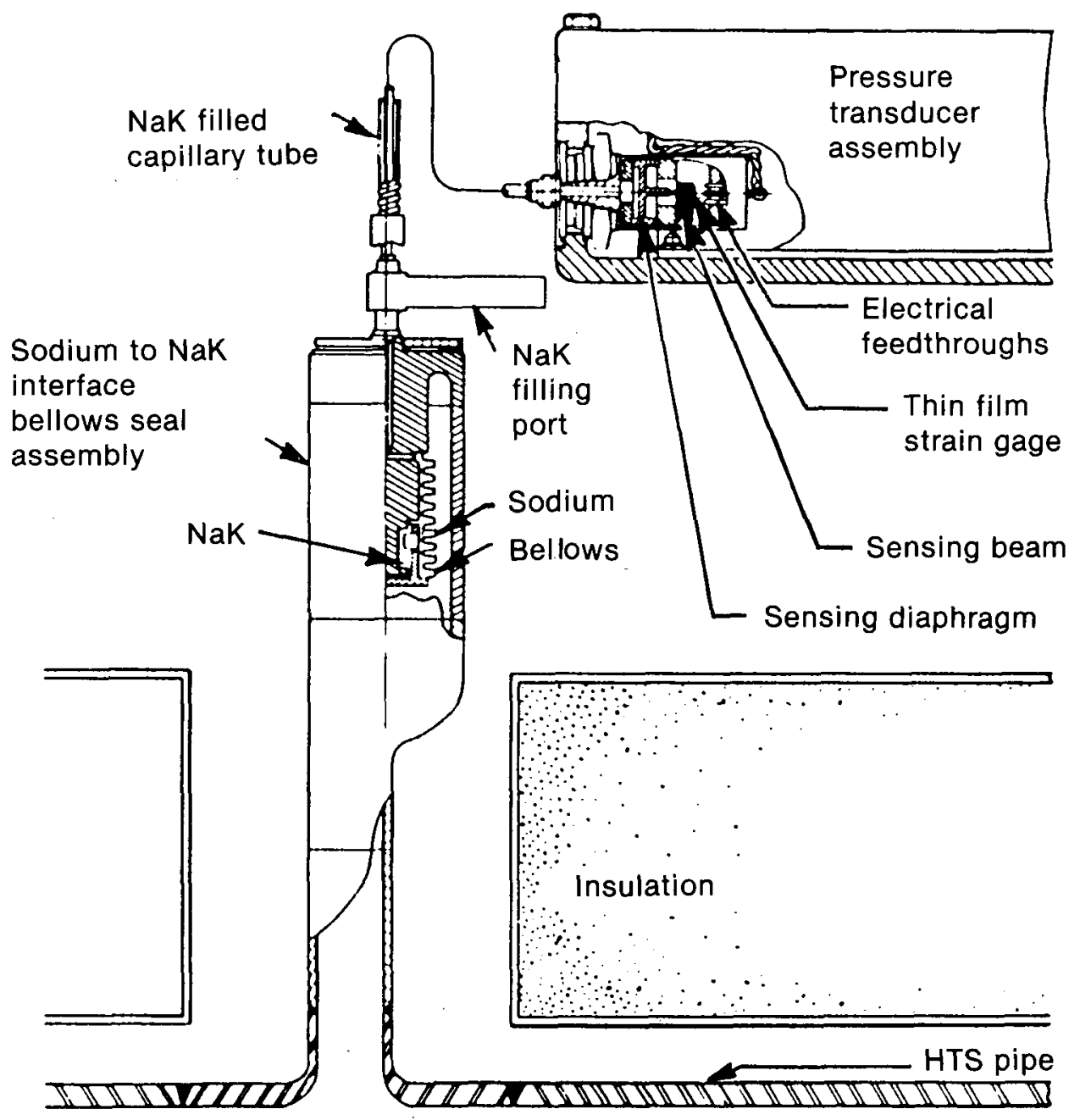

Figure A-26. Pressure sensor installation.

Germanium detectors, which are particularly sensitive to low level gamma detection, are often used in the cover gas system along with highresolution gamma spectrometers. Detection efficiency can be improved by concentrating the xenon and krypton isotopes in the cover gas, which is accomplished by passing the gas stream through a charcoal-packed column. The time for fuel failure detection by cover gas monitoring is a matter of minutes. Another system often used to discover cladding failure relies on detecting delayed neutrons that emanate from fission products circulating in the coolant stream. These neutron emissions are produced chiefly by two fission products, bromine- 87 (56 second half-life) and iodine-137 ( 25 second half-life). Both isotopes are soluble in sodium and enter the sodium via sodium contact on exposed fuel or by fission gas expulsion into the coolant. Delayed neutron detectors, usually consisting of $\mathrm{BF}_{3}$ chambers, typically are located near primary pumps. Overall detection time is obviously a function of primary loop sodium transport times, usually about a minute.

The cover gas monitoring system can be designed such that the fuel assembly containing failed fuel can be determined. Because a large breeder reactor may comprise on the order of $\mathbf{3 0 0}$ fuel assemblies, it is important to have such a technique available to identify the offending assembly.

One technique developed for this identification is gas tagging. Unique blends of stable xenon and krypton gas isotopes are injected into the fission gas plenum of each pin during final fabrication; all pins within the same fuel assembly have identical blends. A three-dimensional network of xenon-26/ xenon-129, krypton-78/krypton-80, and krypton$82 /$ krypton- 80 is used to yield over 100 uniclue gas tags for the fuel and absorber assemblies in the 
FFTF. A-14,-17 The failed assembly is identified by matching the results of the cover gas mass spectrometer analysis with previously determined analysis of all gas tags in the reactor, suitably corrected. for burnup and background (illustrated in Figure A-27).

Sodium Leaks and Level Measurement. The detection of sodium leaks is important for the following reasons:
- Sodium will burn in air

- The primary loop sodium is radioactive

- Loss of substantial amounts of sodium can impair cooling capacity.

The sodium level must be measured in all vessels containing sodium. One method to detect the presence of sodium exploits the electrical conductivity

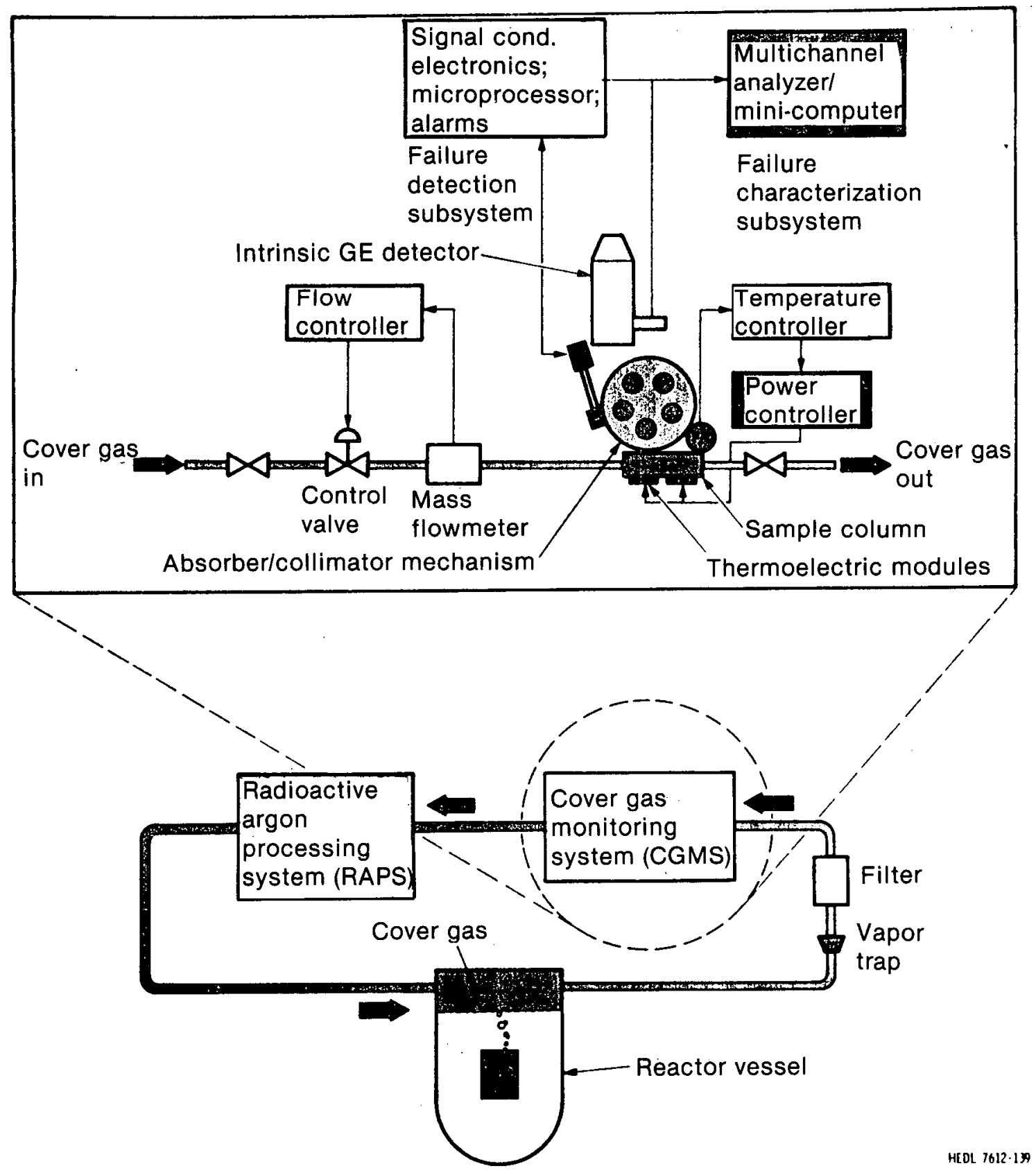

Figure A-27. FFTF cover gas monitoring system. 
properties of the liquid metal. Contact type sensors consist of two electrodes extended to gap at a location where leaking sodium may be expected to collect. The presence of sodium shorts out the electrode gap and allows a signal to be delivered to the control room. Such detectors are often placed under the reactor vessel and at any low point in the vicinity of piping systems that contain flowing sodium. The principal difficulties of such detectors are oxidation of the electrodes and lack of assurance that leaking sodium will actually reach the detector. The latter is a major concern in the case of small leaks. Another type of sodium leak detector checks for the presence of sodium aerosol. Atmospheric gas samples from the area in question can be analyzed by either ionization detection or filter examination. In the ionization technique, the gas stream is passed over a heated filament, which produces sodium ions. Collector electrodes will then induce an ion current if sodium is present. In the filter technique, a replaceable submicron filter is placed in the gas stream, and the filter is periodically removed and analyzed chemically for sodium deposits.

Induction level probes can be used to measure the liquid level of sodium, as illustrated in Figure A-28. The induction field established by the primary coil is modified by the electrical properties of the liquid coolant, thereby leading to a secondary signal that is directly proportional to the sodium level. Though useful for maintaining inventory records in all sodium repositories, this is especially important

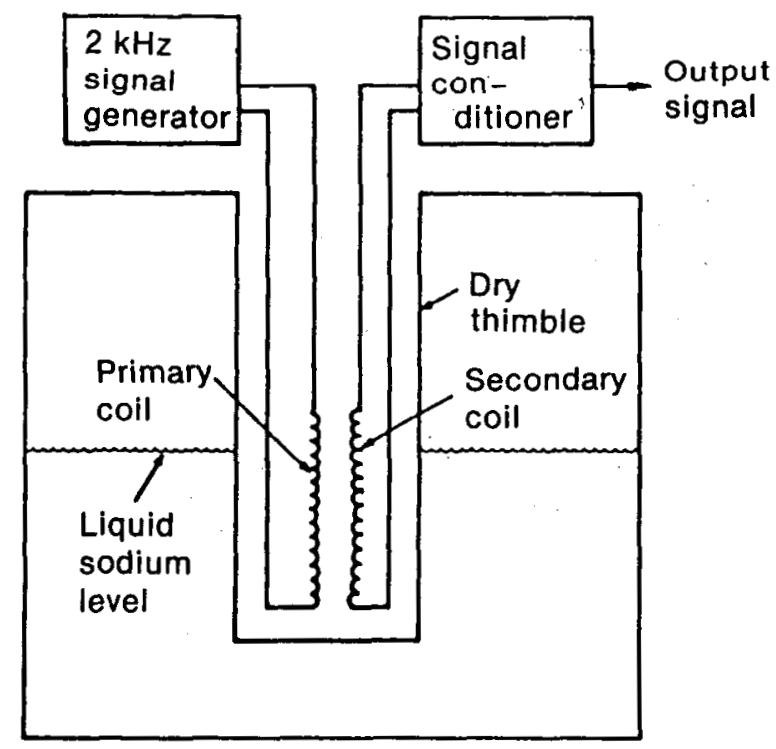

Figure A-28. Induction sodium level probe schematic. within the reactor vessel, where a funclamental safety concern is to guarantee coolant level well above the top of the core at ail times.

Auxiliary Systems. In addition to the major systems discussed above in this section, numerous auxiliary systems exist, which are necessary to support overall plant operation. Many of these are large systems, such as heating and ventilating, but they are not unique to the LMFBR except for the general desire to minimize the presence of water in the immediate vicinity of the sodium system. This section briefly describes auxiliary systems unique to a sodium-cooled plant.

There are numerous ways to categorize such auxiliary systems. The systems described here include (a) inert gas, which recognizes the need for an inert atmosphere surrounding a combustible coolant, (b) trace heating, which is necessary to keep sodium in the liquid phase for low core power levels, and (c) sodium purification.

Inert Gas. An inert cover gas is a requirement for any part of an LMFBR system where a free liquid sodium surface can exist. Prudent design al'so normally requires an inert atmosphere in any of the cells that house sodium piping systems. Whereas the word inert normally implies a noble gas, the essential characteristic of the atmosphere desired is that it be chemically inert to sodium. Nitrogen satisfies this requirement and is both abundant and relatively inexpensive. Hence, it has been almost universally employed as the inert atmosphere for equipment cells. Unfortunately, it cannot he used for high-temperature application $\left(>400^{\circ} \mathrm{C}\right)$ because of the nitriding problems in the steel enclosures. Consequently, argon has been selected as the cover gas within the vessel, the piping systems, and the refueling transfer chambers for all major LMFBR projects to date. Helium has also been used and is still being studied as a potential alternative.

The argon cover gas subsystem provides an inert atmosphere and pressure control for all liquid metal-gas interfaces. Chemical purification features include both sodium vapor and oil vapor traps. Compressors and storage facilities are necessary ingredients of this subsystem, as are pressure equalization lines to keep all cover gases at the same pressure. The purging system needs to have a high enough capacity to allow complete changes of atmosphere to accommodate maintenance operations. Because of the possibility of radioactive contamination, as discussed in the "Shielding" 
section, a key feature of the argon cover gas subsystem is the radioactive argon processing subsystem (RAPS), which removes krypton and xenon radioisotopes. A charcoal bed using a cryogenic still is an effective device to remove the krypton and xenon isotopes from the argon stream. Surge tanks are useful to allow short-lived isotopes in contaminated argon to decay.

A nitrogen subsystem is normally incorporated to control atmospheric pressure and purity in the inerted equipment cells. This is done by means of a feed-and-bleed system to regulate pressure, and by fresh nitrogen purging to minimize contamination, using measurements of the oxygen or water-vapor in the cells as a control signal. Nitrogen is also normally supplied for the sodium water reaction pressure relief system in the steam generator, for cleaning operations and for valve actuation in inerted cells.

A key feature employed to remove radioactive contaminants is the cell atmosphere processing subsystem (CAPS). It works on the same principal as the RAPS system, complete with cryogenic features, but usually has substantially larger capacity. One reason for the large capacity requirement is to allow pressurization of equipment cells through: " pressure testing of plant containment.

Trace Heating. Sodium melts at $98^{\circ} \mathrm{C}$; hence, it must be heated at low reactor power levels to remain in a liquid. Electrical trace heaters are normally used for such heating. A typical trace heating assembly, illustrated in Figure A-29, consists of a nickel-chromium resistant element insulated with magnesia, covered with a nickel-iron-chromium alloy heater sheet; and surrounded by a large thickness of thermal insulation. Such heaters provide a heat flux around 10 to $20 \mathrm{~kW}-\mathrm{m}^{2}$. For a large plant, the trace heating system may consume about $10 \mathrm{MW}$ during initial start-up under cold core conditions. The requirements for trace heating drop off appreciably when primary and secondary pumps are activated, from frictional heating of the pumping action.

Sodium Purification. The principal objective of the sodium purification is to maintain sodium

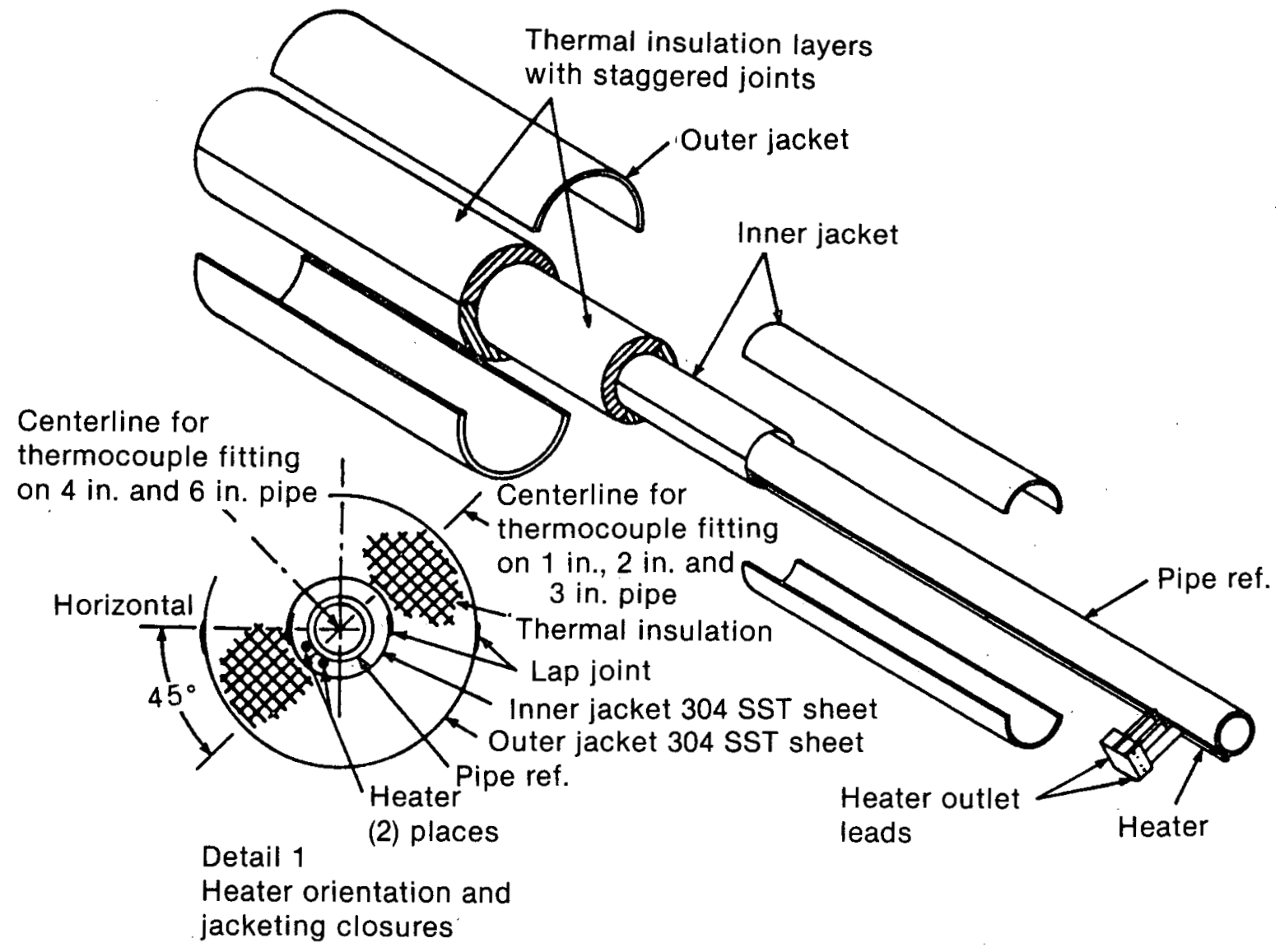

Figure A-29. Trace heating and insulation for 1- to 6-in. pipe. 
clean from chemical or radioactive particulate contaminants. Several trace elements from in-core structural materials dissolve into the flowing sodium coolant during normal operations. Table A-5 lists elements that a typical sodium purification system may be designed to monitor.

\section{Table A-5. Contaminants monitored by a typical sodium purification system}

\begin{tabular}{ll}
\hline Boron & Lithium \\
Carbon & Manganese \\
Cesium-134,137 & Molybdenum \\
Chlorine & Nickel \\
Chromium & Nitrogen \\
Cobalt & Oxygen \\
Iodine-131-135 & Plutonium \\
Iron & Tritium, uranium \\
\hline
\end{tabular}

The main component incorporated in such a system to remove impurities is the cold-trap. This device, connected to a by-pass line from the main sodium loop, removes impurities by crystallization or precipitation at a temperature of $\sim 150^{\circ} \mathrm{C}$, significantly below the main-stream sodium temperature. Figure A-30 illustrates a typical cold trap. Sodium oxide crystallizes on the packing, which is replaced when it begins to plug.

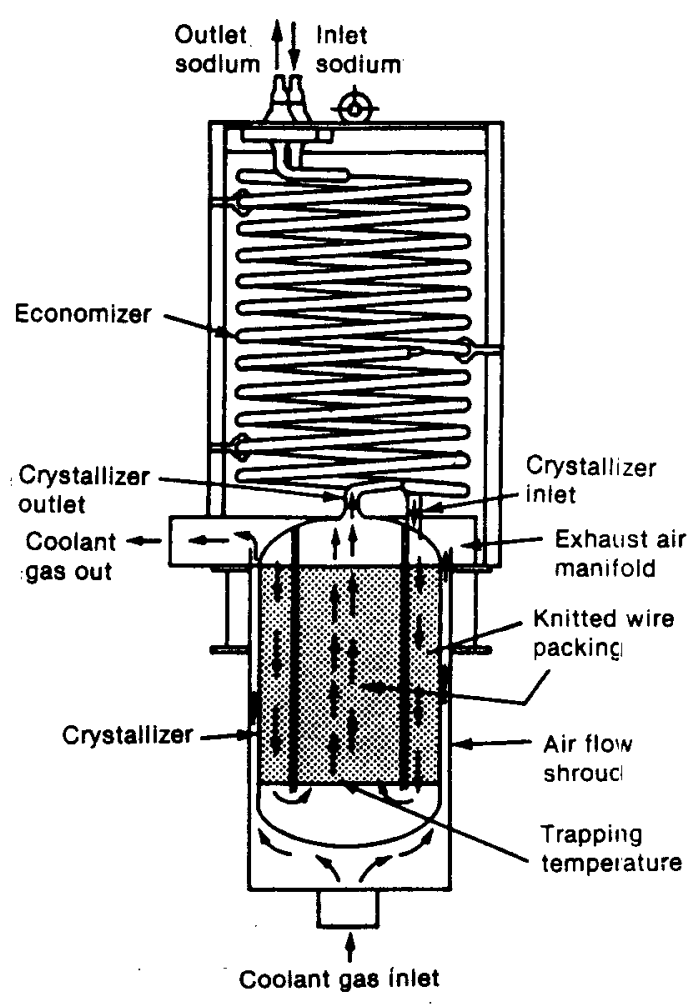

Figure A-30. A typical sodium cold trap.

An interesting feature of a cold trap shown is the economizer. Inlet sodium must be cooled prior to entering the crystallizer, but returning or pırified sodium must be reheated to nearly the bulk coolant temperature prior to returning to the main coolant system. Both functions can be performed by bringing the inlet sodium through a tube concentrically enclosed by an outer tube containing the counterflowing purified sodium. A much smaller auxiliary cooling and heating system is then required to allow satisfactory cold trap performance than would be the case without the economizer. 


\section{OPERATIONAL EXPERIENCE AT LMFBRS}

\section{Early Experimental LMFBRs.}

The first reactor to generate electricity was the U-235-fueled, fast Experimental Breeder Reactor 1 (EBR-1), which started operating in the United States in 1951 . This reactor, cooled by a molten sodium-potassium alloy, had an electrical output of 200 kilowatts. Most effort devoted to fast reactors since that time has continued on the liquid-metalcooled concept: Much of the development on LMFBRs was carried out with early experimental reactor plants in the United States (Clementine, EBR-1, Lampre, Sefor) and the Soviet Union (BR-1, BR-2, BR-5, BR-10). Table A-6 lists the characteristics of these early experimental reactors.

Clementine. Clementine, the first fast reactor and the first to use plutonium-239 as fuel, was developed at the Los Alamos Scientific Laboratory. Although it served primarily as a source of fast neutrons for experimental purposes, it also demonstrated the feasibility of plutonium as a fast reactor fuel. Operations began in November 1946 with a power of one watt. In March 1949, the power was increased to $25 \mathrm{~kW}_{\mathrm{t}}$. After several years of satisfactory operation, failure of at least one fuel element and resulting contamination of the mercury coolant led to the decision to dismantle the reactor. This was effected in 1953. Although the operating temperatures were too low for power production, the reactor was used for research and it did demonstrate the feasibility of plutonium as a fuel for fast power reactors. Sufficient plutonium for such a reactor existed solely at Los Alamos during this period. Figure A-31 is a cross-sectional view of the reactor, a rectangular block-like structure.

The $15-\mathrm{cm}$ diameter core contained 55 fuel and blanket elements. The fuel rods, of delta-phase plutonium, were $1.64 \mathrm{~cm}$ in diameter and $14 \mathrm{~cm}$ long, were clad with a type 1020 steel, $0.5 \mathrm{~m}$ thick, and assembled in a vertical lattice. ${ }^{A-1}$

Control of the reactor was effected by several components. A reflector, consisting of a large block of uranium immediately below the active region, could be raised into position and increase the reactivity, and could be quickly dropped out to reduce it. Two safety rods, located in positions immediately outside the central region, were composed of a section of uranium in a section of
$\mathrm{B}=10$ poison. For shutdown, in one motion the uranium section was dropped out and the B-10 section was inserted into the region. In addition, the reactor had two uranium rods that acted as control rods. ${ }^{A-9}$

The reactor was primarily a research facility, with $25 \mathrm{~kW}_{\mathrm{t}}$ at full power, so requirements for heat removal were quite modest. The mercury coolant was pumped by an eddy-current type of electromagnetic pump at a rate of $0.15 \mathrm{~L} / \mathrm{s}$ through the core and then through a mercury-to-water heat exchanger. In the two heat exchangers, mercury flowed through a helical core of 2.22-mm-ID steel tubing inside a solid water-cooled copper cylinder.

A $117-\mathrm{cm}$-long 15.8-cm-OD and 15.2-cm-ID mild-steel cylinder served as the core container, the fuel cage resting on the bottom of the cylinder. Immediately above the case, and filling the space to the top of the pot, or vessel, was a removable reflector and shield plug. The plug contained a number of layers of various materials, all in a steel cylinder of $0.64-\mathrm{cm}$ wall thickness (Figure A-31). A steel shield, consisting of a permanent assembly of laminations and concrete, also served as a supporting and retaining wall for the reactor parts.

In addition to the 35 plutonium fuel rods, the central active core contained 20 reflector rods of natural uranium, having the same dimensions and cladding as the fuel rods. A 15 -cm-thick reflector/ blanket of natural uranium surrounded the core. A 0.64-cm-thick aluminum jacket, containing a water-cooling tube, removed the heat generated in the uranium blanket. The core and blanket were surrounded by a $15.2-\mathrm{cm}$ steel reflector and a $10-\mathrm{cm}$ thickness of lead shielding. The top shielding was made of a series of blocks that could be removed to give access to the reactor. ${ }^{A-18}$ Since an important purpose of this reactor was to provide fast neutrons for experimental purposes, a number of holes were provided for radiation work. Four horizontal holes ran completely through the reactor. In addition, three reentrant horizontal holes and 10 vertical holes were provided.

Following attainment of criticality in November 1946 , the reactor was operated as a critical assembly; considerable information was obtained concerning the physics of fast reactors. During 
Table A-6. Early experimental LMFBRs

\begin{tabular}{|c|c|c|c|c|c|c|c|}
\hline \multicolumn{8}{|c|}{$\begin{array}{c}\text { Reactor } \\
\text { (Country) }\end{array}$} \\
\hline $\begin{array}{c}\text { CLEMENTINE } \\
(\text { USA) } \\
\end{array}$ & $\begin{array}{l}\text { EBR-1 } \\
\text { (USA) } \\
\end{array}$ & $\begin{array}{c}\text { BR-1 } \\
\text { (USSR) }\end{array}$ & $\begin{array}{c}\text { BR-2 } \\
\text { (USSR) }\end{array}$ & $\begin{array}{c}\text { BR-5 } \\
\text { (USSR) }\end{array}$ & $\begin{array}{c}\text { LAMPRE } \\
\text { (USA) }\end{array}$ & $\begin{array}{c}\text { SEFOR } \\
\text { (USA) }\end{array}$ & $\begin{array}{r}\text { BR-10 } \\
\text { (USSR) }\end{array}$ \\
\hline
\end{tabular}

General

$\begin{array}{llllllll}\text { Date critical } & 1946 & 1951 & 1955 & 1956 & 1958 & 1961 & 1969 \\ \text { Date full power } & 1949 & 1951 & - & - & 1959 & 1961 & 1971 \\ \text { Electrical power, MW } & - & 0.2 & - & - & - & - & - \\ \text { Thermal power, MW } & 0.025 & 1.2 & (30 \mathrm{~W}) & 0.1 & 5 & 1973 & -\end{array}$

Core parameters

Core volume, $\mathrm{L}$
Core height, m
Core diameter, $\mathrm{m}$
Core volume fractions
\%oFuel
$\%$ Sodium
$\%$ Other

Flux, $10^{15} \mathrm{n} / \mathrm{cm}^{2} \cdot \mathrm{s} \quad 0.004$

Power denisty, kW/L

$\Lambda, \mu \mathrm{s}$

$\beta$ eff

Doppler constant, $\mathrm{Td} / \mathrm{k} \cdot \mathrm{dT}-$

Fuel

Fuel type

Fuel pellet forms

$\mathrm{Pu}$

R

Reflector/blanket

Axial material

Radial material

Control

Material

No, assemblies

Reactor vessel

Height, m

Diameter, $m$

Thickness, m

1.2

0.2

0.002

Containment structures

Configuration

Materials

Primary heat transport

Coolant

Cover gas
.14

0.15

5.9
0.22

0.18

$\begin{array}{lll}- & - & 17.2 \\ - & - & 0.28 \\ 0.13 & - & 0.28\end{array}$

$-$

$48 \quad-\quad-\quad-52$

$15 * * \quad-\quad-\quad-\quad-34$

$37 \quad-\quad-\quad-14$

$\begin{array}{llll}0.11 & - & 0.1 & 1.0\end{array}$

1.0

170 - $\quad-\quad 500$

$0.04 \quad-\quad-\quad-$

$0.0068 \quad 0.002 \quad-\quad-$

$-$

$$
\text { - }
$$

USSR)

Enr. U Pu

$\mathrm{S} \quad \mathrm{R}$
${ }^{10} \mathrm{~B}+\mathrm{U}$

$4^{\mathrm{b}}$

$\bar{U}$

$\mathbf{U}$
$\mathbf{U}$

U

12
$\mathrm{U}$
$\mathbf{U}$

\section{U}

$\mathrm{Pu}$

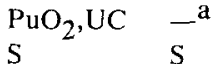

$\begin{array}{ll}\mathrm{UO}_{2}-\mathrm{PuO}_{2} & \mathrm{PuO}_{2} \\ - & \end{array}$

0.15

\section{3}

30

27

-

$-$

0.6

20

$-$

- 35

$-$

0.6

0.0032

$\begin{array}{lll}- & 0.0032 & - \\ - & 0.008 & -\end{array}$

一 


\begin{tabular}{|c|c|c|c|c|c|c|c|c|}
\hline & \multicolumn{8}{|c|}{$\begin{array}{c}\text { Reactor } \\
\text { (Country) }\end{array}$} \\
\hline & $\begin{array}{c}\text { CLEMENTINE } \\
\text { (USA) } \\
\end{array}$ & $\begin{array}{l}\text { EBR-1 } \\
\text { (USA) } \\
\end{array}$ & $\begin{array}{c}\text { BR-1 } \\
\text { (USSR) }\end{array}$ & $\begin{array}{c}\text { BR-2 } \\
\text { (USSR) } \\
\end{array}$ & $\begin{array}{c}\text { BR-5 } \\
\text { (USSR) } \\
\end{array}$ & $\begin{array}{l}\text { LAMPRE } \\
\text { (USA) }\end{array}$ & $\begin{array}{c}\text { SEFOR } \\
\text { (USA) }\end{array}$ & $\begin{array}{r}\text { BR-10 } \\
\text { (USSR) }\end{array}$ \\
\hline Type & Loop & Loop & - & - & Loop & Loop & Loop & Loop \\
\hline No. loops & 1 & 1 & - & - & 2 & 2 & $1^{\mathrm{e}}$ & 2 \\
\hline Pump type & E & $\mathrm{E}$ & - & - & $\mathrm{C}$ & $E$ & $\mathrm{E}$ & $\mathrm{E}$ \\
\hline Total flow, $\mathrm{kg} / \mathrm{s}$ & 2 & 36 & - & - & 60 & 7 & - & - \\
\hline Inlet core temp., ${ }^{\circ} \mathrm{C}$ & 38 & 230 & - & - & 430 & 450 & 370 & - \\
\hline Outlet core temp. ${ }^{\circ} \mathrm{C}$ & 121 & 322 & - & 60 & 500 & 560 & 430 & - \\
\hline Max fuel temp., ${ }^{\circ} \mathrm{C}$ & 135 & 477 & - & - & 1300 & 870 & - & - \\
\hline
\end{tabular}
a. Molten plutonium alloy.
b. Radial uranium reflector also used.
c. 2 Control rods +2 cylindrical reflectors.
d. 4 Control rods + annular reflector.
e. Auxiliary loop also used.

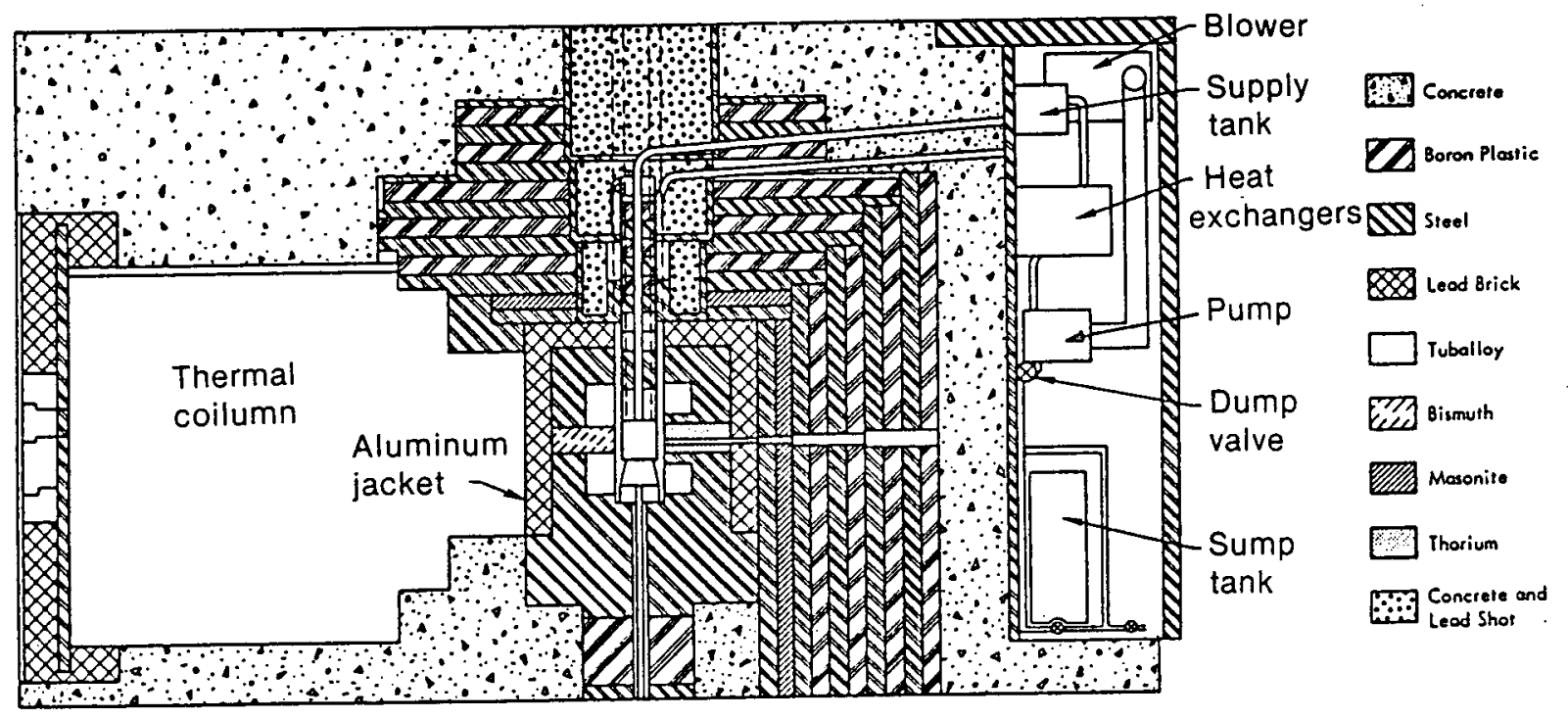

Figure A-31. Cross section to the CLEMENTINE reactor shield. 
low-power operation of the reactor from February 1947 to January 1949, measurements were made of the critical mass, effectiveness of reactor control, temperature coefficient, neutron spectrum, and general behavior. The information obtained was valuable in establishing the feasibility of fast reactor operations, including the demonstration of control by delayed neutrons. $\mathrm{A}-19$

From March 1949 to December 1952, when the rupture of a plutonium fuel rod was noted, the reactor was used for fast-neutron radiation research, as well as for a continuing program of reactor physics research. As a result of the fuel rod rupture, plutonium was released into the mercury coolant circuit, and since the primary objectives of the experiment had by then been achieved, the reactor was dismantled. A-20

EBR-1. The Argonne National Laboratory Experimental Breeder Reactor-1 (EBR-1) is located at the Idaho National Engineering Laboratory, Idaho. It was designed to demonstrate fast reactor breeding and to prove the use of liquid-metal coolants for power production. As a model, a power level of $1 \mathrm{MW}$ thermal was chosen. Electrical power generated about $200 \mathrm{~kW}(\mathrm{e})$. A-21

EBR-1 was based on concepts proposed in 1945 . The research and development program was approved early in 1945, and the Manhattan Engineer District approved construction in November 1945. Design and construction occupied the years from 1948 to 1951 . Criticality with the Mark-1 core was reached in August 1951, and electricity was generated on December 22, 1951. The Mark-II core was installed in 1954. A series of kinetic experiments led to its meltdown on November 20, 1955. A-22-26

The Mark-I and Mark-II cores were similar, with the exception of some changes in spacing ribs and composition, as described in References A-17 through A-31. The Mark-III core was designed primarily to investigate the stability of the fast reactor. The Mark-IV core, loaded in 1962, used plutonium as a fuel and provided a facility in which the general operating characteristics of a solid-plutonium fueled reactor could be investigated. A-31-36

Reactor Features. Design of EBR-1 was a pioneering effort; much of the present nuclear reactor technology had not yet developed. Figure A-32 is a drawing of the reactor installation. The Mark-I core had a power density of $170 \mathrm{~kW}_{\mathrm{t}} /$ liter, and an

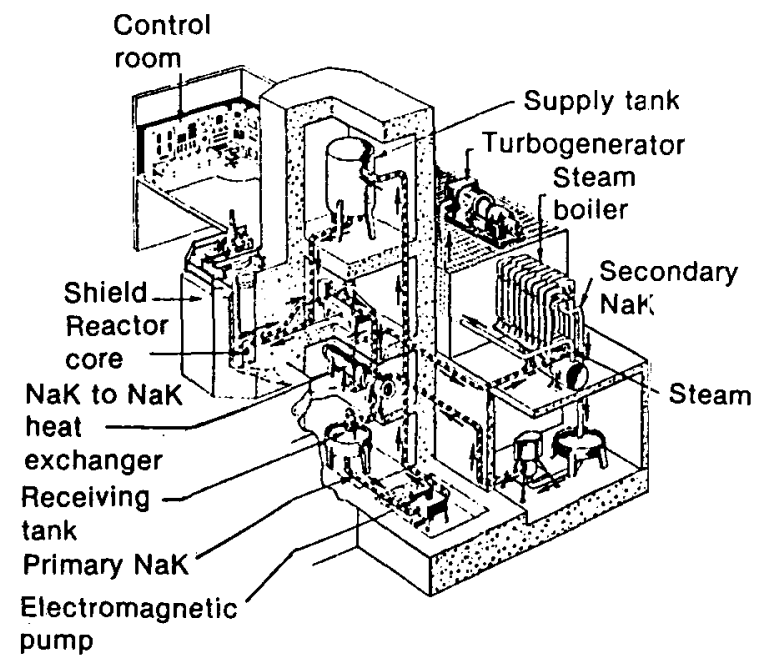

Figure A-32. EBR-I heat transport systern.

average heat flux of $690 \mathrm{~W} / \mathrm{m}^{2}$. Although these values have been exceeded in more recently designed fast reactors, EBR-1 may be considered the first high-power density reactor. Initial plans called for a conservative design that would permit operation at power levels greater than $1 \mathrm{MW}$, but heat generation in the outer blanket proved greater than anticipated, and limited operating power. A-24

Core Arrangement. Figures A-33 and A-34t show the Mark-II core arrangement. The inner fuel rods, 1.14-cm OD, were separated without spacer ribs by $1.7 \mathrm{~cm}$ (the Mark-I core used spacer ribs). Enriched fuel was used in the middle of each rod, and natural uranium was used at the top and bottom to form an axial blanket. An inner blanket consisted of natural-uranium slugs, $2.58 \mathrm{~cm}$ in diameter and $51.44 \mathrm{~cm}$ long, jacketed in $0.056-\mathrm{cm}$ thick stainless steel. The core itself and the inner blanket were cooled by circulating sodiumpotassium $(\mathrm{NaK})$ alloy.

An air-cooled outer blanket is located outside the reactor tank. It consists of 84 keystone-shaped natural-uranium bricks, each weighing $45.5 \mathrm{~kg}$, clad with stainless steel $0.051 \mathrm{~cm}$ thick. This section is movable and contains the control rods. Moving parts are kept outside the liquid metal. Air cooling of the blanket proved to be the limitation on the operating power available for the reactor. Surrounding the external blanket is a graphite reflector $48.3 \mathrm{~cm}$ thick, followed by $2.74 \mathrm{~m}$ of concrete shielding. Six experimental beam holes pierce the concrete shield and graphite reflector. A thermal column and "rabbit hole" also provide facilities for experiments. 


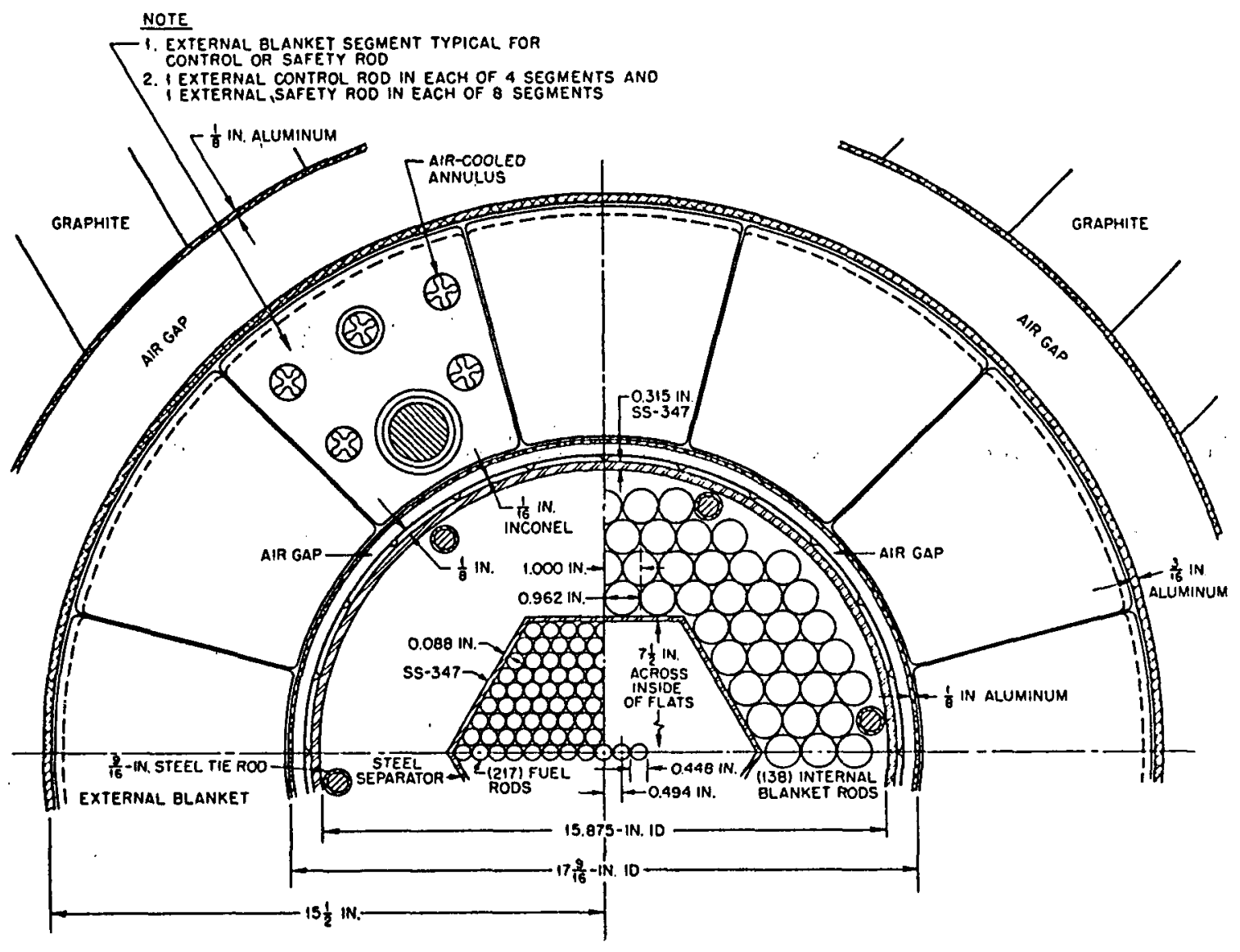

Figure A-33. EBR-I Horizontal cross section at midpoint of MARK-II core.

Fuel. Most of the rods for the Mark-I core were loaded with four 0.923 -cm-diameter slugs, each of which was $4.76 \mathrm{~cm}$ in length. Some of the rods, however, contained 6.35 -cm-long, 0.975-diameter slugs. Below the fuel section, an 11.4-cm-long natural-uranium slug served as a lower blanket, and above the fuel section a 20 -cm-long naturaluranium slug was loaded as the top blanket.

During operation of the first core, experiments showed that an alloy fuel composed of $2 \mathrm{wt} \% \mathrm{U}-\mathrm{Zr}$ was more resistant than beta-quenched uranium to irradiated growth and was free of the irradiationinduced surface-roughening characteristic of betaquenched uranium. Early in 1954, a Mark-II core was installed with a $2 \mathrm{wt} \% \mathrm{U}-\mathrm{Zr}$ alloy in both the fuel and blanket slugs. The fuel slugs were $10.8 \mathrm{~cm}$ long by $0.975 \mathrm{~cm}$ in diameter; with a lower blanket slug of $10.8 \mathrm{~cm}$ and an upper blanket $20 \mathrm{~cm}$ long. As in the Mark-I core, the annulus between the slug and fuel tube was filled with $\mathrm{NaK}$ as a heat-transfer bond.
Control and Instrumentation. There were 12 control rods, each $5.08 \mathrm{~cm}$ in diameter, made of natural uranium with a jacket of stainless steel. These moved vertically in the outer blanket brick. Eight of the control rods normally were used as safety rods. Their time of travel out of the blanket was short: 0.085 seconds to initiate motion, $0.29 \mathrm{sec}-$ onds to reach $40.6 \mathrm{~cm}$. The remaining four rods normally were used as regulating control rods and could be positioned with considerable accuracy. Their maximum speed was $1.63 \mathrm{~cm} / \mathrm{s}$. The entire outer blanket was mounted on a hydraulicallydriven elevator. The main platform of the elevator carried a shield section on which the outer blanket rested. Arrangement permited accurate location of the outer blanket around the reactor. For shutdown the reactor blanket, the fuel plug on which it rests, and the elevator could be dropped quickly.

For Mark-IV, about $45 \%$ of the safety circuits provided signals indicating abnormal operations, five provided signals indicating danger (designed to 


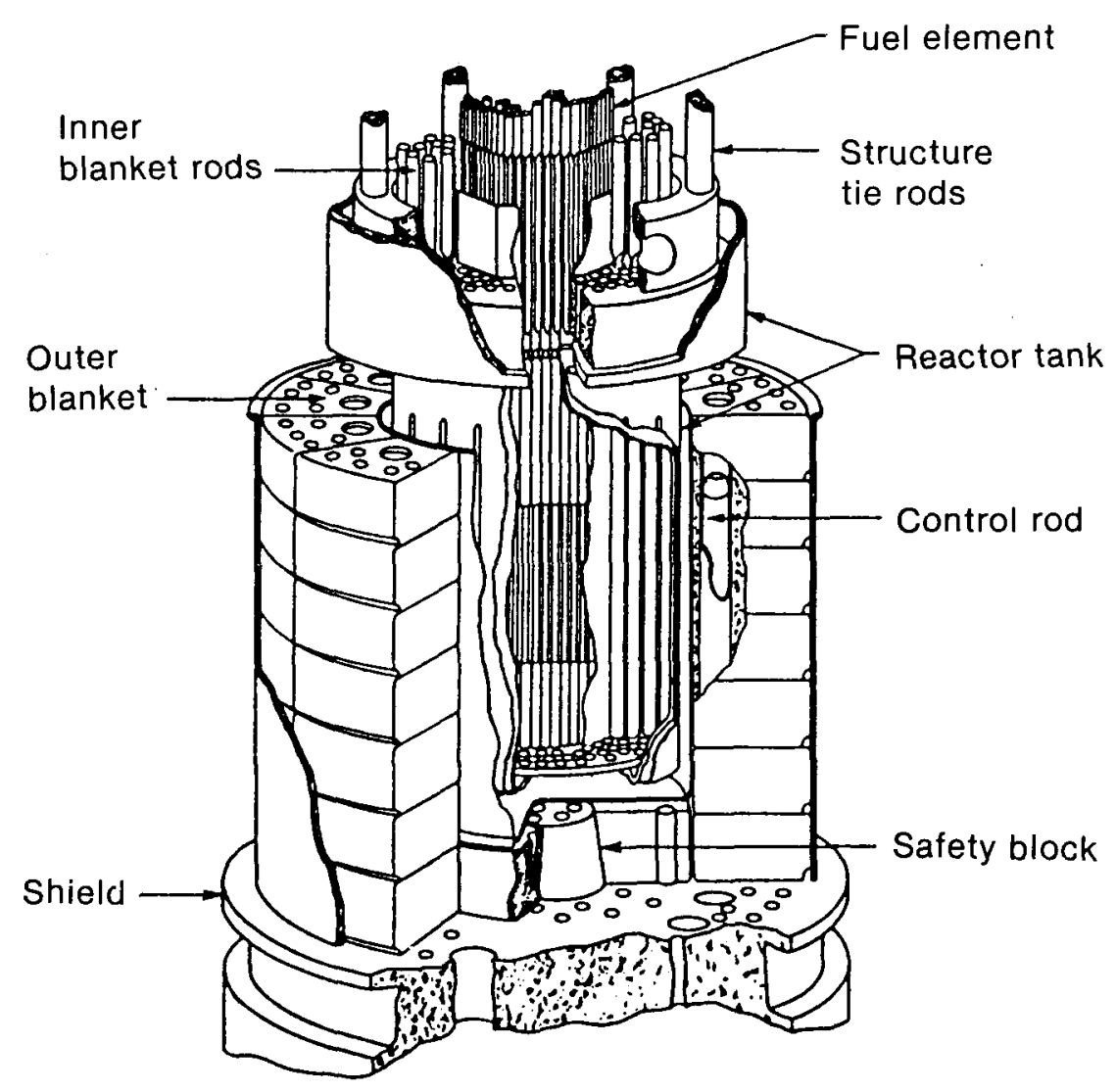

Figure A-34. EBR-I Mark-II reactor-cutaway view.

scram the reactor after 2 minutes without correction), and 16 scrammed the reactor immediately. The immediate scrams were designed to react when any one of the following parameters left its specified range: reactor period, fuel and blanket temperature, coolant flow rate, inlet and outlet coolant temperature, elevator hydraulic pressure, reactor neutron-flux level, or position of any of the four $\mathrm{NaK}$ valves. All safety circuits were duplicated to increase reliability. In addition, checklists were used periodically by the operators, and frequent detailed inspections of all equipment and safety devices were made. ${ }^{A-6}$

Operating controls contained a total reactivity worth of about $1.28 \%$. Safety rods and safety plugs could remove $0.24 \%$ reactivity in $0.38 \mathrm{~s}$, and the external blanket could remove $5.25 \%$ reactivity at an elevated speed of $66 \mathrm{~cm} / \mathrm{s}$. The above temperature coefficient for Mark I was $3.5 \times 10^{-5} \Delta \mathrm{k} /{ }^{\circ} \mathrm{C}$ from 38 to $200^{\circ} \mathrm{C}$. Filling with the coolant added reactivity approximately equal to that added by $2 \mathrm{~kg}$ of U-235. Loss of coolant reduced reactivity. Separate instrumentation was provided for startup, for safety, and for a steady operation, and all safety circuits were duplicated.
Heat Transport System. The primary NaK flow through the reactor, normally $18.4 \mathrm{~L} / \mathrm{s}$, was from an elevated constant-level tank, shown in Figure A-32. The flow proceeded down through the inner tilanket, up through the core, and out of the reactor. The coolant then flowed through the intermediate heat exchanger, returned to a receiving tank, and was then pumped continuously by an electromagnetic pump to the constant-head tank.

In EBR-1, the NaK-to-NaK intermediate heat exchangers were shell and tube design, with primary flow passing through the tubes. The steam generator was divided into an economizer, a boiler, and a superheater. NaK passage through these units was countercurrent to the flow of water and steam. Heat transfer tubes in each component were similar and consisted of a composite assembly of inner nickel, intermediate copper, and outer nickel tubes. The tubes were assembled by a mechanical drawing process, together with a thermal diffusion bonding process, which resulted in good heat transfer between the tubes. Total wall thickness of the tubes was $0.794 \mathrm{~cm}$, of which $0.476 \mathrm{~cm}$ was nickel. An outer stainless steel tube made up the shell of the heat exchanger, and a bellows was used to allow for 
differential thermal expansion. Thus, each heat exchanger was a single-tube-in-a-shell type, for $\mathrm{NaK}$ flow was on the shell side, and water or steam was in the tube.

A forced-air circulation falling-film boiler was used to limit the quantity of water in the system and to increase the heat-transfer rate. Heat exchangers were vertical. A baffle was used to establish a water film at the upper end of the internal tube on its inner surface. The film ran to the bottom where excess water and generated steam were piped into a drum. Steam was led through a separator in the drum out to the superheater, which consisted of horizontal heat exchangers with $\mathrm{NaK}$ in the shell side. The economizer was horizontal and served to heat the feedwater from the deaerating tank to steam temperatures before injection into the boiler drum.

Reactor Vesseland Shielding. The reactor vessel, or tank, was double-walled and extended through the reactor shield. The section of the reactor vessel surrounding the reactor core had an inside diameter of $90.3 \mathrm{~cm}$ and a length of $71.1 \mathrm{~cm}$. Above this small section, the vessel increased in diameter and was filled with shielding material; mostly steel. The whole reactor vessel rested on the shoulder formed by the change in diameter; thus, the reactor core itself projected below the point of support as a smooth cylinder.

The small diameter part of the reactor tank consisted of a stainless-steel vessel with a $0.794-\mathrm{cm}$ thick wall, made by deep drawing. It was surrounded by a second tank made of Inconel, $0.16 \mathrm{~cm}$ thick, which fit snugly on the ribs formed in the Inconel. The upper portion of the reactor vessel also was double-walled. The gas space between the two walls provided some thermal insulation and provided a method for testing vessel integrity. In the event that the inner vessel should develop a leak, the outer vessel would prevent complete loss of sodium.

A 46.7-cm-thick 89-cm-high section of graphite surrounded the outer blanket in the radial direction. Its cooling-air gap is shown in Figure A-33. This graphite layer; in addition to serving as a moderator for fast neutrons for shielding purposes, acted as a reflector to improve the breeding in the outer blanket. Although ordinary concrete was the basic shielding material, a $10.2-\mathrm{cm}$ layer of iron was provided between the graphite and the $2.59-\mathrm{m}$ thick concrete cylinder; this served as a thermal shield by absorbing gamma rays. In the axial direction above the core, layers of steel and $\mathrm{NaK}$ were followed by a $33-\mathrm{cm}$-thick steel plate, a $5.7-\mathrm{cm}$ plate, a $61-\mathrm{cm}$ thickness of concrete, and finally, $20.3-\mathrm{cm}$ thickness of laminated masonite and iron. The bottom shield consisted of a 1.52-m-thick layer of ordinary concrete. Since the elevator room was the only area below the reactor, and since it was a limited access area, the bottom shield design was not considered critical. Additional details of the EBR-1 shield system are given in Reference 19.

At the time EBR-1 was designed, much shield design theory had not been developed. One of the purposes of the reactor was to improve the concept of fast reactor physics and permit experimental measurements of neutron source distribution and other parameters. Flexibility was incorporated in the design to permit addition of more shield thickness if necessary. Since the EBR-1 was of modest power and was located in an unpopulated area, a containment type building was not used.

Operating Experience. When the Mark I reactor was started up in 1951, radiation levels around the reactor were found higher than anticipated. An additional $76.2 \mathrm{~cm}$ of concrete shielding was installed, and operation was resumed. In June 1952, a NaK leak was discovered in the primary heat exchanger, and the reactor was shut down for repair. During the shutdown, 16 fuel elements were removed for examination and were replaced by new elements. More than $1500 \mathrm{MW}_{\mathrm{t}}$ hours of operation had been accumulated by April 15, 1953.

During the four-year period, EBR-1 gave essentially trouble-free operation. Operation of EBR-1 demonstrated, among other things, that breeding was technically achievable with a measured conversion ratio of $1.01 \pm 0.05$, that the use of liquid metal coolant (sodium-potassium alloy) was compatible with breeding economy, and that the system was metallurgically and mechanically feasible. Breeding, based on U-235 fuel, was demonstrated in the first cores. Breeding in a plutonium cycle was demonstrated with operation of the Mark-IV core. ${ }^{37}$ The EBR-1 operation and theoretical determinations also showed that neutron behavior below prompt critical is the same in both fast and thermal reactors.

Under normal operating conditions, the reactor was very stable and did not exhibit a prompt, positive temperature coefficient or a resonance. Under 
purposely imposed and drastically abnormal operating conditions, anomalies were observed: resonance consisting of oscillations in power levels appeared during experiments in which the coolant flow rate was drastically reduced; a prompt positive temperature coefficient appeared during startups undertaken with reduced coolant flow. But even under conditions where the net positive coefficient appeared, the reactor could be operated safely. Oscillator tests successfully demonstrated the presence of instability.

In November 1955, the Mark-II core of EBR-1 partially melted during the last of a series of experiments designed to study its behavior when put on positive power periods with reduced or zero coolant flow. The accident occurred under extremely abnormal operating conditions, purposely imposed on the reactor for the experiment, and recognized to involve a risk of fuel melting. Two of the normally operative safety mechanisms, the flow interlock (which automatically shuts down the reactor if substantially full coolant flow is not maintained) and the period scram meter interlock (which automatically shuts down the reactor if the period becomes too short), were purposely disconnected. Coolant flow was stopped completely. A certain fixed amount of reactivity was put into the reactor with the control rod, and the reactor was started up on a short enough period so that a severe temperature differential would be established in the fuel slugs. The prompt positive temperature coefficient previously observed appeared, and, as the power increased, the reactivity increased, thus further shortening the period. It was planned to scram the reactor when the period reached $0.27 \mathrm{~s}$ and the temperature of the fuel $500^{\circ} \mathrm{C}$. When the period reached 1 second, the operator mistakenly activated the slow-acting motor-driven control rods instead of the faster-acting scram rods. By the time the scram was initiated, the period had reached 0.3 seconds. The temperature overshot, so that the uranium became heated above $720^{\circ} \mathrm{C}$, roughly the temperature in which the uranium-iron eutectic formed. The center of the core melted, forming the eutectic. After the manually operated scram button was pressed (in less than $2 \mathrm{~s}$ ), the reactor shut down and the meltdown stopped. The automatic powerlimiting circuits also operated.

As a result of the accident, melting occurred in 40 to $50 \%$ of the EBR-1 core. No explosive force developed. None of the remainder of the reactor, including the inner blanket and the reactor vessel, was damaged. And neither the operating personnel nor any other person was injured in any way. A negligible amount of radioactive material reached the atmosphere through temporary thermocouple wire seals. Evacuation steps were precautionary. Operating perscinnel returned to the reactor building after a minor amount of surface contamination was removed. The core assembly was removed from the reactor by use of a temporary hot cell and shipped to Argonne National Laboratory for examination and disassembly. Observations during disassembly and subsequent simulated meltdown experiments indicate that the porous structure formed in the core could have resulted from the vaporization entrained $\mathrm{NaK}$. A-38

Mark-II/ Program. After the Mark-II incident, a new core was designed to further study the previously observed instabilities, with the belief that they could be eliminated by changes in the mechanical design. Other objectives included an investigation of channel transient characteristics, such as measurement of transfer functions, reactivity feedback effects, and development of mathematical models to describe the observed results.

Figure A-35 shows a typical fuel rod used on the Mark-III core. Cladding consisted of $0.051-\mathrm{cm}$ of zircaloy metallurgically bonded to the fuel by a coextrusion process, rather than by the arrangement used for Mark-I and Mark-II where NaK served as a heat transfer bond between thi loose fitting slugs and the stainless steel can. On each rod, three $0.117-\mathrm{cm}$ wires were spot welded to the fuel cladding at $0.64-\mathrm{cm}$ intervals, which served to stabilize the rod. At full loading the core contained 252 rods, or $60 \mathrm{~kg}$ of enriched uranium. The central core section of each rod consisted of three slugs welded end-to-end; in the lower and upper blanket section, each rod consisted of a single slug of $2 \mathrm{wt} \% \mathrm{U}-\mathrm{Zr}$ alloy, $9.05 \mathrm{~cm}$ long and $19.7 \mathrm{~cm}$ long, respectively. A triangular tip at the bottom of each rod was provided to simplify insertion in the lower tube sheet during the loading operation. Elanket rods were of identical design, consisting of a single 48.7-cm-long section natural-uranium zirconium alloy.

Fuel rods subassemblies, shown in Figure A-36, contained 37 individual rods supported in a grid at the bottom of each subassembly. A nozzle admitted the NaK to it. One central position was occupied by an expandable tightening rod that forced the rods outward against the hex wall and limited radial movement of the fuel rods. Seven fuel assemblies composed the core assembly, as shown in 


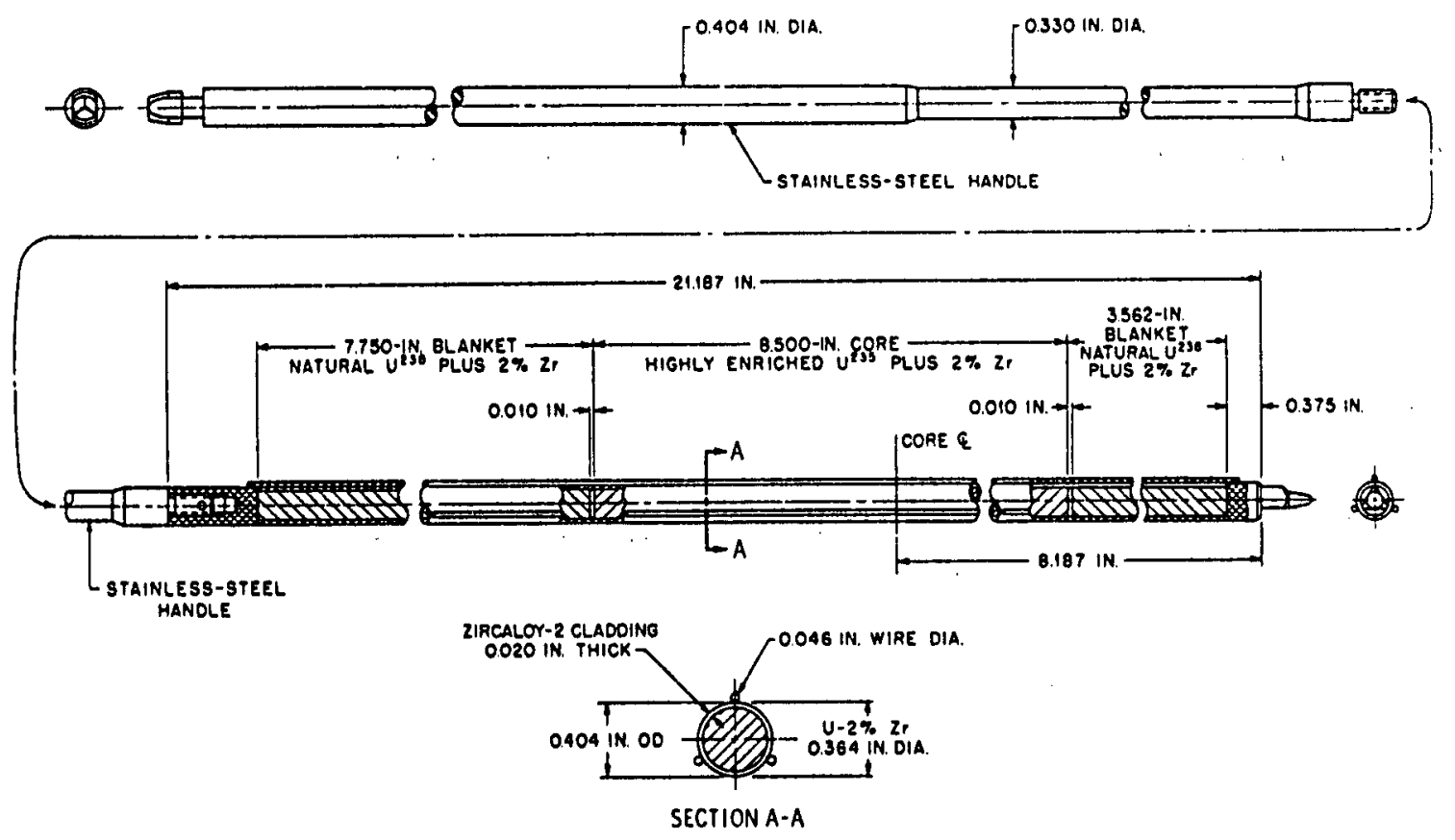

Figure A-35. EBR-I Mark-III fuel rod.

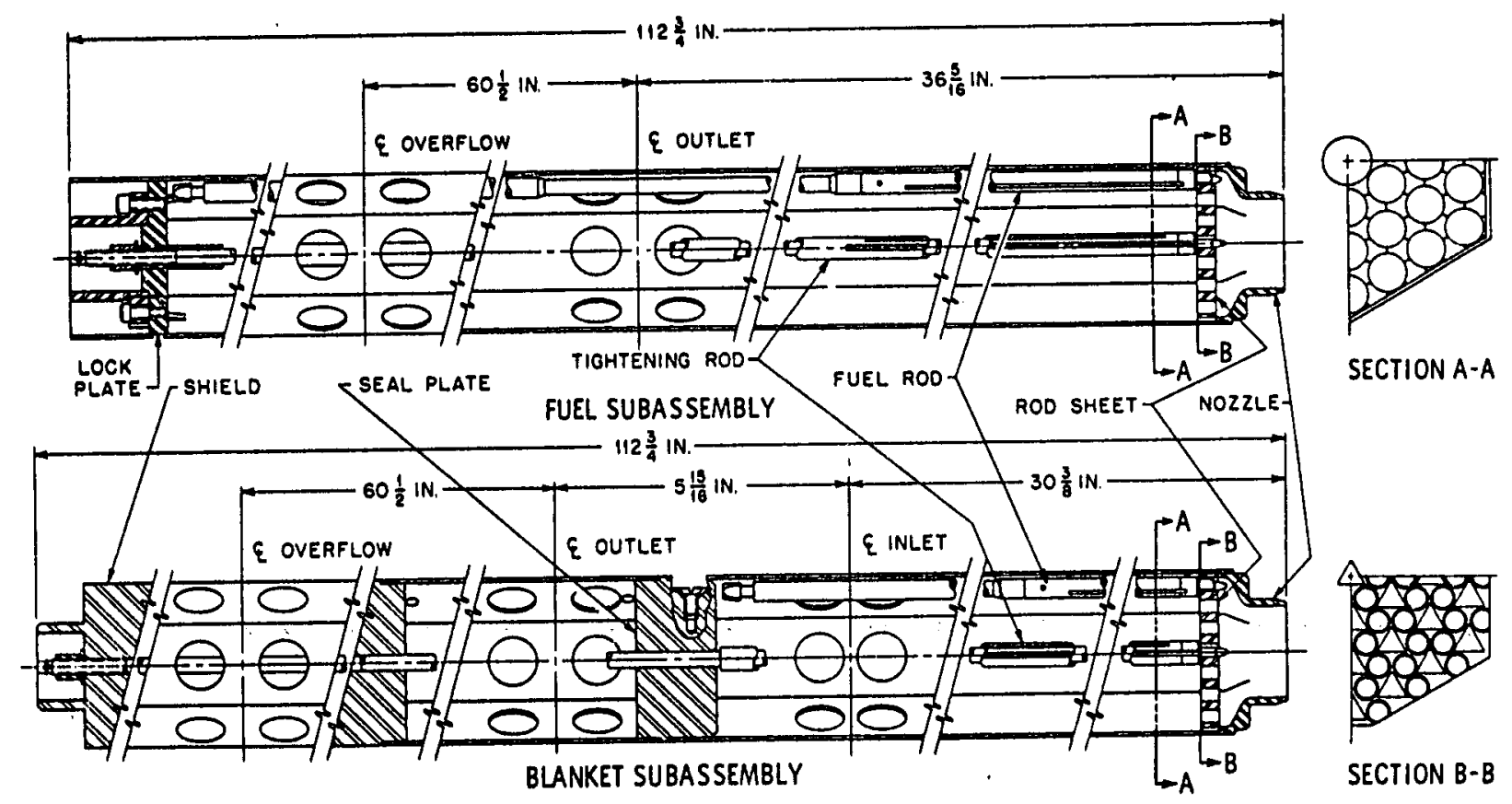

Figure A-36. EBR-I Mark-III fuel and blanket assemblies. 


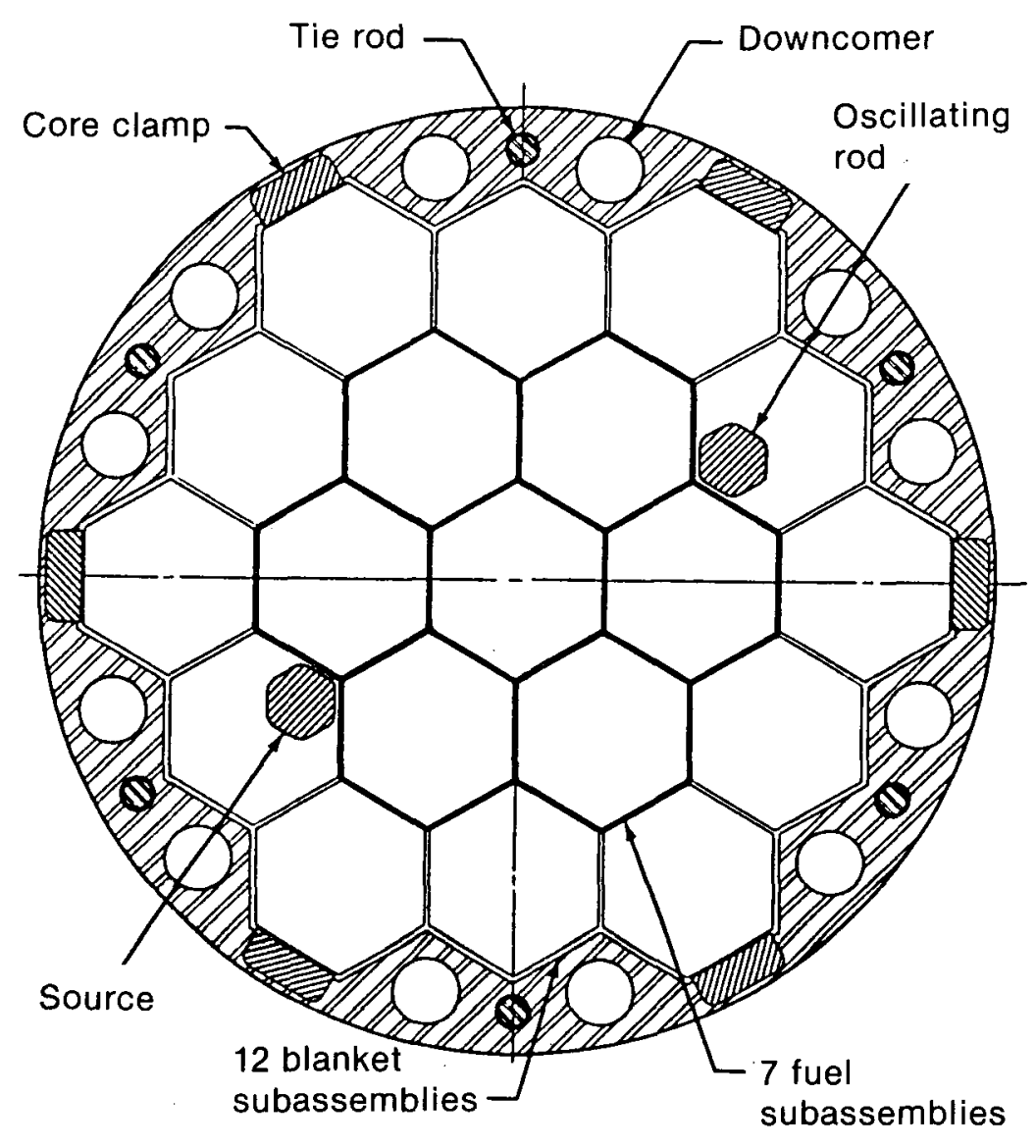

Figure A-37. EBR-I Mark-III core cross section.

Figure A-37. Blanket subassemblies, each containing 37 rods, had a different design for coolant flow. Twelve of the blanket subassemblies surrounded the core. Double-wedge clamps were located on each of the six flaps at the outer periphery of the assemblies at the core center line, and served to force the outer assemblies inward against the center assembly. A second set of six shoe-type clamps mounted along the inner edge of the seal plate limited the by-pass leakage rate and served to lock fuel and blanket assemblies into a rigid array. Also shown in Figure A-37 are the twelve downcomers through which the coolant passed in parallel flow. The six tie-rods held rigid the lower structure, the antimony-beryllium source, and the oscillator rod and thimble.

Figure A-38 is a cutaway view of the inner tank assembly. A tube sheet at the bottom of the structure received, supported, and located the nozzles of the rod assemblies. A seal plate above the outlet plenum restricted by-pass leakage occurring between the tank and the outer edge of the seal plate. Restriction was accomplished by a system of two expandable Inconel seal rings. Seal plate shoes located between the inner edge of the seal plate and the blanket assemblies restricted the leakage.

The coolant, in series flow, entered the annular inlet plenum located immediately below the seal plate and flowed into the outer ring of the twelve blanket assemblies. At the bottom of the blanket assemblies, the flow was reversed 180 degrees, directed up three to seven fuel assemblies, through the outlet holes at the top, and then radially out through the perforated portion of the blanket assemblies into the outlet plenum. The coolant, in parallel flow, flowed into a lower annular plenum located immediately above the mounting plate. Here the coolant was distributed to the twelve downcomers through which it flowed to the lower plenum. Upward flow through fuel and blanket assemblies was partitioned by a series of throttle valves. The actual flow through the core, both in series and parallel, was less than the flow inclicated through the metering of a primary inlet. Of a nominal metered flow of $18.3 \mathrm{~L} / \mathrm{s}$, approximately $16 \%$ was bypassed as leakage and for seal plate cooling in series flow. The remaining $84 \%$ passed through the blanket and core. For a metered flow cof 11.8 


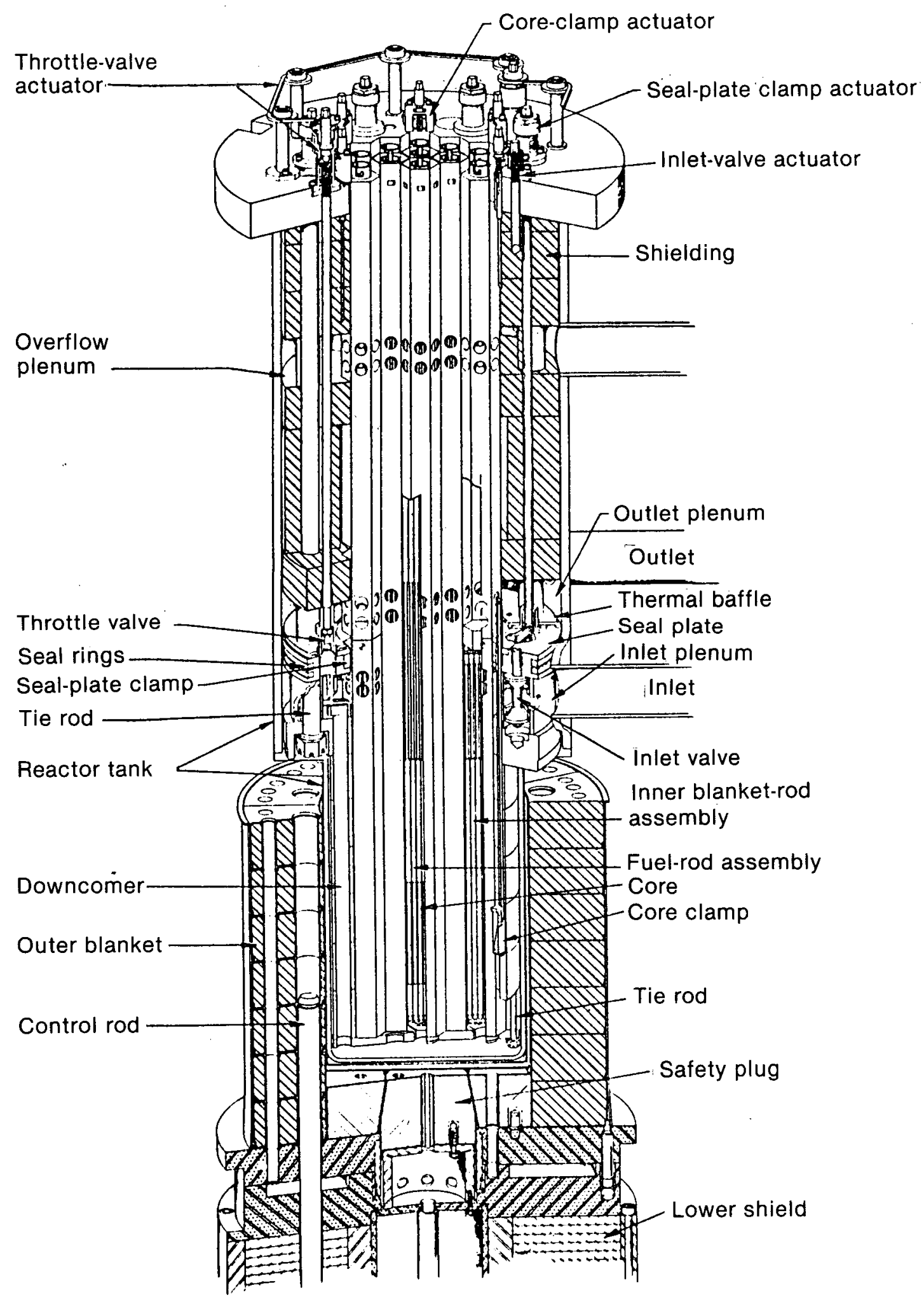

Figure A-38. EBR-I Mark-III inner tank assembly. 
$\mathrm{L} / \mathrm{s}$ in parallel flow, approximately the same fraction, $84 \%$, passed through the core; the remaining $16 \%$ passed through the blanket. Coolant from the blanket outlet cooled the seal plate.

The effects of rod bowing were explored by systematically removing part of the stiffening ribs. Although the rods were rigidly fixed at the upper and lower end, a radial motion in the fuel section accompanied differential expansion during a power increase and resulted in a bow directed at the center high-flux region. In 14 tests involving various types of changes, transfer function measurements showed a progressively larger positive effect consistent with the removal of the ribs. The amplitude of the power feedback decreased, and the phase lag increased as ribs were removed.

It was concluded that the fully-ribbed and rigid Mark-III design was completely stable under normal operating conditions. The ribs provided strong radial coupling between individual fuel rods and between the fuel rods and the hexagonal can, and therefore they provided a large radial contribution to the power coefficient. The positive feedback effect from the inward bowing of the rods during power increases was likewise eliminated. Testing indicated that the core could be brought into a resonant condition at an extrapolated power above $1000 \mathrm{MW}_{\mathrm{t}}$, well above the design value of $1.2 \mathrm{MW}_{\mathrm{t}}$.

Power coefficient nonlinearities were observed, which complicated the interpretation of test data in terms of a single model that could be applied over wide ranges of power, flow, and temperature conditions. These nonlinearities apparently resulted from the power and temperature sensitive clearances existing between rods, between rods and hexes, and between hexes, which are complicated by differences in the coefficient of expansion of the materials involved. Furthermore, the power coefficient itself was found to be sensitive to the temperature inlet cooling.

At one-third flow, the reactor would reach resonant instability at a power of about $10 \mathrm{MW}_{\mathrm{t}}$. At full coolant flow, with the ribs sheared, feedback measurements indicate a probable resonant instability at a power level of $11 \mathrm{MW}_{\mathrm{t}}$.

It has also been shown that rib shearing results in an unexpected and unexplained increase in the magnitude of the delayed structural power coefficient component. An empirical fit of feedback data between models describing the dynamic and static behaviors of the partially sheared core resulted in the following values for the respective promptnegative, rod bowing, and delayed structural power coefficient components:

$$
\begin{aligned}
& -2.21 \times 10^{-6} \\
& +0.543 \times 10^{-6} \\
& -0.873 \times 10^{-6} \Delta \mathrm{k} / \mathrm{k}-\mathrm{kW} .
\end{aligned}
$$

These values correlate in a curious manner with those empirically deduced for the prompt-negative and delayed structural power coefficient components for the fully ribbed core, namely, $-2.21 \times 10^{-6}$ and $-0.330 \times 10^{-6} \Delta \mathrm{k} / \mathrm{k}-\mathrm{kW}$.

The magnitude of the positive power coe:ficient component is equal to the increase and the magnitude of the structural component. Apparently rib shearing introduces two feedback processes, rod bowing, which is prompt and positive, and one of an unspecified nature, which is negative and extremely delayed in time.

Because the model predicts a general shape of the experimentally measured feedback and comes within a reasonable margin of explaining the feedback magnitude, it was concluded that the structural member responsible for the delayed negative power coefficient was the lower shield plate. A credible interpretation of the feedback would involve the concept of a delayed feedback that probably originated at some structural member located downstream of the core. A careful scrutiny of all downstream structural members supplemented by attenuation concepts narrows the suspect region to that included between the lower shield and seal plates. The fact that thermally induced ligamental motion has actually been observed in such a plate, and that the maximum temperature differential across the shield plate occurs close to the natural resident frequency of other reactors, strongly supports this conclusion. The strong increase in the negative structure term does not affect conclusions regarding the resonant stability at the fully or partially sheared cores. The process acted so slowly-the reactor oscillated at frequencies as low as 0.02 cycles $/ \mathrm{s}$ - that it cannot sense the feedback.

The Mark-III core, even with ribs partially sheared, was found to be much more stable than the Mark II. In addition to elimination of the inward rod bowing found in Mark-I, the Mark-III design 
resulted in a negative prompt power coefficient contributed by both axial and radial expansion of the rods. In Mark-II, the negative coefficient associated with axial fuel expansion and coolant expulsion was insufficiently large to cancel the prompt component from rod bowing. It was therefore concluded that the instabilities noted in Mark II were completely the result of the design peculiarities and not an inherent feature of the reactor concept itself. After conclusion of the stability test in 1960, the reactor was used on a part-time basis to study various loading arrangements, radiation effects of different types of fuel elements, and fuel isotopic changes.

Mark-IV Core. The full potential of breeding with a fast spectrum is realized only when plutonium, rather than U-235, is used as the fuel in the core. The EBR-1, Mark-IV core, loaded in 1962, was the first use in this country of plutonium for the full core of a fast breeder power reactor. Operation of this reactor facility with plutonium loading had as its objectives the determination of general operating characteristics, the measurement of breeding gain, and the determination of radiation effects and nuclear parameters.

An alloy of plutonium with $1.25 \mathrm{wt} \%$ aluminum was used in the core. Slugs of the material, $0.59 \mathrm{~cm}$ in diameter and $5.4 \mathrm{~cm}$ long, are contained in zircaloy-fuel tubes, $0.76 \mathrm{in}$. OD with a $0.053-\mathrm{cm}$ wall thickness. Three full-length ribs served to center the slug and the jacket tube. Each fuel rod contained a lower depleted uranium blanket slug $8.95 \mathrm{~cm}$ long, four plutonium alloy fuel slugs totaling $21.6 \mathrm{~cm}$, and a single $19.67-\mathrm{cm}$-long upper blanket depleted uranium slug. A $0.0318-\mathrm{cm} \mathrm{NaK}$ layer bonds the cladding to the fuel. A number of rods had a $0.2-\mathrm{cm}$-diameter zircaloy thermocouple tube attached. Blanket rods were similar to those used in the fuel section; depleted uranium slugs were substituted for the plutonium alloy.

At shutdown, the Mark-III core had operated for $3,220 \mathrm{MW} / \mathrm{hr}$. The core was completely unloaded by November 8,1962 , and the Mark-IV loading went critical on November 27, 1962, with $27 \mathrm{~kg}$ of plutonium-239 (327 fuel rods). Initial loading consisted of 60 fuel rods in the central assembly. Ten subsequent loadings, four of 42 rods each, two of 24 each, two of 18 each, one of 8 , and a final one of 7 rods were made to reach criticality. Foil irradiation runs at low power were carried out in early 1963 to determine constants necessary for the calculation of breeding ratios. After transfer function runs at low and moderate power indicated that the reactor was quite stable, the system was gradually brought up to power, $900 \mathrm{~kW}$ thermal, during April 1963. Although operation was very satisfactory, some loss of reactivity was noted.

EBR-1 was shut down and secured on December 3, 1963. Total power produced by the Mark IV loading was $577 \mathrm{MW} / \mathrm{hrs}$. Eleven fuel rods were removed from the reactor for return to the metallurgical division of Argonne National Laboratory for examination of the irradiated plutonium fuel plugs.

The reactor was secured subcritically by $1.75 \% \Delta \mathrm{k} / \mathrm{k}$ with the controls in their most reactive position, and the reactor temperature at $30^{\circ} \mathrm{C}$. Surveillance of the reactor blanket gas was maintained during this indefinite, extended shutdown period.

\section{LAMPRE-I}

Molten Plutonium Core Concept. Interest in the development of plutonium fuels for fast breeder reactor applications continued at the Los Alamos Scientific Laboratory after the dismantlement of Clementine (see previous section on Clementine, p. A-44. Parallel to this effort has been the development of homogeneous reactors wherein the fissile material was dissolved in an aqueous system. Reactors of this type include the water-boiler series, as well as LAMPRE-I and LAMPRE-II. The resulting specialization in plutonium-fueled fast breeder reactors on the one hand and the homogeneous concept on the other logically led to the concept of using plutonium in the molten state as fuel for a fast breeder system. An early reactor design, for example, called for the plutonium fuel to be obtained in a cylindrical vessel through which tubes carrying sodium coolant would flow in a typical calandria arrangement. However, the need for additional information regarding the behavior of container and fuel material led to the decision to first build a molten plutonium fueled reactor; within such a reactor, the fuel would be contained in cylindrical capsules with the sodium coolant flowing outside. This arrangement, used in LAMPRE-I, could be readily adapted to the testing of a variety of fuel and container material combinations. A cell in an existing building, which had previously been used for the LAMPRE-I reactor, was available for LAMPRE. The limitations of this location fixed the reactor power at $1 \mathrm{MW}(\mathrm{t}) . \mathrm{A}-30-51$ 
Reactor Features. A plain view of the reactor installation is shown in Figure A-39 and an elevated view in Figure A-40. Component design was based on the need for installation in the existing cell facilities. No secondary sodium coolant is used. The heat generated is exchanged to air and is exhausted up a stack. Although thermal performance specifications are high, specific power and power density were not intended to represent optimum values for a larger power reactor system.

Core Arrangement. The core consisted of approximately 140 fuel capsules filled with plutonium iron alloy surrounded by approximately 60 stainless steel reflector pins of similar design. A crosssection of the core region is shown in Figure A-41, and a vertical section of the core is shown in Figure A-42. An annual, moveable stainless steel reflector was contained in an inner vessel outside the core. It was $50.8 \mathrm{~cm}$ in OD by $27.3 \mathrm{~cm}$ ID by $40.6 \mathrm{~cm}$ long. Final control was obtained by moving four control rods, each consisting of a nickel cylinder $9.65 \mathrm{~cm}$ in diameter and $9.46 \mathrm{~cm}$ long, which move vertically in a stainless steel reflector.

Coolant sodium flowed down to a $0.95-\mathrm{cm}$ annulus between the vessel and the flow divider. The coolant stream reversed in a plenum at the bottom of the flow divider. The sodium then flowed through a bottom reflector consisting of an Armco $^{\oplus}$ iron cylinder $17.5 \mathrm{~cm}$ in diameter by
$15.2 \mathrm{~cm}$ high. Flow continued through a locator plate assembly, then finally passed the fuel capsules, through a top reflector region, and into the outlet plenum.

The core arrangement contained several safety features. Double-wall construction of the reactor vessel, with no pipes entering the lower part, prevented accidental drainage of coolant. A ca.tch-pot and diluent plug were designed to contain any fuel, in a noncritical geometry, in the event of a leak in the core. The Armco ${ }^{\circledR}$ iron diluent plug would dissolve in molten fuel to form an alloy with a higher melting point. As the solution continued, the resulting alloy would solidify.

Fuel Elements. A single fuel capsule or "pin," as shown in Figure A-43, was used in each complete element shown in Figure A-44. The components of the capsule assembly shown are the thimble, fuel slug, closure, plug, and adapter. The capsule fuel thimble was constructed of various tantalum types, depending upon the desired materials test. A typical thimble, fabricated from tantalum of $0.1 \mathrm{wt} \%$ tungsten, was $1.08 \mathrm{~cm} \mathrm{OD} \mathrm{and} 20.1 \mathrm{~cm}$ in overall length, with an ID tapered from $0.955 \mathrm{~cm}$ at the top to $0.919 \mathrm{~cm}$ at the cone end. Solid plutonium iron alloy fuel slugs were machined immediately before assembly into the thimbles. These fuel slugs were $0.909 \mathrm{~cm}$ in diameter, and lengths varied depending on the fuel weight required. However, the lengths averaged $16.1 \mathrm{~cm}$.

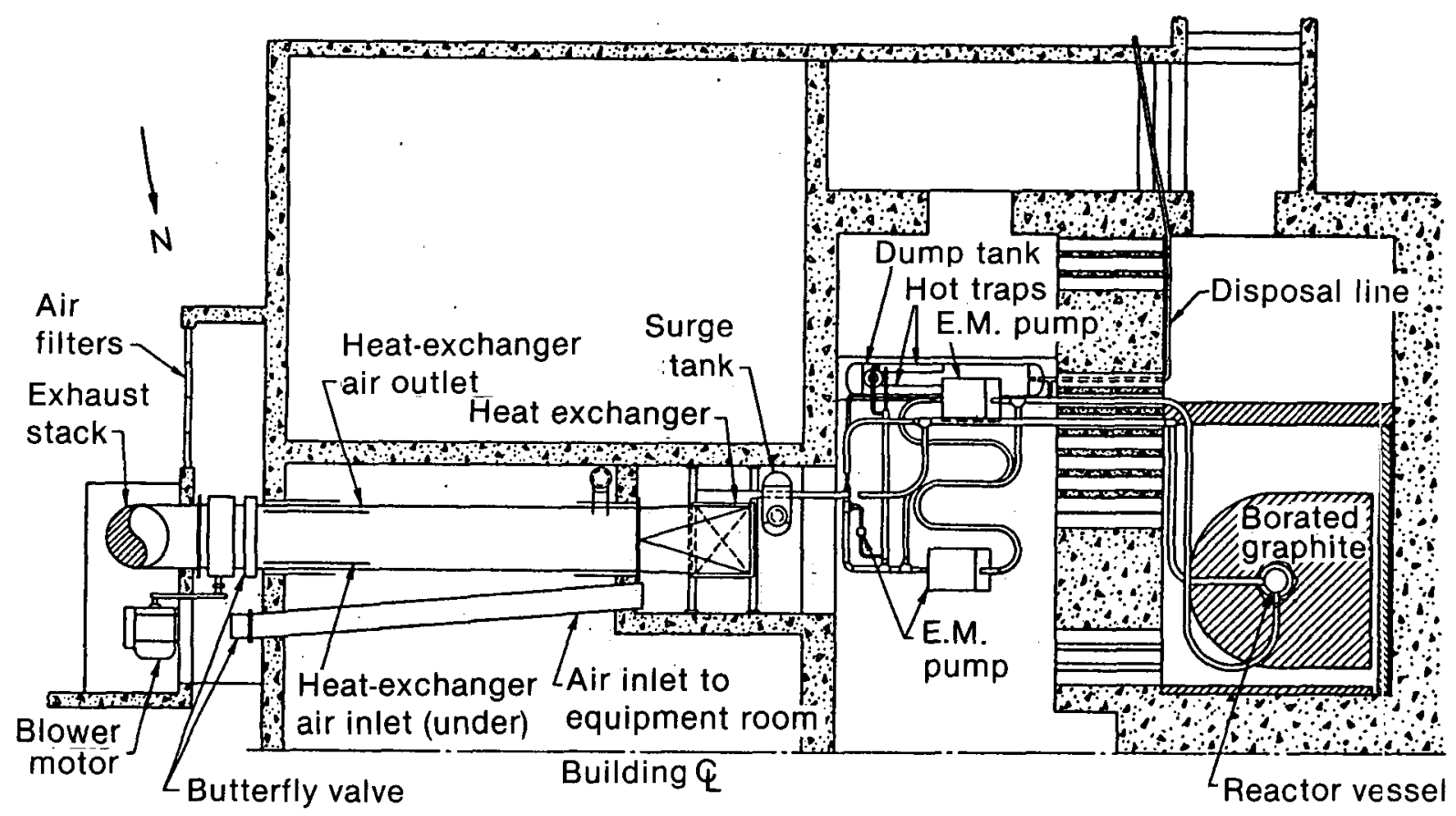

Figure A-39. LAMPRE-I plan view. 


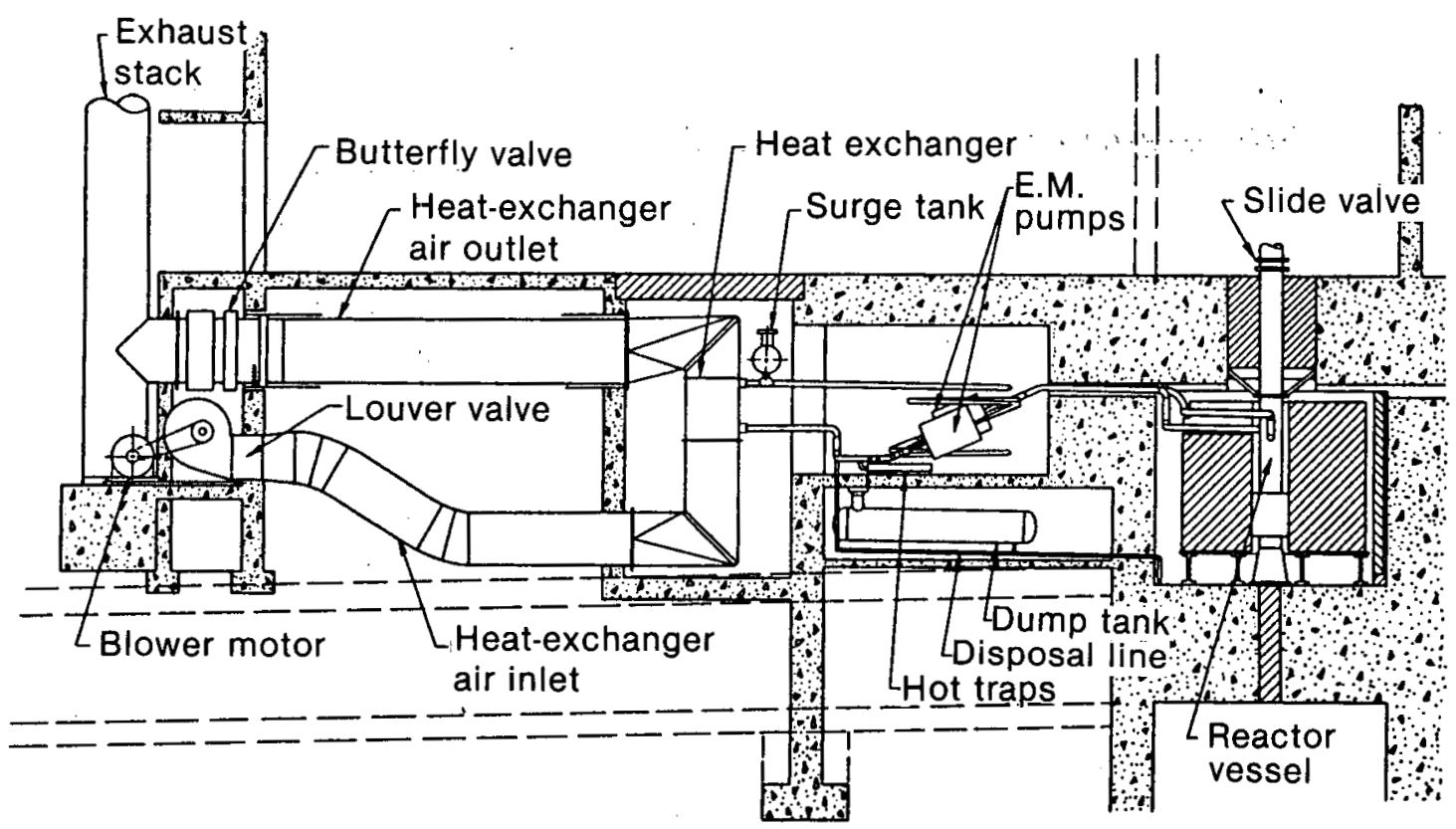

Figure A-40. LAMPRE-I elevation.

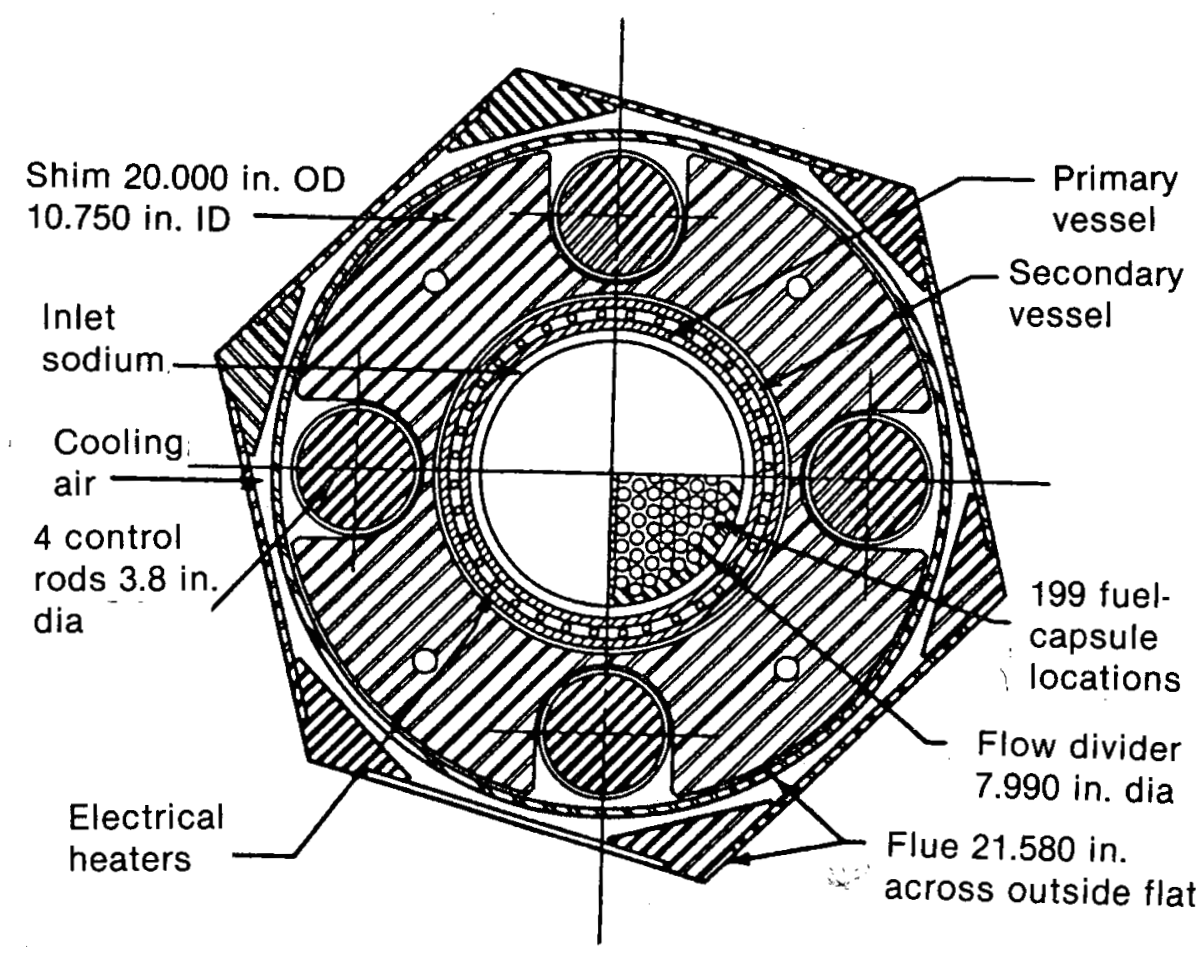

Figure A-41. LAMPRE-I horizontal cross section. 


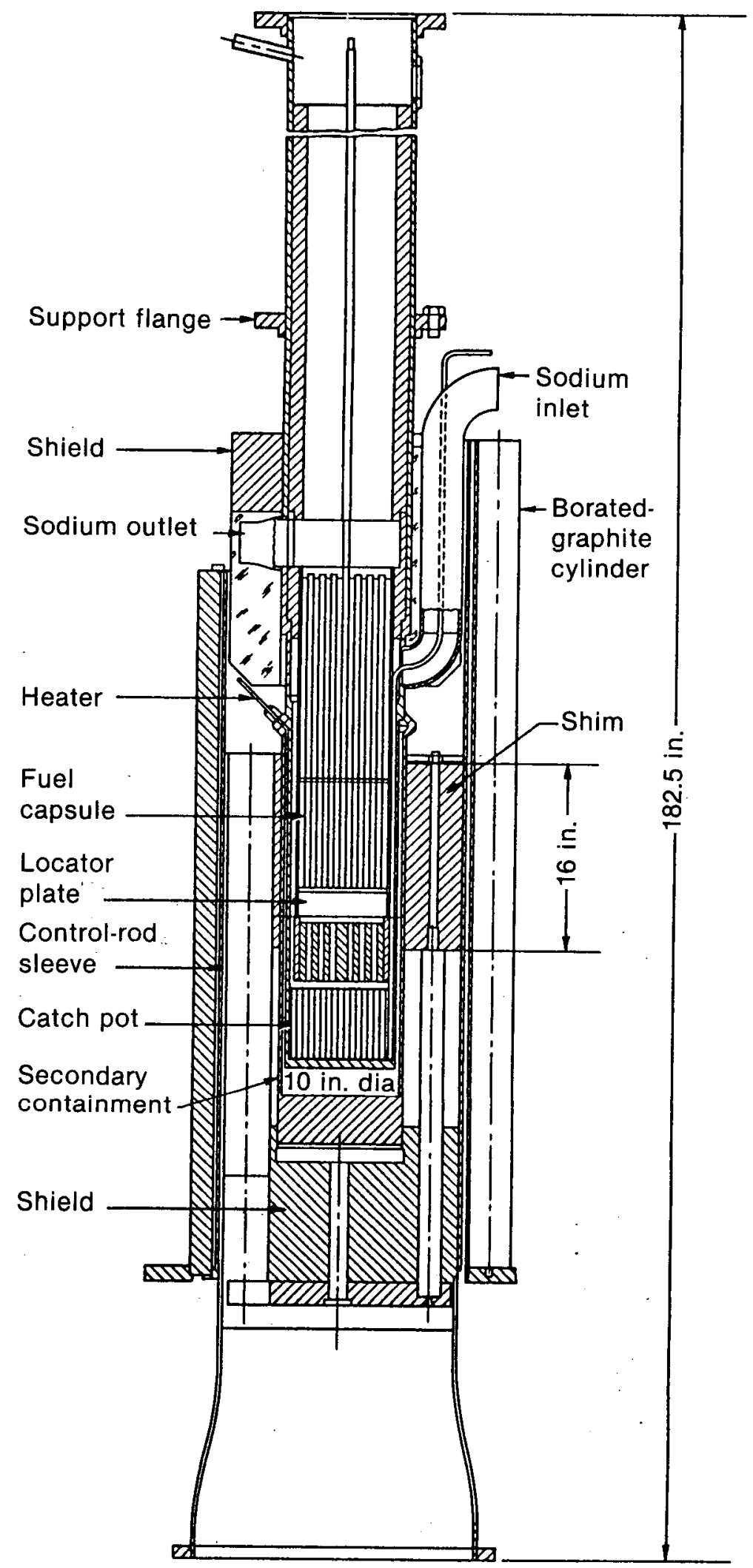

Figure A-42. LAMPRE-I vertical cross section. 


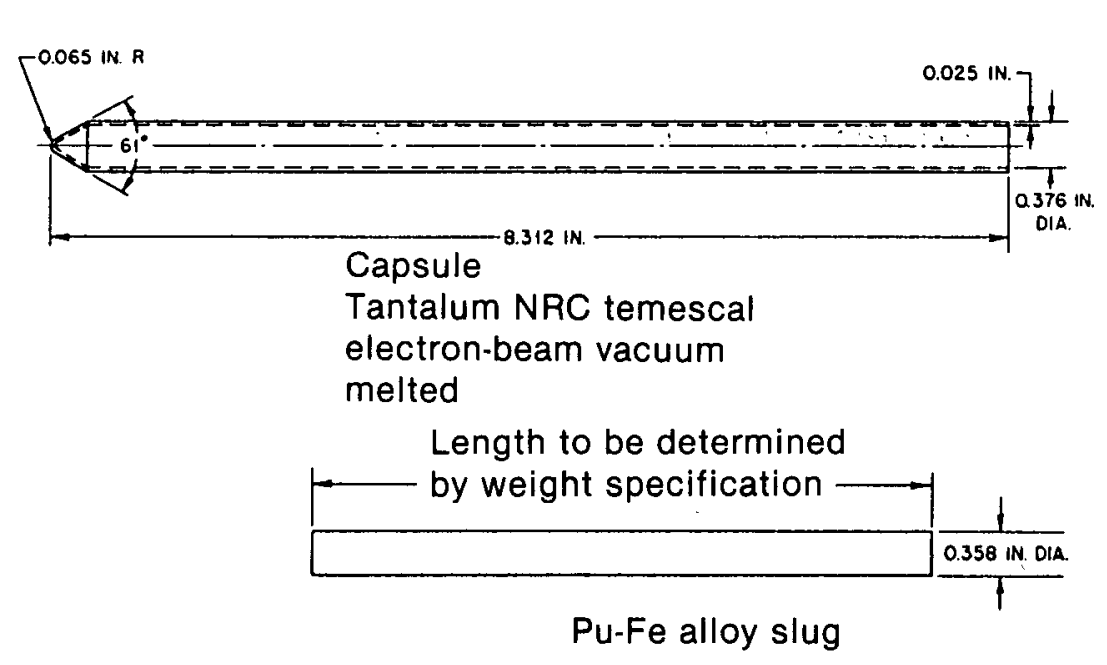

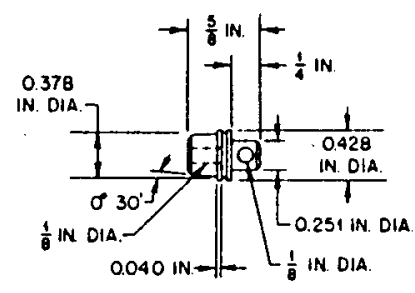

Closure plug and adapter Tantalum NRC commercial grade rod

Figure A-43. LAMPRE-I fuel capsule and slug.

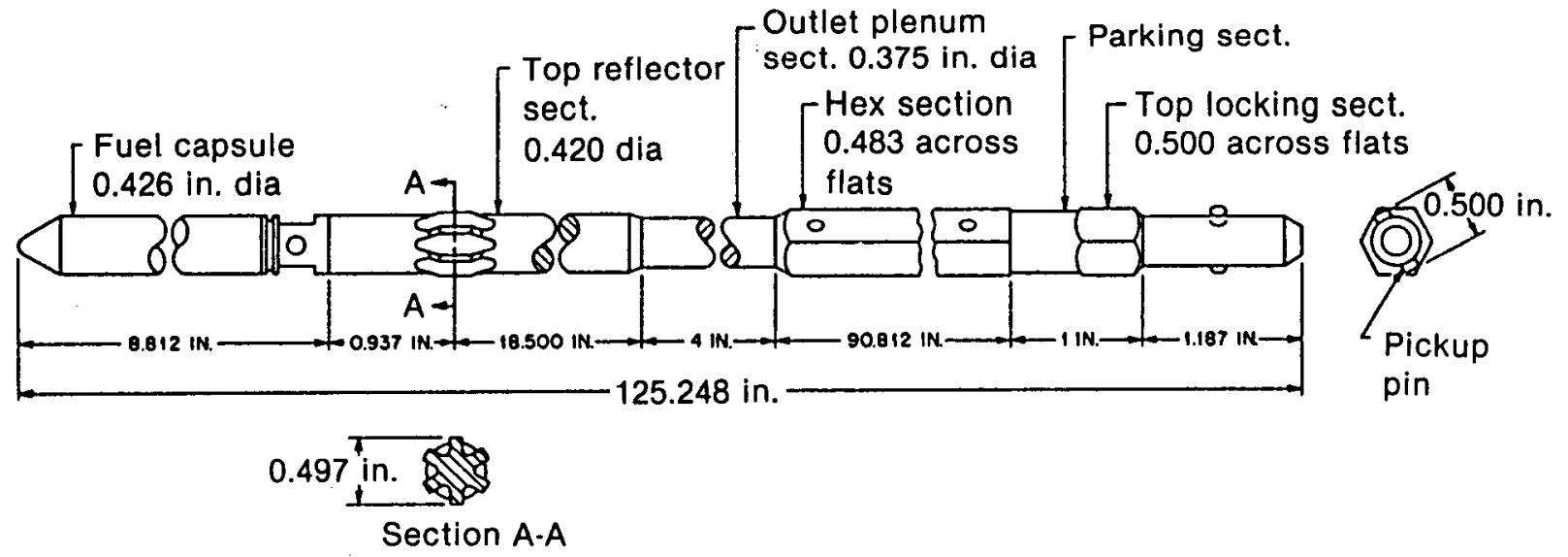

Figure A-44. LAMPRE-I fuel subassembly.

The remainder of the assembly, shown in Figure A-44, included a $2.29-\mathrm{m}$ shielding section and a so-called capsule handle. The capsule handle was constructed of Armco ${ }^{\circledR}$ 17-4 stainless steel and was used to insert and withdraw the fuel capsules from the core. It was also used to maintain the radial core configuration.

Cooling System. The cooling system consisted of two parallel Callery A-C electromagnetic conduction pumps. The pumps, each rated at $63 \mathrm{~L} / \mathrm{s}$ at $1,190 \mathrm{n} / \mathrm{m}^{2}$ head, were used for circulating sodium to the reactor. Heat was removed directly from this primary circulating system to air by a finned section heat exchanger, which exhausted up a stack. The coolant loop, constructed of a $5-\mathrm{cm}$ and 7.62-cm Schedule 40 Type 316 stainless steel pipe, included a number of accessory components: flowmeters, a heating transformer for raising the temperature of the flowing sodium to the melting point of the fuel, three getter hot traps, and a fill and dump tank system.

Shielding. The shielding requirements for this installation were somewhat unusual since the reactor was installed in existing facilities adjacent to the control room. The borated graphite shield, $1.07 \mathrm{~m}$ thick, surrounded the reactor vessel. A $20.3-\mathrm{cm}$ thick lead curtain and a $1.68-\mathrm{m}$ normal concrete wall shielded the control room. Control room radiation levels during initial operations were found to be excessive. The installation of improved shielding in the concrete wall penetrations and a supplementary lead shield reduced the levels to below tolerance values. 
A vertical cross-section of the shielding is shown in Figure A-45. The shield below the core was based on a design specification of $2-\mathrm{mrem} / \mathrm{h}$ dose rate in the exclusion area in the shadow of the shield. In addition, the shield consisted of a 40.6-cm-thick iron bottom reflector in a $2.13-\mathrm{m}$-long floor shield plug filled with lead shot in the bottom $30 \mathrm{~cm}$, and magnetite aggregate in the remainder.

The fuel-capsule handles alone provided approximately $2.7 \mathrm{~m}$ of iron shielding directly above the core. A ceiling shield plug of heavy concrete and steel shot provided the access through the $1.68-\mathrm{m}$ concrete ceiling. During initial low-power operation, it was necessary to add an additional laminated iron masonite shield on top of the shield plug and a concrete shield around and on top of the fuel transfer area.

Operation. The LAMPRE-I reactor was designed as a facility for the study of molten plutonium fuels and containers, and investigation of operating problems that might be unique to the fluid nature of the fuel. The reactor started in 1961 with dry critical and low-power operations. It was brought up to its design power of $1 \mathrm{MW}$ in early 1961. In April 1962, the reactor was reloaded with a Mark-II core. After capsule failure in September 1962, which permitted $75 \mathrm{~g}$ of plutonium iron fuel to enter the coolant, the power level was temporarily limited to $500 \mathrm{~kW}$.

Stability and Control. Although bubbles of fissionproduced gases tend to rise to the surface of the fuel, some separation of large portions of the fuel regions apparently result in reactivity changes with time, as shown in Figure A-46. In the Mark-I loading, solid additives of carbon or plutonium carbide used to inhibit corrosive attack on a tantalum capsule were believed to interfere with the release: of the accumulated gas, accentuating this reactivity loss.

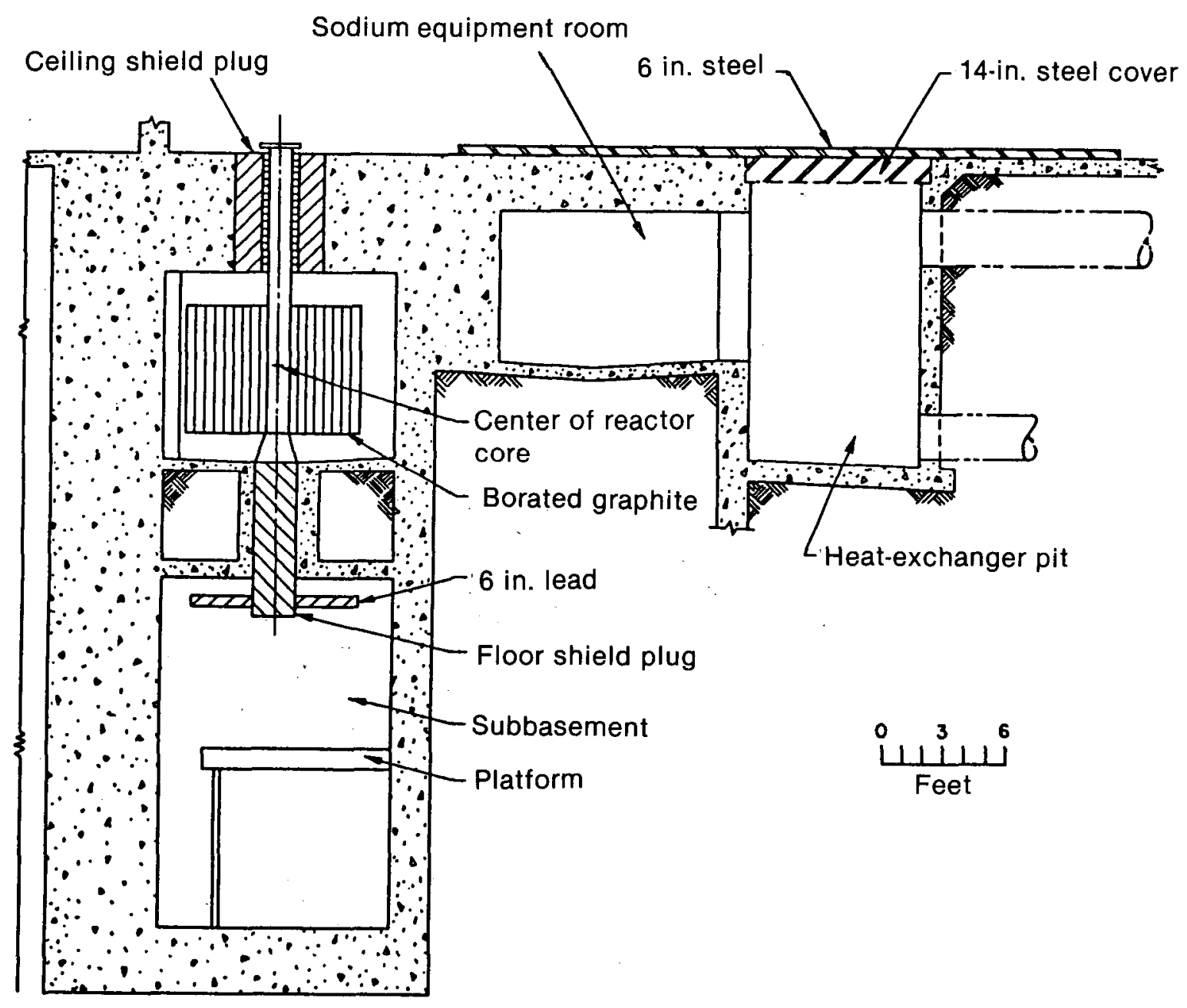

Figure A-45. LAMPRE-I shield, vertical cross shielding. 


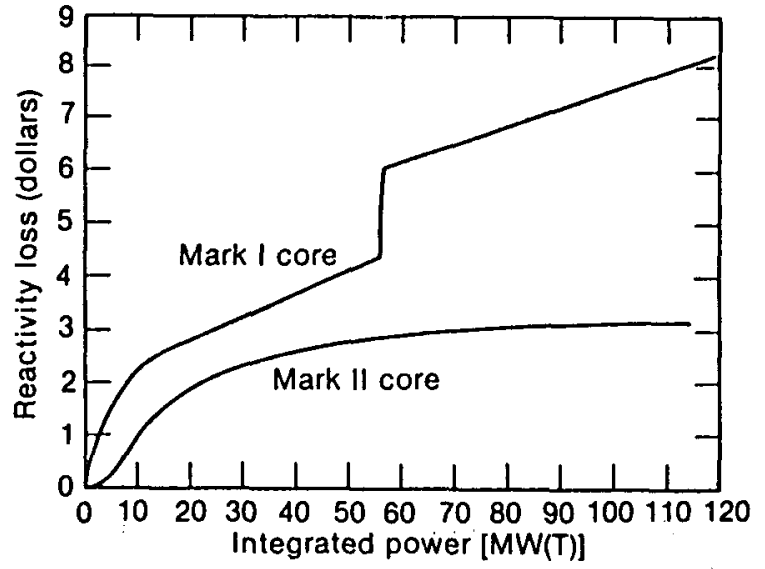

Figure A-46. Reactivity loss during LAMPRE-I operation.

Although approximately $\$ 10$ of reactivity was lost in the Mark-I loading, there was never any indication of instability caused by the froth or low density portion of the fuel. In the Mark-II loading, the disengagement of evolved gases was cleaner, with a smaller reactivity loss; this resulted as a function of integrated power, as shown in Figure A-46. During operation the dynamic characteristics of the reactor were evaluated. Temperature coefficients, power coefficients, and reactor transfer functions were measured. Figures A-47 and A-48 show typical results. Substantial negative temperature coefficients provide a high degree of operational stability.

Fuel Test Program. LAMPRE-I fuel consisted of $24 \mathrm{~g}$ of plutonium alloy, 90 at. $\%$ plutonium, 10 at. $\%$ iron. The rather unusual density characteristics of this alloy (Figure A-49) can lead to a plug during solidification because the lower density solid material tends to float to the top of the remaining fluid portion. In the initial loading, presence of a few hundred ppm of carbon and a plutonium fuel alloy was believed to be effective in reducing the inter-granular attack on tantalum. Subsequent tests, however, indicated that fuel made with pure iron was less corrosive than fuel with added impurities. Likewise, the pure system has the advantage of reducing the froth region formation with its resulting reactivity loss. The fuel alloy used in the Mark-I and Mark-II cores has a high plutonium concentration and is not particularly suitable for high performance reactors because of the heat removal limitation. Attention has therefore been given to ternary alloys, i.e., plutonium-cobaltcerium and plutonium-copper-cerium, which permit plutonium concentrations from 2 to $4 \mathrm{~g} / \mathrm{cm}^{2}$ at

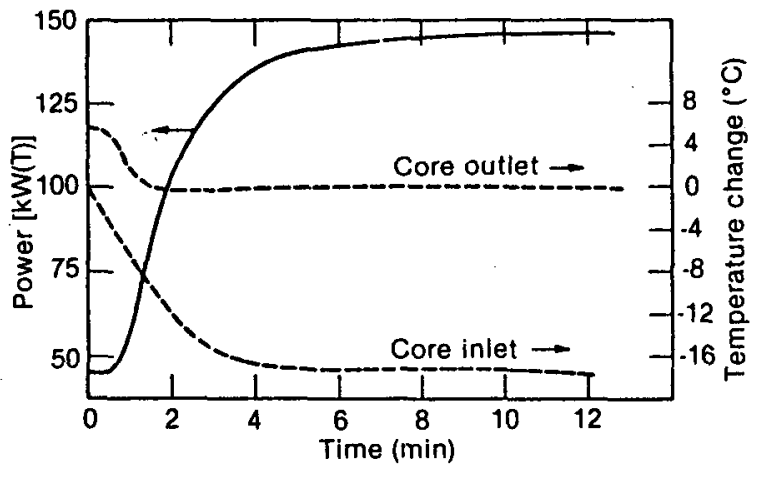

Figure A-47. LAMPRE-I core power and inlet and outlet temperature changes from $45 \mathrm{~kW}(\mathrm{t})$ vs. time.

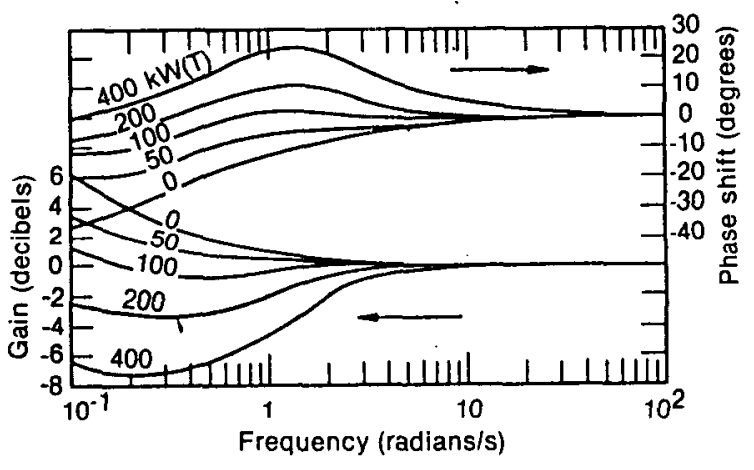

Figure A-48. LAMPRE-I transfer functions for various power levels.

operating temperatures. Some test capsules containing the former alloy have been irradiated in the LAMPRE core.

Following fuel leakage from several elements, the LAMPRE-I was shut down and unloaded. Decision not to reload the reactor was based on a finding that little, if any, new information could accrue from continued operation of the reactor. The maximum fuel exposure obtained was 0.5 at. $\%$ burnup of the plutonium at a maximum specific rating of $60 \mathrm{~W} / \mathrm{g}$. Because of the concentrated nature of the fuel, these modest figures do not emphasize the significant aspects of the fuel experience that had been obtained.

The LAMPRE operation successfully demonstrated satisfactory fuel performance at levels of up to $1 \mathrm{~kW} / \mathrm{cm}^{3}$ of fuel. This figure, translated to more dilute fuel $\left(4-\mathrm{g}\right.$ plutonium $\left./ \mathrm{cm}^{3}\right)$ more appropriate for larger reactor systems, predicted no problems from fission gas evolution at $250 \mathrm{~W} / \mathrm{g}$. The fuel exposure level of $2.4 \times 10^{20}$ fissions per cubic 


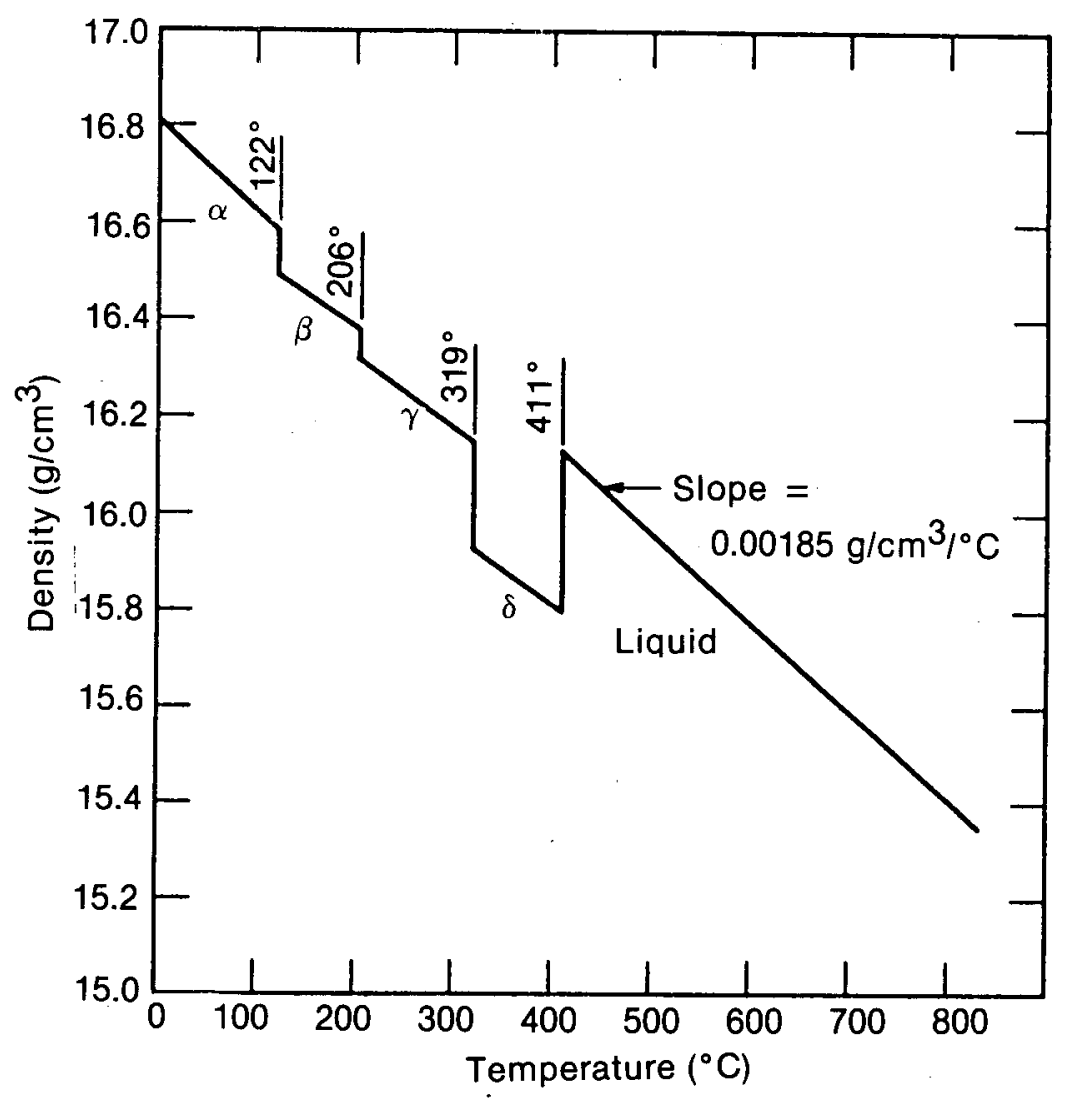

Figure A-49. LAMPRE-I plutonium-iron fuel density vs. temperature.

centimeter also translates to the same fission product density present with a 2.5 to 3 at. $\%$ burnup of the plutonium in the dilute fuel. Thus, with a comparatively modest and inexpensive first experiment with molten plutonium fuel, highly satisfactory control, reactivity behavior, and successful gas disengagement from the fuel was demonstrated. In addition, there were no significant effects observed on the containment from appreciable concentrations of fission products in the fuel.

\section{SEFOR}

Concept. On March 27, 1964, the Atomic Energy Commission, Karlsruhe Laboratory at West Germany, EURATOM, Southwest Atomic Energy Associates, and the General Electric Company formally embarked on a program to construct and operate a $20-\mathrm{MW}$ ceramic-fueled, sodium-cooled, fast flux reactor. The test program to be carried out with this reactor was intended to verify calculations that would indicate that fast ceramic power reactors can be designed to be stable and have desirable operating characteristics. A-52-59 The Southwest Experimental Fast Oxide Reactor (SEFOR) was designed to have physics characteristics similar to those calculated for large fast ceramic power reactors. SEFOR was also designed to be operat $\epsilon$ d with fuel composition, temperatures, and crystalline states characteristic of proposed fast ceramic power reactors. SEFOR was intended to provide experimental data to promote understanding of the behavior of the Doppler effect under operating reactor conditions. It was recognized early in the planning of SEFOR that, in addition to the general concern associated with the design of a then relatively undeveloped reactor system, such as the sodium-cooled fast reactor, unique problems would be involved in SEFOR because of the nature of the experimental program. Requirements for suppression of fuel and core expansion coefficients to permit accurate measurements of the Dcppler coefficient and forced stability of the core during the entire testing program, including the power transient experiments, strongly influenced the design of the core and vessel internal hardware.

Reactor Building. An elevation view of the reactor building is given in Figure A-50. The reactor building is divided into two containment barriers. The 


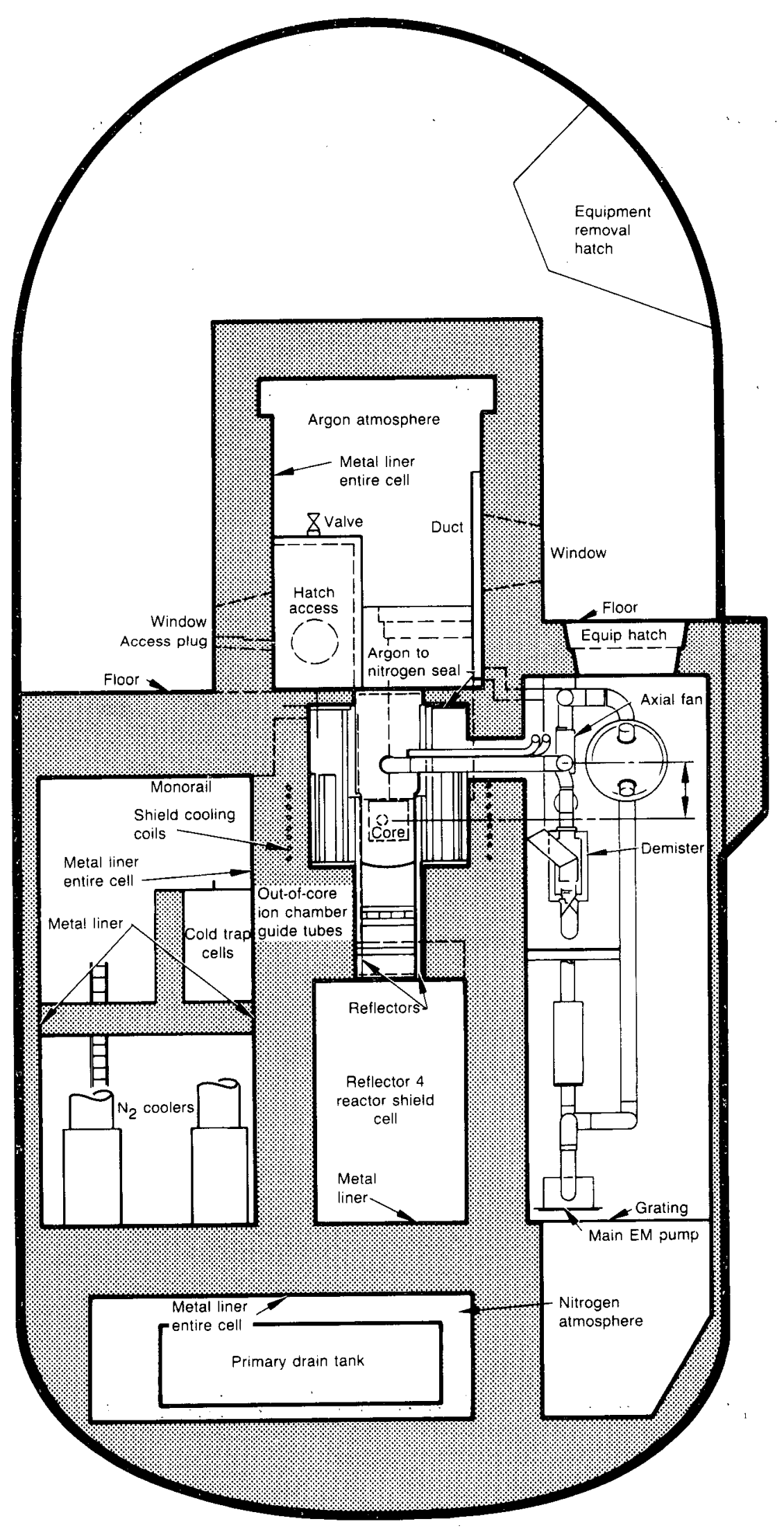

Figure A-50. SEFOR reactor building, elevation view. 
outer containment structure is an all-welded steel cylinder $15.2 \mathrm{~m}$ in diameter and $32.2 \mathrm{~m}$ high, designed for a pressure of $2.63 \times 10^{3} \mathrm{~Pa}$. The outer containment region is normally accessible.

The reactor equipment is located below grade in a refueling cell that extends above grade. The reactor core is contained within a steel liner which forms an inner containment barrier in the event there is a release of fission products. The area below grade contains a nitrogen atmosphere during operation, whereas the refueling cell contains high purity argon. The inner containment barrier, was designed for a pressure of $600 \mathrm{~Pa}$.

During operation of the reactor, the first containment barrier is sealed in the sense that all penetrations to and from this area contain valves or doors in the "closed" position. Fluids required, such as nitrogen and argon, are transferred by pairs of batch tanks arranged such that when fluid is being transferred from a batch tank to an area within the first containment barrier, the batch tank is valved off from external supplies of fluid. Similarly, when the batch tank is being charged with fluid, it is valved off from the inner containment area. A similar scheme is used to remove waste gas from the inner containment. The nitrogen within the first containment barrier is cooled by means of freon refrigeration units arranged so that only closed coils penetrate the first containment barrier. The air region between the steel-lined cells and the outer containment vessel is also cooled by a freon refrigeration unit, but it is normally ventilated via a $15-\mathrm{cm}$ air intake line, and a $15-\mathrm{cm}$ air exhaust line that exhausts to the atmosphere through a small stack.

Reactor Vessel. The general arrangement of the vessel and internal structure is shown in Figures A-51 and A-52. The vessel consists of a lower, small diameter core section and an upper, large diameter shielding section. Design pressure and temperature are $5.3 \mathrm{kPa}$ and $570^{\circ} \mathrm{C}$, respectively. The reactor will normally operate at a positive pressure of approximately $15.2 \mathrm{~cm}$ of water pressure relative to the refueling cell. The vessel head is designed in two pieces: the outer peripheral head which is sealwelded to the vessel flange and the center head which is normally held in place by its static weight. The center head can be removed for refueling the core. The outer head needs to be removed only in the event that major repairs are required in the core support structure. Special accident hold-on structures are provided for both the outer and center heads. The center head contains a fuel core that permits several fuel rods to be removed for inspection without the need for removing the center head.

Coolant System. A simplified diagram of the SEFOR coolant system is shown in Figures A-53 and A-54. The system comprises two parallel loops, each consisting of two loops in series. The numbers in the figures are the elevations of the indicated points relative to the core center. The primary sodium loop transports reactor heat from the reactor vessel to the intermediate heat exchangers. The secondary sodium loop, in turn, transfers the heat to the air blast heat exchangers, where it is clumped into the atmosphere. The main coolant loop was designed for a coolant flow of $315 \mathrm{~L} / \mathrm{s}$, whereas the auxiliary loop was designed for $15.8 \mathrm{~L} / \mathrm{s}$. Type 304 stainless steel piping was used throughout the coolant system.

The loops were designed so a rupture in one loop would not affect the operating ability of the other. This was done by locating the vessel's main coolant system nozzles at an elevation such that a break in the main loop could not drain the vessel's sodium below a point well above the reactor core. To guard against leaks in the reactor vessel itself, a safety vessel in the form of a cuff was placed around the vessel in near the core as shown in Figure A-54. The safety vessel extends up to the main coolant system nozzles, keeping the sodium level well below the auxiliary loop dip tubes in case a vessel leak develops below this elevation. The safety vessel is welded and hermetically sealed to the reactor vessel. Provisions were made to periodically pull a vacuum on the volume between the two vessels to verify the leak tightness of the safety vessel. Sodium leak detectors continuously monitor for sodium leakage into the safety vessel.

Precautions were taken to minimize probable loss of pumping power during an accident. Because electromagnetic pumping systems have low inertia characteristics, the sodium coolant flow would drop suddenly if pumping power were lost. To prevent this, two independent motor-generator sets with built-in flywheel inertia units were used to power the main primary coolant system pump. Each set is connected to one of the two coils operating the pump and is driven by the external power obtained from the incoming $69-\mathrm{kV}$ line. If external power is suddenly lost, these sets coast down on their flywheel inertia and maintain sufficient flow to prevent an increase in the coolant temperature. The flywheels were sized such that the coolant flow 


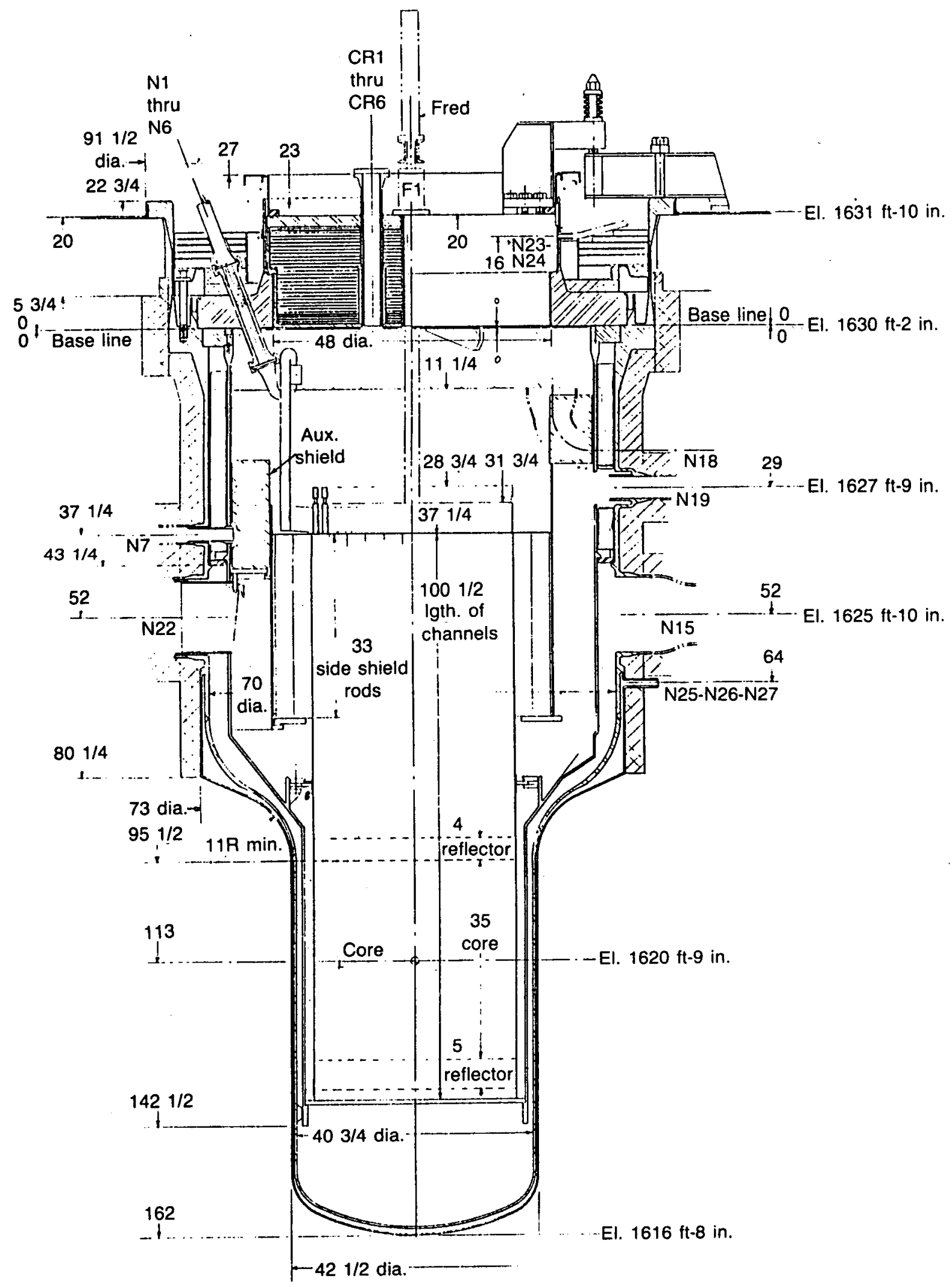

Figure A-51. SEFOR reactor vessel, elevation. 


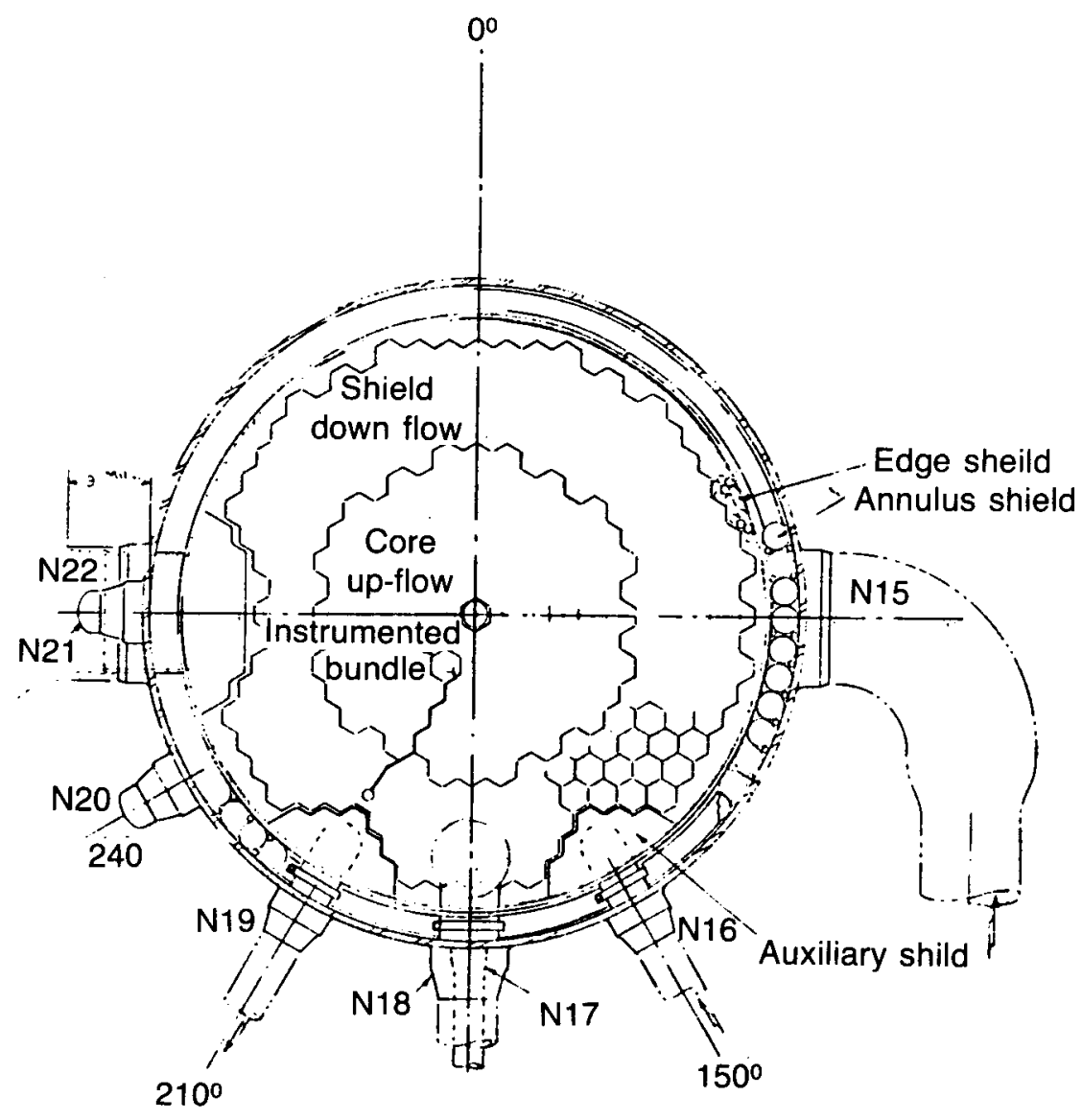

Figure A-52. SEFOR reactor vessel, plan view.

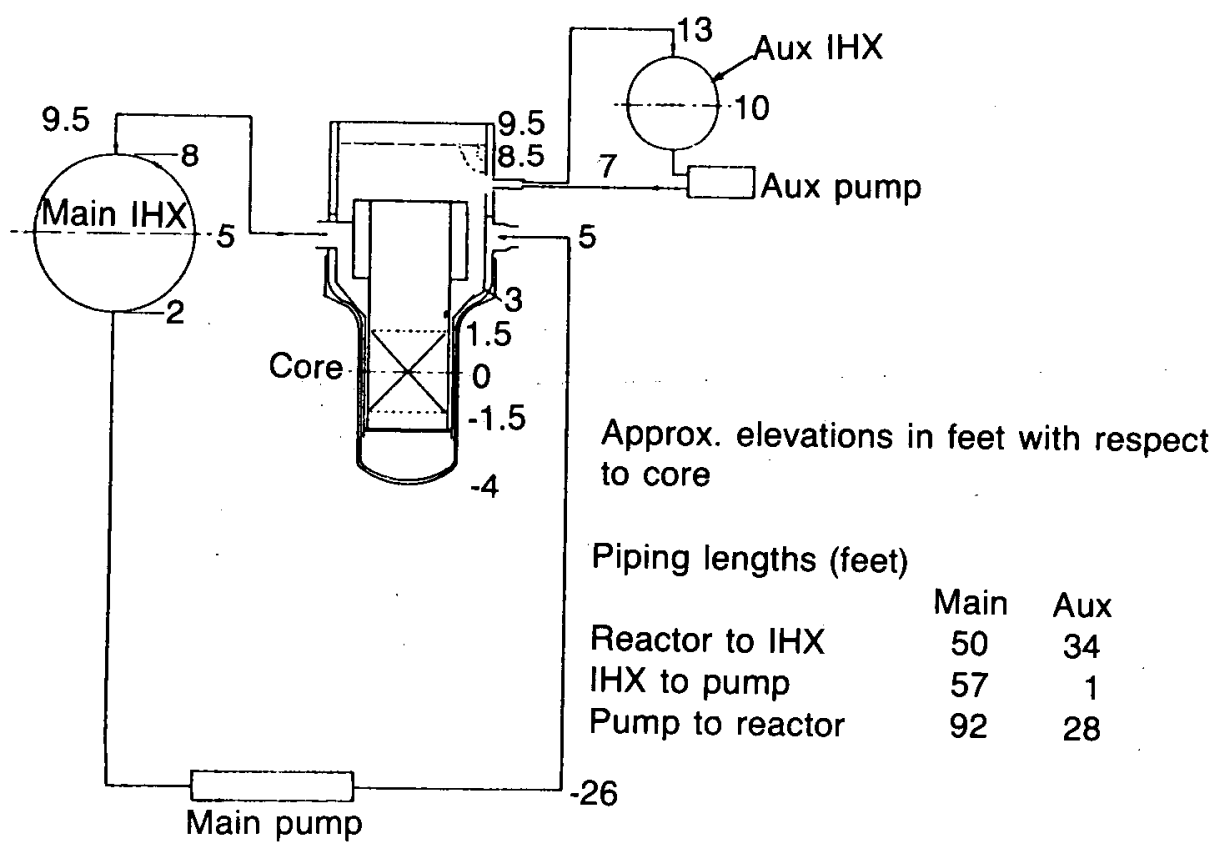

Figure A-53. SEFOR coolant system. 


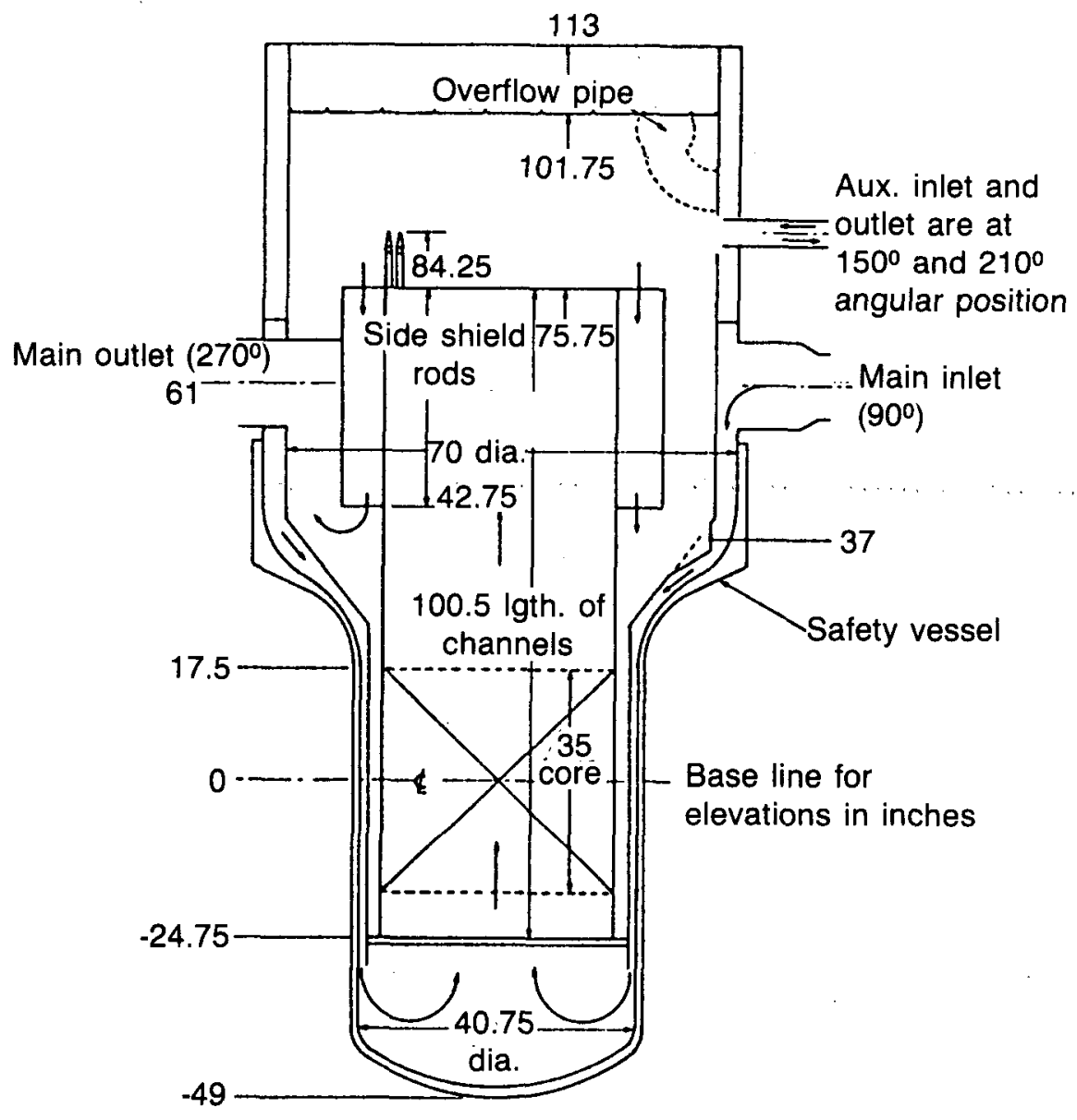

Figure A-54. SEFOR reactor vessel nozzle elevation.

is still greater than $50 \%$ of full flow 15 seconds after loss of power.

Before a significant rise in coolant temperature can occur, simultaneous loss of the two motorgenerator sets or the two independent coils of the EM pump has to take place. Even if such simultaneous failures occur, calculations indicate that the coolant temperature will not exceed $704^{\circ} \mathrm{C}$ when the reactor is scrammed from full power [20 MW(t)].

To further increase reliability of the coolant system, the main coolant system, as well as intermediate and air blast heat exchangers, was located such that decay heating can be removed by natural convection. Thus, shutdown cooling is possible even if no power is available.

The intermediate and air blast heat exchangers of the auxiliary system were also elevated to provide natural circulation. If flow in the main coolant sys- tem ceased, and if all power were lost to the plant at the same time, the auxiliary system's natural circulation could remove the decay heat to stop the sodium in the core from boiling.

Refueling Cell Facility. The refueling cell facility consists of a concrete and steel structure within the reactor building. The cell provides remote access to the fuel elements and other reactor internals. In addition, facilities were included for fuel storage inspection and preparation for shipping.

During periods when the reactor vessel or fuel storage tank is open for access, or when fuel or other irradiated core components are exposed in the cell, the cell serves as the first containment barrier. During normal operation, this cell controls the transfer of gases, vapors, and particulate matter between the cell's interior and all other areas.

Access by personnel to the cell was minimized and only possible when the reactor was inoperable with all irradiated fuel adequately shielded. 
When no alpha contamination was detected within the cell, its argon atmosphere was maintained at a positive $2.54 \pm 1.25 \mathrm{~cm}$ of water relative to the operating room. This was to minimize in-leakage of oxygen. During periods of alpha contamination, the cell atmosphere was maintained in a $-5 \pm 2.5 \mathrm{~cm}$ of water relative to the operating room to prevent out-leakage of contaminants.

A 10-ton multi-speed ridge crane installed in the cell was used to perform most of the handling operations, including the handling of the fuel rods. Special grapple tools were provided for handling various components. Manipulators were used to assist in the handling motions.

The cell had an argon atmosphere and was designed to withstand $2.62 \times 10^{2} \mathrm{kPa}$. The argon was circulated through a purification system to maintain less than 10-ppm oxygen, 10-ppm moisture, and acceptable sodium vapor conditions. The purification system consisted of a NaK bubbler and demister which controlled the impurity limits in a $\mathrm{NaK}$ exchanger and maintained the temperature below the $66^{\circ} \mathrm{C}$ design temperature.

Reactivity Control. SEFOR was controlled by movable reflector control rods surrounding the core outside the reactor vessel. The reflector control provides a cleaner core and is more reliable if structural damage should occur to the core during the transients. Control requirements for the SEFOR are summarized in Table A-7.
The reflector controls are calculated to be worth $\$ 14$, thus leaving a margin in excess of $\$ 5$. The reflector worth was measured in a SEFOR critical experiment at ZPR-III.

Reactor shim control was accomplished by moving the reflector control rods vertically at a constant velocity into positions adjacent to the core. The reactor was scrammed by simultaneously dropping all the reflector rods to a position below the core. The general arrangement of the reflector control system is shown in Figure A-55. The reflector was $15 \mathrm{~cm}$ thick and $86.4 \mathrm{~cm}$ high with the annular cylinder divided into 10 equal sectors. The average worth of each sector is $\$ 1.4$.

The control rod assembly consists of a. reflector structure in a neutron shield. The control is was moved within the reflector guide, which extends from the ceiling of the drive mechanism cell to the top of the core. The channels in the reflector guide both guide the rods and direct the flow of coolant gas over the rods. Each reflector rod is connected to its drive by an extension shaft.

The reflector material chosen for the reference design is "A" nickel, a high nickel alloy containing approximately $99 \% \mathrm{Ni}$. This alloy, though not a high strength material, has a relatively good thermal conductivity, which is effective in minimizing thermal stresses and distortions. The shielding is contained within a steel can with the same geometry as the reflector. Slider pads fit into channels on

Table A-7. Reactivity control requirements

Temperature $\left(177^{\circ} \mathrm{C}\right.$ to $\left.29 \mathrm{MW}\right)$

Doppler

Expansion

Experiments

Burnup

Shutdown
2.7

1.6

2.0

0.3

2.0

8.6 


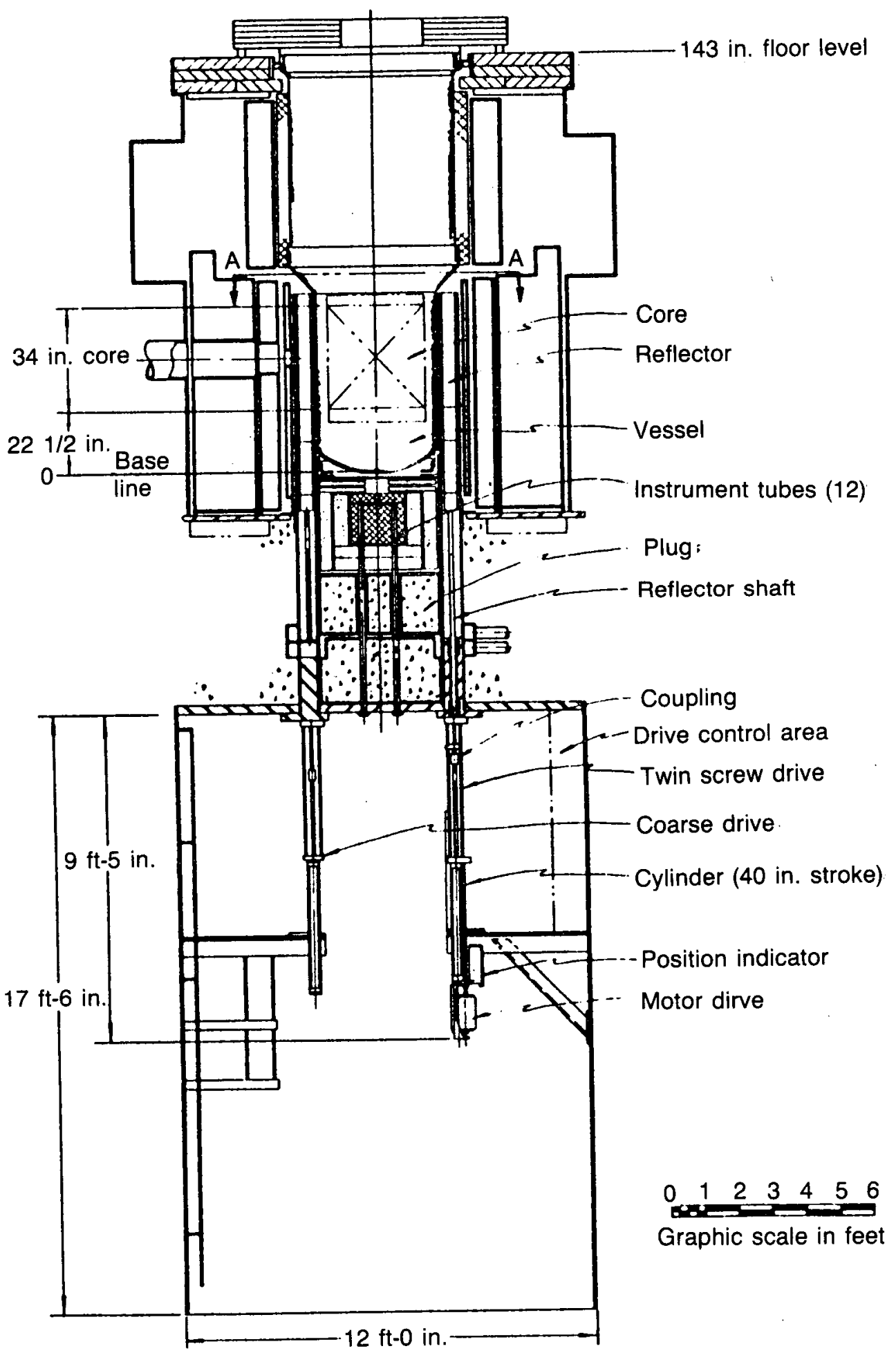

Figure A-55. SEFOR reflector control system. 
the faces of the control rods. The control rods are on rails within the reflector guide. The estimated weight of each control rod is $660 \mathrm{~kg}$.

Two types of drive mechanisms are used, a fine control and a coarse control. The fine control drives are infinitely positionable over their full stroke, whereas the coarse control drives are normally operated fully inserted or fully withdrawn. A twin screw drive, illustrated in Figure A-56, is used as the fine control drive, and has a record of satisfactory performance.

The fine control drive consists of an oil hydraulic cylinder connected directly to the control rod by an extension shaft. The cylinder pressure is normally biased so that the cylinder tends to move the rod in the direction to increase reactivity. However, the cylinder motion is restrained by an adjustable stop, which consists of two translating nuts driven by two synchronized screws. The stop is positioned by a three-phase gear motor through a drive chain that drives and synchronizes the screw. Stop position is indicated by the selsyn transmitter geared to the drive train. Scram was accomplished by deenergizing a scram valve that dumps the supporting oil pressure to a low pressure reserve. The resulting unbalanced force causes the cylinder to retract from the stop at an initial acceleration of about $1.5 \mathrm{~g}$. The rod is decelerated by a hydraulic buffer incorporated in the cylinder head. A limit switch in the adjustable stop automatically signals the drive to move the stop down to maintain contact with the cylinder rod. A speed control orifice in the hydraulic supply line limits the rising speed of the rod in the event of an accidental pressure reversal after disengagement from the stop.

The coarse control drive consists of the hydraulic cylinder alone, because the twin screw positioned stop is not required for this drive. Rod position is indicated by a selsyn transmitter geared to a rack and attached to the cylinder rod. The cylinders for both the fine and coarse control drive are identical. A shock absorber is mounted in the lower cylinder head to decelerate the control rod following a scram.

Core Design. The SEFOR core structure is made up of 109 hexagonal channels resting on a support plate. Each channel is fastened to the support plate by an orifice that is lowered in the channel, inserted through the support plate, and rotated 90 degrees to lock. Fuel and tightener components resting on the orifice prevent unlocking during operation. One-hundred nine channels are clamped around the periphery of the core, making a circle approximately $86 \mathrm{~cm}$ in diameter. Each channel contains a center tightener rod and six fuel rods, one in each corner of the hexagonal channel. The tightener rod is inserted into position after the fuel rods are in place. Fuel rods are individually removed and replaced. Channels are not removed from the reactor during normal servicing. The channels are
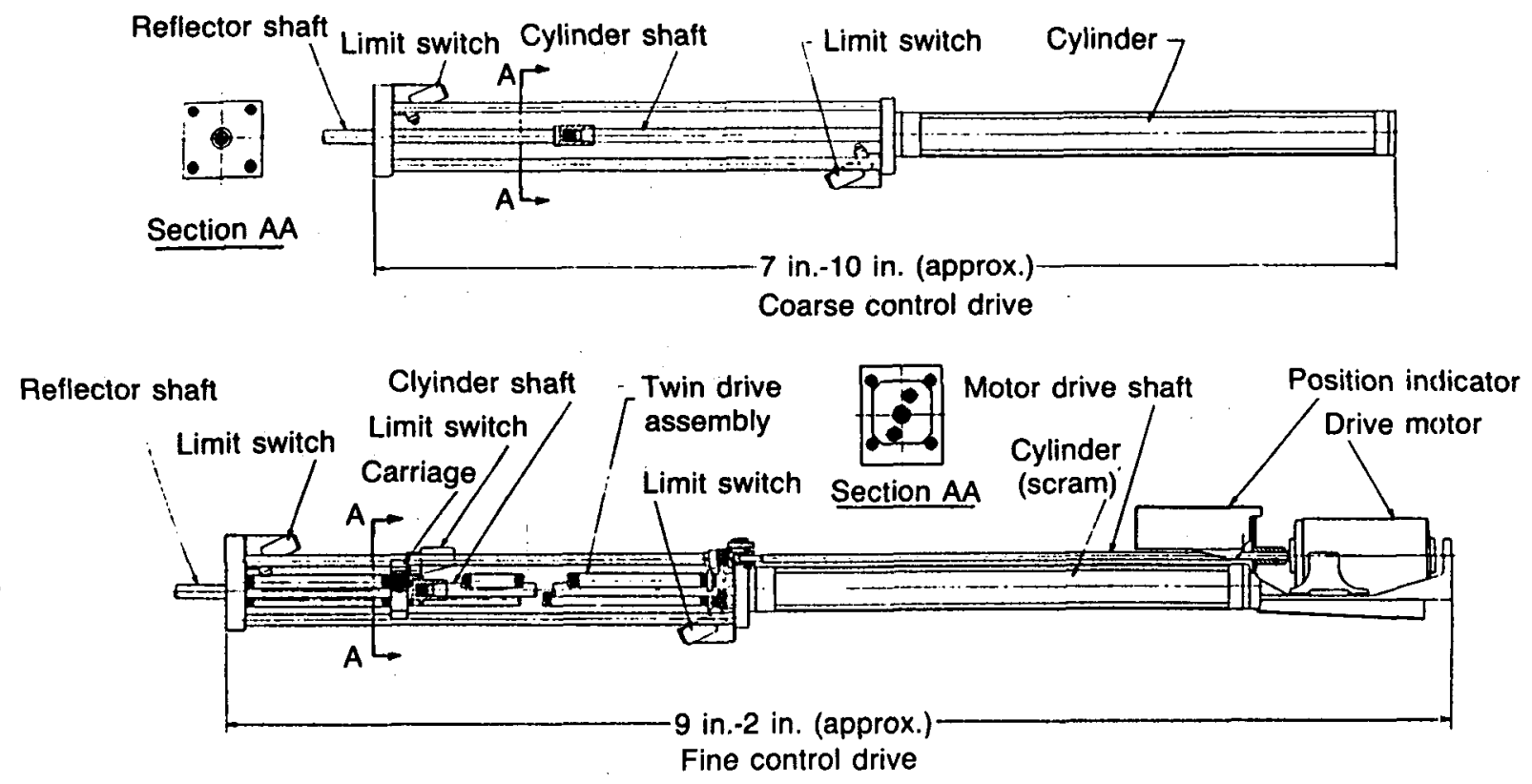

Figure A-56. SEFOR reflector control drive. 
approximately $254 \mathrm{~cm}$ long. The top of the channel is $20.3 \mathrm{~cm}$ below the top of the fuel rods to provide for the routing of instrument leads from the instrumented fuel rods.

The fuel rod assembly consists of two pieces: a fuel rod and an extension rod. The two sections are pinned together to form the fuel rod assembly.

The active fuel column in the core is $85.9 \mathrm{~cm}$ long. A $10.2-\mathrm{cm}$ nickel reflector is located above and below the fuel. Both fuel and reflector are contained inside Type-316 stainless steel tubing, $2.54-\mathrm{cm}$ $\mathrm{OD}, 1.4-\mathrm{m}$ wall thickness. The lower end of the fuel rod fits into a rod sheet in the channel assembly. The upper end provides a connector for attachment to the extension rod.

The fuel extension rod consists of borated graphite pellets contained in $2.22-\mathrm{cm}-\mathrm{OD}$ tubing. A socket at the upper end provides a grapple tool attachment. The upper end of the extension rod and fuel rod are identical so a single grapple tool can handle either section after detachment. Splined regions enlarged the diameter to $2.54 \mathrm{~cm}$ at elevations where the tightening springs are needed. Splines are necessary for passage of adequate coolant.

Development Testing. Early in the planning of the SEFOR program it became obvious that several areas of the reactor would need development testing to ensure satisfactory performance. The variety of power transients, ranging from oscillatory experiments to prompt power excursions, placed unusual operating conditions on the reactor components. It was desirable to have information on core behavior to help interpret the experiments during operation. Consequently, a development test program was planned covering critical experiments: in-pile and out-of-pile testing of fuel assemblies and core; refueling cell mock-up; instrumentation; and special reactivity controls.

A series of critical experiments was conducted with a mock-up of the SEFOR core and the ZPRIII critical facility at the Idaho National Engineering Laboratory. Measurements included the plutonium requirement, Doppler coefficient, and reflector control strength. Results of these experiments were used to check the calculational techniques used in the SEFOR analysis. A-55-57
The mock-up represented four main sections:

- Core

- Radial and axial reflector

- Sodium and steel structure between core and reflector

- Boron carbide neutron shielding surrounding the radial reflector.

Experimental Program. The experiments performed at SEFOR were to obtain power coefficient information applicable to large fast power reactors at steady state conditions and during fast transients. Experiments between these two domains, i.e., for slowly varying oscillatory operations, were also carried out with SEFOR to provide further information. The goal of the SEFOR test program was to make it possible to predict with confidence the safety characteristics of future large fast ceramic power reactors.

It was shown that a low-power experimental reactor, with large-diameter fuel rods, can give information on power coefficients directly applicable to high-power reactors with small-diameter fuel rods under steady state and fast transient conditions. A-58

SEFOR experiments indicate that the reactivity effect caused by the change between two steady state power levels with unchanged fuel clad temperature is independent of fuel rod radius. This reactivity effect is the product of the change in power per unit length of rod and a parameter, G, or

$\Delta \mathrm{k}=\mathrm{G} \Delta(\mathrm{P} / \mathrm{nH})$,

where $\mathrm{n}$ is the number of rods, $\mathrm{P}$ is the power, and $H$ is the rod length. For a given fuel material, $\mathrm{G}$ depends only on $\mathrm{P} / \mathrm{nH}$ and the fuel temperature coefficients.

A similar result was obtained at SEFOR for fast transients during the period when power is changing fast enough that heat conduction of the fuel rod can be ignored. For this case the time-dependent feedback reactivity is

$\Delta \mathrm{k}=\mathrm{Y} \Delta\left(\mathrm{E} / \mathrm{V}_{\mathrm{f}}\right)$, 
where $E$ is the excess energy produced during the excursion to time $t$ and $V_{f}$ is the fuel volume. For a given fuel material, $\mathrm{Y}$ is a function only of the fuel temperature coefficient $\left(\mathrm{P}_{\mathrm{O}} / \mathrm{nH}\right)$, and $\left(\mathrm{E} / \mathrm{V}_{\mathrm{f}}\right)$, where $P_{O}$ is the power level at the start of the excursion. Again, the radius of the fuel rod did not enter explicitly.

Three types of steady state tests were made at SEFOR. The purpose of these was to measure the following:

- The power coefficient associated with changes in fuel temperature only

- The coolant temperature coefficient

- The combined fuel and coolant temperature coefficient

- The flow coefficient and effect of minor changes in structure geometry.

The first test was the reactivity measurement described by Equation (A-7). The reactivity effect caused by changing the steady state power level while holding the average coolant and structure temperature constant was measured. The average coolant temperature was held constant by variation of the primary flow rate and variation in secondary coolant conditions. The channel and BeO temperatures follow the coolant temperature. Second order corrections were made for small changes in average clad temperature. In these steady state tests, the Parameter, G, of Equation (A-7) was measured as a function of $\mathrm{P} / \mathrm{nH}$ for the SEFOR oxide fuel up to $\mathrm{P} / \mathrm{nH}$ equals $11 \mathrm{~kW} / \mathrm{ft}$, the value at $20 \mathrm{MW}$.

To the extent that the thermal conductivity of the SEFOR fuel was known, the Parameter G could be related to the fuel temperature coefficient. SEFOR fuel was designed to minimize the axial fuel expansion coefficient so that the Doppler effect accounts for most of the fuel temperature coefficient. In this way, the first type of steady state test provides a measurement of a Doppler coefficient.

The coolant temperature coefficient can then be measured independently of fuel temperature effects. While operating at a fixed power level, the reactivity effect caused by changing the average sodium temperature is measured. The sodium temperature can be changed either by altering the primary flow rate or by altering the secondary coolant conditions. The effect of radial expansion of the structure is included in the coolant coefficient because the structure temperature follow the sodium temperature. Radial expansion is not controlled by the grid plate in SEFOR so a grid plate coefficient was not included.

The combined fuel and coolant uniform temperature coefficient was measured at zero power by externally heating the sodium. Provisions were made to heat the sodium to $540^{\circ} \mathrm{C}$. The response to reactivity oscillations from zero power to high power was measured to determine the feedback transfer function. At low frequencies, the feedback reactivity provides a measure of a steady state Parameter, G [Equation (A-7)] which involves the Doppler coefficient and the fuel conductivity, $k$. These oscillator results in effect duplicate and verify the steady state measurement. At high frequencies the feedback reactivity provides a measure of a transient parameter [Equation (A-8)], which involves the Doppler coefficient and the heat capacity, or $\mathrm{pC}_{\mathrm{p}}$. The high frequency results provided an independent measurement of the parameters important to the transient behavior of the reactor and permitted a prediction of its transient performance prior to the transient tests. At intermediate frequencies, the feedback reactivity is characteristic of neither steady state nor fast transient operation alone; the results depend on both $\mathrm{k}$ and $\mathrm{pC}_{\mathrm{p}}$.

Fast transient tests were made to obtain information about the energy coefficient $Y$ of Equation (A-8), a parameter relating fuel temperature to the heat capacity. The transient experiments came after a thorough analysis of the steady state and oscillator tests.

Both subprompt critical transient $(\Delta \mathrm{k}<\$ 1)$ and prompt critical transients were run. Reactivity ramps were introduced by injecting poison from the center of the core by means of a fast reactivity excursion device (FRED). Maximum ramp rates and maximum values for FRED depend on the values obtained for the Doppler coefficient from the steady state and oscillator tests. The transient test program was not intended to approach the regime where fuel damage would result.

Demonstration of Equipment Reliability in Oporating Lifetime. Two designs measured the sodium level in the SEFOR reactor vessel. The reliability of either design was satisfactory for short periods, several months, the number of months depending on service conditions during the time. However, without 
frequent cleaning or special care, the performance of either was inadequate for operating periods of several years. A-59

During the more than three years of operation, the electromagnetic sodium pumps operated without a malfunction. Some malfunctions of pump power supply and controllers did occur, but these components were easily and quickly repaired. The reliability of fuel grapples for nearly 4,000 fuel transfers was very good.

\section{USSR BR-5}

The first USSR fast reactor, BR-1, was built in 1955 as a zero energy assembly; it was fueled with plutonium and was used to investigate fast reactor physics. The work was extended by BR-2, a plutonium filled, mercury-cooled reactor built in 1956 and operated to $100 \mathrm{~kW}(\mathrm{t})$. The BR-2 provided the facilities for physics experiments and irradiation of materials in fast neutron fluxes at $10^{14}$ neutrons/ $\mathrm{cm}^{2} / \mathrm{s}$, and furnished experience in operating at temperatures to $160^{\circ} \mathrm{C} . \mathrm{A}-60,61$

The BR-2 was dismantled in parts, such as shielding, for use in construction of the BR-5 reactor which was completed in 1958. It went cold critical in the summer of 1958 and was in operation the summer of 1959. The BR-5 operated at a power of $5 \mathrm{MW}(\mathrm{t})$, was fueled by plutonium oxide, and had sodium inlet and outlet temperatures of 375 and $450^{\circ} \mathrm{C}$, respectively. The main purpose of the reactor was to gain burnup data on fuel elements, to gain experience operating radioactive sodium circuits and to irradiate various materials. Since it was not considered necessary to obtain further data on breeding gain, the design was simplified by omitting the normal blanket of natural or depleted uranium. A-62,63

The reactor started up at zero power July 1958 . From July 1958 to January 1959, the assembly of the primary loop was completed and startup modifications were accomplished. In January 1959, the reactor was started up with sodium coolant. From January to July 1959 , the reactor operated to $1 \mathrm{MW}$. On July 21, 1959, full power of $5 \mathrm{MW}(\mathrm{t})$ was reached. Later, the reactor was operated at various levels to $5 \mathrm{MW}(\mathrm{t})$ to obtain a $450^{\circ} \mathrm{C}$ sodium outlet temperature. The sodium temperature in the primary loop was raised to $500^{\circ} \mathrm{C}$ in December 1960. During 1960 and 1961 , the reactor was used for experiments: (a) calibration of control rods, (b) determination of circulating sodium's effect on reactivity, (c) measurement of temperature and power coefficients, (d) determination of spatial neutron-energy distribution and heat generation, (e) measurements of neutron flux in experimental channel sections of the reactor, and (f) determination of radioactivity effects and safety aspects.

The general arrangement of the reactor is shown in Figure A-57. An unusual feature is the horizontal graphite column, $3.1 \mathrm{~m}$ long, which penetrates one side of the shield and provides a number of locations for horizontal and vertical experiments. Maximum power density was $500 \mathrm{~kW}(\mathrm{t}) / \mathrm{L}$ corresponding to a maximum heat flux of $1.39 \mathrm{MW} /$ $\mathrm{m}^{2}$.

Core Assembly. The core consisted of 88 hexagonal fuel assemblies, $2.6 \mathrm{~cm}$ across flats and $83.8 \mathrm{~cm}$ long, surrounded by two rows of blanket subassemblies. Each fuel subassembly, shown in Figure A-58, contained 19 stainless steel clad pins filled with plutonium oxide pellets and sealed after they had been charged with helium gas. The pins were $0.5 \mathrm{~cm}$ OD. The fuel itself was about $0.41 \mathrm{~cm}$ in diameter, and the cladding was $0.041 \mathrm{~cm}$ thick. The pins were separated by spiral wire spacers. Subassemblies were supported at the bottom by a perforated plate. The core subassemblies and a ring of tubes loaded with natural uranium were enclosed in a stainless steel vessel approximately $36 \mathrm{~cm}$ in diameter. Clearance between subassemblies was $0.05 \mathrm{~cm}$. The core itself was approximately $28 \mathrm{~cm}$ by $28 \mathrm{~cm}$. There was no top plate, and no positive lateral restraint was provided at the center or top. Sodium flowed up through the core from a single inlet at the bottom of the central sodium tube to a single outlet above the core that supplied two cooling circuits.

Control Elements. Movement of an inner and outer cylindrical reflector was used to control the reactor. The inner nickel cylinder, $5.1 \mathrm{~cm}$ thick, was raised or lowered by cables; the outer 10 -cm-thick nickel cylinder had two movable sections that provided fine control. Emergency shutdown was accomplished by electromagnetically releasing these two cylinders. In addition, two controls operating in the outer cylinder provided shim adjustment. Heat generated in the reflector was removed by air. Startup instrumentation was located in the water tank outside the reflector, as shown in Figure A-57.

When the assembly was heated from 40 to $600^{\circ} \mathrm{C}$, the radioactive gas release rate increased by 


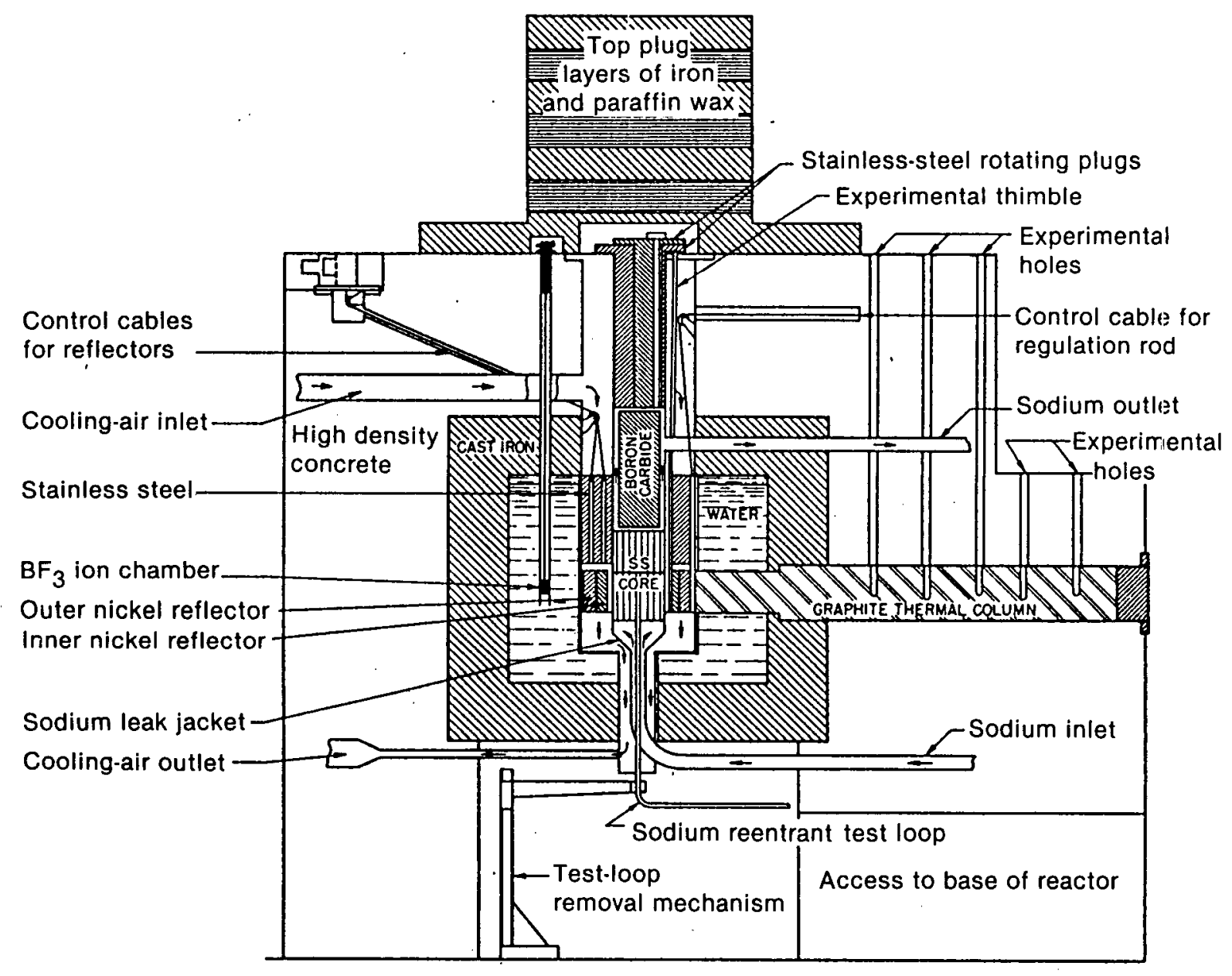

Figure A-57. General arrangement of the USSR fast reactor BR-5.

a factor of $10^{3}$ to $10^{4}$ times. During the course of testing in a storage hood, the two assemblies previously having activities below background level showed very marked gas release when they were heated to $500^{\circ} \mathrm{C}$. Heating to $700^{\circ} \mathrm{C}$ revealed a high activity in the majority of assemblies. To be certain no irreversible changes occurred in the fuel cladding as a result of heating to $700^{\circ} \mathrm{C}$, two of the seven assemblies showing marked activity after heating to that temperature were retested at 40 and $400^{\circ} \mathrm{C}$ after cooling, with no major gas release being observed.

The fuel used for the second loading of the BR-5 reactor's active core zone was uranium monocarbide with a $90 \%$ U-235 enrichment and an overstoichiometric carbon content. The density of the uranium monocarbide was $12 \mathrm{~g} / \mathrm{cm}^{3}$. The original dimensions of the fuel element assemblies were retained, but the design was changed. Each assembly in the new active core zone contained seven fuel elements, having a diameter of $76.5 \mathrm{~cm}$ and a height of $38.0 \mathrm{~cm}$. The fuel in the element was encased in stainless steel cladding. Clearance space between the fuel and cladding was filled with helium, and stainless steel wire $0.4 \mathrm{~m}$ thick was used as a spacer. A space $50 \mathrm{~mm}$ high was left above the fuel elements to collect gaseous fission products. The calculated maximum temperature of the fuel at the center of the elements was $800^{\circ} \mathrm{C}$.

Startup of the monocarbide-fueled BR-5 reactor took place in May 1965. The fuel element assemblies were loaded in the active core zone of the reactor which had previously been filled with sodium. Criticality was reached when 83 assemblies of uranium monocarbide fuel elements $(99 \mathrm{~kg} \mathrm{lJ}-235)$ had been loaded together with 20 blanket assemblies containing natural uranium metal of the original design. The critical mass obtained agreed fairly closely with the data acquired using the twodimensional calculation in the 18-group diffusion 

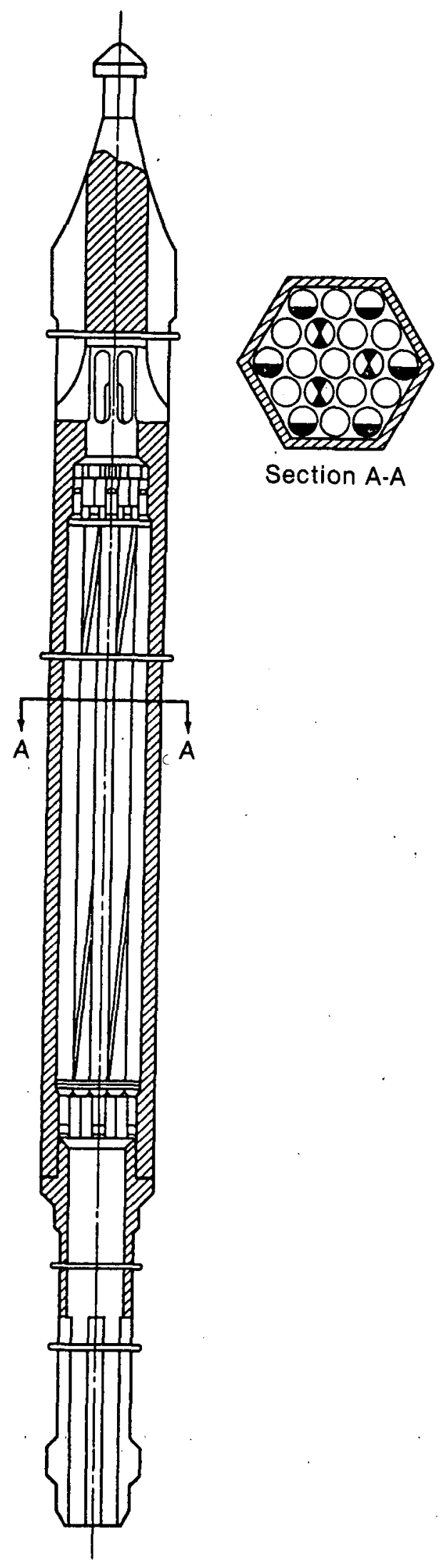

Section A-A approximation, which predicted a critical mass of 89 assemblies.

To conduct further studies on fuel burnup in the reactor, four assemblies of plutonium oxide elements were loaded; these elements previously had been in the facility and had reached a burnup of approximately $6 \%$. At the same time, two assemblies of plutonium dioxide elements and two assemblies of uranium dioxide elements with a burnup to $1 \%$ were inserted in the reactor. The plutonium dioxide was also used as a startup neutron source by using the (alpha, $n$ ) oxygen reaction and the spontaneous fission of plutonium-240.

After the fuel had been loaded, studies were carried out on the reactor characteristics. Heat generation over the radius and height of the active core zone was calculated on the basis of gamma activity distribution in the fuel element assemblies that were mounted at different radii. The effect of the drainage of sodium from the active zone was measured by emptying all the sodium from the central reactor pipe under subcritical conditions. The reactor temperature coefficiert, which is related to the uniformed heating of the elements in the active zone and the increase in the temperature of the sodium at the reactor inlet, was measured at different power levels ranging from 10 to $4000 \mathrm{~kW}$. The temperature coefficient was found to be constant for sodium inlet temperatures ranging from 180 to $430^{\circ} \mathrm{C}$. The steady state power coefficient, which is a function of the nonhomogeneous heating of the reactor elements, was measured on the basis of the change in reactivity as power increased at the constant sodium inlet temperature. The steady state power coefficient was constant throughout the power range measured. The reactor power effect was measured by observing the reactivity curve after power was stepped up by $10 \%$ at a starting value for various sodium flow rates. In each measurement, the inlet temperature of the sodium rose by $75^{\circ} \mathrm{C}$.

Two temperature coefficients of reactivity were measured in BR-5, one relative to the inlet temperature and the second relative to the outlet temperature. These agreed with predictions and were both negative. The fuel elements; supported in a lower support plate, were free to move at the top to take up any tolerances in the lower plate. The pins within the subassemblies were welded together at the bottom. Alternate pins were wound spirally with stainless steel wires, which acted as spacers. Bowing of pins in the subassemblies tended to

Figure A-58. BR-5 fuel assembly.

Fuel pin 
cause the outer element tubes to move outward to reduce reactivity. An increase in coolant flow had a similar effect.

Coolant System. The coolant system was split into two $10-\mathrm{cm}$-diameter primary loops. The pump seal and bearings operated in argon cover gas continuously circulated through a silica gel dryer and then through copper-coated silica gel heated to $250^{\circ} \mathrm{C}$. The totally enclosed pump motor was likewise maintained under an argon gas pressure slightly higher than that of the system, so any possible leakage was through the gland into the system.

Heat was transferred from the primary loops by two intermediate heat exchangers to two secondary loops. One of these NaK-filled secondary loops was provided with a $1.69-\mathrm{MPa}$ steam generator having duplex tubes. Mercury was used as a heat transfer medium in the space between the inner and outer tubes. An air-cooled heat exchanger and a blower, delivering $11 \mathrm{~m}^{3} / \mathrm{s}$ of air, were used to reject the heat in the other loop through a $24.4-\mathrm{m}$ stack. Residual heat after shutdown was also removed in this loop by natural convection.

Shielding, Components, and Structures. A water tank surrounded the core and provided a $51-\mathrm{cm}$ shielding annulus. Surrounding this was a $41-\mathrm{cm}-$ thick cast iron ring followed by a concrete wall with an average thickness of $109 \mathrm{~cm}$, as shown in Figure A-57. Composing the upper shield were a boron carbide plug, two rotating steel plugs, and finally a removable top plug (consisting of layers of parafin wax and iron).

The lower shield consisted of a 20-cm-deep water layer, which allowed entry to the cell under the reactor only during shutdown.

Fuel loading was accomplished through a double eccentric rotating plug arrangement. During refueling, the reactor was shut down, and sodium circulation in a primary loop was stopped. Decay heat was removed by natural convection. A transfer cask unit was used for charging fuel, uranium, and experimental units. The reactor had no outer containment building. The primary loops were housed in separate concrete cells, and the secondary circuit equipment was contained within a single compartment.

Experimental Facilities. The reactor had been designed not only to permit sample radiation under fast flux conditions but also to allow the insertion of special fuel subassemblies in the core in place of normal elements. A 2.54-cm-diameter reentrant tube in the center of the core, designed for testing fuel elements, was cooled with a separate $\mathrm{NaK}$ cooling system. In this central loop, a peak flux of $10^{15}$ neutrons $/ \mathrm{cm}^{2}$. $\mathrm{s}$ was available. A flux of onehalf this value was available in the exposure holes at the end of the core.

Operating Experience. Pump life was mainly determined by ball bearing capabilities; it averaged $8,000 \mathrm{~h}$. Replacement of primary equipment, including cold traps, usually started a week after shutdown following sodium gamma decay. The cold traps in the primary system were replaced four times during the first 4 years of operation.

In October 1960, with about $2.5 \%$ maximum plutonium burnup, the leakage of fission products into the sodium became pronounced. By September 1961, the cesium activity in the sodium was $70 \%$ of total cesium. At this time, the fuel burnup had reached $4.85 \%$. The reactor was unloaded, and the subassemblies were steamblasted clean. During cleaning, some of the subassemblies showed considerable increase of radioactivity in the steam condensate owing to increased failure of fuel pin cladding. Steam cleaning was discontinued, and a leak test, with an ionization chamber, was then made to check each subassembly to measure fission gas activity. Of the 81 subassemblies tested, 8 had been washed with steam; of the remainder, 63 showed normal sodium impurity activity, and 10 had a gas activity higher by a factor of 1,000 . Examination of the $4.85 \%$ burnup pins showed longitudinal cracks in the cladding caused by fuel swelling. The cracks showed up with a clearance between cladding and fuel that was at a minimum.

After fuel removal, the primary system was drained clean with steam at $\sim 0.1 \mathrm{MPa}$ and $\sim 120^{\circ} \mathrm{C}$ by injecting the steam into vent lines and removing the sodium from the low points in the reactor system. The system was kept at about $150^{\circ} \mathrm{C}$ prior to steam injection. About $9,000 \mathrm{~kg}$ of steam was used, and no violent reactions occurred. Contamination of the primary system was reduced $50 \%$. The system was then filled with pure water twice, with no circulation, and drained. There was no decrease in activity. Each section of the primary system, excepting a nickel basket in the reastor, was then cleaned with a solution of $5 \%$ nitric acid at about $70^{\circ} \mathrm{C}$, with three successive flushes to reduce the activity by a factor of two to three. Noreover, two sections were subjected to a $0.5 \% \mathrm{KMnO}_{4}$ 
solution flush for $24 \mathrm{~h}$ at about $70^{\circ} \mathrm{C}$, a $5 \%$ nitric acid and $1 \%$ oxalic acid mixture flush for 3 to $4 \mathrm{~h}$ at $70^{\circ} \mathrm{C}$, and a pure water flush for $1 \mathrm{~h}$ at about $70^{\circ} \mathrm{C}$. The three flushes were repeated five times. Activity was reduced to a value low enough so that repair work could begin. A total of 21 flushes per section were performed, including the steam flush. This indicates the possible consequences of plating out fission products on system components. Radiochemical analysis showed plutonium, zirconium, and cesium as the residual activity. After the final drain, the primary system was dried using vacuum and heat. Following repairs the system was filled with distilled sodium. The reactor was placed back in operation in March 1962 after a 7 month shutdown. Eighty percent of the original bundles were placed back in the reactor. Subsequent reports indicate some of these began to leak soon after startup. A-62-65

After March 1962, the charge in the BR-5 active core zone was replaced by plutonium dioxide and uranium dioxide assemblies. For further operation, the reactor was loaded with $80 \%$ plutonium dioxide assemblies from the original charge, with a maximum burnup of $4.85 \%$ and uranium dioxide assemblies of similar design. $\mathrm{PuO}_{2}$ assemblies were concentrated in the central part of the active core zone. While loading the assemblies they were rearranged in order to equalize their burnup during subsequent operation of the reactor. ${ }^{A-66}$

During 1962 and 1963, BR-5 operated at 20 and $40 \%$ of its rated power. In 1964, the output was stepped up to $3 \mathrm{MW}$ and then $3.5 \mathrm{MW}$, set equal to $70 \%$ of the rated power. After operating 3 years with fuel elements that had reached high burnup and had leaks in the cladding, it was possible to acquire some experience and information about the contamination of the coolant, inert gas, and primary circuit equipment, because of the radioactive fission products. It was found that the release of gaseous and volatile solid fission products from the fuel elements to the coolant was mainly dependent on the reactor power, and therefore on the temperature of the fuel elements. At a power of $1 \mathrm{MW}$, there was virtually no release of fission products from the fuel elements, and a contamination of the circuit was found to consist of Cs-137. The Cs-137 in the coolant was approximately $0.3 \mathrm{mCi} / \mathrm{g}$ of sodium and was caused by the residual contamination of the primary coolant; in addition, the quantity of cesium removed from the sodium by the cold trap was extremely small. At a reactor power level of $3.5 \mathrm{MW}$, the release of fission products increased considerably. The radioactive contamination of the primary circuit, after the decay of the sodium-24, consisted of relatively short-lived fission products: iodine-131, barium-140, lanthanum-140, cesium-136, and cesium-137. The activity of the iodine-131 was greater than that of the other isotopes amounting to $30 \mathrm{mCi} / \mathrm{g}$ of sodium. At the same time, it was found that the amount of iodine-131 released from the leaking fuel elements was usually lower than that of the cesium-137 release. Fission products such as iodine-131, cesium-136, and cesium-137 were efficiently retained by the oxide cold trap. For example, a sodium oxide cold trap that had been in use for 2 years, was cut out of the circuit in the middle of 1964. The total activity of the cesium-137 in this cold trap was found to be 10 times that of the cesium then present in the primary circuit. A-67

The cold trap did not possess any great efficiency with regard to the retention of isotopes such as zirconium-95, niobium-95, barium-140, and lanthanum-140; these radionuclides were mainly deposited on the walls of the equipment and the piping. In 1964, when the reactor was running at 3.5 MW, special studies were performed to examine the influence of the cold trap on activity of the fission products in the coolant and on the walls of the primary circuit piping. With the aid of of a gammaray scintillation spectrometer, measurements were made on the bypass section of the primary circuit. The measurements showed that when the cold trap was working, activity of the coolant in the pipe wells attributable to cesium-137 and iodine-131 were only one-tenth of that when the cold trap was not in use.

Activity of gaseous fission products in the gas spaces markedly depended on the power level. At a power of $1 \mathrm{MW}$, the xenon-133 and xenon-135 activity was of the order of a few tenths of a millicurie per liter; however, at $3 \mathrm{MW}$ it amounted to 20 and $5 \mathrm{mil}-$ licuries per liter and at $3.5 \mathrm{MW}$, to 250 millicurie per liter, respectively. Despite different conditions for the release of gas from the sodium to gas spaces in the circuit (pumps, central reactor pipe) the average xenon-133 activity in the gas blankets was roughly the same. Yet the ratio of xenon-133 to xenon-135 in them was quite different.

At a fairly high iodine-131 content in the coolant and on the walls of the flow equipment, the release of iodine-131 to the gas spaces in the primary circuit was not very marked. The iodine- 131 activity in the gas did not exceed $10^{-2}$ millicuries/liter, 
which was lower than the xenon-133 and xenon-135 activity by a factor of $10^{3}$ to $10^{4}$.

Measurement of circulating gas activity revealed the presence of neon-23 [formed from sodium-23 by the $(n, p)$ reaction] in the inert gas of the primary circuit. Total activity of the neon in the circuit's gas spaces was about 50 curies. Circulating sodium activity in the bypass section was measured a few minutes after reactor power was increased because at that time there would be low sodium 24 activity. It was therefore possible to determine the neon activity in the coolant which was equal to $0.6 \mathrm{Ci} / \mathrm{L}$ or about 1,000 curies for the entire circuit.

In November 1964, additional leaks in the plutonium dioxide fuel elements resulted in major increases in gaseous and solid fission products in the sodium circuit. Consequently, BR-5 was shut down to allow loading of monocarbide fuel into the active core zone. At the time the reactor was shut down for reloading, the maximum burnup in the plutonium dioxide fuel element forming part of the original charge was $6.5 \%$ and that of the $90 \%$ enriched uranium oxide elements $1.4 \%$. At this time, the fuel elements and some of the uranium monocarbide assemblies placed in the reactor in 1964 to study their efficiency had reached a total burnup of $0.8 \%$. Loading the reactor's active core zone was followed by completion of maintenance work, mainly directed at replacing leaky drainage valves in the primary circuit loops. Cables in various control systems associated with the main circuits were replaced, owing to their unsatisfactory electrical insulating properties and the need to attach additional experimental devices to the reactor.

In January 1965, the active core zone was entirely unloaded in $9 \mathrm{~d}$ and placed in the spent fuel storage area. Unloading was carried out without cooling of the assemblies. The sodium and its oxides were not washed from the bundles removed from the active core zone.

In an attempt to examine the possibility of unloading high activity fuel assemblies into molten lead, 10 assemblies which had just been removed from the active zone were immersed in casks containing molten lead at approximately $500^{\circ} \mathrm{C}$. No external signs of a reaction were observed when the sodium on the surface of the assembly dissolved in the lead. The residual sodium was washed off the assemblies when they were replaced in the lead; in addition, the source of any radioactive contamina- tion was localized in the event that any fuel elements in the assembly were defective. The assemblies removed and placed in molten lead consisted of 8 plutonium dioxide assemblies with a maximum burnup of $6.2 \%$ and 2 uraniurn dioxide assemblies with a maximum burnup of $1.4 \%$. A month after fuel unloading, a check was conducted on the leak tightness of the fuel elements' cladding and all the assemblies in storage. Gas was drawn off into an ionization chamber through a pipe mounted in a space between the hood of the storage area and the bundle in it. The temperature of the assemblies was determined on the basis of the afterheat (approximately 40 watts per assembly) and the temperature of the surrounding air. The activity of the gas drawn off the assemblies provided an indication of the leak tightness of the fuel cladding. In this way, checks were carried out on 59 aissemblies containing plutonium dioxide elementis with a burnup of up to $6.5 \%$, and 21 assemblies containing uranium dioxide and uranium morocarbide with a burnup of up to $1.5 \%$. In the course of the check performed, all the uranium assemblies and 32 of those containing plutonium were found to be leak tight; activity of the gas released from them did not exceed that of the gas from the dummy assemblies containing metallurgical specimens. These specimens were removed from the active core zone and, like the hot assemblies, had not been washed free of sodium. Gas activity from the 17 plutonium assemblies with a burnup of more than $5.1 \%$ was greater than the background by a factor of 10-1,000. Measurement of a gamima spectrum of a gas from the assemblies showed the activity was made up of krypton-85 (measurements were performed 4 months after shutdown of the reactor).

To study the active gas released from leaking fuel elements, tests were made on two of the leaking assemblies and 15 assemblies emitting background activity. The tests were performed in a special hood fitted with an electric heating element and a thermocouple. In both leaking assemblies, a marked correlation was observed between the gas release and the assembly temperature.

Early Power and Test Reactors. The early power and test reactors were developed in the Federal Republic of Germany, France, Italy, Japan, United Kingdom, United States, and the Union of Soviet Socialist Republic. They were primarily intended to demonstrate an integrated LMFBR system, including the capability for electrical genera- 
tion. Experiments were conducted on the dynamic behavior of the various reactor systems under operating conditions comparable to those existing in a large-scale power plant. A great number of data have been gathered with respect to fuel-claddingcoolant capability, performance limits of ceramic, alloy, and metallic fuels, reprocessing and recycling technology, basic nuclear data, Doppler coefficients, sodium buoyancy effects, component development, instrumentation and control, and sodium technology. These reactors have provided the performance data needed for the safe design, siting, construction, and operation of prototype and demonstration LMFBRs. The characteristics of the early power and test reactors are summarized in Table A-8.

\section{Federal Republic of Germany}

KNK-2 Operating Experience. Konpakte Natrigumekuhlte Kernreaktoranlage (KNK) at Karlsruhe was the first liquid sodium-cooled power station in Germany. KNK was a turnkey project with Gesellschaft Fur Kernforschung being the owner, Interatom the manufacturer, and KBG the operating company. It has a power rating of $60 \mathrm{MW}(\mathrm{t})$ and $19 \mathrm{MW}(\mathrm{e})$. Construction began in May 1966, and sodium filling was completed by November 1969. The first criticality was achieved in August 1971, and the first electricity was fed into the public grid in August 1972. Because of problems encountered, operation was partially interrupted during the summer of 1973 , and granting of the power operating license was delayed. The problems included sodium frost deposits in the gaps of the rotating shield system and in the second shutdown rods; radiation resistant grease showed insufficient lifetime under certain mechanical loads in the main valve drives; and an intermediate-size leak in the steam generator caused a $\mathrm{Na} / \mathrm{H}_{2} \mathrm{O}$ reaction. The leak was not strong enough to break the rupture disk in the steam generator. In addition, a transient partial blockage of one fuel element remained unexplained. After December 1973, the KNK was operated according to schedule. The operating and $100 \%$ power license was achieved in February 1974. A-68-71

The transformation of a KNK into a fast reactor during 1976 and 1977 necessitated changes to the reactor vessel's internals, the fuel handling system, and the reactivity control system. It also required a new licensing procedure. This procedure posed special problems, as newer safety criteria were being applied to an existing installation; consequently, the decay heat removal capabilities and the redundancy of instrumentation cabling had to be improved.
The core of the KNK-II experimental breeder power plant was designed as a two-zone core. The reactor power was $58 \mathrm{MW}(\mathrm{t})$ and $28 \mathrm{MW}(\mathrm{e})$ with a rod power of $450 \mathrm{~W} / \mathrm{cm}$. This first core of KNK-II has fuel rods with 6-mm-diameter and sparkeroded grid type spacers. Surrounding the test zone are $\mathbf{2 2}$ fuel elements of the dragger zone, as well as the five units of the primary and three units of the secondary shutdown systems.

The first core of KNK-II was decommissioned on August 30, 1982, after an inpile time of 400 equivalent full-power days. The fuel elements of the test zone had obtained peak burnups up to $100,000 \mathrm{MWd} / \mathrm{t}$, exceeding the design level by nearly $20 \%$.

Failed Fuel Rod Detection - In KNK-II, failed fuel elements are detected by continuous global monitoring of the reactor cover gas, of the argon cover gas for fission products, and of the primary coolant for delayed neutrons. Gas monitoring is performed using a gas chromotograph, a xenon absorption bed with an activated carbon filter, three different precipitators, and an on-line gamma spectrometer with a $\mathrm{Ge}(\mathrm{Li})$ detector. The system immediately detected the two fuel element failures of 1979 and 1980. Localization of a failed element is done in the following manner:

- Detection of different count rates of the delayed neutron signal in the two circuits, which allows the failed fuel element to be assigned to either the western or eastern sections of the cooler.

- Comparison of the calculated and the measured xenon $131 /$ xenon 134 ratios, which allows the distinction between a test element and a driver element.

- Behavior of the delayed neutron signal during skewed load operation, which allows the failed fuel element to be assigned to a core quadrant. Localization proper is then carried out by the dry sipping method in the refueling machine.

Disassembly and Postirradiation Examination-The two failed KNK-II fuel elements for the SNR 300 were dismantled in a hot cell without difficulty in a reasonably short time. The postirradiation examination (PIE) of the two fuel rods involved in the 1979 fuel element failure indicated the defects were not caused by design errors. Most probably, the defects were caused by fabrication techniques,

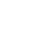

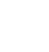


Table A-8. Early power and test reactors

\begin{tabular}{|c|c|c|c|c|c|c|c|c|c|}
\hline & \multicolumn{9}{|c|}{$\begin{array}{c}\text { Reactor } \\
\text { (Country) }\end{array}$} \\
\hline & $\begin{array}{c}\text { DFR } \\
\text { (UK) }\end{array}$ & $\begin{array}{l}\text { FERMI } \\
\text { (USA) }\end{array}$ & $\begin{array}{l}\text { EBR-II* } \\
\text { (USA) }\end{array}$ & $\begin{array}{l}\text { RAPSODIE** } \\
\text { (France) }\end{array}$ & $\begin{array}{l}\text { BOR-60 } \\
\text { (USSR) } \\
\end{array}$ & $\begin{array}{c}\text { KNK-2 } \\
\text { (Germany) } \\
\end{array}$ & $\begin{array}{c}\text { JOYO } \\
\text { (Japan) } \\
\end{array}$ & $\begin{array}{r}\text { FFTF } \\
\text { (USA) } \\
\end{array}$ & $\begin{array}{r}\text { PEC } \\
-(\text { Italy) } \\
\end{array}$ \\
\hline \multicolumn{10}{|l|}{ General } \\
\hline Date critical & 1959 & 1963 & 1963 & $1967 / 1970$ & 1969 & 1977 & $1977 / 1981$ & 1980 & 1985 \\
\hline Date full power & 1963 & 1970 & 1965 & $1967 / 1970$ & 1973 & 1979 & $1979 / 1982$ & 1980 & - \\
\hline Electrical power, MW & 15 & 65 & 20 & - & 12 & 21 & - & - & - \\
\hline Thermal rating, $\mathrm{MW}$ & 60 & 200 & 62.5 & $24 / 40$ & 60 & 58 & $75 / 100$ & 400 & 118 \\
\hline \multicolumn{10}{|l|}{ Core parameters } \\
\hline Core volume, $\mathrm{L}$ & 120 & 400 & 73 & $49 / 42$ & 60 & $250 / 70$ & $304 / 238$ & 1040 & 325 \\
\hline Core height, $\mathrm{m}$ & 0.53 & 0.77 & 0.36 & $0.34 / 0.32$ & 0.40 & 0.60 & $0.60 / 0.55$ & 0.91 & 0.65 \\
\hline Core diameter, $\mathrm{m}$ & 0.53 & 0.7 & 0.51 & $0.43 / 0.41$ & 0.43 & 0.82 & $0.79 / 0.76$ & 1.21 & 0.83 \\
\hline No. enrichment zones & 1 & 1 & 1 & 1 & 1 & 2 & 1 & 2 & 1 \\
\hline Core volume fractions & - & - & - & - & - & - & - & - & - \\
\hline$\%$ Fuel & 40 & 29 & 32 & $40 / 37$ & 40 & 32 & $33 / 35$ & 35 & 35 \\
\hline$\%$ Sodium & 40 & 50 & 49 & $34 / 36$ & 28 & 50 & $41 / 41$ & 41 & 38 \\
\hline$\%$ Other & 20 & 21 & 19 & $26 / 27$ & 32 & 18 & $26 / 24$ & 24 & 27 \\
\hline Peak flux, $10^{15} \mathrm{n} / \mathrm{cm}^{2} \cdot \mathrm{s}$ & 2.5 & 4.5 & 2.5 & $2.0 / 3.2$ & 3.3 & $1.8 / 2.2$ & $3.0 / 5.0$ & 7.2 & 4.1 \\
\hline Ave. flux, $10^{15} \mathrm{n} / \mathrm{cm}^{2} \cdot \mathrm{s}$ & - & 2.6 & 1.5 & $1.2 / 2.3$ & - & 1.0 & $2.0 / 3.0$ & 4.5 & 2.7 \\
\hline Peak linear power, $\mathrm{kW} / \mathrm{m}$ & 37 & 28 & 27 & $39 / 43$ & 56 & $35 / 43$ & $32 / 40$ & 42 & 36 \\
\hline Ave. linear power, $\mathrm{kW} / \mathrm{m}$ & 35 & 17 & 23 & $26 / 31$ & 35 & $16 / 31$ & - & 24 & 25 \\
\hline Peak power density, $\mathrm{kW} / \mathrm{L}$ & - & 774 & 1002 & $650 / 1080$ & 1180 & - & $480 / 701$ & 730 & 512 \\
\hline Ave. power density, $\mathrm{kW} / \mathrm{L}$ & 900 & 458 & 860 & $430 / 770$ & 750 & $150 / 440$ & $279 / 391$ & 460 & 350 \\
\hline$\Lambda, \mu \mathrm{s}$ & - & 0.14 & 0.1 & $0.11 / 0.24$ & - & 0.38 & $0.23 / 0.30$ & 0.5 & - \\
\hline$\beta \mathrm{eff}$ & - & 0.007 & 0.0068 & 0.005 & - & 0.006 & $0.005 / 0.004$ & 0.0032 & 0.0036 \\
\hline Doppler constant, - Tdk/dT & - & - & - & - & - & - & 0.002 & 0.005 & 0.0037 \\
\hline \multicolumn{10}{|l|}{ Fuel assembly } \\
\hline No. driver assemblies & $342^{\mathrm{a}}$ & 102 & $127 / 77$ & $64 / 54$ & 90 & $22 / 7$ & $82 / 67$ & 70 & 78 \\
\hline Fuel type & U-7\% Mo alloy & $-b$ & $-c$ & $\mathrm{UO}_{2}-\mathrm{PuO}_{2}$ & Enr. $\mathrm{UO}_{2}$ & $\mathrm{UO}_{2} / \mathrm{UO}_{2}-\mathrm{PuO}_{2}$ & $\mathrm{UO}_{2}-\mathrm{PuO}_{2}$ & $\mathrm{UO}_{2}-\mathrm{PuO}_{2}$ & $\mathrm{UO}_{2}-\mathrm{PuO}_{2}$ \\
\hline Fuel pellet form & $-{ }^{d}$ & $-^{e}$ & $-^{e}$ & $\mathrm{~s} 2 \times 2$ & A & $\mathrm{s}-2-2 \cdot 02$ & $\mathrm{~s}^{2}-2$ & $s^{2}-2$ & $\mathrm{~A}$ \\
\hline Fuel pellet density, $\%$ TD & - & - & 100 & $96 / 92$ & 93.5 & $90 / 86$ & $94 / 93$ & 90 & 95 \\
\hline
\end{tabular}


Table A-8. (continued)

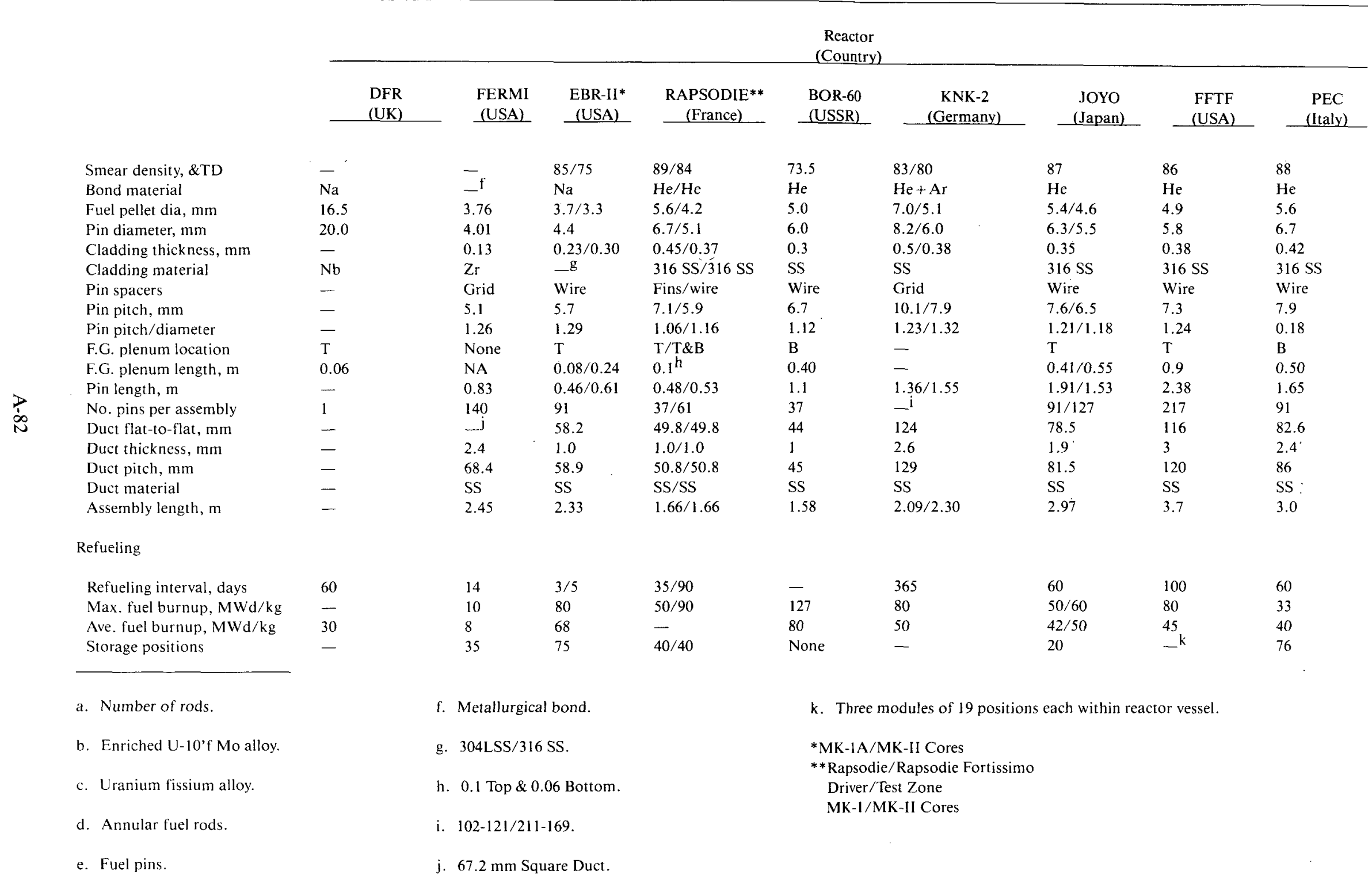


Table A-8. (continued)

\begin{tabular}{|c|c|c|c|c|c|c|c|c|}
\hline & & & & $\begin{array}{c}\text { Reactor } \\
\text { (Country) }\end{array}$ & & & & \\
\hline $\begin{array}{l}\text { DFR } \\
\text { (UK) }\end{array}$ & $\begin{array}{c}\text { FERMI } \\
\text { (USA) } \\
\end{array}$ & $\begin{array}{c}\text { EBR-II* } \\
\text { (USA) }\end{array}$ & $\begin{array}{l}\text { RAPSODIE** } \\
\text { (France) }\end{array}$ & $\begin{array}{l}\text { BOR-60 } \\
\text { (USSR) }\end{array}$ & $\begin{array}{c}\text { KNK-2 } \\
\text { (Germany) }\end{array}$ & $\begin{array}{c}\text { JOYO } \\
\text { (Japan) }\end{array}$ & $\begin{array}{l}\text { FFTF } \\
\text { (USA) }\end{array}$ & $\begin{array}{c}\text { PEC } \\
\text { (Italy) }\end{array}$ \\
\hline
\end{tabular}

Reflector/blanket

Material

Axial

Material form

Material dia, mm

Pin diameter, $\mathrm{mm}$

Top length, $m$

Bottom length, $m$

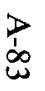

No. pins per assembly

Radial

No. assemblies

Material form

Material dia., $\mathrm{mm}$

Pin diameter, $\mathrm{mm}$

Assembly length

No. pins per assembly

$-^{\mathrm{a}}$
-
-
-
-
-

$\overline{\mathrm{R}}$
$\overline{-}$
34
2.33
1

-g

$\mathrm{UO}_{2}{ }^{\mathrm{c}}$

SS-radial

$\mathrm{UO}_{2}$-axial

$\mathrm{UO}_{2}$

$\mathrm{UO}_{2} / \mathrm{SS}$

Inconel

$\mathrm{UO}_{2}$

Control

Material

No. assemblies

$-^{\mathrm{p}}$

Pins
10.0
11.2
0.43
0.43
16

$-{ }^{b}$

NA $\quad \overline{13.3}$

NA 14.5

$0.35 / 0.39 \quad 0.27 /-$

$0.16 / 0.57 \quad 0.27 / 0.24$

NA $\quad 7+7$ d $/ 7$

$\mathrm{P}$
5.0
6.0
0.10
0.10
37

P

5.1

6.0

0.20

$\begin{array}{ll}0.10 & 0.20 \\ 37 & 217 / 166\end{array}$

$5.4 / 4.6$

$6.3 / 5.5$

$0.40 / 0.30$

$0.40 / 0.35$

$91 / 127$

$\mathrm{P}$
4.8
5.8
0.14
0.14
217

Pins

5.4
5.8

0.18

91

Reactor vessel

Height, m

Diameter, m

6.3
3.2
0.012

537
$R$
10.0
11.2
2.45
25

$\begin{array}{ll}162 / 366 & 500 / 300 \\ \overline{\mathrm{i}}_{\mathrm{NA}} & - \\ \mathrm{NA} & 15.4 \\ 2.33 & 16.5 \\ 6 / 19 & 7.12\end{array}$

168

$-$

14.5

7

5
$P$
8.0
9.2
2.14
121

$176 / 1$

$\mathrm{P}^{\mathrm{k}}$

$13.6 /-$

$15.0 /$

2.97

$19 /-$

${ }_{-\mathrm{f}}^{99}$

$-$

3.7

-

0.012

Enr. $\mathrm{B}_{4} \mathrm{C} \quad-\mathrm{j}$

10

10

Enr. $\mathrm{B}_{4} \mathrm{C}$

$\mathrm{B}_{4} \mathrm{C}$ and $\mathrm{Eu}_{2} \mathrm{O}_{3}$

${ }_{8}^{\text {Enr. } \mathrm{B}_{4} \mathrm{C}}$

Enr. $\mathrm{B}_{4} \mathrm{C}$

6

${ }_{9}^{\mathrm{B}_{4} \mathrm{C}}$

Enr. ${ }_{4} \mathrm{C}$

II

$\begin{array}{llll}11.1 & 2.28 & 9 & 6.2 \\ 4.4 & 2.31 & 2.3 & 1.4 \\ 0.05 & 0.019 & 0.015 & 0.018\end{array}$

10.2
1.9
$0.012-0.016$

9.9
3.6

0.025

$\begin{array}{ll}13.3 & 10.7 \\ 6.3 & 3.2 \\ 0.019 & 0.030\end{array}$


Table A-8. (continued)

\begin{tabular}{|c|c|c|c|c|c|c|c|c|}
\hline & & & & $\begin{array}{c}\text { Reactor } \\
\text { (Country) }\end{array}$ & & & & \\
\hline $\begin{array}{l}\text { DFR } \\
\text { (UK) }\end{array}$ & $\begin{array}{c}\text { FERMI } \\
\text { (USA) }\end{array}$ & $\begin{array}{l}\text { EBR-II* } \\
\text { (USA) }\end{array}$ & $\begin{array}{l}\text { RAPSODIE** } \\
\text { (France) } \\
\end{array}$ & $\begin{array}{l}\text { BOR-60 } \\
\text { (USSR) }\end{array}$ & $\begin{array}{c}\text { KNK-2 } \\
\text { (Germany) }\end{array}$ & $\begin{array}{r}\text { JOYO } \\
\text { (Japan) } \\
\end{array}$ & $\begin{array}{r}\text { FFTF } \\
\text { (USA) } \\
\end{array}$ & $\begin{array}{l}\text { PEC } \\
\text { (Italy) }\end{array}$ \\
\hline
\end{tabular}

Containment structures

\begin{tabular}{|c|c|c|c|c|c|c|c|c|c|}
\hline Configuration & $\mathrm{s}$ & $\mathrm{S}$ & $\mathrm{s}$ & $\mathrm{S}$ & 1 & $\mathrm{CC}$ & $\mathrm{s}$ & $S$ & $\mathrm{D}$ \\
\hline Materials & 1 & 1 & 3.0 & 1 & - & $2 / 1$ & 1 & 1 & $1 / 1$ \\
\hline Des. press., MPa, gauge & 0.137 & 0.22 & 0.17 & 0.24 & - & 0.25 & 0.13 & 0.067 & 0.149 \\
\hline Des. leak rate, vol $\% /$ day & 0.075 & 0.1 & 0.2 & $10^{1}$ & - & 1.0 & $3.0^{\mathrm{m}}$ & 0.1 & 0.5 \\
\hline
\end{tabular}

Heat transport and steam

systems

\section{Coolant}

Cover gas

$\mathrm{NaK}$

$\mathrm{Na} \quad \mathrm{Na}$

$\mathrm{Na}$

$\mathrm{Ar} / \mathrm{He}$

$\mathrm{Na}$

$\mathrm{Na}$

$\mathrm{Na}$

$\mathrm{Ar}$

$\mathrm{Na}$

$\mathrm{Na}$

Primary

\section{Type}

No. loops

Pump type

Pump position

Total flow, $\mathrm{kg} / \mathrm{s}$

Inlet reactor temp., ${ }^{\circ} \mathrm{C}$

Outlet reactor temp., ${ }^{\circ} \mathrm{C}$

Max. fuel temp., ${ }^{\circ} \mathrm{C}$

Max. clad. temp., ${ }^{\circ} \mathrm{C}$

Loop
24
E
Cold
450
200
350
650
500

Loop
3
C
Cold
1120
279
418
602
552

$\begin{array}{lll}\text { Pool } & \text { Loop } & \text { Loop } \\ 1 & 2 & 2 \\ \text { C } & \text { C } & \text { C } \\ \text { Cold } & \text { Cold } & \text { Cold } \\ 481 & 210 / 230 & 260 \\ 371 & 405 / 400 & 340 \\ 473 & 495 / 510 & 520 \\ 688 & 2000 / 2180 & \\ 599 & 585 / 650 & 700\end{array}$

Loop
2
C
Hot
280
360
525
2055
$\sim 685$

Loop
2
C
Cold
600
370
$468 / 500$
$2330 / 2500$
$620 / 650$

$\begin{array}{ll}\text { Loop } & \text { Loop } \\ 3 & 2 \\ \text { C } & \text { C } \\ \text { Hot } & \text { Cold } \\ 2200 & 630 \\ 360^{\circ} & 400 \\ 503^{\circ} & 550 \\ 2250^{\circ} & 2340 \\ 670^{\circ} & 650\end{array}$

Secondary

\section{No. loops}

Pump type

Pump position

\section{2}

E

Total flow, kg/s

2 Hot

Inter, heat exchanger

Number

24

$-$

3

Shell

1
Shell

2

Shell

4
Shell

2
C
Cold
260

2
Cold

Cold
250

2
C
Cold
600

3

C

C

$\begin{array}{ll}\text { Cold } & \text { Cold } \\ 600 & 2200\end{array}$

Primary side

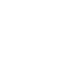


Table A-8. (continued)

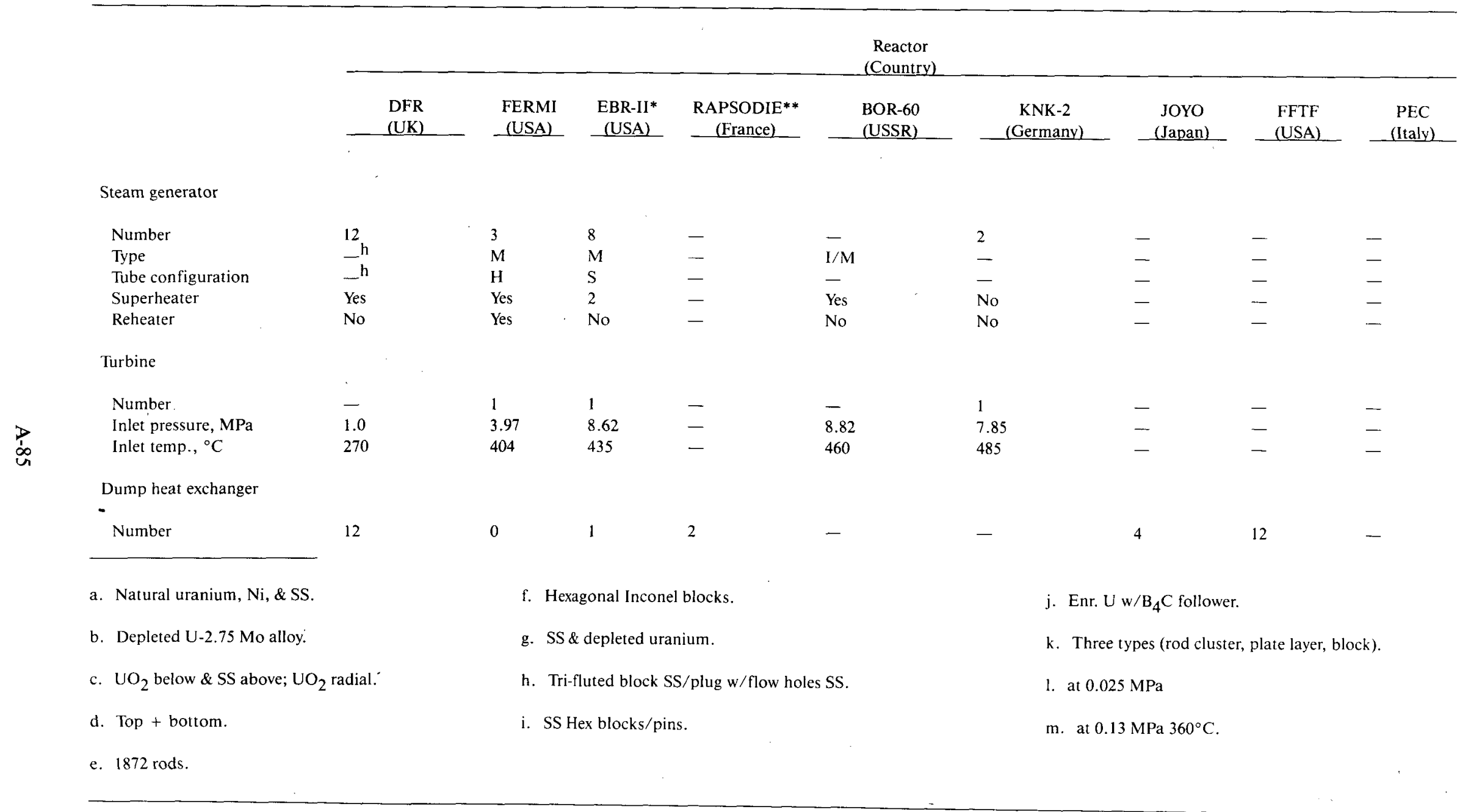


which have since been changed. Friction marks such as material abrasion between the cladding tube and the spacers were not considered to be associated with the defects. Disassembly of the 1980 failed fuel element, which had been run with a fuel rod failure for about 4 weeks, revealed clear marks on the rods adjacent to the defective one and seemed to indicate some interaction. However, detailed investigations have shown there had been no failure propagation. ${ }^{\mathrm{A}-72}$

Thirty-five fuel rods from each of the two failed fuel elements were reprocessed in the Milli facility. The extracted fuel was used for fabrication of the fuel rods of the second core. Thus, in Germany, the breeder fuel cycle has been closed on a kilogram scale. In dissolving the fuel in $7 \mathrm{M}$ nitric acid, some $10 \%$ remained undissolved and had to be retreated with hydrofluoric acid. The low solubility of the fuel is owing to its method of fabrication; highly soluble fuel will be used in the first reload core.

Reactor Instruments-Performance capability was examined of temperature measurement probes and two acoustic transducer probes, magnetostrictive and piezoelectric, which were inserted in KNK-II over a period of 4310 and $6635 \mathrm{~h}$, respectively. These probes are planned for use in the safety system of the German prototype LMFBR, SNR-300. The linearity and temperature errors were demonstrated to be below $2 \%$. Drift errors over a 4 week operating period were less than $2.5 \%$ at sodium flow rates of less than or equal to $1 \mathrm{~m} / \mathrm{s}$. Drift errors were less than $2 \%$, with a sodium flow rate greater than $1 \mathrm{~m} / \mathrm{s}$. A-72

From the beginning, the reactivity signal of KNK-II showed harmonic oscillations of less than 0.5 cents. Sensitive methods of correlation between the reactivity signal and the measured fuel element temperature proved these oscillations were caused by individual fuel elements. Additional measurements performed under various operating conditions and theoretical considerations seem to indicate the reactivity oscillations are initiated by flow-induced mechanical vibrations. Most probably, these are vibrations of entire fuel elements generated by vortex shedding or non-steady fluid jet formation. A-72

Reactor Chemistry-Radial chemical measurements of primary sodium show that the bulk gamma activity after 9,600 effective full power hours of $\mathrm{KNK}-\mathrm{II}$ operation was $1.9 \mathrm{mCi} / \mathrm{g}$. This is considerably below the primary coolant activation normally found in boiling water and pressurized water reactors. The fission product releases from the two failed fuel elements are relatively slight for the iodine and cesium remain in the sodium. The 'sodium represents an additional barrier to fission product releases to the environment.

More precise analyses are conducted on the primary sodium to detect the activation products sodium-24, sodium-22, Ag-110 m, and zinc-65, the activated corrosion products manganese-54, cobalt-58, cobalt-60, iron-59, chromium-51, tantalum-182, antimony-124, the fission products, cesium-137, cesium-134, antimony-125, barium/ lanthanum-140, and iodine-131. Because these radionuclides give rise to radiation exposure of personnel during repair and maintenance work, attempts are being made to remove these products, except sodium-24 and sodium-22, from the primary system. In KNK-II, investigations are concentrating on removal of manganese-54, zinc-65, and tantalum-182 isotopes. These nuclides have been shown to preferentially precipitate on specific metal surfaces. Nickel, for example, lends itself particularly well for use as a radionuclide trap for zinc- 65 and manganese-54. A-72

A stable evaporation zone is formed in LMFBR steam generators caused by the much smaller temperature gradients between the secondary sodium and the water vapor in comparison to the temperature gradient of fossil-fueled heated plants. In addition, there are no pulsating evaporation processes from local superheating. Impurities in the boiler feedwater can become enriched in this stable evaporation zone and produce changes in the protective coating. An extensive measurement program is being conducted at KNK-II in the steam water circuit to determine what effects conductivity and the concentration of oxygen, iron, copper, silicic acid, and sodium have on this phenomenon.

Measurements conducted at KNK-II while working without hydrazine have shown that hydrazine cannot be used to reduce the oxygen concentration to less than $50 \mathrm{ppm}$ when there is increased oxygen content in steam in the presence of hydrazine. Future investigations at KNK-II will be done without hydrazine added but in a combined mode of operation involving an elevated oxygen content and a reduced ph.

Experience with the Heat Transfer System-The sodium systems of KNK-II were started up in 1972. The primary system has since been continuously filled with sodium, even during the KNK-I/KNK-II 
conversion phase. The sodium pumps have operated uninterrupted and have accumulated some $85,000 \mathrm{~h}$. Systems, temperatures, and pressures have remained at the designed level for about $17,500 \mathrm{~h}$. During this entire time, there have been no major malfunctions.

A dip tube has been built that extends vertically through the primary cell. In this dip tube a calibrated ionization chamber can be positioned at various points. The ion chamber is used to measure the radiation dose rate after the sodium-24 decays to background values, about $10 \mathrm{~d}$ subsequent to reactor shutdown. The residual radiation field is caused by activated corrosion products and fission products plated out on the walls of the primary system. More than 10 years of operating experience has shown the radiation exposure both of personnel and of the environment is less than it is in comparable water-cooled reactors. For instance, KNK-II was operated in 1982 using 44 man-rem with 43.9 man-rem acquired during maintenance on the primary system. Greater than $75 \%$ of the radiation workers received less than $0.15 \mathrm{rem}$, and only $5 \%$ received greater than 0.4 rem.

The steam generators of KNK-II consist of parallel helical double tube systems. In 1972, a leakage in a steam generator caused by a weld pore was controlled safely and without any impacts on the environment. One of the steam generators was removed in early 1981 and replaced by a new one having a sampling point in the transition region between water and steam. This afforded an opportunity for metallagraphic reexamination. In the evaporator region of the steam generator, a coating roughly 100 microns thick had developed; in the superheater region, a coating roughly 40 microns thick had developed. The coatings consist of an inner layer of oxidized metal and an outer layer of magnetite. The magnetite is generated whenever the solubility of iron in water is exceeded. Pitting corrosion with a maximum penetration depth of 250 microns is caused by the quality of water which is not controlled in outage periods. The reduction in wall thickness caused by pitting corresponds to $8.6 \%$ of the wall thickness.

\section{France}

Rapsodie. The French LMFBR programs first major milestone occurred in 1967 with the commissioning of Rapsodie. This was originally a $20-\mathrm{MW}(\mathrm{t})$ unit later increased to $24 \mathrm{MW}(\mathrm{t})$ and then to
$40 \mathrm{MW}(\mathrm{t})$. The reactor provided design information and fuel performance for use in France's prototype reactor, PHENIX.

Reactor Features -A view of the reactor assembly is shown in Figure A-59. The fuel assemblies, which contain both a fuel section and an axial blanket section, are in a central region surrounded by radial blanket subassemblies. Removable subassemblies outside this region serve as reflectors. The concentric steel cylinder assembly, as shown in Figure A-60, is used for both a nonremovable reflector and thermal shield.

A jacket located outside the reactor vessel circulates gas for preheating. It also serves for cooling the reactor during shutdown. Steel containers filled with thermal insulation are located outside the preheating jacket. Additional structures consist of a containment tank and a biological shield. An outer blast shield consists of three concentric layers: borated graphite, lightweight cellular concrete, and reinforced concrete. Additional features are shown in Figure A-61. A single sodium inlet pipe is shown with two sodium outlet pipes located in a vertical plane perpendicular to the plane of the inlet pipe.

Core Arrangement-The fuel subassemblies are illustrated in Figure A-62. In the core regicn are the subassemblies, comprised of 37 fuel rods assembled in a stainless steel container with a hexagonal cross-section. Each individual element consists of a number of sintered pellets of mixed uranium and plutonium oxide $\left(25 \mathrm{wt} \% \mathrm{PuO}_{2}\right)$ contained in a stainless steel tube. A spring arrangement maintains contact between the various pellets in the column, and provision is made in the upper region of the element to collect fission gases. Separation between pins is maintained by a wire spiral. A-73

Both the upper and lower blanket sections consist of a cluster of seven large-diameter elements of depleted uranium. A lower base plate is provided to distribute the coolant. The lower end of the subassemblies shaped in the form of a nozzle with an internal venturi section reduces upward forces induced by the coolant flow and aids in positioning. The upper end of the subassembly is provided with a handling lug pierced with three holes for the sodium coolant outlet. The radial blanket subassemblies are similar to the fuel subassemblies, but they contain a continuous seven-rod internal structure of large-diameter depleted uranium elements. Removable stainless steel reflector subassemblies 


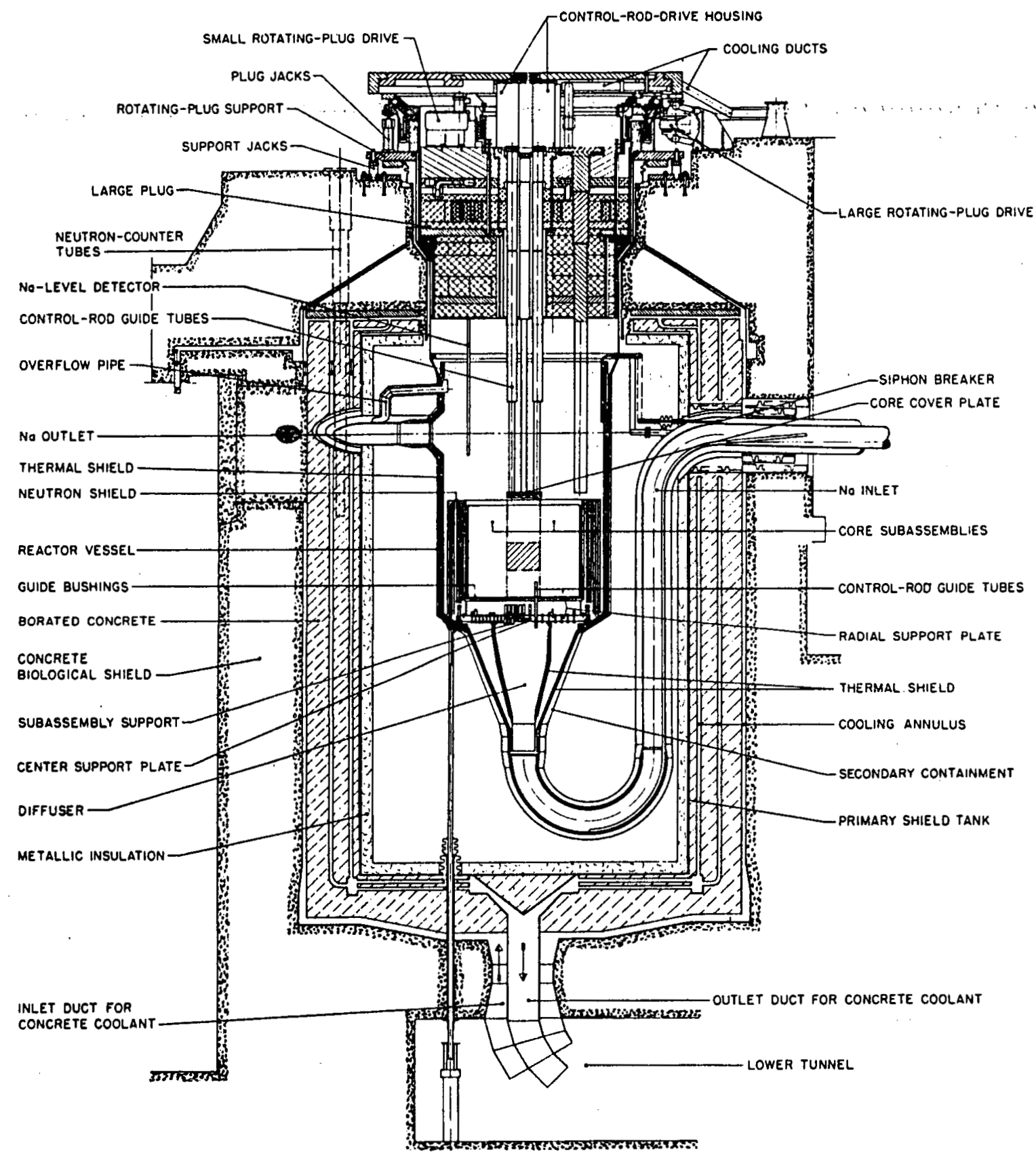

Figure A-59. Vertical cross section of RAPSODIE reactor.

are available to provide flexibility of operation and fuel movement.

Control Elements-A poison-type control system is used that has four safety rods, each containing about $100 \mathrm{~g}$ of $\mathbf{B}^{10}$ as boron carbide. In addition, two regulating rods are provided, each containing about $100 \mathrm{~g}$ of $\mathrm{B}^{10}$.

Each of the six rods located on the boundary between the core and the radial blanket in the highpressure coolant zone move a distance of $46 \mathrm{~cm}$ in a hexagonal guide tube similar to the hexagonal fuel assembly cans. The boron carbide rod is enclosed in a cylindrical can attached to a stellite nozzle and handling head for the drive shaft gripper. Control rod drive mechanisms are located in six sections around the cover plate equipment. Removal of the control rods is accomplished by means similar to those used for refueling a cask car.

Heat Transport System-Sodium is used as the coolant in both the primary and secondary systems. Heat rejection to air is planned for the secondary system, rather than a steam generator 


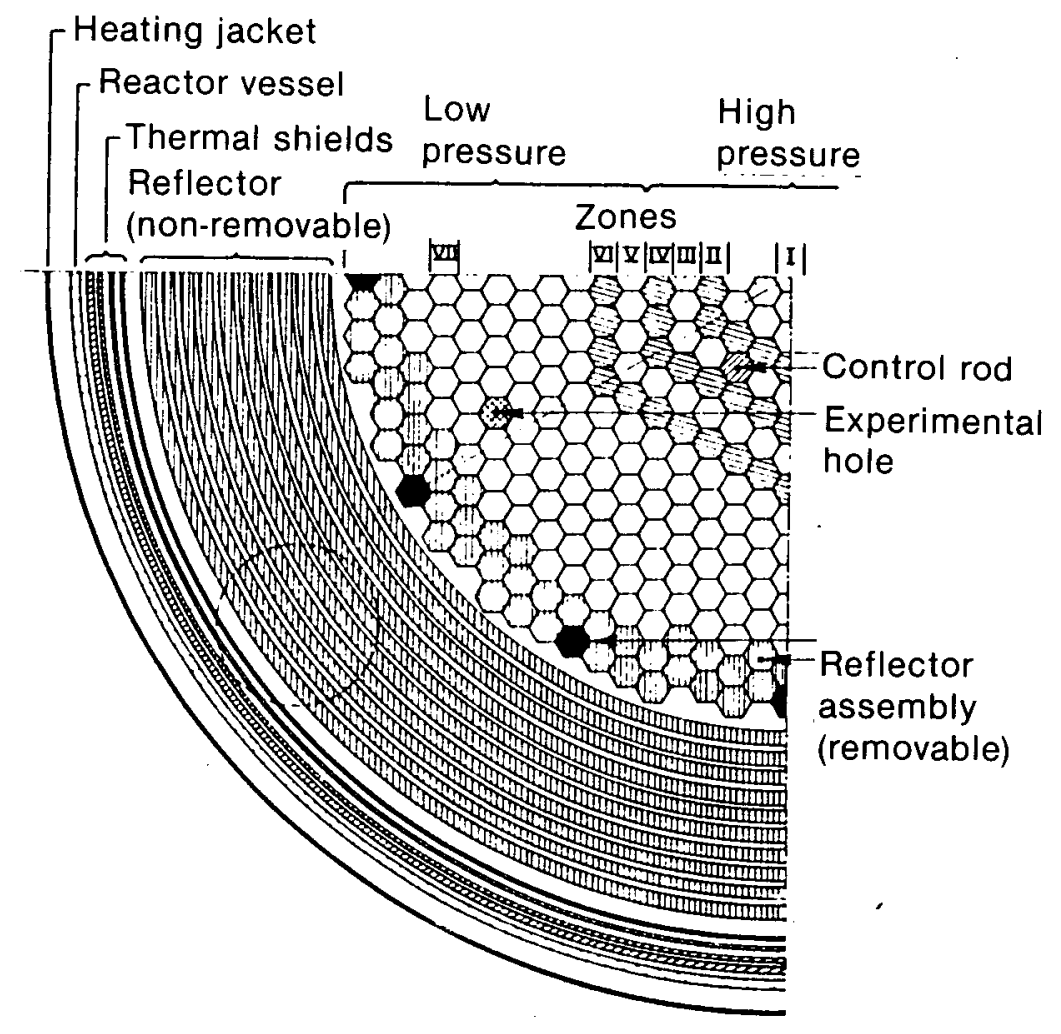

Figure A-60. Horizontal cross section of RAPSODIE reactor.

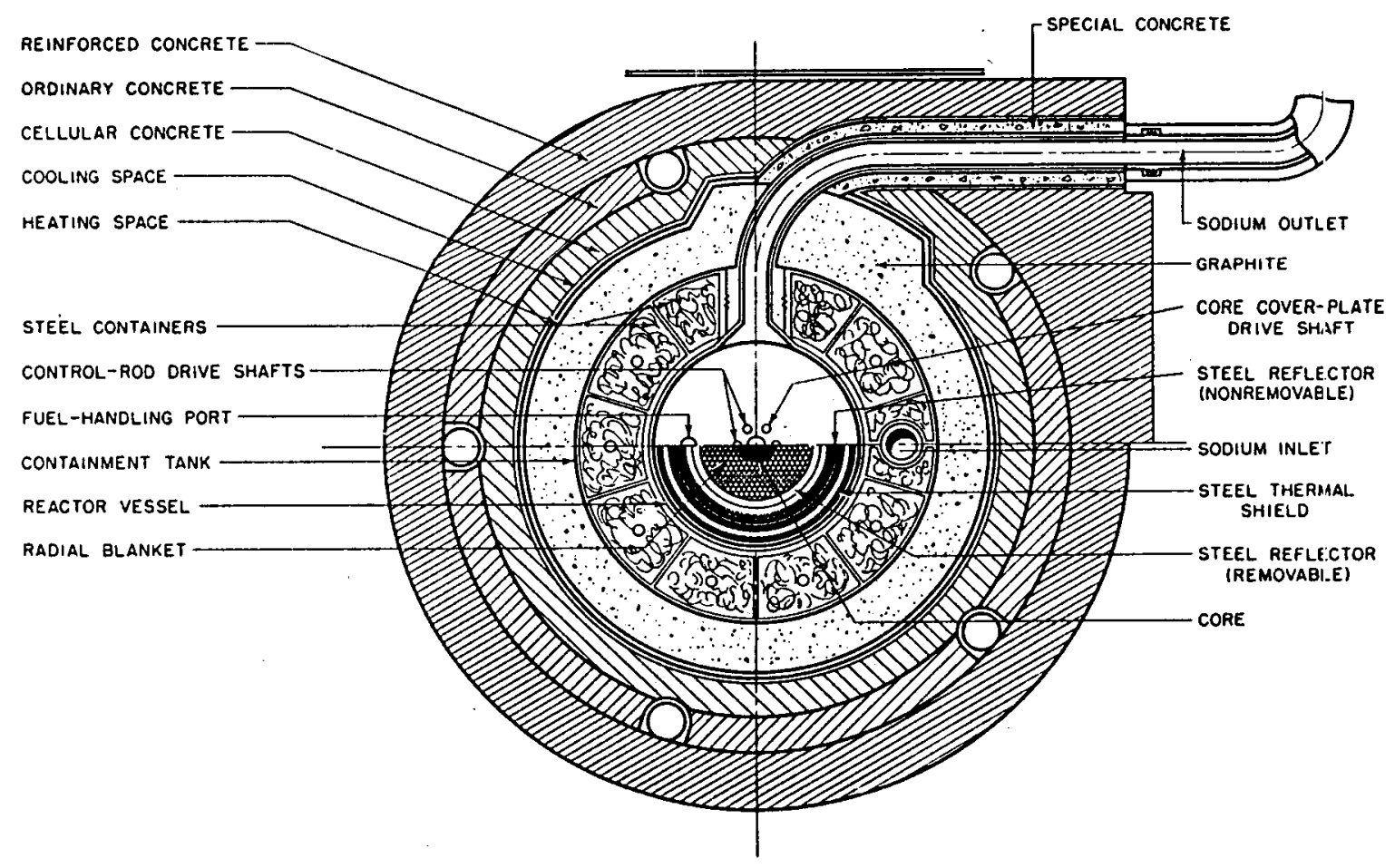

Figure A-61. Horizontal cross section of RAPSODIE reactor and shield. 


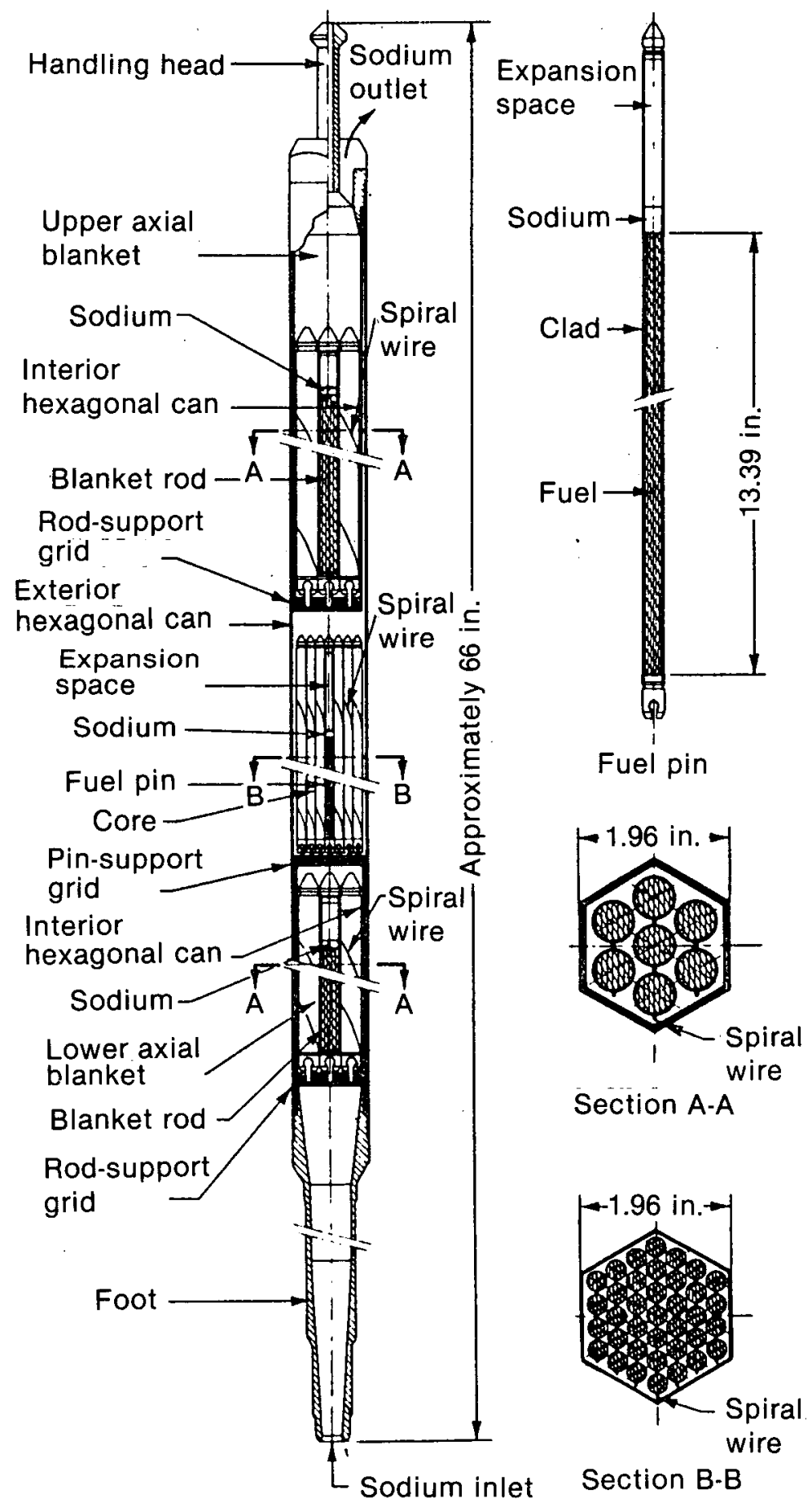

Figure A-62. RAPSODIE fuel subassembly. 
turbogenerator installation. Two coolant loops are provided, each designed for a $10 \mathrm{MW}(\mathrm{t})$ load, utilizing centrifugal pumps.

Sodium is pumped by a vertical centrifugal pump rated at $97.2 \mathrm{~L} / \mathrm{s}$. Discharge from the pump tank enters the lower section of the reactor vessel and then flows into the flow divider. Removal of the control rods is accomplished by means similar to those used for refueling a cask car.

Heat Transport System Assembly-The flow baffle separates the coolant into a high-pressure zone, providing a coolant for the core and inner radial blanket as well as a low-pressure zone for the outer radial blanket. The diffuser assembly provides a noncritical geometry for the collection of fuel in the event of a meltdown accident. The coolant passes from the reactor blanket to the intermediate heat exchanger. Primary sodium circulates through the shell at this vertical stainless steel tube exchanger, and secondary sodium circulates through the tubes. In the design, the upper tube sheet is fixed, and the lower tube sheet is floating to permit thermal expansion of the tube bundle. The tubes themselves are located in 12 concentric sections.

Shielding Structures-Within the reactor vessel, both the removable and nonremovable reflector regions tend to reduce the neutron energy as well as attenuate the flux. The nonremovable portion of the reflector consists of 10 concentric cylindrical shields made of 24-mm-thick stainless steel and separated by an $8-\mathrm{mm}$ space. Outside this assembly is a thermal shield consisting of four concentric cylinders having thicknesses of $4,7,10$, and $10 \mathrm{~mm}$, respectively.

The reactor vessel, shown in Figure A-59, of Type 316 stainless steel, consists of a lower $12-\mathrm{mm}$ thick eliptical cylinder, a main 15 -mm-thick plate, and an upper section located between the fixed plug and a large rotating plug.

Preheating of the reactor vessel is made possible by a 4-mm-thick jacket that permits circulation of an inert gas at $150^{\circ} \mathrm{C}$. Preheating prior to the introduction of sodium minimizes thermal shock and provides for the heating of sodium in the event of freezing.

Illustrated in Figure A-61 are steel containers filled with thermal insulation or steel plates located between the reactor vessel and a cylindrical containment tank to prevent heat transfer by radiation.
The tank acts as a second barrier in the event of vessel rupture. The containment tank is of plain carbon steel $15 \mathrm{~mm}$ thick. Additional containment is provided by a radial biological shield consisting of borated graphite (3\% boron) $600 \mathrm{~mm}$ thick, which is maintained at a minimal temperature of $220^{\circ} \mathrm{C}$ by cooling gas.

Additional shielding includes a 0.4-m-thick wall of cellular concrete, which protects the columns supporting the rotating plug. Also included is a $0.4 \mathrm{~m}$ thickness of ordinary concrete, and finally a 0.65 meter thickness of heavily reinforced concrete maintained below $50^{\circ} \mathrm{C}$. Thermal insulation is provided between the inner graphite and cellular concrete. A fixed plug is located between the containment tank and the reactor vessel, shown in Figure A-59. Internal to the reactor vessel are two rotating plugs: a large concentric rotating plug and a small eccentric rotating plug. Penetrations through the rotating plugs are (a) a fuel handling port, (b) control rod drive shaft ports, (c) core cover plate drive shaft ports, (d) two ports for introducing experimental apparatus, and (e) two ports for liquid level indicators. Two sets of ball bearings are used for rotating the plugs. The liquidmetal seals of tin-bismuth provide a gas tight seal between the exterior atmosphere and the reactor cover gas.

Provision is made in the design for a number of mechanical handling operations, for instance, the removal of fuel assemblies, control rods and their guide tubes, and the introduction of such items. A handling port located in the small eccentric rotating plug provides access for a gripper arrangement attached to a cask car that may reach any subassembly in the reactor. The cask car includes provisions for cooling two irradiated subassemblies.

Transfer of subassemblies and other equipment from the containment building is by means of a secondary handling system, since the primary cask car is at all times within the building. A transfer compartment is provided for the movement of such subassemblies from one cask car to the other. Various other facilities are provided for necessary fuel handling operations.

Operational Experience - An extensive program of fuel evaluation and development has been carried out on the $\mathrm{UO} 2-\mathrm{PuO}_{2}$ mixed oxide fuel and on various uranium-plutonium-molybdenum ternary alloys. The ternary alloy investigated consisted of $75 \mathrm{wt} \%$ uranium, $15 \mathrm{wt} \%$ plutonium, and $10 \mathrm{wt} \%$ 
molybdenum. Although the metal fuel is attractive because of its good heat conductivity at the high power densities, the radiation experiments have indicated excessive swelling. An additional disadvantage of the alloys was their poor compatibility with stainless steel. A double clad design was necessary, consisting of an interior layer of niobium and an exterior layer of stainless steel with sodium bonding. The cladding design prevented the formation of a plutonium-iron eutectic. The oxide fuel was chosen because it presents fewer fabrication problems than the alloy and because there is a greater background of irradiation and production experience with the oxide.

\section{United Kingdom}

Dounreay Fast Reactor (DFR). The Dounreay reactor plant used a sodium-potassium eutectic, $\mathrm{NaK}$, as coolant. The plant was designed for a maximum power of $72 \mathrm{MW}(\mathrm{t})$ and a core power of $60 \mathrm{MW}(\mathrm{t})$. The reactor design evolved from low power experiments performed at Harwell on the ZEUS experiment. Construction was started in 1955, and the reactor went critical in November 1959 . The reactor was operated as a zero power assembly until April 1960. It was then shut down for the installation of a modified core tube nest to facilitate radiation testing of fuel subassemblies for a prototype fast reactor. 58,59 An unusual feature of the reactor was the use of 24 coolant loops, each provided with a pump and heat exchanger to circulate the liquid metal through the reactor core and blanket. This feature resulted from a design decision to use heat exchangers and pumps of a size with which experience had been accumulated in previous experimental loop work.

Reactor Features-The general arrangement of the Dounreay plant is shown in Figure A-63. A containment sphere contains a reactor vessel and the primary coolant system. Provisions were made for shutdown heat removal by a natural convection loop which vented up the stack. ${ }^{A-74}$ The design was not optimized to represent a prototype.

Core Arrangement-The cylindrical core, $53.3 \mathrm{~cm}$ in diameter by $53.3 \mathrm{~cm}$ high with a volume of 0.12 $\mathrm{m}^{3}$, contains 361 enriched uranium vented fuel elements in the form of hollow cylinders. These cylinders, with a $1.8-\mathrm{cm}$ outside diameter and a $0.76-\mathrm{cm}$ inside diameter, are clad on the outside by niobium and on the inside by vanadium. $\mathrm{NaK}$ coolant flows downward, both through the center and around the outside of each fuel element; the ratio of the coolant flow is controlled by pressure drops. An upper axial blanket of natural uranium is included as part of each fuel element assembly. The core is surrounded radially by a natural uranium blanket consisting of 2,000 elements. ${ }^{\text {A-75 }}$

After the EBR-I meltdown incident, the initial core design for Dounreay, which provided for bottom support only, was revised to avoid the possibility of thermal bowing of the fuel elements. The core structure features a tube nest, shown in Figure A-64, which mechanically restrains the fuel elements at the top, center, and bottom. A series of long and short interlocking tubes are used with the long tubes located in counter-board sockets in the top and bottom plates. Side plates enclose the tube nest, and the hole is positioned within the core skirt as a complete unit. A-74-75

Details of the core fuel element are shown in Figure A-65. Beta quenched uranium, enriched to $45 \%$ and alloyed with a 0.5 atomic percent chromium, was used as the initial fuel. The central element design was based on a maximum uranium temperature of $840^{\circ} \mathrm{C}$, a maximum coolant-inner vanadium cladding interface temperature of $610^{\circ} \mathrm{C}$, and a maximum coolant-outer neobium cladding interface temperature of $515^{\circ} \mathrm{C}$. The fuel containers, or cans, are designed to restrict radial swelling and are provided with a free space to accommodate axial expansion. Fission gases are permitted to escape into the coolant through a vent in the upper end of the fuel element. A-74-75

Controland Stability-Control is accomplished by movement of the fuel, a design decision based on the initial unavailability of $\mathrm{B}^{10}$. Twelve groups of control rods, each consisting of 10 fuel elements, are situated around the end of the core. Six operate as control rods, four are for shut-off, and two are safety rods. The reactivity involved is listed as $0.43 \Delta \mathrm{k} / \mathrm{k}$ for control, $0.028 \Delta \mathrm{k} / \mathrm{k}$ for shut-off, and $0.014 \Delta \mathrm{k} / \mathrm{k}$ for safety. Interference with the top plug arrangement and refueling systems is avoided by locating the control rod actuating unit outside the rotating shields. Electromechanical drives are used to avoid gas leakage problems. Movement of the control rod mechanism is obtained by use of a vertical ball-nut and screw actuator driven through an electromagnetic clutch. These features result in a relatively complicated design. Reference A-76 presents a detailed description of a safety control rod. 


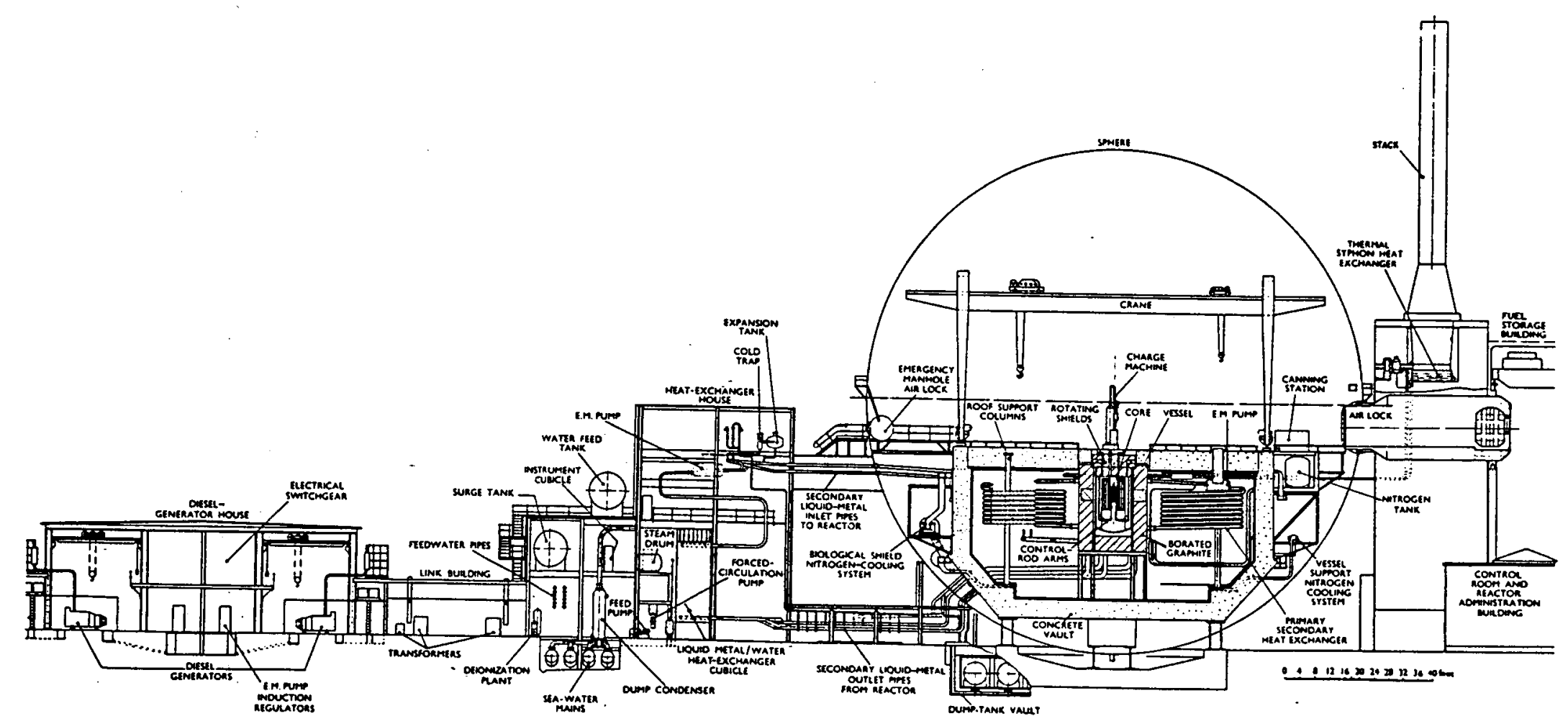

Figure A-63. Dounreay plant elevation. 


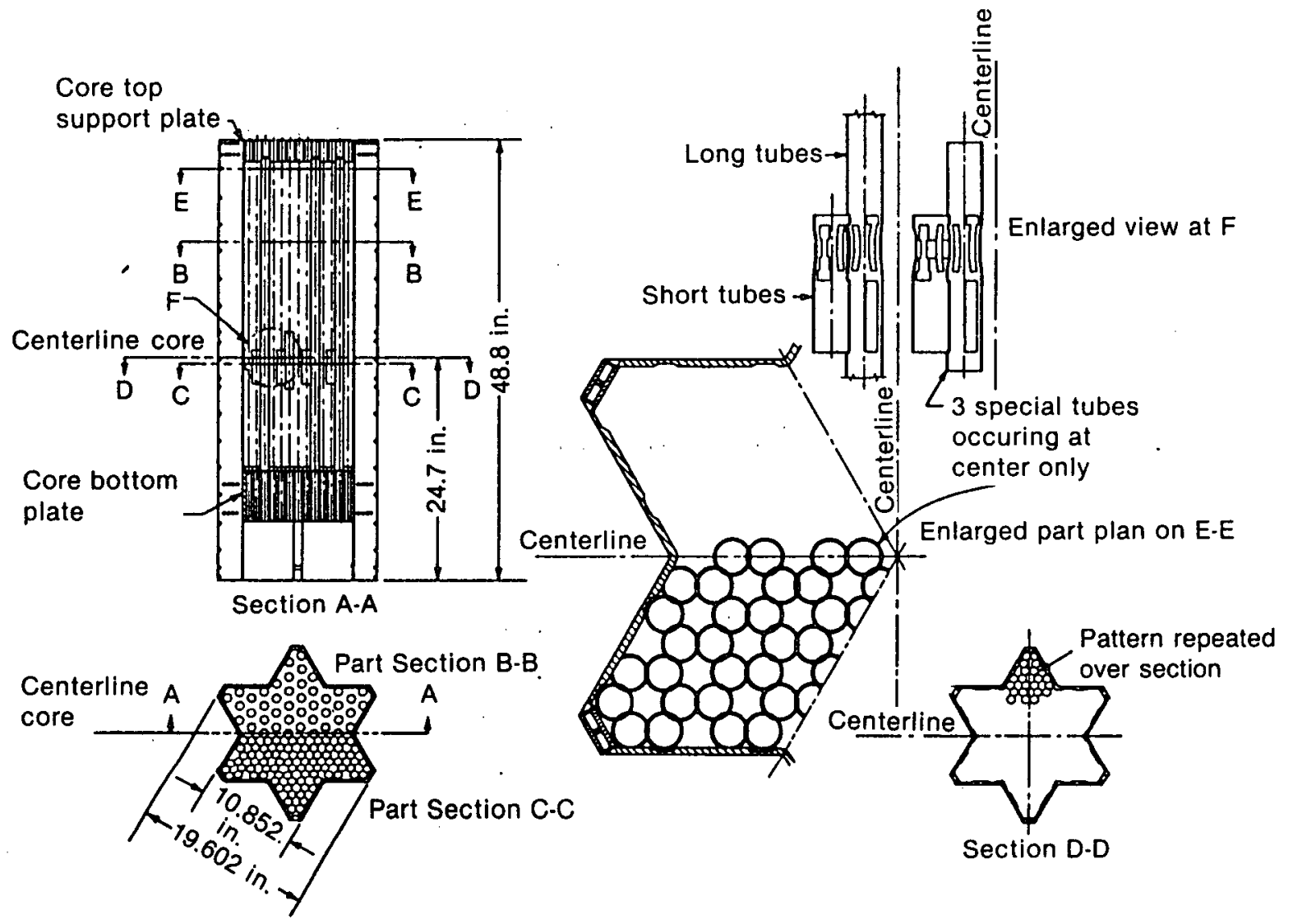

Figure A-64. Details of Dounreay core tube nest.

Heat Transport System-Because the primary objective of the Dounreay reactor was to demonstrate the feasibility of fast reactor core operation, the heat transfer system was not designed as a suitable prototype of an economical system. Instead, it was the most reliable combination of available components that would accomplish the purpose. The coolant loops were constructed of piping varying in diameter from 1.9 to $15.2 \mathrm{~cm}$ without the use of valves. Concentric tube construction was used for the intermediate heat exchangers. These various restrictions led to the design requirement of 24 primary loops. A detailed discussion of the heat transport system is given in Reference A-76. An unusual feature of this heat transport design is the downward flow of coolant through the core. This permits various components at the top of the reactor to operate in cooler regions and simplifies the structural design of the core, since the coolant does not tend to lift the fuel elements.

The 24-loop primary system was designed to remove $60 \mathrm{MW}(\mathrm{t})$ from the core and $12 \mathrm{MW}(\mathrm{t})$ from the breeder blanket. As shown in Figure A-66, the coolant leaves the bottom of the reactor vessel at $350^{\circ} \mathrm{C}$, leaves the intermediate heat exchanger at $200^{\circ} \mathrm{C}$, then passes through the electromagnetic pump in a thermal siphon heat exchanger before reentering the vessel. The pump was installed in the cooler part of the circuit because the coolant operating temperature was restricted at $200^{\circ} \mathrm{C}$ to prevent overheating at the windings. Each secondary loop removes heat from two primary loops, necessitating 12 independent secondary units, each complete with a steam generator. The intermediate heat exchangers, each designed for a $3 \mathrm{MW}(\mathrm{t})$, consist of an inner stainless steel pipe, $91 \mathrm{~m}$ long and $10 \mathrm{~cm}$ in diameter, surrounded by an outer stainless steel pipe of $15 \mathrm{~cm}$ diameter which is formed into seven loops. Each of the 12 secondary loops contains two electromagnetic pumps installed in parallel in a cool return leg from the steam generator. The steam generators, in turn, each have $6 \mathrm{MW}(\mathrm{t})$ capacity and consist of 13 rows of 20 heat transfer elements each. These elements were constructed by spirally winding copper laminations onto stainless steel tubes. Because the tubes containing sodium are connected to the steam generating tube by copper lamination, heat transfer is by conduction from one tube to another via the copper. The 

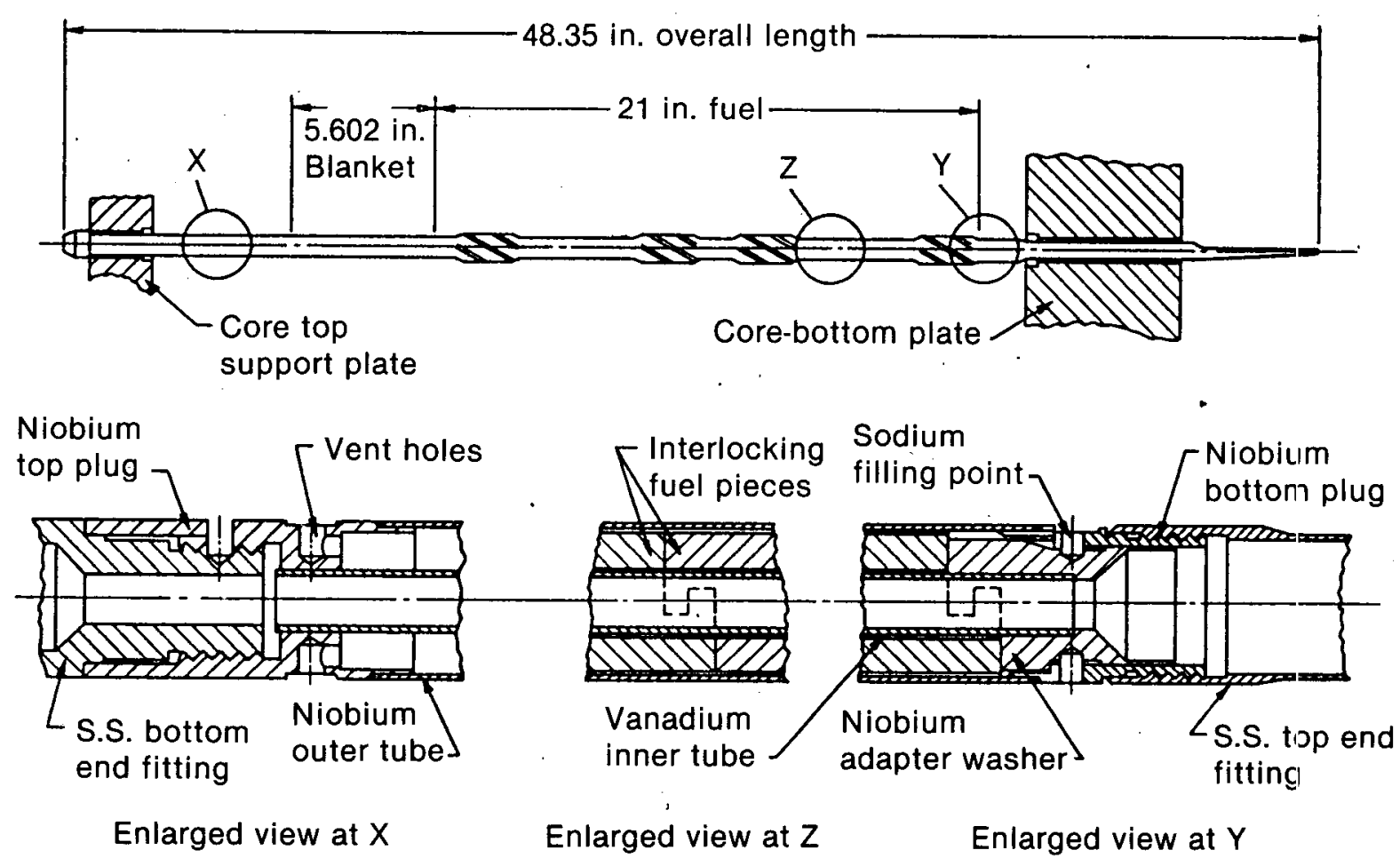

Figure A-65. Details of Dounreay fuel subassembly.

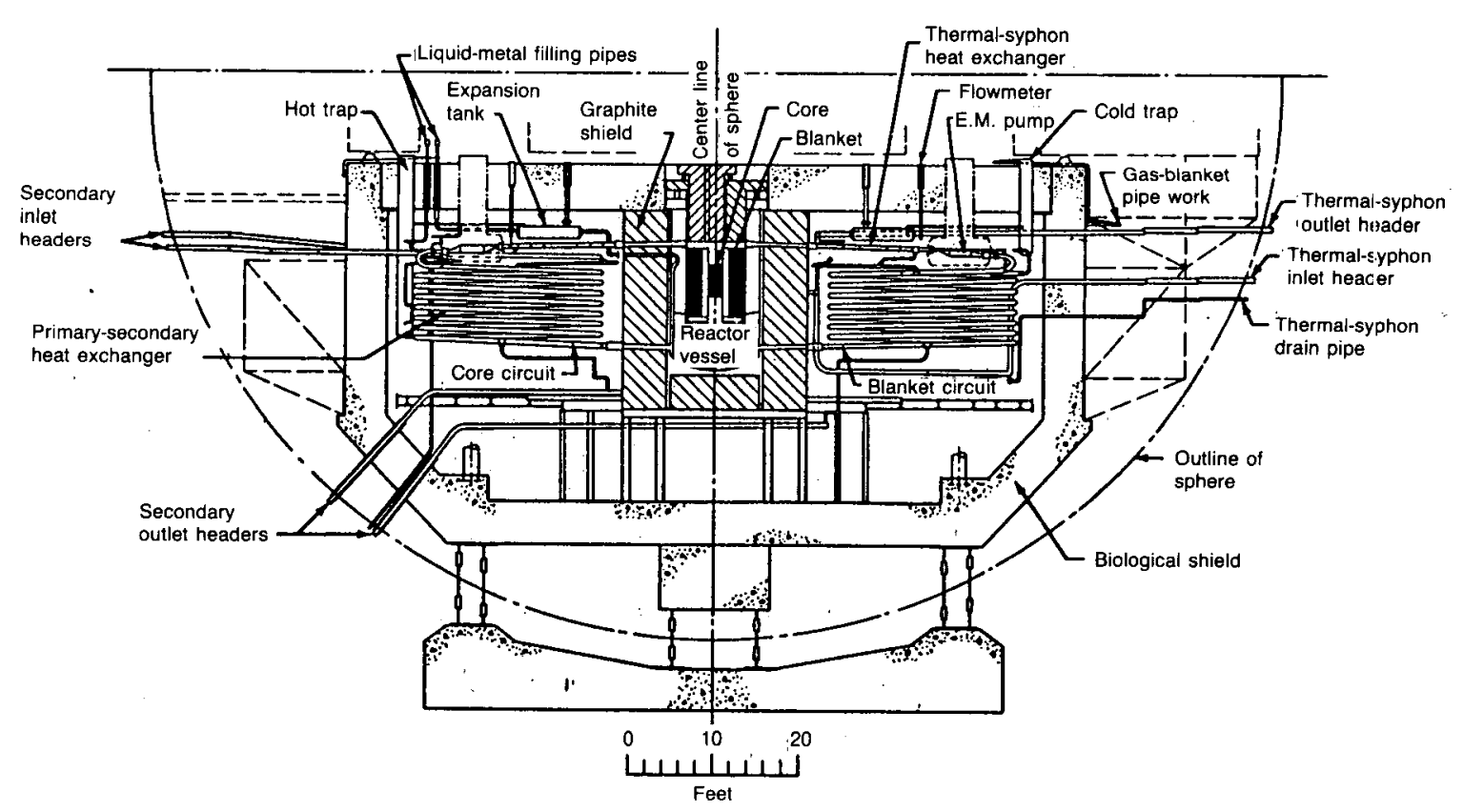

Figure A-66. Arrangement of Dounreay primary circuit pipe work. 
possibility of leakage from the $\mathrm{NaK}$ to the water system is therefore minimized. The heat transport system includes the usual array of accessory equipment; for example, cold traps, hot traps, sampling equipment, filling stations, and an inert gas (nitrogen) system. A thermal siphon system requiring no electrical power was installed to remove the shutdown heat of the core from the primary circuits to a convection air-cooled heat exchanger outside the containment sphere.

Structural and Shielding Components-A view of the reactor vessel assembly with its associated components and shielding is shown in Figure A-67. The core and blanket, weighing approximately $90,000 \mathrm{~kg}$, are supported by an inner structure within the vessel. This system, built up from a flange mounted on the inner skirt of the reactor vessel itself, includes the core skirt, various plates, and other members. In addition to providing the necessary support, the system separates the coolant flow to the core, inner blanket, and outer blanket breeder. A system of rotating plugs forms the closure for the top of the vessel and permits access by the refueling machine to any fuel or blanket element. Details are shown in Figure A-67. The plugs are removed only during shutdown. During normal operation, 0-rings prevent leakage of the cover gas. During refueling, a leak-tight seal around the plugs is accomplished by two concentric metal rings dipping into a trough (a) of sodium-mercury amalgam, in the case of the inner seal, and (b) of mercury in the case of the outer seal. Such a seal is possible during refueling because the reactor pressure is reduced to less than $3.5 \mathrm{kPa}$. When the vessel is pressurized, the liquid metal in these seals is discharged to a dump tank located on the plugs.

The reactor vessel and the primary coolant loop, which contains sodium- 24 activated by a passage through the reactor, is contained in a $41.2-\mathrm{m}$ diameter steel sphere, shown in Figure A-63. The primary coolant system and the intermediate heat exchanger are within the containment sphere (see Figure A-66). Because the secondary NaK coolant is neither radioactive nor likely to contain fission products in the event of a fuel element failure, the secondary loop system, including the steam generators, is not within this sphere. Reference 58 describes the shielding in detail. The design is based on a reactor output of $100 \mathrm{MW}(\mathrm{t})$. Fast neutrons leaking from the vessel are thermalized in a $1.2-\mathrm{m}-$ thick graphite shield containing $0.3 \mathrm{wt} \%$ of boron which surround the reactor vessel. The graphite is cooled by recirculating nitrogen. Zones of pure graphite in the thermal shield allow neutron flux measurements by ion and fission chambers. An outer annulus of $5 \mathrm{wt} \%$ boron in graphite surround these regions. The top shield includes layers of borated graphite and steel plates in a rotating plug and removable concrete block assembly. A $25-\mathrm{cm}-$ thick jabroc and steel shield covers the reactor top and is removable for shutdown operations. Secondary shielding was provided by a 1.5 -m-thick layer of concrete on the inside of the containing sphere, which encloses the reactor and primary heat transport system.

Operating Experience-A number of difficulties were encountered during the initial start-up procedures of DFR. A-77-84 Contamination of the $\mathrm{NaK}$ with oxide proved much higher than anticipated and required considerable cleanup effort. The cold traps installed in each of the coolant loops failed to operate effectively, and installation of a better trap system and more satisfactory impurity measurement instrumentation were found necessary. Starting in late 1961, there was considerable stress corrosion in the 321 stainless steel superheaters and evaporators. The contributory causes were chlorides in the water, aerated conditions, and carbide precipitation, particularly at the surface of the scale. Extensive repairs were made to the steam generators, and careful control of water purity was instituted. Repairs were not completed until April 1963.

Niobium and vanadium fuel cladding failures occurred as a result of hydrogen embrittlement induced by hydride in the coolant. This contamination was believed to have been introduced with the first charge of fuel. Carbon in the system may also have contributed to the embrittlement of the cladding. Considerable work was done to determine the cause. Loops were in operation with a hot trap and specimens of zirconium, zircaloy, Nimonic, and three types of low-carbon stainless steel. Additional efforts were made in the United States to determine the effects of carbon on structural material. An extensive cold and hot trap system was installed to reduce oxygen, hydrogen, nitrogen, and carbon concentrations in the coolant to very low levels. Excessive niobium corrosion was reported as late as March 1963. Considerable gas entrainment in the coolant circuits required a number of modifications. These included changes in the expansion tanks and a separate gas enclosure for the control rod mechanism.

Problems encountered with the control rod thrust head were traced to the pickup of scum from 


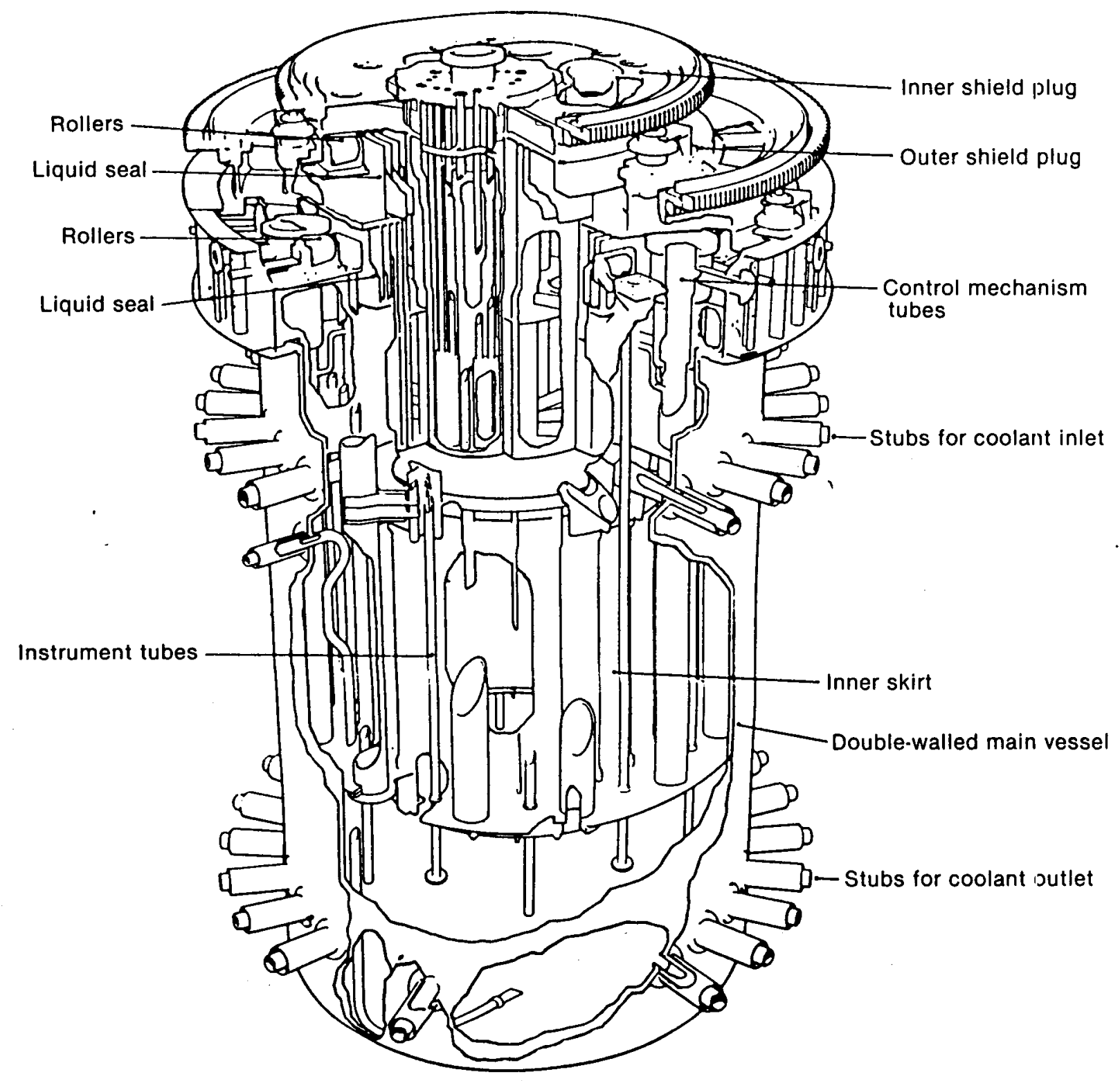

Figure A-67. Cutaway view of the Dounreay reactor vessel and rotating shields.

the contaminated liquid metal surface. These problems were eliminated by the hermetically sealed drive described above and in detail in Reference 76. During startup, problems were also encountered with numerous components, such as the control units and the mercury seals on the rotating shield.

Low-power experiments were concerned with the determination of physics parameters. The predicted critical mass, neutron flux and power distribution for the core region, and the neutron energy spectrum at the core center were reasonably well-confirmed.
The new core tube nest, designed as Core $\mathrm{B}$, was installed in April 1960. Many of the startup problems were consequently solved, and a power level of $11 \mathrm{MW}(\mathrm{t})$ was reached in late 1961 . The second fuel charge of 345 elements was discharged during the period December 21, 1961, to February 9, 1962. After the discharge, the primary system had four complete fills of sodium and 12 dumps. Only after cleanup operations were completed in June 1952, and the holdup of oxide in the clogged bypass circuit eliminated, was the plugging temperature reduced from $230^{\circ} \mathrm{C}$ to about $140^{\circ} \mathrm{C}$. The third fuel loading was 
uranium- $10 \mathrm{wt} \%$ molybdenum, and the loading was completed in the period from June to July 1962. During this loading, the roller bearings on the charge machine were replaced with ball bearings to prevent further bearing seizure previously experienced. Criticality was reached July 26,1962 , and operation at $30 \mathrm{MW}(\mathrm{t})$ was realized August 7, 1962. During this period, the $\mathrm{NaK}$ rose in the rotating plug owing to unbalance in the gas line, contaminating the mercury dip seal and requiring about $590 \mathrm{~kg}$ of mercury to free the seal. New balance lines were added to eliminate this problem. Plugging temperatures were further reduced to $110^{\circ} \mathrm{C}$ while isolating the rotating plug graphite from the reactor cover gas. Testing of uranium-18-at. \%-molybdenum, uranium-20-at.\%molybdenum, and uranium-25-at.\%-molybdenum indicated that the uranium-18-at.\%-molybdenum transformation from gamma to gamma + alpha started in 40 to $45 \mathrm{~min}$ at $480^{\circ} \mathrm{C}$, with completion of transformation in 150 to $250 \mathrm{~h}$. Uranium-20-at.\% molybdenum at $430^{\circ} \mathrm{C}$ took 5 to $7 \mathrm{~h}$ to initiate the same transformation and over $1,000 \mathrm{~h}$ to complete it. But at $550^{\circ} \mathrm{C}$, it took 1 to $2 \mathrm{~h}$ to initiate and 200 to $300 \mathrm{~h}$ to complete. The uranium-25-at. \%molybdenum at $430^{\circ} \mathrm{C}$ took 50 to $70 \mathrm{~h}$ to initiate and was only $5 \%$ complete in $500 \mathrm{~h}$. Examination of the uranium-molybdenum alloy fuels indicated fuel slugs irradiated to burnup at $0.3 \%$ had cracks that increased with fuel temperature, up to $450^{\circ} \mathrm{C}$. Cracking was greatest in slugs that had the large fuel cladding clearances. Increase of molybdenum content from 20 at. $\%$ to 25 at. $\%$ showed how improvement in irradiation behavior had burned up 0.48 to $0.6 \%$. It was hypothesized that steep temperature gradients occurred as high as $790^{\circ} \mathrm{C}$ per $\mathrm{cm}$ in the fuel. Center swelling, produced by gas pressures in the high temperature center of the fuel, acted against the restrained, cooler outer layers. The combined action resulted in the cracks.

The need for shielding the exposed blanket gas pipes had been very well established during 30-MW operations. A-82-84 It became evident that a very high standard of leak tightness was required of the more than 80 joints associated with the instrumentation and gas blanket connections on the rotating shields. For example, during 30-MW operations in August 1962, the airborne activity level in the sphere was a factor of a hundred greater than background, namely $10^{2} \mathrm{~Bq} / \mathrm{m}^{3}$, and during the following run rose to $10^{4} \mathrm{~Bq} / \mathrm{m}^{3}$, which exceeded the maximum permissible concentrations. Gamma spectroscopy showed that the greatest component of the activity was $\mathrm{Rb}-88$, with the other major component being Cs-138. Many of the joints were modified to include double rings. As a result, the airborne contamination level during operation was reduced to about eight percent of the maximum permissible concentration.

Dúring the eàrly high power runs,' operators discovered a slow but steady movement of gas from the top of the reactor vessel to the outer gas ring main. Closing certain gas valves so as to divide the blanket into two separate sections confirmed the phenomenon. It was believed that fission product gas was accumulating above the core and diffusing into the ring main to produce the observed high radiation levels. Isolating the two sections of the blanket system by retaining the more highly active gas within the shielding effected a general reduction in radiation levels by a factor of ten. Regular commoning of the sections was necessary to prevent the buildup of excessive pressure differentials, which would lead to undesirable coolant level variations throughout the system. Further pipe work modifications were made, resulting in a considerable delay being introduced into the time between gas collection over the reactor and its appearance in the ring mains. Except for one or two highly localized areas into which access was normally denied during operation, the net effect of these modifications and the extra shielding, which was installed on the ring main, was to reduce the radiation to within acceptable levels.

Samples of the gas blanket indicate that the main constituents were xenon-133 and xenon-134typical on-power values being $10^{8}$ and $6.2 \times 10^{7}$ $\mathrm{Bq} / \mathrm{L}$, and associated argon activity being 2 to $3 \times 10^{5} \mathrm{~Bq} / \mathrm{L}$. Variation by factors of 100 were possible in these values, depending on the sample point chosen. Whenever changes were made in individual primary pump loads, large variations in gas blanket radiation levels were observed, indicating that gas was moving about the system. It became impractical, without the installation of much more shielding, to transfer the gas blanket to the storage tanks immediately upon reactor shutdown. Normal shutdown procedures were modified to include a delay of about $48 \mathrm{~h}$ before depressurization.

The coolant obviously contained considerable quantities of primary fission products. The coolant monitors servey a small proportion of the primary coolant for delayed neutron emitters, giving a high continuous signal, which was calculated to be equivalent to the exposure of $4 \times 10^{4} \mathrm{~m}^{3}$ of uranium in the core (i.e., $25 \%$ of the fuel surface). The sensitivity of these monitors as indicators of further fuel exposure, namely by element failure, was 
therefore so small they were useless for this purpose.

The coolant had been regularly sampled at power since the installation of the facility, which performed the sampling, and a typical gamma spectrum determination was made in 1964 (described in Table A-9).

The amount of uranium and plutonium in the primary circuit are very small, less than $0.5 \mathrm{~g}$ and $20 \mathrm{mg}$, respectively. The on-power coolant caused by fission products activity is about 100 times that caused by sodium-24, with the dominant isotope being Cs-138 at $2.2 \times 10^{10} \mathrm{~Bq} / \mathrm{g}$.

After a fourth fuel loading, completed in June 1963, the reactor operation reached $55 \mathrm{MW}(\mathrm{t})$ on June 18 , and a subsequent increase to $60 \mathrm{MW}(\mathrm{t})$ in July 1963.

The $60 \mathrm{MW}(\mathrm{t})$ run achieved a fuel burnup of $1.12 \%$. Condition of the fuel cans externally was good. The fuel, as expected, was cracked and swollen. Operations through the fall of 1963 were at a maximum burnup of the uranium-molybdenum of 1.2 at.\%. Electricity was first generated on October 9, 1963, and a tie-in was made to the national grid on October 14, 1963. References A-77-80 cover operating experiments in Dounreay in more detail up to August 1962.

\section{United States}

EBR-II. The Experimental Breeder Reactor II (EBR-II), located at the Idaho National Ergineering Laboratory, is rated at $62.5 \mathrm{MW}(\mathrm{t})$, with an electrical power output of $20 \mathrm{MW}$. EBR..II was originally designed to establish feasibility of metallic-fueled sodium-cooled breeder reactors for power plant service. It was also designed to demonstrate the feasibility of on-site fuel reprocessing techniques. By the mid-1960s all original objectives were met. As interest in fuel breeding developed during the 1970s, EBR-II became the nation's lead facility for the irradiation testing of fuels, materials, and instruments of interest to the breeder program. This testing was done from the viewpoint of designing and constructing more advanced systems. Among EBR-II achievements are the following: generation of over 1.5 billion $k^{\prime} \mathrm{Wh}$ of electricity; irradiation of over 10,000 specimens of fuel, structural, and absorber materials; on-site testing of advanced instrumentation concepts; and successful demonstration of an on-site, diversionproof system for fuel reprocessing.

The demonstration of on-site processirig and fabrication is a procedure believed to have resulted in favorable fuel cycle costs for high-power-tdensity fast reactors, and design of the entire reactor system was affected by this requirement. A comparatively high enrichment necessitates the high power

\section{Table A-9. Gamma spectrum six days after sampling}

\begin{tabular}{llc}
\hline $\begin{array}{c}\text { Energy } \\
(\mathrm{MeV})\end{array}$ & \multicolumn{1}{c}{$\begin{array}{c}\text { Possible } \\
\text { Radionuclides }\end{array}$} & Photons/min-g \\
0.14 & $\mathrm{Ce}-143 / 144$ & $1.5 \mathrm{E}+6$ \\
0.22 & $\mathrm{Te}-132$ & $2.7 \mathrm{E}+6$ \\
0.364 & $\mathrm{I}-131$ & $1.52 \mathrm{E}+7$ \\
0.5 & $\mathrm{Ru}-103 / 106$ & $1.5 \mathrm{E}+6$ \\
0.67 & $\mathrm{I}-132, \mathrm{Cs} / \mathrm{Ba}-137 / 137 \mathrm{~m}$ & $1.63 \mathrm{E}+7$ \\
0.76 & $\mathrm{Zr} / \mathrm{Nb}-95$ & $5.18 \mathrm{E}+6$ \\
1.6 & $\mathrm{Ba} / \mathrm{La}-140$ & $1.95 \mathrm{E}+7$ \\
\hline
\end{tabular}


density, which in turn results in a high rate of fuel burnup. A finely divided fuel is necessary to achieve this high thermal performance. The fuel achieves a high specific activity after irradiation, with the resulting limitations on fission product separation processes. A high level of fission product decay heating also results; thus, there is a need for substantial cooling in the reactor during fuel handling and fuel cycle. The fuel also has a high monetary value, which provides incentive to minimize total fuel inventory by reducing out-of-thereactor processing time requirements.

The fuel cycle involves pyrometallurgical processing, which can be accomplished with relatively small equipment demands and a short cooling time. Incomplete decontamination, however, associated with the process necessitates the use of remote control procedures for the fabrication of new fuel elements from the processed product. The fuel process itself has likewise affected the core design, specifically the composition of the metallic uranium alloy for the first core. The fuel composition is a metallic alloy, $95 \mathrm{wt} \%$ uranium enriched to $65 \%$ uranium-235, and $5 \mathrm{wt} \%$ fissium. Fissium is an equilibrium concentration of fission product elements left by the pyrometallurgical reprocessing cycle designed for EBR-II. It consists of $2.4 \mathrm{wt} \%$ Mo, $1.9 \mathrm{wt} \% \mathrm{Ru}, 0.3 \mathrm{wt} \% \mathrm{Rh}$ and $0.2 \mathrm{wt} \% \mathrm{Pd}$, $0.1 \mathrm{wt} \% \mathrm{Zr}$, and $0.01 \mathrm{wt} \% \mathrm{Nb}$. Fissium contributes desirable characteristics to the fuel. Both reactor and the associated fuel recycle facility were designed to provide a highly flexible installation that would permit investigation and evaluation of various core configurations, types of fuel, fuel element design, and processing techniques. A-21,30$35,81,86-91$

Reactor Features-Figures A-68-70 show the major reactor components. A- 85 The fuel cycle facility is seen to be a major portion of the installation.

The reactor and the primary heat removal system, including the intermediate heat exchanger, are completely submerged in a large bulk volume $\left(300 \mathrm{~m}^{3}\right)$ of sodium within the primary tank. Fuel handling is carried out under sodium.

A steel containment vessel is used to house the primary system components, and power generation facilities are housed in a separate building. Approximately $85 \%$ of the power is generated in the core, with a power density of $890 \mathrm{~kW}(\mathrm{t}) / \mathrm{L}$ and an average specific power of $314 \mathrm{~kW}(\mathrm{t}) / \mathrm{kg}$ of uranium-235.
Reactor Core and Vessel Arrangement-Figure A-70 shows the reactor vessel assembly; Figure A-71 shows the core arrangement. $\mathrm{A}-92$ In the radial direction, the reactor is divided into three main zones: a core, an inner blanket, and an outer blanket. Twelve control rods are located at the outer edge of the core, and two safety rods are located within the core. The core, including the control and safety rods, have an equivalent radius of $21.17 \mathrm{~cm}$ and a height of $36.12 \mathrm{~cm}$, with a total core volume of $0.07 \mathrm{~m}^{3}$. Located in the core zone are 47 core subassemblies, each containing 91 fuel pins, two core assemblies acting as safety rods, and 12 core subassemblies acting as control rods. In addition to the central core section, each core subassembly contains an upper and lower blanket section. The 12 control rods and the two safety rods consist of modified movable core subassemblies. These rods are moved in stationary thimbles having external dimensions and lattice spacing identical to the core and blanket subassemblies.

In each radial zone of the reactor, the hexagonal subassemblies of identical size measure $5.82 \mathrm{~cm}$ across the external flats and have a heavy wall thickness of $0.1 \mathrm{~cm}$. Each subassembly contains a number of fuel and blanket elements with size and shape appropriate to the particular type of subassembly.

The subassemblies are spaced on a triangular pitch with a 5.89-cm center-to-center distance. This provides a nominal clearance of $0.076 \mathrm{~cm}$ between each subassembly to permit removal of the units from the reactor. Each face of a core or inner blanket subassembly hexagonal tube contains a projection or button, $0.95 \mathrm{~cm}$ in diameter by $0.036 \mathrm{~cm}$ high, located approximately at the horizontal center line of the reactor, providing a plane of contact at that location. All subassemblies, including those for control and safety, have an identical upper design and are accommodated by the same handling and transfer devices.

The core subassembly consists of three active sections: an upper blanket, a core section, and a lower blanket. The fuel elements in the core's central section are pin type and consist of a right circular cylinder of fuel alloy fitted into a thin-walled stainless steel tube. A $0.015-\mathrm{cm}$ sodium-filled annulus between the pin and the inside of the tube provides a thermal bond. Above the sodium, an inert gas space is provided to accommodate sodium expansion. The 91 cylindrical fuel elements (pins) contained in the core section are spaced on a triangular lattice by a single helical rib on the outside of 


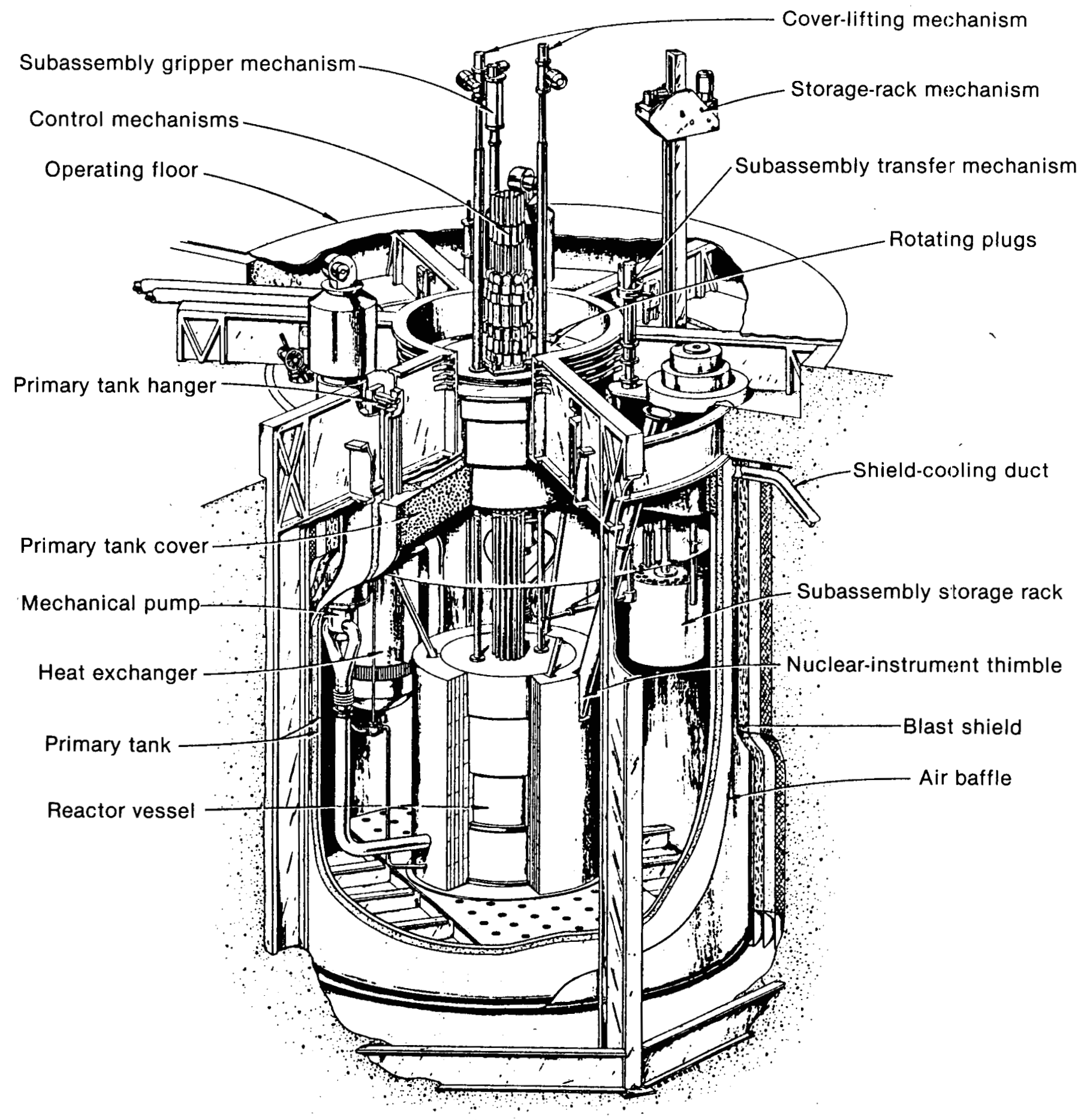

Figure A-68. EBR-II major reactor components and reactor primary tank.

each element. The lower ends of the pin are fastened to a parallel strip support grid with the upper ends unrestrained.

The identical upper and lower blanket sections consist of 19 pin type elements spaced on a triangu- lar lattice. The pins are unalloyed depleted uranium, $0.8 \mathrm{~cm}$ in diameter, and $45.7 \mathrm{~cm}$ long. They are contained within a stainless steel tube having a $0.02-\mathrm{cm}$ sodium-filled annulus to provide the necessary thermal bond. Bond ends of the blanket elements are positioned in the subassembly by a 


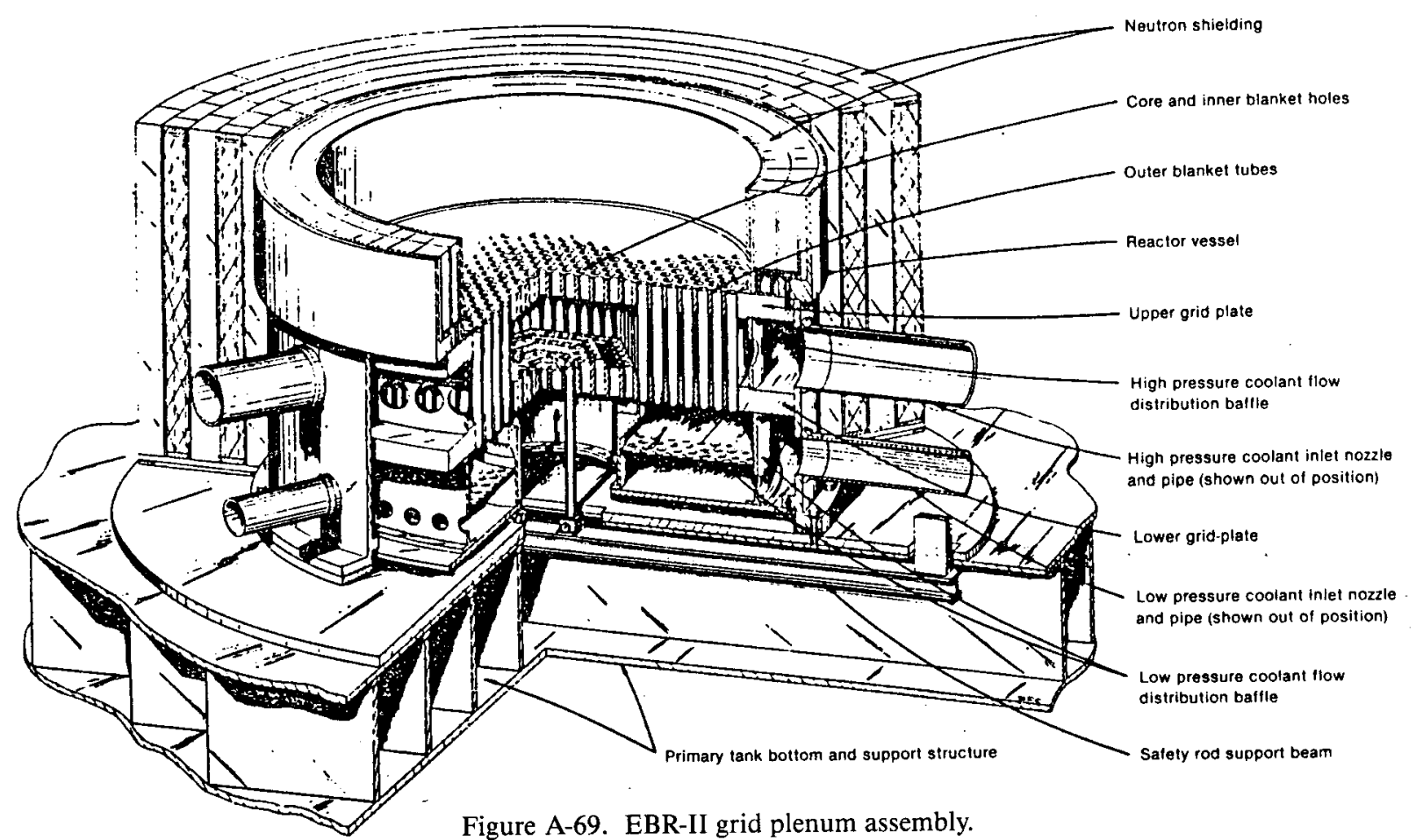

Figure A-69. EBR-II grid plenum assembly.

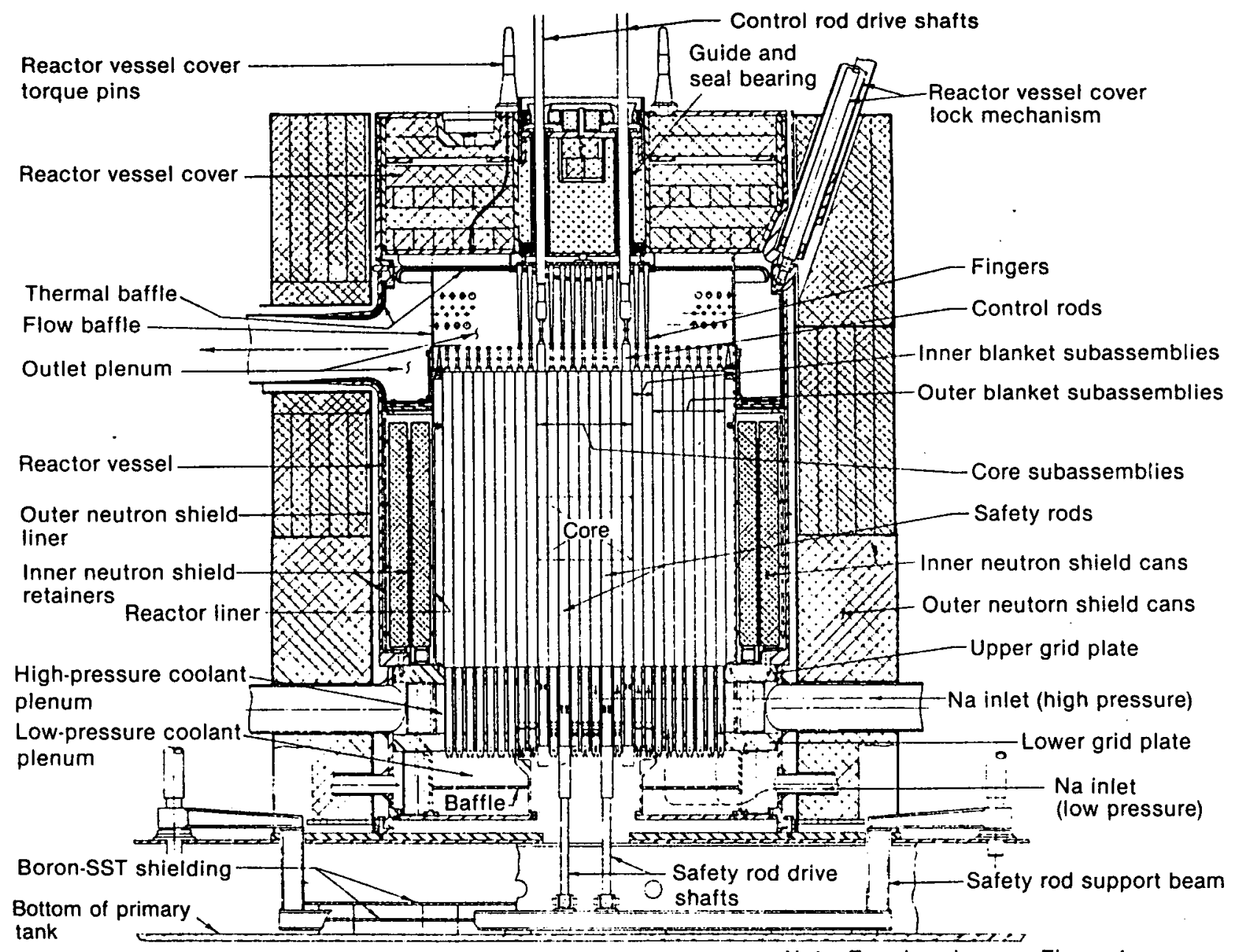

Note: For plan view see Figure 4.

Figure A-70. EBR-II reactor vessel assembly. 


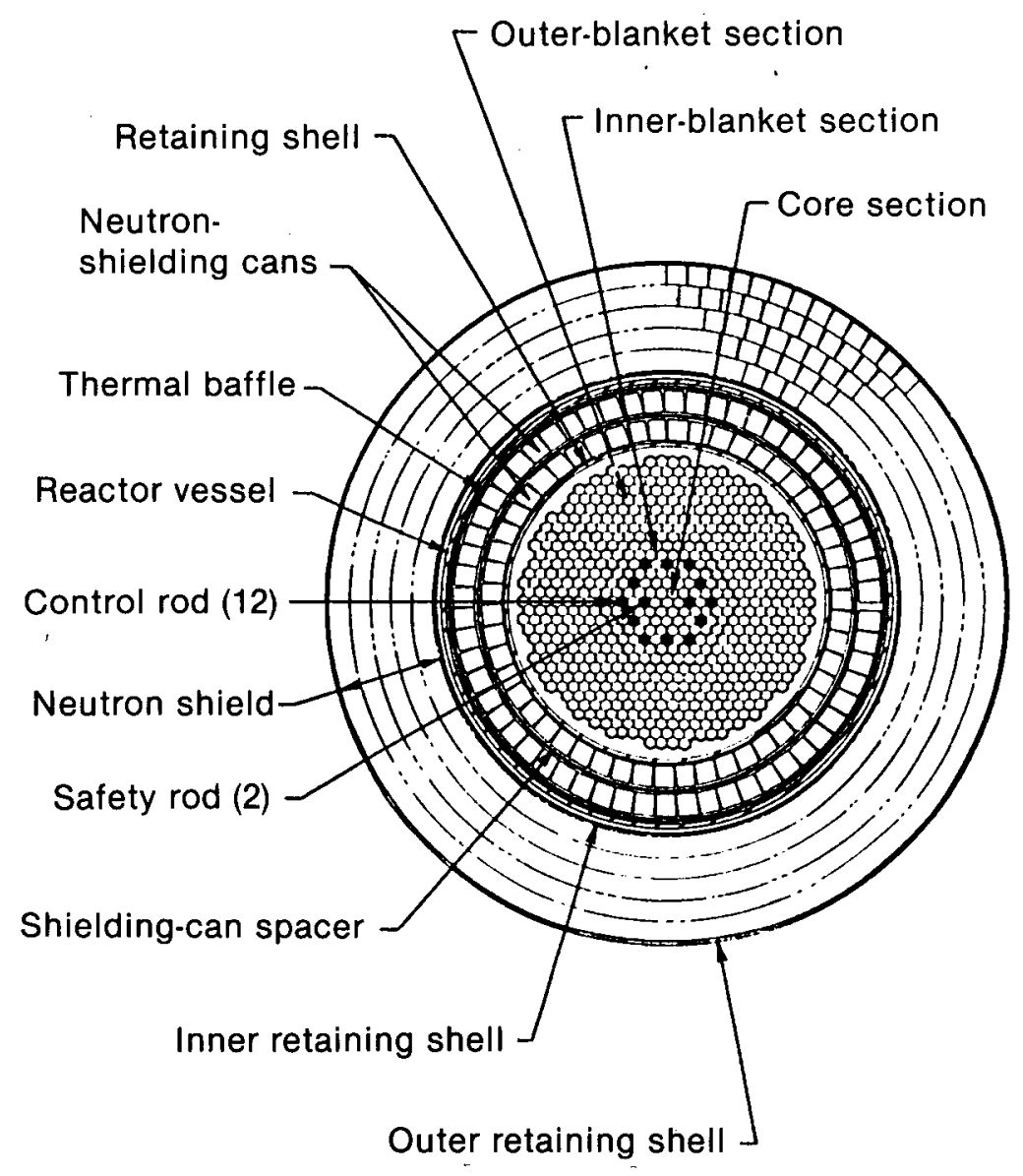

Figure A-71. EBR-II primary neutron shield.

parallel strip grid similar to that used in the field sections. Axial expansion is permitted, but other movements are restricted. The upper adapter of the assembly is provided with an attachment knob for the various fuel handling gripper units and a collar for the transfer arm. The lower adapter is a cylindrical inlet nozzle for the coolant, and also serves as a locating and support plug in the reactor grid plate. The bottom end of the nozzle is closed; the coolant enters the nozzle through holes in the cylindrical wall.

The inner and outer radial blanket subassemblies each consist of 19 cylindrical blanket elements spaced on a closely packed triangular pitch and contained in a hexagonal can. The central active blanket section consists of depleted uranium cylinders $1.1 \mathrm{~cm}$ in diameter and $1.4 \mathrm{~m}$ long. They are contained in a stainless steel tube with a $0.03-\mathrm{cm}$ sodium annulus as a thermal bond and an argon gas expansion region above the sodium. The enclosure unit is sealed with welds. The two types of blanket subassemblies differ from the core subas- sembly only in the design of the lower adapter. In the case of the outer blanket subassembly, a smalldiameter adapter contains an opening at the bottom through which the coolant enters.

Control Rods-Operational control of the reactor is achieved by 12 control assemblies with a fuel pin core section identical to that in other core positions. Control is by removal or insertion of the fuel. Instead of an axial blanket, a void section no:mally filled with sodium is above the core section, and a steel cylindrical tube reflector is below the fuel section. The middle section of the rod consists of a modified core subassembly comprising 61 fuel elements identical to those used in the other core subassembly units. This assembly is encased in a 4.85-cm-across hexagonal tube, which is smaller than the normal hexagonal tube by the equivalent of one row of fuel elements.

The drive arrangement for the control and safety rods is shown in Figures A-72 and -73. The two identical safety rods employed to provide shutdown 


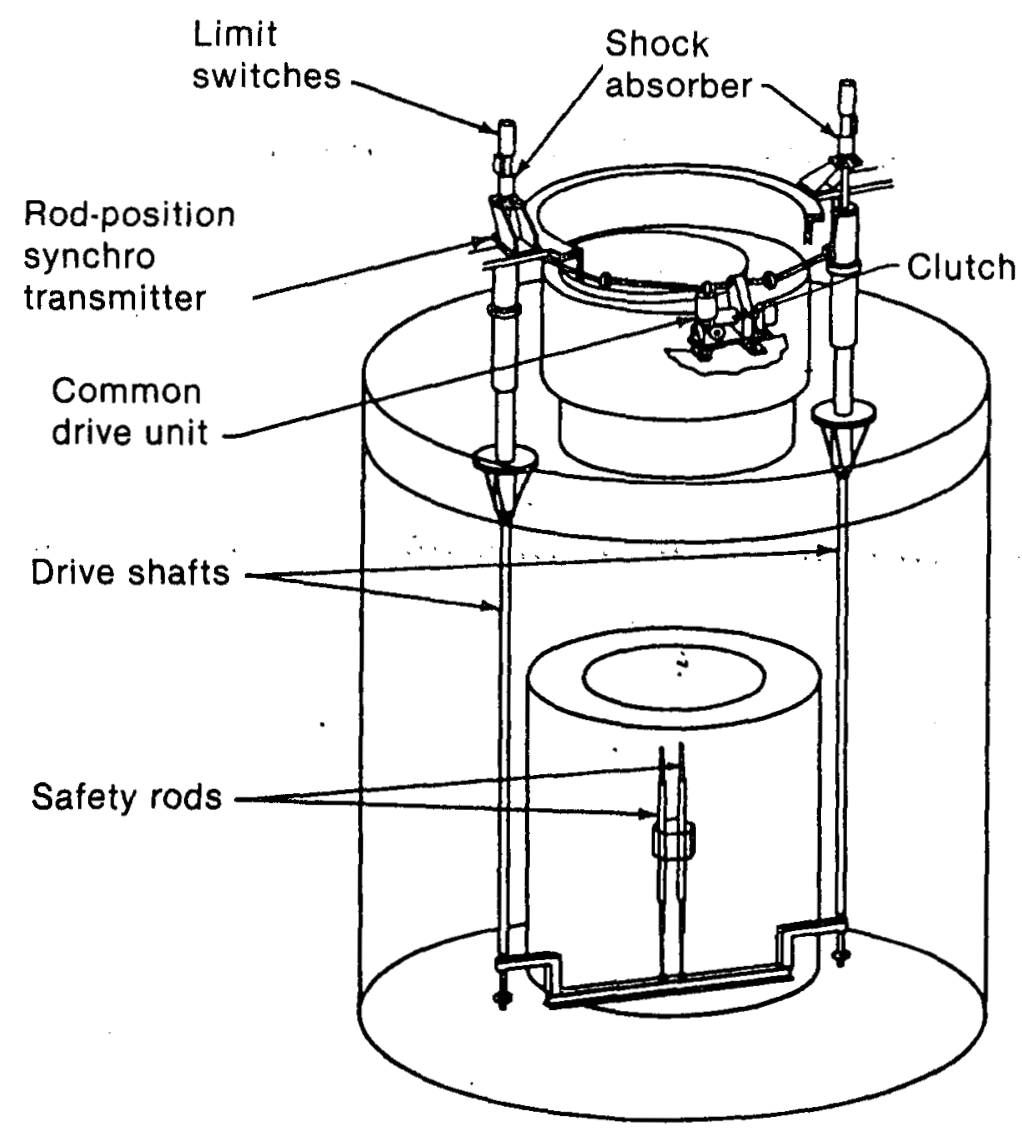

Figure A-72. EBR-II safety rod drive system.

reactivity during reactor loading operations are driven from below the core. They are essentially identical to the control rods except for modifications at the lower end which provide the necessary attachment to the drives.

Heat Transport Systems-A unique feature of the heat transport system is the primary tank. It contains the reactor vessel and primary coolant system submerged in a large volume of bulk sodium, as shown in Figure A-68.

Two identical vertically mounted single-stage centrifugal pumps, operating in parallel, force coolant from the bulk sodium in the primary tank through the reactor at a rate of about $536 \mathrm{~L} / \mathrm{s}$. Flow through the reactor itself is $517 \mathrm{~L} / \mathrm{s}$. Of that flow, $440 \mathrm{~L} / \mathrm{s}$ move from a high-pressure plenum through the core and inner blanket subassemblies; $44 \mathrm{~L} / \mathrm{s}$ flow from a separate low pressure plenum through the outer blanket subassembly; and $32 \mathrm{~L} / \mathrm{s}$ flow through the clearance spaces between subassemblies. The remaining $19 \mathrm{~L} / \mathrm{s}$ represent leakage back to the primary tank through the pump ball seat disconnects and the subassembly holddown devices at the bottom of the vessel. The coolant passes into a common outlet plenum chamber and then out of the reactor through a single outlet nozzle to the intermediate heat exchanger. After passing through the heat exchanger, the coolant returns to the bulk sodium supply at approximately $370^{\circ} \mathrm{C}$. This temperature is slightly above the bulk temperature, since it is necessary to compensate for the small heat losses from the primary system tank. For maintenance, the pumps may be removed from the primary tank by ball seat pipe disconnects. The heat exchanger shell is permanently attached to the cover of the primary tank, but the tube bundle and associated structure are removable as a unit. Additional component details are given in Reference A-93.

In the secondary system, an A-C electromagnetic linear induction pump, which provides close control of the flow rate, circulates sodium through the tubes of the primary heat exchanger at a flow rate of $780 \mathrm{~L} / \mathrm{s}$. The sodium then enters the superheated section of the steam generator at $470^{\circ} \mathrm{C}$ and returns to the pump at $320^{\circ} \mathrm{C}$. 


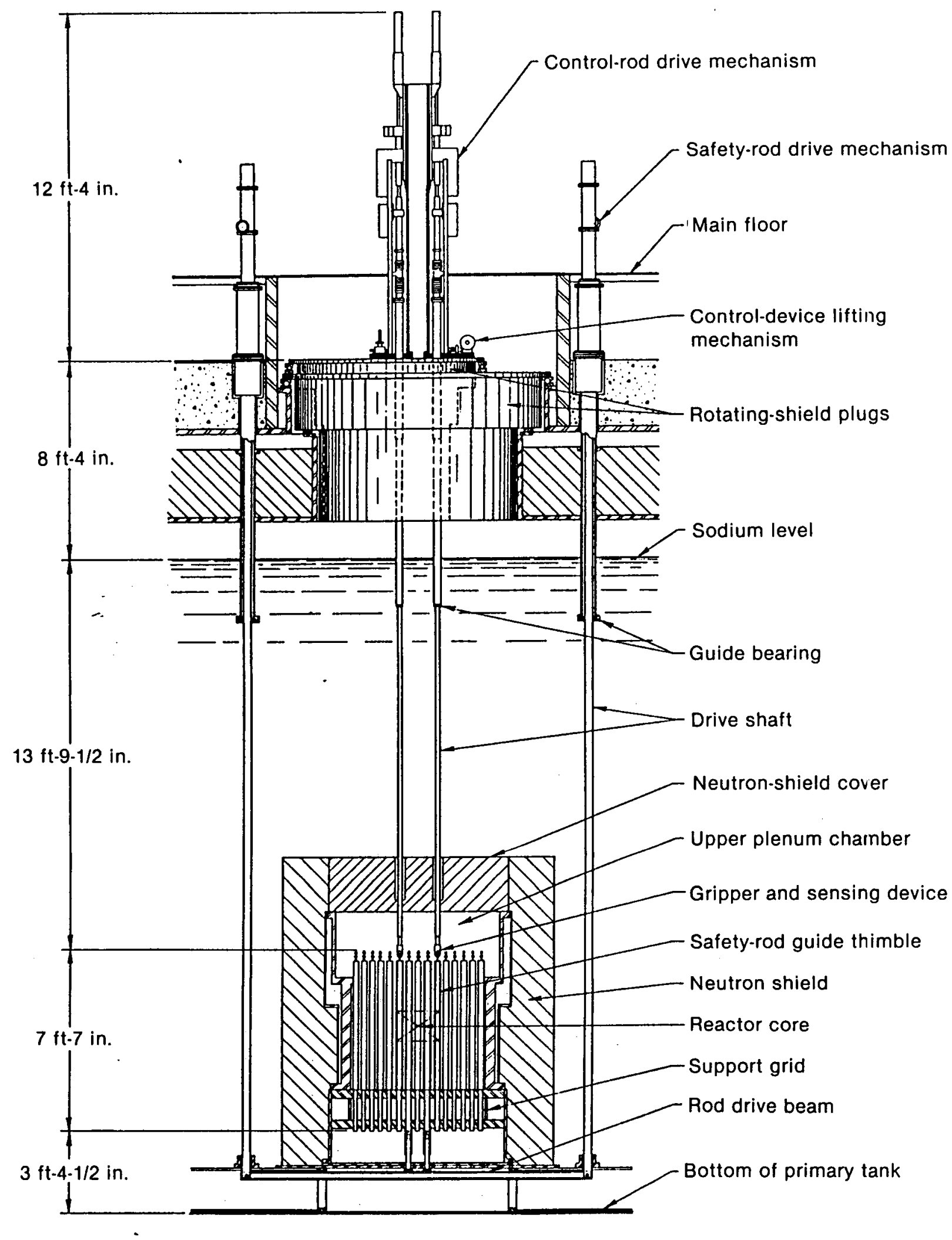

Figure A-73. EBR-II control and safety rod drive systems. 
The steam generator, shown in Figure A-74, is one of the natural recirculation types with separate superheaters and evaporator sections connected to a single steam drum. Each evaporator unit is connected to the steam drum by a single downcomer and riser. Dry and saturated steam from the steam drum passes down through the superheater unit. Double-walled tube construction is used for both the evaporator and superheater units; no welds are used in the portion in contact with the sodium. A-87

At full load [62.5 MW(t)], when the generator produces $20,700 \mathrm{~kW}$ electrical gross, the steam system flow includes $0.63 \mathrm{~kg} / \mathrm{s}$ of steam bypass to the condenser. A full-capacity automatic steam bypass system permits reactor operation without turbine generator operation or with turbine load at any fraction of reactor power. This bypass system prevents major load changes from effecting changes in the secondary system. Feedwater heating is accomplished by extraction from the main turbine, by exhaust from the feedwater pump turbine, and by high-pressure steam from the main steam line.

Structures and Shielding Components-In EBR-II, the reactor vessel assembly is completely submerged within a large volume of bulk sodium contained in the primary tank. The assembly itself is mounted on the bottom structure of the tank in such a manner that the distance from the top of the reactor vessel to the free surface of the bulk sodium is approximately $3.6 \mathrm{~m}$. The reactor vessel assembly, as shown in Figure A-70, includes the lower grid plenum with inlet nozzles and safety-rod drives, an inner radial neutron shield, the subassembly holddown and flow-baffle structure with outlet plenum and outlet nozzles, the vessel cover and hold down structure, thermal baffles, the

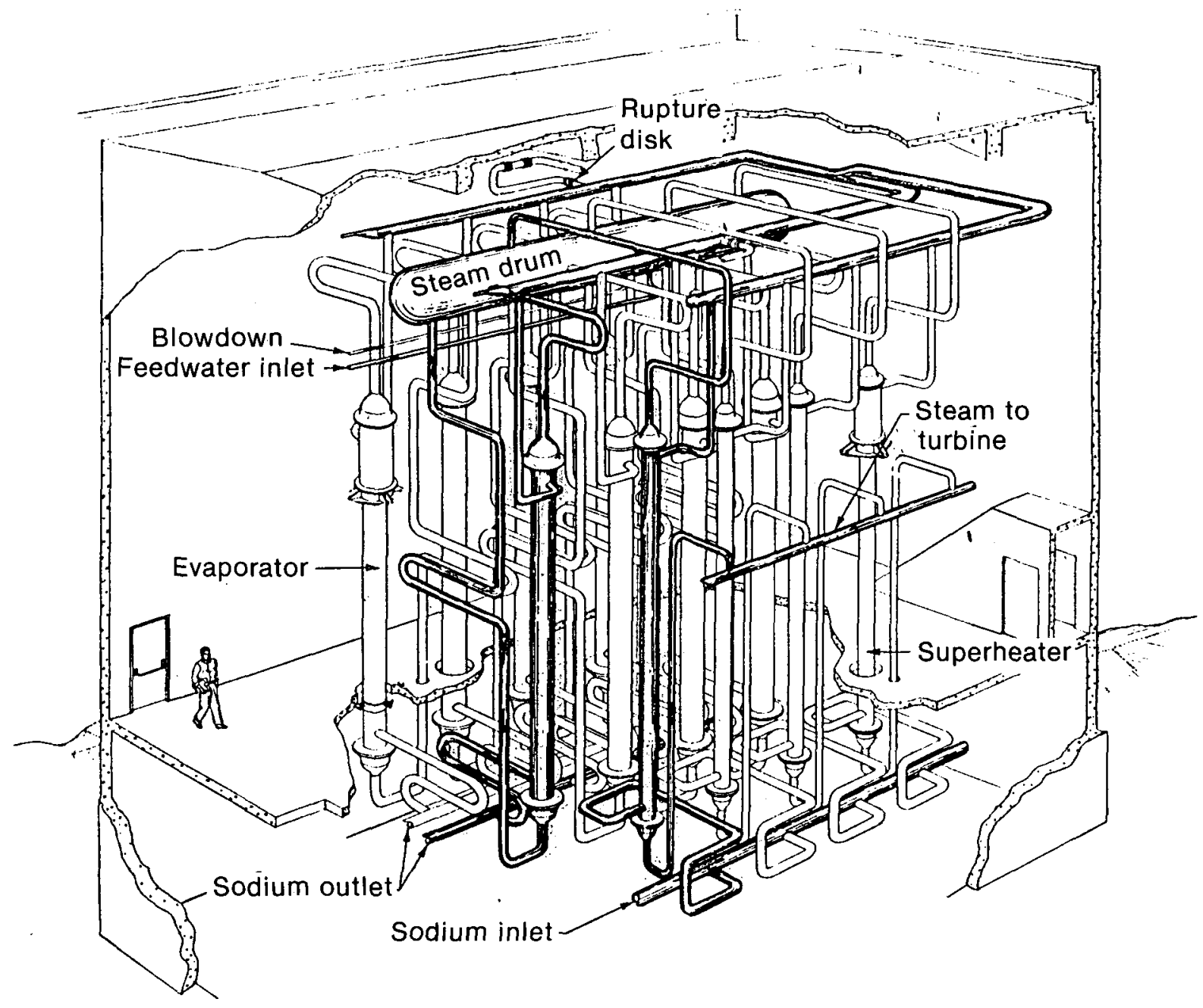

Figure A-74. EBR-II steam generator. 
cylindrical vessel wall, and the outer radial neutron shield. A-68,92

Located within the primary tank, but outside the reactor vessel, are the fuel handling components, which are an important feature of the reactor design. The system, shown in Figure 75, has the capacity to remove a subassembly from the reactor, transfer it to the storage rack, and remove it from the primary tank after a 14-d cooling period. The system consists of a gripper mechanism, a subassembly hold down rod, and transfer arm assembly. Positioning of the gripper mechanism is accomplished by rotating two eccentric plugs in the shield. Details of the fuel handling procedures and equipment are given in Reference A-87.

The shield system consists of two sections. A neutron shield between the blanket and the bulk sodium tank, reduces neutron leakage into the

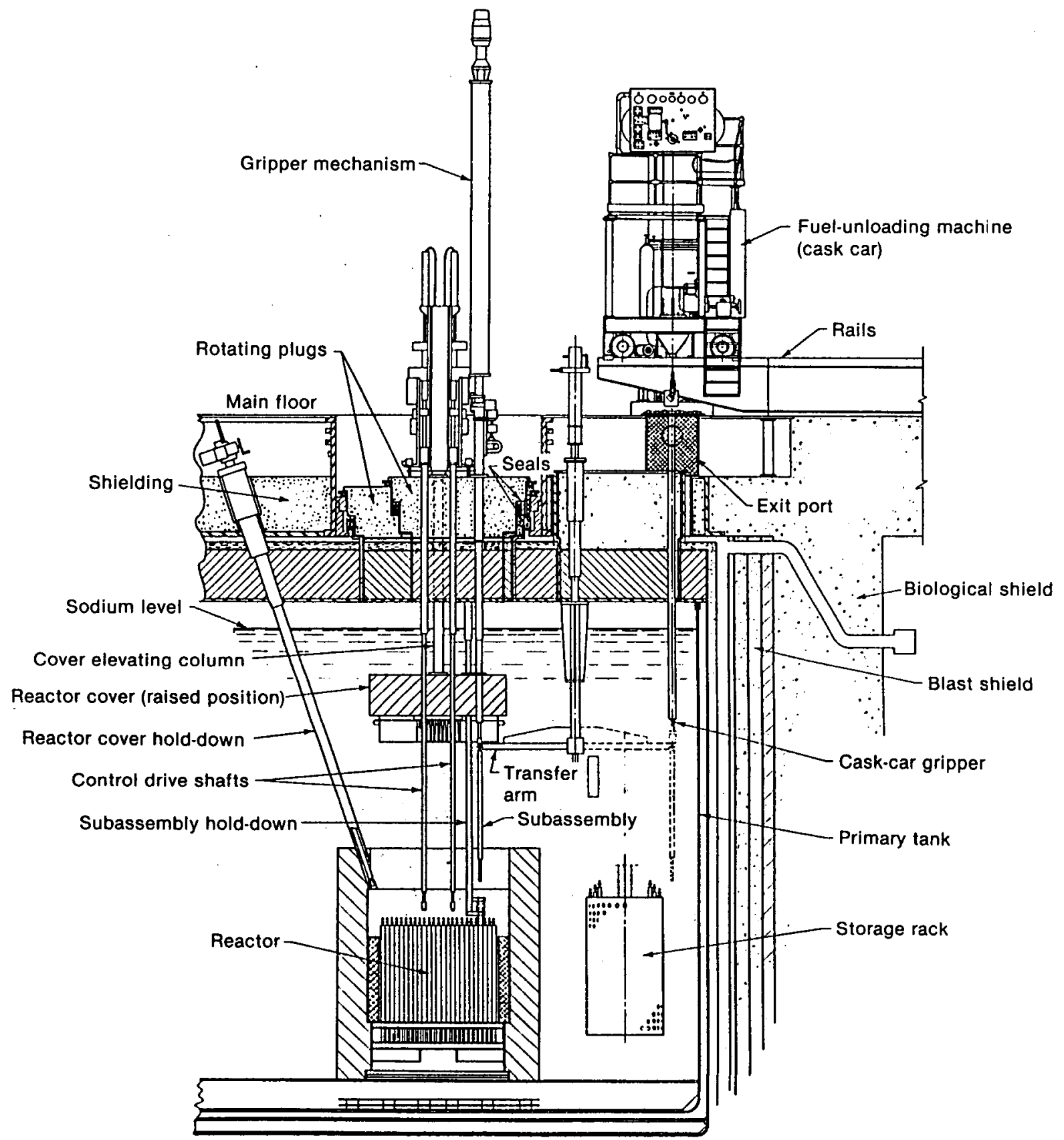

Figure A-75. EBR-II principal fuel handling components. 
sodium and thus reduces activation. A biological shield outside the sodium tank reduces radiation levels to acceptable limits at accessible locations around the reactor. This arrangement is shown in Figures A-76 and A-77. Within the reactor vessel, part of the neutron shield consists of two rows of stainless steel cans, each $10.2 \mathrm{~cm}$ square, filled with graphite. Five additional rows are located outside the reactor vessel; the fifth and seventh rows consist of $3 \%$ boron carbide. Graphite is substituted for the boron carbide in areas immediately adjacent to the neutron detecting instruments. A-87
The primary heat exchanger, located within the primary tank, is surrounded by a $2.5-\mathrm{cm}$-thick shell of $1.5 \%$ borated steel to reduce activation of the secondary sodium system.

The biological shield, outside the primary tank, consists of a $1.8-\mathrm{m}$ thickness of ordinary concrete in the radial direction wherever space is available. Also making up the biological shield is a top shield consisting of a layer of steel balls directly above the primary tank. Heavy concrete is used elsewhere. Rotating plugs in the top shield are stepped to

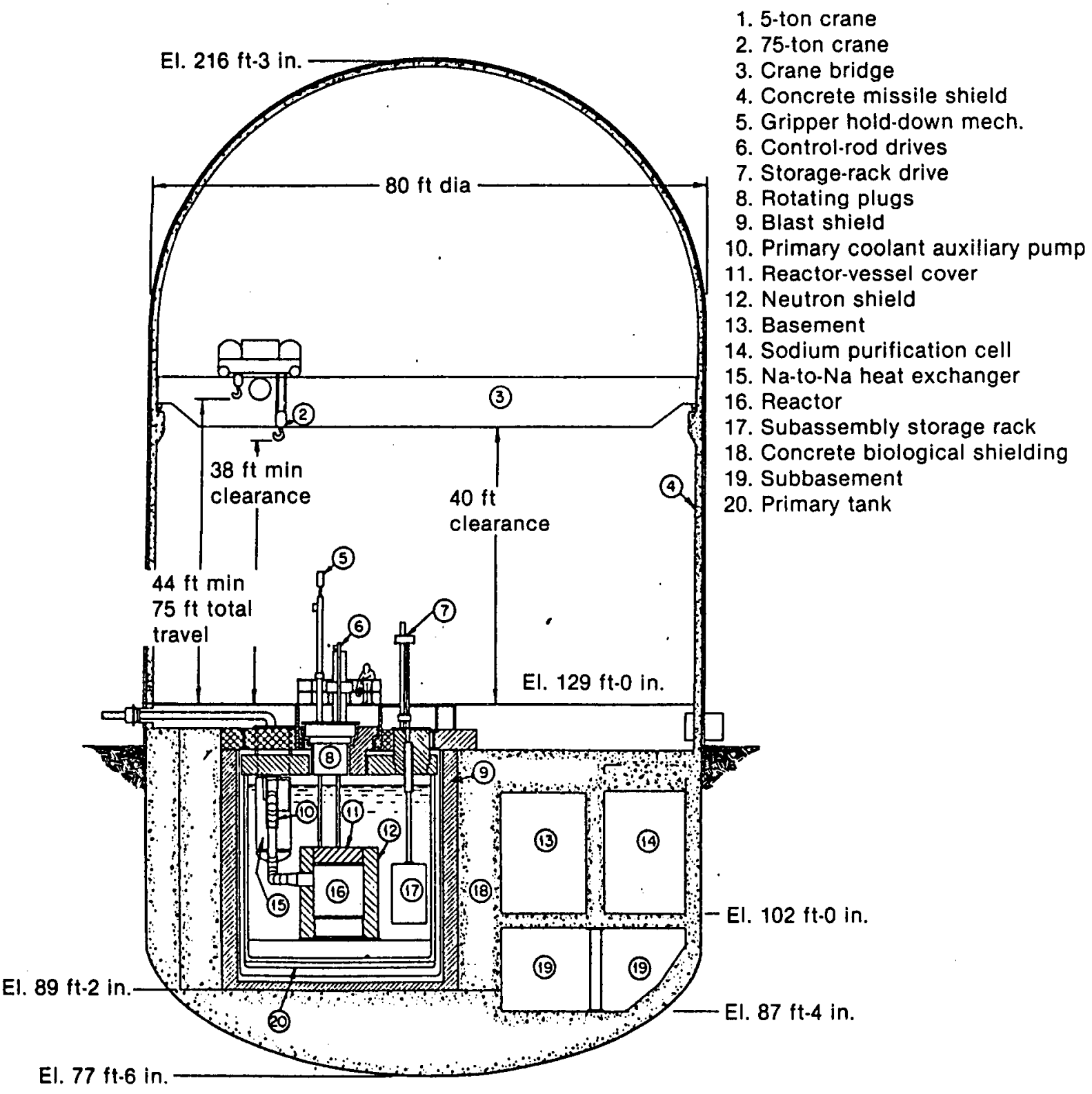

Figure A-76. Vertical cross section of EBR-II reactor building. 


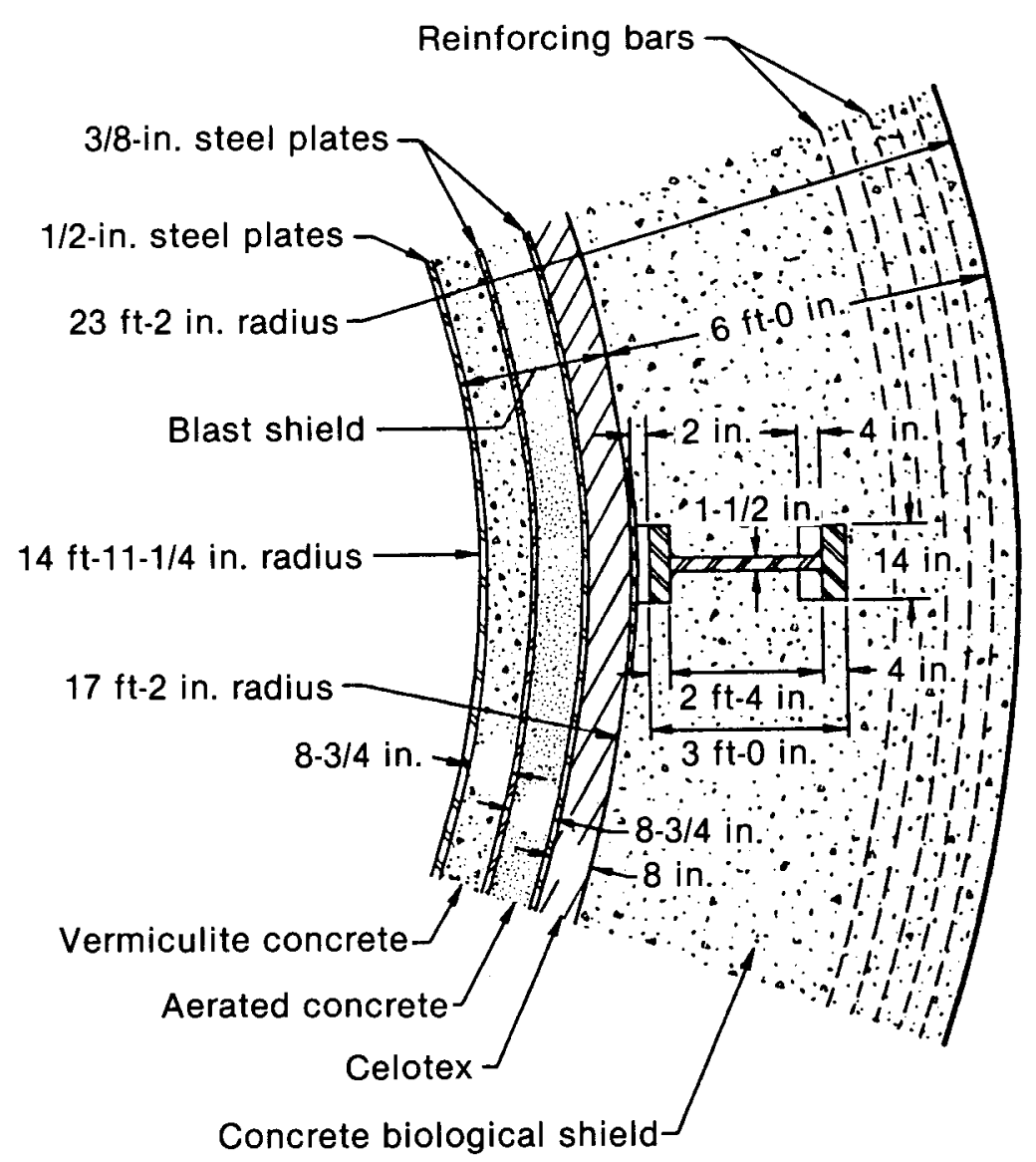

Figure A-77. EBR-II blast shield and biological shield.

reduce streaming through the large number of voids and penetrations necessary to provide access. Control rods, however, are not stepped, but streaming is reduced by keeping clearances as small as possible and providing more thickness than otherwise required. Additional details of the shield system are given in Reference A-92. A steel containment vessel $24 \mathrm{~m}$ in diameter and approximately $42.7 \mathrm{~m}$ high houses the reactor plant.

Instrumented In-core facility - The needs for gathering physical data from subassemblies under irradiation were not considered in the original design of EBR-II. However, as the irradiation program accelerated during the late $1960 \mathrm{~s}$, increased interest was expressed in an in-core irradiation facility. Such a facility would permit cabling connections between sensors in an experimental fuel bundle and the out-ofcore recording instruments. In the late 1960s and early 1970s, two instrumented in-core irradiation facilities were added to provide flexibility to the irradiation program, and to permit continuous monitoring of physical data for specimens being irradiated under typical operating conditions.
The Instrumented Subassembly Test Facility (INSAT) is used primarily for the irradiation of fuel materials. The In-Core Test Facility (INCOT) is used for irradiation of structural materials, absorbers, and sensors. Both differ substantially in design and operation.

The design of INSAT was constrained by two principal considerations: (a) the need ro run instrument leads through a control rod penetration and the reactor vessel cover, (b) the need to keep the discharged fuel bundle under the primary sodium at all times during its removal from the core. These constraints were eventually satisfied by replacing a control rod (and its associated drive) by a single unit that can be loaded from the reactor floor into the reactor grid, and which permits cable connection between the in-core sensors and out-of-core recorders. The unit is a fuel bundle physically similar to a control rod and a double-walled extension tube, and is mechanically latched to the tundle. Cables are led from the sensors up to the cloublewalled tube and into a terminal box located outside the primary tank. During routine operation, the 
fuel bundle occupies the same position as that normally occupied by a control rod. During fuel handling operations, the entire in-core assembly is raised to an elevation that permits normal functioning of fuel handling equipment. Following fuel handling operations, the assembly is lowered back into the core for subsequent irradiation.

When test bundles reach their target burnup and are ready for removal from the core, a special cutting tool is lowered through the extension tube. Rotation of the tool cuts the instrument leads. The extension tube and cutting tool are then drawn up into a pulling pipe, leaving the fuel bundle ready for transfer with the standard fuel handling equipment.

Depending on the needs of the experimenter, as few as one and as many as 61 other specimens may be accommodated in the test vehicle. As of December 31, 1982, seven individual sets of instrumented fuel specimens had been irradiated in the INSAT facility. Typical information derived from the tests include temperature, coolant flow rate, gas pressure, creep rate, and neutron flux.

Test specimens in the INCOT facility may be inserted or removed from the reactor floor area. The distinction between the two facilities is one of use. Because of decay heat considerations, fueled specimens must be kept submerged in the primary sodium following irradiation. Such a constraint is more easily satisfied by treating the test section during its discharge as a spent fuel assembly. Furthermore, attempts to discharge irradiated fuel specimens via the reactor floor would pose major shielding problems.

For nonfuel test specimens, decay heat problems are essentially nonexistent. Associated radiation fields are such that shielding requirements during discharge through the reactor top can be satisfied.

The INCOT facility is, in its simplest form, a thimble assembly that extends upward from the reactor grid (below the core) through the core, reactor vessel cover, and small rotating plug, to the reactor floor level. Instrument leads run directly from test specimens or sensors up the thimble to a top mounted terminal box. Special handling systems permit removal of irradiated test bundles from the facility, reinsertion of reworked irradiated test bundles into the facility, or removal of the facility itself. Removal operations involve the withdrawal of the test bundle into a handling container $11.3 \mathrm{~m}$ long, which is suspended from the building crane. Opera- tion of the container is remotely controlled from a shielded booth. As for INSAT facilities, the entire assembly is lifted prior to fuel handling operations.

Since 1972 , the INCOT facility has been used to irradiate 10 principal series of instrumented experiments. Among these were the irradiation of absorber materials $\left(\mathrm{B}_{4} \mathrm{C}\right.$ and $\left.\mathrm{Eu}-\mathrm{O}_{2}\right)$, self-powered neutron detectors, eddy current flow sensors, acoustical monitors, and biaxial creep specimens.

A more recent in-core instrumented facility, the Breached Fuel Test Facility (BFTF), has been installed. This facility was designed to test the fission product characteristics of breached fuel under normal operating conditions. BFTF consists of a device that monitors the exit sodium from a test vehicle located immediately underneath. The test vehicle, in turn, can contain any one or more of a variety of experimental fuel elements, either intact or intentionally breached. BFTF is equipped with two flowmeters, a delayed neutron detector, and a deposition sodium sampler used to study the plateout of fission products.

Another in-core instrumented facility, the Fuel Performance Test Facility (FPTF), has been installed. Principal features of FPTF include the following: a throttle valve for changing and controlling the coolant flow rate through the facility, a sodium flowmeter, thermocouples, and a delayed neutron detector. Because its coolant flow rate can be changed during operation, FPTF can be used to cycle temperatures in fuel element specimens. FPTF can, of course, be used to study the effects of transient operation in both intact and intentionally breached fuel elements.

At the nuclear Instrument Test Facility (NITF), capability exists for on-site performance testing of nuclear instruments under LMFBR conditions. Two of eight existing instrument thimbles are used for this purpose. In the original configuration, EBR-II was fitted with four J-type nuclear instrument thimbles that extend down from the upper shielding to the primary tank and into the neutron shield around the vessel. Four other O-type thimbles similarly extend down from the upper shielding to terminate outside the neutron shield. One $\mathrm{O}$ thimble and one $\mathrm{J}$ thimble have been converted to instrumented test facilities.

The NITF thimbles are $8.5 \mathrm{~m}$ long and $38 \mathrm{~cm}$ in diameter at the lower ends. Instruments are usually located at core mid-plane elevation. Leads from the 
instruments are led up through the thimble to the reactor operating floor.

Test temperatures ranging from 66 to $370^{\circ} \mathrm{C}$ are made possible by varying the amount of cooling air circulating through the facility. If higher temperatures are needed, thermostatically controlled ovens may be used for instrument heating. Data taken under operating conditions allow the experimenter to evaluate effects of high temperature and intense radiation fields on the performance of various neutron detectors and instrument cables.

The Radioactive Sodium Chemistry Loop (RSCL) is a facility that permits development testing of techniques to measure impurity levels and primary sodium. The facility consists of five shielded cells, a 5.1-cm-diameter main loop, and smaller branch lines that deliver primary sodium to and from the various cells. Coolant is pumped through the main loop by a dc electromagnetic pump at flow rates and pressure variable up to $1.9 \mathrm{~L} / \mathrm{s}$ and $0.11 \mathrm{MPa}$, respectively.

Each cell may be isolated from the main loop, and, after a suitable decay period, physical access is permitted for the installation and maintenance of equipment. Extensive precautions have been taken to prevent, annunciate, and minimize the impact of sodium leakage throughout the entire facility.

The facility has been used extensively as a test bed for proving the application of various on-line impurity measuring devices. Among devices tested in the RSCL are a plugging temperature indicator, tritium monitor, vacuum distillation sampler, oxygen and hydrogen meters, segregated iodine sampler, graphite-cesium trap, and an equilibrium module for carbon analysis.

Fue/ Cycle--Because a very important objective of this reactor is the demonstration of an integral fuel processing facility, some features associated with the fuel reprocessing are given here and are found in more detail in References 94-109. The first fissium core consisted of stainless steel jacketed pins containing $50 \%$ enriched uranium alloyed with $5 \%$ noble-metal fission product elements. Irradiated fuel assemblies were allowed to cool $14 \mathrm{~d}$ in the primary tank and were then removed to the Fuel Cycle Facility (FCF). Transfer operations were relatively simple. Spent fuel subassemblies were placed in the air cell for disassembly operations, using a system of shielded casks, airlocks (between the reactor building and the FCF), and cranes. The operation consisted mainly of slitting the wrapper can and removing individual elements from the fuel bundle. Fuel elements, in turn, were loaded into magazines and moved to the argon cell via an interconnecting lock.

Initial operations in the argon cell consisted of the following: shearing upper and lower ends from the fuel elements, removing spacer wires, removing the cladding, and chopping the spent fuel pins into $3.5-\mathrm{cm}$ lengths. Chopped fuel in amounts of 10 to $12 \mathrm{~kg}$, along with precalculated amounts of enriched uranium, were melted in CaO-coated zirconia crucibles and held for $3 \mathrm{~h}$ at a temperature of $\sim 1,400^{\circ} \mathrm{C}$. During this period, approximately twothirds of the fission products-those with high vapor pressure, such as xenon, krypton, iodine, bromine, cesium, and cadmium-left the melt through volatilization. Less volatile electropositive fission products, such as yttrium, barium, strontium, and the rare earths, reacted with the zirconia to form an oxide that remained within the crucible after pouring operations. The volatized fission products were collected by a Fiberfax cover over the crucible, which also collected sodium used as a thermal bond in the fuel. The purified alloy was poured into the mold to provide the ingot for fabrication; the oxidized fission products, principally the rare earths, were left behind in a sci-called "skull" retained by the crucible.

The pouring operations were never totally efficient. Inevitably, a relatively small but consistent amount of fuel, $\sim 6-8 \%$, remained in the crucible with the dross. These skulls were set aside in hot storage for subsequent uranium recovery.

The process contemplated for recovering the skull material is to convert it to an oxide powder suspended in a molten chloride flux, the noble metals to be removed by reduction and extraction by zinc. A dilute magnesium-zinc alloy would then reduce the uranium oxides and other fission product oxides. A uranium zinc intermetallic compound would be precipitated from this metallic solution by cooling, and the desired uranium recovered in several additional reprocessing steps. Although the melt-refining separation itself is quite simple, the need for the skull recovery process may result in a complicated overall operation.

The first step in fuel pin casting operations consisted of remelting a melt-refined ingot in a thoriacoated graphite crucible with an induction heated vacuum furnace. Also located in the furnace in a 
vertical attitude above the crucible was a cluster of approximately 100 Vycor molds. After the charge was melted, the crucible was raised to a position that immersed the lower end of the mold cluster to a depth of $3.8 \mathrm{~cm}$. The furnace was then rapidly pressurized to $0.17 \mathrm{MPa}$ to drive the melt up into the evacuated molds. After a few seconds, the melt froze and the crucible was lowered to its original position. Following a 4-h programmed cooling period, the furnace was opened and the molds were removed. Unused fuel material in the crucible was broken up and returned to the fuel stream.

The first step in fuel pin processing operations consisted of breaking the Vycor molds away from the castings with a pneumatically actuated crushing system. Pins, collected in trays, were fed by gravity to a shear that cropped the pins to required lengths. Following cropping, the pins were subjected to nondestructive tests that consisted principally of measurements for weight, length, diameter, and porosity. Rejects were fed back to the melt refining operation.

Acceptable pins were loaded into stainless steel tubes containing solid sodium wire ( $\sim 0.65$ to $0.85 \mathrm{~g}$ ). The sodium was melted and the fuel pins settled by gravity. End-plugs were inserted into the jackets and peripherally welded to the jackets with a remotely operated capacitor-discharge welder. To ensure void free sodium bonds, the finished elements, clustered 50 to a magazine, were heated in a furnace $1 \mathrm{~h}$ at $500^{\circ} \mathrm{C}$. The elements were then subjected to $\sim 1,000$ vertical impacts (under $500^{\circ} \mathrm{C}$ conditions) at the rate of 100 impacts per min. The finished elements were then inspected for bond, flaws, and sodium level. The final step consisted of monitoring the elements on a grid system and incorporating the resultant fuel bundle in a fresh hexagonal wrapper can for subsequent return to the reactor.

After nearly 5 years of successful operation, the FCF was shut down in 1969. Subsequent core changes have been made, either by vendors in the commercial sector or by on-site personnel in a companion "cold" line facility. Currently, the argon cell is on standby status. The cell has been stripped of equipment and is in the process of decontamination.

Operating Experience-Operating run lengths of EBR-II are nominally $2,800 \mathrm{MWd}$ or $\sim 50$ fullpower $d$. Two factors determine the run length: the need to discharge the radiation experiments at scheduled intervals and the need to replace spent fuel with fresh fuel. Approximately $7 \mathrm{~d}$ are needed between runs to accommodate refueling operations and perform minor maintenance activities that cannot be carried out with the plant running. Each year the plant is shut down for four to six weeks to carry out comprehensive modification, maintenance, and inspection.

The operation of EBR-II has always been kinetically stable. A prompt negative power coefficient of reactivity from the expansion of coolant and fuel effectively damp the effects of small reactivity changes from inlet temperature variations and control rod motion. The amplitude of the prompt power coefficient component is occasionally measured by rapidly withdrawing reactivity from the system, dropping a special rod, and analyzing the shape of the power decay curve.

During the period from 1976 to 1982, EBR-II operated with plant availability factors greater than $70 \%$. A peak value of $77.1 \%$ was reached during 1980. Plant availability factors in this range compare favorably with those of commercial nuclear and conventional fossil fuel power plants. If down time required by the experimental programs is discounted, the actual plant availability factor during the 1976 to 1982 period exceeded $80 \%$.

Refueling time between runs is not a serious constraint. The capability of interim in-tank storage permits the pre-shutdown transfer of fresh fuel assemblies to the storage basket. Approximately $4 \mathrm{~h}$ after shutdown, spent subassemblies may be transferred from the core to a storage basket and replaced with fresh subassemblies. The turnaround time per subassembly amounts to approximately $1 \mathrm{~h}$. In the absence of problems, the time required for end of run refueling operations amounts to approximately 24 to $48 \mathrm{~h}$. The interim fuel storage feature is beneficial in another important respect. After fulfilling minimum cooling requirements, spent subassemblies may be transferred into and out of storage baskets while the reactor is running.

Routine operations are occasionally interrupted by the release of gaseous fission products from a failed fuel element. The majority of the releases are the result of endurance tests in which fuel elements are intentionally irradiated to failure and beyond. On other occasions, the failure may be the result of a faulty weld or a premature failure of cladding. More recently, the effects of sustained operation 
under breached cladding conditions have been investigated. Fuel elements that failed under irradiation were permitted to remain in the core for periods up to a few weeks to evaluate the effects of sustained operation on the fuel element. Also evaluated were the consequences of releasing fission products for the primary coolant and cover gas system.

A portion of the EBR-II irradiation program is concerned with effects of fission products on the primary sodium and cover gas systems. Species related to the coolant are removed, in part, by means of an externally located cold trap. Gaseous fission products released to the cover gas system are removed by a combination of cryogenic trapping and absorption using liquid nitrogen-cooled charcoal beds.

Several on-line techniques are used to detect, annunciate, and measure releases of fission products from failed elements to the primary sodium and cover gas systems. The fuel element rupture detector (FRED) is used to monitor a small bypass stream of primary coolant for the presence of delayed neutron emitters in the exit coolant. Another device-the germanium-lithium, argon scanning system (GLASS)-analyzes a flowing cover gas stream by means of gamma pulse height spectrometry with a GeLi semiconductor detector.

The origin of a given fission product release may be identified by means of a xenon-tagging technique developed at EBR-II. The gas plenums of all experimental fuel elements are inoculated with small quantities of various but unique mixtures of xenon. Under failure conditions, gaseous fission products and a portion of the xenon tag mixture are released to the cover gas system. An on-line device concentrates the xenon component of the cover gas by cryogenic trapping and analyzes the xenon fraction with a mass spectrometer. A comparison of the measured isotopic ratios with those of library samples provides positive identification of a source.

Various techniques are used to measure impurities in the sodium and the cover gas system. On-line analytical equipment is used to monitor levels of hydrogen, oxygen, and tritium in the primary and secondary sodium systems. The primary cover gas system is continuously monitored for carbonaceous materials-principally methane, carbon monoxide, and carbon dioxide. Routine samples of primary and secondary sodium are chemically ana- lyzed for a wide variety of fission product and corrosion species.

Many years of operating experience have demonstrated the feasibility of conducting routine and specific maintenance on LMFBR systems and components. Considerable maintenance experience with unconventional, relatively accessible, and moderately radioactive components has been achieved. A typical component falling into this category is the transfer arm (part of the fuel handling system). Precautionary measures associated with such an activity is to maintain an argon atmosphere around the component to prevent any leakage of air to the cover gas system. The measure also prevents leakage of cover gas to the reactor building. Such an activity is based on pulling the componert into a rubberized nylon bag sealed by a flange to a penetration in the primary containment tank.

The most difficult components to maintain are those under unconventional, relatively inaccessible, intrinsically radioactive, and radioactively contaminated conditions. Examples of such components are control rod drives, the main core gripper, and the subassembly hold down fixture. Such components penetrate the reactor vessel cover and, as a result, become highly radioactive through neutron activation. The problem of intrinsic radioactivity, sodium contamination, and fission product plateout make direct repair virtually impossible. In such a situation-for example, a malfunctioning control rod drive, the entire unit is removed and replaced. When such components are being removed, the system must be decayed for approximately $5 \mathrm{~d}$ because of the sodium 24 . The component is then pulled into a shielded pipe is handled by the building crane.

EBR-II has been the only operating LMFBR in the world with metallic driver fuel. Several considerations affected the initial design of the EBR-II driver fuel during the early and mid-1950s: relative ease of fabrication, success of prior metallic fuel loadings in EBR-I, excellent heat transfer properties of metals, and superior breeding characteristics of metallic fuels.

As operating experience accumulated, burnup limits were incrementally increased from the original value of 1 at. $\%$ established in 1961 , to 1.2 at. $\%$ in 1966 , to 1.8 at. $\%$ in 1969 , and to 2.6 at. $\%$ in 1975 . Beyond 3 at. $\%$, fuel swelling became a problem. Pressures exerted at the fuel cladding interface 
were so large that cladding strain and subsequent rupture seemed likely. Such limitations were always evident, even in the early days of design. The inevitable penalties were short operating cycles and inefficient use of fuel. However, the impact of the penalties was reduced by the rapid on-site reprocessing of discharged fuel. On certain occasions, discharged fuel was reprocessed and returned to the core within $29 \mathrm{~d}$.

Despite the successful implementation of short turnaround reprocessing techniques, considerable effort was devoted to the development of fuels that could be operated to much higher burnup levels. One concept that seemed particularly promising in the early days of operation was the permissive swelling principle. This concept was premised on the contention that if the fuel material was permitted to swell unconstrained, a point would be reached at $\sim 30 \% \Delta \mathrm{V} / \mathrm{V}$ when pores in the fuel matrix become interconnected. This permits the release of trapped fission product gases to the fuel element plenum. The fuel, in a weakened condition, tends to deform into the pores rather than straining the cladding. Proof of the principle appeared in the form of an improved fuel element design, the MARK-II. The cladding thickness was increased from $0.23 \mathrm{~mm}$ to $0.31 \mathrm{~mm}$ to strengthen the cladding; the pin diameter was reduced from 3.66 to $3.3 \mathrm{~mm}$; the sodium-filled annulus was increased from 0.15 to $0.25 \mathrm{~cm}$; and the gas plenum above the fuel was increased to accommodate the increased release of fission product gases. The uranium-235 enrichment was increased to $67 \mathrm{wt} \%$, and the cladding was changed to annealed Type 316 stainless steel. Intensive irradiation surveillance studies on test specimens were conducted, and, as a result, it was shown that the fuel materials swelled rapidly and made contact with the cladding at approximately 2 at. $\%$ burnup. At this point, the fuel lattice becomes sufficiently porous to permit relatively free flow of fission product gases to the fuel element plenum. Beyond this point, fuel material remains in contact with the inner wall of the cladding. But because the fuel is then porous and "weak," and because the driving force for diametral swelling is low, the cladding strain rate is low. Consequently, the lower stress on the jacket permits much higher burnups to be realized.

Currently the burnup limit for the MARK-II fuel is 8 at. \%. A continuing irradiation surveillance program implies that even higher levels are possible; since endurance testing at EBR-II, up to 18.9 at. $\%$ has been successfully completed. Of con- siderable interest are the following statistics: of approximately 10,000 MARK-II elements irradiated to the burnup level of 6 at. $\%$ and an additional 17,000 irradiated to 8 at. $\%$, none has failed, that is, suffered cladding rupture.

The first use of EBR-II as an irradiation facility began in May 1965 with the insertion of two experimental subassemblies that contained various structural specimens and prototypal fuel rods $\left(\mathrm{PuO}_{2}-\mathrm{UO}_{2}\right.$ and U-Pu alloys). Since that time, the compliment of elements, capsules, and other specimens may be broken down as follows: mixed U-Pu oxide fuels, 3189; driver fuel elements (surveillance and run to failure program) 5173; other LMFBR fuels (principally mixed U-Pu nitrides and carbides), 755; cladding and structural specimens, 1343; absorber materials, 219; and miscellaneous, 360. Mixed U-Pu oxide fuels have been irradiated to a heavy atom burnup of $19.9 \%$; cladding temperatures of greater than $800^{\circ} \mathrm{C}$ have been achieved; and neutron fluences of $2.1 \times 10^{23}$ neutrons $/ \mathrm{cm}^{2}$ have been accumulated in structural materials. Absorber materials have been irradiated to $16.5 \times 10^{21}$ neutron captures $/ \mathrm{cm}^{3}$, and EBR-II driver fuel has been irradiated to heavy atomic burnup of $18.9 \%$.

Enrico Fermi Atomic Power Plant. The Enrico Fermi Atomic Power Plant was the first full-scale industrial fast reactor power plant in the United States. Some features of the FERMI reactor are similar to those of EBR-II. However, EBR-II is of lower capacity, $20 \mathrm{MW}(\mathrm{e})$; the FERMI reactor, although developmental, was designed for an ultimate capacity of $65 \mathrm{MW}(\mathrm{e})$, comparable to an average-size conventionally fueled unit of its time.

Reactor Features - The arrangement of components within the primary reactor tank is illustrated in Figure A-78. The reactor core and blanket, as well as the fuel transfer system, were contained within an irregularly shaped lower section of the reactor vessel. Attention is drawn to the open region between the reactor vessel and the primary tank, which was filled with graphite shielding. The upper section of the reactor vessel contained a large sodium pool above the core and blanket. Access to the core was accomplished by a rotating top shield plug arrangement.

The location of other plant equipment is shown in Figure A-79. Several connected buildings adjacent to the reactor building contained steam generators, a turbo generator, and control equipment. 


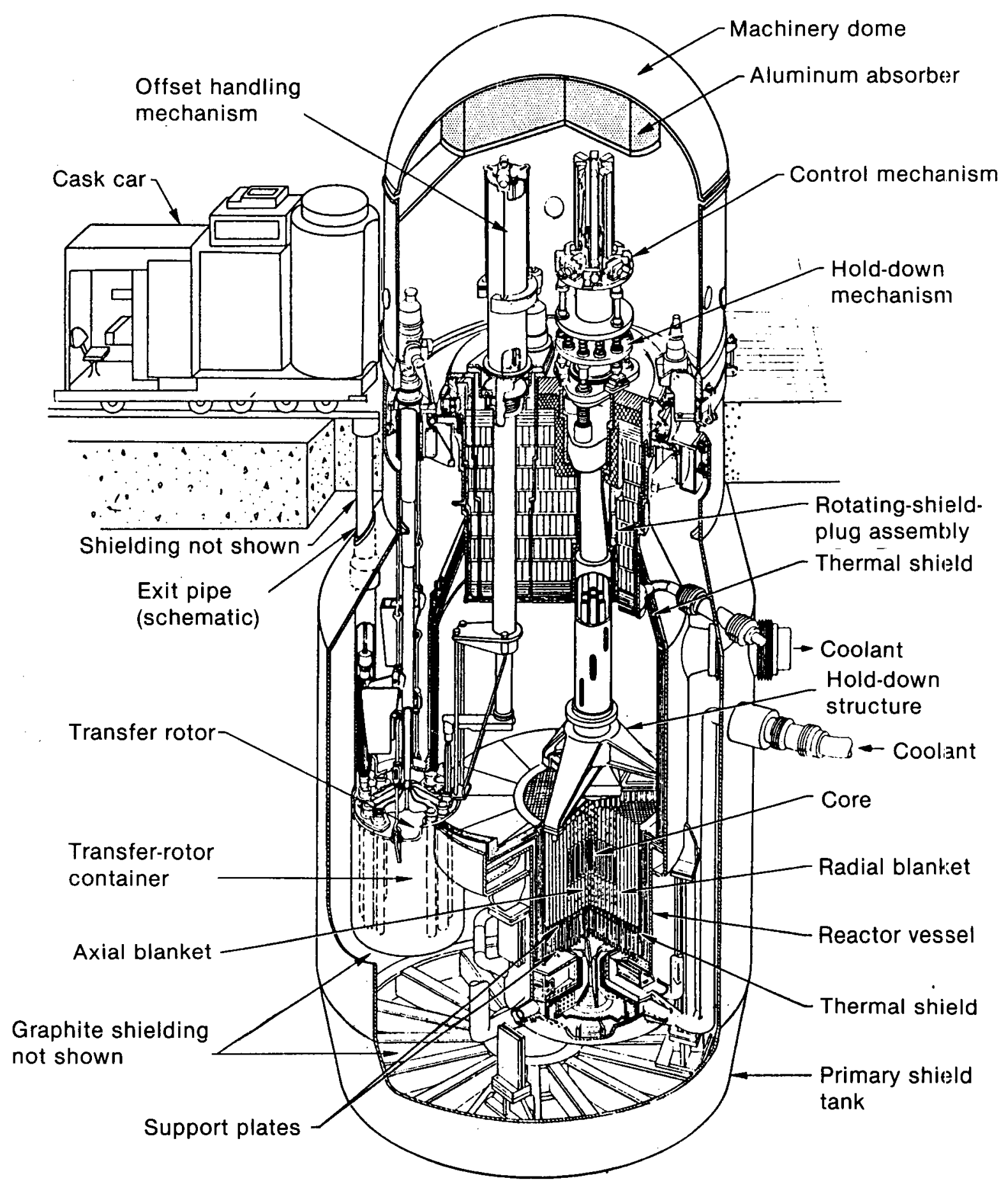

Figure A-78. Perspective view of FERMI reactor. 


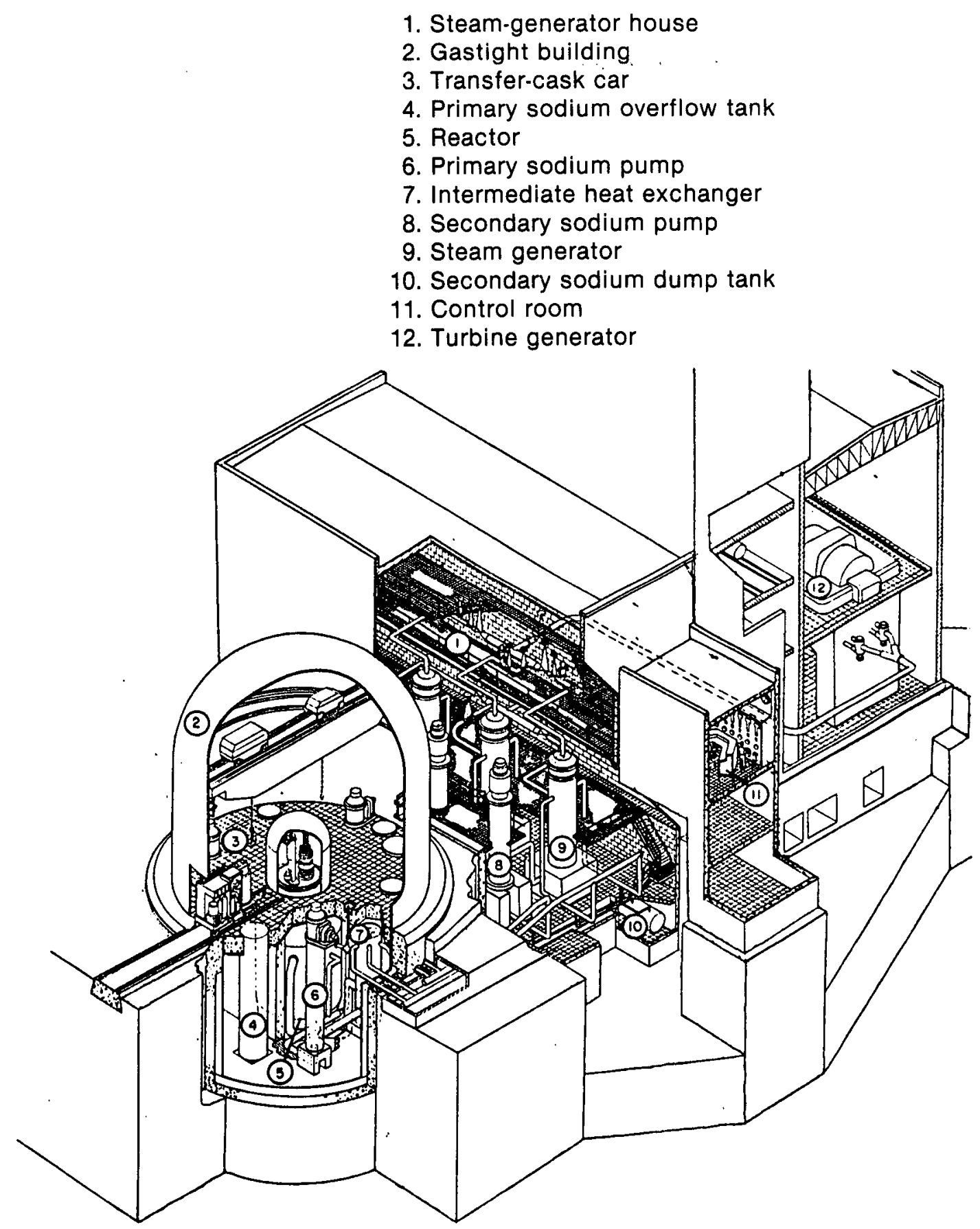

Figure A-79. FERMI plant layout.

Performance data were generally based on an initial power level of $200 \mathrm{MW}(\mathrm{t})$ planned for the first core. The heat removal system had a design capacity of $430 \mathrm{MW}(\mathrm{t})$ for subsequent core design.
Core Arrangement-The lower reactor vessel, core, and blanket, shown in Figures A-80 and -81, were located asymmetrically in the primary tank for fuel handling purposes and to permit decay heat 


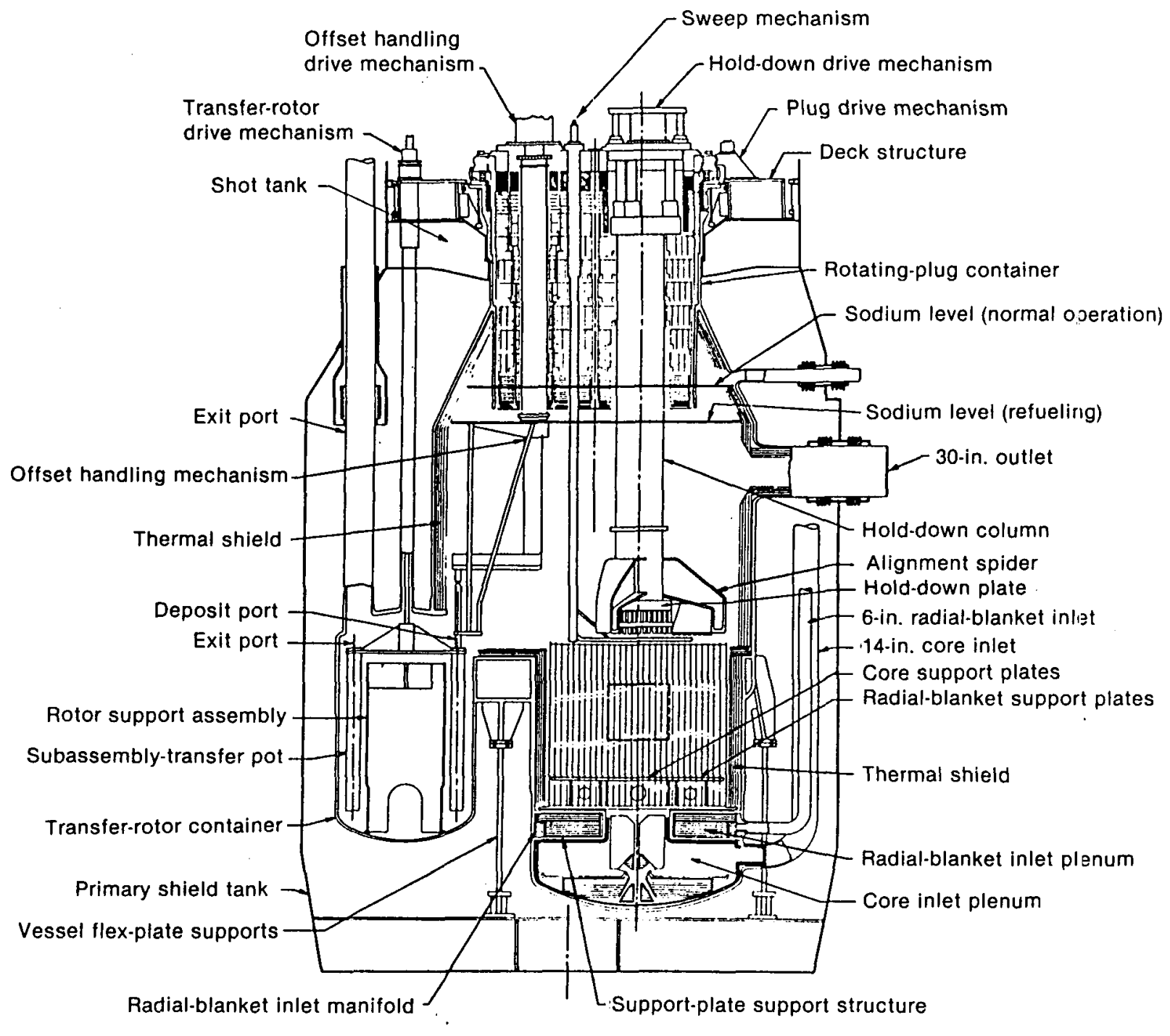

Figure A-80. FERMI reactor vessel.

removal during shutdown by natural circulation. The coolant flow was upward in its natural circulation system; the large supply of sodium in the primary system $(136,000 \mathrm{~kg})$ provided the heat capacity needed to reduce transients.

A cylindrical section in the lower reactor vessel, 2 meters in diameter and $1.78 \mathrm{~m}$ high, contained the core and square blanket subassemblies. The central core region, which was surrounded by the breeder blanket, was in the form of a 78.7- $\mathrm{cm}$ diameter cylinder, also $78.7 \mathrm{~cm}$ high. Figure A-82 is a reactor cross-section plan view illustrating the core and blanket subassembly arrangement. For $200-\mathrm{MW}(\mathrm{t})$ power level operation, 105 central lattice positions contained fuel subassemblies. Within this region, 10 positions were provided for control rods. Each of the core subassemblies (Figure A-83) contained an upper and lower axial blanket section in addition to the central fuel bearing core region.

An inner radial blanket region, with provisions for 34 subassemblies, was provided outside the core. These position's, identical in design to those in the core, could be used for additional fuel subassemblies if needed. The orifice design in each type of subassembly, however, controlled the amount of coolant received.

The fuel region of each core subassembly consisted of 140 fuel pins, each having a nominal length of $83.26 \mathrm{~cm}$. Each pin also had an an outer diameter of $0.401 \mathrm{~cm}$, consisting of uranium$10 \mathrm{wt} \%$ molybdenum alloy with an uranium 


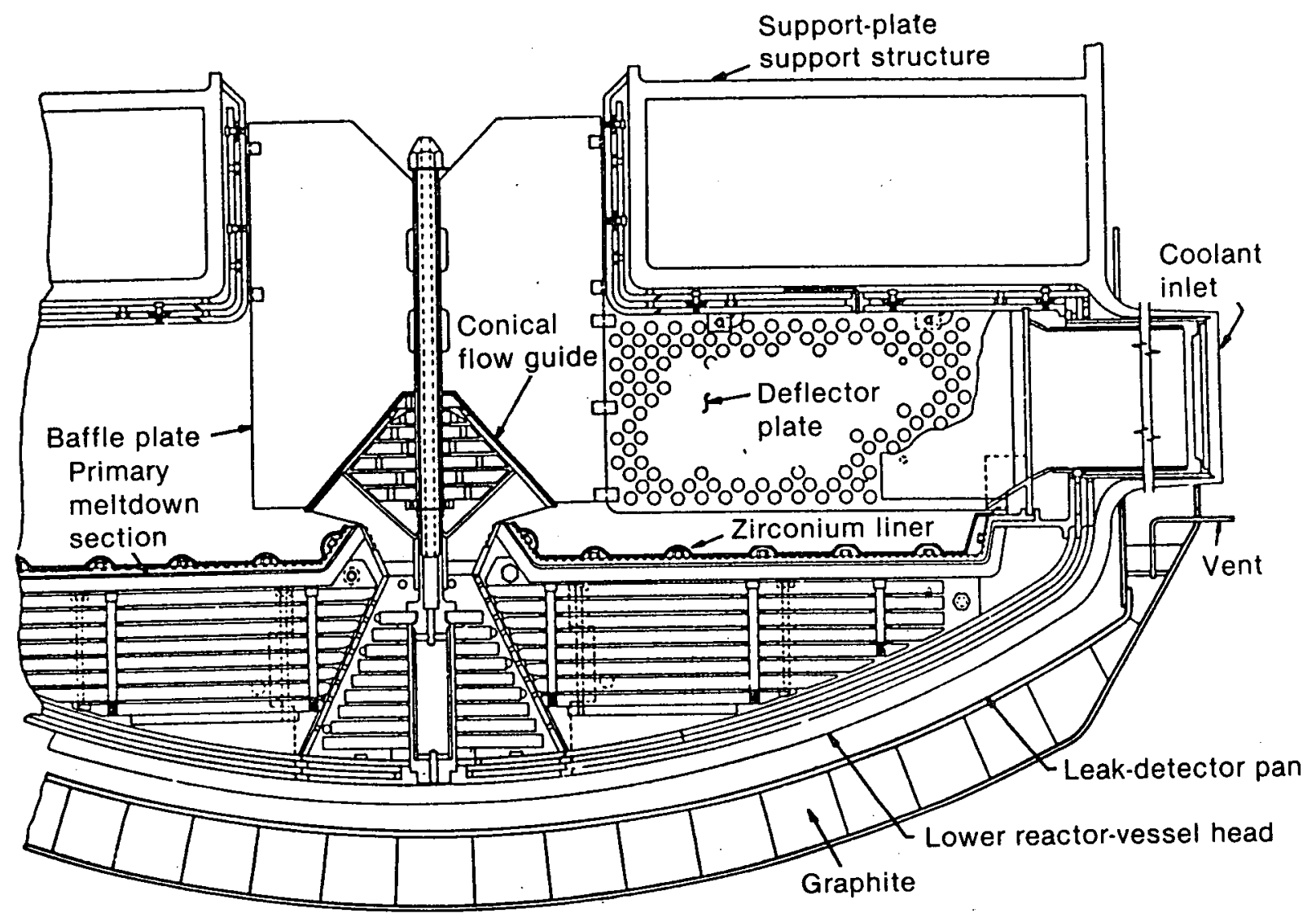

Figure A-81. FERMI meltdown section.

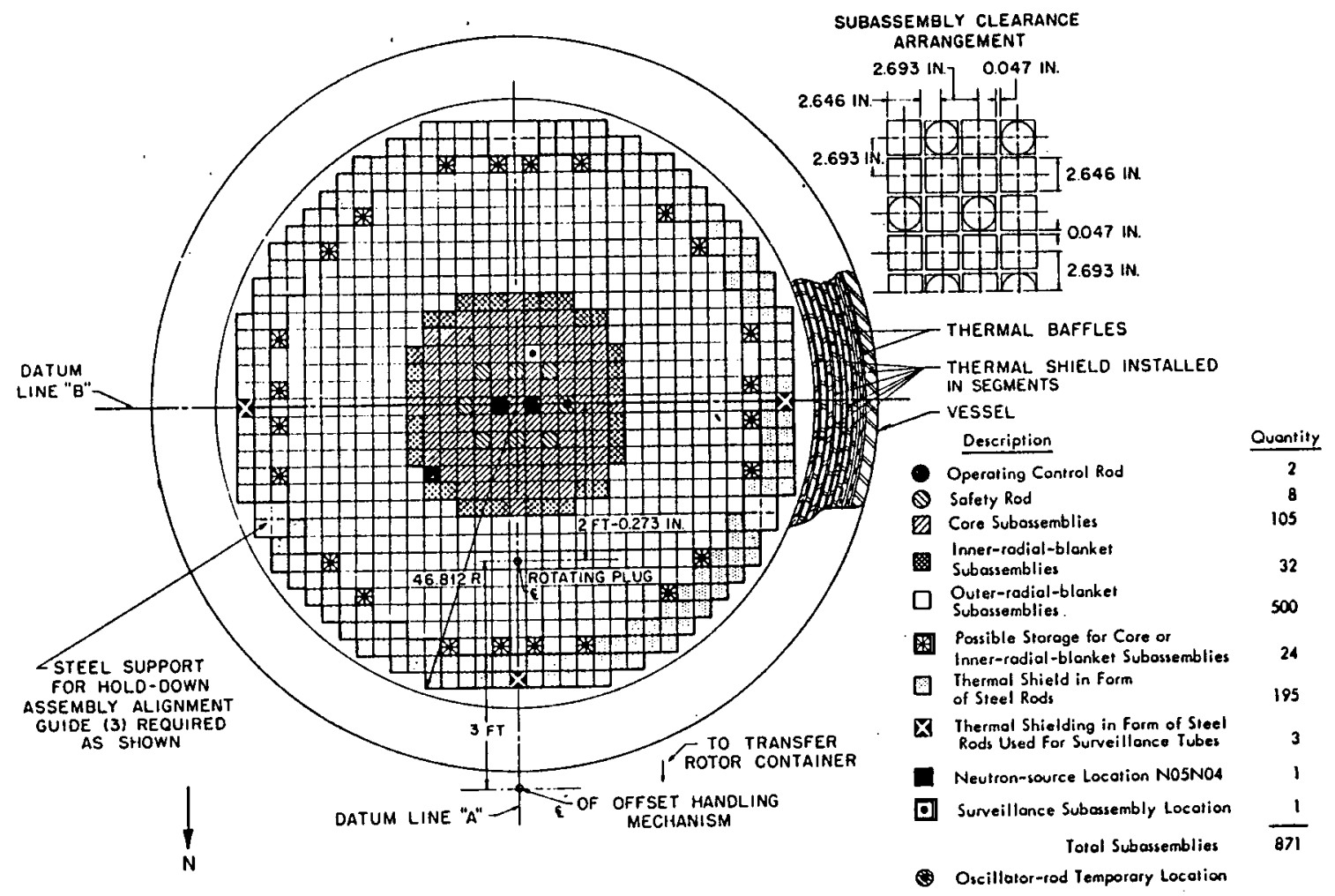

Figure A-82. FERMI reactor cross section. 


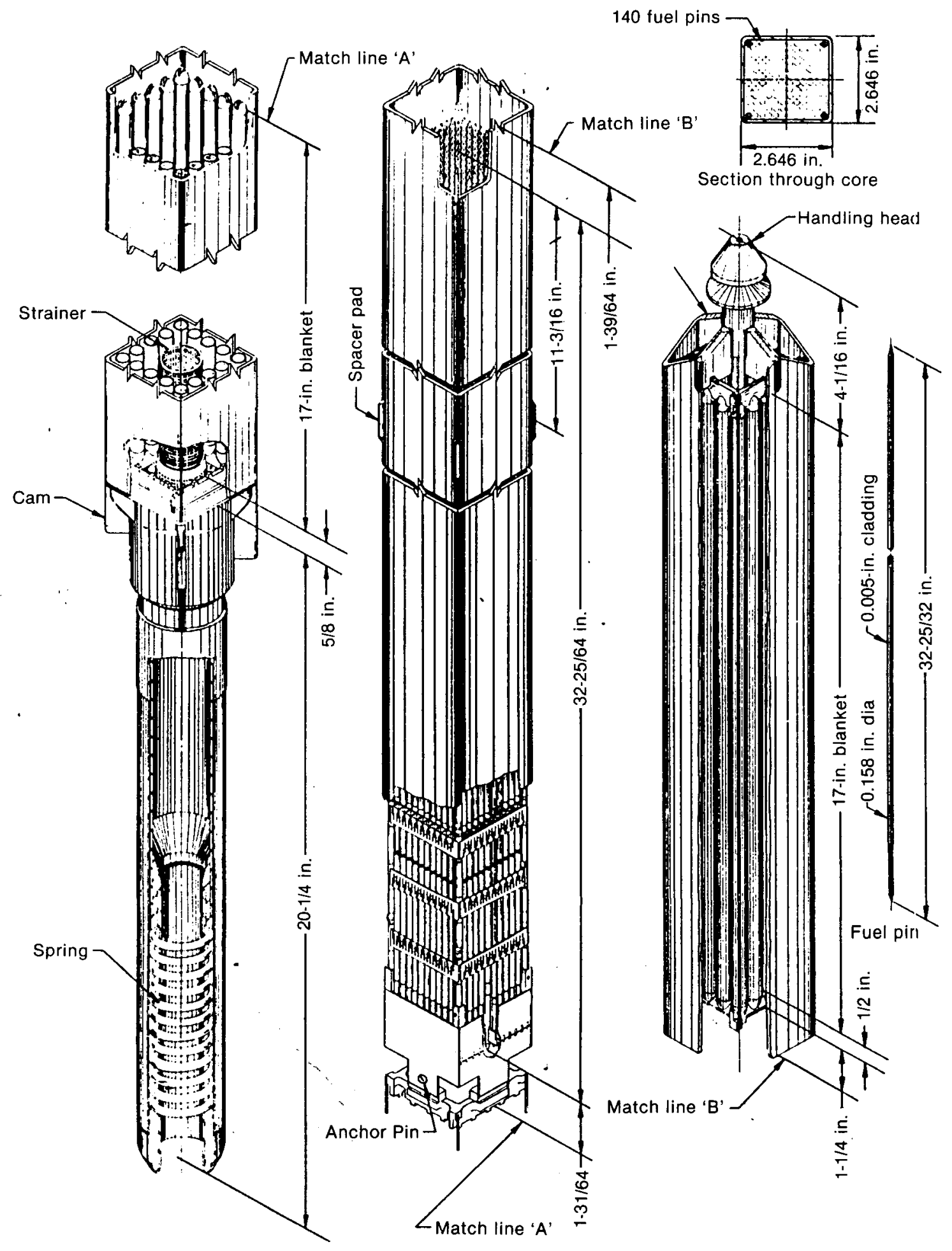

Figure A-83. Isometric view of FERMI fuel assembly. 
enrichment of $25 \%$ U-235. Each pin was clad with $0.0127 \mathrm{~cm}$ of reactor grade zirconium metallurgically bonded to the fuel alloy. Zirconium end caps served as closures at the top and bottom. The lower end of each pin was fastened to the support structure by anchor bars inserted through slots in the bottom end caps. The upper ends were free to accommodate changes in length resulting from temperature changes and radiation effects. As shown in Figures A-83 and -84, the core subassembly was enclosed in an outer stainless tube of square cross-section, measuring $6.72 \mathrm{~cm}$ on each side and having a nominal wall thickness of $0.244 \mathrm{~cm}$. The square subassembly shape permitted a plate type fuel to be used in a subsequent core, if found desirable. At the top of the outer tube was a combination handling head and holddown contact. A lower support section, the nozzle consisting of two concentric round tubes, was attached at the bottom. The spring, shown in Figure A-83, permitted the thermal expansion of the subassembly structure. A strainer was also provided at the inlet of each core

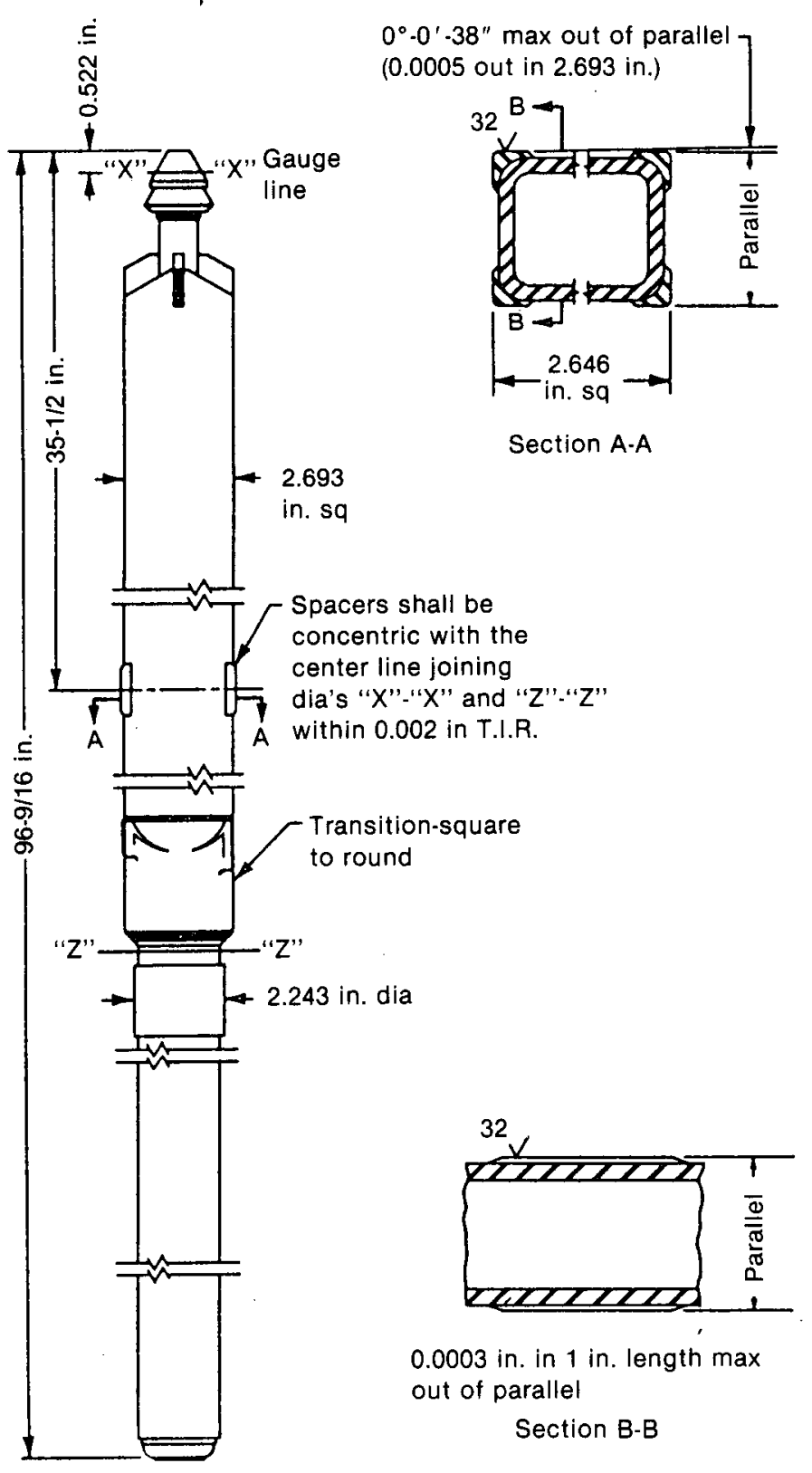

Figure A-84. FERMI fuel subassembly (external side view). 
subassembly. The upper and lower axial blanket regions of the core subassemblies contained 16 uranium rods $1.0 \mathrm{~cm}$ in diameter $-3 \mathrm{wt} \%$ molybdenum alloy, with the uranium depleted to $0.35 \%$ U-235. A $0.025-\mathrm{cm}$-thick stainless steel cladding was used for these rods. Both the inner and outer blanket subassemblies used a lattice of 25 rods, each having the same diametral dimensions as the axial blanket rods. In the case of the inner blanket subassemblies, the support structure included a thermal expansion spring arrangement identical to that used in the core units (Figure A-84). Outer radial blanket subassemblies could fill the remaining 500 positions, shown in Figure A-82. These had a simple support structure, as indicated in Figure A-84.

Control Elements - In this reactor, poison control was used rather than fuel or reflector control. Details on the control rods can be found in References A-110-113. Available excess reactivity was intentionally kept small. Furthermore, the fuel management scheme minimized the reactivity changes caused by fuel burnup. The eight safety rods and two operating control rods used Boron, 10 in boron carbide as the absorber. One of the operating control rods used for regulating purposes had a maximum reactivity insertion rate of $0.67 \$ / \mathrm{s}$. The other, used for shim control, was designed for $1 \varnothing /$ min insertion. The eight safety rods, spaced uniformly as shown in Figure A-82, provided a shutdown reactivity of over $\$ 8$, and the two operating rods had a total worth of $92 \not$.

Each of the control elements was housed in a cylindrical guide tube which, in turn, was mounted inside a square tube having the same outside dimensions as a core assembly. Heat generated by a control rod was removed by sodium flowing from the core inlet plenum through pressure breakdown orifices inserted in the section between the two support planes. Flow was directed up through the control rod assembly and then through the annulus formed by the control rod assembly and inner round guide tube.

During reactor operation, the safety rods were held just above the upper axial blanket by a latch on each safety rod drive unit. Reactivity adjustment for startup, power level changes, and burnup compensation were made by means of the two operating control rods. These two rods were raised and lowered at different rates, as mentioned above.

Heat Transport System-In the primary coolant system, three coolant loops were used. Each con- tained a pump and intermediate heat exchanger. The pump-a vertical shaft, single-stage centrifugal pump rated at $745 \mathrm{~L} / \mathrm{s}$ and driven by a $1,000 \mathrm{hp}$ motor-circulated sodium to the core through a $35.6-\mathrm{cm}$-diameter pipe. About $13 \%$ of the total flow was pumped through a $15.2-\mathrm{cm}$ pipe to the radial blanket (Figure A-85). Core coolant flowed up from the lower inlet plenum of the core, both through the reactor core itself, and then to the upper reactor vessel, which served as an exit plenum, shown in Figure A-86. The hot sodium then flowed by gravity from this pool to the shell side of the intermediate heat exchanger through a $76.2-\mathrm{cm}$ line. The intermediate heat exchangers were counterflow shell and tube units constructed of Type 304 stainless steel. The primary sodium stream, by this time at lower temperature, returned to the primary pump. Additional details on the primary cooling system are given in Reference A-114. A system of secondary containment for the primary system consisted of a welded, leak-type enclosure for the reactor vessel, primary system, pump tanks, and the intermediate heat exchanger shells. This structure, which protects against loss of sodium, is described in detail in References A-114 and 115 .

Three secondary coolant loops were provided, each corresponding to a primary loop. Heat was transferred from the intermediate heat exchanger to the shell side of a steam generator by sodium. This sodium was circulated by an $840 \mathrm{~L} / \mathrm{s}$ pump driven by a $350 \mathrm{hp}$ motor. The steam generators were vertical shell and tube exchangers of single-wall tube construction arranged for a combination of crossflow and counterflow. A number of design features provided protection against any leaks within the unit. The tube to tube sheet joints, for example, were located in an inert gas space above the sodium to reduce thermal shock.

Structural and Shielding Components-The reactor vessel and internal components are shown in Figure A-78. Core and blanket subassemblies were contained within the lower reactor vessel; the upper reactor vessel section, at approximately atmospheric pressure, served as a mixing pool for the hot sodium. The upper section contained a core holddown device and offset fuel handling mechanisms. The holddown device maintained radial alignment of the core assembly's upper end and prevented subassembly movement induced by the uplift force of the sodium flow. 

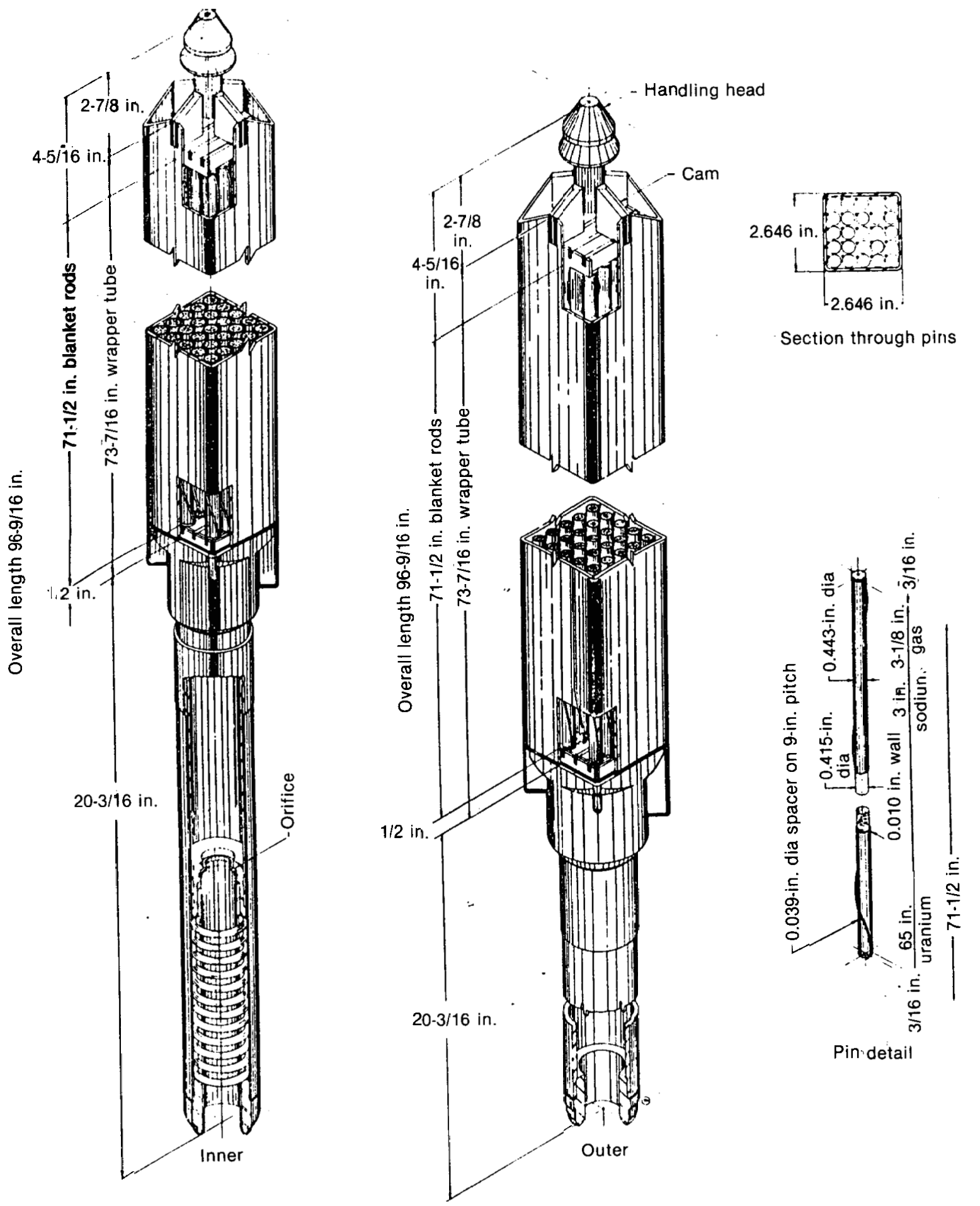

Figure A-85. FERMI radial blanket subassemblies. 


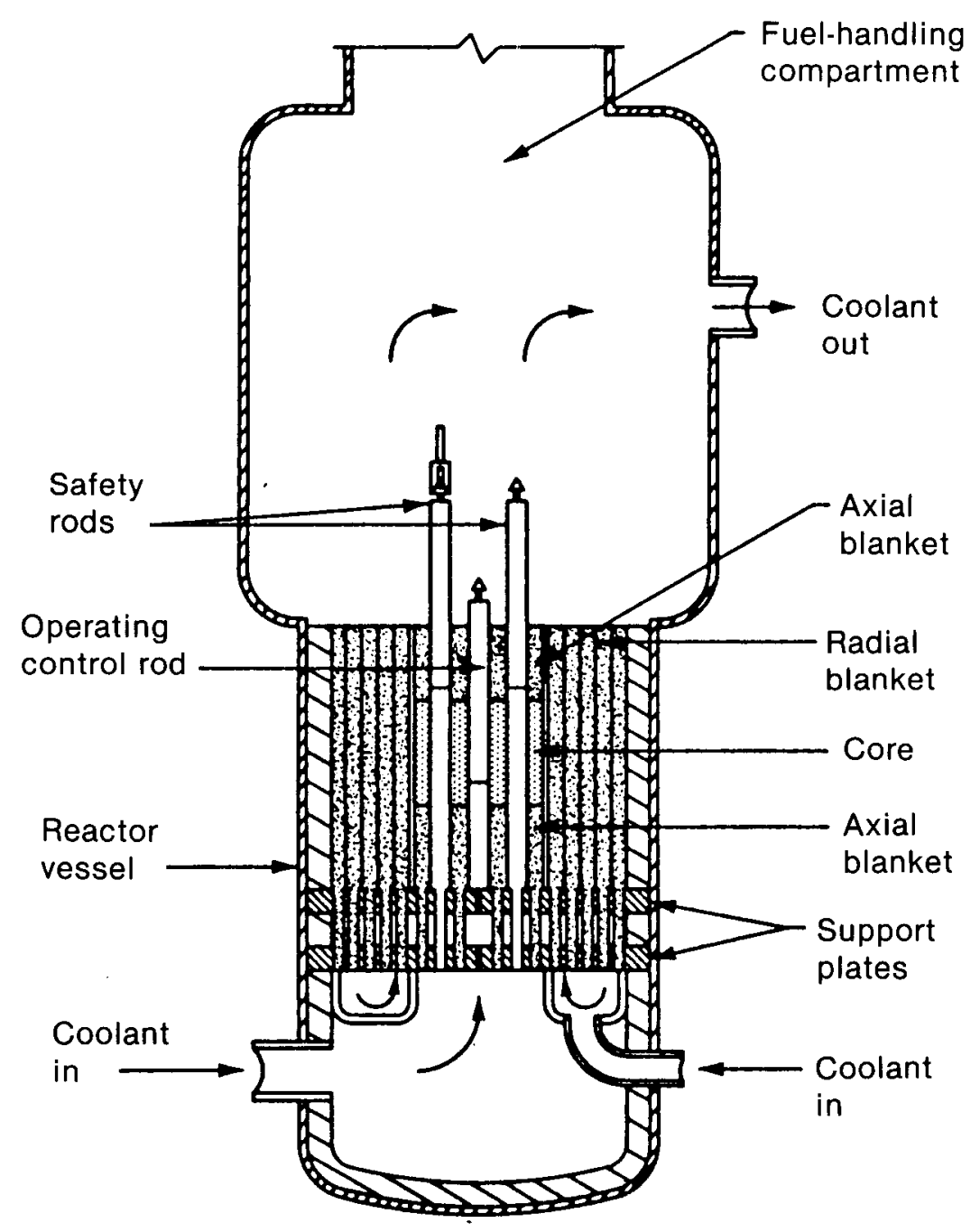

Figure A-86. FERMI reactor vessel arrangement.

Spent fuel and blanket subassemblies were removed from the reactor vessel and deposited in a transfer container by the offset handling mechanism. Each subassembly in a transfer pot could be transported by the transfer rotor container to the exit port; then the subassemblies were raised vertically into a cask car by the cask car gripper. Spent fuel was unloaded from the cask car in the fuel and repair building, where the fuel was placed in decay storage prior to shipping operations. Both the hold-on device and offset handling mechanism were mounted eccentrically on the rotating plug so the holddown device would be swung away when the handling mechanism was swung over the core.

The lower reactor vessel included provisions for safe containment of molten fuel in case of core meltdown. This section, located in the inlet plenum, was arranged so that the thickness of molten material in the region would be about $3.18 \mathrm{~cm}$. A conical flow guide was installed to prevent a buildup of fuel in the center of the meltdown section by dispersing the molten fuel as it entered the plenum. A detailed description of the fuel system is given in References A-113, A-116-119. The reactor vessel was surrounded by a graphite neutron shield located in a nitrogen atmosphere inside the primary shield tank (Figure A-80). The shield system also included a 30.5 -cm-thick laminated steel thermal shield inside the reactor vessel wall. A secondary shield consisting of a $76.2-\mathrm{cm}$ thickriess of concrete surrounded the primary shield tank and prevented neutron activation of the secondary sodium system. A 1-1/2-m-thick biological shield outside the containment vessel completed the radial shielding system. 
The containment vessel, shown in Figure A-87, was a vertical cylinder with a hemispherical top head and semiellipsoidal bottom head. It housed the reactor and the primary system. The inside. diameter was $22 \mathrm{~m}$, and the overall height was $36.6 \mathrm{~m}$, of which $15.5 \mathrm{~m}$ was below grade. Design specifications based on containment of the sodium-air reaction provided for the possibility of an internal pressure of $0.22 \mathrm{MPa}$.

Operating Experience-Starting in July 1959 and terminating on May 31, 1961, a series of nonnuclear tests were performed at FERMI on components in the reactor portion of the plant. The so-called test facility included the reactor vessel, primary shield tank, rotating shield plug, fuel han- dling mechanisms, safety rod drives, and one primary system sodium loop. These components, together with sodium purification, were used in conducting a full-scale mechanical and hydraulic test of the reactor. The tests were isothermal up to temperatures of $540^{\circ} \mathrm{C}$. The overall results of the nonnuclear tests were satisfactory, though modifications were necessary. Experience with the use of sodium was excellent. The operation of equipment in sodium and other environments presented no major difficulty. It also indicated the high purity of large amounts of sodium (up to $181,000 \mathrm{~kg}$ ) and that the system could be maintained without difficulty. The test indicated construction materials used in the system were compatible with the sodium.

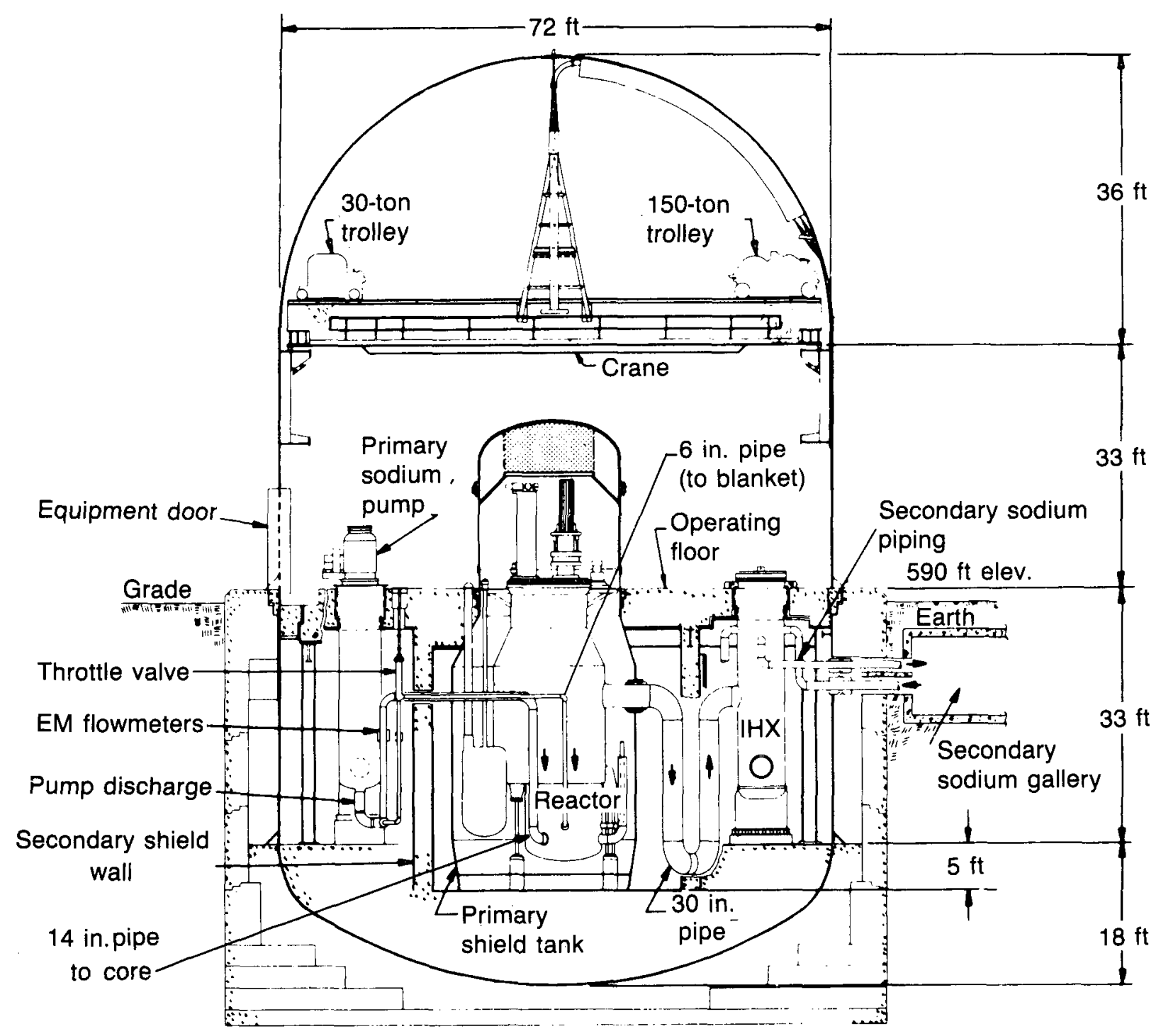

Figure A-87. Vertical cross section of FERMI reactor building. 
Starting July 1, 1961, the FERMI plant was incorporated around the test facility and preoperational tests began preparatory to nuclear testing. Testing to $538^{\circ} \mathrm{C}$ for a period of about 1 week checked out the operation of safety rods, fuel handling mechanisms, and sodium pumps. In general, the system performed satisfactorily. Following the $538^{\circ} \mathrm{C}$ test, tests of graphite directly around the reactor vessel (inside the insulation) indicated that the material failed to withstand the high temperature test. Tests indicated the borated graphite did not conform to design specifications and would have to be replaced. Tests on the remainder of material outside the insulation in the primary shield tank indicated this graphite material also needed replacement. It was apparent that moisture and oxygen control was a must in the use of hightemperature graphite. All graphite in the primary shield tank was replaced with high-density, hightemperature reactor grade graphite. Any boron used was in the form of boron carbide. The reinstallation of the graphite shield was a primary factor in delaying the reactor's completion.

During the test of the offset fuel handling mechanism (OHM), it became jammed by malfunction and misoperation. The OHM became bent when an inadvertent attempt was made to move it laterally before it was delatched from a partially raised dummy subassembly. An innerlock had been disconnected for the purpose of carrying out the test. The OHM was removed with a lightweight removable container such as not to violate the inert gas integrity of the reactor. After disassembly, it was found that the gripper and stabilizer foot were not in their proper positions. After removal of the OHM and reduction of the sodium level, observation of the core and blanket subassembly indicated a number of displaced subassemblies. Investigation showed the subassembly heads had stuck to the holddown plate fingers when the holddown was raised. When the plug was rotated with the heads engaged with the fingers, the fingers and other subassemblies were bent. Subsequent lowering of the holddown resulted in further damage and in unseating some subassemblies in the support plate, causing further flow erosion of the support plate holds. For repairs, the reactor vessel was drained of sodium, and personnel in protective suits entered the reactor. They removed the center support plate and the holddown plate with its fingers, and redesigned the holddown finger sockets. Other modifications were made to the control and safety rod guide tubes. The center support plate had stellite bushings inserted into the holes to prevent further possibility of erosion. The OHM was modified to strengthen the gripper linkage. The modification ensured enough strength would be available to permit application of impact loads and force the gripper open. The stabilizer foot was redesigned to ensure the OHM would not be locked over a partially raised subassembly. The stabilizer assembly and its attachment to the rotating tube was strengthened to withstand higher lateral loads. The possibility of obstructions interfering with future operations was avoided by installing a new mechanism called a sweep arm; it was used to check for obstructions in the upper plenum above the core and blanket. About 2,000 man hours were expended in the vessel by personnel using protective suits within the argon atmosphere to accomplish results. $\mathrm{A}-120$

In July 1961, a series of hydrostatic tests at $5.86 \mathrm{MPa}$ on the No. 2 steam generator tubes indicated leaks. Subsequent checks indicated 71 tubes were cracked through the tube wall. All of them were located opposite one of the two sodium inlets. Testing the tubes indicated that residual stresses, corrosion effects, and elevated temperatures induced stress corrosion cracking. The entire tube bundle of No. 2 steam generator was retubed at the fabricator. All three units were stress relieved and inspected prior to reassembly.

In December 1962, a sodium water reaction took place in the No. 1 steam generator, blowing the rupture disk installed for just such an event. The water was dumped manually by an operator to prevent further introduction of water. The No. 1 secondary loop was drained, and the tube bundle was removed and cleaned in $\sim 3 \mathrm{~m}^{3}$ of alcohol. The largest cleaning operation to 1963 to remove sodium from one component was performed without incident. Examination showed extensive tube damage caused by vibration of the tube against the support structures, as well as erosion from the sodium water reaction during the period between a reaction and the rupture disk blowout. Small- and full-scale models in water of the tube bundle and its baffle indicated vibration of the tubes at the sodium inlet had been as high as $0.635 \mathrm{~cm}$. Baffling and lacing of the tubes were carried out to reduce this vibration to a negligible quantity.

A program was initiated to modify the check valves in the primary system. The 40.6 -cm check valves induced high-pressure surges when one of the loops was shut down with either one or two of the loops operating. A program was carried out to 
install new check valves-modified to include dash pots and springs - to reduce the surge pressure to negligible values.

Each of the more than 3,000 cans in the rotating plug containing graphite was vented by $0.16-\mathrm{cm}$ holes to the argon cover gas above the sodium in the reactor. The primary system tests at $538^{\circ} \mathrm{C}$ and at lower temperatures released material in the graphite binder to the primary system. This release resulted in carbon and other contamination of the primary system. Extensive programs of sodium sampling, analysis, and filtration were carried out to determine what contaminants were present and how they affected the system. Tests of the materials in the primary system indicated some degree of carbonization but not sufficient to affect operation of the reactor.

Three operational tests prior to criticality on August 23, 1963, were successfully completed; only minor modifications of the control safety rods and control drives were required.

The low-power nuclear test program for FERMI was originally scheduled for $182 \mathrm{~d}$ of reactor time. The program was to verify the soundness of the basic physics design of the fast breeder. Each individual test was completed within the allotted time. However, delays caused by systems external to the reactor, extended testing throughout 1964 . The systems primarily responsible for the delays were the cask car and the steam generators. Twenty-seven tests were scheduled at low power; all but two were completed by the end of 1964 . The reactor was taken critical over 250 times, using 500 different core configurations that required movement of 1,400 subassemblies and more than 3,500 movements of the fuel handling mechanism and rotating shield plug. A-122

Throughout the tests, the plant operated very stably and was easily controlled. Predictions of the reactor's parameters were, in general, substantiated. The predicted isothermal coefficient was reduced by $7 \%$. Reactivity worths of the control rods were found to be $8 \%$ lower than predicted, and safety rod worths were $15 \%$ lower than predicted. A-123

The test plan for the nuclear program during high power ascension comprised the oscillator, pulse, power coefficient, automatic reactor programming, and scram tests. Results of all tests through $20 \mathrm{MW}(\mathrm{t})$ showed satisfactory operation.
It was decided to interrupt the test program because hydrogen levels in the No. 3 steam generator indicated possible leaks. Inspection showed numerous leaks existed at the welded joints between the tube and tube sheet. In addition, feedwater control for the steam generator was noted to be a problem because of fluctuation in the sodium outlet temperatures but with a temperature amplitude of about $5^{\circ} \mathrm{C}$. Relocation of the temperature detectors eliminated most fluctuations, thus averting any potential single circuit shutdown while on automatic control. A-124

The tests of greatest interest were the reactor's stability tests. The test program was developed to answer whether an operating characteristic could make the reactor unstable and whether the reactor fuel bowed inward enough to cause a significant positive bowing coefficient. Oscillator tests through $100 \mathrm{MW}(\mathrm{t})$ showed no evidence of instability or positive bowing coefficient. After the power run August 5 through 7, only a few other tests at $67 \mathrm{MW}(\mathrm{t})$ were conducted later in the month. Testing was conducted primarily for obtaining plant test data, as opposed to nuclear testing, in such tests as shielding, reactor vessel temperature differentials, and core subassembly outlet temperatures. A-125-128

Fuel Melting Incident-During a $100,000-\mathrm{kW}$ power run in August, temperature measurements were made of sodium flowing out of the top of several of the 103 core subassemblies. This was accomplished by reading the output of thermocouples installed in the holddown finger. The thermocouples were installed just above the subassembly handling heads in about one-fifth of the core and inner radial blanket subassemblies. Such measurements allowed increased sodium heat to be determined as the sodium flowed through and reduced the heat in a given subassembly. This increase in heat content could then be checked against the calculated heat generation rate of a given subassembly for consistency. Such comparisons were not taken to be precise. High precision would also require an accurate determination of the sodium flow rate through individual subassemblies-something that was not directly measurable.

Abnormal temperatures first appeared in June, when the outlet sodium temperature for one subassembly was as much as $19^{\circ} \mathrm{C}$ higher than expected. The temperature returned to normal during the July run and then ran high again during the August runs. While unexplained phenomena are always of 
concern, the higher-than-expected temperature readings were in all cases lower than the normal sodium outlet temperature of the hot test subassembly located at the center of the core. Therefore, observed temperatures were all well within designed margins of the subassemblies and $480^{\circ} \mathrm{C}$ below the boiling point of sodium. It was decided to continue the test program but to shift the misbehaving subassemblies to different locations. It could then be determined whether the temperature anomalies were the result of a fault in the fuel subassembly itself, a fault in the thermocouple, or a fault in the associated environment.

As part of the continuing plant test program, it was planned on October 5 to bring the reactor to an indicated thermal power level of $74,000 \mathrm{~kW}$, a level surpassed several times before. Several tests were to be performed, including checking a new pressure control adjustment on the main steam bypass line, adjusting the automatic feedwater control, and measuring temperatures on the troublesome No. 1 steam generator, across the core outlet, and near the transfer rotor. In addition, oscillator tests were planned because operation was to involve a particular combination of two loops that had not been tested at this power level. Information was to be obtained on the previously observed unexpected subassembly outlet temperatures by observing the temperature of the three deviant subassemblies in their new locations under thermocouples that had previously indicated normal temperature readings.

The reactor was started up the night before and kept at a $1.0 \mathrm{MW}(\mathrm{t})$ over night. It was intended to begin a power ascent at $8 \mathrm{a} . \mathrm{m}$. on October 5 , but a malfunction in a steam generator valve postponed beginning the power increase until 1:45 p.m. At 2:15 p.m., with the power at $5 \mathrm{MW}(\mathrm{t})$, difficulty was experienced in the control system of the east boiler feedwater pump, and the power was reduced to $2 \mathrm{MW}(\mathrm{t})$ to start another pump. At 2:20 p.m., the rise in power was began and continued until $8 \mathrm{MW}(\mathrm{t})$ was reached, when there was a brief hold to put the reactor on automatic control. An automatic system took the reactor up in power at a controlled rate and involved a somewhat complex withdraw pattern of the two operating control rods.

During the automatic startup, the meter recording the time and rate of change of power $(\mathrm{dn} / \mathrm{dt})$ gave erratic signals. A similar but independent device was connected to the safety system so that if the measured power decrease exceeded $6 \mathrm{MW} / \mathrm{s}$ the safety rods would drop into the core, thereby shut- ting down the reactor. Experience at other facilities indicated that several of the previous reactcr malfunctions involved anomalous negative reactivity. Erratic behavior of the $\mathrm{dn} / \mathrm{dt}$ meter that had been experienced before was only 1 or $2 \mathrm{MW} / \mathrm{min}$, and was thought to be a noise pickup in the control system. Indeed, it soon disappeared. During the incident, the reactor was placed on manual control, but was returned to automatic following a clearup of the dn/dt signal. A-129

At 3:05 p.m., the feedwater flow control system was put on automatic. Variations on the $\mathrm{dn} / \mathrm{dt}$ meter were observed. It was noted that the two operating control rods appeared to be withdrawn further than normal for the approximately $30 \mathrm{MW}(\mathrm{t})$ power level that the reactor had now attained. This indicates an unexplained source of negative reactivity; one possible cause would be higher-than-expected heating. So, the power increase was halted, and a check was made of subassembly outlet temperatures. During this sheck, alarms sounded from the radiation monitors in the upper reactor building ventilation exhaust ducts, resulting in automatic isolation of the containment building. The area radiation monitor in the fission product detector building also exceeded its setpoint, isolating the fission product detector system. A Class-I radiation emergency was announced. Reactor power reduction was begun in accordance with operating procedures, and by $3: 20 \mathrm{p} . \mathrm{m}$. assessment of the reactor information was complete and the reactor was shut down by a manual scram, with insertion of all six safety rods ir to the core, terminating the chain reactions within seconds. A-129

The following information was developed during the first few days after the accident, which demonstrated that the extent of fuel damage was low.

- Freedom of movement of the six safety rods was verified the next day. The overall structural integrity of the core was not damaged enough to cause gross destruction of the safety rod guide tubes.

- Primary coolant system flow was maintained without primary coolant leakage, indicating no credible mechanism for massive core melting.

- A subcritical reactivity check performed on October 7 indicated there must: have been some net fuel motion away from the 
center of the core, and that the movement was equivalent to the complete removal of about half the fuel of an average subassembly.

- Review of the chart of the core subassembly outlet temperature recorded suggested that overheating and corresponding fuel melting were located in or near one core assembly (M-140).

- On October 20, samples of the core cover gas were extracted and sent to Argonne National Laboratory for analysis. Based on the analysis, it was concluded that the amount of fuel melted was almost equivalent to that contained within one complete subassembly. A-130

Recovery operations must include removal of the subassemblies, and normal subassembly removal requires raising the holddown mechanism. This device is mounted on top of the rotating plug and extends all the way to the top of the core, for individual fingers exert a downward force against each core subassembly, holding them in place against the upward force of the flowing coolant (Figure A-80). Such operation might have caused core movement.

Two more investigations were conducted to shed further light on the extent of core damage and to assess the potential for secondary criticality accidents before subassembly removal procedures were begun. One investigation involved a pressure drop measurement, which was carried out on October 21, 1966; it was concluded that flow blockage in the core ranged between zero and six subassemblies completely plugged.

In November of 1966 , shortly after the pressure drop measurements were completed and chances for a secondary criticality situation were assessed as negligible, the holddown mechanism (HDM) was raised. A special procedure was used incorporating strain gauges and acoustic and reactivity readings to detect any irregularities as the HDM was raised in small increments.

The mechanical arm of the sweep mechanism was operated manually and passed over the top of the core and then over the blanket subassemblies. No protruding subassemblies were indicated.

An offset handling mechanism (OHM) was used to confirm that all subassembly handling heads were in their correct position to within the tolerance of the OHM and the subassemblies. Then, by outfitting the OHM with a dial indicating lighter spring gauges, it was used to establish the pulling force required to lift each subassembly a specified distance.

Very high lifting forces were required in the area of the two subassemblies shown by thermocouple readings to be running hot during the October 5 run. It was determined that the two subassemblies were stuck together.

After the decay heat had diminished to a point where the sodium was no longer needed, the sodium was drained from the reactor vessel by a siphon procedure to a level $2.5 \mathrm{~cm}$ below the underside of the top core support plate. The core was viewed through a boroscope inserted through one of the access ports of the rotating plug at the top of the vessel. A sharp wedge on an extension handle was lowered between the subassemblies to chisel the subassemblies apart. On July 1967, the bond between the subassemblies that were stuck together was broken and the subassemblies were removed and shipped to a hot cell for examination.

Surface examination of these two subassemblies revealed definite damage. They were bent and there were holes in the wrapper can. Though the weights had not changed, the center of gravity had shifted downward, $1.75 \mathrm{~cm}$ in one subassembly and $3 \mathrm{~cm}$ in the other.

One subassembly was cut longitudinally; the other was cut transversely in four places. A significant portion of the fuel was found to have melted and sloughed downward, though a number of fuel pins remained intact. No evidence could be found to indicate that molten fuel had flowed from one subassembly to another.

In August 1967, the sodium was drained further to below the level of the primary meltdown section, which effectively emptied the inlet plenum of sodium. In September, a boroscope viewing device and light were lowered through access ports in the rotating plug down to the meltdown pan located $10.7 \mathrm{~m}$ below the operating floor.

On the zirconium liner of the meltdown section was an object appearing as a crumpled, folded piece of sheetmetal. Stereoscopically viewed, a three-dimensional map of the object was developed. And from the map, a model was made of 
what the object probably looked like before crumpling. The unfolded version appeared to be flat, pie-shaped piece of sheetmetal about $1 \mathrm{ft}$ long, which was identified as one of six zirconium liners of the conical flow guide. It had become detached and was thrust up against the inlet flow nozzle of the effected subassemblies by the force of the flowing liquid sodium coolant.

Repair of FERMI I-Removal operations were conducted in two phases. The first phase involved removal of the detached zirconium segment. The second involved both detachment and removal of the remaining five segments still believed to be bolted to the conical flow guide.

Plans for the first phase were initiated immediately on discovery of the object, even before it was identified. The approach taken was to retrieve the object intact through the $35.6-\mathrm{cm}$ primary line, aided by a manipulator inserted through the rotating plug and support plate holes. The spine tool manipulator, resembled a human spine. It consisted of a 91.4-cm length of a series of round disks with egg-shaped cross sections. A series of cables allowed bending in any desired direction and controlled a jaw at the far end that was used for grasping the object. Control was at the operating floor level, some $12.2 \mathrm{~m}$ away from the jaw end.

The retrieval device was a $1.5-\mathrm{m}$ section of $12.7-\mathrm{cm}$ diameter flexible metal hose attached to a $12.2-\mathrm{m}$ length of helical spring cable. A remotely controlled grabber was mounted on a trolley within the flexible hose. The retrieval device was inserted into the $35.6-\mathrm{cm}$ primary sodium line through a $15.2 \times 17.8-\mathrm{cm}$ hole cut into the pipe just outside the secondary shield wall, $10.7 \mathrm{~m}$ from the object to be removed. A specially designed glove box was attached at the position of the opening in the pipe to maintain the inert atmosphere of the primary system. Figure A- 88 shows the relative location of these devices.

The tools and procedures were all checked in a full-scale mockup of the lower plenum and the $35.6-\mathrm{cm}$ inlet sodium line.

In March 1968, the first phase of retrieval began. Tool operators were positioned at the top of the rotating plug and at the glove box over the opening in the $35.6-\mathrm{cm}$ sodium pipe. These operators were separated and were not in visual contact (see Figure A-88). Only the spine tool operator atop the rotating plug could view the lower plenum region; communication with the other operator was by phone. The object was pulled by the retrieval tool up $10.7 \mathrm{~m}$ of the $35.6-\mathrm{cm}$ line at a rate of $1.5 \mathrm{~m}$ every 20 min to allow cooling of the segment so it would not burn the plastic glove box. Examination confirmed its tentative identification as a zirconium segment, originally installed in the conical flow guide.

The remaining five zirconium segments were detached by removing the three tack welded screw heads holding each plate and melting them with an electric arc. Following detachment, the segments were then retrieved by the same method used for the first segment. An arc melt tool was designed that fit through the same $4.1-\mathrm{cm}$ holes in the support plate, that could be remotely operated in a hot argon atmosphere, and that could be sufficiently articulated to allow positioning over each of the screw heads. Such a tool was successfully tested on the full-scale mockup in August 1968.

In November 1968, the arc melting tool was lowered into the inlet plenum and the screw removal process began. The proper gap between the electrode and the arc melting tool and the screw to be melted was determined optically by observing the length of a high-frequency low-current spark discharged from the electrode. When the proper position was obtained, a $1350-\mathrm{amp} \mathrm{dc}$ arc was initiated for 14 seconds. All of the screw heads were thus melted without incident before any of the segments were retrieved. Following screw head removal, the segments remained in position, slightly welded to the flow guide by the arc melting operation. It was necessary to insert a special chisel between the segments in the conical flow guide and to slightly twist them to pry them free. Removal of the segments from the vessel was then accomplished without incident by an retrieval device improved from the earlier retrieval experience. On December 16, 1968, about three weeks after the first screw was removed, the last of the six zirconium segments was retrieved.

Following retrieval of the segments, the arc melting tool was used to weld the zirconium screw shanks to the conical flow guide. The inlet plenum region was inspected for debris and cleaned by a vacuum. The primary system was again filled with sodium, followed by cold trapping operations that caused impurities to precipitate in the cold trap, thus maintaining acceptable sodium purity. In a very real sense, damage to the reactor caused by the 


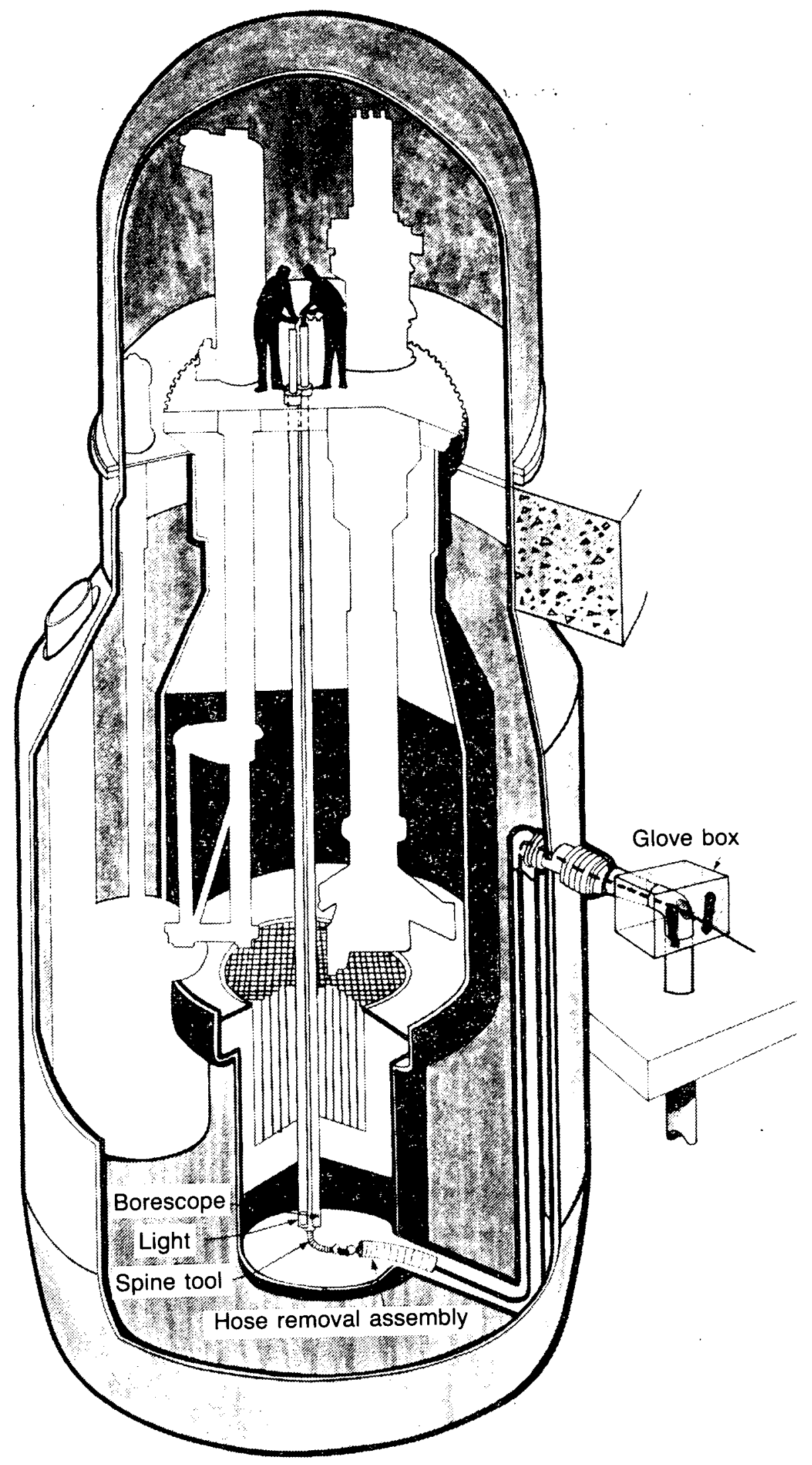

Figure A-88. Perspective view of the segment removal operation. 
October 5, 1966, fuel melting incident was now repaired. Before resuming operations, the following was done:

- A photographic examination of the metallic fingers of the holddown mechanism assured that distortion of the damaged subassemblies had not damaged the holddown mechanism

- All core subassemblies in the reactor during the melting incident were replaced by new subassemblies stored on site

- Added to the instrument system to aid in the operation and detection of steady state reactor anomalies were a digital computer (malfunction detection analyzer), two delayed neutron detectors that could detect a high power level failure area equal to $3 \%$ of 1 fuel pin, a very accurate ammeter connected to the reactor power monitors, and digital readouts for the thermocouple accurate to $0.06^{\circ} \mathrm{C}$.

The accident demonstrated that thoughtful preparation for malfunctions, coupled with a design philosophy that incorporates redundancy and indepth defense, provides a safeguards envelope that will adequately respond to a real accident and provides an ample margin between actual consequences and public harm, even though reactor accidents seldom progress exactly as envisioned during design. The maximum credible accident defined for FERMI I is complete blockage of one subassembly at full power; the AEC staff defined it as blockage of two subassemblies. The predicted, most likely cause of the accident, is rapid melting and injection of fuel from the core, followed by automatic scram from the resulting rapid power drop. Consequences of such an accident poses no hazard to public or plant personnel. The real accident involved a slower, partial melting of only part of the fuel in two adjacent subassemblies. It was detected by anomalous reactivity loss and radiation release to the containment followed by manual scram. The consequences posed no public or plant personnel hazard. The containment system was designed to accommodate a secondary criticality accident involving collapse of one half of the total core into the other half. The real accident resulted in melting less than $1 \%$ of the core.

Inserts were designed for the bottom flow nozzle of each subassembly. When a modified subassem- bly was loaded into the core, these inserts, called flow guards, extended approximately 2 inches below the support plate. These flow guards were basically a hollow cross with a pointed trottom. Design studies showed that the possibility of an object blocking flow through these inserts was nil.

The steam generators presented a problem during the preincident test: gross instability whenever the temperature of the sodium entering the steam generator reached the saturation temperature of the water. This instability caused severe thermal cycling at the water header and twice caused the plant to shutdown. The problem was solved by irserting smaller tubes inside the original downcomer: tubes. With water flowing inside the smaller tubes, heat transfer resistance from sodium was increased such that boiling could not start until the water entered the risers. The steam generators showed no indication of instability in all the tests after modification.

Once the cause of the fuel melting incident was determined, and modifications were installed to ensure that such an incident could not happen again, planning began for resumption of plant operation.

One of the first items to be determined was which fuel subassemblies should be used. There were three types of fuel for the ongoing program: (a) fresh, unused fuel, (b) fuel with recorded proof that it was not overheated, and (c) fuel that was examined by metallurgically analyzing a tip cut from the end cap on a fuel can and carefully measuring the subassembly for distortion (called requalified fuel). These three types of fuel were of sufficient quantity to operate the reactor for a substantial period.

It was decided that after completing a power escalation program, the plant would be operated to do the following:

\section{- Demonstrate plant operability}

- Further debug and tune the equipment

- Obtain revenues from the sale of electricity

- Develop and demonstrate the technique for routine fuel reloading and removal from the sodium-filled system.

To ensure operational readiness, all equipment underwent a formal, complete calibration and operational check before plant operation was 
resumed. More than 50 preoperational tests were written, reviewed, conducted, reported, and approved in this program. By the end of June 1970, all preoperational testing was completed; 93 core subassemblies had been loaded into the core; seven central core positions were temporarily occupied by blanket subassemblies; and 12 core subassemblies were in storage ready for exchanging with those in the core lattice, all to provide reactivity necessary for criticality in the $200-\mathrm{MW}(\mathrm{t})$ operation and demonstration program.

The power demonstration program began on November 20, 1970; with a 5-1/2-d continuous operation period. During the run, $8160000 \mathrm{kWh}$ of electricity were generated. Following the run, the plant operated on an intermittent basis for continued testing of equipment. By June 28, 1971, the decrease in core reactivity owing to burnup had reached the point where the maximum power attainable with all rods withdrawn was $163 \mathrm{MW}(\mathrm{t})$. At this time, the maximum burnup in the central core subassembly was 0.28 at. $\%$.

It was decided that it was too early to send the subassembly for the examination scheduled for 0.4 at. $\%$ burnup. Rather, changes first were made to the core configuration to increase its reactivity, so that 0.4 at. $\%$ burnup could be attained while operating at full power. Up to this point, the plant had generated $23370000 \mathrm{kWh}$ of electricity. Changes included adding several new subassemblies and removing the oscillator equipment. Because some evidence of subassembly bowing was observed following the 1966 fuel melting incident, the decision was made to measure the degree of bowing in every subassembly prior to lowering the holddown mechanism.

Additional information drawn from the melting incident follows:

- Distributed and redundant safety rod capability is basic to ensuring shutdown during an accident. The scram following the meltdown involved insertion of six safety rods; one rod would have been sufficient to shut the reactor down. However, there could well have been rod binding in the safety rod channel near the meltdown region. Whereas even partial insertion of the rod during the FERMI incident could probably have shut the reactor down, it is reasonable to assume that subassembly melting could produce sufficient distortion to preciude insertion of a nearby rod.
- Last minute design changes must be subject to the same design quality and review as the original design. The basic cause of the FERMI meltdown was the detachment of one of the zirconium segments added after construction was well underway. Had there been more careful design review and model testing of this late addition, techniques could have been used to preclude their detachment-or they might not have been added at all.

- Despite environmental extremes within the core of a sodium-cooled reactor following operation, perseverance and ingenuity and special tool design can permit extensive inreactor repairs.

- Considerable thought should be given in designing nuclear plants to provide access for major repairs, should they be necessary.

- Reactor accidents usually are preceded by anomalous, though sometimes complex, reactor behavior. If a plant instrumentation system is designed to detect and help interpret such behavior, the probability of occurrence of such accidents can be reduced. For example, the anomalous temperatures and reactivity preceding the FERMI meltdown led to subsequent installation of a malfunction detector analyzer.

- The ability to preserve a continuing record of plant data is a valuable tool for diagnosis and assessment of plant system response in the event of an accident. Process computers offer immense capability for such a task.

- Local geometry and off-normal operating conditions should be carefully considered in designing thermocouple installations and interpreting their output.

During the incident, the maximum temperature reading of $379^{\circ} \mathrm{C}$ was below the normal full-power bulk outlet sodium temperature of $428^{\circ} \mathrm{C}$, and far below the sodium boiling point of $882^{\circ} \mathrm{C}$. One subassembly melted, yet a neighboring subassembly did not. Heat conduction to neighboring subassemblies, rather than convection through the lowflow partially blocked subassembly, became the predominant heat removal mechanism. 
The outlet sodium temperature was further reduced by conduction of the surrounding sodium as it flowed through the hole in the subassembly handling head to the thermocouple; thus, the temperature rise through a partially blocked subassembly as measured by an outlet thermocouple is no longer inversely proportional to the flow rate for low flows. As the flow to such a subassembly is decreased, the measured coolant temperature will reach a peak and then drop. Thus, whereas departures from normally observed temperatures at a given power are indicative of flow abnormalities, such temperature readings in FERMI could not directly indicate a condition of sodium boiling or fuel melting.

Renewed Operation at FERMI--During the recovery phase, one of the basic decisions was to modify the plant so as to be absolutely certain that a condition resulting in fuel melting could not occur again. The problem was attacked by removing the possibility of a flow blockage, and equipping the control room with instrumentation to detect such a blockage at a very early stage, before melting could take place. After completing the plant changes, the power demonstration program was resumed.

The measurements were completed on August 26, 1971; the holddown mechanism was lowered on August 31; reactor operations resumed on September 1. The period culminated with a 10-d high-power run, from November 20 to December 1, 1971. Total power generated by the plant from critically in 1970 to this point was $32260000 \mathrm{kWh}$. At completion of the run, the maximum burnup in the core reached 0.4 at. $\%$.

After its best operating run to date, the FERMI reactor shut down December 1, 1971, for a 2- to 3-month period for destructive examination of a fuel subassembly and application for a license to go from 0.4 to 0.6 at. $\%$ burnup, a probable core limit. The reactor supplied 9 million $\mathrm{kWh}$ to the Michigan power grid from November 19 through December 1, 1971. Of the $142 \mathrm{~h}$ of operation in that period, $80 \%$ was at the full $200 \mathrm{MW}(\mathrm{t})$ licensed power level.

Decommissioning of FERMI-The major retirement activities and plan for maintaining the plant in perpetuity formed the framework of the decommissioning program. The buildings, reactor vessel, major primary sodium piping, and many auxiliary facilities remained intact. Blanket elements were sent to the Idaho Chemical Processing Plant at the
Idaho National Engineering Laboratory (INEL) near Idaho Falls, Idaho. Radioactive primary sodium remains at the site awaiting delivery to the Clinch River Breeder Reactor project. Nonradioactive secondary sodium was sold and shipped to West Virginia and processed into sodium methylate; the primary cold and hot traps, including miscellaneous piping, were shipped to Beatty, Nevada, for burial; the least enriched uranium was sent to the Savannah River Plant; the blanket subassemblies were sent to the subsurface storage area of the Radioactive Waste Management Complex at INEL; other miscellaneous radioactive or contaminated items were buried. The last category includes dummy subassemblies, oscillator rods, neutron sources, special reactor and pool handling tools, etc. Whenever possible, miscellaneous hardware, such as pool racks, were decontaminated and sold as scrap. When this was not possible, they were shipped for burial.

The plant boundary was revised to exclude many nonradioactive areas, such as the office and turbine buildings. The new boundary is marked by a $7-\mathrm{ft}-$ high chain link fence, and building walls that enclose the fuel and repair building, reactor building, health physics building, sodium storage building, and cold trap room. The cold trap room contains some contaminated piping. The sodium storage building contains three $57-\mathrm{m}^{3}$ tanks of primary sodium. The health physics building will remain functional and within the enclosed area until the primary sodium has been shipped off site. There are also 630 barrels of primary sodium temporarily stored in the reactor building. The reactor vessel contains a nitrogen and carbon dioxide cover gas. This atmosphere extends to caps on secondary sodium pipes external to the reactor building, to piping within the reactor building, and into the primary shield tank. Cover gas pressure is maintained by a bottled gas system. The overflow tank was isolated on the surface system, passivated with $\mathrm{CO}_{2}$ and opened to the air atmosphere of the lower reactor building. The sodium service system piping was cut in the cold trap room and in the reactor building and caps were welded onto the pipes where they connect to the primary system. Sodium service piping between the reactor building and the cold trap room was closed by valves at one end and by welded caps at the other end, wherever they were cut. The insides of the pipes are contaminated with a very thin layer of sodium. One of the tunnel lines contained sodium and this line was sealed with a welded cap in the lower reactor building. The auxiliary fuel storage facility was sealed after 
100 pounds of $\mathrm{CO}_{2}$ were added to passivate any residual sodium that may have drifted from the fuel storage pots.

Because all irradiated structural materials and all large quantities of sodium that cannot be drained are behind shielding, there were no radiation levels in the above-floor region of the reactor building above $0.1 \mathrm{mR} / \mathrm{h}$, except from the barrels of sodium, and none in the below-floor region above $0.3 \mathrm{mR} / \mathrm{h}$. The fuel and repair building transfer tank and overflow tank were drained, sealed, and passivated with $\mathrm{CO}_{2}$, then opened to the air atmosphere of the tank room. If the building is dismantled, these tanks will require special handling since they still contain a small yield of residual sodium. The four circulation cold trap systems associated with the transfer tank have been completely removed, disassembled, and shipped for burial.

The three $57-\mathrm{m}^{3}$ tanks in the sodium storage building contain a total of $144 \mathrm{~m}^{3}$ of sodium. The maximum radiation level in December 1973 was $9 \mathrm{mR} / \mathrm{h}$ at the installation surface. Once the sodium was transferred to drums, the tanks were passivated with $\mathrm{CO}_{2}$. At some future date, the tanks may be cut up, scraped, or shipped for burial, depending on the difficulty of decontamination. The cold trap room is vacant except for sections of service piping. Radiation levels in the cold trap room in December 1973 were $2 \mathrm{mR} / \mathrm{h}$, and contamination was less than $100 \mathrm{~d} / \mathrm{m} /$ decimeter $^{2}$. Access to the tunnel between the reactor building and the cold trap room can only be obtained by removing a welded cover. From the cold trap room, the tunnel is closed off by a concrete barrier. Radiation levels in the tunnel have not been measured, but contamination levels in December 1973 were less than $100 \mathrm{~d} / \mathrm{m} /$ decimeter $^{2}$. The liquid waste in sump pump system has been deactivated but left intact so any potential ground water leakage can be pumped from the sump to the fuel and repair building liquid waste storage tanks for later discharge when a sufficient quantity has accumulated.

Access to the FERMI facility is through locked gates and fencing within the exclusion area of the present nuclear and fossil power plant. All gates are locked except when personnel are inside, and a visual inspection of the fence and building is made weekly to determine that all gates and doors are properly closed.

The moisture detector in the biological shield wall cavity in the reactor building was modified to respond to water levels by the insertion of copper probes 3 inches into the floor drain. A similar modification was made to the moisture detector in the fuel and repair building hot sump. The moisture monitor in the lower reactor building remains intact.

A carbon dioxide cover gas is maintained in most systems containing residual radioactive sodium. Cover gas pressure is maintained above atmospheric pressure and below $35 \mathrm{KPa}$. The cover gas system is checked during inspection of the facility. A backup supply of gas is available to supply the system for eight days under normal conditions. Extensive details on the deactivation and surveillance of FERMI I can be found in Reference A-131.

It is a notable achievement that no worker was ever exposed to an excessive effluent release during the life of the FERMI project. This is in the face of the extensive maintenance and repair work required in an extremely difficult environment following the 1966 fuel melting incident.

FFTF. The Fast Flux Test Facility (FFTF) is a $400 \mathrm{MW}(\mathrm{t})$ LMFBR designed and constructed for irradiation testing of breeder reactor fuels and materials. The reactor provides extensive capability for in-core irradiation testing, including eight core positions that may be used with contract instrumentation attached to all or part of the test specimen. Four of these positions may be used for independently cooled (closed) loops.

In addition to irradiation testing capabilities, the FFTF provides long-term testing and evaluation of plant components and systems for liquid metal fast breeder reactors. The fast test reactor is equipped with structures for heat removal, containment, core component handling and examination, instrumentation and control, and for supplying utilities and other essential services. The reactor is located in a shielded cell in the center of the containment. Heat is removed from the reactor and liquid sodium circulated by three primary loops including primary pumps, piping, and intermediate heat exchangers (also located in containment). The secondary sodium loop transports the reactor heat from the intermediate heat exchangers to the air cooled tubes "dump" heat exchangers (DHX). Heat from the two closed loops is removed by similar but much smaller heat transport systems.

The FTFF has capabilities for receipt, conditioning, and storage of a reactor core, and core component and test assemblies are routinely installed and 
removed. Unlimited examination and packaging are also available (for outside shipment). For a detailed description of the FFTF facility, see Reference A-132.

Reactor Features-The reactor vessel is constructed of Type 304 stainless steel. It is approximately $13.1 \mathrm{~m}$ high and has a $6.1-\mathrm{m}$ inside diameter. Its wall thickness varies from 6 to $7 \mathrm{~cm}$. A pool of liquid sodium fills the reactor vessel from the bottom to the apron cover gas zone near the top. Sodium coolant enters the reactor vessel through three $40.6-\mathrm{cm}$ nozzles in the lower part of the vessel, flows through the core and other equipment, and then out directly through three $71.1-\mathrm{cm}$ outlet nozzles located approximately at the vessel mid-height (Figure A-89).

The reactor vessel is suspended from its upper section and nested in a bottom-mounted Type 304 stainless steel reactor guard vessel whose purpose is to ensure that the reactor vessel nozzle remains submerged in sodium in the event of a leak. The reactor head is the closure for the reactor vessel and is $7.62 \mathrm{~m}$ in diameter, about $56 \mathrm{~cm}$ thick, and weighs 195 tonnes. Equipment mounted on the head includes drive mechanisms for in-vessel components, seals, and shielding for openings, thus providing access to the vessel interior and coolant piping for independently cooled test loops.

Core Arrangements-The FFTF reactor core generates up to $7 \times 10^{15} \mathrm{n} / \mathrm{cm}^{2}$ s of neutron flux ( 60 to $65 \%$ greater than $0.1 \mathrm{MeV}$ ) at a power level of $400 \mathrm{MW}(\mathrm{t})$.

The core comprises 199 core assemblies. The design includes 74 positions for $\mathrm{PuO}_{2}-\mathrm{UO}_{2}$ driver fuel assemblies, which generate the nuclear flux; nine boron carbide control rod absorber assemblies; and eight positions that may be used for independently instrumented tests of fuel specimens or reactor core materials. All eight independently instrumented positions may be used for open tests cooled by the reactor primary coolant system. Four of these positions may be used for independently cooled closed loops. In these closed loops the coolant system is completely separated from the FFTF heat transport system. This permits testing of fuels and materials over a wide range of temperatures in a controlled environment.

In addition to the testing capabilities of the open test and closed loops, the 74 positions designed for driver fuel may be used for statistical testing of fuels. These positions are cooled by the main reactor coolant. For each of these positions, coolant output flow and temperature are measured by instrumentation suspended above the position.

Nonfissioning materials may be tested in the fueled portion of the core and also in some of the 108 core positions surrounding the fueled zone. The neutron flux in these peripheral positions vary from 0.5 to $4 \times 10^{15} \mathrm{n} / \mathrm{cm}^{2} / \mathrm{s}$. Nominally, the 108 positions contain Inconel reflectors.

The core periphery positions may also include a variable number (up to 15 ) absorber assemblies. They remain fixed in the core periphery for reactivity adjustment during a particular fuel cycle. The other peripheral positions are occupied by Inconel reflectors, which are surrounded by radial shielding contained in a core barrel. The core barrel supports six core restraint mechanisms that hold the core assemblies in proper orientation during nuclear operation. The core barrel is supported by a core support structure welded to the reactor vessel. The reactor internals consist of the reactor core, three instrument trees that support flow and temperature measuring instruments over the core, nine nuclear control drive mechanisms, radial shielding around the core, the core support structure, a core barrel that contains the core, six core restraint mechanisms, a horizontal baffle and seal to control sodium flow in the reactor vessel, three low level flux monitor thimbles, and three in-vessel storage modules. The locations of these components are shown in Figure A-90.

The reactor core and other reactor internals are immersed in a pool of liquid sodium. The liquid sodium fills the free volume inside the reactor vessel from the bottom to a cover gas zone near the top of the vessel. The sodium coolant enters the reactor vessel through three $40.6-\mathrm{cm}$ inlet nozzles, flows through the core and other equipment, and out through three $71.1-\mathrm{cm}$ outlet nozzles.

Each driver fuel assembly, which consists of 217 individual fuel pins, can be used for statistical testing of fuel pins under actual operating conditions. Each assembly can also be used for operational testing of alternative designs and materials for the nonfissioning components of fuel assemblies.

The core will also accommodate up to eight independently instrumented test assemblies. They may be used for testing either fissioning materials, 


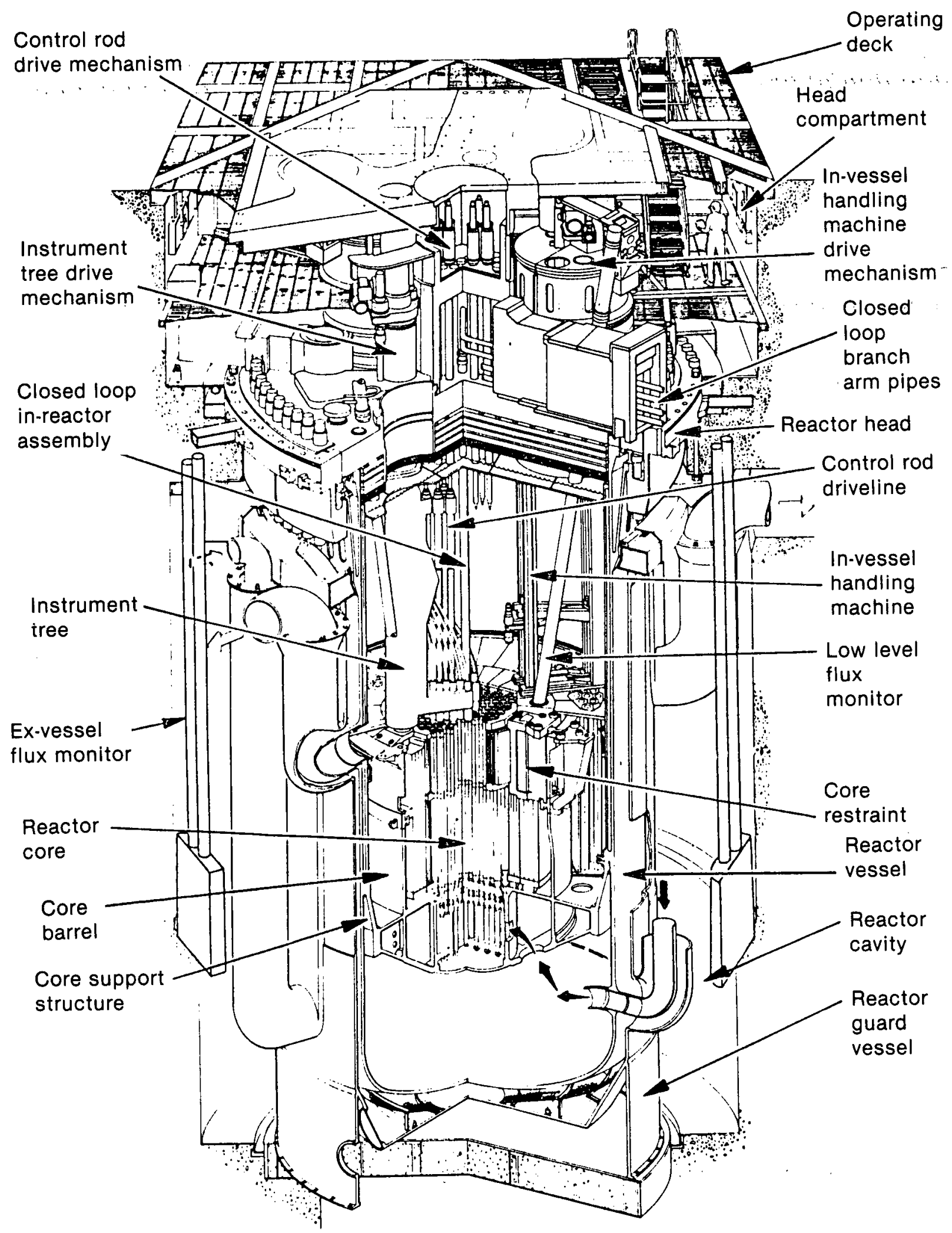

Figure A-89. FFTF reactor cutaway. 


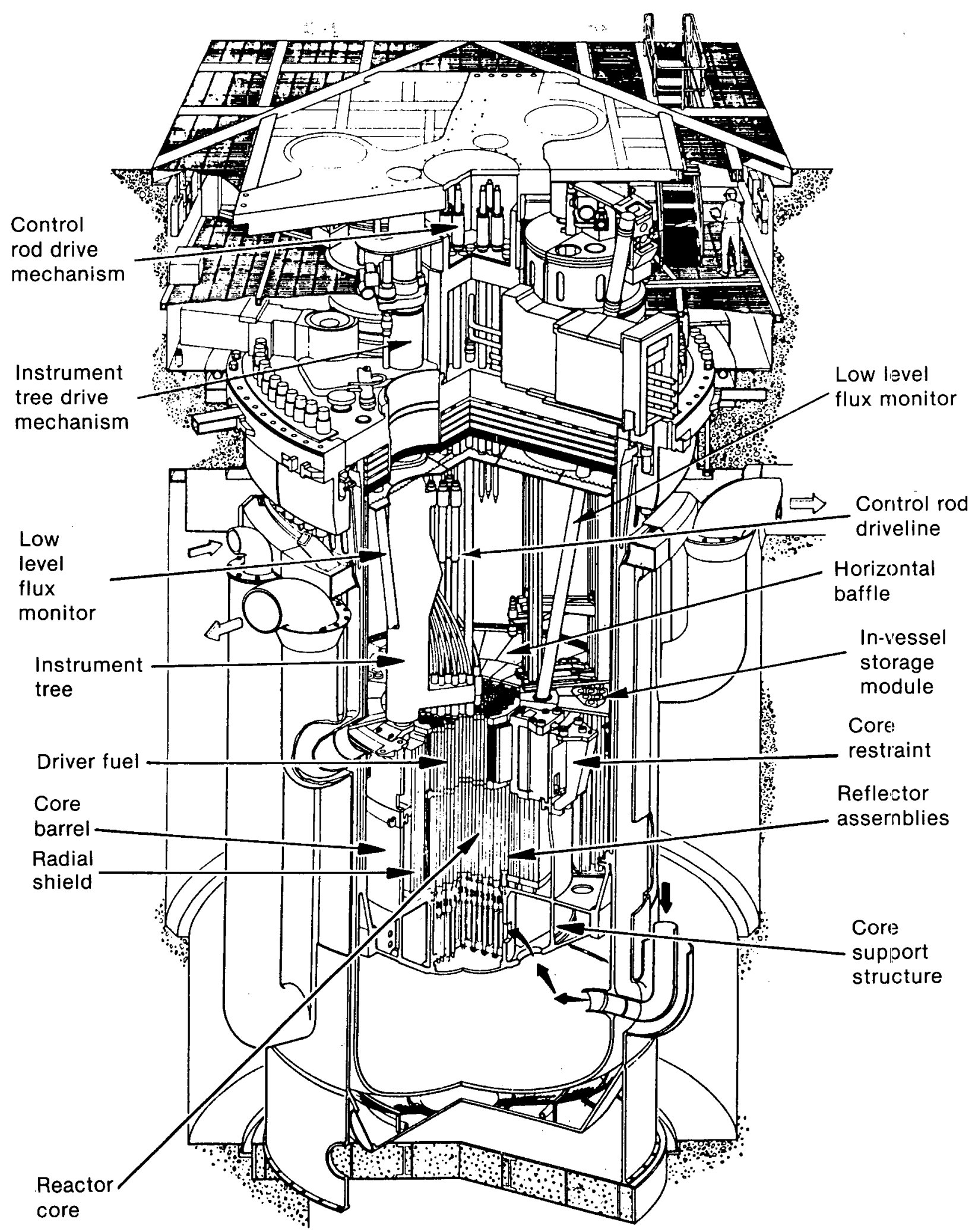

Figure A-90. FFTF reactor internals. 
advanced fuel, or nonfissioning materials. The independently instrumented test assemblies may include up to four independently cooled closed loop in-reactor assemblies: The independently instrumented test assemblies are $12.2 \mathrm{~m}$ long. The other core assemblies are $3.7 \mathrm{~m}$ long, except for some slightly shorter reflectors.

The three instrument trees (see Figure A-91) are a unique feature of FFTF since they cover the core; the control rod drives (Figure A-92) pass through guide tubes in the instrument trees. To obtain access to the core for refueling, the instrument trees must be rotated away from the core into a stored position. Before such rotation, the control rod drive lines must be disconinected remotely at the top and bottom of the instrument tree guide tubes. The actual nuclear control absorber assemblies remain in the core.

The core support structure, which is welded to the reactor vessel (Figure A-93), positions the core components within the reactor vessel. The core basket is centrally located within the core support

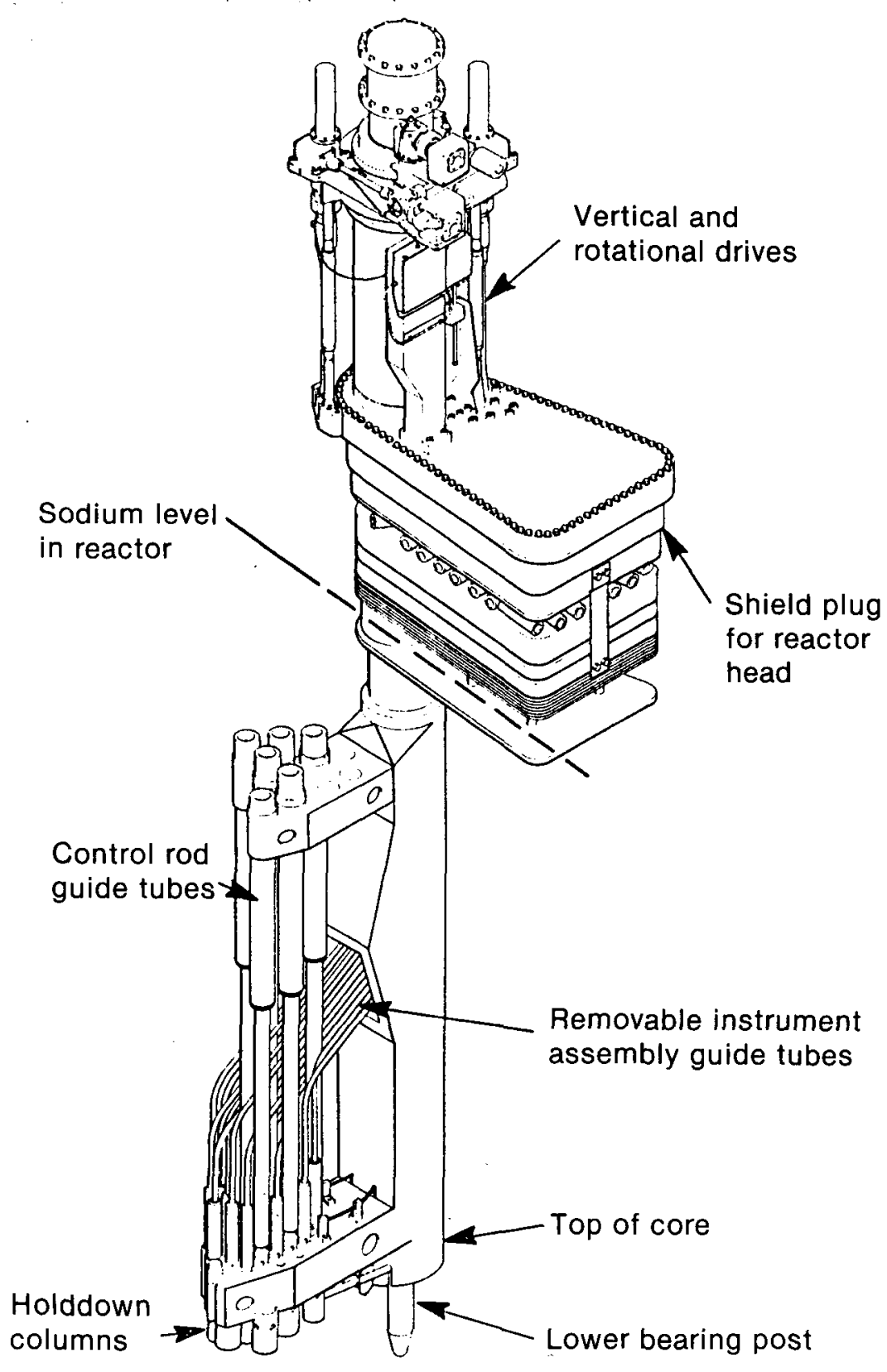

Figure A-91. FFTF instrument tree schematic. 


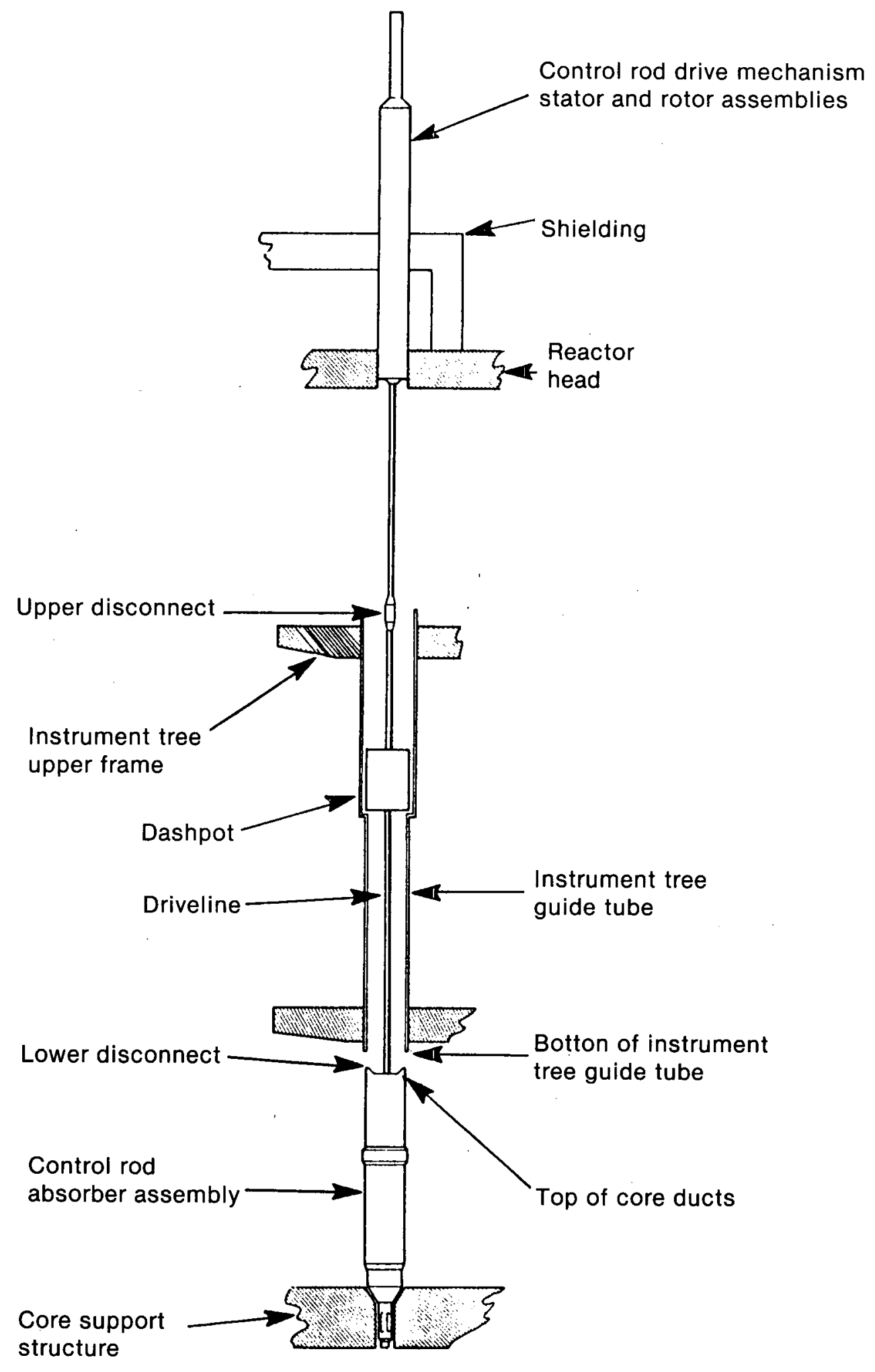

Figure A-92. FFTF nuclear control system. 


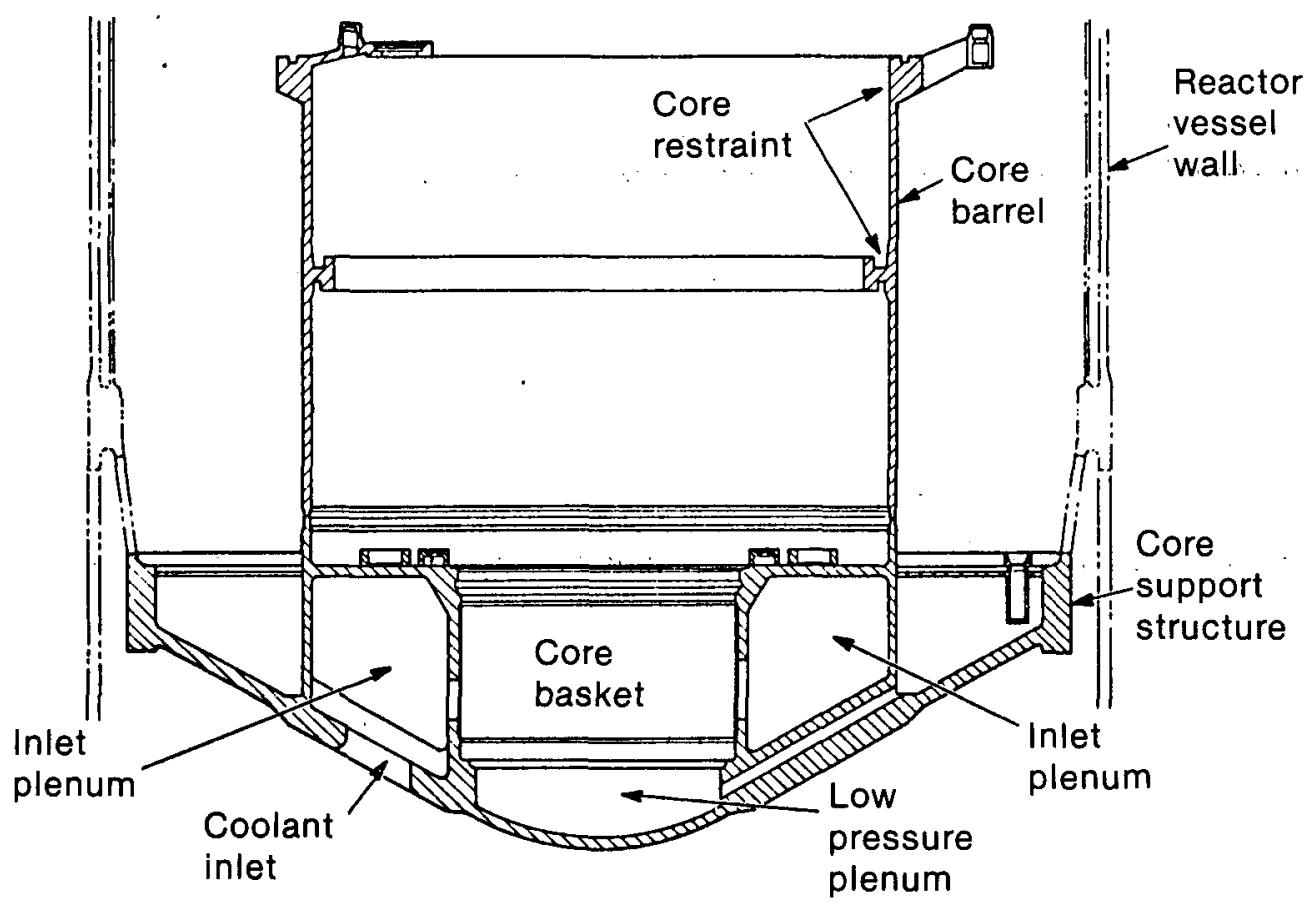

Figure A-93. FFTF core support structure and core barrel.

structure and provides vertical support for the driver fuel, test, absorber, and inner reflector assemblies. The basket is a closed cylinder with 151 tubular receptacles connecting the upper and lower tube sheets.

Different sizes and shapes of receptacles are used to ensure that the core assemblies are properly placed. The cylindrical section of the basket has 12 rectangular flow slots fitted with flow strainers through which the incoming sodium flows. The core support structure and core basket are made of Type 304 stainless steel.

The core barrel is a Type 304 stainless steel cylinder about $0.35 \mathrm{~m}$ high and $3.5 \mathrm{~m}$ in diameter. The core barrel surrounds the radial shield of the core and is supported by and welded to the core support structure.

The radial shield consists of six inner blocks and six outer shield blocks arranged around the periphery of the radial reflector region. The inner and outer shield blocks are composed of vertical Standing-Type 304 stainless steel plates. The radial shielding is supported by the core support structure.

The core restraint mechanisms (Figure A-94) apply radial force to the load pad of the core assemblies to hold them in position for power operation.
The core restraint mechanisms are mounted on the core barrel. Six mechanisms are equally spaced around the periphery of the core and are actuated by shafts extending through the reactor head.

The horizontal baffle mounted at the upper end of the core barrel acts as a thermal insulator and flow barrier between the hot outlet plenum of the reactor vessel and the relatively cool inlet plenum. The baffle is sealed to the reactor vessel liner by the baffle liner interface seal.

In-vessel storage modules are located in three sections of the annular region between the core barrel and the reactor vessel thermal liner. Each module (Figure A-95) has 19 natural convection-cooled Type 304 stainless steel receptacles for core components and one transfer port position for the core component top.

Assemblies from material surveillance samples are also located in the in-vessel storage modules. During reactor operations, these samples are exposed to the sodium, thermal, and radiation environment. Figure A-96 shows the location of two of the in-vessel storage modules.

The low-level flux monitoring (LLFM) instrumentation for determining the reactor's reactivity status during subcritical and low-power conditions 


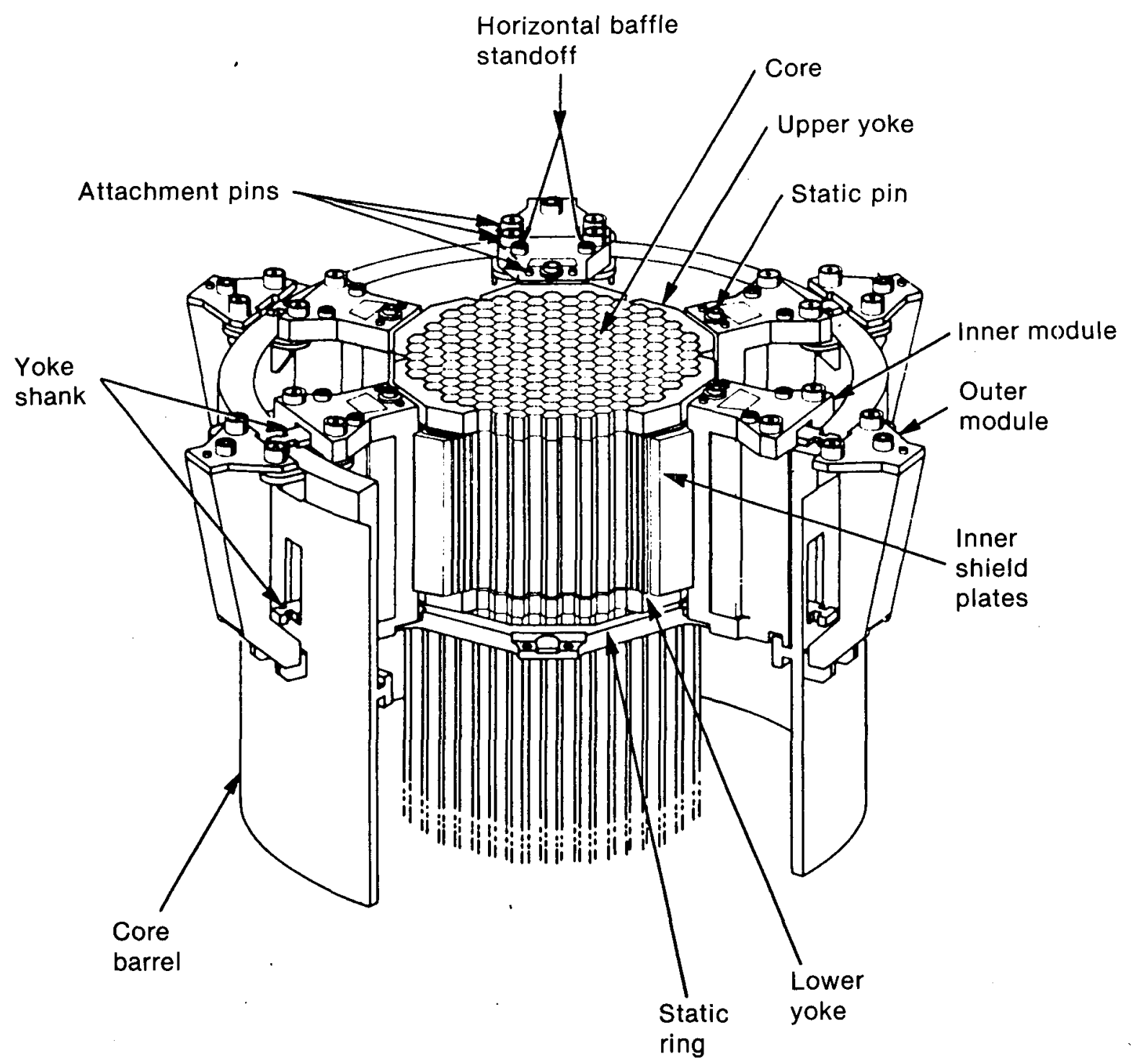

Figure A-94. Arrangement of core strain mechanisms around core.

comprises three assemblies. The assemblies are located 120 degrees apart in the reactor vessel. Each assembly (Figure A-97) is made up of a composition thimble, a sensor drive unit, a sensor with cable, and a nitrogen gas cooling system that maintains the neutron sensor in its cabling below $150^{\circ} \mathrm{C}$.

The drive mechanism, mounted above the vessel head, positions the neutron sensor axially within the thimble. The sensor is located at the core midplane during reactor shutdown and startup operations. Prior to full power operation, the sensor is retracted to a higher elevation.

The FFTF core contains $\mathrm{PuO}_{2}-\mathrm{UO}_{2}$ driver fuel assemblies, positions for independently instrumented open test assemblies, positions for independently instrumented and independently cooled closed loop assemblies, boron carbide neutron absorbers for nuclear control, and Inconel ${ }^{\circledR}$ connectors.

Whereas the general design of all 199 core assemblies is similar, details of the handling sockets and nozzles differ to ensure proper location of various types of assemblies in the core.

The core is arranged in concentric hexagonal rings of assemblies surrounding a central assembly. Rows one through four are known as the inner enrichment zone, rows 5 and 6 the outer enrichment zone. These first six rows constitute the core's fueled zone, which is $0.91 \mathrm{~m}$ in axial length and 


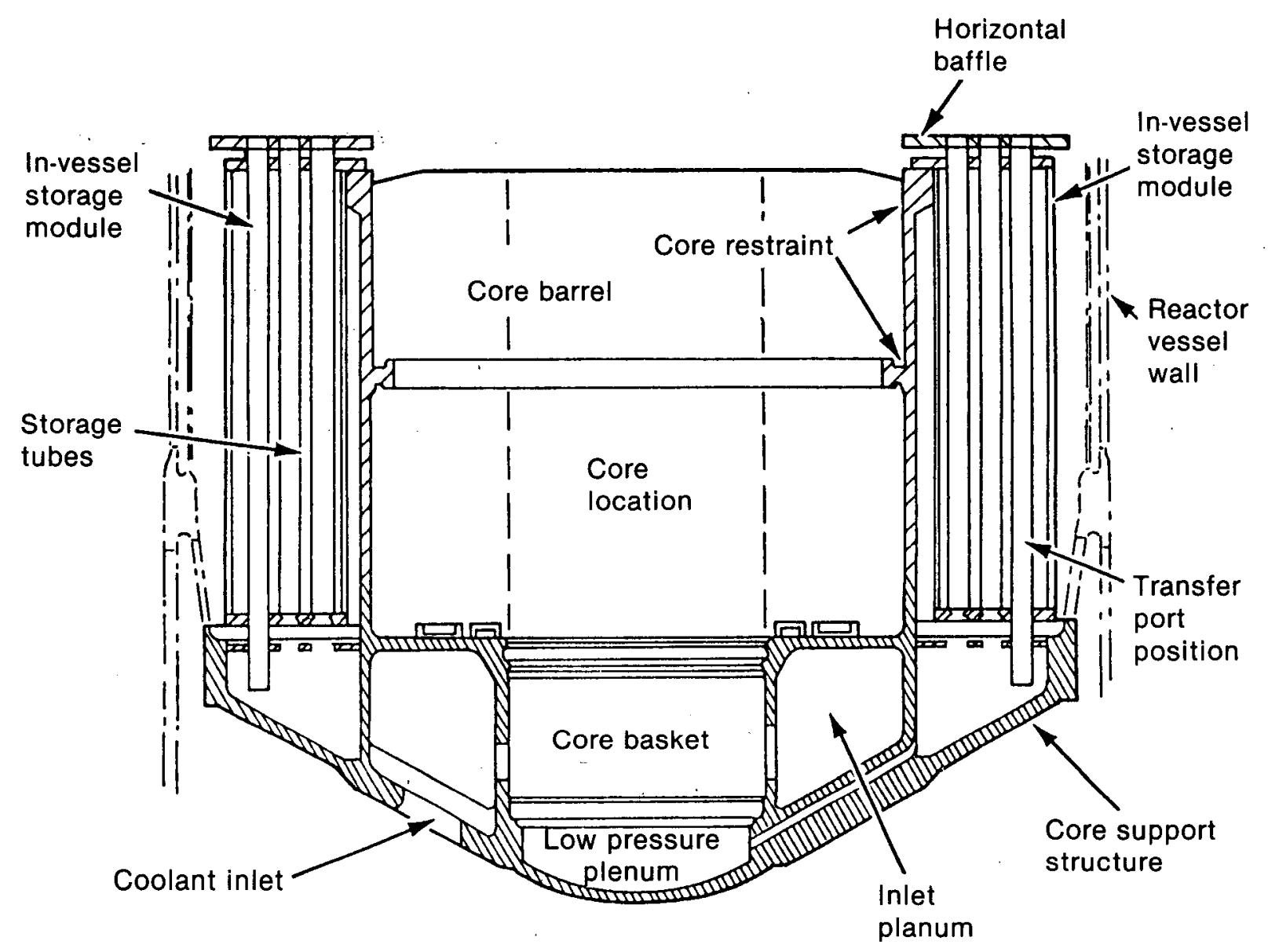

Figure A-95. Location of in-vessel storage modules.

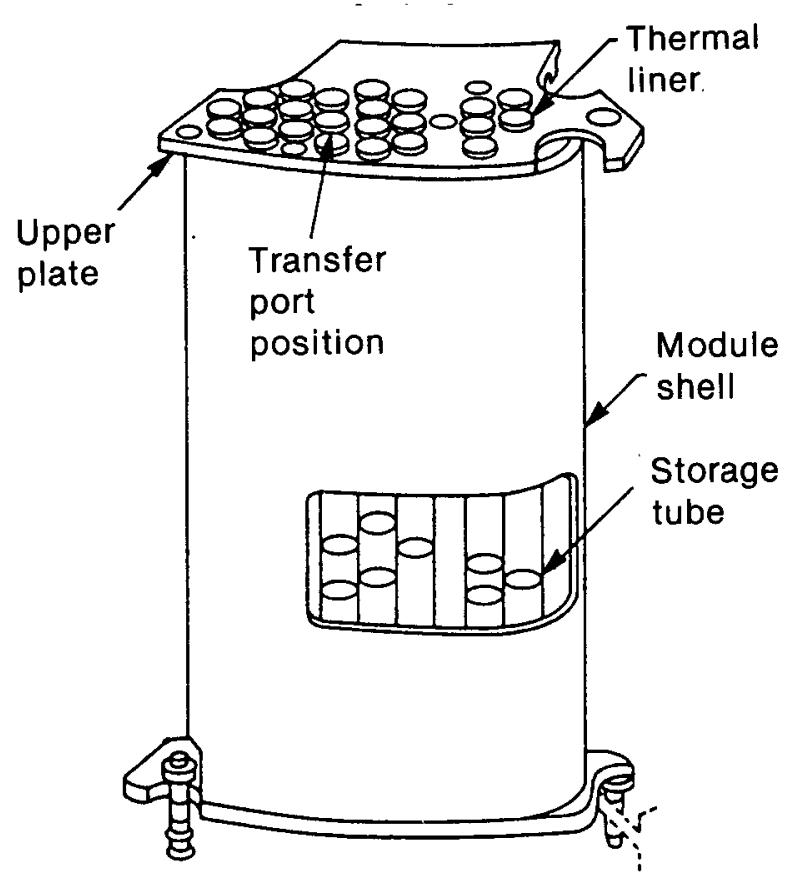

Figure A-96. In-vessel storage module. 


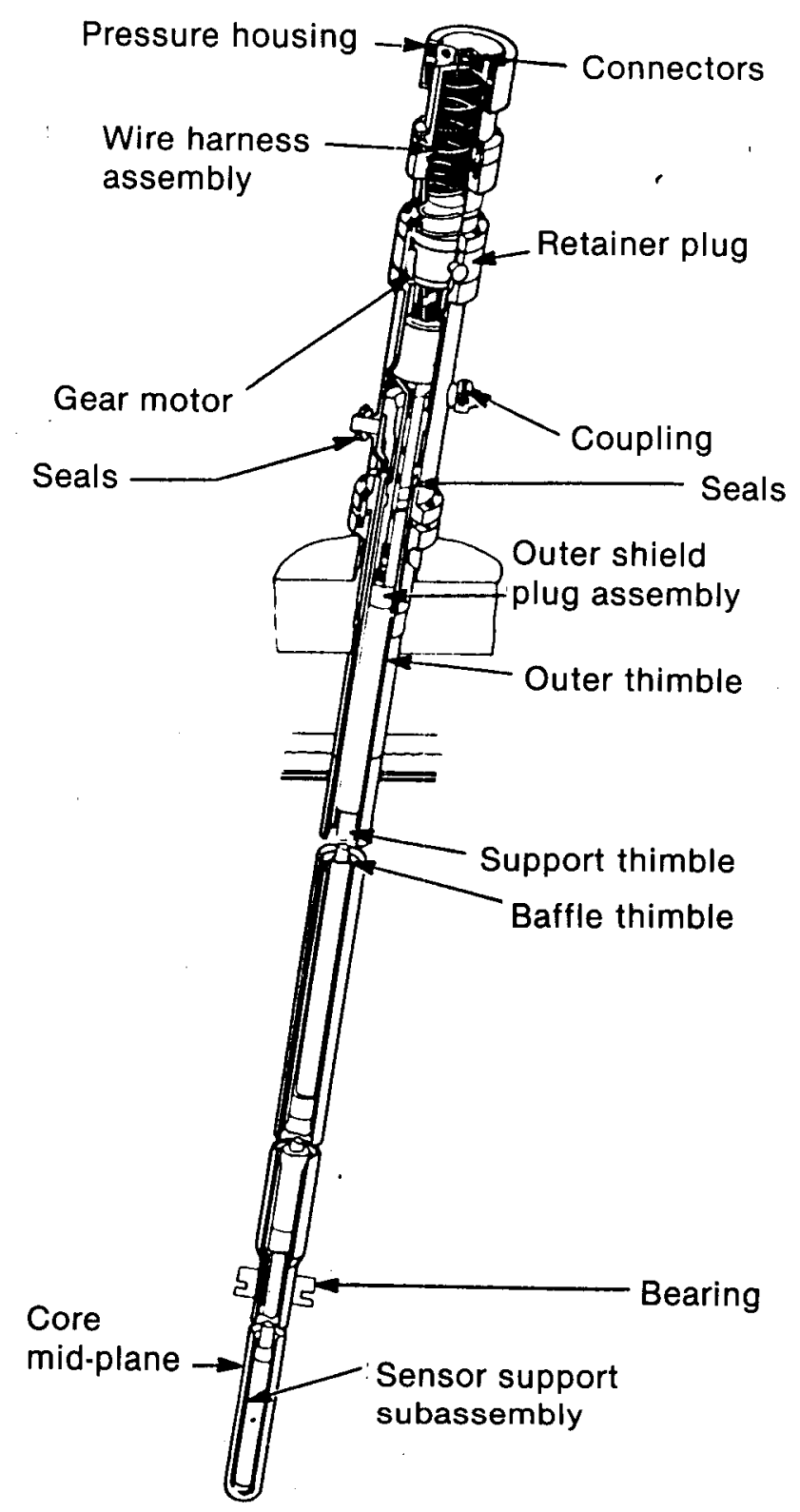

Figure A-97. Low-level flux monitor assembly.

$1.2 \mathrm{~m}$ in equivalent diameter. These six rows contain the driver fuel assemblies, nine control rod assemblies, and up to eight independently instrumented test assemblies.

Control System-The reactor plant control system provides equipment for stable and reliable control, both manual and automatic, of the reactor and heat transport systems during normal operation. Routine controls include removal of decay heat during reactor shutdown and neutron flux control, and also coolant flow and the dump heat exchanger bulk sodium outlet temperature for each of the three heat transport system cooling circuits (see Table A-10).

The neutron flux control system operates three primary control rods and six secondary control rods. During normal operation, the three primary rods are fully withdrawn while the secondary rods are used for control. The primary and secondary rods have separate control equipment. The flux controller provides stable, automatic control of reactor power, which is accomplished by operating the secondary control rods using flux as the feedback signal. The power setpoint is adjusted by the 
Table A-10. Reactor plant control systems

\begin{tabular}{|c|c|c|c|}
\hline Function & $\begin{array}{c}\text { Controlled } \\
\text { Variable }\end{array}$ & Sensor & Actuator \\
\hline Flux control & Neutron flux & $\begin{array}{l}\text { Compensated ion } \\
\text { chamber }\end{array}$ & Control rod \\
\hline Primary flow control & $\begin{array}{l}\text { Primary loop sodium } \\
\text { flow }\end{array}$ & Magnetic flow meter & $\begin{array}{l}\text { Liquid rheostat of } \\
\text { primary pump motor }\end{array}$ \\
\hline $\begin{array}{l}\text { Secondary flow } \\
\text { control }\end{array}$ & $\begin{array}{l}\text { Secondary loop } \\
\text { sodium flow }\end{array}$ & Magnetic flow meter & $\begin{array}{l}\text { Liquid rheostat of } \\
\text { secondary pump } \\
\text { motor }\end{array}$ \\
\hline $\begin{array}{l}\text { Secondary cold leg } \\
\text { temperature control }\end{array}$ & $\begin{array}{l}\text { DHX bulk sodium } \\
\text { outlet temperature }\end{array}$ & Thermocouple & $\begin{array}{l}\text { Air flow (fan speed } \\
\text { and/or damper } \\
\text { position) }\end{array}$ \\
\hline
\end{tabular}

operator. The feedback signal is the auctioneered high of the three secondary power range nuclear signals. The controller also provides secondary rod withdrawal stops based on high flux and high fluxflow ratio. As a result, all secondary rods are blocked for withdrawal when the allowable flux or flux-flow ratio is exceeded.

The control rod selection logic ensures that only one control rod in the primary system or one in the secondary system can be manually withdrawn at a time It also ensures that the automatic control can operate only one secondary rod at a time. Rod position is measured and indicated by two completely independent methods: a relative broad position indicator and an absolute rod position indicator.

The major elements of the control rod system are the flux controller, the control rod selection logic, the rod position indicators, the motor generator (MG) set, the control rod drive mechanism (CRDM) controllers, and the power supplies.

Separate MG sets, circuit breakers, and 3.6-phase transformers are provided for the primary control rod and secondary control rod systems.

The MG set provides three-phase power for input to the three- to six-phase transformers, which in turn provide the power sources for the CRDM controllers. These controllers supply pulsed dc to energize the CRDM stator coils. The CRDM motor is a six-coil six-phase step type that requires dc to energize the coils.

The sodium flow control system includes all equipment necessary to provide stable control of sodium flow in each heat transport system loop. The control is obtained during all modes of operation by varying the pump speed through use of liquid rheostats. The system includes a flow setpoint generator and six control subloops-one for each pump. Feedback signals are derived from the loop flow instrumentation.

The flow controller output drives the liquid rheostat position control system. The liquid rheostat provides the capability to vary the motor resistance of a wound rotor motor, thereby changing motor speed. A speed ratio of approximately $2: 3: 1$ is available, providing flow control over a range of about 50 to $100 \%$ of design flow.

The dump heat exchanger (DHX) control system provides stable control of airflow, thereby maintaining limits of the DHX sodium outlet temperature. Included are interlocks and equipment required to rapidly reduce airflow after reactor scram.

Each of the 12 DXH modules has a control subloop to operate the fan's variable speed control and the controllable outlet dampers (a coarse control damper with six blades and fine control damper with two blades). 
The reactor plant control system provides an integrated design to monitor, control, and coordinate the decay heat removal process for plant shutdown operations. Following a scram or shutdown to refueling temperature, the decay heat of the reactor and stored heat in the HTS are dissipated by the primary and secondary loops at pony motor flow conditions. The DHX modules (Figure A-98) are cooled by natural air circulation.

The reactor plant control system also provides the monitoring control and coordination functions necessary to ensure decay heat removal under completely natural circulation conditions if all electrical power (off-site power and on-site emergency power) were lost. Special instrumentation, separate from the normal control system, has operated from a Class IE battery power source. Manual control of the fine damper is provided from the control room for each of the 12 modules; the DHX outlet temperature for each module is displayed adjacent to the manual controller.

Heat Transport System-Heat generated by the $400-\mathrm{MW}(\mathrm{t})$ reactor is removed via the heat transport system (HTS). The HTS pumps $27400 \mathrm{~L} / \mathrm{s}$ of sodium through the reactor vessel at a nominal inlet temperature of $360^{\circ} \mathrm{C}$, inlet pressure of about $0.917 \mathrm{MPa}$, and a nominal outlet temperature of $530^{\circ} \mathrm{C}$. The actual inlet and outlet temperatures depend on the operating conditions selectecl.

Dry argon cover gas is used to blanket the sodium in the reactor vessel and throughout the heat transport system to avoid contact between sodium and air. The heat transport system has three 133-MW stainless steel circuits (Figure A-99). Each circuit consists of both a primary (radioactive) and a secondary (nonradioactive) loop. The reactor vessel and its head are part of each primary loop; additional primary loop equipment consists of a primary pump with two motors, two isolation valves, one check valve, required piping, and a shell side of the intermediate heat exchanger (IHX). The IHX isolates radioactive primary sodium from the secondary loop.

Each main component and each vertical run of piping in the primary loops are provided with a guard vessel. The primary loops transport reactor heat to the intermediate heat exchangers that thermally link the primary and secondary loops. The three primary loops have common flow paths

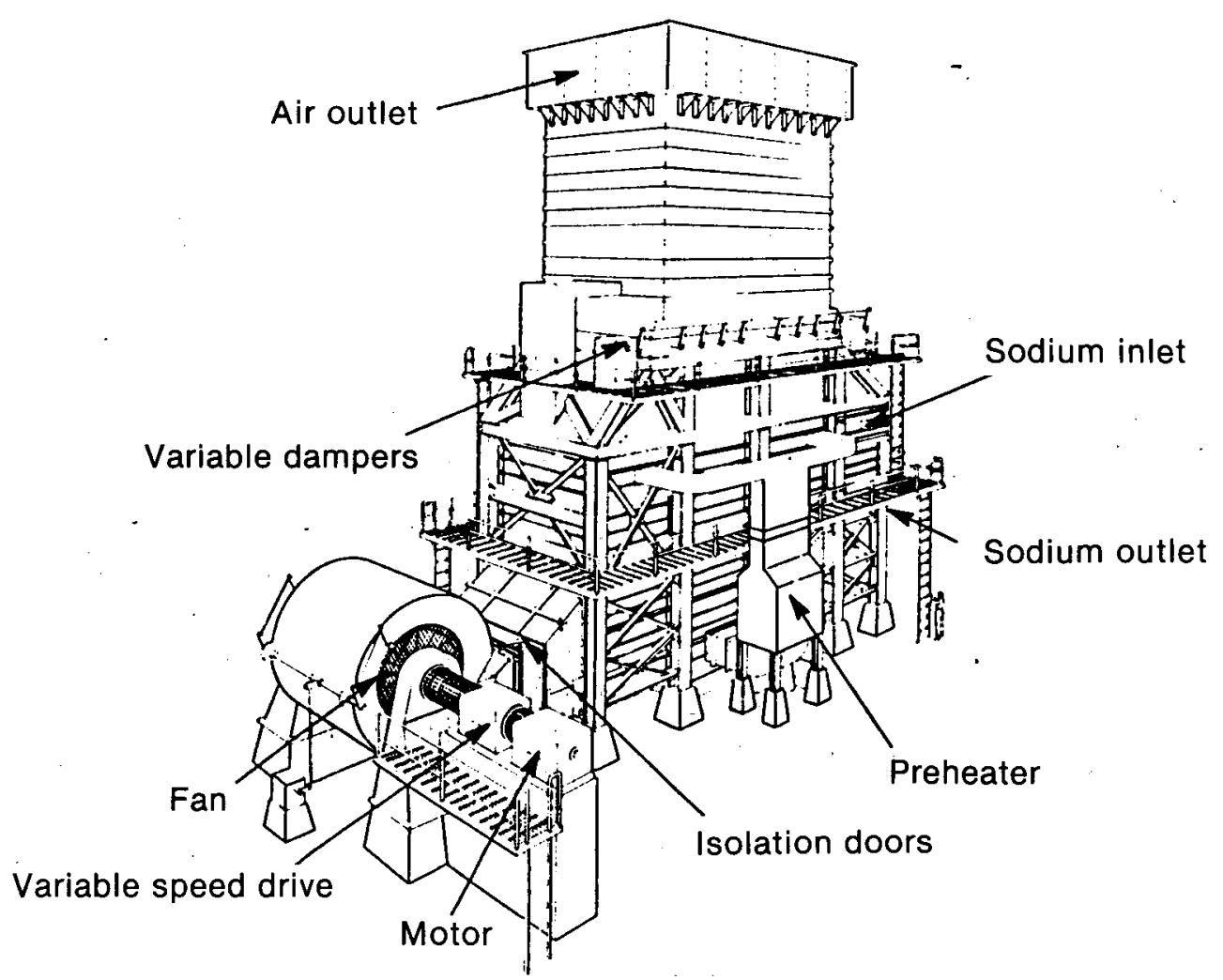

Figure A-98. Dump heat exchanger module. 


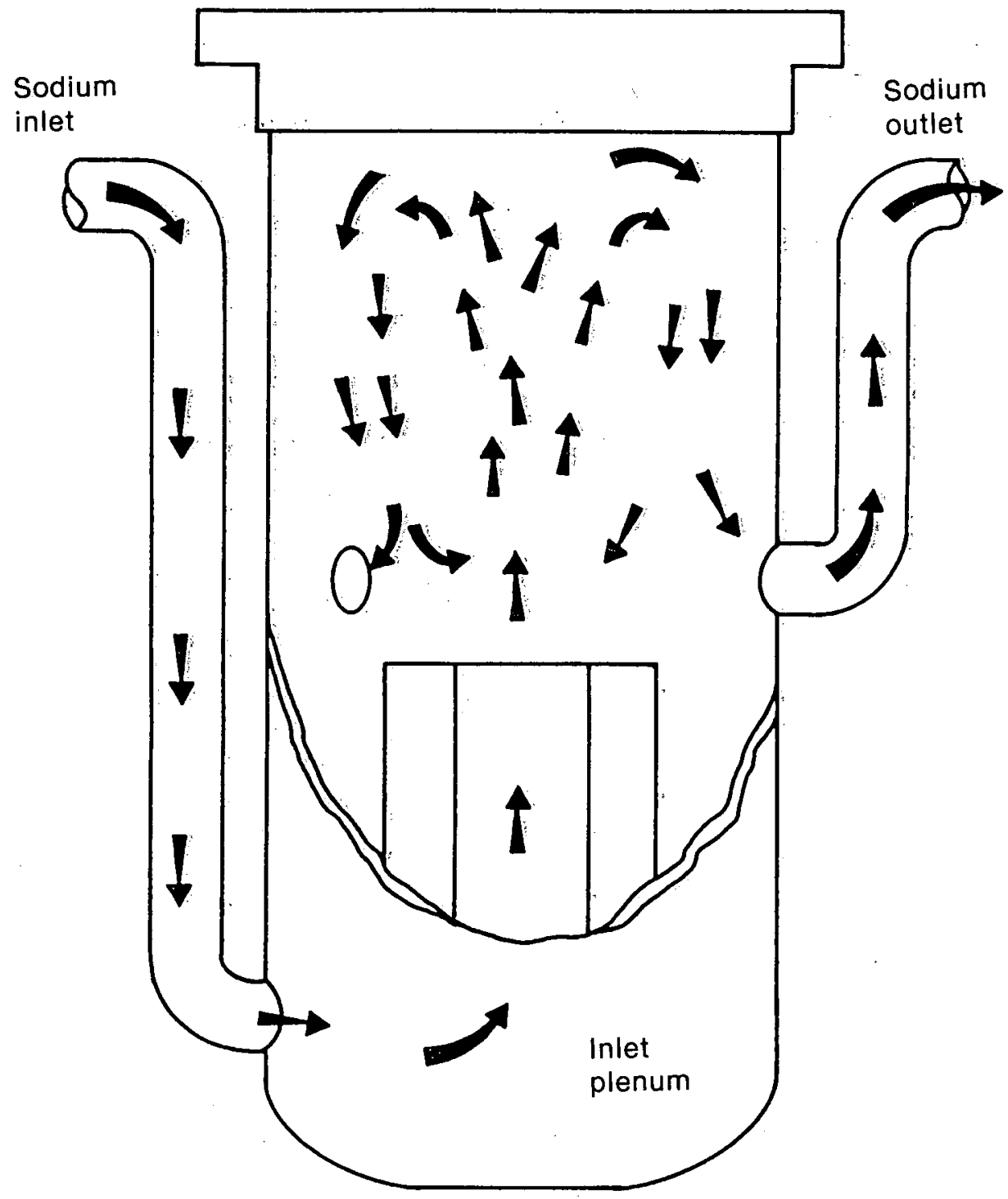

Figure A-99. Sodium flow through FFTF reactor vessel.

through the reactor vessel but operate independently otherwise, except for a cover gas equalization line common to all three loops, linking all primary pumps with the reactor vessel.

Each secondary loop consists of the tube side of the IHX, a secondary sodium pump with two motors, an expansion tank, and a sodium-to-air dump heat exchanger (DHX). The DHX consists of four 33-MW heat exchanger modules per loop, and required piping and isolation valving.

The sodium coolant enters the reactor vessel below the bottom of the core, flows up through the core and reactor internals, and out slightly above midplane of the reactor vessel (Figure A-99).
Heated sodium flows from the reactor outlet nozzle through the hot leg isolation valve to the section of a centrifugal free surface pump (Figure A-100). Sodium from the pump discharge is circulated to the shell side of the intermediate heat exchanger where the heat is transferred to secondary sodium. From the intermediate heat exchanger outlet, the primary sodium flows through a check valve and a cold leg isolation valve. It then goes to the reactor vessel inlet and through the reactor, thus completing the flow cycle. Covered guard vessels around each primary pump and IHX retain the sodium in the likely event of a leak.

Piping from the reactor vessel to the pump section is $71.1 \mathrm{~cm} \mathrm{OD}$; the remaining piping from the 


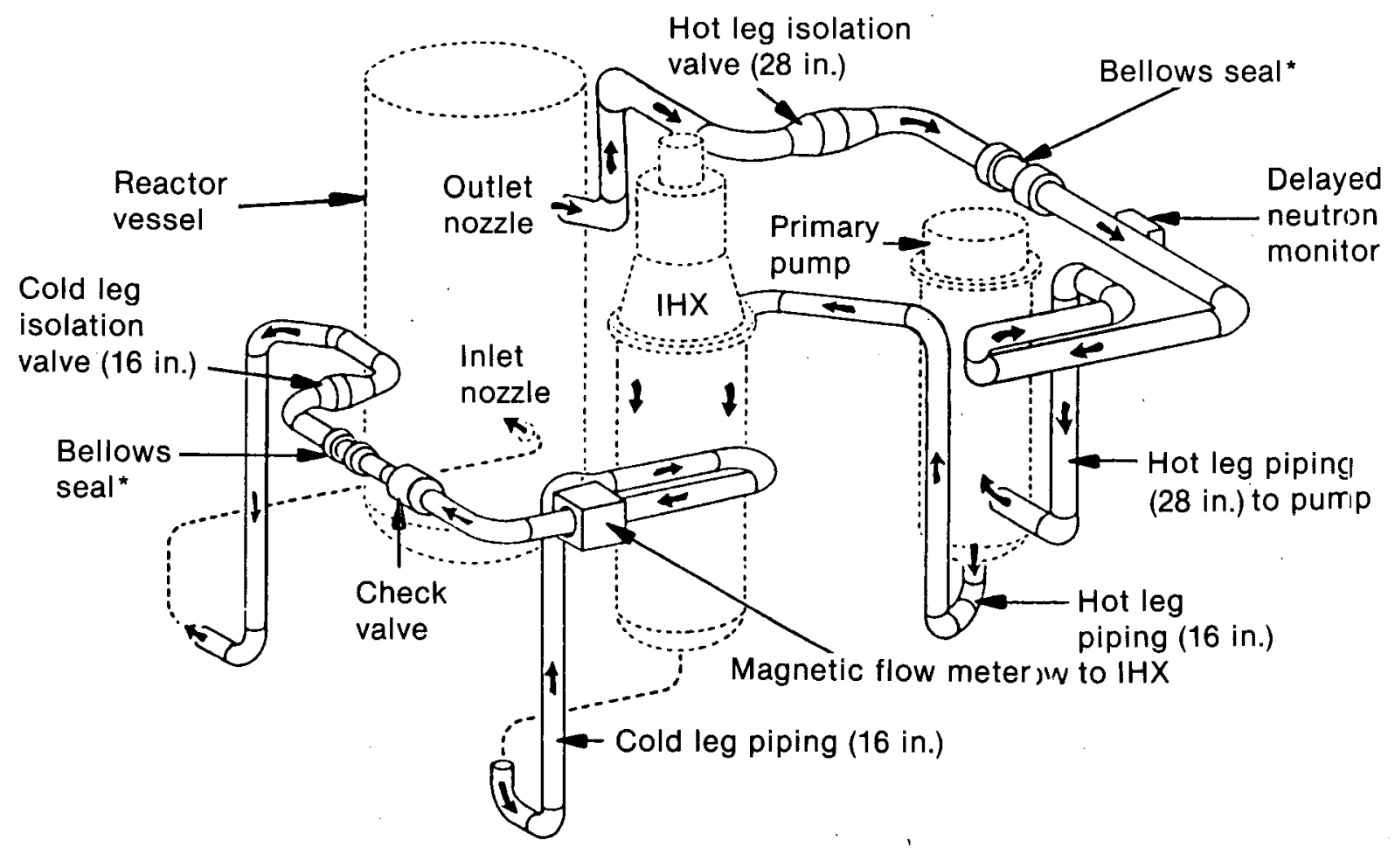

* Provides atmospheric seal between HTS cell and HTS pipeway

Figure A-100. Heat transfer system primary loop piping.

pump discharge to the reactor vessel inlet nozzle is $40.6 \mathrm{~cm}$ OD. The decision to make the reactor vessel outlet pipe $71.1 \mathrm{~cm}$ was governed mainly by the frictional pressure losses in this line.

The sodium flow rate is measured by a permanent-magnet flowmeter located downstream of the IHX outlet; flow is adjustable by a variable speed drive pump. Maximum fluid velocity is less than $9.14 \mathrm{~m} / \mathrm{s}$, to limit coolant cavitation, pipe erosion, and pipe vibration. The primary hot leg piping (i.e., reactor to IHX) is Type $316 \mathrm{H}$ stainless steel. The cold leg piping (i.e., IHX to reactor) and components are Type $304 \mathrm{H}$ stainless steel.

Equipment and piping containing primary sodium are installed inside steel-lined shielded cells that contain inert gas (nitrogen) during normal reactor operations.

Each primary pump (Figure A-101) is a vertical, single-stage, single-suction, controlled inlet, free surface centrifugal pump located in the primary hot leg piping. The suction nozzle is $78.1 \mathrm{~cm}$ in diameter, the discharge nozzle $40.6 \mathrm{~cm}$ in diameter.
The pump is driven by a $2,400-\mathrm{V}$ ac-wound rotor induction motor. The motor is hand-controlled by a liquid rheostat variable speed control. An auxiliary $480-\mathrm{V}$ ac pony motor on each primary pump performs low-flow decay heat removal at low power and standby conditions. The pony motors are driven by the FFTF emergency generators if normal power fails.

Typical primary coolant pump design features are as follows:

- A design flow of $915 \mathrm{~L} / \mathrm{s}$ of sodium at $1.24 \mathrm{MPa}$ and $566^{\circ} \mathrm{C}$

- A variable speed ratio of $2.3: 1$, which provides flow control over a range of about 50 to $100 \%$ of design flow

- A stable head capacity curve between flows of $26.5 \mathrm{~m}^{3} / \mathrm{min}$ and $68.1 \mathrm{~m}^{3} / \mathrm{min}$ at design speed, with drawdown of $1.5 \mathrm{~m}$ or less at design flow 


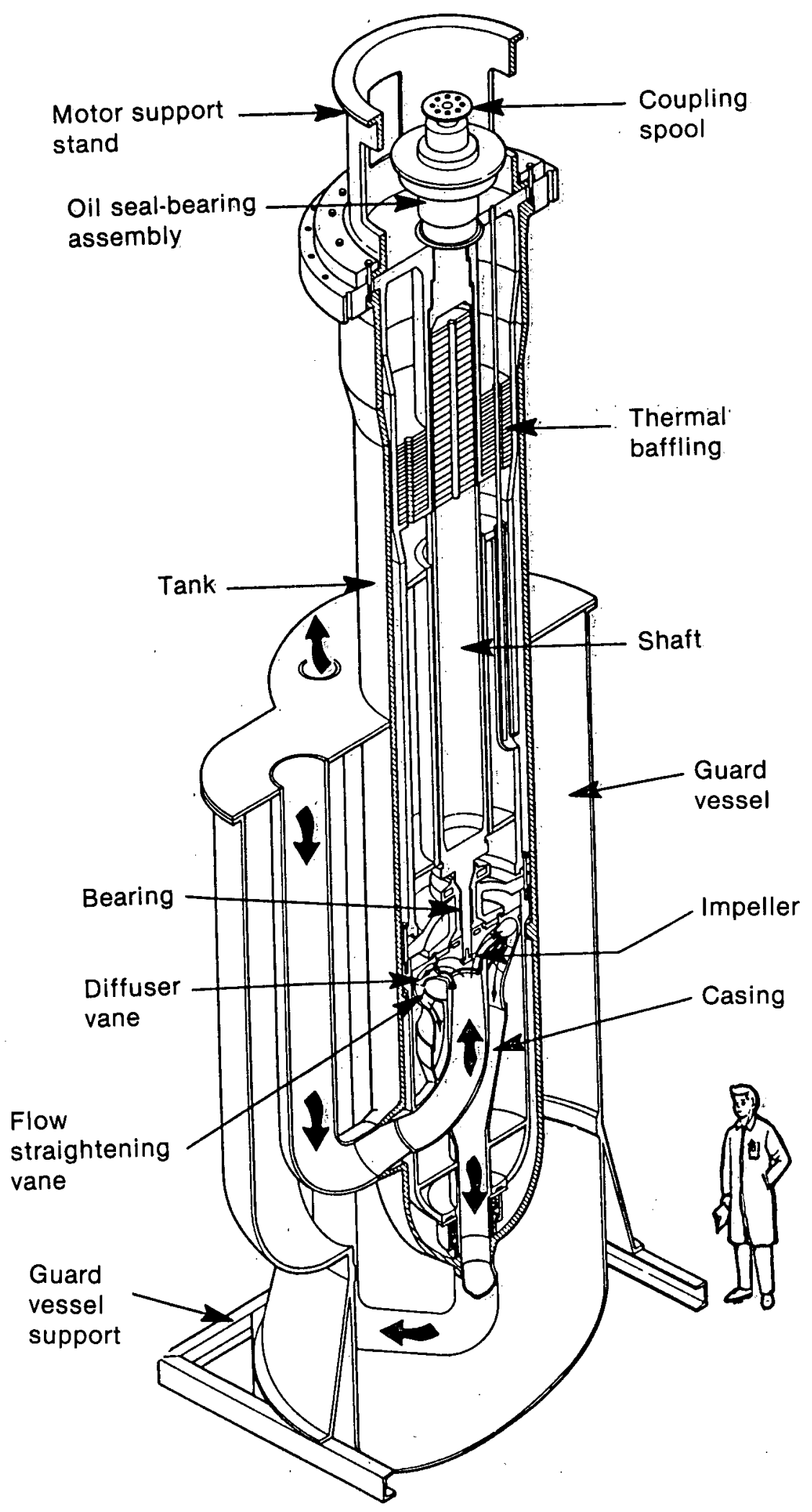

Figure A-101. Heat transfer system primary pump with guard vessel. 
- A seal system to prevent escape of radioactive argon from the primary system, or inflow of Iubricants or fluids to the pump

- Optimized coastdown characteristics to minimize thermal transients and to provide adequate reactor core cooling after a scram

- $\quad$ Pony motor drive to provide about $7.5 \%$ of design flow at $9.9 \mathrm{kPa}$ with automatic takeover from main motor to pony motor during coast down, preventing any flow interruption

- Completely drainable system.

Each HTS pump has a lubrication circulation system to carry away heat generated by frictional losses in the seals and bearings.

The IHX (Figure A-102) is a vertical counterflow design. It transfers reactor heat from the primary loop to the secondary loop. This is achieved via the primary flow outside the tubes and secondary flow inside the tubes.

Primary sodium enters the IHX below the top of the upper tube sheet and is directed around the tube bundles down along the outside of the tubes. A small percentage of flow (about 1\%) is continuously returned to the primary pump tank through a $5.1-\mathrm{cm}$ orificed line. As a result of this return, gas collection in the upper regions of the primary (shell) side of the IHX is prevented. The primary sodium leaves the bundle area just above the bottom tube sheet. It then flows into the annulus between the shell and bottom plenum and out the nozzle in the shell hemisphere.

Secondary sodium enters the top of the unit, flows down through the central downcomer into the lower hemispherical plenum, and up through the inside of the tubes into the upper plenum area. The secondary flow then leaves the IHX through the horizontal outlet nozzle.

One IHX is located in each of the three HTS circuits downstream of the primary pump and ahead of the check valve.

To meet the system operating requirements, typical design features in the IHX are as follows:
- Design pressure of $1.65 \mathrm{MPa}$ on the primary side and $1.82 \mathrm{MPa}$ on the secondary side

- Maximum pressure of $70 \mathrm{kPa}$ on the primary side and $100 \mathrm{kPa}$ on the secondary side at design flow rate

- Effective tube length geometric center of at least $4.6 \mathrm{~m}$ above the reactor core geometric center, ensuring adequate thermal driving head for natural convection cooling

The three secondary loops, shown in Figure A-103, circulate nonradioactive sodium coolant to tiansport heat from the tube side of the IHX to the air-cooled dump heat exchangers (DHX). No direct sodium interconnection exists among the loops.

Heated secondary sodium leaving the IHX flows to the air-cooled DHX through 40.6-cm-diameter piping via a containment penetration. Near the DHX, the piping branches and reduces to $20.3 \mathrm{~cm}$ diameter and connects to a 20.3-cm-diameter hot leg DHX isolation valve. From this valve, the pipe connects to an inlet header of an individual DHX module (of which there are four to each secondary loop, 12 total for the heat transport system).

Cooled sodium from the outlet of each module flows through a $20-\mathrm{cm}$-diameter cold leg DHX isolation valve; the piping then expands from 20 to $40 \mathrm{~cm}$. Finally, it connects to the 71.1-cm-diameter suction line of the secondary pump. From the pump discharge, the sodium piping enters the HTS cell through a penetration in the reactor containment building and connects to the IHX. At that point, the flow path is completed. Sodium flow rate is measured by a permanent-magnetic flowmeter located downstream of the pump discharge. The flow rate is adjustable by a variable speed pump drive. A Venturi flowmeter, located upstream of the secondary pump, is used for flow calibration of a secondary-loop permanent-magnetic flowmeter.

The 40.6-cm-diameter secondary hot leg piping and the section of $71.1 \mathrm{~cm}$ cold leg piping at the inlet to the secondary pump are of Type $316 \mathrm{H}$ stainless steel. The $40.6-\mathrm{cm}$ cold leg and the $20-\mathrm{cm}$ piping and components are of Type $304 \mathrm{H}$ stainless steel.

The secondary piping loops are designed for a pressure of $1.72 \mathrm{MPa}$ throughout. This design 


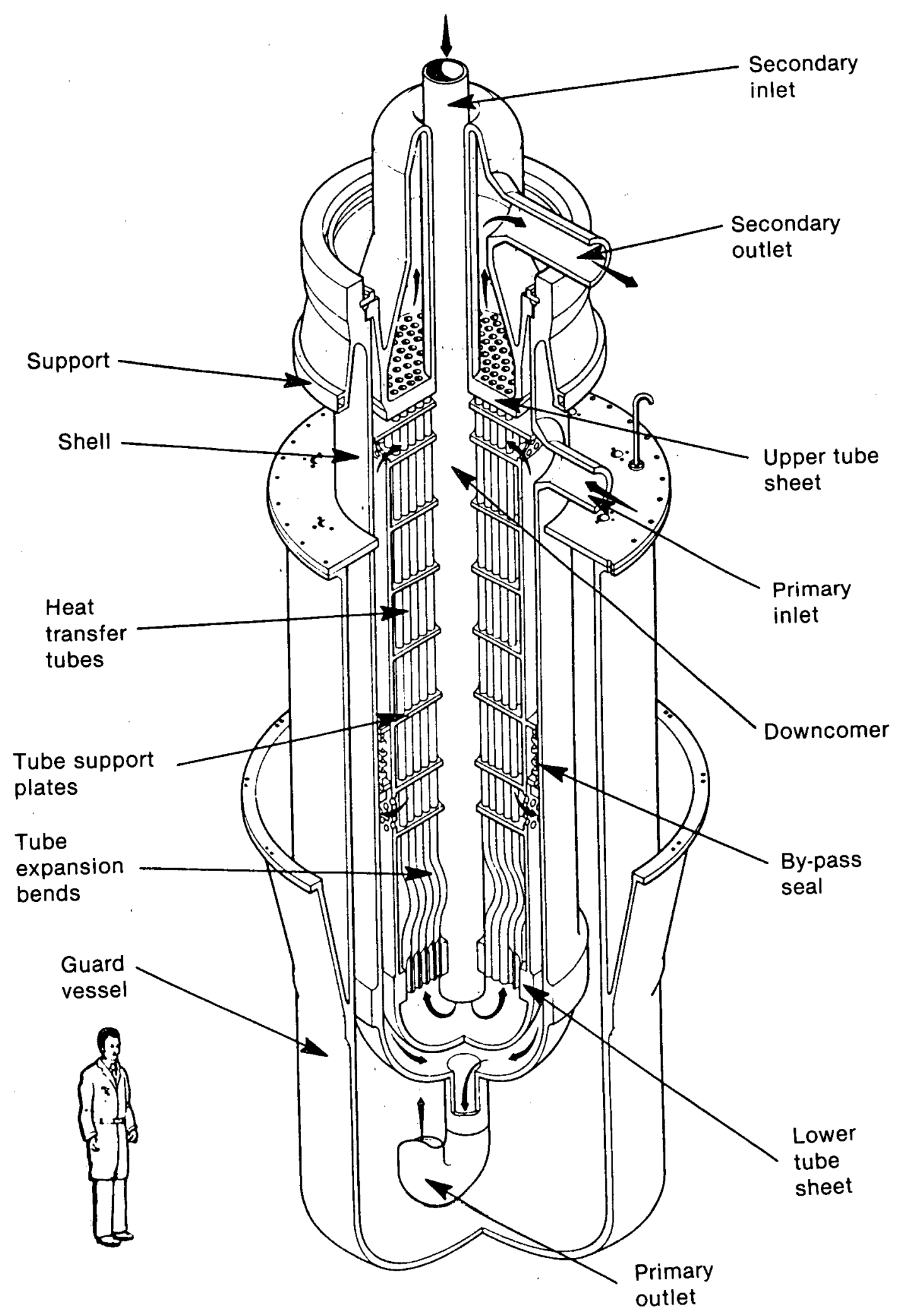

Figure A-102. HTS intermediate heat exchanger and guard vessel. 


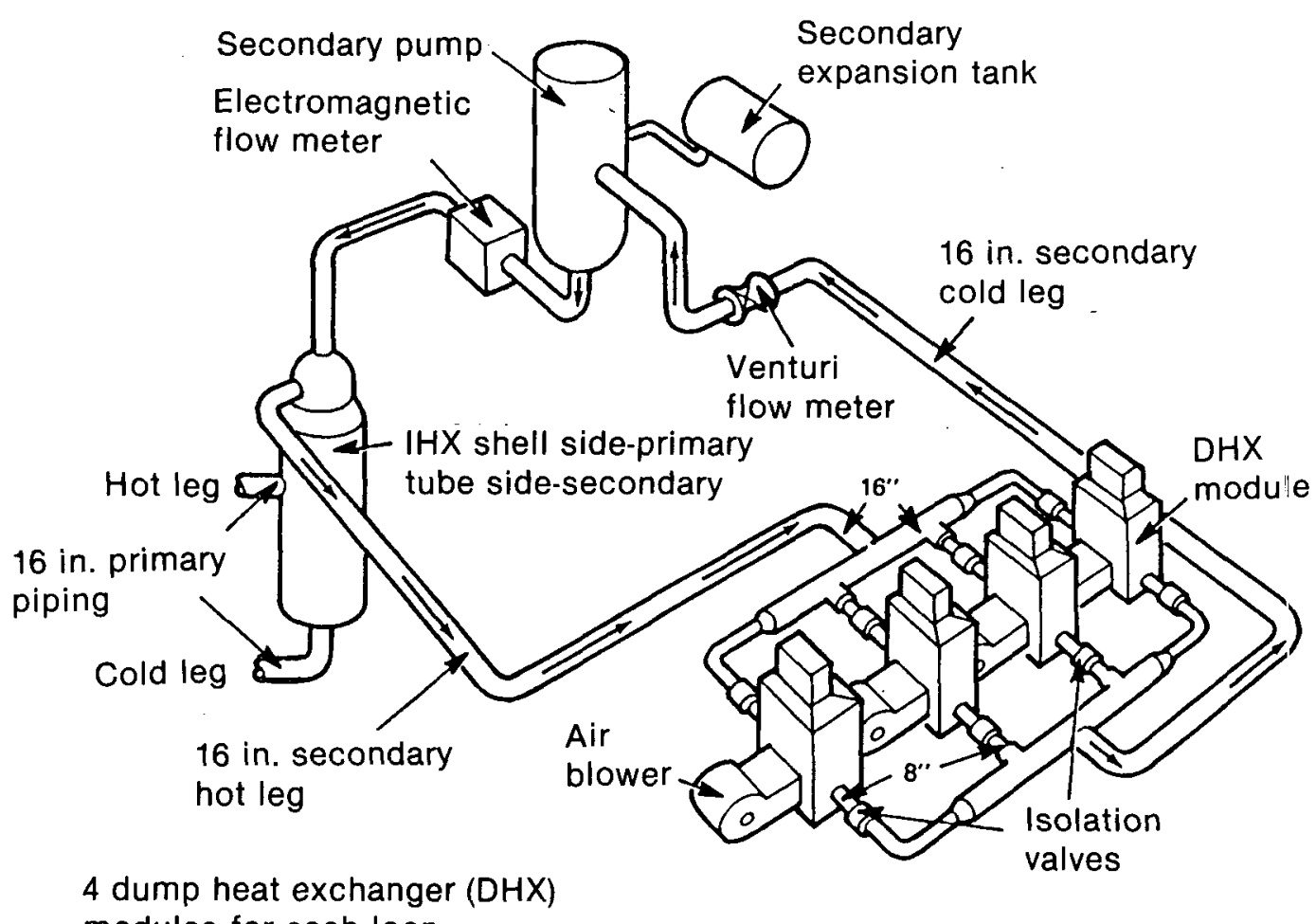
modules for each loop

Figure A-103. HTS secondary loop schematic.

pressure allows the secondary loop to operate at a high pressure in the IHX, so that if a leak occurs in the IHX tubing, the leakage would be from nonradioactive sodium of the secondary loop into the primary loop.

An expansion tank having a surge volume filled with argon gas is provided in each secondary loop to accommodate sodium thermal expansion and to pressurize the system. Secondary loop sodium pressure at the intermediate heat exchangers is always maintained above the primary loop pressure.

Each secondary sodium cooling pump is a vertical, single-stage, single-suction, controlled inlet, free surface centrifugal pump (Figure A-104). Its design is similar to that of the primary pump, except that the secondary pump has a shorter, smaller shaft and a slightly smaller impellor. Similar main motors and pony motors are used. The second pump is located in the secondary cold leg piping between the DHX and the IHX.

The secondary sodium pump is designed for $915 \mathrm{~L} / \mathrm{s}$ sodium flow at $440^{\circ} \mathrm{C}$ in $1 \mathrm{MPa}$. It is designed for a variable speed ratio of 2.3:1 which provides flow control over a range of about 50 to
$100 \%$ of design flow and accommodates a sodium level change of $0.91 \mathrm{~m}$ caused by secondary loop sodium volume change. The pony motor drive provides $10 \%$ of design flow at $0.91-\mathrm{m}$ head, with automatic takeover from main to pony motor during coastdown to give uninterrupted flow.

DHXs are sodium-to-air exchangers that transfer heat from the secondary loop sodium to the ambient air (Figure A-105). One DHX unit of four modules is located in each of the three secondary loops. Each DHX module is equipped with a fan having variable inlet vans, fan-drive motor, fine and coarse control dampers, isolation gates, manual and automatic controls, tube-bundle, oil-fired preheaters, ducting, stack, and airflow turning vents. The nominal thermal rating of the DHX module is $33 \mathrm{MW}$ at $32^{\circ} \mathrm{C}$ inlet air.

The DHX tube-bundle is made up of a bank of 66 four-pass serpentive tubes located between horizontal upper and lower headers. The four-pass serpentine tubes consist of thinner sections $9.1 \mathrm{~m}$ long joined by bare U-2 return vents. Suitable baffling at the side and ends minimizes bypass of air. Turning vans are provided to ensure uniform airflow over the tube-bundles. 


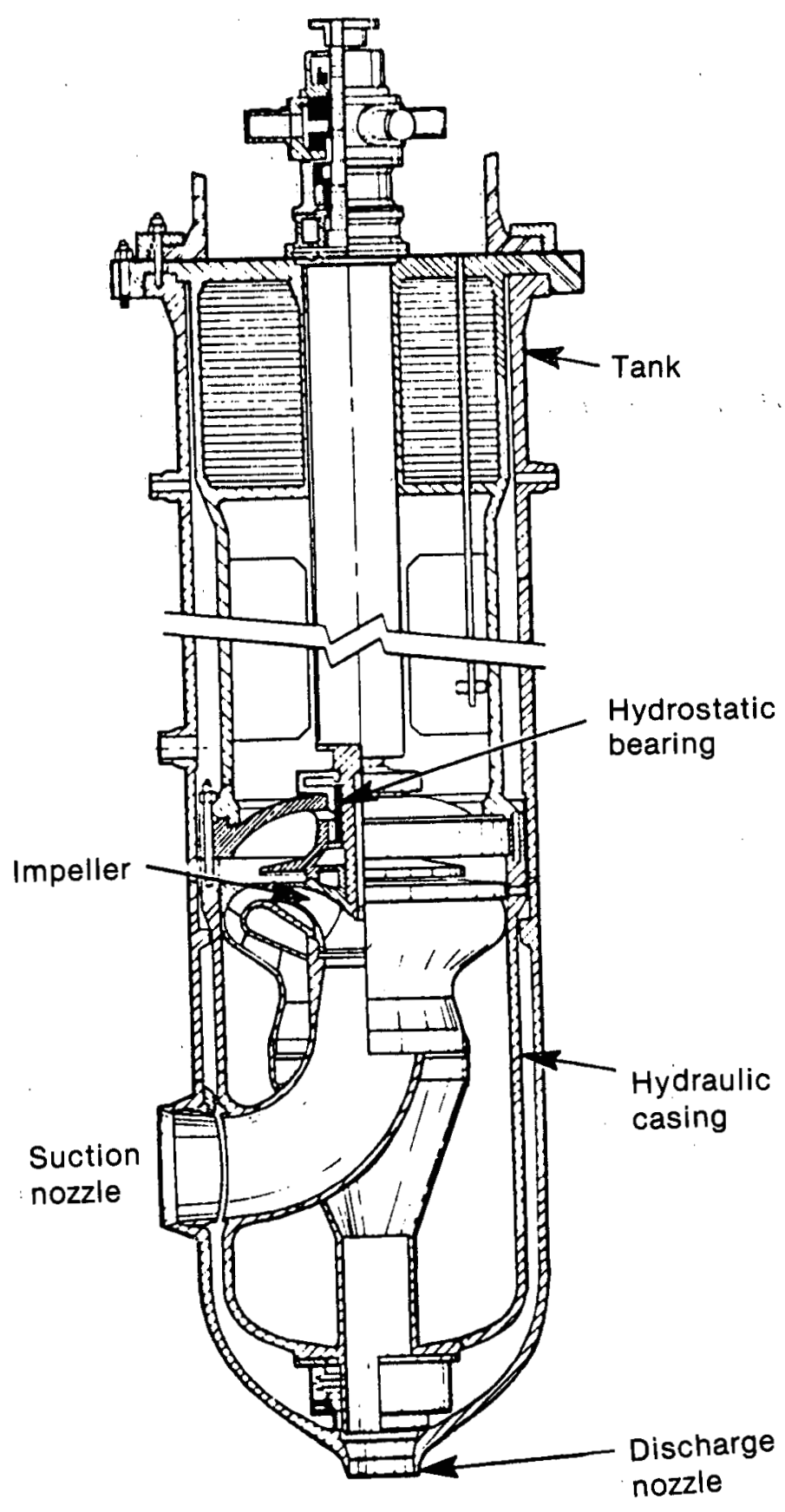

Figure A-104. HTS secondary pump. 


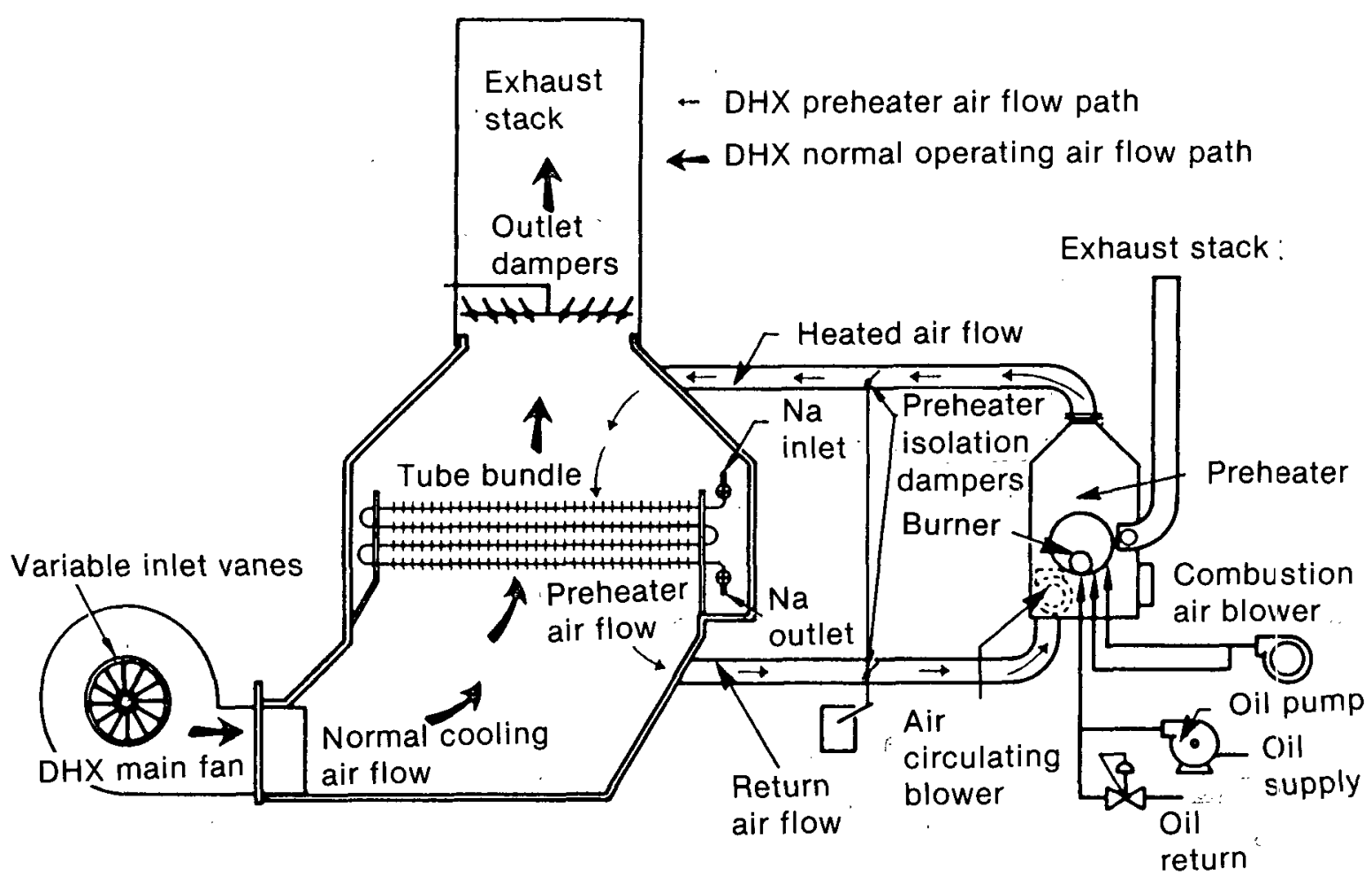

Figure A-105. HTS DHX Air flow diagram.

The air supply system has a double-width double-inlet centrifugal fan with airflow control provided by a variable speed coupling (to vary van speed) and by variable inlet guide vans. The fan is driven by a 1,250 -hp electric motor It provides airflow of $280 \mathrm{~kg} / \mathrm{s}$ with air side pressure drops of $2.75 \mathrm{kPa}$ of water. Other design features incorporated into the DHX to meet the system operating requirements include the following:

- DHX tube-bundle geometric center $9.1 \mathrm{~m}$ above the IHX geometric center to ensure adequate thermal driving head for natural convection cooling, if required

- Sufficient natural air draft through the tube bundle to dissipate a minimum of $10 \%$ of design power

- Instrumentation to detect any sodium leakage.

Each DHX bundle is preheated through a circulation system with air heated by an oil-fired burner. These heaters establish or maintain a temperature of $200^{\circ} \mathrm{C}$ during standby when sufficient decay or pump heat is not available.

\section{Structural and Shie/ding Components}

Containment-The reactor containment system consists of a cylindrical carbon steel reactor containment vessel $56.9 \mathrm{~m}$ high by $41.2 \mathrm{~m}$ in diameter. Also included are several principal structures and equipment pieces within the vessel. Steellined reinforced concrete cells occupy the lower portion of the containment vessel from grade level to approximately $78 \mathrm{ft}$ below grade.

In the operating area, a shielded operating floor is located at grade level.

Cells and Pipeways-Below the operating floor are the cells and pipeways (Figures A-106 and A-107). These internal structures are made of reinforced concrete. Cells and pipeways thar house piping and/or equipment containing primary system sodium are provided with an inert nitrogen gas atmosphere. Steel liners contain the inert atmosphere and protect the concrete from exposure to sodium in case of a spill. Cells containing large quantities of sodium are designed with liners backed with insulating brick.

The reactor cavity, located in the center of the containment vessel, houses the reactor vessel, the 


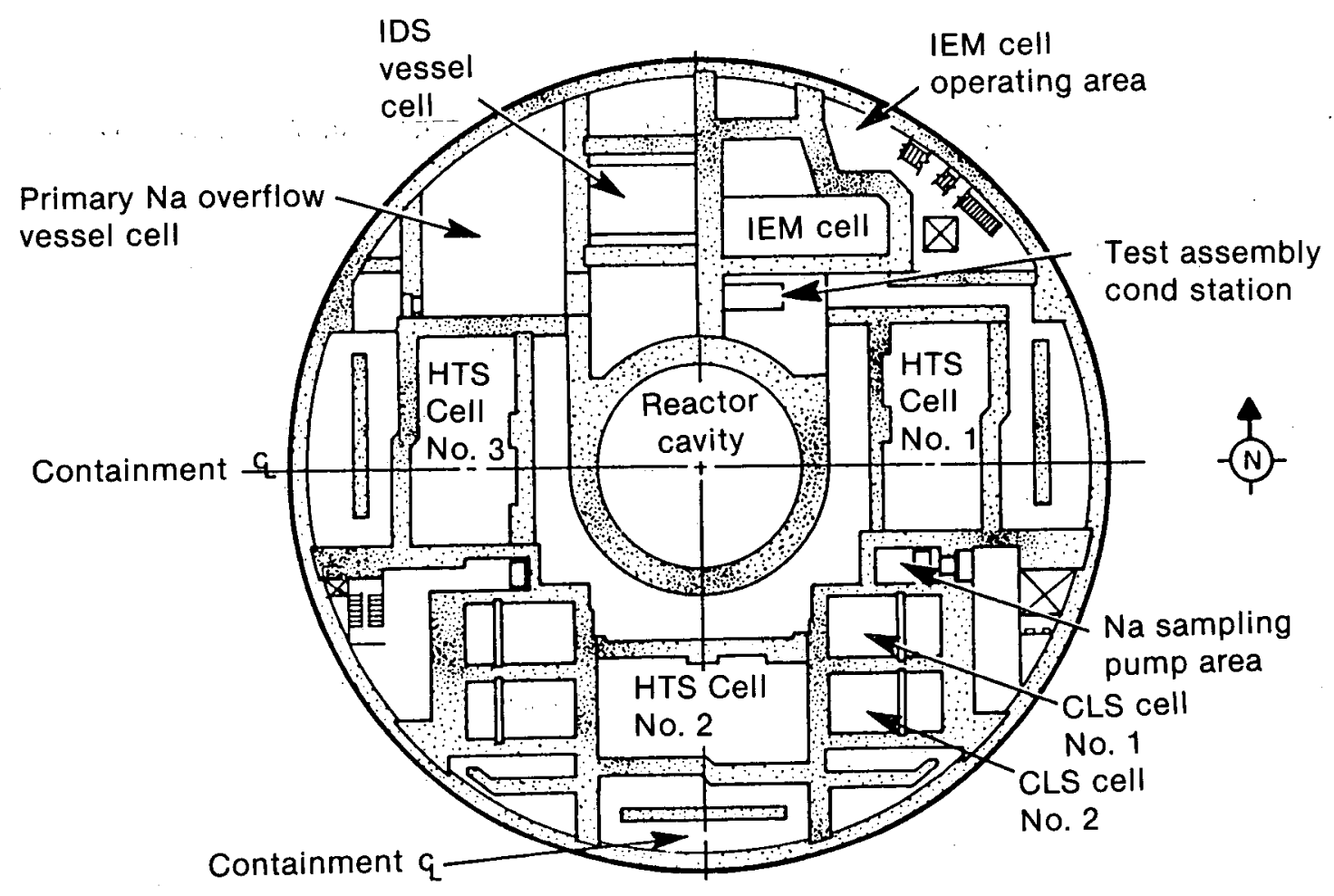

Figure A-106. Typical plan of internal structures within the containment vessel.

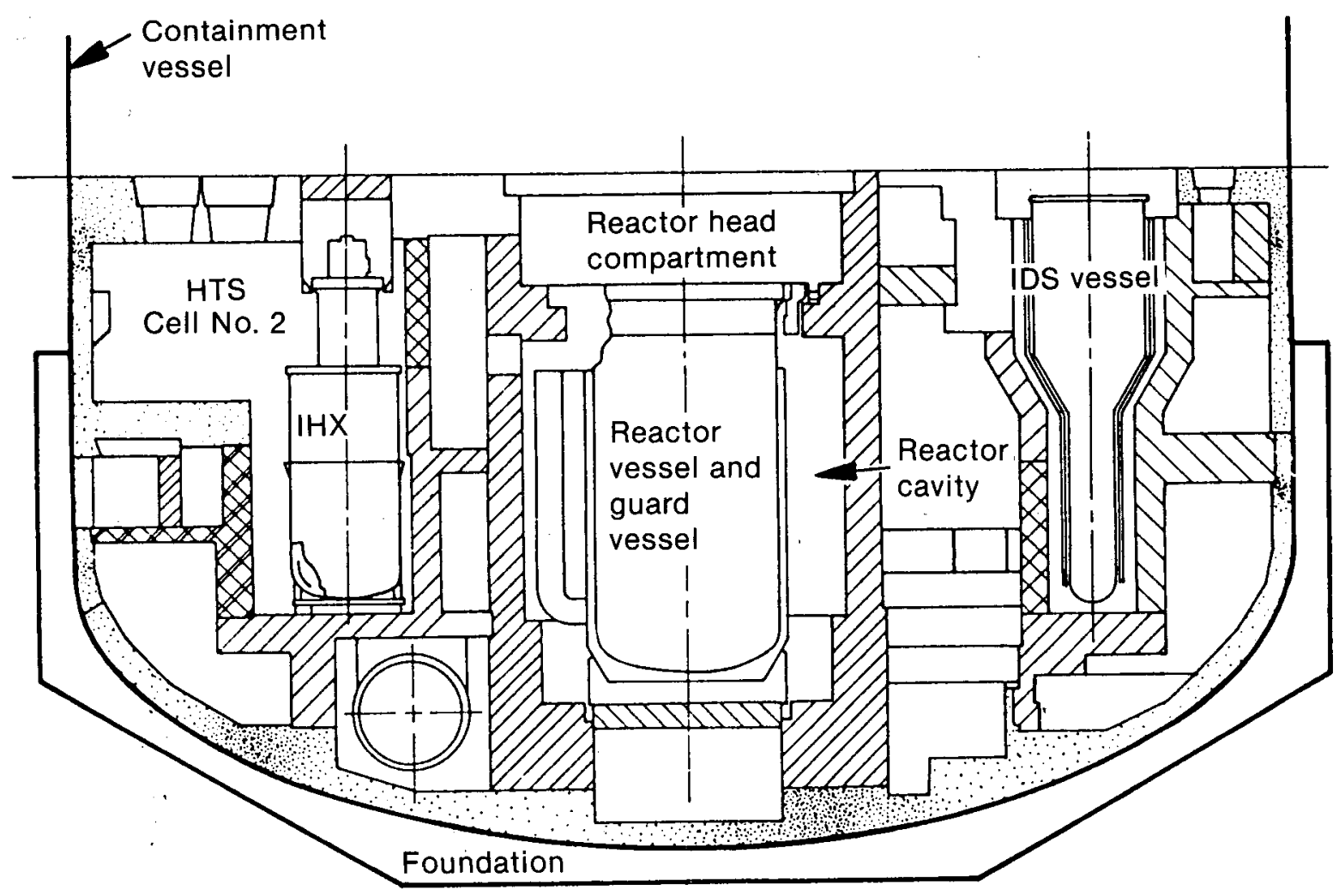

Figure A-107. Typical cross section of internal structures within the containment vessel. 
guard vessel, the main reactor support structure, associated shielding, and reactor piping. The cavity is insulated and temperature controlled to maintain allowable temperatures for concrete. Three HTS cells are adjacent to the reactor cavity on the east, south, and west sides. These three cells house the primary sodium pump and intermediate heat exchangers as well as associated equipment, piping and instrumentation for each of the three primary heat transport system loops.

Four closed loop systems (CLS) cells and associated pipeways are located between the east and south HTS cells and between the west and south HTS cells. The CLS cells are designed to contain pumps, heat exchangers, piping, equipment, and instrumentation associated with the CLS primary removal systems.

The northwest quadrant of the containment, below the operating floor, is the location for the interim decay storage (IDS) vessel cell. Also found in this area are cells for the auxiliary liquid metal system equipment, piping, and valves.

Cell access closure consists of shielding access plugs, rolling shield plugs and steel shielding doors, and soft shielding plugs or shielding blocks, as applicable.

Shielding access plugs are steel-lined (sides and bottom), tapered, and stepped concrete plugs that fit into an embedded steel frame in cell or pipeway ceilings. These plugs are equipped with seals to contain the inert cell atmosphere.

Rolling shield plugs are steel lined, tapered, and stepped concrete plugs mounted on wheels that roll on tracks in the floor. Cells utilizing rolling plugs have bulkhead type, gas tight doors behind the plugs to contain the inert cell atmosphere.

Soft shielding plugs are made of concrete cast into a steel plug frame in a cell wall. The soft plug is removed by breaking up the concrete mechanically and is replaced by casting new concrete in place. The cell liner is continuous and must be cut out to secure cell entry. Soft plugs provide for future access to areas that have no present requirements for maintenance access.

An equipment air lock and two personnel air locks are provided for access. Each lock has two doors in series. Each door is equipped with redundant seals and a pressure equalization valve. Inter- locks are provided so that neither a door nor its equalizing valve can be opened unless the other door is locked and sealed. Also, a welded construction hard patch on the containment vessel can be cut open if needed.

The equipment air lock is used for all transfers of fuel into and out of containment. It will also be used for transfer of large equipment if it is needed for maintenance.

The equipment air lock is approximately $7.6 \mathrm{~m}$ in diameter with doors at opposite ends, each with a clear opening $3.4 \mathrm{~m}$ wide by $5.1 \mathrm{~m}$ high. An emergency escape hatch in the air lock provides an opening $61 \mathrm{~cm}$ in diameter. This air lock extends into the reactor service building.

The personnel air lock is $3.05 \mathrm{~m}$ in diameter and $3.66 \mathrm{~m}$ long, with doors $2.03 \mathrm{~m}$ high and $1.07 \mathrm{~m}$ wide. This air lock extends into the Auxiliary Equipment Building East in an area converient to the control room.

The emergency air lock is $1.83 \mathrm{~m}$ in diameter and $3.66 \mathrm{~m}$ long doors $0.62 \mathrm{~m}$ in diameter. This air lock extends into the HTS Service Building West, below grade level.

Operating History-FFTF initiated its first operating cycle April 16, 1982. Full power, steady state operation began April 23 following a planned $36 \mathrm{~h}$ hold at $92 \%$ power to allow restructuring of new fuel in the core. On May 14, a small fission gas leak was detected and subsequent analysis identified the faulty element. After $30 \mathrm{~d}$ of continuous operation, the plant was automatically shut down due to an inadvertent valve operation during routine maintenance. During the shutdown period after the scram and during a routine start of primary sodium pump, P-1, a flashover occurred in the brush/slip ring of the pump motor. The resulting pump overspeed and flow imbalance among the three primary coolant loops forced the sodium into the shaft annulus. This contributed to the shaft binding on the primary sodium pump, P-3. The upper portion of the pump was disassembled, revealing a reduced shaft clearance in the pump baffle area. The reduced clearance was attributed to sodium residue in this area. The residue came from an unplanned transient caused by a high sodium level in the pump tank. The pump was freed by heating the shield plug and pump tank. After reassembly, vibration and coast down measurements were taken to verify no additional problems existed. 
On August 26, the FFTF returned to power operation to complete the first operational cycle, Cycle 1. During the startup some DHX fan speed control problems occurred resulting in an isolation of a DHX module. A shutdown was conducted to return the DHX module to service. After returning to power, a reactor scram occurred during a routine calibration of the primary system flowmeters. On September 12 , the reactor obtained $100 \%$ power and remained at full power until November. In November, a special shutdown evolution was conducted to investigate the phenomena of the reactor's pressure drop. On November 11, 1982, after 53 consecutive days at full power, the FFTF's first operating cycle was completed with a planned reactor shutdown.

During the early part of Cycle 1 , the pressure drop around the primary system began to increase slowly. This increase continued throughout the operating portion of the cycle. An engineering and operations effort was expended evaluating and testing this anomaly. No cause has yet been identified, and investigation will continue into Cycle 2. A-133

On May 13, the cover gas monitoring system detected a small burst of fission gas released to the cover gas volume. This initial signal was not large enough to trip the fission gas high alarm; a cover gas sample taken later in the day was found not to contain any detectable fission gases. The next day, at approximately $1800 \mathrm{~h}$, a much larger burst of fission gas was observed; this event was large enough to trip the fission gas high alarm, and follow-up action was taken. Plant operators took three cover gas samples, and the failed element location team (FELT) was notified. FELT was composed of members from physics and irradiation testing, chemistry and analysis, nuclear analysis, core evaluation, and FFTF plant operations. The FELT was responsible for coordinating leakerlocating activities. Another of its responsibilities was making recommendations to the FFTF plant manager regarding identification of the leaking subassembly and follow-up actions. Cover gas samples taken on May 14 failed to give a definitive indication of tag gas or fission gas from the leaking pin.

On May 15, a third and still larger burst of fission gas was observed beginning at about $300 \mathrm{~h}$. This burst was approximately three times larger than the May 14 event. A cover gas sample was taken and analyzed; the amount of detectable tag in this sample was only one-tenth of the amount considered necessary to make a tag identification. By supplementing the standard tag isotopic ratios with fission product ratios and by using a novel probabilistic treatment, a tentative location of the leaking test pin was made.

Fission gases continued to be released from the leaking pin. But amounts were too small to make a positive tag identification until May 21 at approximately $1500 \mathrm{~h}$, when another large spike of fission gas was released. This gas release occurred about $1 \mathrm{~h}$ after reactor power was reduced to $98 \%$ because of high ambient temperature. This time, tag gas concentrations were large enough to make an absolute determination of the tag; tag $\mathrm{T}-12$ was confirmed in two successive cover gas samples. Upon making an identification, FELT drafted a statement of results and recommendations to present to the plant manager. In addition to identifying the test assembly as containing the leaking pin, FELT recommended some supplementary surveillance activities to be performed while operating with a known leaker in a core.

Plant operations continued until $1320 \mathrm{~h}$ on May 24, when the pump controller failure scrammed the plant. Concurrent with the scram, an extremely large burst of fission gas (roughly 25 times greater xenon-133 activity than the May 21 burst) was observed. Analysis of cover gas samples taken at this time showed only tag T-12 was present; this confirmed the AB-1 test assembly contained the leaker. During the shutdown, the AB-1 test, which contained the leaking fuel pin, was replaced by a driver fuel assembly. (Reference A-134 describes the event in detail).

During Cycle 1 a total of $9.69 \mathrm{~m}^{3}$ of solid radioactive waste with a total activity of $19.8 \mathrm{mCi}$ was transferred from FFTF for processing. The waste originated from the following activities:

- Interim examination and maintenance cell decontamination and maintenance

- Maintenance and storage facility decontamination and maintenance

- Sodium removal system maintenance

- Heat transport system south sampling and maintenance

- Miscellaneous maintenance in the plant

- Radioactive liquid waste sampling and load out station. 
Also transported were $8 \mathrm{~m}^{3}$ of liquid waste with a total activity of $1.76 \mathrm{nCi}$. This liquid was generated from maintenance activities on the sodium removal station in the reactor service building.

General area radiation levels during Cycle 1 were very low with dose rates measured in routinely occupied areas less than $0.2 \mathrm{mrem} / \mathrm{h}$. The few exceptions to the design levels involved low level, small area streaming through shield penetrations. For example, the maximum shield contact rating was $8 \mathrm{mrem} / \mathrm{h}$ on a shield located about $3 \mathrm{~m}$ above lower level. Other streaming locations were equally inaccessible or in areas with extremely low occupancy.

Routine radiation survey data are summarized in Table A-11. The values presented were extracted from weekly routine survey reports. These values do not reflect special situations such as entry into cells containing primary sodium and maintenance on radioactive systems. Special radiation surveys were performed for these operations, and the data are discussed below. Routine radiation contamination surveys were also conducted. No contamination was detected in the routinely occupied areas. Local contamination control areas were established for special tasks being performed under radiation work procedures.
Radiation surveys conducted in support of radiation work in the plant showed direct levels ranging from background to about $1 \mathrm{rem} / \mathrm{h}$. Contaraination levels ranged from background to about $60,000 \mathrm{dpm} /$ $\mathrm{dm}^{2}$. The $1 \mathrm{rem} / \mathrm{h}$ direct radiation was associated with primary sodium cover gas sampling evolutions. The radiation level was at contact with the gas tag sample trap prior to installation of the shipping cover. With the shipping cover in place, the contact radiation level was $80 \mathrm{mrem} / \mathrm{h}$, and personnel exposure during the sampling evolution was limited to about $5 \mathrm{mrem}$. The $60,000 \mathrm{dpm} / \mathrm{dm}^{2}$ contamination level was associated with fuel handling and was a direct reading on a sodium contaminated floor valve. Removable contamination on the floor valve was $5,000 \mathrm{dpm} / \mathrm{dm}^{2}$.

An entry into Cell 489 on July 8, 1982 showed general area radiation levels to be less than $0.5 \mathrm{mrem} / \mathrm{h}$. A maximum reading of $1 \mathrm{rnrem} / \mathrm{h}$ was obtained in contact with a pipe containing primary sodium.

An entry into Cell 490 on June 26, 1982 showed general area levels to be less than $1 \mathrm{mrem} / \mathrm{h}$. The maximum loose contamination level in Cell 490 was about $5,000 \mathrm{dpm} / \mathrm{dm}^{2}$. Radiation ard contamination levels associated with the interim examination and maintenance cell, the sodium removal

\section{Table A-11. Summary of routine radiation survey data during FFTF Cycle 1}

\begin{tabular}{|c|c|c|c|c|c|c|}
\hline \multirow{2}{*}{\multicolumn{2}{|c|}{ Location }} & \multicolumn{4}{|c|}{$\begin{array}{l}\text { Dose Rate } \\
(\mathrm{mrem} / \mathrm{h})\end{array}$} & \multirow[b]{2}{*}{ Comments } \\
\hline & & \multirow{2}{*}{$\begin{array}{c}\begin{array}{c}\text { General Area } \\
\text { Average }\end{array} \\
\text { During Cycle }\end{array}$} & \multirow{2}{*}{$\begin{array}{c}\begin{array}{c}\text { Maximum } \\
\text { Local During } \\
\text { Cycle }\end{array} \\
4\end{array}$} & \multirow{2}{*}{$\begin{array}{l}\text { Maximum } \\
\text { Local On } \\
10 / 30 / 82 \\
0.5\end{array}$} & \multirow{2}{*}{$\begin{array}{c}\begin{array}{c}\text { Dose Rate } \\
\text { Dependent } \\
\text { On Reactor } \\
\text { Power }\end{array} \\
\text { No }\end{array}$} & \\
\hline 1. & RSB, 500, Radioactive & & & & & $\begin{array}{l}4 \mathrm{mrem} / \mathrm{h} \text { due to temporary storage } \\
\text { of IEM Cell components. }\end{array}$ \\
\hline 2. & RSB, 550, General Area & 0.2 & 1 & 1 & No & $\begin{array}{l}1 \mathrm{mrem} / \mathrm{h} \text { due to floor valve } \\
\text { adapter. }\end{array}$ \\
\hline 3. & RSB, 520, Rm 204 & 0.2 & 0.2 & 0.2 & No & $\begin{array}{l}\text { Looking for potential leakage to } \\
\text { secondary chilled water from IEM } \\
\text { Cell Removal System. }\end{array}$ \\
\hline 4. & RSB, 520, General Area & 0.2 & 0.2 & 0.2 & No & $\begin{array}{l}\text { Local dose could be dependent on } \\
\text { cladding breach and release of } \\
\text { fission gasses. }\end{array}$ \\
\hline 5. & RSB, 543, General Area & 0.2 & 0.2 & 0.2 & No & Same comment as for 4 \\
\hline 6. & RSB, 533, General Area & 0.2 & 4 & 0.2 & No & $\begin{array}{l}4 \mathrm{mrem} / \mathrm{h} \text { due to small leak of }{ }^{41} \mathrm{Ar} \\
\text { from RAPS instrument line. }\end{array}$ \\
\hline
\end{tabular}




\begin{tabular}{|c|c|c|c|c|c|c|}
\hline \multirow{2}{*}{\multicolumn{2}{|c|}{ Location }} & \multicolumn{4}{|c|}{$\begin{array}{l}\text { Dose Rate } \\
\text { (mrem/h) }\end{array}$} & \multirow[b]{2}{*}{ Comments } \\
\hline & & $\begin{array}{l}\text { General Area } \\
\text { Average } \\
\text { During Cycle }\end{array}$ & $\begin{array}{c}\text { Maximum } \\
\text { Local During } \\
\text { Cycle } \\
\end{array}$ & $\begin{array}{l}\text { Maximum } \\
\text { Local On } \\
10 / 30 / 82 \\
\end{array}$ & $\begin{array}{c}\text { Dose Rate } \\
\text { Dependent } \\
\text { On Reactor } \\
\text { Power } \\
\end{array}$ & \\
\hline 7. & HTS-S, 550, General Area & 0.2 & 0.2 & 0.2 & No & $一$ \\
\hline 8. & HTS-S, Rooms $481,493, \& 482$ & 0.2 & 2 & 2 & Yes & $\begin{array}{l}2 \text { mrem } / \text { h due to valve stem } \\
\text { penetration (P-633) into Cell } 489 \text {, } \\
\text { reactor at } 100 \% \text { Source }{ }^{24} \mathrm{Na} \text {. }\end{array}$ \\
\hline 9. & HTS-S, 550, Room 485 & 0.2 & 3 & 2 & Yes & $\begin{array}{l}2 \text { and } 3 \mathrm{mrem} / \mathrm{h} \text { due to }{ }^{24} \mathrm{Na} \\
\text { radiation streaming around shield } \\
\text { plus to Cell } 492-\mathrm{E} \text {, reactor at } 100 \%\end{array}$ \\
\hline 10. & RCB, 580, Mezzanine & 0.2 & 3 & 1 & Yes & $\begin{array}{l}1 \text { and } 3 \mathrm{mrem} / \mathrm{h} \text { due to contact } \\
\text { measurement on low level flux } \\
\text { monitor cooling system. Source is } \\
\text { transported activation products and } \\
16_{\mathrm{N}} \text {. }\end{array}$ \\
\hline 11. & RCB, 550, General Area & 0.2 & 0.5 & 0.2 & No & $\begin{array}{l}\text { General area dose rates in RCB at } \\
\text { full power are not significantly } \\
\text { different from background. } 0.5 \\
\mathrm{mrem} / \mathrm{h} \text { in Primary Sodium Pump } \\
1 \mathrm{Pit} \text {. }\end{array}$ \\
\hline 12. & RCB, Head Compartment & 0.2 & 6 & 6 & No & $\begin{array}{l}6 \mathrm{mrem} / \mathrm{h} \text { due to depleted uranium } \\
\text { shielding in two small local areas. } \\
\text { General area } 0.2 \mathrm{mrem} / \mathrm{h} \text {. }\end{array}$ \\
\hline 13. & RCB, 520, Room 540 & 0.2 & 0.2 & 0.2 & No & - \\
\hline 14. & RCB, Stairway 517 (West) & 0.2 & 0.6 & 0.6 & Yes & - \\
\hline 15 . & RCB, 500, Room 564 & 0.2 & 0.5 & 0.5 & Yes & $\begin{array}{l}0.5 \mathrm{mrem} / \mathrm{h} \text { at locked barrier to } \\
\text { restricted access radiation zone. }\end{array}$ \\
\hline 16. & RCB, 520, Room 554B & 0.2 & 0.2 & 0.2 & No & - \\
\hline 17. & RCB, 500, Room 562 & 0.2 & 0.2 & 0.2 & No & - \\
\hline 18. & RCB, 500 , Room 570 & 0.2 & 9 & 9 & Yes & $\begin{array}{l}9 \mathrm{mrem} / \mathrm{h} \text { due to }{ }^{24} \mathrm{Na} \text { radiation } \\
\text { streaming around shield plug to } \\
\text { Cell } 567 \text { (EM pump cell), reactor at } \\
100 \% \text { power. }\end{array}$ \\
\hline 19. & RCB, 520, Room 553B & 0.2 & 0.2 & 0.2 & No & - \\
\hline 20. & $\mathrm{RCB}, 500$, Room 565 & 0.2 & 0.2 & 0.2 & No & - \\
\hline 21. & RCB, 520, Room 536B & 0.2 & 8 & 6 & Yes & $\begin{array}{l}8 \mathrm{mrem} / \mathrm{h} \text { due to }{ }^{24} \mathrm{Na} \text { radiation } \\
\text { streaming through penetration in a } \\
\text { small, localized area about } 10 \text { feet } \\
\text { above floor. }\end{array}$ \\
\hline 22. & RCB, 500, Rooms $561 \& 563$ & 0.2 & 0.5 & 0.5 & Yes & $\begin{array}{l}0.5 \mathrm{mrem} / \mathrm{h} \text { due to }{ }^{24} \mathrm{Na} \text { radiation } \\
\text { streaming around shield door to } \\
532 \mathrm{C} \text {. }\end{array}$ \\
\hline 23. & RCB, 520, Room 552B & 0.2 & 0.5 & 0.5 & Yes & $\begin{array}{l}0.5 \mathrm{mrem} / \mathrm{h} \text { at locked gate to } 552 \mathrm{~A} \text {, } \\
\text { source is } 24 \mathrm{Na} \text { radiation streaming } \\
\text { into } 552 \mathrm{~A} \text { from HTS-1 (521). }\end{array}$ \\
\hline
\end{tabular}


system, and the radioactive liquid waste system were low-less than $18 \mathrm{mrem} / \mathrm{h}$ and less than about $10,000 \mathrm{dpm} / \mathrm{dm}^{2}$ removable contamination.

Plant personnel radiation exposures were low, as shown in Table A-12. The values shown are within the statistical variation in the dosimetry system for very little doses and are at preoperational levels. The maximum individual dose for a quarter was 220 mrem and was associated with maintenance personnel working at another reactor facility. The highest exposure for personnel not associated with work at another reactor facility was less than 50 mrem for a quarter.

\section{Japan}

JoYo. The experimental fast breeder reactor, JOYO, is Japan's first experimental LMFBR. It is designed to serve as an irradiation test facility and to provide construction and operational experience for future LMFBRs. JOYO has been constructed on the site of the Oarai Engineering Center of PMC, located on the Pacific coast approximately 193 kilometers north of Tokyo.

The JOYO plant consists of four main buildings: reactor building, main cooler building, waste disposal building, and maintenance building. The reactor is located below ground in a containment vessel. In addition to the reactor itself, the reactor building contains the principal components of the primary cooling system, such as the intermediate heat exchanger and the primary sodium pumps. The main coolant building contains the secondary cooling system with the secondary sodium pumps and the air blast heat exchangers (see Figure A-108).

JOYO is fueled with a mixed oxide of plutonium and uranium. The reactor is a loop type and has two identical cooling circuits, each having a heat removal capacity of $50 \mathrm{MW}(\mathrm{t})$. Each circuit consists of a primary loop, intermediate heat exchanger, and secondary loop. The heat generated in the core is finally dissipated to the atmosphere through sodium to the airblast heat exchangers. Reactor power is controlled by two regulation rods and four safety rods.

Reactor Features - The reactor vessel is a stainless steel vessel with an inner diameter of $3.6 \mathrm{~m}$, a wall thickness of $25 \mathrm{~mm}$, and a height of approximately $10 \mathrm{~m}$ (Figure A-109). The vessel is doublewalled, and nitrogen gas fills the space between the two walls. The gas serves to warm the vessel when introducing liquid sodium into the vessel, as well as preventing fire by accidental sodium liakage through the inner wall. The lower part of the vessel has two inlet nozzles for sodium coolant. The upper part has two sodium outlet nozzles and some other smaller nozzles, such as those for an auxiliary cooling system, argon cover gas system, and an overflow system to maintain the sodium level in the vessel constant. A spent fuel storage rack is installed near the reactor core within the vessel. Outside the storage rack, there are steel irradiation shield plates to attenuate the radiation flux to the reactor vessel. Just inside the vessel, there is another rack on which to place the irradiated specimens of the vessel material for surveillance testing.

Table A-12. FFTF personnel exposure summary during Cycle 1 operations

\begin{tabular}{|c|c|c|c|c|c|c|}
\hline \multirow[b]{2}{*}{ Group } & \multicolumn{2}{|c|}{$\begin{array}{c}\text { 1st Quarter } \\
\text { CY-82 }\end{array}$} & \multicolumn{2}{|c|}{$\begin{array}{l}\text { 2nd Quarter } \\
\text { CY-82 }\end{array}$} & \multicolumn{2}{|c|}{$\begin{array}{c}\text { 3rd Quarter } \\
\text { CY-82 }\end{array}$} \\
\hline & $\begin{array}{c}\text { Number in } \\
\text { Average Group }\end{array}$ & $\begin{array}{l}\text { mrem/ } \\
\text { Person }\end{array}$ & $\begin{array}{c}\text { Number in } \\
\text { Average Group }\end{array}$ & $\begin{array}{l}\text { mrem/ } \\
\text { Person } \\
\end{array}$ & $\begin{array}{c}\text { Number in } \\
\text { Average Group }\end{array}$ & $\begin{array}{l}\text { mrem/ } \\
\text { Person }\end{array}$ \\
\hline Operations & 105 & 27 & 99 & 9 & 105 & 4 \\
\hline Maintenance & 143 & 16 & 138 & 16 & 134 & 2 \\
\hline IEM Cell & 22 & 4 & 23 & 4 & 33 & 1 \\
\hline Others & 65 & 16 & 61 & 7 & 97 & 6 \\
\hline
\end{tabular}



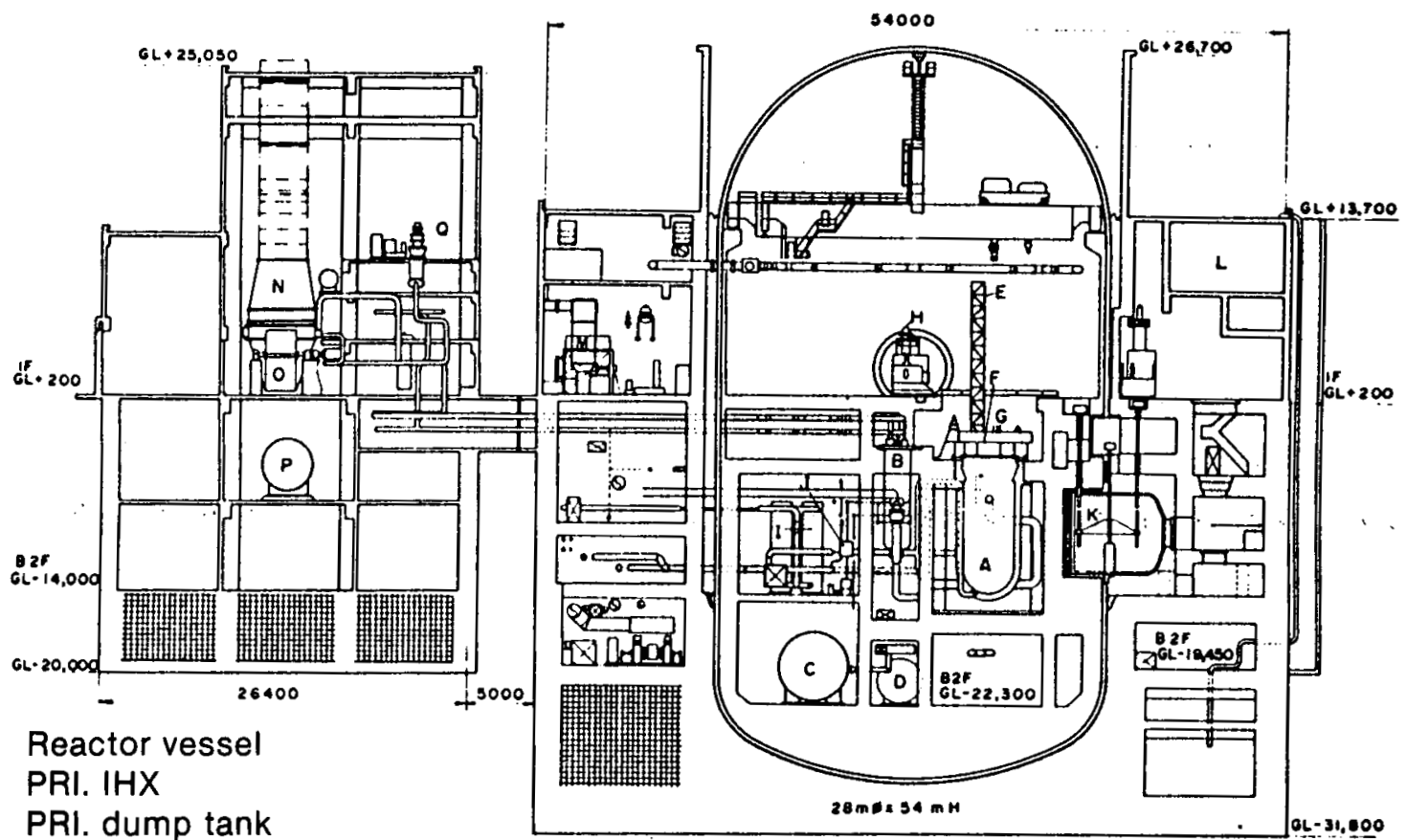
A. Reactor vessel
B. PRI. IHX
C. PRI. dump tank
D. PRI. overflow tank
E. Fuel handling machine
F. Large rotating plug
G. Control rod drives
$H$. Fuel charge/discharge machine
I. Cold trap
J. EM flowmeter
K. Transfer rotor
L. Main control room
M. AUX. air blast cooler
N. Main air blast cooler
O. Blower
P. SEC. dump tank
Q. SEC. main pump

Figure A-108. JOYO cutaway view.

Thermocouples are located above the reactor core for measuring coolant temperatures at each core fuel subassembly outlet. A double rotating plug serves as the lid of the reactor vessel. The function of the plug is to shield radiation emanating from the core and also to position various devices such as the refueling machine. The large plug has a diameter of approximately $4.7 \mathrm{~m}$ that can be rotated \pm 180 degrees. The small plug has a diameter of $2.9 \mathrm{~m}$ and rotates from 0 to 180 degrees. Both plugs have freeze metal seals to keep gas tightness during reactor operation. The plugs are designed for pressure and shock equivalent to an explosion of 50 kilograms of TNT. Total thickness of the plugs are $2.5 \mathrm{~m}$ and the upper part of each plug is cooled by nitrogen gas.

All control rod drive mechanisms are mounted on the small plug and extend down to the core region for driving the neutron absorbers. Refueling and inspecting inside the vessel are accomplished through holes in the small plug. Outside the reactor vessel, there is a graphite shield approximately $1 \mathrm{~m}$ thick. A steel safety vessel surrounds the graphite shield and the reactor vessel and will contain the reactor core under sodium coolant during any possible accident condition.

Core Arrangement-The reactor core consists of core fuels, blanket fuels, control rods, and a neutron source all made up of subassemblies $2.9 \mathrm{~cm}$ long of identical hexagonal cross sections. Integral type core fuel subassemblies are employed; the length of the core fuel zone is $60 \mathrm{~cm}$, and the length of the upper and lower blanket fuel zone are both $40 \mathrm{~cm}$. The core fuel subassembly contains 91 fuel pins, $6.3 \mathrm{~mm} \mathrm{OD}, 1.91 \mathrm{~m}$ long, separated from each other with a wrapping wire. The blanket subassembly contains 19 fuel pins, $15 \mathrm{~mm} O D$, and an effective link of $1.4 \mathrm{~m}$. The fuel pins contain fuel pellets of mixed plutonium and uranium dioxide, and the blanket pins contain fuel pellets of depleted uranium. The control rod subassembly (two regulation rods and four safety rods) contains a neutron 


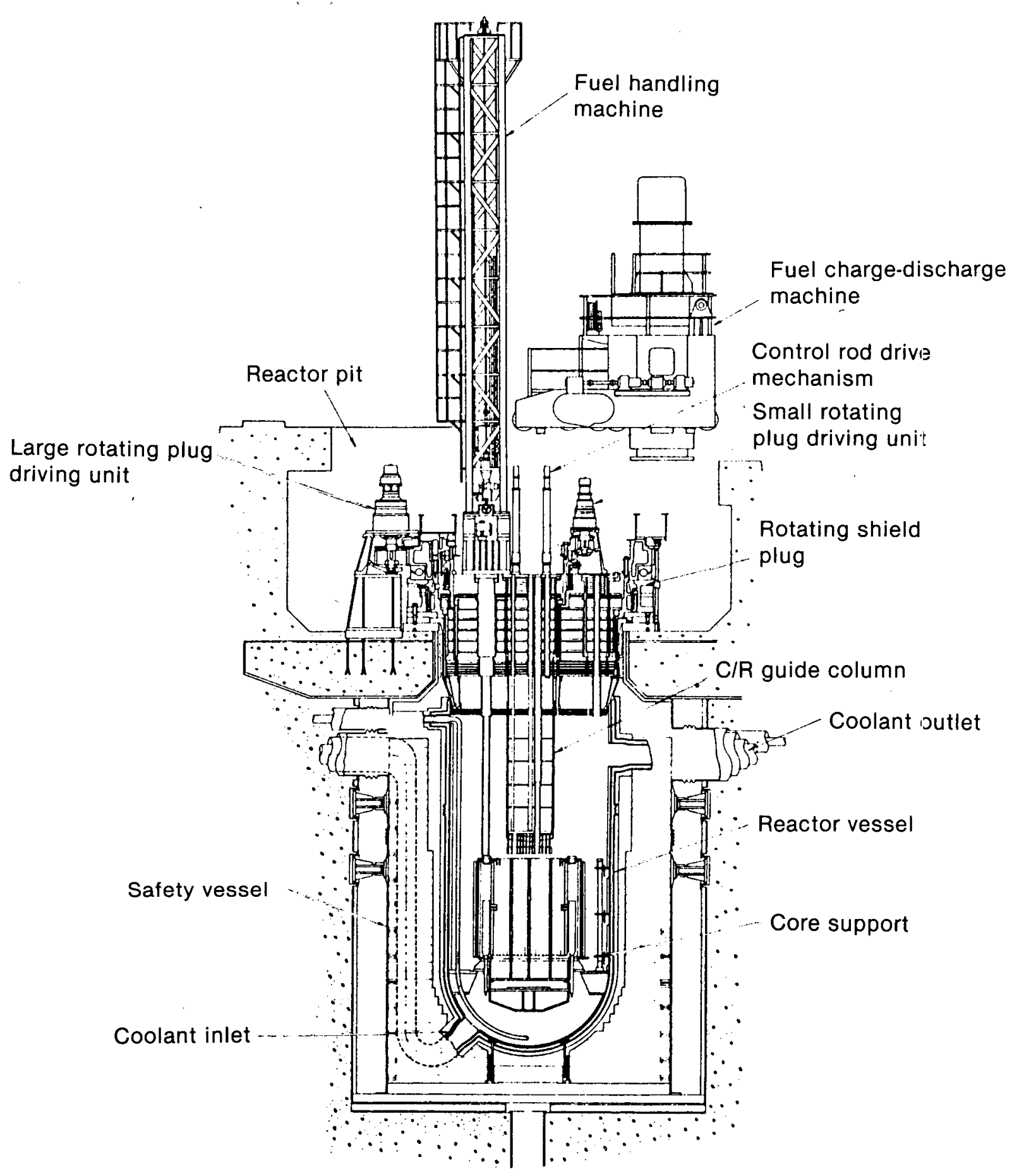

Figure A-109. Vertical cross section of reactor and core configuration of JOYO. 
absorber of boron carbide enriched $91 \%$ with boron. ${ }^{10}$ The neutron source subassembly is of antimony-beryllium and located in the radial blanket region. For proper neutron economy and shielding, reflectors are arranged in the outermost region of the core (Figure A-110).

Control System-JOYO's core is so designed that the reactivity coefficients from Doppler, sodium void, and thermal bowing effects are negative. The reactor power level is controlled manually by means of control rods.

The coolant temperature at the reactor inlet is automatically controlled so as to be constant regardless of the reactor power level. The heat balance in the plant system is regulated by the flow rate of the airblast heat exchangers.

The reactor protection system is designed to secure the safety and to prevent damage of the plant from malfunction or misoperation. According to the level of anomaly, two classes of protective actions can take place.

The most severe protective action taken to shut down the reactor is a scram. A scram is accomplished by the prompt insertion of the safety rods to prevent an excursion and prevent any damage to the facility. It is initiated by the detection of a high neutron flux level, short reactor power oscillations, low coolant flow in the primary loops, loss of power, an earthquake, or whenever the reactor containment isolation mode is automatically tripped. The containment isolation mode is initiated by the detection of high temperatures, high pressure, or high radiation levels in the reactor containment vessel. This is done to prevent the spread of high levels of radioactive contamination.

The next level of protective action is insertion of the control rods at normal speed to prevent a serious reactor condition. This action is initiated by high coolant temperatures, low coolant flow at the secondary loops, or a pump trip of the secondary loops.

Neutron detectors are installed to measure neutron flux and the reactor period over a dynamic range of 10 decades from source level to full power. This wide range is subdivided into three ranges: source range, intermediate range, and power range, which are monitored by two, three, and three detectors, respectively.

Fission detectors are used in the source and intermediate ranges and are embedded in a graphite neutron shield outside the reactor vessel. They can be

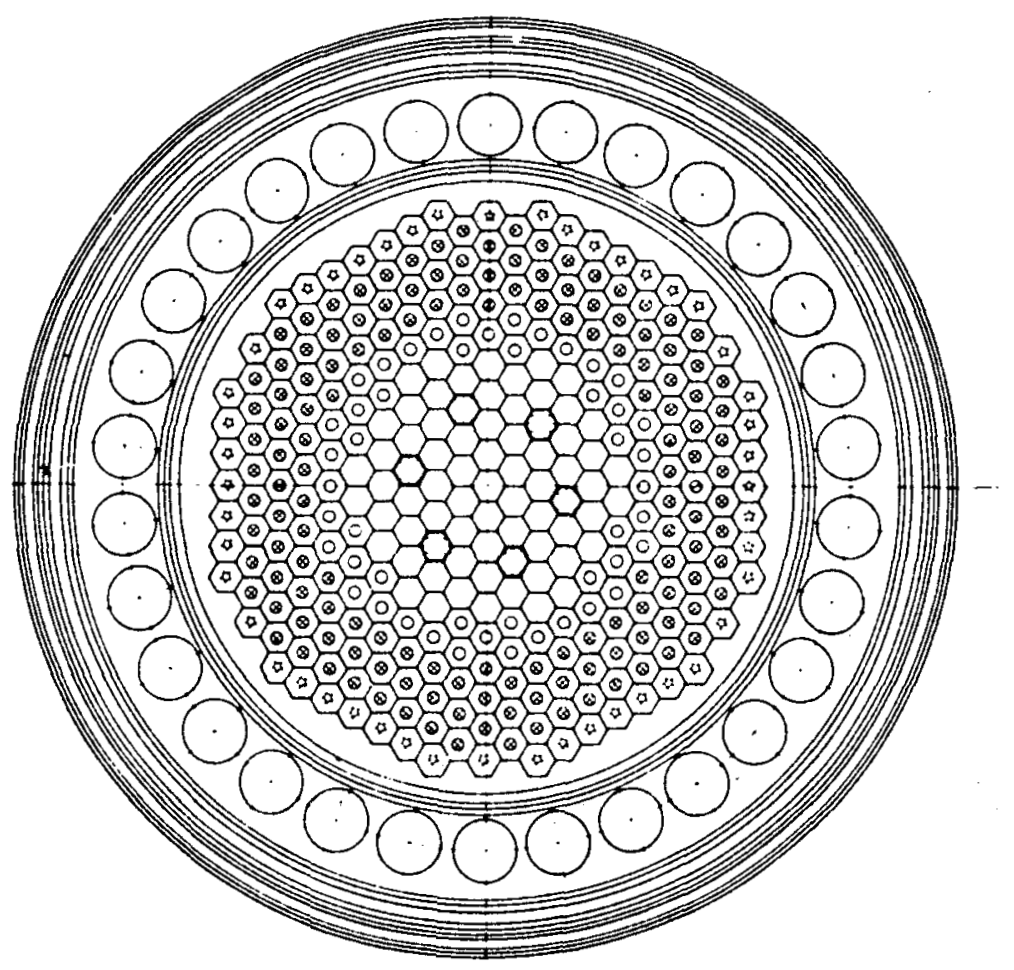

$\bigcirc$ Regulating rod

$\checkmark$ Safety rod

() Inner blanket subassembly

(•) Outer blanket subassembly

(9) Reflector

O Core fuel subassembly

Figure A-110. JOYO core diagram. 
pulled back to avoid unnecessary deterioration caused by neutron flux at the higher ranges. Compensated ion chambers are used in the power range and are installed outside the graphite shield.

Two different types of fuel failure detection instruments are used: delayed neutron detectors and precipitation detectors.

A neutron detector mounted in a graphite neutron shield near the coolant outlet nozzle of the reactor vessel is used to detect delayed neutrons emitted by iodine 137 and bromine 87 . The argon cover gas above the core is continuously sampled and sent to the precipitator to monitor the gaseous fission products.

The temperature of the coolant outlets of the subassemblies are measured to monitor the core behavior. Double junction thermocouples are installed above the core fuel assemblies for this purpose.

Heat Transport System-The main cooling system consists of two loops, each with a primary and secondary sodium circuit connected by an intermediate heat exchanger. Heat transport capabilities from the core by the loops is $100 \mathrm{MW}(\mathrm{t})$ and $50 \mathrm{MW}(\mathrm{t})$ by each loop at normal operating conditions. In both the primary and secondary circuit of a loop, the coolant flow is approximately 1100 tonnes $/ \mathrm{h}$. In the secondary circuit of each loop, there are two identical 25-MW forced air-cooled heat exchangers where the heat from the core is dissipated.

All piping and equipment in the primary circuit, except dump dip tanks, are made of stainless steel, and the main circuits are double-walled. Any leaking sodium from the inner wall should be retained in the space between it and the outer wall. Filling gas for the space is nitrogen and is used as preheating gas for the piping and equipment. The entire primary coolant can be drained into two dump tanks made of carbon steel. The overflow tank is made of stainless steel and has no leak jacket. There are no valves in the main primary piping, except a check valve installed at the inlet of the primary pumps.

All the piping and equipment in the secondary circuit, except the pumps and electromagnetic flowmeters, are made of ferritic steel. The main piping has no isolation valves. Therefore, a portion of the secondary circuit within the reactor containment vessel acts as part of the containment boundary. The four main pumps, all in cold legs of the cooling circuits, are mechanical type and use hydrostatic bearings of sodium.

The intermediate heat exchanger is shell and tube type, with a free surface of sodium. The primary coolant flow is on the shell side, and the secondary coolant flow is on the tube side. The pressure of the secondary coolant in the heat exchanger is higher than that of the primary coolant; therefore, there is little chance that radioactive primary sodium will leak into the nonradioactive secondary sodium. The inlet and outlet temperatures of secondary coolant at the heat exchanger are 355 and $420^{\circ} \mathrm{C}$, respectively. The reactor has an auxiliary cooling system having a heat removable capacity of 2.6 MW. The auxiliary cooling system is used to remove decay heat from the reactor core whenever the main cooling system is not operable. The auxiliary system also consists of a primary and a secondary circuit, with an intermediate heat exchanger and a forced air cooled heat exchanger. However, all pumps used in the system are the electromagnetic type.

Sodium coolant purification systems with cold traps are installed to remove impurities, especially sodium oxide. The system maintains the oxide impurity below $10 \mathrm{ppm}$ in the primary coolant and $20 \mathrm{ppm}$ in the secondary coolant. Total sodium in the primary coolant is approximately 126 tonnes, and that of the secondary is 73 tonnes.

Structural Components-A fuel handling machine is used to move fuel subassemblies within the reactor vessel. The machine is set on top of the small plug of the double rotating plug during refueling. The machine can grip any fuel assembly within the vessel and can transfer it to any position in the fuel storage rack without exposing the subassembly above the sodium level.

The fuel storage rack is used as a relay station for fuel subassemblies at refueling and is also used to decay spent fuel.

To introduce a fuel subassembly into or take it out of the vessel, another machine, a fuel chargedischarge machine, is set on a bridge and can be moved in an X-Y direction. It is used to transfer a subassembly between the reactor vessel and a transfer rotor. 
The transfer rotor serves as a relaying device for passing a subassembly through the reactor containment boundary. Transfer of a subassembly between the transfer rotor and a new fuel storage facility or spent fuel storage facility is achieved by a cask car. Spent fuel is stored in a water pool after removing sodium on the surface (see Figures A-111 and -112).

The reactor containment vessel contains all the essential parts of the reactor plant, such as the reactor, primary coolant circuits, and refueling machines, and is made of steel. The top is semispherical with a radius of $14 \mathrm{~m}$, the body is cylin- drical, and the bottom is semi-elliptical. Total height is approximately 54 meters, and roughly half of it is above ground level. The cylindrical part of the vessel is surrounded by a concrete wall; the space between the vessel and the wall is maintained at negative pressure, thus making up a semi-double containment. All penetrations of the containment boundary-such as those for electric cables, personnel air locks, and piping-are located in the annular space. The operating floor within the containment vessel is approximately the same level as the ground level. The space below the floor is normally filled with nitrogen gas in order to prevent fires in the case of sodium leakage.

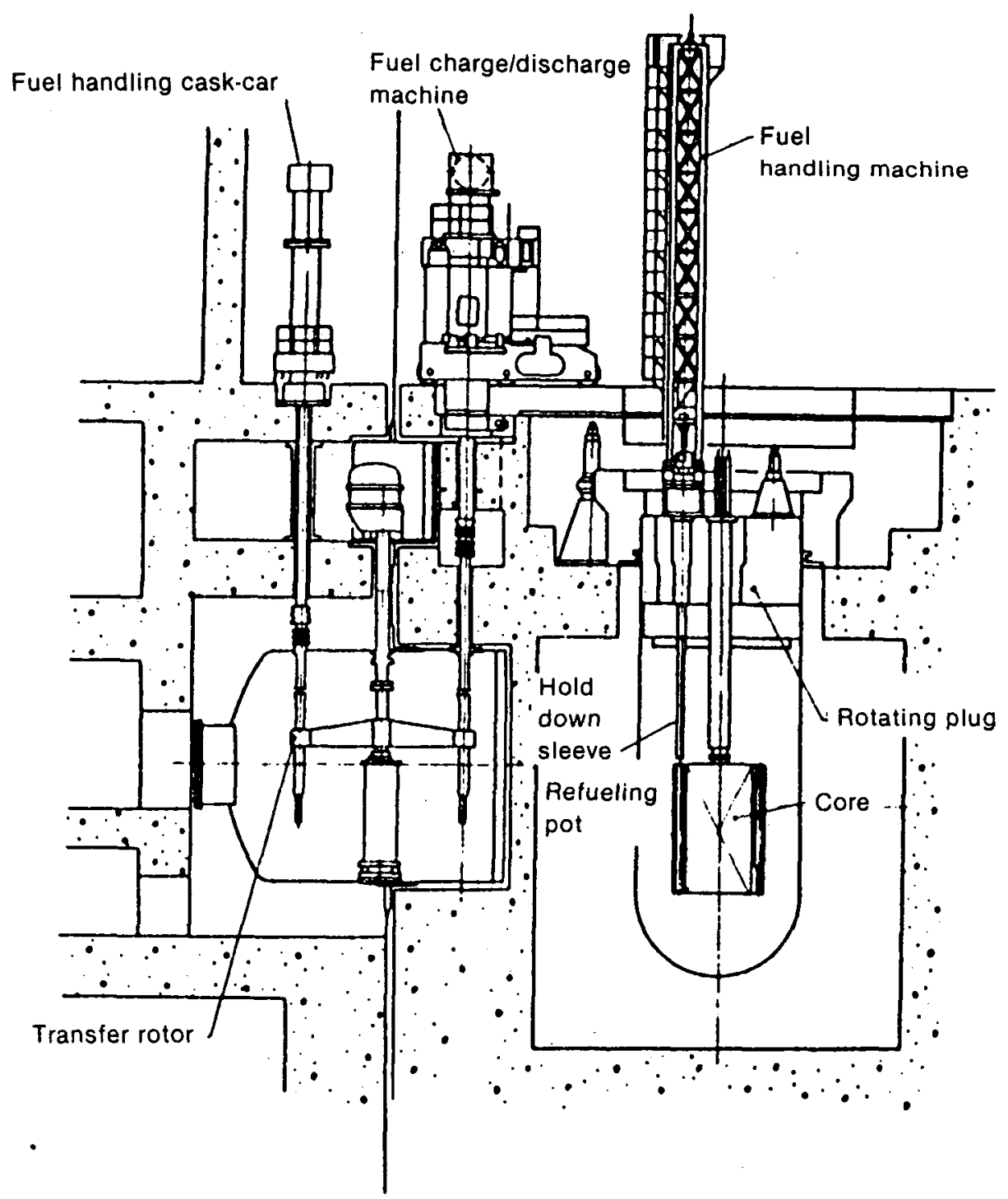

Figure A-111. Fuel handling, charge/discharge mechanism. 


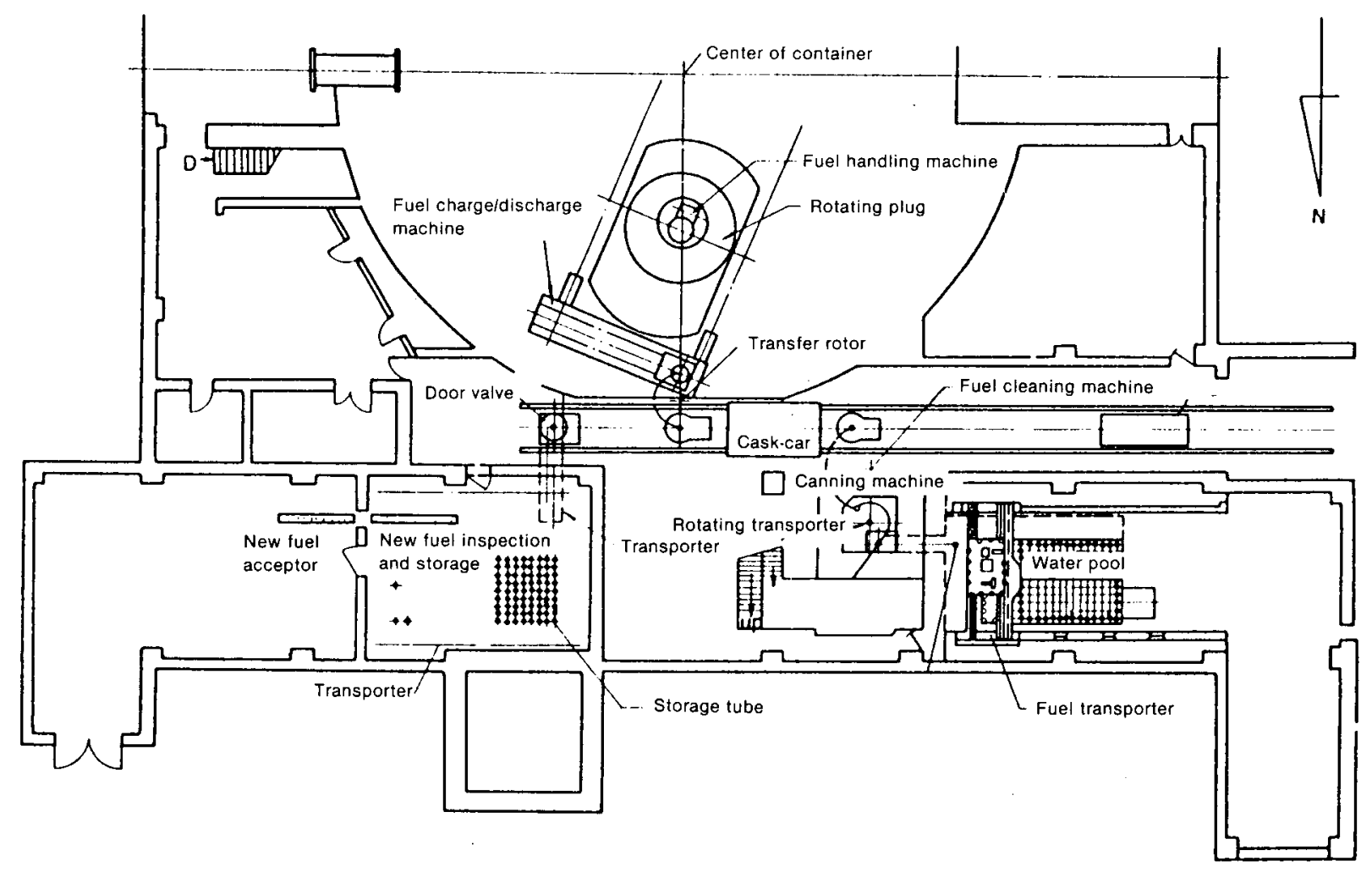

Figure A-112. Fuel handling and storage facility.

Operational Experience-Fabrication and installation of all JOYO's components were completed at the beginning of 1975. Preoperational function tests were immediately started and continued until the end of 1977. The preoperational function test consisted of the following phases:

Phase 1: Nonnuclear function test. Cold test

Hot test

Sodium test

Phase 2: Critical Test

Phase 3: Low Power Test

Phase 4: Power Testing to $50 \mathrm{MW}(\mathrm{t})$

Phase 5: Power Raising Test to $75 \mathrm{MW}(\mathrm{t})$

Phase 6: Power Raising Test to $100 \mathrm{MW}(\mathrm{t})$.

During the nonnuclear function test period, a final check of the design was performed, and as a result, some modifications had to be carried out. For example, the pipe heating system in the primary loop had to be modified to mitigate the thermal stress in the transient state. The primary sodium mechanical pumps were modified to enlarge the operating range. The approach to criticality started in the spring of 1977, and the reactor achieved criticality on April 24, 1977, with 64 fuel subassemblies.
Following attainment of criticality, the additional excess reactivity required for further experiments was determined, and low power nuclear tests were started. A series of low-power tests was completed in the middle of November 1977, and regular plant inspection began.

There was excellent agreement between measured values on JOYO and predicted values in the design base. The design base was determined from measurements of the physics and engineering nuclear mockup made on the fast critical assembly located at the Japan Atomic Energy Research Institute. However, the differential data of the sodium void effect showed a comparatively large discrepancy from predicted value. Nuclear parameters measured in the critical and low-powered nuclear tests were as follows:

- Minimum critical mass

- Control rod characteristics

- Reactivity measurements including fuel subassembly work, isothermal temperature coefficient, and sodium void coefficient 
- Reactor kinetic parameters

- Reaction rate distribution.

The minimum critical mass requiring $61 \pm$ five fuel subassemblies was predicted from measurements on the mockup using the fast critical assembly and correcting for temperature and heterogenetic terms. The measured value of a minimum critical mass was 63.2 fuel subassemblies. Measurements of control rod worth was made using positive period and substitution methods. Rod drop and neutron multiplication methods were also used. All of these results agreed with each other to within $10 \%$. The design value of the control rod worth underestimated the measured value by $12 \%$. No discrepancy was observed between measured and predicted reactivity worths caused by replacement of the blanket fuel subassembly with the core fuel subassembly. However, the change in reactivity caused by replacing a blanket or core fuel subassembly with sodium showed a somewhat different value from the corresponding predicted value. The kinetic parameter beta/ $\mathrm{L}$ was measured by the neutron noise method. This parameter was measured while on the fast critical assembly using the pulsed neutron method. Agreement was excellent. During the initial power ascension test to $50 \mathrm{MW}$ in 1978, up to $75 \mathrm{MW}$ in 1979 , and nominal power operation cycles at $50 \mathrm{MW}$, activity coefficient measurements were carried out, as were a number of plant performance and reactor surveillance tests.

When post irradiation examinations were made on fuel assemblies that had been irradiated during this second cycle of $15 \mathrm{MW}(\mathrm{t})$ and the first cycle at $75 \mathrm{MW}(\mathrm{t})$, wear marks were found on the surface of several fuel pins. These wear marks were apparently caused by spacer wires wrapped on the adjacent fuel pins. The depth of the wear marks was at most $0.06 \mathrm{~mm}$. Because this phenomena had not been anticipated in the fuel design, the potential effect of these wear marks on the inner pressure stresses of the fuel elements was examined, and adequate operational margins to proceed with the second and third $75 \mathrm{MW}(\mathrm{t})$ duty cycles were confirmed. Postirradiation tests were also conducted after the third, fourth, and fifth $75 \mathrm{MW}(\mathrm{t})$ cycles, and similar wear marks of about the same size as the initial wear marks were also observed.

The wire-wrap parameters, i.e., the wrapping wire pitch and bundle porosity (defined as the bundle-duct clearance divided by the number of hexagonal rings), were selected for three modified assemblies. The irradiation was conducted in
Row 1 of the core. Detailed postirradiation examination and evaluation showed that no significant wear marks were observed on the modified fuel assemblies:

Unexpected power coefficient behavior was observed when the power was initially raised from 50 to $75 \mathrm{MW}(\mathrm{t})$ after two cycle operations at $50 \mathrm{MW}(t)$. The cumulative burnup at this time was approximately $10000 \mathrm{MWd} / \mathrm{t}$. The following characteristics were observed:

- A larger reactivity loss than predicted occurred when power was initially increased from 50 to $75 \mathrm{MW}(\mathrm{t})$

- This anomaly occurred only once and has not been observed in any subsequent power increases from 50 to $75 \mathrm{MW}(\mathrm{t})$

- This reactivity loss was approximately $40 \varnothing$ at $250^{\circ} \mathrm{C}$ isothermal conditions.

This phenomena was not anticipated from core design or from low-power core characteristic test results. To investigate the cause of the anomaly, several factors were considered:

- Composition change of fuel pellet

- Cracking of fuel pellet

- Elongation of effective fuel length

- Abnormal behavior of control rod drive mechanism or control rod

- Increase in the effective diameter of the core.

Through detailed investigation and analysis, the second and third items above were considered as the most probable causes of anomaly. This judgment was based on the fact that the postirradiation examination of the irradiated fuel in JOYO showed that the pellets crack and elongated to between 3 and $5 \mathrm{~mm}$, which corresponds to a $40 \varnothing$ reactivity loss. In addition, the fuel pellet cracking increased significantly after the $75 \mathrm{MW}(\mathrm{t})$ power ascension. The mechanism causing the anomaly could be explained as follows:

1. The fuel burnup reached about $10,000 \mathrm{MWd} / \mathrm{t}$ at the end of the $50 \mathrm{MW}(\mathrm{t})$ second duty cycle, and the resulting fission 
gas was almost entirely retained in the fuel pellets.

2. On the occasion of the initial power ascension from 50 to $75 \mathrm{MW}(\mathrm{t})$, fission gas release from the fuel pellets began increasing at a power level slightly above $50 \mathrm{MW}(\mathrm{t})$.

3. The release of fission gas reduced the gap conductance and caused an increase in fuel pellet temperature and the appearance of pellet cracks. These phenomena induced the fuel pellet's length to elongate abruptly. The fuel temperature increase and fuel pellet length elongation induced the fuel expansion reactivity effect. This caused the Doppler reactivity effect to increase, resulting in the anomalous behavior of the power coefficient.

4. After the initial $75 \mathrm{MW}(\mathrm{t})$ power level, the fuel pellet length did not respond to the reactor power change as it had before the $75 \mathrm{MW}(\mathrm{t})$ operation. As a result, the magnitude of the power coefficient became smaller. At the shutdown of the reactor, the core average fuel stack length became elongated, and the reactivity of about $40 \varnothing$ was lost from the core.

On July 26, 1981, a slow scram occurred, and the reactor was shut down automatically from a $75 \mathrm{MW}(\mathrm{t})$ power level. An electromagnetic pump of the sodium overflow system tripped in the process of a sodium draining operation prior to operating the fuel failure detection (FFD) system. As a result, a plant protection signal of "overflow system pump trip" was generated. This signal caused the reactor to scram. It was found that the sodium draining procedure might have caused argon cover gas internment into the overflow pump, resulting in a trip of the pump. The procedure was revised to eliminate this occurrence. On November 16, 1981, a "Loop A Secondary Flow Rate Low" signal was observed when the reactor was in operation at $75 \mathrm{MW}(\mathrm{t})$. The reason for this signal activation was excessive wear of one of the three sets of resistor brushes in the secondary main pump. Thus, there was a drop of motor power. The reactor was shut down, and maintenance work on the pump was performed.

The faulty pump had been in use for more than one year, which is the period for replacement designated by the pump manual. The brush conditions had been fair when checked in the annual inspection. It was decided to replace all brushes with new ones at annual inspections regardless of their condition.

\section{Prototype Reactors}

Prototype plants are intermediate plants of a particular type, generally in the 250-350 MW(e) range, built to provide data and experience to scale up to commercial size plants. Presently there are four operating prototype LMFBRs: $\mathrm{BN}-350$ and $\mathrm{BN}-600$ in Russia, PFR in the United Kingdom, and PHENIX in France.

PHENIX. The PHENIX nuclear plant, built and operated by the Commissariat a l'Energie Atomique and Electricite de France, is located at the Marcoule center in the south of France. It is an exact prototype of the power reactors in the French reactor system with a rated power of $563 \mathrm{ME}(\mathrm{t})$ and $250 \mathrm{MW}(\mathrm{e})$. Construction started at the end of 1968. The first reactor criticality was carried out on August 31, 1973, and the system was first connected into the network of the Electricite de France on December 13, 1973. On July 14, 1974, it was declared to be an industrial operation. The entire construction and testing phase, therefore, took place over a period of 5.5 years.

Reactor Features. The reactor building is a controlled leakage structure capable of containing an overpressure of $40 \mathrm{kPa}$, in which the internal atmosphere is maintained at a negative pressure of $5 \mathrm{kPa}$.

All primary radioactive circuits (sodium and argon) are contained in basement cells of the reactor building. Within the basement, the reactor block lies north to south and slightly to one side of the building's center line-toward the special handling building The handling building is joined to the reactor of the fuel handling system and is where the fuel storage drum is located (Figures A-113 and -114).

The sodium and argon systems are situated with respect to the reactor at levels that eliminate the risk of accidental draining or filling.

Neither the mechanical handling system linking the reactor block with the fuel storage drum nor the equipment handling building can tolerate any differential settling of the two structures; hence, the concrete supporting them is common to both. 


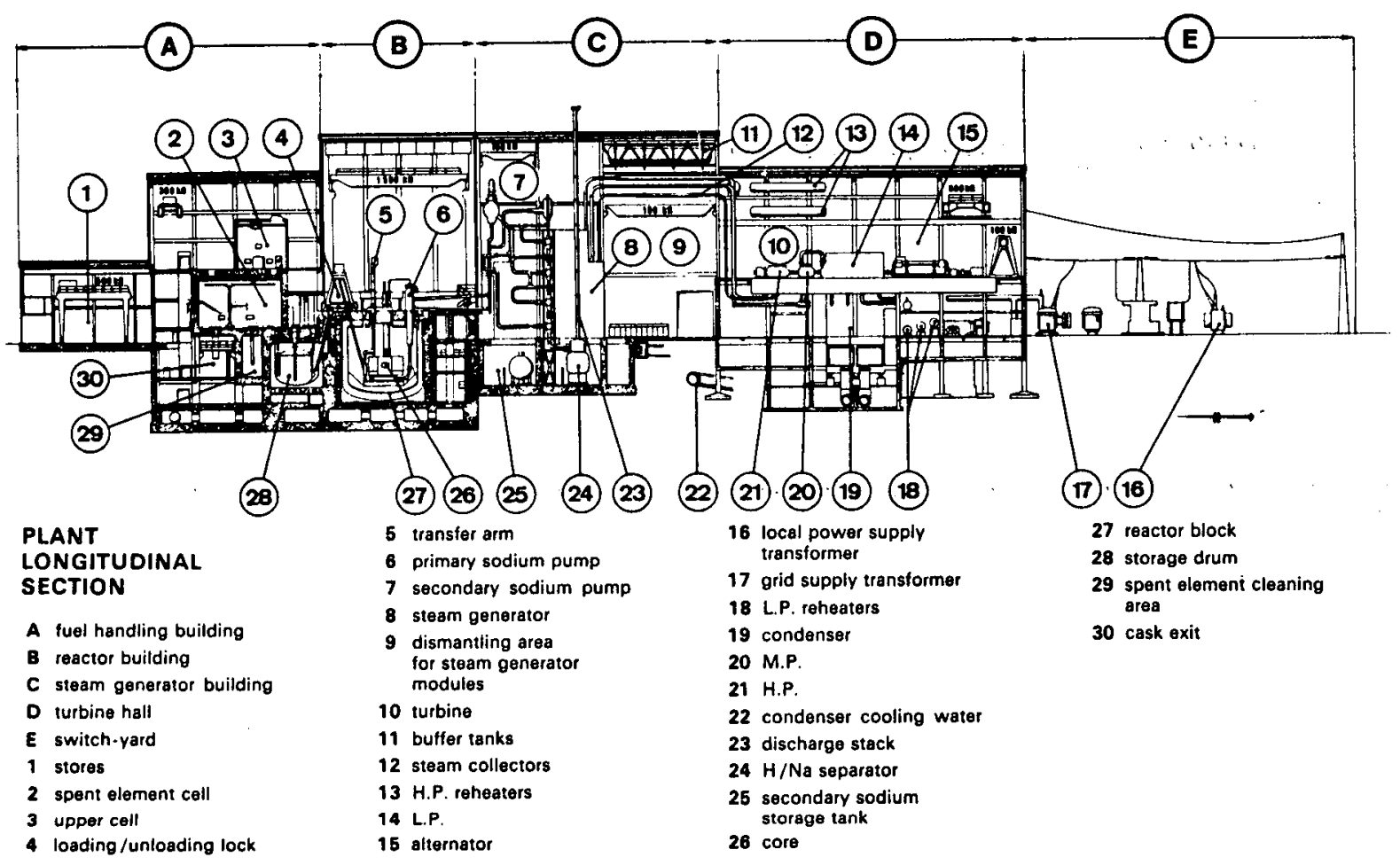

Figure A-113. Plant logitudinal section.

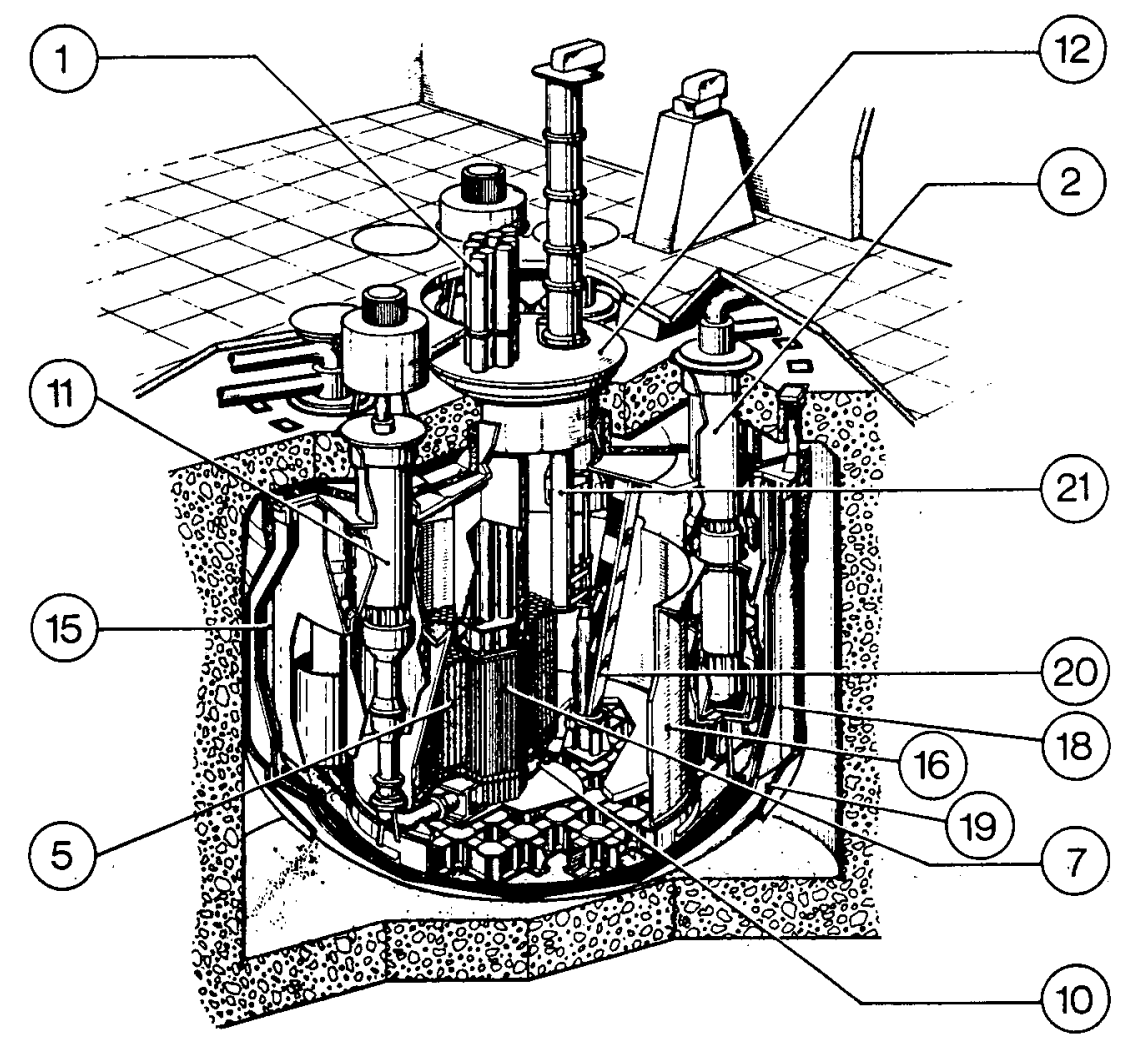

REACTOR BLOCK

1 control rod drives

2 intermediate exchanger

3 leak detector

4 upper neutron shielding

5 lateral neutron shielding

6 blanket

7 core

8 lat. shielding support

9 conical support collar

10 fuel support slab

11 primary pump

12 rotating plug

13 slab

14 roof

15 main vessel

16 primary vessel

17 core cover

18 double envelope vessel

19 primary containment

20 transfer ramp

21 transfer arm.

Figure A-114. PHENIX reactor block-cutaway view. 
The main reactor vessel is $11.8 \mathrm{~m}$ in diameter. The sodium in the vessel is separated to form two zones: (a) the hot sodium, at the center, in a primary tank, from which it flows into the intermediate heat exchangers, and (b) the cold sodium, which is taken from a peripheral annular space between the primary tank and the wall of the main reactor vessel, which contains the three primary circuit pumps and six primary heat exchangers suspended from the upper slab.

Outside the main vessel is a safety containment. It is designed to both contain any sodium leakage and to prevent a drop in the sodium level of the main vessel that may affect the cooling of the core.

Finally, an outer containment in which both the above mentioned vessels are lodged is provided to contain any radioactive products liable to escape from the main vessel during an accident. This containment also encloses a cooling circuit that maintains the concrete of the reactor block at a reasonable temperature. Moreover, it is capable of acting as a standby cooling circuit during residual power decay after shutdown should all the secondary sodium circuits be out of service.

A number of other devices enter or are located in the main vessel: the fuel transfer arm, the six con- trol rods, neutron flux detectors, thermocouples, failed element detection and location facilities, and the sodium boiling detection system components.

An accessory circuit covers the sodium surface with argon to prevent any air contact.

The main vessel is closed at the top by a flat roof with openings for pumps and exchanger pipes. It is associated with the cylindrical seating of a rotating plug in the slab that forms the top of the reactor block.

Core Arrangements. The reactor core, in which most of the power is generated, is surrouncled by a fertile blanket and neutron shielding, provided to prevent activation of the secondary sodium while flowing through the intermediate heat exchanges.

The fuel is enriched uranium oxide mixed with plutonium oxide. It is contained in 103 assemblies, each containing 217 pins. The pins, in turn, consist of a stack of centered oxide pellets $5.5 \mathrm{~mm}$ in diameter and are in a stainless steel cladding. The pins are assembled in clusters in a stainless steel outer shell of hexagonal cross-section. They also contain the upper and lower fertile blanket pins (of depleted uranium oxide) and the upper neutron shield (Figure A-115).

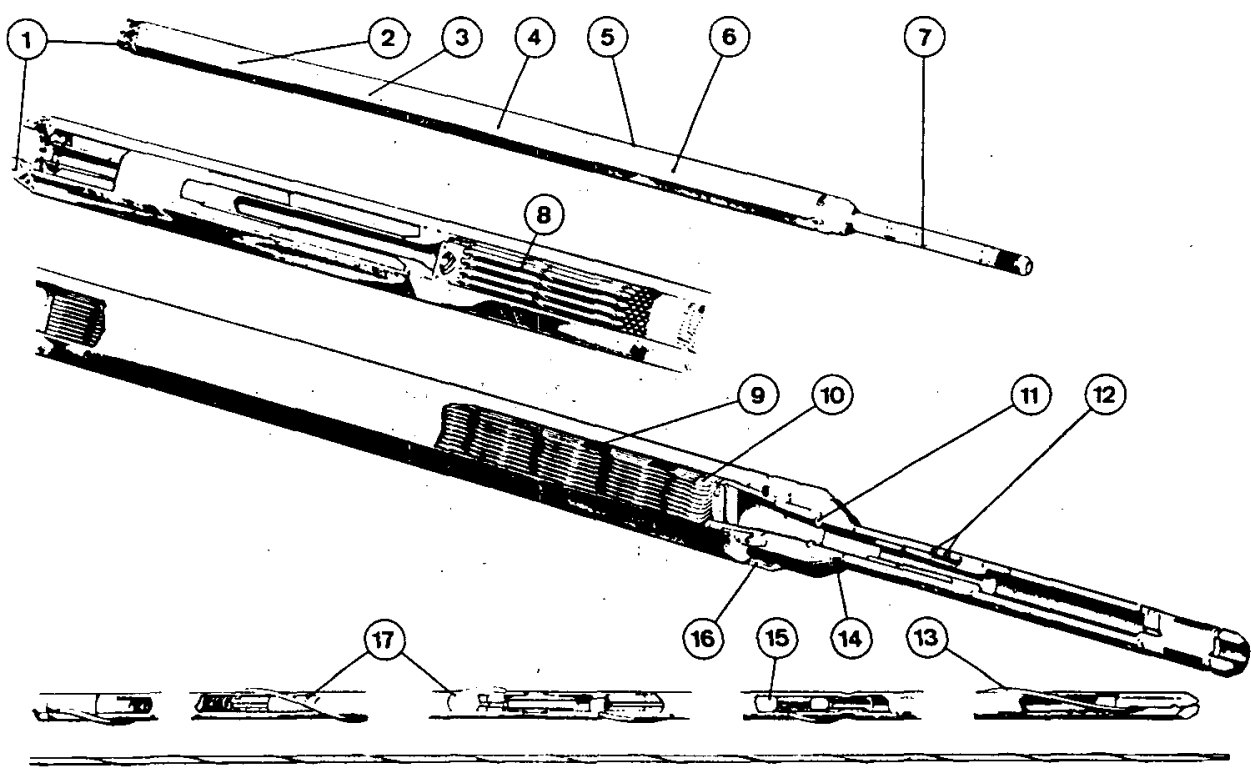

FUEL ASS EMBLY

1 guide not: $h$

2 upper neu tron shielding

3 upper axial blanket

4 core

5 hexagonal sheath

6 lower axial blanket

7 foot

8 37 upper ixist blanket

9217 fuel pins

10 pin suppoit

11 orifice

12 sodium inlet

13 helicoidal spacer

14 spherical tearing

15 vo.

16 positioningl slug

17 UO. - PulJz

Figure A-115. PHENIX fuel assembly. 
The following are within the fuel assemblies:

- A foot at the lower end for engagement with the sodium flow distribution plenum (a disk-shaped manifold) through which the sodium is fed by the primary pumps

- A notched head at the top to facilitate introduction and removal by the fuel handling gripper.

The lateral blanket is composed of depleted uranium oxide in the shape of pellets measuring $12.15 \mathrm{~mm}$ in diameter in 90 assemblies having 61 pins each.

The structural components of these assemblies are identical to those of the fissile assemblies, sodium flow being through the foot engaged in the sodium plenum.

Lateral neutron shielding, distributed from the blanket outward, consists of the following:

- Rows of steel elements of the same hexagonal cross section as the fuel assemblies

- Rows of circular cross section elements of graphite, steel, and boron-doped graphite, respectively.

Forty-one holdup pins are provided in the lateral shielding for fuel elements removed from the core before they go to the discharging ramp.

Control System. The operational characteristics of each subassembly in the core are first calculated and then measured while the reactor is in operation, essentially by means of thermocouples.

Calculations are made using a core management program, which takes into account flux perterbations caused by each core component. This code gives an evaluation of the power and of the sodium temperature increase through each subassembly.

The outlet sodium temperature of each subassembly is continuously monitored by two thermocouples and handled through two independent computers. A temperature increase of more than $3 \%$ with respect to the average core temperature increase triggers an alarm. A scram is triggered if the increase is greater than $7.5 \%$.
Loss of cladding integrity can be detected by a fission product detection system, either through measuring the fission product integrity in the argon gas or in the sodium. Failures are localized by a system based upon measurements of the fission products in the sodium.

The joints between the roof and the vessel, fitted with power-regulated heated panels, are closely monitored; during transient operations, thermal gradients must not exceed $600^{\circ} \mathrm{C}$ per meter.

Three different devices are used to make the sodium level measurements:

- The primary sodium level is measured using eddy current probes

- The main vessel protection baffle sodium is monitored using argon bubbling and sodium bubblers along with pressure measurements

- Inlet pump sodium flowrate is monitored using a magnetic flowmeter.

From these measurements, structural temperatures can be deduced and cross checked.

Reactor power is regulated by a remote adjustment of the primary sodium pumps. The difference in temperature of the primary sodium at the inlet and outlet of the core is maintained steady at $160^{\circ} \mathrm{C}$ by insertion or removal of the six control rods. Steam temperature at the evaporator outlet is maintained steady at $375^{\circ} \mathrm{C}$ by automatic regulation of the feedwater. The temperature of the superheat steam is maintained steady at $512^{\circ} \mathrm{C}$ by adjustment of the secondary sodium circulating pumps. The temperature of the resuperheat steam is maintained at $512^{\circ} \mathrm{C}$ and follows the superheat steam temperature, the distribution of the sodium flow to the superheater and resuperheater being predetermined. This temperature may vary slightly with the load (between 512 and $490^{\circ} \mathrm{C}$ ). Steam pressure at the boiler outlet is maintained at $168 \mathrm{kPa}$ by automatic regulation of the admission valves. Any malfunction in the primary or secondary sodium circuits (e.g., seizure of a pump) automatically initiates reactor shutdown.

Heat Transport System. The three primary circulating pumps are variable speed units (150 to $970 \mathrm{rpm}$ ) 
delivering about $950 \mathrm{~kg}$ of sodium per second at $825 \mathrm{rpm}$, which is their normal service speed. The circulating sodium enters the core at $400^{\circ} \mathrm{C}$ and leaves the core at $560^{\circ} \mathrm{C}$ to six heat exchangers that are associated in pairs with the three independent secondary circuits. Auxiliary circuits are provided for storage, filling, draining, and purification of primary sodium. The primary sodium is purified by the use of cold trap precipitators.

Each secondary loop is connected to a steam generator consisting of an evaporator, superheater, and resuperheater, in 12 modules. Each module has seven tubes in a cylinder containing water in counterflow to the sodium pumped through the cylinder. The sodium flows to the superheater and resuperheater in parallel, from which steam at $512^{\circ} \mathrm{C}$ and a pressure of 165 and $34 \mathrm{kPa}$ respectively is obtained. The total sodium flow then goes to the evaporator, which is fed water at $246^{\circ} \mathrm{C}$ and supplies steam at $375^{\circ} \mathrm{C}$.

The steam generators are equipped with a waterto-sodium leakage detection system operating on the basis of sodium/hydrogen concentration measurements. As a safeguard against the pressure effects of sodium leaks, rupture disks in the sodium manifold will burst and discharge sodium water reaction products to a separator, from which the reaction hydrogen can escape into the atmosphere. Fast-closing valves are provided for automatic rapid shutoff of the steam generators from both the water and sodium circuits. Pollution of the entire secondary circuits is thereby prevented, and the quantity of waste involved in a possible reaction is limited. Figures A-116-118 illustrate the primary pump, the expansion tank and secondary pump, and the generator respectively.

Operational Experience. The nature of the startup testing carried out for PHENIX was the result of both the prototype nature of the plant and its size. The startup testing took place over a three-year period, and the tests were grouped into four phases delineated by the following major events: loading the main circuits with sodium, loading the reactor core, and the onset of power buildup.

The first phase included the testing of circuits related to the reactor vessel, the testing of sodium and argon auxiliary circuits, and the loading of sodium in the main circuits. This phase was completed in January 1973. The second phase began at that time, with the filling of the sodium circuits and was continued until the end of July 1973, with isothermic and inactive sodium testing. The first buildup of temperature to $450^{\circ} \mathrm{C}$ was carried out during March. The temperature was built up by progressive stages to enable testing for ary failed elements, hydrogen detection, measurements of pressure and flow rates, and very thorough testing of fuel handling at $250^{\circ} \mathrm{C}$.

The third phase began with replacing the dummy fuel with actual fuel. The first criticality took place on August 31, with a core of 91 assemblies. Lowpower nuclear testing took place throughout the entire month of September. The steam generators were put into service in October 1973.

The fourth phase started in November 19,73 with a low-power buildup. It proceeded in stages, obtaining as rapidly as possible a period of operations approaching nominal operating conditions. The initial connection to the electrical network was carried out on December 13, 1973. Successively increasing power, full power was achieved on March 12, 1974. The principal reactor operating parameters were then compared to those of the preliminary design phase. Additional testing under power then took place until June.

The first phase of operation was characterized by a load factor of $69.5 \%$ and an availability rate of $75.5 \%$. The gross electrical output exceeded $265 \mathrm{MW}$ against a planned $250 \mathrm{MW}$. Gross efficiency was $45 \%$. This period of operation was marked by a few minor sodium leaks in the secondary circuits and water leakage in the steam generators.

On three occasions small cracks appeared in a joint weld of a large diameter valve on a steam generator sodium inlet pipe. The amount of sodium lost was approximately one liter and was accompanied in each case by the slow and spontaneous combustion of insulation material. The sodium circuits were not pressurized at the time, so were drained in order to stop the leak and carry out repairs. These leaks were eliminated by a modification in the steam generator.

As mentioned in the previous section, the modular steam generators are made of seven exchange tubes filled with water-steam and are located inside larger tubes conveying sodium. The flow rate distribution in the seven tubes is regulated by a diaphram system on the side of the steam generators. Disturbances in the fluid flow caused by the diaphrams, and the flow rate of highly pressurized water, 


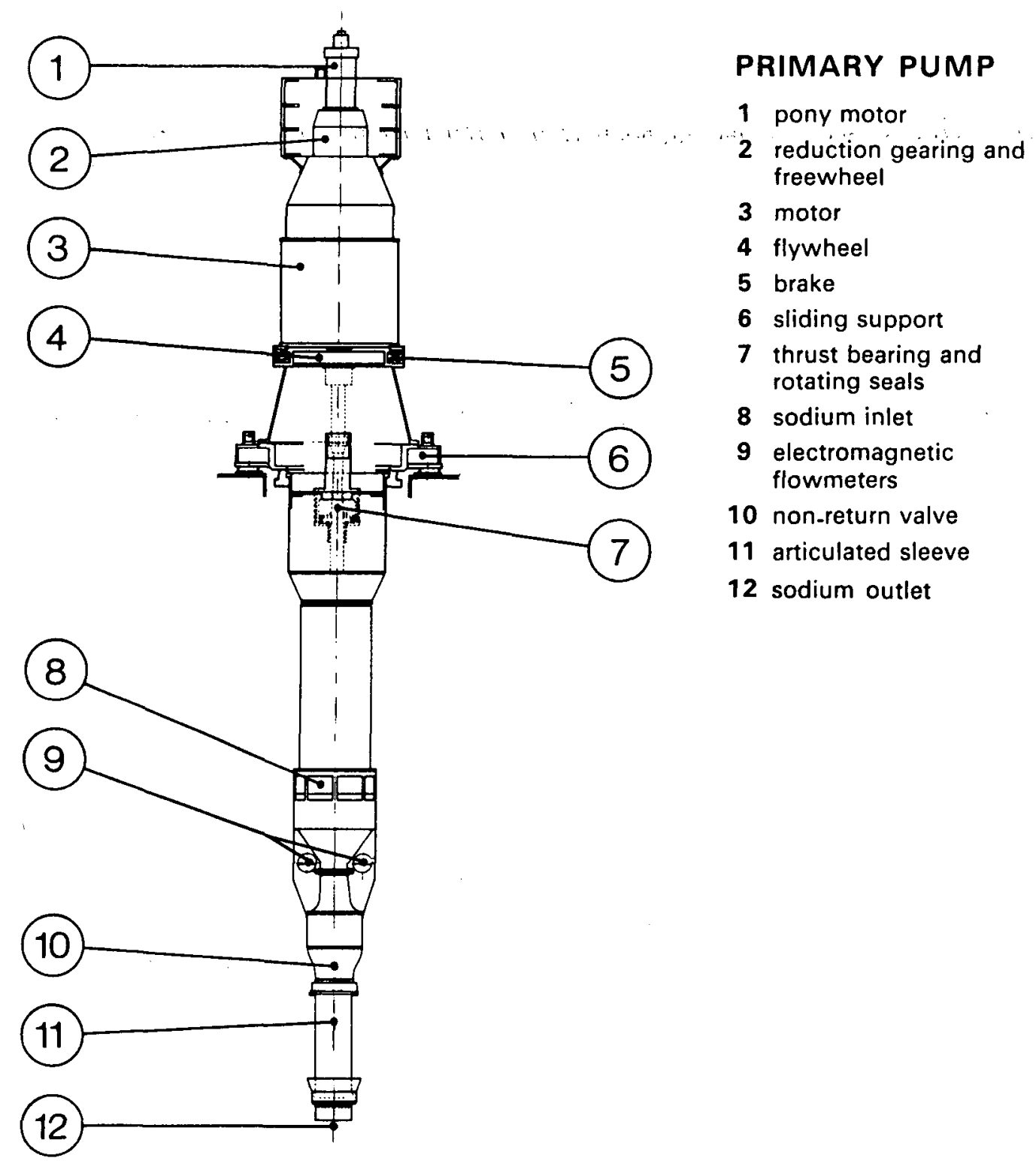

Figure A-116. Primary pump.

caused wear in these tubes. On four occasions this wear resulted in sodium leaking into the watersteam tubes. These incidents involved an unavailability during the last month of 1975 . The modifications made to remove these troubles consisted in an improvement in the geometry of the components, the addition of a protective skirting, and a jet baffle screen downstream of the diaphram. The inlets into the steam generator modified in this manner have caused no further problems.

The second phase of PHENIX operations from July 1, 1976 to April 20, 1978, was characterized by repair work and modifications made to the intermediate heat exchangers. There were very few periods of reactor operation.

The first major sodium leak occurred July 10,1976 . It occurred on a component whose internal detector was not functioning. The leak was therefore only detected when it flowed over to the outside. It was situated on the top of the heat exchanger, above the reactor slab, under the sheetmetal floor of the reactor hall (see Figure A-119). A fire started in some insulation but was quickly brought under control by the systems provided for that purpose. The second incident, on October 5, 1976, was detected at the very outset before the sodium was able to reach the outside. The progress 


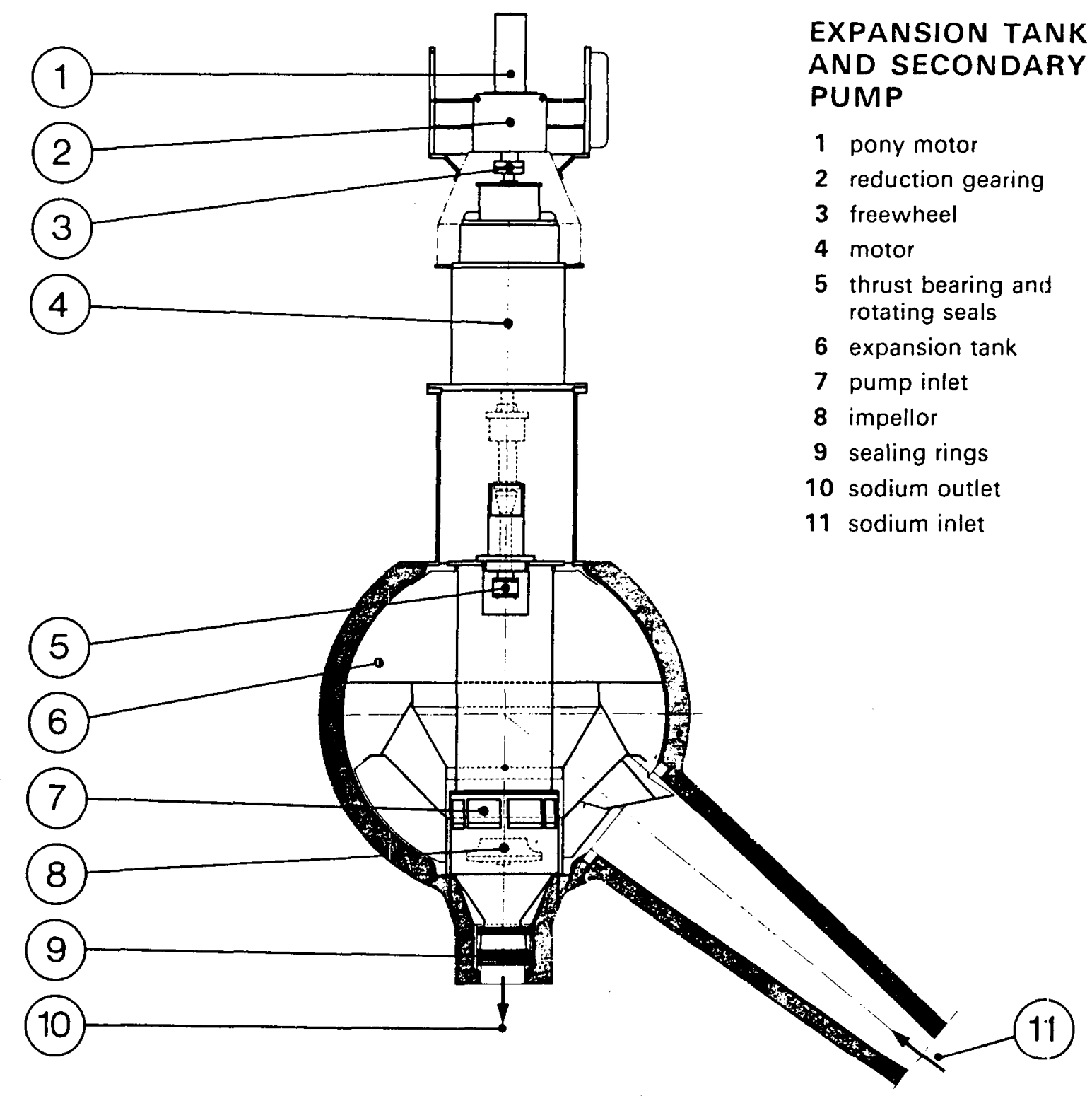

Figure A-117. Expansion tank and secondary pump.

and development of that leak was monitored for two days, and the leak and fire were brought under control immediately.

The leak occurred in a joint weld of the plate closing off the secondary sodium outlet at the top of the exchanger. This rigid plate connects two very long barrel plates of different temperatures; the differential expansion of these two plates caused a crack in the weld. The temperature differential in the sodium was caused by nonturbulent mixing that had not been anticipated in the computer modeling of the sodium in the intermediate heat exchangers. The rigid plate was replaced by a flexible closure.

All six heat exchangers were removed from the reactor core, using the existing handling transfer cask, and were then transferred into a washing pit installed at the time of construction. The first operation consisted of removing the remaining scidium. This procedure was performed by sweeping with nitrogen gas, containing an ever-higher moisture content, then with steam, and finally by immersion in water. Decontamination entailed a sequence consisting of an acid wash, an alkaline wash, and rinsing. The maximum dose rate from the exchanger at 


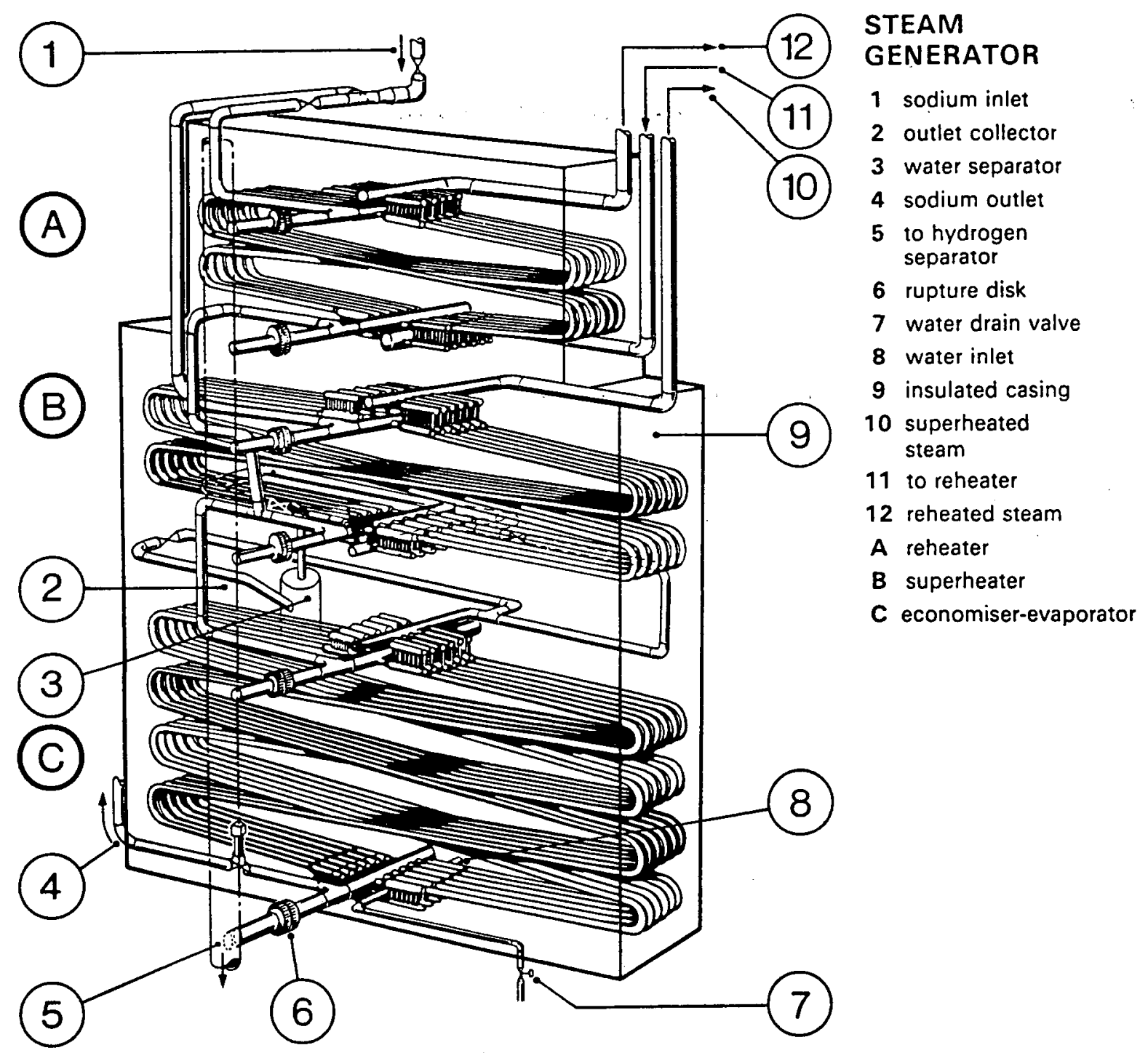

Figure A-118. PHENIX steam generator.

the outset of decontamination was $10 \mathrm{rem} / \mathrm{h}$; at the end of decontamination, the rate was brought down to $10 \mathrm{mrem} / \mathrm{h}$. At that point, repairs on the heat exchanger became an operation consisting of standard sheetmetal work machining.

Following these preliminary steps, the disassembly of the heat exchangers went routinely. The first heat exchanger to be withdrawn was completely dismantled with the exception of the bundle of tubes itself. This bundle of tubes was very carefully inspected and found acceptable. The other heat exchangers did not need to be disassembled so extensively, and work was devoted to slowly replacing the upper parts.
The washing and decontamination of the two units produced $440 \mathrm{~m}^{3}$ of liquid waste, representing an activity of $68 \mathrm{Ci}$. This waste was shipped for treatment at the Marcoule Center.

The doses received by the personnel responsible for the decontamination and repair work on the heat exchangers was an average of $69 \mathrm{mrem} /$ person, for a total of 6.3 man-rem.

There were very few losses of material on the tubes in the heat exchanger as shown by analysis of the washing products and ultrasonic measurements of tube thickness. 


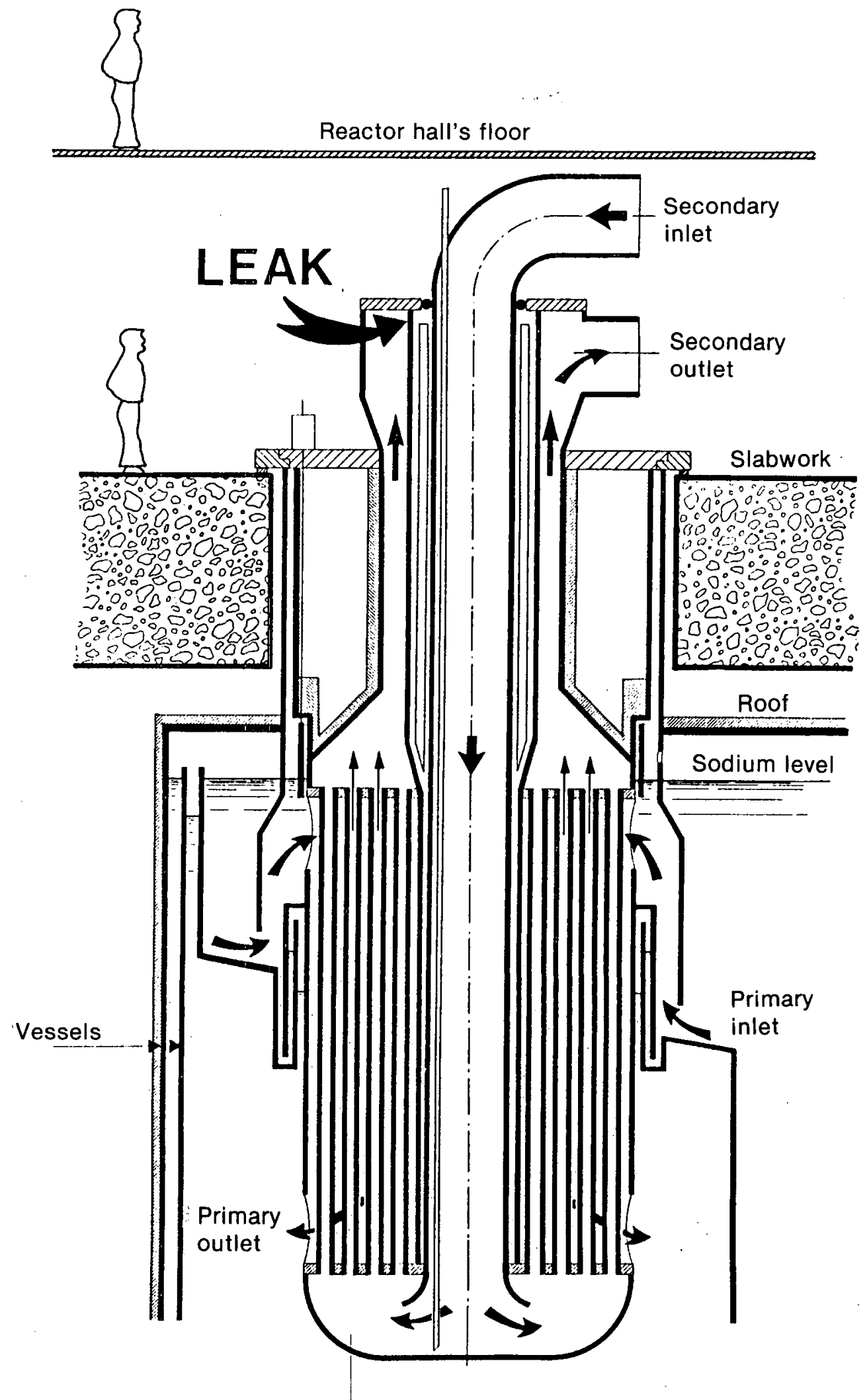

Figure A-119. PHENIX intermediate heat exchanger. 
The heat exchanger components were rinsed to remove all washing products, and checks were made at several points to ensure they were clean. Checks were also made by operating the IHXs inpile for over $1,000 \mathrm{~h}$ in hot sodium. After repair, the IHXs were radiographed and ultrasonically examined.

Work performed in radiation fields is very strictly controlled at PHENIX. Each work site is inspected prior to the beginning of work, and all necessary protective systems are set up so as to avoid exceeding a dose rate greater than $10 \mathrm{mrem} / \mathrm{h}$. Any work involved in a radiation exposure area greater than $10 \mathrm{mrem} / \mathrm{h}$ needs higher management approval. An indication of the effectiveness of this system is shown by examination of the dosimetry records of the PHENIX plant during its first 9 years of operation. The number of employees working at the plant generally vary between 200 and 400 . The total dose received by all persons working in the plant from its commissioning through the end of calendar year 1982 was less than
68 man-rem. The average annual dose per person never exceeded $40 \mathrm{mrem}$. The maximum dose received by the most exposed individual in any year was $1.8 \mathrm{rem}$. This latter figure is exceptional, and by way of indication, only five employees have ever exceeded 0.5 rem during any one year. Another way to compare the radiation exposure at the PHENIX plant with other types of nuclear generating stations is to examine the total gross dose equivalent per unit of energy produced per calendar year. The PHENIX plant produced $7450697 \mathrm{MWh}(\mathrm{e})$ during the years 1974 through 1980 at a cost of 46 man-rems. This is equivalent to 0.054 man-rems/MWy(e). The average total dose equivalent per unit of energy produced per calendar year for boiling water reactors is approximately 1.8 man-rem/MWy(e), whereas for pressurized water reactors it is $\sim 1.1$ man-rems/ $\mathrm{MWy}(\mathrm{e})$. These light water reactor plants then cost $\sim 20$ to 30 times more collective dose equivalent per unit power of energy in a calendar year than does the PHENIX LMFBR.A-135-137 


\section{REFERENCES}

A-1. G. R. Keepin, Physics of Nuclear Kinetics, Additon-Wesley Publishing Co., Inc., Reading, Massachusetts, 1965.

A-2. K. Ott, "An Improved Definition of the Breeding Ratio for Fast Reactors," Transactions of the American Nuclear Society, 12, 1969, pp. 719ff.

A-3. H. L. Wyckoff and Greebler, "Definition of Breeding Ratio and Doubling Time," Nuclear Technology, 21, 1974, pp. 158ff.

A-4. E. Paxon (ed.), Radial Parfait Core Design Study, Westinghouse Advanced Reactors Division, WARD-353, Waltz Mill, Pennsylvania, 1977.

A-5. D. C. King, and R. A. Sunderland, "Comparison of the Neutronic Performance of Homogeneous and Heterogeneous designs for 1300 MWE LMFBR," in Fast Reactor Fuel Cycles, British Nuclear Energy Society, London.

A-6. A. K. Agrawal and M. Khatib-Rahbar, "Dynamic Simulation of LMFBR Systems," Atomic Energy Review, 18, 2, IAEA, Vienna, 1980.

A-7. $\quad$ M. Aubert et al., "Temperature conditions in an LMFBR Power Plant from Primary Sodium to Steam Circuits," Optimization of Sodium-Cooled Fast Reactors, British Nuclear Energy Society, London, 1978.

A-8. A. E. Waltar and A.B. Reynolds, Fast Breeder Reactors, Pergamon Press, New York, 1981.

A-9. S. Dryer, "The Heat Transfer System of SNR-300," Nuclear Engineering International 21, 1976, pp. 246ff.

A-10. A. A. H. Dorsser von, "Man Heat Transfer Components for SNR-300," Nuclear Engineering International, 21, Clinch River Breeder Reactor PSAR, 1976, pp. 246ff.

A-11. A. S. Gibson, P. M. Murphy, and W. R. Gee, Jr., System Description and Cost for a 1000 MW(e) Sodium Cooled Fast Reactor, Task II Report, AEC Follow-On Study, General Electric Company, GEAP-5678, 1968.

A-12. K. C. Gross et al., Fission-Product Releases to the Primary System of EBR-II from April 1980 to March 1981, Argonne National Laboratory, ANL-83-80, Chicago, Illinois, 1983.

A-13. G. E. Meadows et al., FFTF Sodium and Cover Gas Characterization 1978-1980, Westinghouse Hanford Co., Richland, Washington, HEDL-TME 80-75, 1981.

A-14. W. C. Miller and F. E. Holt, FFTF Fuel Failure Detection and Characterization by Cover Gas Monitoring, Hanford Engineering Development Laboratory, Richland, Washington, HEILL-SA$1183,1977$.

A-15. J. A. Figg and R. Sanchez, Reactor Assembly Failure Location Analysis Program (FLAP) Users Guide, Hanford Engineering Development Laboratory, Richland, Washington, HEDL-TME-82$36,1983$.

A-16. R. Schmittroth, "A Probabilistic Method for Identifying Failed Fuel Elements Using a Gas Tag System," Nucl. Sci \& Eng., 52, 1973, pp. 95ff. 
A-17. F. E. Holt, "On-Line Radiometric Analysis of FFTF's Cover Gas-Basic Analytical Features," International Conference on Liquid Metal Technology in Energy Production, Champion, Pennsylvania, 1976.

A-18. E. T. Jurney et al. (eds.), Los Alamos Fast Plutonium Reactor, Los Alamos Scientific Laboratory, Los Alamos, New Mexico, US AEC Report TID 10048, 1954.

A-19 J. G. Yevick and A. Amorosi (eds.), Fast Reactor Technology: Plant Design, MIT Press, Cambridge, Massachusetts, 1966.

A-20. G. T. Arnold et al., Disassembly of the Los Alamos Fast Reactor, Los Alamos Scientific Laboratory, Los Alamos, New Mexico, US AEC Report LA-1575, 1953.

A-21. Civilian Power Reactor Program, Status Report on Fast Reactors as of 1959, Book 1, Part III, US AEC Report TID-8518 (BK-1), Superintendent of Documents, U.S. Government Printing Office, Washington.

A-22. R. R. Schmidt et al., Instability Studies with EBR-I, MARK III, US Argonne National Laboratory, Argonne, Illinois, USAEC ANL-6266, 1963.

A-23. R. O. Haroldsen et al., Safety Analysis Report, EBR-I, Mark IV, Argonne National Laboratory, Argonne, Illinois, USAEC ANL-6411, 1963.

A-24. H. V. Lichtenberger et al., "Operating Experience and Experimental Results Obtained from a $\mathrm{NaK}$ Cooled Fast Reactor, Proceedings of the First United Nations International Conference on the Peaceful Uses of Atomic Energy, Geneva, 1955, Vol. 3, pp. 345-360, United Nations, New York, 1956.

A-25. "EBR-I Operating Experience," Nuclear Safety, 3, 2, 1961.

A-26. N. Grotenhuis, "EBR-I Shield Design," Notes, International School of Nuclear Science and Engineering, Argonne National Laboratory, Argonne, Illinois, 1961.

A-27. R. R. Smith et al., A Mechanism Explaining the Instability of EBR-I, Mark-III, Argonne National Laboratory, Argonne, Illinois, USAEC ANL-6354, 1961.

A-28. R. E. Rice et al., EBR-I, Mark III-Design Report, Argonne National Laboratory, Argonne, Illinois, USAEC ANL-5836, 1958.

A-29. Experimental Power and Test Reactors, A Technical and Pictorial Summary, USAEC TID-4562, 1956.

A-30. S. Lawroski et al., Reactor Development Program Progress Report, Argonne National Laboratory, Argonne, Illinois, USAEC ANL-6233, 1960.

A-31. S, Lawroski et al., Reactor Development Program Progress Report, Argonne National Laboratory, Argonne, Illinois, USAEC ANL-6269, 1960.

A-32. S. Lawroski et al., Reactor Development Program Progress Report, Argonne National Laboratory, Argonne, Illinois, USAEC ANL-6328, 1961.

A-33. S. Lawroski et al., Reactor Development Program Progress Report, Argonne National Laboratory, Argonne, Illinois, USAEC ANL-6343, 1961. 
A-34. S. Lawroski et al., Reactor Development Program Progress Report, Argonne National Laboratory, Argonne, Illinois, USAEC ANL-6355, 1961.

A-35. S. Lawroski et al., Reactor Development Program Progress Report, Argonne National Laboratory, Argonne, Illinois, USAEC ANL-6433, 1961.

A-36. L. J. Koch et al., Experimental Breeder Reactor II (EBR-II) Hazard Summary Report, Argonne National Laboratory, USAEC ANL-5719, May 1947, and Addendum, USAEC ANL-5719 (ADD), 1964.

A-37. G. Fischer et al. (eds.), Proceedings of the Conference on the Physics of Breeding, Argonne National Laboratory, Argonne, Illinois, USAEC ANL-6122, 1959.

A-38. R. O. Brittan, "Analysis of the EBR I Core Meltdown," Proceedings of the Second United INations International Conference on the Peaceful Uses of Atomic Energy, Geneva, Switzerland, 1958.

A-39. H. G. Barkman et al., Los Alamos Molten Plutonium Reactor Experiment, LAMPRE, Hazard Report, Los Alamos Scientific Laboratory, Los Alamos, New Mexico, USAEC LA-2327, 1959.

A-40. S. Glasston (ed.), Quarterly Status Report on LAMPRE Program for a Period Ending May 20, 1960, Los Alamos Scientific Laboratory, Los Alamos, New Mexico, USAEC LAMS$2438,1960$.

A-41. S. Glasston (ed.), Quarterly Status Report on LAMPRE Programs for a Period Ending August 20, 1960, Los Alamos Scientific Laboratory, Los Alamos, New Mexico, USAEC L,AMS$2462,1960$.

A-42. Quarterly Status Report on LAMPRE Programs for a Period Ending November 20, 1960, Los Alamos Scientific Laboratory, Los Alamos, New Mexico, USAEC LAMS-2487.

A-43. Quarterly Status Report on LAMPRE Program for Period Ending February 20, 1961, Los A.lamos Scientific Laboratory, Los Alamos, New Mexico, USAEC LAMS-2531.

A-44. Quarterly Status Report on LAMPRE Programs for a Period Ending May 20, 1961, Los Alamos Scientific Laboratory, Los Alamos, New Mexico, USAEC LAMS-2564.

A-45. Quarterly Status Report on LAMPRE Program for Period Ending August 20, 1961, Los Alamos Scientific Laboratory Los Alamos, New Mexico, USAEC LAMS-2620.

A-46. Quarterly Status Report on LAMPRE Program for Period Ending November 20, 1961, Los A.lamos Scientific Laboratory, Los Alamos, New Mexico, USAEC LAMS-2647.

A-47. B. M. Carmichael and G. L. Ragan, "The Startup of the First Molten Plutonium Reactor," Transactions of the American Nuclear Society, 4, 2, 1961.

A-48. B. M. Carmichael and G.L. Ragan, "Some Effects Peculiar to Liquid Metal Fuel of LAMPRE-1," Transactions of the American Nuclear Society, 4, 2, 1961.

A-49. Quarterly Status Report on LAMPRE Program for Period Ending May 20, 1962, Los Alamos Scientific Laboratory, Los Alamos, New Mexico, USAEC LAMS-2681.

A-50. Quarterly Status Report on LAMPRE Program for Period Ending May 20, 1962, Los Alamos Scientific Laboratory, Los Alamos, New Mexico, USAEC LAMS-2720. 
A-51. LAMPRE-1 Final Design Status Report, Los Alamos Scientific Laboratory, Los Alamos, New Mexico, USAEC LA-2833.

A-52. D. B. Hall, "Los Alamos Molten Plutonium Program," Proceedings of the National Topical Meeting on Fast Reactor Technology, American Nuclear Society, Detroit, Michigan, 1965.

A-53. Horst, Hutchins, Leitz, and Wolfe, Core Design for a 500 MW(e) Fast Oxide Reactor, GEAP-3721, 1961.

A-54. M. J. McNelly, Liquid Metal Fast Breeder Reactor Design Study [1000 MW(e) $\mathrm{UO}_{2}-\mathrm{PUO}_{2} \mathrm{Fuel}$ Plant], GEAP-4418, 1965.

A-55. K. N. Horst, Southwest Experimental Fast Oxide Reactor Development Program, Second Quarterly Report, July-September 1964, GEAP-4742, 1964.

A-56. K. M. Horst, Southwest Experimental Fast Oxide Reactor Development Program, Third Quarterly Report, October, 1964-January 1965, GEAP-4799, 1964.

A-57. L. R. Kelman, H.V. Rhude, and H. Savage, "Development of a Metal Fuel Alloy for the SEFOR Fast Critical for ZPPR," ANS Transactions, 1964.

A-58. Hafele et al., "Static and Dynamic Measurements on the Doppler Effect in an Experimental Fast Reactor," Third United Nations Conference on the Peaceful Uses of Atomic Energy, Geneva, Switzerland, 1964.

A-59. J. O. Arterburn and K. Hikido, SEFOR Operating Experience and Significance to LMFBRs, Engineering of Fast Reactors for Safe and Reliable Operation, Kernforschungszentrum Karlsruhe, Germany, 1972.

A-60. A. I. Leipunsky et al., "Experimental Fast Reactors in the Soviet Union," Proceedings of the Second United Nations International Conference on the Peaceful Uses of Atomic Energy, Geneva, 1958, 9, United Nations, New York, 1959, p. 348.

A-61. A. I. Leipunsky et al., "Experimental Fast Reactors in the Soviet Union, in Physics and Fast Intermediate Reactors," Proceedings of the IAEA Seminar in Vienna, August 3-11, 1961, 3, Series STI-PUB-49, Vienna, Austria, 1962.

A-62. R. R. Matthews, "Soviet Fast Reactors-BR-5," Nuclear Engineering, 4, 41, and "Fast Reactors: A Soviet Outlook," Nuclear Energy, 7, 71, 1962

A-63. M. C. Pinchasik, "Operating Experience with the BR-5 Reactor, in Power Reactor Experiments," Proceedings of the IAEA Symposium in Vienna, October 23-27, 1961, 1, Series STI-PUB-51, Vienna, Austria, 1962.

A-64. M. S. Pinkhasik et al., "Certain Problems Relating to Operating Experience of the BR-5 Fast Reactor," Seminar on Fast and Intermediate Reactor Physics, Paper No. SM21-29, Vienna, Austria, 1961.

A-65. A. I. Leipunskii et al., "The Physical Characteristics at the BR-5," Seminar on Fast and International Reactor Physics, Paper No. SM18/82, Vienna, Austria, 1962.

A-66. A. I. Leipunskii et al., "Operating Experience of the BR-5 Reactor," Conference on Operating Experience of Power Reactors, Paper No. CN15/40, Vienna, Austria, 1963. 
A-67. A. I. Leipunskii et al., "Experience Gained from the Operation of the BR-5 Reactor, 1964-5," Proceedings of the London Conference Organized by the British Nuclear Energy Society, 17-19th May, 1966, Paper No. 2-3, Pergamon Press, Oxford, England, 1966.

A-68. G. Brudermuller et al., "Operating Experience with the KNK Reactor and Preparations for a Fast Mix Oxide Core (KNK II)," Proceedings of the International Conference Organized by the British Nuclear Energy Society 11-14 March 1974, Institution of Civil Engineers, British Nuclear Energy Society, London, 1974.

A-69. G. Brudermuller, W. Marth, and H. Tebbert, "Erfahrungen Bei der Durchfuhrung Des Projektes KNK," Atomwirtschaft, 18, 841973.

A-70. W. Marth and K. Dumn, "Problems Associated with Sodium Steam Generators as Discussed by the Example of a Leak in the Steam Generator of a Sodium Cooled Power Station KNK," Proceedings: Experience from Operating and Fueling Nuclear Power Plants, IAEA, V Wien, Federal Republic of Germany, 1973.

A-71. H. Andrae and W. Marth, "Das Projekt KNK II," Atomwirtschaft, 18, 93, 1973.

A-72. R. Huper, Status of Fast Breeder Reactor Development in the Federal Republic of Germany, Belgium and the Netherlands, prepared for the International Working Group on Fast Reactors of the International Atomic Energy Agency, Vienna, and for the Fast Reactor Coordinating Commitiee at a Commission of the European Communities, Brussels, Kernforschungszentrum Karlsruhe GmbH Karlsruhe, Federal Republic of Germany, 1983.

A-73. F. Sebilleau and C. P. Zalesski, "Plutonium as a Fuel for the Fast Reactor RAPSODIE," Proceedings of the American Nuclear Society Topical Meeting, Richland, Washington, September 13-14, 1962, Paper 15 in Plutonium as a Power Reactor Fuel, General Electric Company, USAEC.

A-74. H. Cartwright et al., "The Dounreay Fast Reactor-Basic Problems in Design, Proceedings of the Second United Nations International Conference on the Peaceful Uses of Atomic Energy, Cieneva, 1958, 9, United Nations, New York, 1959, pp. $316 \mathrm{ff}$.

A-75. Proceedings of the Symposium on the Counreay Fast Reactor, London, December 7, 1960, arranged by the Institution of Mechanical Engineers under Aegis of the British Nuclear Energy Conference, Institution of Mechanical Engineers, London.

A-76. Fast Reactor Descriptive Manual: Dounreay, the Control System and Electrical Supplies and Reactor Instrumentation, Sections A.2.4, A.5 and A.7, British Report IG-170 (D).

A-77. J. Allen, "Coolant Cleanup in DFR," Nuclear Engineering, 7, 76, 1962.

A-78. D. C. D. Smith and K. W. Brindley, "Physics Experiments at DFR," Nuclear Engineering, 7, 76, 1962.

A-79. J. L. Phillips, "Operating Experience with the Dounreay Fast Reactor-I," Nuclear Power, 7, 75, 1962.

A-80. J. L. Phillips, "Operating Experience with the Dounreay Fast Reactor-II," Nuclear Power, Vol. 7 , $76,1962$.

A-81. F. G. Dawson, "Plutonium as a Power Reactor Fuel," Proceedings of American Nuclear Society Topical Meeting, Richland, Washington, September 13-14, 1962, General Electric Cornpany, USAEC HW-75007, 1962. 
A-82. J. L. Phillips, "Achievement of Full Power Operation at the Dounreay Fast Reactor," Nuclear Engineering, August 1964.

A-83. J. L. Phillips, "Instrumentation of Fast Reactors," New Scientist, August 24, 1961.

A-84. D. C. G. Smith et al., Third International Conference on the Peaceful Uses of Atomic Energy, Geneva, Switzerland, Paper 173, 1964.

A-85. Meeting of the Advisory Committee on Reactor Safety, EBR-II, Arco, Idaho, March 17-18, selected illustrations distributed by Argonne National Laboratory 1961.

A-86. "Physics of Fast and Intermediate Reactors," Proceedings of the IAEA Seminar Held in Vienna August 3-11, 1961, Proceedings Series STI/PUB-49, Vol. 3, Vienna, Austria.

A-87. L. J. Koch et al., Experimental Breeder Reactor II (EBR-II) Hazard Summary Report, Argonne National Laboratory, Argonne, Illinois, USAEC ANL-5719, 1957; and Addendum to Hazard Summary Report, Experimental Breeder Reactor-II (EBR-II), USAEC ANL-5719 (ADD), 1964.

A-88. J. R. Dietrich and W. H. Zinn, Solid Fuel Reactors, Addison-Wesley, Publishing Company, Inc., Cambridge, Massachusetts, 1958.

A-89. Power Reactor Technology, 4, 4, September 1961.

A-90. M. Grotenhuis, A. E. McArthy, and A.D. Rossin, Experimental Breeder Reactor-II (EBR-II) Shield Design, Argonne National Laboratory, Argonne, Illinois, USAEC ANL-6614, 1962.

A-91. W. B. Lowenstein, "The Physics Design of EBR-II, and Physics of Fast and Intermediate Reactors," Proceedings of the IAEA Seminar Held in Vienna August 3-11, 1961, Proceedings Series STI/PUB-49, Vol. 3, Vienna, Austria, 1962.

A-92. J. Adamson, AERE, private communication to H. E. Hungerford, APDA, 1961.

A-93. L. J. Koch, W. B. Lowenstien, and H. O. Monson, Addendum to Hazard Summary Report Experimental Breeder Reactor-II (EBR-II), Argonne National Laboratory, Argonne, Illinois, USAEC ANL-5719, 1962.

A-94. "Pyrometallurgical Fuel Processing," Reactor Fuel Processing, a Quarterly Technical Progress Review, 3, 1, January 1960 , p. 25; 3, 2, April 1960, p. 27; 3, 3, July 1960, p. 24; 4, 1, January 1961, p. $25 ; 4$, 2, April 1961, p. 38; 4, 3, July 1961, p. 30; 4, 4, October 1961, p. 37; 5, 1, January 1982, p. 38; 5, 2, April 1962, p. 27-33.

A-95. L. Burris et al., "Recent Advances in Pyrometallurgical Processes," Transactions of the American Nuclear Society, 4, 2, 1961, pp. 192ff.

A-96. V. G. Trice and N. R. Chellew, "The Melt Refining of Irradiated Uranium: Application to EBRII Fast Reactor Fuel: VI. The Behavior of Plutonium in the Melt Refining Process," Nuclear Science Engineering, 9, 1, 1961, pp. 55ff.

A-97. A. Schneider and N. R. Chellew, "The Melt Refining of Irradiated Uranium: Application to EBR-II Fast Reactor Fuel: VII. The Evolution of Xenon and Krypton," Nuclear Science Engineering, 9, 1, 1961, pp. 59ff.

A-98. N. R. Chellew, G. A. Bennett, and V. G. Trice, "The Melt Refining of Irradiated Uranium: Application to EBR-II Fast Reactor Fuel: VIII. The Behavior of Rare Earth, Yttrium, Barium, Strontium, and Cesium," Nuclear Science and Engineering, 9, 1, 1961, p. 64. 
A-99. J. Wolkoff and A. A. Chilenskas, "The Melt Refining of Irradiated Uranium: Application to EBR-II Fast Reactor Fuel: IX. Absorption and Retention of Sodium and Cesium Vapor on Stationary Beds at Elevated Temperature," Nuclear Science and Engineering, 9, No. 1, p. 71.1961.

A-100. N. R. Chellew and V. G. Trice, 1961. "The Melt Refining of Irradiated Uranium: Application to EBR-II Fast Reactor Fuel: X. The Behavior of Zirconium," Nuclear Science and Engineering, 9, 1, pp. $78 f f$.

A-101. N. R. Chellew and N. Ader, "The Melt Refining of Irradiated Uranium: Application to EBR-II Fast Reactor Fuel: XI. Behavior of Iodine in Melt Refining," Nuclear Science and Engineering, 9, 1,1961, pp. 82ff.

A-102. N. R. Chellew and G. A. Bennett, "The Melt Refining of Irradiated Uranium: Application to EBR-II Fast Reactor Fuel: XII. The Behavior of Ruthenium, Molybdenum, Polladium, Technetium, Antimony, Cadmium, Rhodium, and Tellurium," Nuclear Science and Engineering, 9, 1, 1961, pp. $87 \mathrm{ff}$.

A-103. L. Burris et al., "The Melt Refining of Irradiated Uranium: Application to EBR-II Fast Reactor Fuel: I. Introduction," Nuclear Science and Engineering, 6, 6, 1959, pp. 493ff.

A-104. G. J. Bernstein et al., "The Melt Refining of Irradiated Uranium: Application to EBR-II Fast Reactor Fuel: II. Experimental Furnaces," Nuclear Science and Engineering, 6, 6, 1959, pp. 496ff.

A-105. D. C. Hampton et al., "The Melt Refining of Irradiated Uranium: Application to EBR-II Fast Reactor Fuel: III. Preparation of Experimental Alloys," Nuclear Science and Engineering, 6, 6, 1959, p. 501.

A-106. C. L. Rosen et al., "The Melt Refining of Irradiated Uranium: Application to EBR-II Fast Reactor Fuel: IV. Interaction of Uranium and its Alloys with Refractory Oxides," Nuclear Science and Engineering, 6, 6, 1959, pp. 504ff.

A-107. G. A. Bennett et al., "The Melt Refining of Irradiated Uranium: Application to EBR-II Fast Reactor Fuel: V. Yield of Fissionable Material Upon Pouring," Nuclear Science and Engineering, 6, 6, 1959, pp. $511 \mathrm{ff}$.

A-108. M. Gazith, Literature Survey in Pyrometallurgical Purification of Metals, Israel Atomic Energy Commission, Israel LF-93, 1961.

A-109. EBR-II Since 1964, Argonne National Laboratory-West, Idaho Falls, Idaho, 1983.

A-110. Power Reactor Development Company, Technical Information and Hazards Summary Report, ENRICO FERMI Atomic Power Plant, 1962.

A-111. Analysis and Simulation Study of the Operating Control System for the ENRICO FERMI Atomic Power Plant, Holly Carburetor Company, 1959.

A-112. ENRICO FERMI Atomic Power Plant, Atomic Power Development Associates, Inc., Report APDA-124, 1959.

A-113. Specifications for the Main Instrumentation and Controls of the ENRICO FERMI Atomic Power Plant, Revision No. 1, Atomic Power Development Associates, Inc., 1958.

A-114. ENRICO FERMI Atomic Power Plant Technical Information and Hazards Summary Keport, Vol. 1, 2, and 3, Power Reactor Development Company, 1962. 
A-115. J. G. Yevick and A. Amorosi (eds.), Fast Reactor Technology: Plant Design, MIT Press, Cambridge, Massachusetts, 1966.

A-116. H. E. Hungerford and R. F. Mantey, "Shielding the ENRICO FERMI Fast Breeder Reactor," Nucleonics, 16, 11, 1958.

A-117. ENRICO FERMI Atomic Power Plant, Technical Information and Hazards Summary Report, No. 3, Power Reactor Development Company, 1961.

A-118. H. E. Hungerford, R. I. Beaudry, and W. F. Chaltron, "Detailed Conceptual Design of a Graphite Primary Shield for the ENRICO FERMI Fast Breeder Reactor," APDA Technical Memorandum No. 23, Atomic Power Development Associates, Inc., 1959.

A'-119. "Replacement of a Modification to the Primary Shield Graphite in the ENRICO FERMI Reactor," Exhibit T-60 to the 15th Quarterly Report to the United States Atomic Energy Commission, 1962.

A-120. "Effects of Release of Carbonaceous Gases from the Graphite in the ENRICO FERMI Reactor Rotating Shield Plug," Exhibit T-61 to the 15th Quarterly Report to the United States Atomic Energy Commission.

A-121. E. P. Alexanderson (ed.), FERMI-I, New Age for Nuclear Power, American Nuclear Society, LaGrange Park, Illinois, 1979.

A-122. G. Ball, Results of the Low Power Nuclear Test Program for the EFBR, Atomic Power Development Associates, APDA-302, 1967.

A-123. E. L. Alexanderson et al., "Operating Experience at the ENRICO FERMI Atomic Power Plant," ANS-100, 1956.

A-124. "Unit 1 Operating Experience Through 200 MW(t),"ENRICO FERMI Atomic Power Plant, EFAPP-200-1, 1971.

A-125. H. A. Bethe, Reactor Safety and Oscillator Tests, Atomic Power Development Associates, APDA117, 1956.

A-126. H. E. Hungerford, Phase B: Preoperational Shield Test Program for EFAPP, H-62-11-0702, 1962.

A-127. R. J. Beaudry, Phase A: Preoperational Shield Test Program for EFAPP, pp. 63-6, 1963.

A-128. R. J. Beaudry, Operational Shield Test for EFAPP, Atomic Power Development Associates, APDA-221, 1968.

A-129. Fuel Damage Incident at the ENRICO FERMI Atomic Power Plant October 5, 1966, Status as of February 24, 1967, Atomic Power Development Associates, Power Reactor Development Company.

A-130. Report on the Fuel Melting Incident in the ENRICO FERMI Atomic Plant on October 5, 1966, Atomic Power Development Associates, APDA-233, 1968.

A-131. Retirement of the ENRICO FERMI Atomic Power Plant, Power Reactor Development Company, DNP-200047 and NP-200479 (Supplement 1), March 1974 and October 1975; reports on file at the U.S. DOE Office of Public Affairs, Technical Information Center, Oak Ridge, Tennessee. 
A-132. C. P. Cabell, $A$ Summary Description of the Fast Flux Test Facility, Hanford Engineering Development Laboratory, Westinghouse Hanford Company, Westinghouse Electric Company, Richland, Washington, HEDL-400, 1980.

A-133. A. D. Gadeken (ed.), FFTF Operating Report, April 16-November 11, 1982, Cycle 1, Hanford Engineering Development Laboratory, operated by Westinghouse Hanford Company, Richland, Washington, HEDL-401, 1983.

A-134. D. M. Lucoff, Report of the Failed Element Location Team-May 14, 1982: Fission Gas High Alarm, Hanford Engineering Development Laboratory, operated by Westinghouse Hanford Company, Richland, Washington, HEDL-TC-2236, 1982.

A-135. IAEA/NEA International Symposium on Occupational Radiation Exposure in Nuclear Fuel Cycle Facilities, Los Angeles, June 1979.

A-136. SFRP International Workshop on Provisions Taken at Design and During Operation to Reduce Occupational Exposure at LWRs, Paris, December 1979.

A-137. F. Conte, "Chapter 3: Radiation Protection at LMFBRs," The PHENIX Nuclear Plant after Six Years of Operation, Centrale Phenix, Bagnols Sur Ceze, France, 1980. 


\begin{tabular}{|c|c|c|c|}
\hline \multicolumn{2}{|c|}{ 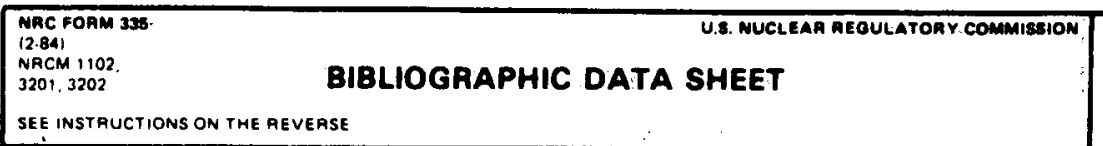 } & \multicolumn{2}{|c|}{ 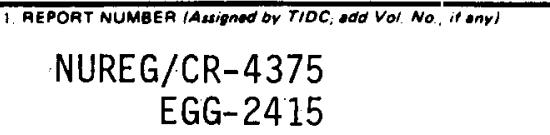 } \\
\hline \multirow{2}{*}{\multicolumn{2}{|c|}{$\begin{array}{l}\text { Theory, Design, and Operation of Liquid Metal } \\
\text { Fast Breeder Reactors, Including Operational } \\
\text { Health Physics }\end{array}$}} & \multicolumn{2}{|l|}{ I LEAVE OLANK } \\
\hline & & October & $T_{1985}^{\text {YEAA- }}$ \\
\hline \multicolumn{2}{|c|}{ Steven R. Adams } & $\frac{6}{\text { October }}$ & $\prod_{1985}^{\text {EPOAT ISSUED }}$ \\
\hline \multicolumn{2}{|c|}{ 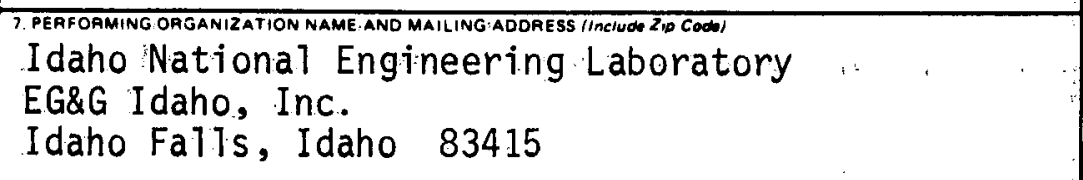 } & \multicolumn{2}{|c|}{$\begin{array}{l}\text { 8. PAOJECT/TASK/WORK UNIT NUMBER } \\
\text { 9:FIN OR GAANT NUMBEA } \\
\text { 'FIN NO. A63.14 }\end{array}$} \\
\hline \multicolumn{2}{|c|}{ 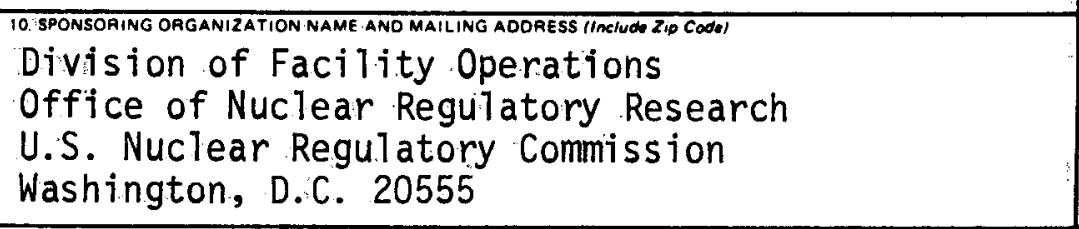 } & \multicolumn{2}{|c|}{ 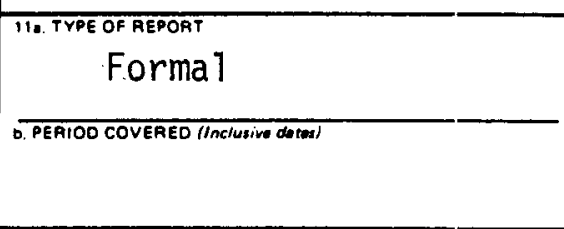 } \\
\hline \multicolumn{4}{|c|}{12 SUPPLEMENT ARY NOTES } \\
\hline \multicolumn{4}{|l|}{13 ABSTAACT (200 wordis or coses) } \\
\hline \multicolumn{4}{|c|}{$\begin{array}{l}\text { A comprehensive evaluation was conducted of the radiation protection practices } \\
\text { and programs at prototype LMFBRs with long operational experience. Installations } \\
\text { evaluated were the Fast Flux Test Facility.(FFTF), Richland, Washington; Experimen- } \\
\text { tal Breeder Reactor II (EBR-II) Idaho Falls, Idaho; Prototype Fast Reactor (PFR) } \\
\text { Dounreay, Scotland; Phenix, Marcoule, France; and Kompakte Natriumgekuhlte } \\
\text { Kernreak Toranlange (KNK II), Karlsruhe, Federal Republic of Germany. The evalua- } \\
\text { tion included external and internal exposure control, respiratory protection proce- } \\
\text { dures, radiation surveillance practices, radioactive waste management, and } \\
\text { engineering controls for confining radiation contamination. The theory, design, and } \\
\text { operating experience at LMFBRs is described. Aspects of LMFBR health physics } \\
\text { different from the LWR experience in the United States are identified. Suggestions are } \\
\text { made for modifications to the NRC Standard Review Plan based on the differences. }\end{array}$} \\
\hline 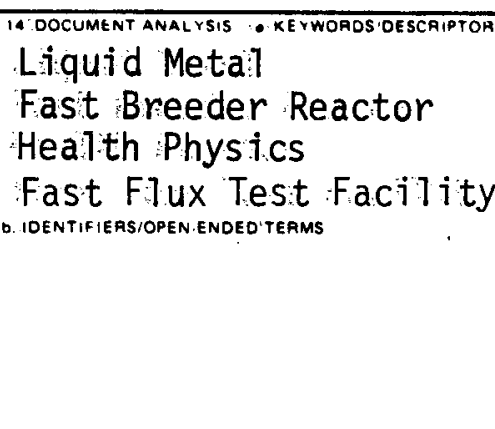 & $\begin{array}{l}\text { FFTF } \\
\text { Prototype Fast Reactor } \\
\text { P.FR } \\
\text { Phenix } \\
\text { KNK II } \\
\text { Experimental Breeder } \\
\text { EBR } \\
\text { LAMPRE } \\
\text { SEFOR }\end{array}$ & $\begin{array}{l}\text { FERMI } \\
\text { BR-5 }\end{array}$ & 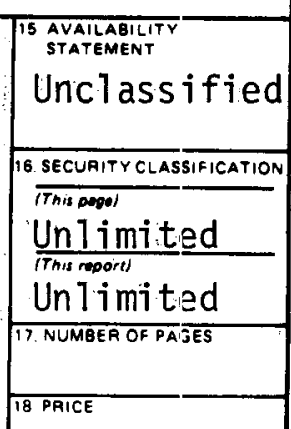 \\
\hline
\end{tabular}

